\title{
EL ESTADO CONSTITUCIONAL
}

PETER HÄBERLE 
EL ESTADO CONSTITUGIONAL 


\section{INSTITUTO DE INVESTIGACIONES JURÍDICAS \\ Serie DOGTRINA JURÍDICA, núm. 47}

\section{GOORDINACIÓN EDITORIAL}

Lic. Raúl Márquez Romero

Secretario Técnico

Lic. Wendy Vanesa Rocha Cacho

Jefa del Departamento de Publicaciones

Isidro Saucedo

Cuidado de la edición y formación en computadora

Vanessa Díaz

Apoyo editorial

Edith Gálvez Aguilar

Elaboración de portada 


\section{EL ESTADO \\ GONSTITUCIONAL}

Segunda edición

Estudio introductorio

DIEGO VALADÉS

Traducción e indices

HÉGTOR FIX-FIERRO
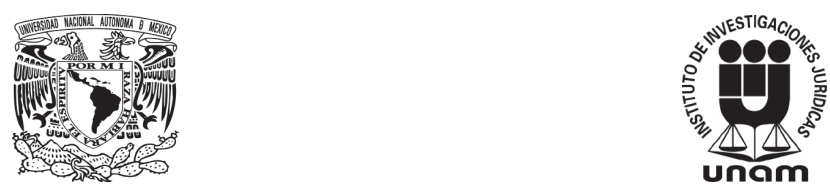

UNIVERSIDAD NACIONAL AUTÓNOMA DE MÉXICO INSTITUTO DE INVESTIGACIONES JURÍDICAS MÉXICO, 2016 
Primera edición: 5 de septiembre de 2001

Segunda edición: 8 de diciembre de 2016

DR (C 2016. Universidad Nacional Autónoma de México

\section{INSTITUTO DE INVESTIGACIONES JURÍDICAS}

Circuito Maestro Mario de la Cueva s/n Ciudad de la Investigación en Humanidades Giudad Universitaria, 04510 Ciudad de México

Impreso y hecho en México

ISBN 978-607-02-8556-1 


\section{GONTENIDO}

Preámbulo a la segunda edición $\ldots \ldots \ldots \ldots \ldots \ldots \ldots \ldots$ XXI Diego VALADÉS

Estudio introductorio XXIII Diego VALADÉS

I. Peter Häberle: un jurista para el siglo XXI XXIII

II. Peter Häberle: autorretrato de un jurista universal a los ochenta años de edad

CAPÍTUlo PRIMERO. Concepto, fundamentación del objeto y métodos de trabajo. . . . . . . . . . . . . . . . . .

I. El tipo del Estado constitucional como conquista cultural . . . .

II. El concepto de Constitución. "Concepción mixta de la Consti-

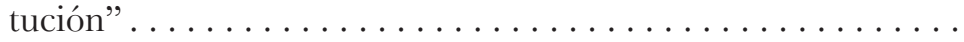

III. La inclusión de los Estados reformados, los micro Estados y los

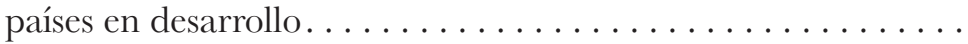

1. Palabra clave: los Estados reformados de Europa oriental . .

2. Los países en desarrollo en el campo de fuerzas de los procesos de crecimiento del Estado constitucional . . . . . . . . . .

IV. La teoría de la Constitución como ciencia jurídica de los textos

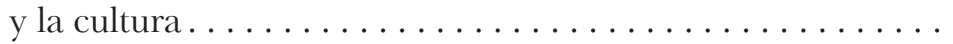

V. La triada de los ámbitos republicanos: privado-público-estatal 
1. Planteamiento del problema ................. 15

2. Lo privado, protección de la privacía. ............. 16

3. Lo público .......................... 17

4. Lo estatal en el Estado constitucional .............. 18

5. Una revisión de los "elementos del Estado"; la cultura como "cuarto" elemento; el ejemplo del territorio y los símbolos

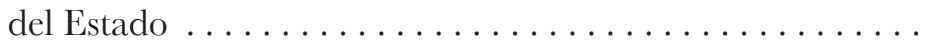

A. Los llamados tres elementos del Estado, y el "cuarto" elemento: la cultura . . . . . . . . . . . . . . . . . . 19

B. El ejemplo del "territorio del Estado" ............ 20

C. La Constitución del pluralismo: formas de diferenciación cultural y de apertura externa del Estado constitucional .

D. La verdad como problema en el Estado constitucional: la libertad a partir de la cultura ...............

E. En particular: los llamados símbolos del Estado en el contexto de la nueva etapa de desarrollo textual .........

6. "República"-“monarquía constitucional”...........

A. La nueva vida de la cláusula republicana: un ejemplo de procesos de crecimiento en la cultura constitucional .... 33

B. La "monarquía constitucional". ..............

Capítulo SEgundo. La evolución histórica. La dimensión del

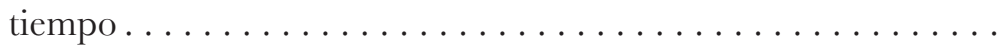

I. Grandes fechas y grandes personajes..............

II. Los textos de los clásicos en la vida constitucional. Siete tesis iniciales desde la perspectiva de la ciencia cultural .........

III. El pensamiento de las posibilidades como parte de una triada (junto con el pensamiento de la realidad y las necesidades)....

1. Introducción, problemática, tesis inicial . ........... 
2. Del pensamiento de las posibilidades (pensamiento pluralista de las alternativas) en lo particular .............

A. Explicación del concepto. . . . . . . . . . . .

B. Inventario . . . . . . . . . . . . . . . . .

C. Requisitos teórico-constitucionales del pensamiento de las posibilidades - límites de este pensamiento . . . . . . . .

3. La integración de la realidad, las posibilidades y las necesidades en el proceso (del pensamiento y la acción) de la interpretación y la política constitucionales abiertas ..........

A. La relación de las tres formas de pensamiento entre sí (competencia y cooperación, confrontación e integración) . . .

B. La valoración de lo real, lo posible y lo necesario en el horizonte de lo normativo ...............

C. Límites

IV. El Estado constitucional desde la perspectiva evolutiva; las dos dimensiones de esta perspectiva: el tiempo y el espacio . . . . . .

1. La comparación jurídica en el tiempo: la historia constitucional . . . . . . . . . . . . . . . . . . . . . . . . .

2. La comparación jurídica en el espacio: comparatística contemporánea, comunidad universal de producción y recepción en materia del Estado constitucional. . . . . . . . . . . .

V. Tiempo y cultura constitucional: instrumentos y procedimientos para el procesamiento del factor tiempo en el presente y en el fu-

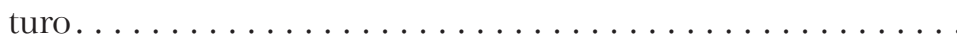

1. Cláusulas relativas al futuro y al progreso . . . . . . . . . 58

2. Mutación constitucional a través de la interpretación..... 59

3. Votos particulares. . . . . . . . . . . . . . . . . 60

4. Mandatos al legislador . . . . . . . . . . . . . . . . . 60

5. Efectos anticipados de las leyes . . . . . . . . . . . . 60 
6. Cláusulas de experimentación y de experiencia ........ 61

7. Modificaciones constitucionales................ 61

VI. La europeización y la internacionalización - el "Estado constitucional cooperativo"- . La visión del mundo del Estado constitucional .............................

1. La europeización del Estado constitucional. . . . . . . . . . .

A. La europeización a través del derecho europeo en sentido

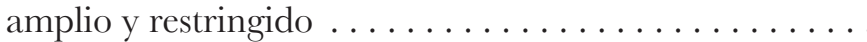

B. El "derecho constitucional común europeo". . . . . . . . . . 64

C. "Derecho constitucional nacional de Europa" ........ 64

2. El Estado constitucional cooperativo..............

A. Causas y trasfondo. . . . . . . . . . . . . . .

B. Límites y peligros . . . . . . . . . . . . . . .

C. Derecho internacional de la coordinación y la cooperación: elementos constitucionales de la comunidad de naciones

D. Del Estado nacional soberano al Estado constitucional co-

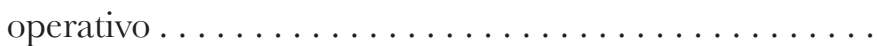

3. La imagen del mundo del Estado constitucional: "comunidad universal de los Estados constitucionales" .............

CAPÍtUlo Tercero. Tratamiento por la ciencia cultural ...... .

I. Evolución de las etapas textuales en el espacio y el tiempo ....

II. Riqueza de las especies y diversidad de funciones de los textos constitucionales en el espejo de una concepción "mixta" de la

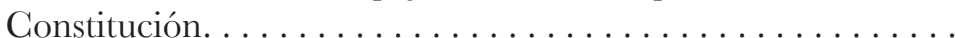

1. Riqueza de las especies y multiplicidad de estratos de los textos constitucionales . . . . . . . . . . . . . . . . . . . . 
A. Planteamiento del problema . . . . . . . . . . . $\quad 78$

B. Inventario en la selección; la diversidad de los ejemplos . . 78

C. Consecuencias . . . . . . . . . . . . . . . . . . . . . 105

D. Perspectivas . . . . . . . . . . . . . . . . . . 107

2. Diversidad de funciones de los textos constitucionales .... 108

A. Planteamiento del problema . . . . . . . . . . . . . 108

B. Las funciones particulares de los textos en el marco de una concepción antropocéntrica de la Constitución ........

III. La relevancia potencial de los proyectos de Constitución (el mo-

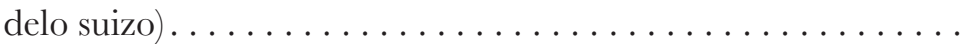

IV. Problemas de las fuentes del derecho en el Estado constitucional: un pluralismo de lo escrito y lo no escrito de múltiples espacios y

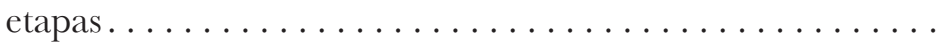

1. El cuestionamiento de la metáfora de la "fuente" ........

2. Apertura y pluralidad de las fuentes del derecho en el Estado

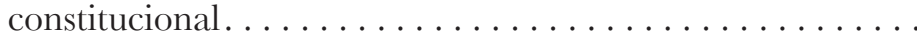

3. En particular sobre las "nuevas" fuentes del derecho ......

4. Influencias recíprocas en lugar de la supra o subordinación de las fuentes del derecho . . . . . . . . . . . . . . . .

5. Despedida del estatismo nacional de la doctrina de las fuentes del derecho; la "europeización" de las fuentes del derecho. .

CAPÍTUlo GUARTO. Proceso constituyente. Modificación e interpretación de la Constitución. Jurisdicción constitucional . . . . . . . .

I. Proceso constituyente $\ldots \ldots \ldots \ldots \ldots \ldots \ldots \ldots \ldots$

1. Un catálogo de problemas, preguntas y respuestas .......

A. Planteamiento de la cuestión.................. 
B. El catálogo de problemas: cinco conjuntos de cuestiones como continuum en la transformación de los textos constitu-

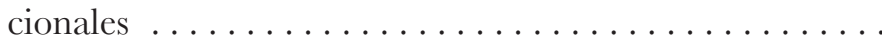

C. Respuestas . . . . . . . . . . . . . . . .

D. Los dos planos: el proceso constituyente en el tipo del Estado constitucional y en un pueblo concreto en el contexto de su individualidad e identidad culturales. .........

E. La normativización y constitucionalización del poder constituyente del pueblo. ...................

2. Consideraciones de política constitucional ..........

3. El proceso constituyente como proceso pluralista, normación de lo "políticamente significativo" . . . . . . . . . . .

II. Modificación de la Constitución $\ldots \ldots \ldots \ldots \ldots \ldots \ldots \ldots$. . . . .

1. Preguntas iniciales $\ldots \ldots \ldots \ldots \ldots \ldots \ldots \ldots \ldots \ldots$

2. Un catálogo de problemas de política constitucional en materia de modificación de la Constitución . . . . . . . . . . . .

3. Los límites a la modificación de la Constitución: las cláusulas de eternidad como garantías de la identidad del Estado constitucional . . . . . . . . . . . . . . . . . . . .

III. La "sociedad abierta de los intérpretes de la Constitución" . . .

1. Tesis básica, estado de la cuestión . . . . . . . . . . .

A. El planteamiento de la teoría de la interpretación constitucional hasta el momento . . . . . . . . . . . . . . . . . .

B. Nuevo planteamiento y tesis . . . . . . . . . . . . . 142

C. Explicación de la tesis, concepto de interpretación...... 142

D. La sociedad abierta de los intérpretes de la Constitución 


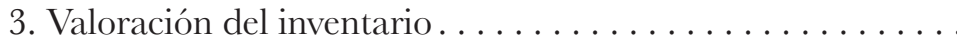

A. Posibles objeciones, crítica . . . . . . . . . . .

B. Legitimación proveniente de los criterios de la teoría del derecho, de la norma y de la interpretación. . . . . . . . . .

C. Legitimación proveniente de consideraciones de teoría constitucional . . . . . . . . . . . . . . . . . .

D. En particular: consideraciones de teoría democrática como legitimación. . . . . . . . . . . . . . . . .

4. Consecuencias para la interpretación "jurídica" de la Consti-

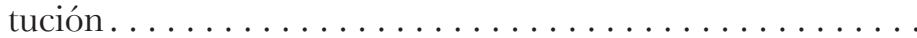

A. Relativización de la interpretación jurídica; nueva noción de sus funciones. . . . . . . . . . . . . . . . . . .

B. De la extensión e intensidad del control judicial, en particular; diferenciación en vista del grado de participación . . .

C. Consecuencias para la configuración y aplicación del derecho procesal constitucional .................

IV. La comparación jurídica como "quinto" método de interpretación y como comparación cultural ...............

V. Incurso: jurisdicción constitucional institucionalizada en el Estado constitucional $\ldots \ldots \ldots \ldots \ldots \ldots \ldots \ldots \ldots \ldots \ldots \ldots$

1. El Tribunal Constitucional Federal alemán como tribunal constitucional - como "tribunal social" de naturaleza propia, su función en la garantía y el desarrollo del contrato social (del contrato de las generaciones) . . . . . . . . . . .

A. El TCFA como "tribunal constitucional" - como "tribunal social" de naturaleza propia . . . . . . . . . . . .

B. La jurisdicción constitucional "en" el contrato social: el TCFA como regulador en los procesos continuos de la garantía y el desarrollo de la Constitución como contrato social . . 
C. Posibilidades y límites de la capacidad de acción del TCFA - el TCFA en el marco de la cultura política del orden fundamental de libertad y democracia de la LF .........

2. Política constitucional en materia de jurisdicción constitucional

I. La dignidad humana como "premisa antropológico-cultural" del Estado constitucional, la democracia como "consecuencia

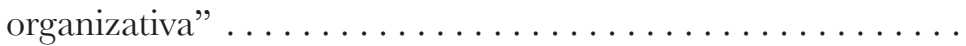

1. La dignidad humana como "premisa antropológico-cultural"

A. Planteamiento del problema ................ 161

B. Algunas consecuencias........................ 162

C. La dignidad humana en relación con el tú y en la solidaridad de las generaciones. . . . . . . . . . . . . . 163

D. La dignidad humana en el cambio cultural. .......... 164

2. La vinculación entre dignidad humana y democracia. .... . 164

A. El pensamiento "clásico" de la separación y su crítica ... 164

B. Cambios en los textos constitucionales ........... 165

3. Los derechos humanos fundamentales en el Estado constitu-

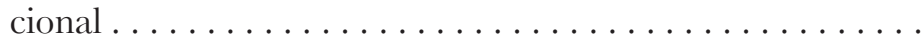

Referencias del Estado y los textos constitucionales a los derechos humanos - una tipología comparativa: la progresiva "constitucionalización" de los derechos humanos

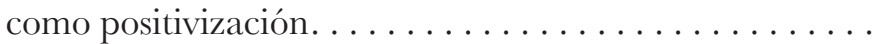

II. "Aspectos de filosofía de las imágenes": imagen del hombre, del Estado, del pueblo, de Dios, del mundo ..............

III. "Libertad cultural", libertad a partir de la cultura, los derechos humanos fundamentales en el Estado constitucional. . . . . . . . . 
1. Libertad cultural . . . . . . . . . . . . . . . . . . . . .

2. En particular: los "derechos fundamentales", la distinción entre "derechos humanos" y "derechos ciudadanos", y en particular: el "status mundialis hominis" . . . . . . . . . . . . . . . . . .

IV. Fines de la educación (los derechos humanos como fines educativos), "pedagogía constitucional" y valores orientadores .... .

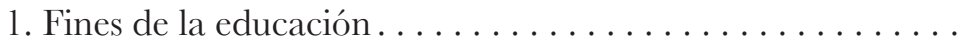

A. Los fines de la educación como elementos formadores de consenso en el Estado constitucional . . . . . . . . . . . .

B. Los fines de la educación como condiciones de base de la Constitución del pluralismo . . . . . . . . . . . .

C. Los fines de la educación como medios para una "pedago-

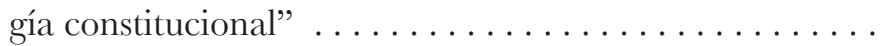

D. La educación de la juventud: un mandato de la "Constitución como contrato" ....................

2. Valores orientadores......................

V. La democracia como consecuencia organizativa de la dignidad

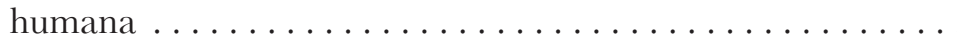

1. Variantes de la democracia ..................... 183

2. Reflexiones de teoría democrática como legitimación. .....

VI. La división de poderes en sentido estricto y en sentido amplio - constitución de los órganos y división de funciones en interés de la realización de tareas . . . . . . . . . . . . . . . . . .

1. La división de poderes en sentido amplio y en sentido estricto

2. Constitución de los órganos y división de funciones en interés del cumplimiento de las tareas estatales ............

A. El Parlamento . . . . . . . . . . . . . . . . . . . . . . . . . 199

B. Excurso: el jefe de Estado: presidente o monarca . . . . . . 203 
C. El gobierno $\ldots \ldots \ldots \ldots \ldots \ldots \ldots \ldots \ldots \ldots \ldots \ldots \ldots \ldots \ldots$

D. La administración . . . . . . . . . . . . . . . . 207

E. La jurisdicción . . . . . . . . . . . . . . . . . . . 209

VII. El Estado social de derecho . . . . . . . . . . . . . . . . 211

VIII. Estado de cultura y derecho constitucional de la cultura: el concepto abierto de cultura . . . . . . . . . . . . 216

1. Ámbitos materiales en Alemania . . . . . . . . . . . . 216

2. Formas técnico-jurídicas de manifestación .......... 217

A. Diversidad técnico-jurídica de las normas constitucionales de la cultura en los "viejos" Estados constitucionales....

B. Los países en desarrollo en el campo del derecho constitucional de la cultura . . . . . . . . . . . . . . 219

C. El concepto abierto de cultura como fundamento ..... 228

D. La relación con la teoría constitucional como ciencia cultural. . . . . . . . . . . . . . . . . . . 228

IX. Bien común y tareas del Estado (el enfoque material y procesal) 229

1. Bien común . . . . . . . . . . . . . . . . . . . . . . . 229

2. Tareas del Estado............................ 232

X. Trabajo y propiedad, economía social y ecológica de mercado 239

1. Elementos de una "teoría constitucional del trabajo" ..... 239

2. Economía social y ecológica de mercado............ 243

XI. Federalismo y regionalismo como pluralismo territorial y división cultural de poderes. . . . . . . . . . . . . . 246

1. Federalismo: el "Estado federal cultural", la concepción culturalista del Estado federal - la teoría "mixta" del Estado federal. . . . . . . . . . . . . . . . . . . . . . . 246

A. Fundamentación ...................... 246 
B. El principio federativo en la LF y los elementos determinantes del tipo del Estado federal . . . . . . . . . . . . . 248

2. El regionalismo desde la perspectiva culturalista y comparativa

A. El concepto constitucional de "región": un conjunto abierto de diversas magnitudes mixtas - lineamientos textuales, la imagen de la "escala" ....................

B. Las siete causas de legitimación (del federalismo y el regio-

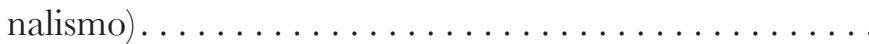

XII. Máximas de justicia en el Estado constitucional . . . . . . . . 254

1. Planteamiento del problema . . . . . . . . . . . . . 254

2. Elementos de un inventario . . . . . . . . . . . . . . . . 255

3. Análisis, primeras conclusiones téorico-constitucionales . . . 257

XIII. Preámbulos, referencias a Dios, derecho constitucional de la religión, así como el derecho del domingo y los días festivos. . . . .

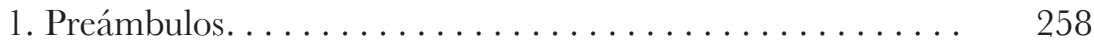

A. El preámbulo como fundamentación y profesión de fe... 258

B. La función de puente en el tiempo . . . . . . . . . . 260

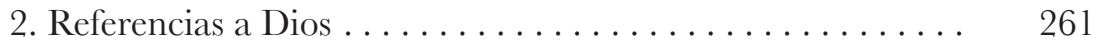

3. "Derecho constitucional de la religión" en el Estado constitucional .............................. 262

4. Días festivos-domingos...................... 264

A. Días festivos . . . . . . . . . . . . . . . . . . . . . . . 264

B. Domingo y cultura dominical en el Estado constitucional, comportamiento dominical en la sociedad del tiempo libre, realidad del domingo $\ldots \ldots \ldots \ldots \ldots \ldots \ldots \ldots$

XIV. Defensa de la Constitución ...................... 269

Capítulo SeXTO. Necesidades de reforma en el Estado constitucional de la etapa evolutiva actual. ................ 
I. El Estado constitucional en la perspectiva de la evolución histórica. Métodos de su comprensión científica, caracterización de sus contenidos esenciales . . . . . . . . . . . . . . . . .

1. Métodos de comprensión científica: procesos mundiales de producción y recepción desde hace siglos, enfoque culturalista y empírico, textos clásicos, el paradigma de las etapas textuales, comparación jurídica "en clave cosmopolita"....

2. Caracterización de los contenidos esenciales (principios) del Estado constitucional. . . . . . . . . . . . . . .

II. Política constitucional y utopías . . . . . . . . . . . . . . . 282

1. Política constitucional ("pensamiento de las posibilidades") . 282

2. Utopías de todos los campos del arte . . . . . . . . . . . 285

III. Campos ejemplares de la política constitucional: tareas actuales de la política de reforma en el Estado constitucional.........

1. Reformas necesarias hoy, selección de un inventario.......

A. Reformas necesarias referidas al Estado constitucional nacional. . . . . . . . . . . . . . . . . . . . . . . . . . . . 288

B. Reformas necesarias referidas al mundo o a la humanidad $\quad 290$

2. Perspectivas $\ldots \ldots \ldots \ldots \ldots \ldots \ldots \ldots \ldots \ldots \ldots \ldots \ldots \ldots \ldots \ldots$

Addendum: el constitucionalismo universal desde las Constituciones parciales nacionales e internacionales. Siete tesis . . . . . . . . .

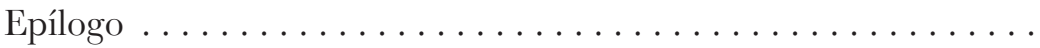

Peter HÄBERLE

I. Observación preliminar: agradecimiento-bibliografía. . . . . 297

II. Primera parte: resonancias en Latinoamérica . . . . . . . . . . . 297

III. Segunda parte: fases evolutivas posteriores de la teoría constitucional comparada como ciencia de la cultura de Peter Häberle (2001 a 2016) . . . . . . . . . . . . . . . . . . . . 
IV. Perspectiva y conclusión: optimismo científico

Fuentes (colecciones de textos constitucionales) . . . . . . . . 303

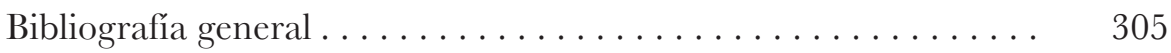

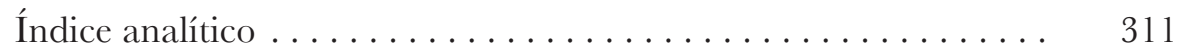

Índice de nombres...................... 321

Índice geográfico y de documentos constitucionales citados . . . . . 325 
Este libro forma parte del acervo de la Biblioteca Juridica Virtual del Instituto de Investigaciones Juridicas de la UNAM

\section{PREÁMBULO A LA SEGUNDA EDICIÓN}

El interés por la obra de Peter Häberle ha ido en ascenso en América Latina. Su presencia en diversas universidades latinoamericanas, donde ha sido objeto de merecidos homenajes, y la multiplicación de las traducciones de su obra, lo convierten en una fuente de referencia obligada tanto para la doctrina como para la jurisprudencia en el hemisferio. Sin duda, Häberle es una de las figuras estelares del constitucionalismo de nuestro tiempo.

La presente obra, traducida por Héctor Fix-Fierro, fue publicada por el Instituto de Investigaciones Jurídicas de la Universidad Nacional Autónoma de México en 2001. Dos años más tarde apareció una coedición de la UNAM con la Pontificia Universidad Católica de Perú y en 2007 con la Editorial Astrea, de Buenos Aires. Durante este periodo se hicieron reimpresiones en los tres países y se han publicado otros estudios del autor.

Por mi parte compilé un volumen al que titulé Conversaciones académicas con Peter Häberle, publicado por el Instituto de Investigaciones Jurídicas en 2006, y traducido, por Carlos Dos Santos, al portugués como Conversas acadêmicas com Peter Häberle, editado por Editora Saraiva-Instituto Brasiliense de Direito Público en 2009.

Ahora se presenta la segunda edición, cuya traducción ha sido revisada por el profesor Fix-Fierro y a la que el autor adiciona un epílogo. Debido a una inteligente y oportuna sugerencia de Francisco Balaguer Callejón, aceptada por el autor, también se incorpora un breve y muy sugerente texto que contiene siete tesis sobre "El constitucionalismo universal desde las Constituciones parciales nacionales e internacionales".

A mi estudio introductorio añado un texto al que denomino "Peter Häberle: autorretrato de un jurista universal a los ochenta años de edad", basado en las referencias autobiográficas que aparecen en Conversaciones académicas. Lo incorporo en esta edición porque contribuye a comprender mejor la trayectoria intelectual de nuestro autor. La selección del material la realicé con motivo del homenaje por sus ochenta años que se llevó a cabo en Lisboa, en mayo de 2014, bajo la cuidadosa organización de Vasco Pereira da Silva, de la Universidade Classica de Lisboa, y Francisco Balaguer, de la Universidad de Granada y presidente de la Fundación Peter Häberle. 
Este libro forma parte del acervo de la Biblioteca Juridica Virtual del Instituto de Investigaciones Juridicas de la UNAM

La Fundación auspicia el Centro de Investigación "Peter Häberle", cuya sede es la Facultad de Derecho de la Universidad de Granada. Ambas instituciones son un buen ejemplo del impacto que ha tenido el pensamiento del jurista alemán en el mundo euroamericano. La Fundación está encabezada por Francisco Balaguer Callejón, Miguel Azpitarte Sánchez, Pedro M. Serrano León y Gregorio Cámara Villar; son corresponsales Domingo García Belaunde (Perú), José Joaquim Gomes Canotilho (Portugal), César Landa (Perú), Gilmar Mendes (Brasil), Jorge Miranda (Portugal), Paolo Ridola (Italia), Ingo Sarlet (Brasil) y Diego Valadés (México); entre sus colaboradores figuran Augusto Aguilar Calahorro (España), Andrea Buratti (Italia), Arianna Cascelli (Italia), Gianpiero Coletta (Italia), Valentina Faggiani (España), Greta Massa Gallerano (Italia), Hugo Cesar Gusmão (Brasil), Maria Pia Iadicicco (Italia), Sarah Löw (Alemania), Cristina Elías Méndez (España), Cláudia Perotto Biagi (Brasil) Tommaso Poli (Italia), Mariana Rodrigues Canotilho (Portugal), Marina Salvetti (Italia), Angelo Schillaci (Italia), Johann Justus Vasel (Alemania) y Fausto Vecchio (Italia). Esta es una buena muestra del impacto que tiene la obra del eminente jurista y del interés por difundirla.

El Estado constitucional de Peter Häberle es ya un clásico, si por tal entendemos una obra destinada a perdurar como fuente de inspiración y de referencia, cuya lectura orienta para entender el fenómeno del Estado y de la Constitución de nuestros días, al tiempo que servirá a quienes lo hagan en el futuro. Se trata de realidades en evolución constante para cuyo estudio las teorías del profesor Häberle resultan de excepcional utilidad. 
Este libro forma parte del acervo de la Biblioteca Juridica Virtual del Instituto de Investigaciones Juridicas de la UNAM

\section{ESTUDIO INTRODUGTORIO}

\section{Peter Häberle: UN JURISTA PARA EL SIGLO XXI}

\section{Preliminar}

Aunque Peter Häberle es un autor muy conocido en lengua española y el Instituto de Investigaciones Jurídicas ya ha publicado trabajos suyos, ésta es la primera obra de gran alcance del autor que se publica en México. En 1998, en un breve pero ilustrativo texto, el profesor Ignacio Gutiérrez hizo una sugerente presentación a la obra Libertad, igualdad, fraternidad, también del profesor Peter Häberle. El título de esa presentación me resultó llamativo: "Una teoría de la Constitución para el siglo XXI". No puedo estar más de acuerdo; pero en mi caso, y para la obra que ahora tiene en sus manos el lector, decidí ir aún más lejos. Confío en que quienes ya conocen la obra completa del profesor Häberle coincidan conmigo cuando lo caracterizo como un jurista para el siglo XXI. La amplitud de sus aportaciones a la ciencia del derecho, y el cúmulo de problemas que permite anticipar y resolver, así lo justifican. Con esa idea en mente, me interesa destacar algunas de las más significativas contribuciones científicas del ilustre y admirado jurista alemán.

\section{Perfil del autor}

A manera de breve registro biográfico: Peter Häberle nació en Göppingen en 1934. Sus estudios jurídicos los realizó en Tubinga, Friburgo, Bonn y Montpellier. Obtuvo el doctorado en la Universidad de Friburgo en 1961; su tesis versó sobre el artículo 19.2 de la Ley Fundamental de Bonn, según el cual en ningún caso podrá verse afectado el contenido esencial de un derecho fundamental. Como bien apunta Francisco Balaguer (p. 9), hoy se trata de una obra clásica. A los treinta y cinco años alcanzó la cátedra en Friburgo, luego la ocupó en Marburgo y desde 1981 la ejerce en Bayreuth y en St. Gallen. Su extensa obra, a la que parcialmente nos referiremos aquí, ha sido objeto de traducciones al español, italiano, griego, polaco, japonés 
Este libro forma parte del acervo de la Biblioteca Juridica Virtual del Instituto de Investigaciones Juridicas de la UNAM

y coreano. El primer texto suyo publicado en México, "El Estado constitucional europeo", apareció en Cuestiones Constitucionales (enero-junio, 2000).

En 1997 el profesor Häberle sostuvo un importante ("brillantísimo", dice con razón Zagrebelsky) diálogo académico con el catedrático granadino Francisco Balaguer. En tanto que Balaguer es un eminente constitucionalista y un profundo conocedor de la obra del profesor alemán, el texto presenta una formidable síntesis de las ideas de Häberle al tiempo que ofrece la posibilidad de adentrarse en la multifacética personalidad del erudito y del artista. Difícilmente se puede entender el concepto central de Peter Häberle, de la relación indisociable entre Constitución y cultura, sin tener presente su formación filosófica, artística, literaria y jurídica.

En el diálogo con Balaguer aparece una afirmación llamativa: Häberle se declara "discípulo de sus discípulos". No se trata de un juego de palabras ni significa sólo una actitud de modestia; es mucho más que eso. Cuando la doctrina de un maestro es proseguida de manera creativa por otros autores significa que se ha encontrado una rica vertiente en la construcción normativa. Así se podrá confirmar en las páginas de esta obra, que representan una gran síntesis de las ideas del autor.

La entrevista con Balaguer aporta guías muy valiosas. En lo que podríamos denominar como "genealogía" doctrinaria de Häberle, identifica a Rudolf Smend como maestro de Konrad Hesse, y a éste, a su vez, como el suyo propio. "De Smend puedo considerarme su nieto", declara a Balaguer (p. 11). En este punto debe tenerse presente la dura polémica que sostuvieron Kelsen y Smend con motivo de las presuntas implicaciones de la teoría de la integración con el fascismo (Abignente, pp. 224 y ss.). Smend - y así lo recuerda Häberle - formuló diversas correcciones a su teoría muchos años después. No obstante, su concepto de la integración personal sigue siendo objeto de fuertes críticas (por ejemplo, Roehrssen). Debe subrayarse que en este punto, en el que Smend (pp. 70 y ss.) justifica la concentración del poder en una persona equiparándolo a un símbolo nacional, no es seguido en forma alguna por Häberle.

También dice, en ese esclarecedor diálogo, que a Hermann Heller "le debe más que a nadie". La relación entre algunas ideas de ambos autores la podremos ver en esta importante obra, pero vale la pena retener la declaración del profesor en el sentido de que "en el plano científico debo a Heller la comprensión profunda de una teoría del Estado culturalmente integrada, que yo he intentado continuar bajo la idea de una teoría científico-cultural de la Constitución". En particular debe tenerse presente la poderosa teoría que Heller (p. 269) construye en torno a la relación entre norma y normalidad: "Así como no pueden estimarse completamente separados lo dinámico 
Este libro forma parte del acervo de la Biblioteca Juridica Virtual del Instituto de Investigaciones Juridicas de la UNAM

y lo estático, tampoco pueden serlo la normalidad y la normatividad, el ser y el deber ser en el concepto de la Constitución". Dentro de esa misma idea se incluyen los factores culturales que, como es obvio, forman parte de la realidad (o normalidad). Heller formula así su conocida distinción entre Constitución normada y no normada. Esta última es la Constitución real, que puede consistir en una normalidad sin normatividad, pero lo contrario no es posible. La Constitución normada a su vez puede serlo jurídicamente y extrajurídicamente (por la costumbre, la moral, la urbanidad, la moda, por ejemplo). Las implicaciones democráticas de la tesis de Heller son claras: la normalidad (lo que ocurre), ha de coincidir con la normatividad (lo que debe ocurrir). Heller formuló esta tesis en 1934 y, seis años después, Mortati (por ejemplo, p. 56) aludió a la relación entre normalidad y normatividad, pero no intentó examinar las implicaciones profundas de esa relación porque le habría sido imposible fundamentar, por esa vía, las bases constitucionales del Estado fascista.

Son asimismo importantes las posiciones que Häberle toma con relación a Hans Kelsen y a Carl Schmitt. A propósito del primero, apunta que se separa de él en el aspecto metodológico, aunque se acoge a sus aportaciones sobre la "construcción escalonada del sistema jurídico", que conduce al concepto de norma de normas. En cuanto a Schmitt es, comprensiblemente, muy severo. Distingue entre el autor de una de las más importantes obras sobre teoría de la Constitución, por su "fuerza sistemática y sus innovaciones", y el autor del "indescriptible trabajo" denominado "Los judíos en la ciencia jurídica alemana", y del "nefasto" artículo "El Führer protege el derecho". Concluye con una expresión significativa: "veo con pesar que, en algunos países latinos..., se ha producido una especie de renacimiento de Schmitt" (Balaguer, p. 16).

En este punto es oportuno señalar que el profesor Häberle también ha manifestado, en diversos textos, que le ha sido de gran importancia la teoría del status de Jellinek. Para este "sabio", como solía llamarlo Adolfo Posada, fue útil tomar "del derecho antiguo" la voz status, para denotar con ella la posición de la persona respecto del Estado. Jellinek identificó cuatro status (libro III, cap. XIII): negativo, positivo, activo y pasivo. Encontró que los términos de la relación entre el individuo y el Estado se traducen en la libertad para el individuo de hacer todo lo que no se le prohíbe, en exigir del Estado aquello a que está obligado, en participar en las acciones del Estado y en acatar las decisiones del Estado. Alexy apunta (pp. 248 y ss.) que, con base en esa trascendental aportación de Jellinek, se han desarrollado otras teorías del status: el status constituens, de E. Denninger; el status de derecho constitucional y de derecho político general, de K. Hesse; el status libertatis, 
Este libro forma parte del acervo de la Biblioteca Juridica Virtual del Instituto de Investigaciones Juridicas de la UNAM

de E. Grabitz, y el status activus processualis, de P. Häberle. Admite que este último acierta cuando critica la teoría del status de Jellinek porque no abarca la situación completa del ciudadano activo "en el que las normas de derecho fundamental deben colocar al individuo". Aunque a continuación Alexy formula algunas observaciones a la afirmación de Häberle, no controvierte sus razones de fondo.

Los temas de nuestro tiempo son objeto de reflexiones relevantes en ese intenso diálogo. El profesor español va planteando inteligentemente los temas, y el profesor alemán ofrece respuestas breves pero orientadoras: la reunificación interior alemana es una tarea pendiente que ahora corresponde a la cultura política; las elecciones de jueces sujetas a la negociación política en los congresos (como es el caso en Estados Unidos), abren la vía a excesos; las aportaciones constitucionales de los países del este europeo representan un rico caudal de innovaciones que debe ser examinado con atención; se requiere una teoría constitucional del mercado que determine las fronteras del pensamiento económico unilateral y rescate el concepto de dignidad del hombre; se debe impulsar la protección constitucional de las minorías. Son éstos algunos de los aspectos que figuran en la entrevista y que han sido desarrollados ampliamente por Häberle en numerosos estudios.

Otro importante testimonio del proceso formativo de Peter Häberle aparece en la entrevista que sostuvo con el jurista peruano César Landa. Aunque el tema central del diálogo (pp. 245 y ss.) se refiere a las perspectivas de la enseñanza del derecho constitucional, queda clara la posición del jurista alemán en cuanto a la necesidad de preservar una formación tan amplia como fuere posible de quienes se preparan para el ejercicio del derecho, sea como jueces, abogados o profesores. De ahí que defienda la vigencia de los exámenes de Estado para quienes aspiran al ejercicio de la abogacía en Alemania, como un elemento que seguirá estimulando la formación del "jurista integral". En esa entrevista aparece un elemento directamente vinculado con las tesis de Häberle. Subraya la conveniencia de que en el Tribunal Constitucional estén representados diversos grupos profesionales: ex parlamentarios, abogados postulantes, miembros de la magistratura y académicos. ¿La razón? Es muy explicable: la pluralidad de perspectivas en un tribunal de esa naturaleza enriquece las posibilidades de interpretación abierta que el autor postula en otros trabajos. 
Este libro forma parte del acervo de la Biblioteca Juridica Virtual del Instituto de Investigaciones Juridicas de la UNAM

\section{La teoría de la Constitución como ciencia de la cultura}

El estudio de Häberle "Teoria de la Constitució com a ciéncia de la cultura en lexemple dels 50 anys de la llei fonametal" aporta claves muy importantes de su pensamiento. En especial subraya la relación entre cultura y dignidad (p. 45), que es el eje de su gran concepción teórica para afirmar categóricamente que "no existe una libertad cultural previa a la cultura". El examen de cincuenta años de vigencia de la Ley Fundamental de Alemania lo lleva a identificar el proceso a la luz de las categorías centrales de su tesis. La teoría de la Constitución, como ciencia de la cultura, ofrece instrumentos que permiten analizar cincuenta años de vida constitucional alemana desde una perspectiva que va más allá de los solos enunciados normativos. Por eso Häberle introduce entre las categorías de análisis del Estado constitucional la idea del tiempo: "el Estado constitucional vive en el 'curso del tiempo' para arribar a la dialéctica entre estática y dinámica, entre conservación y cambio" (p. 49). Es, sin duda, un acierto, porque el aspecto temporal debe tenerse presente en todos los procesos de cambio político y constitucional. Linz (esp. pp. 35 y ss., y 61 y ss.) también le ha dado una gran relevancia al estudio del tiempo en los cambios de régimen y ha examinado, desde la ciencia política, la secuencia temporal en las crisis y en los cambios de régimen, y el valor del tiempo como variable vinculante en los procesos políticos.

$* * *$

A partir de 1982 el profesor Häberle inicia el esfuerzo programático de configurar la teoría de la Constitución como una ciencia cultural. Aquí subraya la importancia que para él han representado las obras de Hermann Heller y Max Weber. Entre las ideas rectoras de esa indagación, Häberle cita la tesis de Rudolf Smend en el sentido de que aunque dos normas (o Constituciones) se expresen en los mismos términos, no necesariamente tienen igual significado. Georg Jellinek (p. 121) ya había señalado que una misma norma puede tener distinto sentido en tiempos diferentes; Smend extendió la pluralidad de contenidos de la norma al establecer que incluso en momentos coincidentes, la norma puede variar conforme al lugar de su aplicación. Así, un mismo texto puede cambiar conforme a condiciones temporales y espaciales. Es claro que el elemento que explica esa variación tiene que ser de índole cultural. 
Este libro forma parte del acervo de la Biblioteca Juridica Virtual del Instituto de Investigaciones Juridicas de la UNAM

En cuanto a la idea de Häberle de la Constitución del pluralismo, señala como uno de sus referentes la obra de Karl Popper, de quien toma la idea de la sociedad abierta. Declara, empero, que Popper no aborda el problema de que toda sociedad abierta requiere de un consenso cultural fundamental (el orden constitucional) que haga posibles la apertura y la cohesión. Este es un aspecto de la mayor relevancia en tanto que si bien la democracia "es la forma estatal que se corresponde con la dignidad del ser humano", en una sociedad abierta también existen ámbitos donde la democracia no es el principio dominante (Balaguer, p. 33). Es el caso de las organizaciones académicas, artísticas o deportivas. La existencia y el funcionamiento jerarquizado de estas organizaciones, empero, no desvirtúan la vigencia de la democracia constitucional.

\section{$* * *$}

De la obra de nuestro autor se desprende que la Constitución traduce un doble proceso cultural: por una parte el de naturaleza temporal y por otra el de naturaleza espacial. Ambos presentan a su vez una dualidad. En cuanto al proceso temporal hay un elemento diacrónico, que resulta de la experiencia histórica, y otro sincrónico, que corresponde al proceso constituyente. En efecto, cada Constitución tiene como antecedente cultural la suma de las experiencias propias que el constituyente toma en cuenta para seleccionar las instituciones y darles un contenido determinado; pero también incluye una serie de demandas y expectativas que se producen en la sociedad en el momento mismo en que se lleva a cabo el acto constitutivo.

En cuanto al proceso espacial, a lo largo de la obra del profesor Häberle se identifican los elementos que diferentes actos constituyentes han aportado al Estado constitucional de nuestro tiempo. Aquí se puede hablar de los patrones culturales cuya génesis corresponde a una sociedad en especial y que se han irradiado al resto de las sociedades para convertirse en referentes comunes, o que han venido siendo incorporados selectivamente por diferentes sociedades. A manera de ejemplos pueden señalarse el federalismo, de origen norteamericano, adoptado y convertido en parte de la cultura política de diversas sociedades en el mundo, y los derechos humanos, cuyas primeras manifestaciones normativas se registran en Inglaterra, Estados Unidos y Francia, que en la actualidad han sido interiorizados por todas las sociedades contemporáneas donde existe el Estado constitucional.

Ese doble proceso cultural tiene a su vez sus respectivas díadas, lo que permite valorar la riqueza de la teoría del profesor Häberle. Las contribu- 
Este libro forma parte del acervo de la Biblioteca Juridica Virtual del Instituto de Investigaciones Juridicas de la UNAM

ciones de cada sociedad, en cada etapa histórica, tienden a incorporarse a la cultura compartida, sin perjuicio de que cada sociedad, al interiorizar las experiencias ajenas, lo haga aportando sus propios matices y generando, a su vez, nuevos elementos que se incorporen al intercambio creciente de patrones culturales, que hace cada vez más homogéneos a los Estados constitucionales. El Estado constitucional es un producto multicultural.

El sustento cultural de las Constituciones corresponde a uno propio de la cultura autónoma, con efectos limitados al ámbito nacional del Estado donde rige la Constitución, y a otro que forma parte de lo que podría denominarse, utilizando ideas e imágenes de la obra del profesor alemán, cultura cooperativa, que comparten las sociedades con vocación de afinidad. Esto último nos permite identificar, como en el derecho comparado, familias culturales muy claramente vinculadas o diferenciadas por sus expresiones constitucionales. En derecho privado comparado, Arminjon, Nolde y Wolff identificaron (pp. 14 y 18) en 1950 siete grupos jurídicos: francés, germánico, escandinavo, inglés, ruso, islámico e hindú (en esa época todavía era prematuro hablar del chino); treinta años más tarde René David (pp. 5 y ss.) lo simplificó en familias jurídicas romano-germánica, socialista, del Common Law, derechos religiosos y tradicionales. En derecho constitucional comparado sólo enuncia una variedad de estilos constitucionales: democracia racionalizada, democracia social, democracia socialista y sistemas autoritarios.

Los cambios operados en materia civil llevarían hoy a una nueva clasificación. En cuanto a la materia constitucional podemos hacer también variaciones. Si atendemos a la forma de organizar el poder, podemos reconocer la familia presidencial y la familia parlamentaria; si atendemos a la protección de los derechos humanos podemos identificar la familia moderna (donde esos derechos están garantizados e incluso se mantienen en desarrollo) y la familia tradicional (donde subsisten normas adversas a los derechos fundamentales, porque todo orden constitucional que no está expresamente comprometido con esos derechos debe ser considerado adverso a ellos); si atendemos a la organización del Estado, hay una familia federativa (que incluye expresiones federales y regionales) y una familia unitaria; si atendemos a los contenidos de prestación, tendremos una familia social (donde se prevén las obligaciones de prestación a cargo del Estado), y una familia programática; si atendemos a los procedimientos democráticos adoptados tendremos una familia representativa (donde existe la centralidad del Congreso o del Parlamento), y una familia participativa (donde prevalecen los instrumentos de consulta popular directa), y finalmente si atendemos a los instrumentos de control político y jurisdiccional tendremos una familia responsable (donde Congresos y tribunales son eficaces en el ejerci- 
Este libro forma parte del acervo de la Biblioteca Juridica Virtual del Instituto de Investigaciones Juridicas de la UNAM

cio de sus tareas) y una familia arcaica (donde existen relaciones asimétricas entre los órganos del poder).

En un sugerente ensayo, Mârtires Coelho intenta relacionar las teorías de Lassalle, Hesse y Häberle. Se trata de un esfuerzo inteligente aunque no necesariamente convincente. Entre el discurso de Lassalle, de 1862, y el ensayo de Hesse, de 1959, se da una vinculación expresa; a su vez entre el trabajo de Hesse y el de Häberle, de 1975, existe también una conexión temática. Pero no encuentro elementos que evidencien un vínculo entre Lassalle y Häberle en este punto. El propio Mârtires Coelho acepta (p. 80) que Häberle no hace referencia alguna a la obra de Lassalle.

El problema al que alude Hesse es el concerniente a la tensión entre la Constitución y el derecho constitucional; en otras palabras, entre la norma y la realidad. Por eso recuerda, al inicio de su ensayo (p. 61), la célebre conferencia de Lassalle. A la pregunta ¿qué es una Constitución?, sigue la respuesta categórica: lo que deciden los que ejercen el poder. La Constitución es "la suma de los factores reales de poder", dijo (Lassalle, p. 63), después de haberlos identificado como la nobleza, la burocracia, el ejército, los banqueros, los industriales y los terratenientes. Hesse (en "La fuerza normativa de la Constitución") demuestra el mutuo condicionamiento entre la "Constitución real" y la "Constitución jurídica" a través de una vía de ida y vuelta que consiste en la "adaptación inteligente a las circunstancias" por parte de la Constitución jurídica y en "convertirse en una fuerza actuante" sobre la Constitución real. Por ende, los límites de la fuerza normativa de la Constitución se encuentran donde la norma deja de identificarse con la realidad, bien porque no la reconoce, bien porque ya no puede influir en ella.

Allí es donde se da el punto de contacto con lo que después desarrollaría su discípulo: del reconocimiento del entorno histórico, de Smend (p. 75), Häberle da un paso más para señalar, de manera directa y expresa, la vinculación amplia, dinámica y constructiva entre Constitución y cultura. Queda atrás, como se puede apreciar, el problema escueto de los actores reales de poder. Más aún: debe recordarse, como lo hace Heller (Las ideas..., p. 169), que el argumento de Lassalle estaba orientado en el sentido de armonizar la idea del Estado de Hegel con las doctrinas económicas de Marx, para culminar con un "Estado de la clase obrera". Esto es muy claro si, además de la célebre y muy mencionada conferencia dictada por Lassalle el 16 de abril de 1862, se revisa la que pronunció en noviembre de ese mismo año, 
Este libro forma parte del acervo de la Biblioteca Juridica Virtual del Instituto de Investigaciones Juridicas de la UNAM

como continuación de la anterior, con el desafiante título de "¿Y ahora?”. Ahí se cierra el argumento: el nuevo factor real de poder debía ser el pueblo organizado para la democracia. Meses después (febrero de 1863) enunció (p. 169), en un breve párrafo, la esencia de su argumento: "sólo en la democracia reside el derecho, y en ella residirá también, en toda su integridad, el poder". Como se puede ver, entre el planteamiento de Lassalle y el de Häberle no puede establecerse relación alguna. En un caso se atiende a las relaciones de fuerza y en otro a los vínculos culturales.

Por su parte, Rodríguez Olvera (p. 70) hace una observación relevante cuando examina el concepto de Constitución en sentido cultural. No se trata, señala, de un criterio que se integre en "una clasificación analítica". Tiene razón en tanto que, a diferencia de las clasificaciones constitucionales (escritas y no escritas, rígidas y flexibles, por ejemplo), no se puede hablar de unas Constituciones como culturales y de otras como no culturales. Esta reflexión merece atención, porque ciertamente el profesor alemán no propone un criterio clasificador, sino un significado común a todas las Constituciones. Pero cabe entonces plantear a qué tipo de Constitución resulta aplicable la relación entre la norma suprema y la cultura.

Entre las diversas formas de clasificar las Constituciones recogemos ahora dos. La de Jorge Carpizo (pp. 417 y ss.) que, entre otras, las divide en democráticas, cuasidemocráticas, de democracia popular y no democráticas, y la de Karl Loewenstein (pp. 216 y ss.), que las agrupa en normativas, nominales y semánticas. Veamos cómo se puede leer a Häberle con relación a estos autores.

En cuanto a la propuesta de Jorge Carpizo conviene tener presente que numerosos constitucionalistas se acogen al enunciado clásico del artículo 16 de la Declaración de los Derechos del Hombre y del Ciudadano, conforme al cual "toda sociedad en la que la garantía de los derechos no está asegurada, ni determinada la separación de poderes, carece de Constitución". Desde esta perspectiva no estarían dispuestos a admitir que pueda haber una Constitución no democrática. Esta objeción podría hacerse también a la clasificación de Karl Loewenstein, porque se diría que una Constitución es o no es, y que por lo mismo no cabría que fuera nominal o semántica.

Sin embargo el debate no puede ser tan sencillo. La reserva del artículo 16 mencionado opera sólo para lo que certeramente Häberle denomina Estado constitucional, cuya relación con la Declaración es indudable. Como 
Este libro forma parte del acervo de la Biblioteca Juridica Virtual del Instituto de Investigaciones Juridicas de la UNAM

bien señala Miguel Carbonell (pp. 25 y ss.), Häberle sintetiza brillantemente las aportaciones de la Declaración a esa forma de Estado (Constituciones escritas, derechos fundamentales intransferibles e imprescriptibles, codificación del derecho, poder constituyente del pueblo, separación de poderes, la ley como expresión de la voluntad general). En un solo texto se condensaron diversas expresiones doctrinarias previas, que se consideran definiciones necesarias del Estado constitucional; pero ni siquiera esos elementos representan, hoy, la totalidad de la gama de aspectos a los que atiende ese tipo de Estado, ni es el Estado constitucional el único que existe.

Todo Estado tiene un estatuto jurídico, escrito o consuetudinario, al que denominamos Constitución, independientemente de las orientaciones políticas que adopte y del contenido de la norma suprema que lo rija. El constitucionalismo moderno y contemporáneo se orienta en un sentido decididamente democrático; pero esto no implica que no existan otras modalidades de organización normativa del poder. En este sentido, la Constitución no democrática se explica culturalmente en tanto que existan las condiciones de poder que la imponen y forme parte de una realidad social determinada, así repugne admitirlo.

En el caso de la clasificación de Karl Loewenstein el problema es de otra naturaleza. Aun cuando la aportación de Loewenstein a la teoría de la Constitución es una de las más relevantes, su clasificación de las Constituciones presenta dos puntos débiles. El primero es que alude a un criterio "ontológico" de las Constituciones. En este sentido incurre en una contradicción al afirmar que la Constitución nominal "carece de realidad existencial". Eso sólo es posible que ocurra en el caso de las Constituciones escritas, porque se puede aceptar que una Constitución escrita determinada no se aplique, pero no es admisible que en un Estado no exista ninguna disposición normativa que se aplique, porque entonces no hay Estado. El otro problema que presenta esta parte de la teoría de Loewenstein consiste en que al encuadrar su clasificación desde una perspectiva ontológica, excluyó la posibilidad de que un mismo texto pudiera ser, en distintos momentos, objeto de aplicación o de no aplicación; y más todavía, no permite examinar separadamente las diversas partes que componen el texto para establecer el grado de cumplimiento de la norma. Al determinar que una Constitución es nominal, por ejemplo, se afirma que toda ella carece de "realidad existencial".

Desde esa perspectiva el concepto cultural de la Constitución no es aplicable. En cambio, si trasladamos el esquema de Loewenstein de una categoría irreductible (sentido ontológico) a una forma de expresión de las Constituciones escritas (sentido fenomenológico), entonces se produciría una 
Este libro forma parte del acervo de la Biblioteca Juridica Virtual del Instituto de Investigaciones Juridicas de la UNAM

plena coincidencia con Häberle, y se tendría una forma más de corroborar lo adecuado de su concepto. Sobre este aspecto ya he afirmado (El control del poder, pp. 427 y ss.) que en diversas etapas de su vigencia, una Constitución escrita puede caracterizarse como normativa o nominal, según su nivel de eficacia, con independencia de su contenido; y que también es posible identificar, en un mismo momento, que diversas disposiciones constitucionales son aplicadas en tanto que otras se encuentran sujetas a desarrollo por parte del legislador, por ejemplo. No entremos aquí al tema de la inconstitucionalidad por omisión, sino sólo examinemos si en este caso estaríamos ante una Constitución normativa, porque algunos de sus preceptos se aplican, o nominal, porque sólo cuando se cumple con la totalidad de las disposiciones constitucionales se puede hablar de Constitución en sentido normativo. Si fuera este último el entendimiento adoptado, tendríamos que concluir que ninguna Constitución que prescriba el bienestar social sería normativa.

Si le damos un giro al criterio de Loewenstein, para llevarlo al mundo fenomenológico, y admitimos la fluidez de las Constituciones como un dato de la realidad, podremos advertir hasta qué punto es funcional la teoría de Häberle. Gracias a ella podremos explicarnos que un texto constitucional se convierta en la expresión normativa de planteamientos sociales, o induzca nuevas formas de conducta social. Únicamente desde esa perspectiva se podrá captar toda la potencial fuerza transformadora de una Constitución y entender que su naturaleza es tan dinámica como la propia colectividad en la que se aplica. Häberle con frecuencia recurre a una expresión de Goethe, señalando que la "Constitución es forma nacida de la vida", y tiene razón, porque la Constitución, como la sociedad en la que rige, tiene su propia vida; no es una estructura rígida, estática, sino un rico entramado elaborado para organizar el complejo proceso del poder y la intensa vida social (Goethe, Egmont, actos II y IV). Desde esta perspectiva la Constitución no se produce como un reflejo de la sociedad, ni la sociedad la adopta como un modelo ajeno a su forma de ser actual o a su proyecto de transformación futura; sencillamente ocurre que la Constitución es una parte de la vida social organizada. Cuando nuestro autor alude, por ejemplo, a la realidad del federalismo germano, señala ("Problemi...", p. 3369) que en el curso del tiempo las tres formas del Estado federal (dual, "unitario" y cooperativo), se presentan en combinaciones que ofrecen en cada momento aspectos nuevos y diferentes. 
Este libro forma parte del acervo de la Biblioteca Juridica Virtual del Instituto de Investigaciones Juridicas de la UNAM

La Teoría de la Constitución como ciencia de la cultura es una obra imprescindible. La primera edición alemana de 1982 fue actualizada en 1996 y traducida al español en 2000. En ese trabajo capital el profesor Häberle ofrece las claves de naturaleza científico-cultural que explican la racionalidad de las construcciones constitucionales, opone la naturaleza cultural del constitucionalismo al decisionismo, identifica su teoría con un intenso diálogo interdisciplinario, y subraya la relevancia de la teoría cultural de la Constitución en cuanto a la seguridad que genera para la norma suprema y para el Estado. Si de la abstracción pasamos a la concreción, veremos que todo esto no quiere decir otra cosa que convertir las convicciones de libertad, dignidad, seguridad, justicia y equidad que sustenta una comunidad, en conducta y en norma de garantía a la vez. La dimensión cultural de la Constitución impide fluctuaciones arbitrarias de la norma, hace predecible y controlable el funcionamiento de las instituciones, reduce la tensión entre gobernantes y gobernados, matiza la naturaleza agonista de la lucha por el poder, y refuerza el Estado de derecho mediante un sistema espontáneo, general y duradero de adhesión a la norma.

\section{La interpretación constitucional}

En 1975 el profesor Häberle publicó un ensayo clave para la teoría constitucional. "La sociedad abierta de los intérpretes constitucionales" propone de una forma original la relación entre la norma suprema y un amplio número de agentes culturales. Ya no se trata de los solos agentes políticos (partidos, dirigentes, representantes) ni de los agentes sociales (medios, líderes de opinión, organizaciones y dirigentes sociales), sino que se extiende hasta otra categoría a la que podemos denominar "cultural" porque comprende todas las expresiones susceptibles de producirse en un medio espacial y temporal determinado. La tesis sustentada por Häberle en ese trabajo (p. 18) se sintetiza así: "en los procesos de interpretación constitucional se insertan potencialmente todos los órganos estatales, todas las potencias públicas, todos los ciudadanos y grupos. ¡No hay números clausus de los intérpretes constitucionales!". Con esto, el profesor alemán abre un nuevo capítulo en materia de interpretación constitucional.

Los enfoques tradicionales acerca de la interpretación concernían a las funciones y objetivos de la interpretación, así como al método para su de- 
Este libro forma parte del acervo de la Biblioteca Juridica Virtual del Instituto de Investigaciones Juridicas de la UNAM

sarrollo. En cuanto a los participantes o agentes susceptibles de practicarla, Häberle formula una propuesta que apunta en un doble sentido: convertir la interpretación constitucional en un supuesto democrático e identificar la interpretación constitucional como un elemento más de la cultura. Lo primero ocurre en tanto que se produce una especie de descentralización de la facultad de interpretar la norma suprema; lo segundo porque sólo una comunidad que ha interiorizado la norma está en posibilidad de interpretarla. Por eso Gomes Canotilho ("A mais...", p. 19; Constituiçao..., p. 91) afirma, certeramente, que con la tesis del pluralismo de intérpretes se lleva la concepción cultural de la Constitución hasta las últimas consecuencias. Los factores mencionados implican, además, dos requisitos: la estabilidad de la norma (decisión política) y la adhesión a ella de la comunidad (fenómeno cultural). Sin estabilidad y adhesión la acción interpretativa abierta es imposible. De acuerdo con lo anterior puede decirse que la interpretación abierta sólo es posible en el Estado constitucional. Todo embona adecuadamente, como piezas de una gran teoría constitucional.

A manera de respuesta a Rousseau, cuando al señalar las deficiencias del sistema representativo aduce que el pueblo (británico) únicamente es libre en el breve momento en que emite su voto (Discours..., III, xv), el profesor Häberle afirma ("La sociedad...", p. 33) que "el pueblo no es precisamente una majestad unitaria que emana sólo el día de las elecciones... El pueblo como majestad pluralista no es menos presente y legitimador para las interpretaciones en el proceso constitucional...”. De ahí que los participantes en la función interpretativa de la Constitución sean los órganos estatales, los "participantes" (partes en juicio, peritos, partidos políticos, lobbystas, medios de comunicación, iglesias, centros de enseñanza, agrupaciones profesionales, por ejemplo). La amplia gama de agentes que interpretan la Constitución son, en general, todos los integrantes de la sociedad abierta. Procede distinguir, entonces, entre los efectos jurídicos, políticos y morales de los actos interpretativos. Todo acto de interpretación puede surtir los tres efectos o alguno de ellos, pero en todo caso contribuirá a fijar el sentido y alcance de la norma constitucional. Sea que se ejerza una acción, que se emita una sentencia, que se adopte una posición política, que se pronuncie una opinión, que se difunda un hecho o un punto de vista, se está contribuyendo a determinar lo que en una sociedad abierta significa la norma suprema que la rige.

La teoría häberliana corresponde a un tipo evolucionado de sociedad. Es, en ese sentido, una teoría europea de la interpretación, en tanto que la sociedad abierta de los intérpretes constitucionales tiene que ser, a la vez, una sociedad altamente informada e integrada. Sin caer en la tesis reduc- 
Este libro forma parte del acervo de la Biblioteca Juridica Virtual del Instituto de Investigaciones Juridicas de la UNAM

cionista de Treitschke en el sentido de que el protestantismo es el fundamento del mundo moderno, no puede excluirse entre los orígenes de la sociedad informada la poderosa tradición protestante que ha auspiciado la interpretación directa de los textos fundamentales. "Es más recomendable ver la Biblia con los ojos propios que con los ajenos", postuló Lutero ("Charlas...", p. 443), e inició lo que Troeltsch (p. 102) ha denominado "la captación viva de la Biblia". Para una sociedad con esos fundamentos, la posibilidad de ampliar la gama de intérpretes constitucionales está dentro de sus patrones de normalidad.

Pero por europea que resulte la teoría häberliana, también debe reconocerse que la fuerza expansiva de las instituciones y de los comportamientos constitucionalistas es un dato de la cultura en otros espacios políticos más allá de Europa occidental. La realidad actual permite hablar de realidades sociales diferenciadas en los demás continentes, en la medida en que varía la densidad de la población informada. En términos generales tiende a extenderse la adopción de un modelo constitucional propio de las sociedades abiertas. Como corolario, y a pesar de las resistencias que resultan de tradiciones internas, entre ellas las religiosas, proclives a estructuras verticales de poder, el modelo de apertura va afianzándose. En este sentido, las tesis del profesor alemán tienen una doble función: explican una realidad donde ya se produce, e indican una dirección, ahí donde apenas se está configurando una nueva realidad. Así como el constitucionalismo democrático tuvo una enorme fuerza expansiva, que simultáneamente generaba problemas y transmitía soluciones compartidas en todas las latitudes, las formulaciones teóricas que lo acompañaron a su vez encontraron resonancia en los diferentes espacios políticos del orbe. Hasta nuestros días todas las grandes concepciones de teoría de la Constitución han procedido de Europa; su traducción a otros ámbitos ha sido cuestión de tiempo, y el caso de Peter Häberle no será una excepción.

Debe tenerse en cuenta, sin embargo, que la transposición de instituciones y de teorías sólo puede darse como parte de un proceso de identificación cultural. Así como en los ámbitos espaciales regional, nacional y aun continental es posible hablar de factores de identidad cultural, en los nuevos desarrollos de la teoría häberliana habrá que explorar cuáles son las formas de identificación entre culturas diferentes. De esas formas de identificación dependerá que algunas modalidades de organización y funcionamiento institucional y de comportamiento cultural puedan compartirse con niveles semejantes de éxito. Esto de ninguna manera supone desconocer que las mismas instituciones produzcan diferentes resultados en distintos espacios, o en diversos momentos aun en los mismos espacios. Lo que se puede ex- 
Este libro forma parte del acervo de la Biblioteca Juridica Virtual del Instituto de Investigaciones Juridicas de la UNAM

plorar es en qué medida los mecanismos de identificación cultural permiten reproducir resultados más o menos similares en medios culturales muy diferenciados. A este respecto Häberle alude a los procesos de recepción cultural ("Desarrollo...", p. 17), que "codeterminan" al Estado constitucional en el mundo, dentro de las correspondientes peculiaridades nacionales.

Es posible que, aplicando la teoría häberliana, podamos encontrar regularidades transculturales que se reproducen a partir de un modelo original, incluso en espacios heterogéneos. Sería el caso del concepto de control del poder. En todas las construcciones constitucionales contemporáneas está presente el concepto de un poder controlado. Aunque los instrumentos varían, el principio ya está generalizado. Aun así, algunos instrumentos tienden a ser adoptados de manera generalizada. Así ocurre, por ejemplo, con la separación orgánica de las funciones del poder y con algunos mecanismos para la defensa de los derechos humanos (ombudsman). Ahora bien, si esas regularidades transculturales se producen es porque hay factores de homogeneización parcial o paulatina, según se les vea en términos temporales o espaciales, que están funcionando en el sentido de una identificación cultural creciente. Häberle apunta ("La revisión...", p. 77), por ejemplo, que a veces las costumbres de un Estado constitucional son adoptadas de manera formal por otro. Considero que lo contrario también es cierto, y el conocimiento de normas expresas puede alentar el surgimiento de conductas constitucionales en otro espacio geográfico o temporal.

Por otra parte, el profesor Häberle ha incorporado ("Derecho constitucional...", pp. 191 y ss.) el criterio de los estándares al derecho constitucional, con lo cual se alcanzan dos objetivos: facilitar el ejercicio comparativo y explicar los procesos de recepción del derecho constitucional. Como se sabe, en su origen el concepto de estándar jurídico se aplicó al derecho comparado privado. La idea de los estándares jurídicos fue propuesta por Roscoe Pound en el congreso de la American Bar Association en 1919. Pound dijo que los juristas se enfrentan a cuatro elementos jurídicos: reglas (disposiciones imperativas adoptadas por el legislador o por los tribunales), principios (imperativos genéricos que resultan de un conjunto de reglas), conceptos (enunciados abstractos) y estándares ("medida media que corresponde a una conducta social correcta") (Tunc, p. 248). Con fundamento en esa tesis de Pound, Tunc ha observado que los estándares están íntimamente asociados a procesos culturales (p. 259), con lo cual coincide la afirmación de Häberle en el sentido de que "el derecho comparado se convierte en cultura comparada" ("Derecho constitucional...", p. 201). Podemos agregar, por ende, que el estándar es una regularidad cultural que caracteriza a un núcleo de normas dentro de un sistema jurídico y permite identificar y valorar 
Este libro forma parte del acervo de la Biblioteca Juridica Virtual del Instituto de Investigaciones Juridicas de la UNAM

lo que socialmente se estima adecuado. En el ámbito del derecho privado fue una pauta de clasificación de un conjunto de conductas de relevancia jurídica; esa pauta es susceptible de ser adoptada, como lo hace el profesor alemán, por el derecho constitucional comparado.

En cuanto a las posibilidades de que se generalice la interpretación abierta de la Constitución, como se plantea en la teoría häberliana, parecería necesaria una mayor homogeneidad cultural de la que en este momento se advierte. En principio parecería que la "sociedad abierta de los intérpretes constitucionales" sólo funcionaría en un ámbito altamente integrado y que sólo ahí podría contribuir a sostener la cohesión social y a preservar la adhesión a la Constitución. Por el contrario, en una sociedad muy fragmentada, la multiplicación de los intérpretes constitucionales podría generar cargas adicionales de tensión que harían difícil el funcionamiento de las instituciones, la integración social y la consolidación del sentimiento constitucional. Desde esta perspectiva y en este aspecto podría decirse que la teoría häberliana es esencialmente europea, y que la modalidad de la sociedad abierta de los intérpretes constitucionales es tendencialmente posible, en tanto que se desarrollará en la medida en que se reproduzca el modelo de cohesión social cultural que ya existe en numerosos países de ese continente. Sin embargo, es más probable que incluso en una sociedad con escisiones el proceso comunicativo de la interpretación abierta contribuya a cohesionarla. Esta es, por cierto, la convicción de Häberle, como bien ha interpretado Estévez Araujo (p. 87). Se trata de un tema que tendrá que ser analizado con mayor detenimiento en las sociedades con problemas de integración, como la mexicana. El propio profesor de Bayreuth advierte ("Problemi...", p. 3367) que todavía no ha sido elaborada una teoría del Estado constitucional con pretensiones de universalidad. Todo modelo teórico, agrega, expresa una verdad parcial y provisional, circunscrita en el tiempo y en el espacio. A lo más que podemos llegar, concluye en este punto, es a considerar al Estado constitucional como un "proyecto tendencialmente universal". En palabras de Francisco Vitoria podría decirse que "el orbe es una República", no en tanto que se organice en un solo Estado, pero sí en cuanto a la fuerza expansiva de numerosas instituciones jurídicas y a las similitudes culturales que progresivamente se acentúan.

$* * *$

La fluctuación constitucional está relacionada con cambios formales pero también con procesos interpretativos. En este sentido los intérpretes 
Este libro forma parte del acervo de la Biblioteca Juridica Virtual del Instituto de Investigaciones Juridicas de la UNAM

constitucionales juegan un papel de gran importancia para fijar el contenido de la norma constitucional. La interpretación no es únicamente una forma de interiorizar el texto, sino también de modificarlo. En tanto que haya criterios interpretativos que se generalicen, la cohesión social y la identidad cultural se mantendrán; pero en la medida en que se generen contrastes y aun contradicciones, podrá inocularse una tendencia disruptiva que sólo podrá eludirse o superarse precisamente en virtud de la presencia de valores culturales que, por su naturaleza, tienen una gran fuerza cohesiva. Por eso la tesis häberliana de los intérpretes constitucionales refuerza la teoría de la relación entre Constitución y cultura. En este punto parece aplicable la teoría de la acción comunicativa que, según Habermas (p. 171 y ss.), se basa en un "proceso cooperativo de comunicación". Conforme a ese proceso los participantes relativizan su interpretación en tanto que consideran que su validez queda puesta "en tela de juicio" por parte de otros intérpretes. En estos términos, tal vez sería adecuado hablar también de proceso cooperativo de interpretación, en tanto que los agentes sociales que la practican no lo hacen para disolver o atomizar la sociedad y su orden normativo, sino para integrarlo y cohesionarlo. Este es, por lo demás, un punto de convergencia que vincula a Smend, Habermas y Häberle: por vías distintas se orientan a identificar los elementos que permiten o explican la integración de la sociedad.

Habermas (pp. 196 y ss.) entiende por cultura "el acervo de saber en que los participantes en la comunicación se abastecen de interpretaciones para entenderse sobre algo en el mundo". En este sentido, la interpretación constitucional abierta de la teoría häberliana encuentra un importante refuerzo porque la interpretación abierta, lejos de contribuir a la fragmentación o al acrecentamiento de las tensiones, genera exactamente lo contrario: cohesión. La interacción de los intérpretes se lleva a cabo dentro de un marco cultural que, por definición, les provee de instrumentos homogéneos de interpretación. Esto representa una garantía mínima para mantener la identidad cultural del conjunto, sin limitar la libertad de cada uno de los agentes de la interpretación. La teoría häberliana, por tanto, cuenta con una sólida base que permite aplicarla, con las reservas de circunstancia tanto espacial como temporal que él mismo reconoce, en diversos ámbitos culturales.

$* * *$

El tema de la intercomunicación entre sistemas es desarrollado por el profesor Häberle en su trabajo "Elementos teóricos de un modelo general 
Este libro forma parte del acervo de la Biblioteca Juridica Virtual del Instituto de Investigaciones Juridicas de la UNAM

de recepción jurídica". Allí demuestra (pp. 151 y ss.) de qué manera la recepción jurídica forma parte de procesos generales de recepción cultural. Es un ensayo innovador, indispensable para comprender cómo se reproducen las instituciones en derecho comparado, y cómo van adquiriendo diversos matices en el tiempo y en el espacio. El autor identifica dos grandes motores de la recepción jurídica: la necesidad de innovación, que lleva a mirar hacia otros sistemas para identificar opciones, y la generalización de los problemas que, por lo mismo, implica la generalización de las soluciones. En este caso se encuentran, por ejemplo, las normas de protección del ambiente. Los "elementos teóricos" se encaminan hacia una verdadera teoría, que seguramente el profesor Häberle desarrollará más adelante. Tal vez sea posible distinguir entre recepción, que en sentido lato corresponde a la incorporación de disposiciones generadas en otro espacio, y recuperación, que concierne a la reincorporación de una institución preexistente en el mismo Estado. Así ha ocurrido en México, por ejemplo, con el sistema federal, adoptado por la Constitución de 1824, derogado en 1836, restablecido efímeramente en 1847 y definitivamente desde 1857. En tanto que las sucesivas generaciones tienen el derecho de actualizar el pacto social, lo que no descarta que en determinado momento se adopten disposiciones vigentes en otros tiempos, quizá también pueda incorporarse la recuperación normativa dentro del amplio espectro de la recepción.

$* * *$

Otro problema que puede ser examinado con relación al de la recepción, es el de las interacciones institucionales. El profesor Häberle subraya (Teoría..., p. 78) que una Constitución debe estar bien estructurada "desde sus cimientos". Esta es una cuestión que todavía no se desarrolla con suficiente amplitud en el derecho constitucional, ni siquiera en los trabajos sobre "ingeniería constitucional", como el publicado por G. Sartori en 1994. Por lo general, las instituciones son estudiadas de manera individual, y cuando se utiliza el método comparativo se determina cómo funcionan en diversos sistemas, pero no se les suele relacionar con otras instituciones del mismo sistema para determinar la manera en que interactúan. Por interacciones institucionales se pueden entender los efectos que entre sí producen las diversas instituciones de un mismo sistema. Esta interacción puede ser positiva o negativa, si potencia o inhibe los resultados esperados de cada institución. El tema es relevante en el momento de un diseño constitucional porque en ocasiones los procesos de recepción se practican de manera indiscrimina- 
Este libro forma parte del acervo de la Biblioteca Juridica Virtual del Instituto de Investigaciones Juridicas de la UNAM

da, y acaban por incorporarse instituciones con potencialidades adversas. Este es el caso, por ejemplo, de las instituciones representativas y participativas. En muchos sistemas han sido incorporados instrumentos propios de la democracia semidirecta, sin advertir que en algún momento entrarán en tensión con los órganos de representación política. Así, una interacción negativa puede generar bloqueos institucionales no previstos; por el contrario, las instituciones entran en sinergia merced a una adecuada identificación y acomodo de sus respectivas posibilidades.

\section{El derecho europeo}

Entre las indagaciones llevadas a cabo por el profesor Häberle con relación al derecho constitucional europeo, figura su ensayo "Programas sobre Europa en Constituciones y proyectos constitucionales recientes. El desarrollo del "derecho constitucional nacional sobre Europa". Publicado originalmente en 1995, es una parte importante de su teoría constitucional. A través de las cláusulas europeas contenidas en las Constituciones y en los proyectos constitucionales, cuya tipología desarrolla, se puede apreciar el proceso de construcción normativa de Europa como concepto cultural integrador.

Sobre este punto debe subrayarse la modernidad del concepto mismo de Europa. Es a partir del siglo XVI cuando el concepto de Europa se desarrolla con vigor y aparecen una nueva cartografía y numerosas obras referidas expresamente a temas "europeos". El gentilicio "europeo" es, comprensiblemente, posterior al constructo "Europa". En inglés y en español los primeros registros de la utilización de ese gentilicio corresponden al siglo XVI, y sólo se generaliza al principiar el XVII (véanse Knolles y Ovalle, por ejemplo). Hasta antes del descubrimiento de América se hablaba de "cristianos", no de "europeos", y la "cristiandad" era el conjunto de países que hoy corresponde a Europa.

La historiografía propiamente referida a "Europa" también corresponde al siglo XV. La historia general de Blondus, que comprende de 472 a 1440, publicada en Venecia en 1483, todavía se denomina Historiarum ab inclinatione romanorum imperii decades. Una de las primeras alusiones a Europa aparece en la obra de Eneas Silvio Piccolomini publicada en 1490. Fueter (t. I, p. 130) subraya que esta obra póstuma de Silvio, escrita en Bohemia, quedó inconclusa. En todo caso su contenido es fundamentalmente lexicográfico y geográfico, por lo que se explica la referencia a "Europa". Además, Silvio, ungido como Pío II en 1458, fue considerado un papa dotado de excepcional erudición y elocuencia (Ranke, pp. 33 y ss.), cuyo interés por 
Este libro forma parte del acervo de la Biblioteca Juridica Virtual del Instituto de Investigaciones Juridicas de la UNAM

la cultura continental quedó demostrado por sus hábitos de viajero y de lector infatigable. En buena medida, Silvio es un auténtico renacentista y, en el tema que nos ocupa, un precursor. En realidad las primeras obras que directamente incluyen en su denominación y contenido el concepto europeo, corresponden ya al siglo XVI.

En este proceso debe tenerse en cuenta que la inesperada presencia americana en Europa aceleró la ruptura con la Edad Media. Un nuevo grupo humano, una nueva fuerza cultural y una nueva geografía produjeron un importante impacto en el espacio europeo, en un momento en el que las artes y la ciencia ya habían comenzado a experimentar profundas transformaciones a partir del siglo XV. "Fue el Nuevo Mundo lo que repercutió primariamente sobre el mundo humano todo y la idea de él", ha demostrado Gaos (p. 230). El descubrimiento de América contribuyó a su vez al "descubrimiento", o más propiamente a la "invención" de Europa. Hale (pp. 47 y ss.) sustenta que "gracias a la suprema confianza que les inspiró el descubrimiento de América, los europeos hicieron un mayor esfuerzo por plantearse la cuestión de su identidad". La fuerza del contraste y la conciencia de haber encontrado un mundo nuevo también ayudaron a poner fin a la fragmentación medieval. Entre Europa e Iberoamérica existe un paralelismo cultural a partir del encuentro de los dos mundos, como le ha denominado Miguel León Portilla (pp. 21 y ss.), que debe tenerse presente cuando se examina la teoría constitucional.

El profesor Häberle subraya ("Programas...", pp. 118 y 129) que las Constituciones europeas han intensificado su programa europeo, y propone que "toda buena política constitucional" considere el tema europeo dentro de la norma suprema. La observación se inscribe dentro de su teoría constitucional y, como otros de sus enunciados, son susceptibles de traslación a otros espacios constitucionales-culturales. Adoptando la terminología y el esquema analítico adoptado por el profesor alemán, podemos advertir que las cláusulas iberoamericanas tienen ya una presencia significativa, como demuestran las Constituciones de Bolivia, de 1967 (artículo 37, 1); Brasil, de 1988 (artículo 4o.); Colombia, de 1991 (artículo 9o.); Cuba, de 1976, reformada en 1992 (artículo 12); Ecuador, de 1998 (artículo 4o., 5); Nicaragua, de 1995 (artículo 9o.); Uruguay, de 1967 (artículo 6o.), y Venezuela, de 1999 (artículo 153). Además, las Constituciones de Costa Rica, de 1949 (artículo 14, 3); El Salvador, de 1996 (artículo 90, 3); Guatemala, de 1994 (artículo 145); Honduras, de 1982 (artículo 24, 1), y Nicaragua, de 1995 (artículo 17), contienen referencias a Centroamérica. Aunque falta un ejercicio para establecer la tipología de estas cláusulas y valorar su función, en general puede 
Este libro forma parte del acervo de la Biblioteca Juridica Virtual del Instituto de Investigaciones Juridicas de la UNAM

decirse que es válida en este hemisferio la recomendación que el profesor alemán dirige a Europa: el proceso está en marcha y debe intensificarse.

La mirada siempre atenta del jurista no deja escapar la oportunidad que le ofrece la Constitución suiza de 2000 para identificar los nuevos aportes que esa norma suprema ofrece al derecho ("La revisión...", pp. 74 y ss.). Ciertamente, esa novísima Constitución lo es tanto por lo reciente de su vigencia cuanto por el contenido de sus preceptos. Häberle en especial subraya la pulcritud y precisión del preámbulo; la técnica de las "disposiciones generales"; el compromiso con "el bienestar de los débiles"; la inclusión de los principios del Estado de derecho (que incluye la obligación del Estado de actuar de manera "razonable"), de la subsidariedad y de la proscripción de la arbitrariedad, y numerosas disposiciones concernientes al proceso cultural, incluyendo la responsabilidad cultural de los medios de comunicación. Al profesor Häberle le llama la atención, con todo, la ausencia de referencias en esa Constitución a Europa. No por ello, aclara, deja de representar un nuevo modelo para el constitucionalismo europeo.

Por otra parte, a propósito de la función de los preámbulos constitucionales, con toda propiedad el profesor Häberle (Teoría..., p. 56) nos llama la atención hacia el de la nueva Constitución suiza. En unas cuantas líneas, con maestría literaria, se sintetiza el compromiso de un Estado basado en la renovación del pacto social, el fortalecimiento de la libertad y la democracia, el respeto por la diversidad, la responsabilidad ante las generaciones sucesivas y una categórica aseveración: "la fortaleza de un pueblo se mide por el grado de bienestar de sus miembros más débiles". La función de los preámbulos es analizada con amplitud (Teoría..., pp. 96 y ss.) porque permiten que, mediante un texto muy concentrado, la Constitución llegue directamente a la ciudadanía, "sin circunloquios". La relevancia de los preámbulos ha sido desarrollada de manera exhaustiva por el profesor español Javier Tajadura en diferentes y valiosos estudios; sus conclusiones, ampliamente documentadas, coinciden con la tesis häberliana. 
Este libro forma parte del acervo de la Biblioteca Juridica Virtual del Instituto de Investigaciones Juridicas de la UNAM

Refiriéndose al proceso europeo Häberle ("El Estado...”, pp. 94 y ss.) apunta que la Constitución se proyecta esencialmente sobre tres aspectos: en el ámbito nacional; en la demanda de descentralización del poder, que se traduce en formas federales o regionales, y en la apertura de los Estados constitucionales hacia la comunidad internacional. En realidad habría que considerar si esos tres horizontes del constitucionalismo que el profesor identifica en Europa, no están presentes también en las expresiones del constitucionalismo contemporáneo en el resto del mundo.

Con relación a la dimensión nacional del orden constitucional, Häberle afirma que "todos los Estados constitucionales tienen que ser concebidos de manera pluralista". En este sentido se apunta la nueva dimensión de la democracia, que en la actualidad tiende a combinar el principio mayoritario para la integración del gobierno con una amplia gama de derechos para las minorías. En este ámbito se inscriben los derechos culturales, cuya incorporación a las Constituciones lleva un ritmo creciente, y los derechos de naturaleza política propios de las minorías, que también cuentan ya con diversas expresiones constitucionales. Entre éstos figuran los derechos de los partidos de oposición, por definición minoritarios, y los derechos de las minorías parlamentarias.

En cuanto al segundo aspecto, referido al proceso de descentralización, Häberle señala que incluso en los Estados de tradición unitaria, y cita el caso de Francia, se está avanzando hacia la regionalización. Otro tanto podría decirse del caso británico, donde la devolución de facultades ha significado un cambio importante en la organización y funcionamiento local del poder en Escocia y Gales, e incluso en la ciudad de Londres. Se trata, asimismo, de un proceso generalizado acerca del cual es necesario ejercer una cuidadosa observación. Si por una parte la descentralización del poder es una manifestación del constitucionalismo contemporáneo, por otra, si no se produce conforme a procedimientos responsables y bien articulados, puede auspiciar una nueva tendencia a la entropía, particularmente en sistemas constitucionales relativamente frágiles, como los latinoamericanos, donde a veces el federalismo o el regionalismo han servido para encubrir fenómenos de concentración local del poder, conocidos como "caciquismo".

Por eso es importante tener en cuenta que las características atribuidas por el profesor Häberle al constitucionalismo europeo contemporáneo forman parte de un conjunto, de suerte que si se pierde cualquiera de esas notas, las restantes quedan sin sentido. En el caso comentado, si sólo se tuviera 
Este libro forma parte del acervo de la Biblioteca Juridica Virtual del Instituto de Investigaciones Juridicas de la UNAM

presente la descentralización del poder, pero se omitiera la convergencia con los derechos de las minorías, la concentración local del poder haría nugatorios los efectos de la organización constitucional. Los tres factores, por ende, deben darse en un mismo tiempo y en un mismo espacio; no corresponden a expresiones de naturaleza diacrónica sino sincrónica.

El tercer rubro concierne a la apertura del Estado constitucional hacia la comunidad internacional. Este es un aspecto que debe verse con atención para no confundir "apertura" con "integración". El "constitucionalismo cooperativo" que propone nuestro autor ("El Estado...", p. 96) reposa en una "comunidad mundial de Estados constitucionales". Vale la pena reiterar que, por definición, sólo existe el Estado constitucional donde hay soberanía. En esta medida la propuesta de Häberle nada tiene que ver con las temerarias afirmaciones de que el nuevo orden internacional y la nueva dimensión del Estado conducen a una "soberanía restringida". Esta afirmación carece de base conceptual y práctica, y entraña una contradicción que está resuelta desde el siglo XVII por Hobbes cuando enunció el axioma de que por encima del Estado no puede existir otro poder, porque si existiera, ése sería el Estado.

La comunidad mundial de Estados constitucionales que propone nuestro autor, supone, precisamente, la presencia de un órgano constituyente que no puede ser sino soberano. Desde esta perspectiva, el planteamiento implica una forma de interacción horizontal, responsable y libre, entre los integrantes de la comunidad internacional. Esta posición es relevante, sobre todo ante el discurso, propuesto por Nozick (esp. en Anarchy, State and Utopia), que aboga por el denominado "Estado mínimo". El Estado contemporáneo está haciendo frente a un doble embate: desde su interior, donde se le quiere desmontar para transferir sus potestades a los particulares y a las regiones; y desde el exterior, donde la llamada mundialización se presenta como una garantía en contra del estatismo que identificó en especial a los sistemas socialistas.

En diversos textos (por ejemplo, en "El Estado...", pp. 102 y ss.; "Problemas...", pp. 1186 y ss.; "El eterno combate...", pp. 105 y ss.) del profesor Häberle está presente la referencia al "jurista europeo". El concepto incluye tres elementos: la difusión continental de algunos autores de diversos países; la utilidad de que sean impulsados estudios comparativos sobre temas de cuño reciente, como los sistemas regionales, y el nuevo papel del derecho 
Este libro forma parte del acervo de la Biblioteca Juridica Virtual del Instituto de Investigaciones Juridicas de la UNAM

comparado como quinto método de interpretación, de suerte que los tribunales constitucionales practiquen y utilicen una comparación valorada de derecho, yendo más allá de sus fronteras.

En realidad, esa figura que ha propuesto Häberle puede extenderse a la de jurista continental, interesado en las innovaciones que se van produciendo a lo largo del mundo. Él mismo es un buen ejemplo de ese quehacer, pues sus trabajos reflejan hasta qué punto está atento al acontecer asiático, africano, latino y norteamericano. Hablar de un "jurista universal" podría resultar jactancioso y desproporcionado; pero si por continental se puede entender al que observa y analiza lo más relevante a lo largo y ancho del orbe, se trata de un ejercicio tan necesario como posible.

La insularidad de los sistemas jurídicos ha quedado rota por varias razones. Una de ellas es la red de comunicaciones; pero más importante todavía es la comunidad de intereses. La defensa y desarrollo de los derechos humanos, por ejemplo, encuentra su más efectivo soporte en que constituyen una aspiración colectiva de la humanidad. Las formas de organización política conciernen a cada sociedad en particular; pero los elementos que se integran a las cualidades del ser humano son objeto de interés, de preocupación y aun de expresión solidaria en todos los cantos de la Tierra. De ahí que pueda retomarse la idea del jurista europeo del profesor Häberle y extenderla al planeta.

\section{La Constitución alemana}

$\mathrm{Al}$ revisar la forma en que ha sido aplicada la Constitución alemana, el profesor Häberle ("Teoria de la Constitució...", p. 56) nos recuerda que sólo en una ocasión (1982) se ha aplicado el voto de censura constructivo. Esto lo explica en tanto que, por las experiencias negativas, la Ley de Bonn fue concebida como una "contra Constitución" de Weimar. Este notable texto constitucional había sido el producto de una asamblea proclive a los compromisos y con una mayoría fluctuante (Peukert, pp. 35 y ss.) que en no mucho tiempo demostró la incapacidad de las instituciones para preservar la integridad del territorio nacional (como fue el caso de la ocupación francobelga del Ruhr en enero de 1923) y para asegurar la estabilidad financiera del país (como el desmesurado derrumbe del marco entre enero y agosto de 1923). Diez años después de su establecimiento, el sistema parlamentario estaba en proceso de disolución (Mommsen, pp. 269 y ss.), y se abría la puerta al totalitarismo. Carl Schmitt había iniciado en 1923 el más duro embate posible contra el sistema parlamentario (El parlamentarismo, esp. pp. 42 y ss.) 
Este libro forma parte del acervo de la Biblioteca Juridica Virtual del Instituto de Investigaciones Juridicas de la UNAM

al negar su carácter democrático; recibió una inteligente respuesta de Kelsen en 1925 (El problema del parlamentarismo) pero culminó su ataque en 1932 (Legalidady legitimidad, esp. pp. 13 y ss.). De que ahí la certera caracterización häberliana como "contra Constitución" aluda, esencialmente, a la decisión de la Ley Fundamental de 1949 en el sentido de dar estabilidad al sistema político y no volver a correr los riesgos de un retorno al totalitarismo. Häberle agrega que un concepto clave es el de una "democracia defensiva". Ésta es una tesis central.

Cuando el profesor alemán habla de que la democracia sea capaz de defenderse no alude a los procedimientos jurisdiccionales de defensa de la Constitución, ni a la dictadura constitucional (o comisoria) sino a la estructura constitucional del poder que garantice la vigencia de la democracia. Es en este sentido que orienta el ensayo en el que revisa las aportaciones de la norma suprema de su país. En Alemania se tuvo el buen tino de equilibrar las instituciones políticas con una adecuada configuración de derechos tutelares de la libertad, la igualdad, la equidad, la propiedad, la seguridad jurídica y la dignidad. Se trata de un haz de instituciones que generan un poderoso efecto de sinergia democrática. Lo más llamativo de esa Ley consiste, precisamente, en que se potencian todas las ventajas de las diversas instituciones previstas, y se eluden las interacciones negativas.

El ensayo de Häberle deja ver claramente cómo el entramado institucional produce una singular complementación cuyo resultado es precisamente esa "democracia defensiva". Algunos autores han querido ver en la moción de censura constructiva al único instrumento relevante para la estabilidad democrática en Alemania, pero pasan por alto por lo menos otros igualmente importantes, que Häberle tiene buen cuidado en identificar: la protección del sistema representativo (como también ocurre en Estados Unidos, donde algunos procedimientos de democracia directa sólo se aplican en los estados, pero no en el nivel federal); los principios del Estado social; la prohibición de la arbitrariedad, que ya han adoptado también las Constituciones de Argentina (artículo 43), Chile (artículo 20), España (artículo 9.3) y Suiza (artículo 9o.); y un federalismo muy flexible. El caso de la norma fundamental alemana denota hasta qué punto es funcional la teoría de la Constitución como ciencia cultural. Precisamente la relación entre la formulación normativa y su entorno cultural permite explicar ese singular equilibrio institucional que da estabilidad a la democracia alemana. 
Este libro forma parte del acervo de la Biblioteca Juridica Virtual del Instituto de Investigaciones Juridicas de la UNAM

El federalismo cooperativo germano se ha transformado a partir de 1990, con motivo de la reunificación. Häberle llama la atención ("Problemi...”, p. 3360) acerca de las nuevas formas de ayuda financiera y de colaboración administrativa y jurídica ofrecida a los Länder, que han originado a su vez nuevas expresiones de responsabilidad por parte del poder federal. El riesgo que presenta esta ampliación del federalismo cooperativo es el de alentar los efectos del federalismo centralizador, en palabras de Hesse. Este apunte preventivo de Häberle es aplicable a la mayor parte de los estados federales. En México, por ejemplo, el federalismo ha carecido de peso cultural, por lo que ha sido extraordinariamente vulnerable y, en buena medida, ha constituido una pieza declarativa. Además, en los últimos años se ha acentuado una fuerte aunque imperceptible corriente para desnaturalizar el federalismo; la reforma constitucional de 1996 introdujo el sistema de senadores de representación proporcional, con lo cual modificó la base territorial para la elección de la segunda cámara, que siempre habían sido los estados federados. Los efectos del "federalismo centralizador" se han dejado sentir, sin encontrar respuesta. Este fenómeno se explica con los instrumentos de análisis häberliano, en tanto que en México el proceso cultural está intensamente centralizado. En el área metropolitana de la ciudad capital se localizan la mayor concentración demográfica nacional y uno de los dos más importantes centros industriales del país; allí está el nudo nacional de comunicaciones aéreas, terrestres y electrónicas; allí se concentra el grueso de la renta nacional. La capital política del país también es la capital financiera y cultural nacional. En la ciudad de México están los más importantes centros de educación superior e investigación científica, las editoriales, los medios impresos y electrónicos de comunicación, las instalaciones culturales (teatros, librerías, auditorios, salas de exposiciones, de conciertos y de cinematógrafo); ahí reside el mayor número de intelectuales del país. Hace años se acuñó la despectiva frase "fuera de México todo es Cuautitlán”, para denotar, por referencia a lo que entonces era un modesto municipio rural colindante con la gran ciudad, que lo que no estuviera en ella era marginal y secundario. Se trata de una realidad cultural que, como es comprensible, tiene su correlato en la organización y funcionamiento del poder. El fenómeno mexicano confirma la tesis häberliana de que no puede haber federalismo sin lo que él llama "soberanía cultural" de los Estados. 
Este libro forma parte del acervo de la Biblioteca Juridica Virtual del Instituto de Investigaciones Juridicas de la UNAM

$\mathrm{Al}$ analizar el tema de la unidad política y el pluralismo cultural en Alemania, el profesor de Bayreuth nos ofrece lo que podemos denominar como nueva teoría dual del federalismo. El federalismo, nos dice, combina "de manera eficaz" la unidad, que corresponde a un proceso político, con el pluralismo, que concierne a un proceso cultural: "el corazón del federalismo germano radica en la soberanía cultural de los Länder", dice ("Unità...", p. 178; "Problemi...", pp. 3373 y ss.). Denominamos "nueva" a esta teoría, porque el dualismo tradicional alude a separación de competencias entre los estados federales y las entidades federativas. En este caso lo que Häberle hace es aplicar los principios generales de su doctrina al caso del federalismo, e introducir el elemento cultural que la identifica.

$* * *$

Con relación al Tribunal Constitucional alemán es interesante advertir que Häberle ("El recurso...", p. 235) no considera negativos los compromisos entre los partidos políticos cuando cada una de las cámaras (Bundestag y Budesrat) elige a los diferentes jueces que lo integran, a pesar de que reconoce (ibidem, p. 248) que en la actualidad esos acuerdos corresponden al arcano de la política. Su expresión se basa en el reconocimiento de que los jueces han mostrado su independencia con relación a todos los partidos. Con todo, también opina (ibidem, pp. 236 y 275) que el sistema de designación podría mejorar si también se diera participación en la designación al presidente de la república (como en Italia) y si los candidatos al cargo fueran objeto de interrogatorio público, como en Estados Unidos y en México, por ejemplo.

$\mathrm{Al}$ examinar el funcionamiento del Tribunal, el autor subraya la importancia que han tenido los votos particulares, establecidos legalmente a partir de 1971. Ese tipo de voto se inscribe en el proceso de apertura en cuanto a la interpretación constitucional postulada por Häberle ("Los derechos...", p. 14) y contribuye a que las resoluciones del Tribunal permitan resolver una cuestión controvertida, e identificar la riqueza de posibilidades que ofrecen la ley y el derecho para dirimir conflictos. Por eso incluso los califica como "jurisprudencia alternativa". Con ese mismo criterio, Häberle valora positivamente la cuestión de inconstitucionalidad, susceptible de ser promovida por un tercio de los integrantes del Bundestag, que al proteger a la minoría también supone una forma de ampliar el número de intérpretes constitu- 
Este libro forma parte del acervo de la Biblioteca Juridica Virtual del Instituto de Investigaciones Juridicas de la UNAM

cionales. Desde esta perspectiva todo esfuerzo constitucional que se haga para extender y garantizar los derechos de las minorías es un paso más en el sentido de universalizar la defensa del orden constitucional, en los términos propuestos por el profesor alemán.

Pero el punto más relevante y original que nos presenta Peter Häberle en cuanto a la jurisdicción constitucional, consiste en su afirmación ("El recurso...", pp. 242 y ss.) en el sentido de que el Tribunal Constitucional tiene una "responsabilidad mancomunada" en la garantía y en la actualización de la Constitución como expresión del contrato social. En el caso de la Corte norteamericana incluso alude a que es considerada una especie de "congreso constitucional permanente, por el carácter pionero que adquieren sus decisiones", y en el caso alemán admite que lleva a cabo modificaciones constitucionales materiales. Esta forma de entender el papel del Tribunal no ha sido planteada por ningún otro autor, y confiere a los tribunales constitucionales un papel central en la vida de los Estados constitucionales. Esta tesis häberliana es consistente con toda su concepción cultural de la Constitución. Es comprensible que el órgano del Estado que tiene como función ejercer el control constitucional, al interpretar la norma suprema de manera sucesiva en el tiempo también vaya incorporando nuevos elementos que surgen de varias fuentes: de los actores en juicio, de la renovada configuración de la judicatura, de las fuerzas políticas, y en general de los múltiples agentes que van dando forma a la vida política (y a la cultura política) de una sociedad en cada momento de su historia. He aquí donde se inserta la novedosa tesis häberliana: la Constitución en un sistema democrático es la elaboración normativa que se funda en el constructo denominado "pacto o contrato social". En tanto que constructo, esto es, una hipótesis valorativa, el contrato social explica las libertades individuales y públicas, de suerte que toda la estructura y el funcionamiento de las instituciones tiene que basarse en la asunción de ese contrato. Si la función de un tribunal constitucional consiste en preservar la norma suprema, se trata, a la postre, de mantener la vigencia del contrato social. La relación advertida por Häberle es incontrovertible y tiene, como es natural, importantes consecuencias. Eso nos explica, entre otras cosas, que en algunos sistemas, por ejemplo el norteamericano, la Corte Suprema desempeñe un papel relevante en el proceso de reforma constitucional. Recuérdese, por ejemplo, que la sentencia en el caso Dred Scott (1857) contribuyó a precipitar la guerra civil en Estados Unidos, precisamente porque la resolución de la Corte no correspondió a la necesidad de preservar el pacto social y, por el contrario, introdujo en su resolución elementos que lo fracturaban. En otros numerosos casos, por el contrario, la Corte ha iniciado nuevas formas de ver y aplicar la Constitución. 
Este libro forma parte del acervo de la Biblioteca Juridica Virtual del Instituto de Investigaciones Juridicas de la UNAM

Cuando identifica al control jurisdiccional de la Constitución como parte central del contrato social, Häberle actualiza el significado de la teoría contractual y le imprime un nuevo alcance, diferente del que sustentan las corrientes neocontractualistas de nuestro tiempo. Más aún: puede decirse que las bases del acuerdo social residen en el principio de que los bienes sociales fundamentales (libertades, acceso a la riqueza, dignidad) deben ser compartidos en igualdad de condiciones, y que la vulneración de ese pacto genera situaciones de injusticia e inequidad que hacen insustentable un orden constitucional democrático. La necesidad de que existan reglas básicas, socialmente compartidas y entendidas como el sustento de todo el orden normativo, a lo que podemos denominar "pacto social", convierte a los órganos de control del poder en elementos clave para la preservación del pacto mismo.

$\mathrm{Al}$ examinar este tema debe tenerse cuidado en no restringir el alcance de la teoría häberliana. Para su autor, los jueces son guardianes de la Constitución, pero no todos los guardianes. Téngase presente que en la sociedad abierta de los intérpretes constitucionales "jtodos nosotros somos (políticamente) 'guardianes de la Constitución!'” ("El recurso...”, p. 244). La consecuencia de esta posición es importante: el control jurisdiccional de la Constitución puede inducir hacia la desconfianza en relación con las demás instituciones de la democracia y a una "confianza desproporcionada" en la función jurisprudencial. Esto lleva al autor a subrayar la relación entre política y derecho, precisamente porque admite que se trata de funciones complementarias en una república. Y apunta a la diana de uno de los problemas cruciales del Estado contemporáneo: la pérdida de confianza en la función de la política. Ahora bien, como históricamente se sabe que los episodios de desconfianza en la política y en las instituciones que se nutren de ella han propiciado el surgimiento del caudillismo, Häberle nos precave con relación a la hegemonía de los jueces. Tal prevención no parte de que él, a su vez, tenga algún tipo de desconfianza con relación a esos magistrados, sino porque el equilibrio exige mantener relaciones simétricas en las responsabilidades y funciones públicas. Además, las sobrecargas de demandas dirigidas a algunos órganos del poder en especial pueden producir insatisfacción para aquellos que las generan. En este punto es fundamental comprender que Häberle entiende ("El recurso...", p. 243) por cultura política las representaciones, experiencias y expectativas subjetivas de los ciudadanos respecto a las instituciones, y por ende incluye el comportamiento objetivo, las actuaciones de los responsables políticos, las prácticas parlamentarias, la actividad de los órganos jurisdiccionales, el grado efectivo de libertad y de pluralismo. Por otra parte, entiende por cultura constitucional (Teoría..., p. 36) la suma de actitudes, ideas, experiencias, valores y expectativas subjetivas 
Este libro forma parte del acervo de la Biblioteca Juridica Virtual del Instituto de Investigaciones Juridicas de la UNAM

y de acciones objetivas, individuales y colectivas, que resultan de un texto constitucional precedente y hacen posible su estabilidad. Estos conceptos son fundamentales para entender la teoría de Häberle en toda su amplitud. Desde esa perspectiva todas las expresiones que impliquen la distorsión del pluralismo y afecten la adecuada percepción de las instituciones, debe ser considerada extraña a la teoría häberliana de la Constitución.

La relación entre cultura y los problemas sociales es indisociable en la teoría häberliana. Aquí se advierte también la renovación del concepto de Estado en general y del Estado social de derecho de Heller, en particular. Con relación al concepto de Estado, Häberle advierte ("El Estado...", p. 88) que la doctrina clásica sólo reconoce tres elementos que lo integran (pueblo, territorio y poder). La Constitución, que "no tiene sitio en esa tríada", debe ser considerada un cuarto elemento característico del Estado. La relevancia de esta propuesta debe ser examinada a la luz de la propia teoría constitucional del profesor alemán, en tanto que a través de la integración de la Constitución también se estaría incorporando al Estado la idea de cultura, hasta ahora reservada al concepto de nación. Se trata, desde luego, de un tema que debe ser explorado con detenimiento, pero que en todo caso apunto como una idea que complementa la visión constitucional de Häberle

Por otra parte, Häberle señala ("Desarrollo...", pp. 32 y 41) que la estabilidad institucional, en el caso de Alemania, tiene mucho que ver con esa idea del Estado social; y al examinar la experiencia germana en el ámbito de la evolución constitucional europea contemporánea señala que el desempleo es una cuestión directamente vinculada con la naturaleza del Estado constitucional. "El desempleado por tiempo indefinido pierde un poco su identidad..., se le despide del 'contrato social'..., es marginado. El Estado constitucional y la sociedad constituida de ciudadanos tienen que hacer frente a todo esto". Como se ve, el componente social está directamente vinculado con el proceso constitucional. Es un enfoque distinto al que se ha presentado por otros autores; no se alude a lo social como una categoría de la justicia, sino como parte consustancial del Estado constitucional. Es una forma radical de entender la integración entre pacto social y norma suprema. Todo ciudadano, en un sistema constitucional abierto, debe mantener una relación simétrica respecto de los demás. Esto explica también la preocupación de Häberle por las minorías, incluidas, como es natural, las religiosas. En la sociedad de ciudadanos no caben exclusiones de ningún 
Este libro forma parte del acervo de la Biblioteca Juridica Virtual del Instituto de Investigaciones Juridicas de la UNAM

tipo. Y el desempleo es, según esta novedosa perspectiva, una forma de segregación del cuerpo ciudadano, incompatible con el Estado constitucional. A partir de esta tesis pueden distinguirse las políticas públicas de relevancia social, cuya intensidad puede variar conforme a la inclinación del electorado al elegir a sus representantes, y las disposiciones constitucionales del Estado democrático, que obligadamente deben incluir los instrumentos de garantía para la pluralidad y la equidad.

Véase que Häberle no argumenta a favor del Estado intervencionista, porque esto también se opone a su concepción de la sociedad como eje de la vida constitucional; pero tampoco se acerca a las formulaciones doctrinarias que identifican las reglas de la democracia con las del mercado. La gran diferencia es que el mercado se basa en la exclusión del adversario mediante un proceso de libertad competitiva, en tanto que el Estado constitucional se basa en la integración de todos los miembros de la sociedad en un ámbito de libertades individuales y públicas, irrenunciables e imprescriptibles. La función del Estado constitucional no invade ni desplaza la de los ciudadanos; tampoco se limita a observar y arbitrar en los casos de conflicto; su función es promover la vigencia del sistema de libertades, asegurar que no se produzcan distorsiones que lo afecten, y corregir las desviaciones tantas veces como se produzcan. El Estado constitucional no es invasivo ni pasivo, porque tampoco es un simple aparato de dominio en acción o en receso. El Estado constitucional es, para expresarlo sumariamente, un Estado integrador en el que la sociedad dispone de órganos específicos para el ejercicio del poder, pero en el que ella misma ocupa el espacio central.

\section{El nuevo derecho en Europa oriental}

Desde la perspectiva de la teoría cultural de la Constitución, el proceso constituyente de Europa oriental ofrece al profesor Häberle un ámbito de extraordinaria riqueza para confirmar sus planteamientos. En pocas ocasiones se ha ofrecido una oportunidad semejante a un tratadista, porque el cambio constitucional que se generalizó a partir de 1989 no tiene precedente por su extensión, intensidad y rapidez. El amplio registro de esa experiencia nos permite, a partir del estudio de Häberle (“Avances...", pp. 150 y ss.), identificar tres constantes: incorporación de instituciones jurisdiccionales que garanticen las libertades individuales y públicas, como reacción ante el pasado comunista; adopción de instituciones sociales que hagan posible un cambio sin el trauma de la violencia; adopción de instituciones políticas que permitan consolidar la democracia. 
Este libro forma parte del acervo de la Biblioteca Juridica Virtual del Instituto de Investigaciones Juridicas de la UNAM

Para alcanzar esos objetivos, los constituyentes de Europa oriental también han presentado patrones de conducta semejantes: intensa utilización del derecho comparado, como vía de inserción en la comunidad internacional y particularmente en la europea; retorno a los principios clásicos del derecho occidental, como elemento doctrinario para fundamentar la elaboración normativa; equilibrio normativo para no generar una sobrecarga de expectativas prestacionales que los nuevos Estados no estarían en posibilidad de satisfacer.

Se advierte, por otra parte, lo que también es una tendencia generalizada allí donde la política y los políticos han sido objeto de considerable desprestigio: el fortalecimiento de los jueces. La judicatura está desempeñando la arriesgada tarea de recuperar la confianza colectiva en la función de las instituciones y en las figuras públicas. El problema es que ese papel está llevando a los tribunales numerosos asuntos de índole política y está transformando a los tradicionales actores silenciosos de la justicia en protagonistas de la moral pública.

La conclusión del profesor Häberle en cuanto a los avances constitucionales en el este europeo se sintetiza en dos grandes apartados. Por una parte advierte que ha sido mucho lo realizado, y en un periodo relativamente breve; por otro lado, señala que algunos de los textos adoptados "aún se encuentran prácticamente en el aire", precisamente porque falta la infraestructura sociocultural que les confiera positividad.

Este análisis del profesor Häberle nos permite corroborar la relación sinérgica entre la norma constitucional y la cultura. De las experiencias examinadas se pueden desprender algunas consideraciones útiles para entender procesos constitucionales pretéritos, frustráneos, y para prevenir que los sistemas en vías de transformación se aseguren de acompañar los cambios normativos con intensos programas de cultura jurídica. América Latina ha resentido, en especial a lo largo del siglo XIX, el problema de construir sistemas constitucionales sin sustento cultural. Algunos países sufrieron esa dolorosa realidad incluso ya bien entrado el siglo XX. Las tradiciones autoritarias, autóctona y española, se potenciaron recíprocamente e impidieron que las formulaciones normativas elaboradas en las sociedades plurales más experimentadas, pudieran rendir todos sus frutos. No se tuvo en cuenta que también lo fáctico ejercía una poderosa fuerza normativa, que funcionó como elemento derogatorio de la norma escrita.

En sociedades mejor comunicadas como las actuales es posible emprender cambios normativos de gran calado, como los observados en Europa oriental, con la seguridad de que pueden ser asimilados con relativa rapidez por la sociedad. Las actitudes de resistencia al cambio tienden a hacerse me- 
Este libro forma parte del acervo de la Biblioteca Juridica Virtual del Instituto de Investigaciones Juridicas de la UNAM

nos duraderas y menos enfáticas en sociedades progresivamente más abiertas, de manera que la adopción de nuevas instituciones contribuye a generar también nuevos patrones culturales.

Todo lo anterior indica que una de las más importantes experiencias contemporáneas de renovación constitucional es la que ofrecen los países del este europeo. A través de algunas Constituciones de esos países se está produciendo la incorporación al constitucionalismo democrático de principios a los que no pueden renunciar las sociedades que durante varias décadas se habituaron a la vigencia de medidas tutelares de la salud, la educación, la vivienda y el empleo, entre otras. La recuperación de las libertades individuales y públicas ha venido acompañada de planteamientos relacionados con medidas de bienestar colectivo. A pesar de que en numerosas construcciones constitucionales están prevaleciendo las tesis que hacen girar a las instituciones públicas en torno a los intereses del mercado, las Constituciones de los países del este presentan características y matices muy particulares en ese aspecto.

El profesor Häberle, en su ensayo "Avances constitucionales en Europa oriental desde el punto de vista de la jurisprudencia y de la teoría constitucional", ofrece importantes datos y reflexiones sobre este aspecto. El análisis de esos procesos le permite demostrar la pertinencia de su teoría sobre el constitucionalismo cultural. Kant, recuerda (p. 141), formuló la "premisa cultural y antropológica del Estado constitucional". Conforme a esa premisa se ha implantado fuertemente "la fascinación" por las Constituciones escritas. Esta tendencia, apunta el autor, se ve reforzada por la tradición de respeto por la palabra escrita que se inspira en los grandes libros religiosos, la Torá, la Biblia y el Corán. Así, el constitucionalismo escrito encuentra un poderoso soporte cultural en la arraigada confianza que inspiran los textos en que se sustenta la fe de millones de personas.

Habría que agregar, en la misma dirección señalada por el profesor alemán, que sólo el 16\% de la población mundial no profesa religión alguna (cfr. wrere.adherents.com), y que el $22 \%$ que cultiva el hinduismo y el budismo, en adición al 53\% de cristianos, musulamanes y judíos, también se inspira en los formidables textos escritos que conforman la literatura védica (véase, Max-Müller y De Mora) y búdica (véase, Tachibana). La hipótesis del profesor Häberle la confirma el hecho, significativo, de que la Constitución escrita sea objeto de adopción generalizada en el mundo, precisamente a 
Este libro forma parte del acervo de la Biblioteca Juridica Virtual del Instituto de Investigaciones Juridicas de la UNAM

partir de una cultura que confiere a la palabra escrita una función central en la vida espiritual de todas las sociedades.

Un aspecto procedimental que señala Häberle ("Avances...", p. 144) consiste en la figura de las "mesas redondas" para denotar espacios de deliberación y acuerdo. Adoptada en Polonia por Lech Walesa, se irradió a Hungría, Checoslovaquia, República Democrática Alemana, Bulgaria, Rumania y Sudáfrica. La necesidad política de negociar para evitar rupturas violentas y construir un orden normativo viable, desembocó en las "mesas redondas", cuya sola denominación ofreció una imagen de horizontalidad en la participación de las diversas fuerzas políticas. Las Constituciones derivadas de esas mesas tienen, como apunta nuestro autor, el sentido de un contrato social renovado.

Las Constituciones de Europa oriental se inclinan por el concepto de economía social de mercado, de manera que el derecho a la propiedad privada de los medios de producción sea compatible con el derecho al empleo, la huelga y la seguridad social. Ahora bien, si en este punto el profesor Häberle manifiesta su coincidencia, por lo que considera que en esa zona europea se localiza "un enorme taller constitucional" ("Avances...", p. 148), también identifica "rasgos regresivos" (p. 161), particularmente en lo que concierne a la intensificación del nacionalismo y a la superficial protección de las minorías. La primera la explica como un intento por llenar el vacío generado por la caída del socialismo, y la segunda porque el reconocimiento de las minorías requiere de un largo periodo de aprendizaje.

\section{Federalismo y regionalismo}

El tema del federalismo y el regionalismo es abordado por Häberle con notable precisión. Esencialmente sustenta ("Problemas...", pp. 1176 y ss.) dos grandes cuestiones: la diferencia entre federalismo y regionalismo y las características propias del regionalismo. En cuanto al primer aspecto es muy enfático al señalar que, aun siendo "parientes cercanos", federalismo y regionalismo no son lo mismo; más aún, el regionalismo ni siquiera puede considerarse una etapa previa al federalismo. Sus orígenes, estructuras, funciones, fines y estrategias, corresponden a motivaciones, instrumentos, procedimientos, intereses y objetivos diferentes. Está presente, una vez más, 
Este libro forma parte del acervo de la Biblioteca Juridica Virtual del Instituto de Investigaciones Juridicas de la UNAM

el contenido cultural que define a la norma. Esto lo demuestra el autor con una abundante serie de datos obtenidos del derecho comparado.

Las características propias del regionalismo que Häberle identifica corresponden a una triple dimensión: la relación entre la región y el Estado; la relación entre las regiones, y la organización interna de la región. En lo que atañe al primer aspecto señala que los rasgos generales de la estructura regional deben figurar en la Constitución; que deben existir procedimientos para las formas de cooperación y la solución de conflictos entre región y Estado; que deben existir "pequeñas cláusulas de homogeneidad" que garanticen la "lealtad regional", y que las regiones deben contar con un derecho de intervención en la toma de decisiones del Estado. En lo que corresponde al segundo punto, debe existir un procedimiento para las formas de cooperación y la solución de conflictos entre las regiones. Y en cuanto al tercer aspecto, señala la naturaleza necesariamente democrática que debe existir en la estructura y el funcionamiento del poder en el ámbito regional.

Concluye este tema apuntando que la ciencia del regionalismo comparado apenas está dando sus primeros pasos. Si bien esto fue dicho en 1994, sigue siendo cierto siete años después. Es evidente que el estudio comparativo de los sistemas federales ha alcanzado mayor profundidad, aunque también es verdad que se ha dispuesto de mayor tiempo. De alguna manera el regionalismo está todavía en construcción: la devolución de facultades en Gales y Escocia, por ejemplo, es muy reciente, y no es posible todavía apreciar sus aciertos y sus debilidades; el debate en Italia no se ha cerrado porque subsiste la tensión con el Piemonte; en España persiste el temor a desatar un proceso centrífugo que vaya más allá de la mera descentralización, particularmente por la situación de Cataluña y del País Vasco, y en Francia están divididas las opiniones, sobre todo por el tema de Córcega, para sólo apuntar unos casos. Como sea, ésta es una vertiente de estudio en la que todavía falta un desarrollo doctrinario amplio, que ayudaría a encontrar respuestas en los Estados donde se produce una confusión entre regionalismo y nacionalismo.

Los nuevos enfoques sobre este asunto tendrán que tomar en cuenta los aportes teóricos häberlianos, en especial los siete factores de legitimación del regionalismo que, con amplitud, presenta el profesor en su ensayo "El regionalismo como principio estructural naciente del Estado constitucional y como máxima de la política del derecho europeo”. Aquí se considera la legitimación del regionalismo como parte de la teoría de los derechos fundamentales, en especial por lo que concierne a la libertad cultural; como parte de la teoría de la democracia, que incluye la protección de las minorías; como parte de la teoría de la separación de poderes, en su variante de 
Este libro forma parte del acervo de la Biblioteca Juridica Virtual del Instituto de Investigaciones Juridicas de la UNAM

separación vertical; como parte de las políticas económica y de desarrollo; como expresión de la integración, por sus contenidos de solidaridad; como parte de la cultura europea, que implica la conjugación de los principios de diversidad y unidad, y como factor de descentralización y fortalecimiento del principio de subsidiariedad, conforme al cual la unidad mayor (Estado) no debe asumir funciones que la unidad menor (región) pueda realizar satisfactoriamente. A lo largo de la obra häberliana vamos a encontrar como una idea recurrente la invocación al principio de subsidiariedad, según la cual el poder central no debe hacer aquello que pueda realizar el poder local ni el Estado debe actuar en lo que puedan llevar a cabo los individuos. Con esto no se trata de volver al individualismo liberal, sino de asegurar el espacio de libertades del Estado constitucional.

Esos enunciados son susceptibles de extrapolación también al Estado federal no europeo, incluido el último aspecto referido a la cultura, que se puede aplicar por igual en los ámbitos nacionales. En Iberoamérica, por ejemplo, la armonización de los principios de diversidad y unidad cultural pueden tener aplicación nacional en casi todos los Estados. Con excepción de, por ejemplo, Uruguay y Costa Rica, que presentan una gran homogeneidad, los demás Estados son culturalmente complejos.

\section{Los derechos fundamentales}

El problema de los derechos fundamentales está presente de diversas formas en toda la obra de Peter Häberle. Con tratamientos más amplios o más ceñidos, es una cuestión que late de manera continua en su obra. A veces, como fue el caso de un discurso en la Facultad de Derecho de la Universidad de Granada en 2000 ("La cultura...", pp. 532 y ss.) le bastan unos cuantos párrafos para precisar ideas medulares. Una de ellas concierne a la fuerza expansiva de los derechos fundamentales. Häberle subraya que esa fuerza expansiva se despliega en el transcurso del tiempo, y en efecto podemos observar que los derechos fundamentales cuentan con una dinámica propia que les permite desdoblarse hacia nuevos espacios y ensanchar su contenido. Es evidente que existe una relación directa entre el desarrollo de los derechos fundamentales y los procesos culturales, que no hace sino confirmar empíricamente la teoría häberliana. El argumento de que el tiempo contribuye a consolidar la eficacia de los derechos fundamentales también queda corroborado en todos los estudios de caso, e indica hasta qué punto se armonizan estos derechos con los ámbitos culturalmente más avanzados. Lo más importante es que ambos procesos (el normativo y el cultural) entran 
Este libro forma parte del acervo de la Biblioteca Juridica Virtual del Instituto de Investigaciones Juridicas de la UNAM

en sinergia y se estimulan recíprocamente. Lo contrario de alguna manera también puede ocurrir: en la medida en que se deteriora el entorno cultural (por regresiones autoritarias, ausencia de políticas culturales adecuadas, y deficiencias institucionales, por ejemplo) o las funciones normativas se ven entorpecidas (el Estado de derecho se ve condicionado por tensiones políticas no resueltas, diseños constitucionales insuficientes, crisis de naturaleza económica o social que afectan los procesos institucionales, y corrupción, por ejemplo), se advierte un retroceso de los derechos fundamentales.

Una prueba del proceso expansivo de los derechos fundamentales en el tiempo la ofrece Häberle al examinar la evolución de la jurisprudencia del Tribunal Constitucional alemán, y dentro de los casos mencionados un ejemplo muy sugerente es el de la eficacia frente a terceros de los derechos fundamentales. La naturaleza de la sociedad contemporánea presenta nuevos desafíos para el concepto tradicional de Estado de derecho. En nuestro tiempo, ante la aparición de una especie de Estado intangible, se hace necesaria la defensa de los derechos fundamentales también ante los particulares. "La visión unidimensional individuo/Estado es notoriamente insuficiente", dice Häberle ("Recientes...", p. 154). En efecto, es demostrable que no solamente los órganos del poder estatal pueden infligir perjuicios e infringir derechos fundamentales. El reconocimiento de este fenómeno ha generado dos modalidades de respuesta: previsiones constitucionales expresas en cuanto a la procedencia del amparo contra particulares, como en Argentina (artículo 43) y Colombia (artículo 86), además de los casos que identifica Peter Häberle ("Los derechos...", p. 21) en Alemania, en la Constitución de Brandemburgo (artículo 5.1), y en Suiza, en las Constituciones cantonales de Aargau (artículo 7.1 y 2) y de Berna (artículo 27.1), o fórmulas de protección desarrolladas jurisprudencialmente, como ocurrió en Alemania a partir del caso Lüth, en 1958, y donde el denominado "efecto de irradiación" (Alexy, p. 507) de los derechos fundamentales sobre el derecho civil ha permitido sustentar resoluciones en que se declara que esos derechos fundamentales también están presentes en el tráfico jurídico privado; como sucede asimismo en Estados Unidos, donde se ha recurrido a la ficción de la "acción estatal" indirecta para proteger los derechos individuales frente a particulares cuando ejercen actividades que requieren autorización, concesión o incluso simple registro público; y como ya se advierte en España, donde el Tribunal Constitucional ha adoptado una interpretación amplísima del concepto de Estado social de derecho para concluir que a los órganos del Estado, entre ellos los tribunales, les incumbe el deber de velar por que también los agentes sociales acaten los derechos fundamentales. Normas supremas, jurisprudencia y doctrina (véase, por ejemplo, Estrada, 
Este libro forma parte del acervo de la Biblioteca Juridica Virtual del Instituto de Investigaciones Juridicas de la UNAM

Bilbao, García Torres) van confirmando la razón a la observación de Häberle y dan cuenta de la expansión de los derechos fundamentales en el mundo. Las garantías procesales de los derechos fundamentales han encontrado nuevas expresiones, como señala el autor ("Los derechos...", p. 25), a través de la reclamación constitucional, susceptible de ser planteada por quien considere que el poder público ha afectado alguno de sus derechos fundamentales, y que en Alemania complementa al recurso de amparo.

La función de los derechos fundamentales en el tiempo tiene otra expresión advertida por Häberle: la protección de generaciones sucesivas. "El aspecto generacional atraviesa progresivamente el orden constitucional" dice el autor ("Los fundamentos...", p. 43; "El concepto...", pp. 111 y ss.), y alude al caso de la protección del medio ambiente y a la formación de una cultura de los derechos fundamentales, como conjunto de valoraciones que se van formando en el tiempo y tienden a perdurar. Una vez más infiere otra consecuencia del contractualismo y nos habla de un "contrato entre generaciones" para denotar el compromiso sucesivo entre una generación y otra en cuanto a la preservación y transmisión de derechos. Esta tesis permite una lectura extensiva, aplicable a la defensa del Estado constitucional como parte del compromiso contractual generacional. La idea misma del consenso está presente en la construcción häberliana ("La ética...", p. 162) de la teoría de los derechos fundamentales, y el consenso, como expresión de la autonomía de la voluntad colectiva, representa una actualización constante del pacto social.

Esa tendencia en el sentido de la expansión de los derechos fundamentales ha dado lugar también a la aparición de las que Häberle identifica como "cláusulas de desarrollo" ("El concepto...", pp. 92 y 108), que son los enunciados constitucionales que prevén la posibilidad de otros derechos no expresamente recogidos por la norma suprema. Estas cláusulas no deben ser confundidas con los principios que, según Alexy (pp. 86 y ss.), son "mandatos de optimización".

Una vía adecuada para alcanzar este objetivo es posibilitar la interpretación judicial conforme a la Constitución, originada en Suiza. En México un grupo de especialistas encabezado por el profesor Héctor FixZamudio ha propuesto enmendar el artículo 107 constitucional, para incorporar la posibilidad de que la Corte pueda establecer la interpretación de la ley conforme a la Constitución. Esta idea se ajusta a los principios de igualdad ante la norma y de racionalidad en el ejercicio de los controles jurisdiccionales. Si esta reforma llega a ser adoptada, permitirá evitar desviaciones de las autoridades, sobre todo de las fiscales. La interpretación conforme a la Constitución es una manera inteligente, seria y eficaz de desarrollar los de- 
Este libro forma parte del acervo de la Biblioteca Juridica Virtual del Instituto de Investigaciones Juridicas de la UNAM

rechos fundamentales. En la dirección de un incesante enriquecimiento de los derechos fundamentales el profesor Häberle advierte ("El concepto...", p. 106) que las situaciones de peligro para la sociedad generan la necesidad de nuevos derechos. Para hacerles frente se requiere una disposición abierta que permita ofrecer respuestas creativas. Uno de los ejemplos que invoca es el de la soberanía informativa, como en el caso de la protección de datos ("Recientes...", p. 165). En todo caso, la evolución cultural va presentando nuevos estadios de desarrollo que requieren planteamientos jurídicos, muchas veces directamente relacionados con nuevos contenidos y expresiones de los derechos fundamentales. Como se puede apreciar, esta posición es una forma adicional de asumir las implicaciones de la teoría häberliana del Estado constitucional. En este particular punto pueden mencionarse, como ejemplo adicional, las técnicas de clonación, ante las cuales se están produciendo diversas respuestas éticas y normativas.

Un tema abordado con menor frecuencia por la doctrina es al que Häberle denomina "obligaciones fundamentales" ("El concepto...", p. 116). En su infatigable labor precursora, Peter Häberle aborda esta nueva cuestión y la deja para un desarrollo ulterior más amplio. Una de las características de Peter Häberle es su capacidad para identificar problemas y encontrar soluciones. En este caso subraya que "pequeños textos de obligaciones fundamentales se contraponen a catálogos completos" de derechos. Deja abierta la cuestión de si ese fenómeno se debe a que la ética de las obligaciones ciudadanas es difícilmente trasladable a definiciones jurídicas. Una de las consecuencias de esa percepción es la teoría häberliana del status activus processualis, o deberes de protección del Estado, que su autor ha configurado a partir de 1971 (véase, "Recientes...", p. 157).

Acierta P. Häberle, una vez más, al indicar (Diritto..., p. 31) que en la medida en que los derechos humanos se han convertido en una materia del mayor interés para la comunidad internacional, también han influido para que la cuestión de la verdad haya pasado a ser parte del derecho internacional. Nos explicamos este fenómeno al que alude el profesor alemán, por la confluencia de factores endógenos y exógenos en la vida del Estado contemporáneo. Por una parte, las guerras civiles (España, por ejemplo), los sistemas totalitarios (stalinismo, polpothismo, por ejemplo), el terrorismo (Irlanda, por ejemplo), el separatismo (Chechenia, por ejemplo) y las guerras por razones étnicas (Bosnia, por ejemplo); por otra parte, las guerras 
Este libro forma parte del acervo de la Biblioteca Juridica Virtual del Instituto de Investigaciones Juridicas de la UNAM

internacionales a lo largo del siglo XX dejaron una huella terrífica en la historia de la humanidad y generaron una explicable reacción en favor de los derechos fundamentales. La barbarie a la que asistimos durante el siglo XX no tiene precedente. Téngase en cuenta que en ese siglo perdieron la vida casi doscientos millones de personas como resultado de conflictos armados y de actos contrarios a la humanidad perpetrados por motivos políticos. Brzezinski (pp. 18 y ss.) ha demostrado que esa cifra de fallecimientos por violencia de origen político es superior al total de la registrada en los diecinueve siglos precedentes.

\section{El problema de la verdad}

El problema de la verdad se plantea como una cuestión central en el constitucionalismo contemporáneo. El derecho a la verdad, según la cita que Häberle hace de Grocio (Diritto e verità, p. 32), se funda en la libertad de juicio del destinatario de la comunicación. Desde esta perspectiva es imposible construir un sistema constitucional democrático que no presuponga la salvaguarda del derecho individual y colectivo a la verdad. Así no esté expresamente enunciado, se trata de un principio incorporado en el derecho a la información. Con este tema el profesor Häberle desarrolla un trabajo elocuente, elegante y erudito. Diritto e verità es uno de los más fascinantes textos sobre derecho publicados en las últimas décadas. El autor acude, con la maestría de siempre, a las fuentes del derecho comparado y a la doctrina, pero en esta ocasión alterna las referencias al derecho y a la filosofía con abundantes ejemplos de poesía que imprimen a su obra una dimensión difícil de alcanzar en un estudio jurídico. Publicado en alemán en 1995 y traducido al italiano en 2000, este texto pone de relieve la relación inextricable entre derecho y cultura, y deja ver el compromiso ético y el perfil renacentista del profesor de Bayreuth.

Desde las primeras líneas de la edición italiana el autor advierte que, en el lustro transcurrido desde su aparición en Alemania, el tema de la verdad ha adquirido en el mundo una presencia de creciente amplitud. Este hecho, corroborable, es una prueba empírica de la vinculación entre la verdad y la democracia. El derecho a la verdad es una expresión más del reconocimiento de la dignidad como un derecho fundamental. 
Este libro forma parte del acervo de la Biblioteca Juridica Virtual del Instituto de Investigaciones Juridicas de la UNAM

El profesor Häberle ofrece extensos y convincentes argumentos para probar que aun cuando la verdad da lugar a una polisemia (Diritto..., pp. 9 y ss.), representa un valor esencial del derecho contemporáneo. Sea cual fuere el concepto que adoptemos, la verdad funciona como un elemento integrador de las relaciones sociales en todas las escalas, y sin ella no es viable el desarrollo de la cultura.

Para dar coherencia a su argumentación, y con la notable capacidad que tiene para identificar los elementos de relevancia teórica cuando analiza un problema, Häberle encuentra (ibidem, pp. 77 y ss.) siete modalidades de expresión normativa concernientes a la verdad, que aunque refiere expresamente a Europa del Este, pueden ser aplicables como útil esquema de encuadramiento en otros sistemas constitucionales: cláusulas que proscriben la ideología de Estado; cláusulas del pluralismo; obligación de los funcionarios de producirse con verdad; cláusula de neutralidad científica; cláusula de libertad de información y enmienda; cláusula de responsabilidad judicial, y cláusula de objetividad política ("separación entre el Estado y los partidos").

Pocos trabajos han calado tan hondo en cuanto a la relación entre verdad y derecho, como el de Peter Häberle. Desde otra perspectiva, el conjunto de cinco conferencias dictadas por Michel Foucault en 1973 (La verdady las formas jurídicas), había marcado un nuevo derrotero para la investigación; pero mientras que el profesor francés, a partir de un novedoso enfoque de Edipo, se orienta a resolver las incógnitas de la historia externa de la verdad, donde se sitúa el derecho, el profesor alemán formula una teoría concernida con el Estado constitucional moderno y contemporáneo. Uno y otro enfoques pueden complementarse si se tiene en cuenta que Foucault acentúa la relación entre la búsqueda de la verdad jurídica y el desarrollo de diversas ciencias del conocimiento que han significado una sucesión de profundos cambios en la cultura a través de la historia.

\section{La idea de dignidad}

La idea de dignidad tiene una importante implicación para el profesor alemán. La democracia, dice ("El Estado...", p. 93), es "la consecuencia organizativa de la dignidad del hombre" y en otro texto reafirma que la dignidad es la premisa cultural antropológica del Estado constitucional ("De- 
Este libro forma parte del acervo de la Biblioteca Juridica Virtual del Instituto de Investigaciones Juridicas de la UNAM

recho constitucional...”, p. 222). Aquí nos encontramos, sin duda, con una tesis central. La ilustración centró sus preocupaciones en los grandes temas que nutrieron al constitucionalismo desde su origen. El catálogo de derechos fundamentales se agotó con las diversas expresiones de cuatro principios: libertad, igualdad, justicia y seguridad jurídica (que incluye el derecho a la propiedad). Siempre habrá que tener presente el argumento renacentista de Pico della Mirandola (De hominis dignitate oratio) como precursor de la defensa de la dignidad; el imperativo categórico de Kant, enunciado en 1785 (Fundamentación..., pp. 54 y ss.) y reiterado en 1797 (La Metafisica..., p. 335), con sus claras resonancias en Hegel ("sé una persona y respeta a los demás como personas", núm. 36) y más tarde en Stammler (con los "principios del respeto" en el derecho justo, núm. 95). Sin embargo, Larenz (cap. II) y González Pérez han demostrado que la dignidad como contenido explícito de la norma corresponde a un estadio cultural relativamente reciente. En el ámbito constitucional el desarrollo de la dignidad sólo se ha producido a partir de la Ley Fundamental alemana de 1949. Es, por lo mismo, la aportación más original que se ha hecho en cuanto a los derechos fundamentales desde el siglo XVIII. "La dignidad del hombre es intangible. Los poderes públicos están obligados a respetarla y protegerla", establece el artículo 1o. de esa Ley.

Tiene razón Häberle al identificar a la dignidad como causa de la democracia; es una aportación germana al constitucionalismo contemporáneo. Resulta comprensible que después de la tragedia bélica, el constitucionalismo de la posguerra se haya orientado por incluir la dignidad como un derecho fundamental. Es significativo que las Constituciones de países que han pasado por severas crisis de principios éticos presenten, desde su inicio, una referencia a la dignidad. Así ocurre también con el artículo 1o. de la Constitución de Sudáfrica. En el caso de Alemania, refiriéndose a la primera posguerra, Ernst Troeltsch había dicho que todos los excesos que dan lugar a la glorificación del Estado se hacen a expensas de la libertad y de la dignidad humanas. No menos se puede decir en la segunda posguerra y en los días de nuestro tiempo, ante la intolerancia, con expresiones de racismo y fundamentalismo, que afecta la vida de numerosas sociedades.

Es previsible que ante una serie de nuevas reivindicaciones, que tienen como eje el respeto a la dignidad, se generalice la incorporación constitucional del precepto germano. El derecho a la intimidad, que justifica algunos aspectos del derecho a la información; a las preferencias sexuales, y a las decisiones sobre la disposición de la vida, como la eutanasia, son sólo algunos ejemplos de cuestiones que están directamente relacionados con la protección jurídica de la dignidad. 
Este libro forma parte del acervo de la Biblioteca Juridica Virtual del Instituto de Investigaciones Juridicas de la UNAM

\section{El problema del fundamentalismo}

Un tema de especial trascendencia es el que corresponde a la relación entre fundamentalismo y Estado constitucional. En este punto, el enfoque del profesor Häberle contiene dos aportaciones centrales: la caracterización del fundamentalismo y de sus diversas expresiones (religioso, político, económico, científico, ecológico), por una parte, y por la otra una convocatoria a la apertura hacia el reconocimiento de las diversidades culturales. Lejos, por ende, de situarse en una posición de rechazo y descalificación, y congruente con la función integradora de la cultura a través del orden constitucional, la doctrina häberliana ofrece una respuesta constructiva ante los peligros, que identifica, representados por las distintas formas de fundamentalismo.

Cuando el profesor Häberle perfila ("El fundamentalismo...", pp. 146 y ss.) los rasgos definitorios de los fundamentalismos, encuentra una pluralidad de elementos que podríamos agrupar en varias categorías. Algunos tienen aspectos negativos (monismo, intolerancia, reacción frente al cambio); otros tienen implicaciones parcialmente negativas combinadas con otras positivas (positivo: volver a las raíces o fundamentos, negativo: excluir la convivencia con otras expresiones culturales; positivo: búsqueda de identidad, negativo: afectar o desconocer los derechos humanos, alentar la violencia), y advierte como elemento positivo que, contra lo que suele considerarse en el sentido de que el fundamentalismo maneja "cuestiones engañosas de siglos anteriores", se plantean problemas de nuestro tiempo. Ante este haz de elementos ofrece una doble respuesta: un debate cultural profundo y un esquema constitucional que permita "organizar pragmáticamente la convivencia de los muchos fundamentalismos de nuestro tiempo". Como se ve, lejos de una posición intransigente, la teoría häberliana demuestra que el constitucionalismo contemporáneo cuenta con los instrumentos para conciliar diferencias extremas. Los fundamentalismos representan un desafio mayor para la convivencia entre y dentro de las naciones. Orientar el sentido posible de la absorción de los conflictos que plantean es una posición constructiva que prueba, además, las posibilidades integradoras de la teoría häberliana.

Debe tenerse presente que la diversidad de fundamentalismos a que alude el propio autor también conduce a pensar en soluciones constitucionales diferentes. Es sensiblemente menos complicado atenuar los efectos del fundamentalismo económico (excesos de la economía de mercado) o ecológico (inhibición del desarrollo en algunos aspectos científicos y tecnológicos), que superar los problemas del fundamentalismo religioso (intolerancia) 
Este libro forma parte del acervo de la Biblioteca Juridica Virtual del Instituto de Investigaciones Juridicas de la UNAM

y político ("limpieza étnica", separatismo). Con todo, como no resulta aceptable que los conflictos queden sin solución ni que ésta pueda adoptarse al margen de los instrumentos del constitucionalismo, es menester hacer un esfuerzo en el sentido señalado por el profesor Häberle.

\section{El derecho cultural}

Como es natural, una de las áreas de interés del profesor Häberle corresponde a las normas concernientes a los bienes del patrimonio cultural. "La protección de los bienes culturales ha hecho 'carrera' como tema de la política y las ciencias, especialmente en los últimos años", declara ("La protección...", p. 11). Para corroborar su aserto ejemplifica con diversos instrumentos internacionales y con los casos de las Constituciones colombiana, checa, eslovaca, española, guatemalteca, hondureña, paraguaya, peruana, rusa, salvadoreña, ucraniana, además, por supuesto, de la propia alemana. Podemos agregar que en el caso de México la Constitución también alude a la naturaleza pluricultural de la nación (artículo 2o.) y faculta al Congreso para legislar en cuanto a la defensa del patrimonio cultural (artículo 73, $\mathrm{XXV}$ ). Pero lo más relevante no es el detenido examen de los ejemplos ofrecidos por el derecho cultural comparado, sino lo que él denomina a partir de 1980 como "una modesta teoría constitucional de la protección de los bienes culturales" (ibidem, pp. 26 y ss.). Esa teoría en esencia sustenta que la protección de los bienes culturales es una de las piezas fundamentales para la comprensión de la Constitución como cultura. No debe entenderse que el profesor alemán circunscribe su concepto a las Constituciones que incluyen referencias expresas a la cultura o a los bienes culturales; estos son elementos testigo de la naturaleza cultural de las Constituciones, pero aun las Constituciones que no los incorporan textualmente son siempre una autorrepresentación cultural de un pueblo.

Las siete tesis que componen esta fascinante parte de la teoría häberliana brindan un amplio campo para la reflexión: la comunidad mundial de los Estados culturales, que ofrece un nuevo fundamento para la cooperación internacional; el contrato social mundial en materia de cultura y naturaleza, que resulta central para la preservación del planeta y que representa una nueva dimensión del contractualismo; la libertad mundial gracias a la cultura, que introduce una dimensión mucho más amplia que la tesis de Marshall McLuhan de la "aldea global", sólo por la acción de los medios de comunicación; el patrimonio cultural universalmente protegido, que explica la relevancia de las minorías; la percepción de la humanidad en el Estado 
Este libro forma parte del acervo de la Biblioteca Juridica Virtual del Instituto de Investigaciones Juridicas de la UNAM

constitucional, que confirma la fuerza expansiva de los derechos humanos; la construcción de la humanidad a partir de la protección internacional de los bienes culturales, donde una vez más el profesor de Bayreuth deja ver sus vínculos con el profesor de Königsberg (La paz perpetua), y la relación de interdependencia entre la protección nacional y la internacional de los bienes culturales, que ofrece una nueva base doctrinaria para atenuar los efectos excluyentes de los fundamentalismos.

\section{La evolución constitucional}

El profesor de Bayreuth, en una de sus obras centrales (Teoría de la Constitución como ciencia de la cultura, p. 35) deja caer una aseveración fundamental: "los propios textos constitucionales deben literalmente ser 'cultivados' para que devengan auténticamente Constitución". Como consecuencia de esta tesis podrían resultar numerosas consideraciones y hasta conclusiones. "Cultivar" un texto constitucional puede tener varias implicaciones en la teoría de Peter Häberle: buscar acuerdos constituyentes entre los agentes políticos prevalecientes; construir instituciones que progresivamente deriven hacia el objetivo final predeterminado, después de un cuidadoso proceso adaptativo; abrir espacios para ir modelando las nuevas instituciones por la vía del ensayo y el error; evitar resistencias al cambio; alentar la interiorización individual y colectiva de nuevas conductas; identificar las expectativas en su fase larvaria para darles forma y cauce; asociar eficazmente los elementos tradicionales de la cultura con las tendencias culturales innovadoras; tender puentes de integración cultural que superen la inercia de lo existente y no generen quiebres históricos traumáticos. Ahí encuentra nuestro autor la "auténtica Constitución": en el punto donde convergen norma y normalidad para expresarse como cultura.

Un concepto que debemos tener muy presente es el que atribuye a la cultura una función mediadora en la formulación de la norma (Häberle, "Teoria de la Constitució...", p. 44). No se trata de una tesis paralela a la enunciada por Habermas en cuanto a la función mediadora de la norma. La norma es, desde la perspectiva de Häberle, una forma de autorrepresentación cultural de la sociedad. En este sentido, la norma es el medio de que se vale la sociedad para articular su organización y funcionamiento y la expresión misma de la forma de ser de esa sociedad. 
Este libro forma parte del acervo de la Biblioteca Juridica Virtual del Instituto de Investigaciones Juridicas de la UNAM

En su ensayo sobre la Constitución europea, Häberle ofrece una serie de consideraciones atinentes a los procesos constitutivos. Entre ellos rescato su inclinación por el gradualismo ("Colloquio...", p. 203) traducido en aproximaciones progresivas, en cuanto a la adopción de reformas. Para evitar reacciones que invaliden las reformas y para dar a esas reformas tiempo suficiente de adaptación, la gradualidad es muy recomendable. Esta posición es explicable dentro de la teoría häberliana; más aún, es una consecuencia natural de ella. Como elemento de la cultura, la Constitución tampoco puede ser objeto de sacudidas intempestivas, a menos que se produzcan como parte de un proceso revolucionario. Los cambios por aproximación sucesiva no se pueden identificar con una actitud conservadora; por definición el cambio no es conservador. Lo que debe valorarse es que sólo el cambio voluntarista, impuesto, puede serlo en gran escala. Este tipo de cambio no corresponde a un proceso cultural y por ende no encaja en el Estado constitucional. El cambio drástico y completo obedece a impulsos que van más allá de la interacción con el entorno cultural y, por lo mismo, además de no ser necesariamente democrático corre el riesgo de quedarse en la epidermis social, de no pasar de una declaración sin correspondencia con la realidad. Podría decirse que su objetivo es modificar la realidad, y que oponerse a ese proceso es una actitud refractaria al cambio. No lo veo así, en tanto que los cambios constitucionales tienen que ir acompasados con los cambios culturales, a menos que como ya se dijo sean producto de una revolución, que por su misma esencia representa un quiebre cultural. Si los cambios constitucionales se producen sin considerar el entorno cultural, muy probablemente desembocarán en cualquiera de dos destinos: serán norma huera, o para su imposición podrán dar pábulo a excesos de poder. Ninguno es saludable. La posición de Häberle permite superar ese doble problema. El cambio normativo corresponde a un proceso cultural o lo induce, pero no lo desconoce.

Un buen ejemplo de esos cambios paulatinos es el que invoca P. Häberle cuando alude a los tribunales constitucionales. En una sugerente entrevista con Landa ("El rol...", p. 281) afirma, a propósito de la jurisdicción constitucional, que su "cimentación en la cultura política" de un pueblo sólo se produce en un periodo muy amplio. "Las Constituciones jóvenes, agrega, no deberían otorgarle demasiadas competencias a los tribunales constitucionales". Esta inteligente advertencia la hace a partir de su convicción del cambio paulatino. Repárese que de ninguna manera niega que esos tribunales sean incorporados al orden jurídico; más aún, subraya que su presencia es 
Este libro forma parte del acervo de la Biblioteca Juridica Virtual del Instituto de Investigaciones Juridicas de la UNAM

muy frecuente en los casos de transición a la democracia. Pero una cosa es que se instituya la jurisdicción constitucional, y otra que se le sobrecargue. La generación de expectativas excesivas con relación a nuevas instituciones con frecuencia tiene dos tipos de resultados negativos: o bien las instituciones se deforman y actúan por encima o por debajo de su ámbito competencial, o bien la percepción social acerca de su funcionamiento se torna adversa, aun cuando su actuación corresponda a la previsión normativa. La peor de las combinaciones se produce cuando a pesar de la atrofia de las instituciones (por distrofia o hipertrofia), la opinión pública muestra satisfacción, porque denota un problema cultural profundo.

De manera muy esquemática puede decirse que la respuesta al absolutismo del ochocientos fue la afirmación de la igualdad de los hombres ("es una de las cuestiones más interesantes que la filosofía puede proponer y de las más espinosas que los filósofos puedan resolver", decía Rousseau, Discours..., p. 17); que la consecuencia de la gran Revolución fue la lucha por la libertad en el siglo XIX; que la reacción frente a la exclusión y a la concentración de la riqueza, fue la bandera de la equidad en el siglo XX. El siglo XXI tal vez sea el periodo en el que se desenvuelvan los derechos concernientes a la dignidad, entre los que se incluye la verdad. Se trata de etapas sucesivas en la construcción de un orden normativo menos imperfecto. Es un proceso acumulativo que permite confirmar, históricamente, que la organización del Estado se reconstruye de manera permanente y paulatina, y que entre derecho y cultura se produce un efecto sinérgico que va generando, progresivamente, instituciones renovadas, primero, y renovadoras, después. Como producto de la creación cultural, en el Estado constitucional se puede observar un desarrollo autopoiético del derecho. Una formidable síntesis de ese proceso evolutivo basado en el compromiso (contrato social) se debe a Nietzsche (pp. 240-2) cuando afirmó que la transformación del gobierno autoritario en gobierno constitucional no se consigue mediante nuevos repartos de violencia, "sino por transformaciones graduales" alcanzadas a través de compromisos colectivos. Cuando el filósofo alemán escribía su "Ojeada sobre el Estado" en 1874, advertía premonitoriamente que para llegar a ese gobierno constitucional por la vía evolutiva "podría hacer falta aún un siglo"; casi acertó.

Acerca del problema de la reforma constitucional existe una amplia bibliografía entre la que sobresalen dos obras fundamentales: la de G. Jellinek: Reforma y mutación de la Constitución, y la de P. de Vega: La reforma constitucional y la problemática del poder constituyente. Häberle ("Desarrollo...", pp. 15 y ss.) 
Este libro forma parte del acervo de la Biblioteca Juridica Virtual del Instituto de Investigaciones Juridicas de la UNAM

introduce un concepto novedoso: el de "desarrollo constitucional", como una categoría temporal. Aquí aparece una consecuencia más de la teoría häberliana. En tanto que la Constitución es parte de un proceso cultural, incluye por igual los procesos expresamente normados y los informales. La Constitución, por ende, forma parte de la fluidez cultural que incluye la creación, recepción, estabilización, transformación e interacción de conocimientos, valores, creencias, comportamientos, actitudes, estilos y tradiciones. El tiempo juega un papel axial en ese flujo incesante, en el que Häberle localiza un nuevo factor: la fuerza normativa de la opinión pública. Este es un rico filón sobre el que seguramente el profesor alemán seguirá explorando en todos sus ricos pliegues. Es un elemento innovador en el que tal vez sea posible encontrar algunas resonancias de Jellinek (la fuerza normativa de los hechos) y de Habermas (la acción comunicativa), pero que apenas ha sido esbozada y está en espera de un tratamiento más extenso. Numerosas claves podrían ser identificadas a partir de esa sugerente aportación häberliana. En su trabajo "Desarrollo constitucional y reforma constitucional" aborda extensamente un aspecto del cambio constitucional en el tiempo, vinculado con la acción de los tribunales constitucionales y, desde luego, de los órganos y procedimientos formales de reforma. Sus referencias a los cambios informales, empero, son las más relevantes. No escapa a su análisis que la tensión entre estabilidad y cambio genera "toda una escala de procesos formales e informales" cuyo desenlace en el tiempo va produciendo efectos diferenciados. Seguramente éste será un tema sobre el que el profesor volverá, y con nuevos hallazgos.

\section{El Estado constitucional}

En un hombre universal como Peter Häberle es comprensible lo que podríamos llamar "ecumenismo institucional", que se manifiesta en la disposición a recibir nuevas influencias culturales y a coexistir con ellas. El concepto de cultura en el que basa su teoría de la Constitución le permite concebir a la norma suprema como un sistema normativo muy abierto. Esto se hace evidente, por ejemplo, cuando alude, en diversos ensayos, a la necesidad de admitir la realidad islámica como parte de la cultura europea. La idea de un "Euro-Islam" está presente en varios de sus trabajos, y corresponde a un hecho cultural que se viene extendiendo por Europa. En realidad, el islamismo ha sostenido su proceso expansivo constante desde el año 711 . A partir del Medio Oriente, ha alcanzado el Lejano Oriente, África, algunos países europeos, con diversa intensidad, y tiene inequívoca presencia en Estados 
Este libro forma parte del acervo de la Biblioteca Juridica Virtual del Instituto de Investigaciones Juridicas de la UNAM

Unidos. El islamismo es parte de la cultura de países muy distintos entre sí; su reconocimiento, como propone Häberle, corresponde a una de las características centrales de la cultura occidental: la tolerancia.

La tesis häberliana con relación al Islam corresponde a una disposición ecuménica, pero tiene también una implicación positiva que debe subrayarse: la asimilación cultural del islamismo en occidente podrá alentar una actitud más receptiva de los valores de la tolerancia en los países musulmanes. Después de todo, el fundamentalismo - en el que con tanta precisión ahonda Häberle - es una impostura que no corresponde a la verdadera tradición islámica que durante la Edad Media representó los altos valores del humanismo.

En 1998 el profesor Häberle publicó en alemán, y con diferencia de meses en español, un ensayo de extraordinaria importancia para entender los alcances de su teoría de la Constitución como ciencia de la cultura. Tomando la tríada conceptual revolucionaria francesa, libertad, igualdad, fraternidad, el profesor de Bayreuth (Libertad..., pp. 45 y ss.) desarrolla una profunda reflexión en torno a esa gran cantera constitucional representada por los textos fundamentales franceses, asociándolos con los textos británicos, a partir de 1215, y norteamericanos. Häberle retoma el artículo 28 de la declaración de derechos que precede a la Constitución francesa de 1793 ("ninguna generación puede imponer sus propias leyes a las generaciones futuras"), para corroborar su argumento de la "eterna peregrinación hacia el tipo Estado constitucional" (ibidem, p. 58). Este formidable ensayo no es un trabajo de interpretación histórico-jurídica, sino una serie de hallazgos mediante los que el autor confirma (ibidem, p. 90) que la actualización del contrato social es un trabajo acumulado en cuya realización están concernidas todas las generaciones.

***

El lector de El Estado constitucional corroborará que se encuentra, como bien ha dicho E. Mikunda Franco (Häberle, Teoría, p. 17), ante un inspirado demócrata que ha sabido encontrar en la relación entre derecho y cultura uno de los más sólidos sustentos del pacto social. Ese perfil del profesor de Bayreuth se complementa con la reseña que de su entorno doméstico nos 
Este libro forma parte del acervo de la Biblioteca Juridica Virtual del Instituto de Investigaciones Juridicas de la UNAM

hace Domingo García Belaúnde (p. 73). El profesor habita una casa en cuya sala están presentes las efigies de Kant, Savigny, Marco Aurelio y Beethoven.

A Häberle le es aplicable el concepto griego de paideia que tan bien ha analizado Jaeger. Como concepto omnicomprensivo, paideia denota lo que en términos modernos se identifica como cultura, civilización, ciencia, literatura o educación. Por eso Jaeger (p. 439) alude a que las grandes obras de la paideia se identifican como poesía, ciencias, arte, política, leyes, y acaba siendo "la morfología genética de las relaciones entre el hombre y la polis" (p. 465). Es así como entiendo la teoría del profesor Häberle: como una nueva lectura del mundo clásico; como un nuevo gran retorno al origen del pensamiento occidental. Desde esta perspectiva la teoría häberliana es auténticamente renacentista. Es la primera de las grandes construcciones teóricas de la Constitución que rescata los auténticos valores y principios del clasicismo. Häberle, ciertamente, ha conseguido ver más allá que aquellos que le enseñaron; que aquellos en cuyo saber abrevó; que aquellos que le precedieron en el tiempo cercano y lejano. Su gran valor reside en que ha sabido entender lo que otros han dicho, y ha sabido innovar con maestría. En su teoría se advierten las pulsaciones de un saber acumulado por siglos y están presentes las ideas nuevas que servirán para fijar el derrotero de la ciencia constitucional en los años por venir. Por eso es un jurista para el siglo XXI.

$* * *$

He querido ofrecer al lector un cuadro general de la prolífica obra del profesor Peter Häberle, que sin reserva alguna puede ser considerada una de las más importantes contribuciones al constitucionalismo en las dos últimas décadas y, más todavía, se perfila como la construcción conceptual más sugerente al inicio del siglo. Las claves de la cultura y el derecho permitirán descifrar las incógnitas que todavía reserva el Estado constitucional.

El pensamiento häberliano es rico en sugerencias y abundante en ideas e imágenes que a su vez conducen a nuevas consideraciones. Fiel a su idea de que siempre es posible ver más lejos, nos conduce por los peldaños del constitucionalismo con tal maestría que además de brindar un panorama diferente a los antes vistos, invita e incita a seguir avanzando. A través de Peter Häberle podemos contemplar viejos paisajes con mirada diferente, y nuevos panoramas con la sorpresa del descubrimiento. 
Este libro forma parte del acervo de la Biblioteca Juridica Virtual del Instituto de Investigaciones Juridicas de la UNAM

Miguel Ángel decía que él no inventaba las formas; que sólo le quitaba a la piedra lo que le sobraba. Parece como si Peter Häberle hubiera procedido con el mismo toque genial, y que al ir desgranando ideas, párrafo tras párrafo, sólo procediera a descubrir lo que, como en el mármol del genio renacentista, ya estaba ahí. Y es que ni el artista ni el jurista se han apartado un ápice de la realidad; lo que cada uno ha hecho, en su tiempo y en su esfera, es descubrir lo que permanecía oculto para los demás. Tampoco Newton inventó las leyes de gravedad ni Mendel las de la herencia. El artista advierte la belleza ante lo que otros quedan indiferentes, y el científico encuentra nuevas verdades donde otros se conforman con lo establecido.

El lector tiene ahora en sus manos una obra en la que el profesor de Bayreuth ha vertido la quintaesencia de sus ideas. En la plenitud de la madurez intelectual, el profesor Häberle seguirá produciendo y beneficiándonos con otras aportaciones. La suya es la vida de un investigador y de un pensador infatigable. La fecundidad de su poderosa inteligencia y de su insaciable curiosidad científica nos depararán muchas nuevas obras suyas. Ahora podemos asomarnos, desde el hombro que como generoso soporte nos ofrece, para contemplar mediante la provechosa lectura de esta obra, lo que a lo largo de varios años ha acumulado un excepcional jurista de nuestro tiempo. Es probable que a partir de esta notable obra de Peter Häberle haya quien, como él mismo diría, alcance a ver más lejos; muchos, sin embargo, nos sentiremos satisfechos con que, orientados sabiamente por él, podamos ver tanto como nos enseña este texto lúcido e innovador.

El profesor Häberle señala la importancia institucional que tuvieron los acontecimientos de 1989, "annus mirabilis". En términos de Jaspers podemos decir que ese año representa un nuevo eje histórico en el mundo. Pero, como en todos los cambios históricos, ese año ha generado una tendencia en el sentido de transformar al Estado constitucional en la dirección que apunta Häberle, mientras que otra corriente ha aprovechado el fenómeno histórico para intentar desarticular el Estado constitucional.

El desprestigio de las grandes burocracias, la corrupción desarrollada con el pretexto del Estado de bienestar, y el autoritarismo institucionalizado han tenido una doble respuesta antitética: el impulso del Estado constitucional y el desmantelamiento del Estado. Para ofrecer una base conceptual a ambas tendencias, se ha generado una importante literatura jurídica y política, y así como el profesor Häberle manifiesta que sus reflexiones están 
Este libro forma parte del acervo de la Biblioteca Juridica Virtual del Instituto de Investigaciones Juridicas de la UNAM

en línea con muchas tesis de Heller, por ejemplo, hay otros que sintonizan con las de Hayek (esp. The road to serfdom), para sólo mencionar dos figuras paradigmáticas.

El Estado constitucional ofrece una amplia gama de argumentos que en torno a la consolidación de la democracia a través de la Constitución, y presenta un enfoque original para entender las relaciones simbióticas entre norma y cultura. Se trata de una de las formulaciones teóricas de la Constitución más relevantes del siglo anterior, y será sin duda una de las más esclarecedoras en el que comienza. Para soportar sus argumentos el autor recurre a la doctrina y a las aportaciones legislativa y jurisprudencial de numerosos países, pero, sobre todo, se apoya en su formidable capacidad de asociar información y de formular, de manera persuasiva y clara, ideas que aportan nuevas luces a viejos problemas. Es importante también hacer notar que estas virtudes de la obra original no serían suficientes si no se contara con la traducción pulcra, precisa y elegante que ha hecho Héctor FixFierro. Es comprensible que así sea, porque Fix-Fierro además de dominar la lengua alemana es un jurista de gran talla.

El profesor, doctor, doctor honoris causa múltiple, Peter Häberle, es un jurista cuyos aportes científicos permitirán descifrar las claves del poder, complejo y proteico, de un siglo que se caracterizará por la expansión y consolidación de los derechos culturales. El ilustre hombre de derecho alemán, en cuyas páginas el lector encontrará una nueva forma de agrupar la información y una nueva cantera de ideas, corresponde a la mejor tradición ilustrada europea. Es comprensible que vea las relaciones entre Constitución y cultura con la diafanidad que expone en esta obra, porque él mismo encarna una admirable conjunción de científico y artista. El derecho, la filosofia y la historia, por una parte; la música y la poesía, de otra, enriquecen la vida de Peter Häberle. Su obra es prometeica porque nos ofrece una nueva luz sobre el secular problema de organizar el poder y asegurar la libertad y la justicia. Seguramente el profesor habrá releído muchas veces a Goethe, uno de sus favoritos, cuando dice "cubre tu cielo, Zeus / con bruma y con nubes, / e igual que el infante / que juega a desmochar el cardo, / ejerce tu poder sobre las encinas en la cumbre del monte. / Pero deja mi tierra, / y mi pobre cabaña, que no es obra tuya, / y mi hogar, / que al iluminarme / enciende tu envidia". 
Este libro forma parte del acervo de la Biblioteca Juridica Virtual del Instituto de Investigaciones Juridicas de la UNAM

\section{PEter HÄBERLE: AUTORRETRATO DE UN JURISTA UNIVERSAL A LOS OCHENTA AÑOS DE EDAD}

El 13 de mayo de 2014, el eminente profesor Peter Häberle cumplió ochenta años de edad. Su andadura académica comenzó como estudiante en las universidades de Tubinga, Bonn, Montpellier y Friburgo. En esta última se doctoró con honores en 1961 y ahí mismo comenzó más tarde su labor docente, que continuaría en Marburgo y culminaría en Bayreuth, donde ahora es emérito, y en la Universidad de St. Gallen, donde es profesor visitante permanente. Sus lecciones han sido escuchadas por el público universitario de varios países europeos y asiáticos; en América Latina ha dictado conferencias en Argentina, Brasil, México y Perú.

$\mathrm{Su}$ voluminosa obra comprende medio centenar de libros, incluidas las traducciones, y casi setecientos ensayos, artículos y reseñas (Mikunda Franco, 2009). Muchos de ellos han sido traducidos a diversos idiomas y son estudiados con atención e interés crecientes por los juristas iberoamericanos. Esto explica que haya sido editado en Argentina, Brasil, Colombia, España, México y Perú.

Sobre el profesor Häberle se han escrito muchos ensayos y monografías. Sólo en el documentado estudio del profesor Emilio Mikunda Franco, de la Universidad de Sevilla, son citados treinta y tres, aparecidos Alemania, Argentina, Brasil, Corea, Croacia, España, Italia, Japón, México, Perú y Portugal.

La lectura del jurista alemán nos pone ante textos de enorme riqueza conceptual. Su sólida formación filosófica, jurídica, histórica, literaria y musical permite que sus trabajos alcancen una gran profundidad y confirmen los argumentos centrales de su teoría cultural de la Constitución. Pero, además de los trabajos de su autoría disponemos de otra rica cantera para abrevar en su pensamiento. En 2006, recopilé en un volumen las diversas entrevistas especializadas que hasta ese momento había concedido el profesor Häberle (Conversaciones académicas con Peter Häberle, 2006, pp. 204). Para tener un panorama de su formación e ideas, en sus propias palabras, reproduzco a continuación algunos fragmentos de esas conversaciones, con relación a temas específicos. También incorporo la entrevista que le hizo Jorge León Vásquez en 2014, la más reciente de todas.

Me atrevo a llamar "autorretrato" a este texto. Si bien la selección es mía, las páginas que siguen son todas del profesor Häberle. Las agrupé en diversos rubros, para facilitar su lectura. 
Este libro forma parte del acervo de la Biblioteca Juridica Virtual del Instituto de Investigaciones Juridicas de la UNAM http://www.juridicas.unam.mx

\section{Autobiografia intelectual}

Comencé mis estudios jurídicos en Tubinga, continuándolos en Friburgo; estuve después un semestre en Bonn, otro posterior en Montpellier, volviendo luego a Friburgo, de cuya facultad de entonces guardo los mejores recuerdos que puedan imaginarse. Inicialmente me concentré en el derecho penal y estudié con el muy conocido, también en España, profesor Jescheck. Pero entonces, era mi quinto semestre, en el año 1956, asistí por primera vez al nuevo seminario del joven profesor Konrad Hesse, con el que, desde el principio me entusiasmé, sobre todo por su arte para conducir un seminario de manera sistemática ("Entrevista de Francisco Balaguer Callejón...", Conversaciones académicas con Peter Häberle, 2006, p. 17).

Me he esforzado siempre en desarrollar el derecho constitucional sobre la base de sus profundas dimensiones filosófico-jurídicas (ibidem, p. 19).

He presentado propuestas concretas para los trabajos constituyentes en Polonia, que se han publicado en el Fahrbuch des öffentlichen Rechts que dirijo y que se han traducido, además, al polaco y al inglés. Esas propuestas han sido tenidas en cuenta, especialmente en relación con la garantía del contenido esencial de los derechos o las fuentes del derecho (ibidem, p. 22).

Me considero afortunado de haber vivido, en 1989, en Bayreuth, porque antes se encontraba en la frontera alemana. Hoy se encuentra en medio del corazón de la reunificada Alemania. Para mí representa la reunificación, en el aspecto social, la experiencia más feliz de mi biografía. Y lo más importante no es la reunificación de un Estado nacional, sino la reunificación de Alemania entendida como nación cultural, y porque de esta manera nos encontramos en el camino de aquello que exigió Thomas Mann: una Alemania europea ("Entrevista de Zvonko Posavec", Conversaciones..., p. 151).

Yo fui ingenuo hasta el año 1989, si usted así lo quiere, partidario de la idea del hombre de John Locke. Pero frente a la confrontación en sus Balcanes, en la ex Yugoslavia, frente al exterminio de minorías étnicas por los serbios, frente a los sucesos en Kosovo entre serbios y ortodoxos, para mí incomprensible, contra la minoría islámica, frente a todo eso, he comenzado a dudar si somos justos insistiendo en una idea optimista del hombre tanto para con el Estado constitucional como para el hombre mismo" (ibidem, p. 156).

\section{Fuentes de inspiración}

Es manifiesto que yo le debo más que a nadie, tanto en el aspecto personal cuanto en el científico, a Hermann Heller. Él es, para todos nosotros, un modelo debido a su integridad personal e independencia, su compromiso democrático y, ciertamente, su inclinación a España, donde pudo encontrar 
Este libro forma parte del acervo de la Biblioteca Juridica Virtual del Instituto de Investigaciones Juridicas de la UNAM

asilo en su exilio. En el plano científico, debo a Hermann Heller la comprensión profunda de una teoría del Estado culturalmente integrada, que yo he intentado continuar bajo la idea de una teoría científico-cultural de la Constitución ("Entrevista de Francisco Balaguer Callejón...", Conversaciones..., pp. 24 y 25).

$\mathrm{Al}$ profesor Hesse le debo yo la formación en un pensamiento disciplinado y estrictamente sistemático, así como la disposición para una revisión permanente de las propias posiciones y la cercanía a la jurisprudencia del Tribunal Constitucional Federal. Él fue uno de los pocos jueces no vinculado a los partidos, de los considerados como jueces neutrales; quizá el último (1975-1987). Por lo demás, me ha alentado desde el principio, desde los tempranos tiempos de estudiante en Friburgo hasta hoy y me ha honrado con su dedicación amistosa (ibidem, p. 26).

Mis maestros Konrad y Horst Ehmke llamaron mi atención sobre la riqueza del pensamiento de Hermann Heller en relación con los temas como: derecho como ciencia de la realidad, o también: teoría del Estado como ciencia de la cultura. Sin importar que el punto de partida de las reflexiones de Hermann Heller sea siempre el Estado, cuando para mí el punto de partida es la Constitución. Esa es una diferencia clara entre ambos ("Entrevista de Zvonko Posavec", Conversaciones..., p. 150).

Como trasfondo de la idea expresada por mí, por primera vez en 1991, del "derecho constitucional común europeo", puede mencionarse la teoría de Josef Esser que, como privatista, formuló la concepción del carácter «principal» del derecho, con referencia a Hermann Heller. En mi opinión hoy ha sonado ya la hora del derecho constitucional común europeo, que no comprende sólo principios escritos sino, ante todo, principios no escritos. Puedo ponerle ejemplos: derecho constitucional común europeo se encuentra en la dignidad humana, la división de poderes, el principio de Estado de derecho, el principio de igualdad como prohibición de arbitrariedad, la democracia ("Entrevista de Francisco Balaguer Callejón...", Conversaciones..., p. 52).

Un escritor austriaco (Robert Musil) ha hablado sobre el hombre posible. Yo distingo entre tres formas del pensamiento: el pensamiento posible, el pensamiento real y el pensamiento necesario. A través del pensamiento posible gana el intérprete mayor espacio de juego. El pensamiento necesario, relacionado sobre todo al aspecto del bienestar común, determina lo que es necesario para alcanzar ciertas metas. El pensamiento real lo incluyo dentro del canon interpretativo con ayuda de una antigua consigna: la realidad orientada a la interpretación de la Constitución ("Entrevista de Zvonko Posavec", Conversaciones..., p. 133).

La sociedad abierta y sus enemigos, de Popper... me inspiró... como paradigma de explicación y publicar La sociedad abierta de los intérpretes de la Constitución. Esto significa que no sólo los juristas interpretan la Constitución, sino también 
Este libro forma parte del acervo de la Biblioteca Juridica Virtual del Instituto de Investigaciones Juridicas de la UNAM http://www.juridicas.unam.mx

cualquier ciudadano común dentro de una democracia ciudadana (ibidem, p. 138).

Rudolf Smend fue quien con su escrito de 1954 en memoria de Walter Jellinek colocó en el centro del interés de la teoría alemana del Estado de derecho el aspecto público. En seguida debo mencionar a mi profesor Konrad Hesse, quien desarrolló el aspecto público de los partidos políticos. Jürgen Habermas, a quien usted ya ha entrevistado, escribió su trabajo de habilitación en Marburgo, que ha resultado ser un clásico a la fecha, sobre los cambios en la estructura de lo público. Sobre la base que crearon estos tres autores he intentado desarrollar mi teoría sobre el aspecto público de la Constitución (ibidem, p. 146).

A lo largo de mi carrera he intentado explicar la influencia que la poesía y los textos clásicos de la literatura y del pensamiento ejercen en la Constitución como concepto de cultura. Los ejemplos son innumerables; para empezar podríamos citar a Schiller, quien ya estableció una relación directa entre poesía y política en las Cartas sobre la Educación Estética del Hombre, o a Rousseau, que había escrito poesía además de sus conocidos textos filosóficos ("Entrevista de Héctor López Bofill”, Conversaciones..., p. 188).

\section{Crítica doctrinaria}

Unas palabras sobre Kelsen. No necesito decirle que yo me separo del mundo de Kelsen en el aspecto metodológico; pero debo señalarle igualmente que su gran contribución sigue viva, por un lado en cuanto a la teoría de la construcción escalonada del sistema jurídico. Hoy tenemos en muchas constituciones nuevas la indicación expresa de la primacía de la Constitución norma suprema, como norma de las normas lo que es claramente también un gran mérito de Kelsen. Finalmente Kelsen es, por otro lado, uno de los padres de la jurisdicción constitucional en Europa ("Entrevista de Francisco Balaguer Callejón...", Conversaciones..., p. 25).

...un padre del Estado constitucional que siempre debe leerse es J. Locke ("Entrevista de César Landa. Reforma...", Conversaciones..., p. 79).

Necesitamos un John Locke para toda Europa y para la teoría constitucional con el fin que encuentre una conceptualización adecuada para este nuevo constructo, incluso en caso de ser necesario con la ayuda de categorías de una utopía concreta. Recordemos que cuando John Locke desarrolló los elementos del Estado constitucional en la Inglaterra de su tiempo, pasaban sus ideas por meras utopías, no obstante hoy día sean para muchos de nosotros realidad. En ese sentido exijo a los juristas, como parte de su tarea, incluir quantos utópicos en su pensamiento con el fin de anticipar la realidad ("Entrevista de Zvonko Posavec", Conversaciones..., p. 155). 
Este libro forma parte del acervo de la Biblioteca Juridica Virtual del Instituto de Investigaciones Juridicas de la UNAM

Necesitamos un Montesquieu que revise la teoría original de la división de poderes en función de la nueva realidad europea ("Entrevista de Héctor López Bofill”, Conversaciones..., p. 200).

Mi pregunta a Popper - nosotros hablamos de ello en su extraordinaria conferencia que ayer sostuvo aquí en Bayreuth - que él no es justo con Platón, como tampoco con Hegel, cuando habla del pensamiento-oráculo. Popper establece una línea de conexión entre Platón, Hegel y la totalidad de las formas aparecidas del joven Estado mundial. Esto es a todas luces injustificado ("Entrevista de Zvonko Posavec", Conversaciones..., p. 139).

La doctrina del enemigo-amigo, que formuló Schmitt en su "teología política", se entiende en el contexto del fracaso de Weimar y del advenimiento de los Estados totalitarios. Esta doctrina ganó tanta fuerza en Europa, y por tanto también en Alemania, por la manera tan brillante en que fue expuesta. Es sin lugar a dudas falsa, y por eso mismo peligrosa, y fatal en sus consecuencias históricas. La sociedad política de las naciones y la comunidad política europea, como actualmente se desarrolla hacia una comunidad constitucional, no puede vivir dentro del pensamiento de la doctrina del enemigo-amigo sin desembocar en una guerra civil. En el contexto político, los enfrentamientos con el opositor exigen, sobre todo en determinados procesos, honestidad y tolerancia (ibidem, p. 148).

\section{Metodología}

El gran Rudolf Smend se ha dedicado más bien a la historia jurídica, no a la comparación jurídica. Yo, por mi parte, me he centrado más en la comparación en el espacio y he hecho raramente comparación en el tiempo ("Entrevista de Francisco Balaguer Callejón...", Conversaciones..., p. 41).

Podemos alegrarnos ante todo por el hecho de que la Constitución alemana no se haya inclinado a favor de alguna teoría constitucional (correcta), sino que ha trabajado con las puertas abiertas a nuevos desarrollos teóricos, liberándose con esto de una mentalidad encajonada ("Entrevista de H. Kuriki", Conversaciones..., p. 126).

\section{Constitución y cultura}

En 1982 emprendí un primer intento programático de conformar la teoría de la Constitución como una ciencia cultural. Ello recurriendo a los debates de la época de Weimar, en particular a Hermann Heller, aunque también a otros grandes autores, como Max Weber o Gunter Holstein. Lo que se pretende decir es lo siguiente: las normas constitucionales no pueden interpretarse de manera, por así decirlo, autónoma, sólo en sí y de por sí, sino que deben 
Este libro forma parte del acervo de la Biblioteca Juridica Virtual del Instituto de Investigaciones Juridicas de la UNAM http://www.juridicas.unam.mx

situarse, desde el principio, en su contexto cultural ("Entrevista de Francisco Balaguer Callejón...", Conversaciones..., p. 43).

Entendemos por cultura constitucional algo más que el texto jurídico o la legislación, sino la expresión de un Estado cultural que sirve de medio para la autoconciencia de un pueblo, que funge como espejo de su legado cultural y fundamento de sus futuras expectativas ("Entrevista de Paolo Ridola", Conversaciones..., p. 90).

Una teoría constitucional europea, entendida como teoría de la cultura, debe recordarnos que no todo es susceptible de ser reducido a mercado, que el mercado tiene límites, que si bien la libre competencia es en algunos aspectos productiva, no obstante está sujeta a condiciones culturales (ibidem, p. 99).

En 1975 aventuré el paradigma de la "sociedad abierta de los intérpretes constitucionales". Con ello se quería expresar lo siguiente: quien tiene relación con las formas, participa también, de manera consciente o inconsciente, en su interpretación. El ciudadano que interpone un recurso de amparo, el partido que promueve un proceso ante el Tribunal Constitucional, influyen finalmente en la interpretación de las normas constitucionales ("Entrevista de Francisco Balaguer Callejón...", Conversaciones..., p. 45).

El concepto de cultura política es un invento de los autores norteamericanos Almond y Verba. Ese mismo concepto de cultura política se impuso más tarde en Alemania. Yo, por mi parte, propuse en 1982 el concepto de «cultura constitucional», al que usted de manera amistosa se ha referido. Este concepto significa lo siguiente: que la Constitución no es sólo un texto jurídico junto con sus instrumentos de interpretación, sino que el hecho de que nosotros podamos vivir en una Constitución, o dispongamos de una Constitución viva, es necesariamente porque cuenta también la mentalidad de los pueblos, su herencia cultural ("Entrevista de Zvonko Posavec", Conversaciones..., p. 136).

Los poetas proporcionan la suficiente dosis de utopía que orienta el sentido de la realidad constitucional. Podría citarse el caso de la nueva Constitución Federal Suiza de 1999, una parte de cuyo preámbulo fue concebida por el poeta suizo A. Mushg al proclamar que la fuerza del pueblo se mide en el bienestar de los débiles ("Entrevista de Héctor López Bonfil", Conversaciones..., p. 189).

Considero la encuesta llevada a cabo por el Instituto de Investigaciones Jurídicas de la Universidad Nacional Autónoma de México (Concha, Hugo et al., 2004) como una contribución pionera de primer nivel, sin precedentes, hasta donde conozco, en Europa o el resto del mundo. La encuesta debe hacer escuela, tanto en sus métodos como contenidos, al servicio del tipo del Estado constitucional y de sus procesos de crecimiento interno y de difusión externa. De este modo se esboza una sociología de la cultura de la Constitución, entendida como sociología cultural de la Constitución y como sociología de la cultura constitucional ("Entrevista de Héctor Fix-Fierro y Diego Valadés”, Conversaciones..., p. 173). 
Este libro forma parte del acervo de la Biblioteca Juridica Virtual del Instituto de Investigaciones Juridicas de la UNAM

\section{Derechos fundamentales}

En relación con su pregunta sobre el doble carácter de los derechos fundamentales. Desarrollé esa tesis del doble carácter de todos los derechos fundamentales en mi tesis doctoral de 1962. La idea directriz era la siguiente: todos los derechos fundamentales tienen una doble faceta, una subjetiva-individual y una objetiva-institucional. Yo estaba entonces fuertemente influido por el gran teórico del Estado Maurice Hauriou. Tan sólo la faceta institucional, jurídico-objetiva permite reconocer las necesidades de conformación de todas las libertades, que no nos son naturalmente dadas ("Entrevista de Francisco Balaguer Callejón...", Conversaciones..., p. 30).

Sobre la idea del status corporativus, propuesta por mí por primera vez en 1980, se trata de lo siguiente: muchos catálogos de derechos fundamentales de los primeros tiempos son, por influencia de la Declaración de Derechos de 1789, ahora como antes, unilateralmente orientados en sentido individualista. Hoy sólo hay correcciones parciales... Este principio me ha inspirado la idea del status corporativus, en base al cual puede decirse que el ser humano no vive sólo como individuo aislado para sí, sino que vive desde el principio en una plenitud de grupos sociales, comenzando por la familia, culminando acaso en una asociación Mozart o Goethe, mostrándose en los sindicatos, manifestándose en cierto modo también en las sociedades religiosas. Casi la totalidad de la vida individual tiene también una referencia de grupo, incluida la libertad ideológica y de creencias (ibidem, p. 36).

\section{Tribunales constitucionales}

Una parte de los jueces... debería ser elegida por las entidades que dan las leyes; otra parte por los presidentes de la república... y la tercera parte por un órgano... de jueces y abogados ("Entrevista de César Landa. El rol...", Conversaciones..., p. 8.)

El proceso de elección de los jueces, practicado en este momento en Karlsruhe me parece digno de sospecha, no obstante que los resultados desde hace 50 años hayan sido tan positivos. La razón es que los partidos se comportan como los señores de las sillas de los jueces, y, además, como es necesario lograr la mayoría con sus dos tercios, tienen que ponerse de acuerdo los grandes partidos. Por lo mismo, personalidades de los pequeños partidos, o que no realizan servicio alguno a los grandes partidos, han perdido toda oportunidad. Así es como falta al partido verde un vínculo con los jueces de la Corte Constitucional, no obstante que su importancia a nivel federal es mucho mayor que el FDP (liberales) que dispone de su lugar para limpiarse los zapatos gracias a sus coaliciones con los grandes partidos (CDU y SPD). Rara vez obtienen algún 
Este libro forma parte del acervo de la Biblioteca Juridica Virtual del Instituto de Investigaciones Juridicas de la UNAM http://www.juridicas.unam.mx

lugar en la Corte Constitucional Federal alemana personalidades que no pertenecen a partido alguno. Mi profesor K. Hesse fue un caso excepcional en 1975 ("Entrevista de H. Kuriki”, Conversaciones..., p. 120).

Una sentencia judicial termina convirtiéndose en texto constitucional (“Entrevista de Francisco Balaguer Callejón...”, Conversaciones..., p. 47).

\section{Interpretación}

El profesor Häberle sostiene que a los cuatro métodos clásicos de interpretación (gramatical, lógica, histórica y sistemática) que canonizó F. C. Savigny en 1840, debe agregarse uno más. "Pienso que, desde 1989 la época ya está madura para un quinto método de interpretación, a saber, el derecho comparado". Esto, porque "la comunidad mundial de Estados constitucionales hoy está en camino hacia una comunidad de derechos humanos". Aclara que "Este planteamiento... debe entenderse como una comparación cultural... (no como una trasposición esquemática). Esto quiere decir que los contextos culturales deben «corresponderse»" (ibidem, p. 11).

\section{9. Ética}

En Inglaterra observamos un puritanismo quizás exagerado. Ciertos políticos tienen que dimitir rápidamente por faltar al decoro y a la moral en ámbitos muy personales de su vida privada. Lo mismo vale para Estados Unidos. En este aspecto no sería yo tan riguroso, ¡a pesar de que soy protestante!.... Tiene que haber un mínimo de ética en la vida política. Pero no podemos desconocer que los políticos se dedican a la res pública, a menudo con grandes sacrificios personales (ibidem, p. 65).

El jurista es alguien que se asienta en el bien común, en la democracia como modo de organización de la colectividad, en el derecho como estructura de convivencia ("Entrevista de Héctor López Bofill", Conversaciones..., p. 194).

\section{Estado constitucional}

El Estado constitucional debe mantenerse preparado para la reforma y apto para ser reformado ("Entrevista de Francisco Balaguer Callejón...", Conversaciones..., p. 59).

El Estado constitucional debe eludir el dirigismo, la imposición de criterios estéticos, debe ser receptivo a la ebullición de tendencias que disputan en la sociedad y en la que libremente (y en constante alternancia) se discute la cali- 
Este libro forma parte del acervo de la Biblioteca Juridica Virtual del Instituto de Investigaciones Juridicas de la UNAM

dad y la excelencia de las distintas aportaciones ("Entrevista de Héctor López Bofill”, Conversaciones..., p. 193).

\section{Estado social}

La transformación del Estado social necesita un enorme impulso en atención a las cuestiones relativas al derecho constitucional laboral ("Entrevista de Francisco Balaguer Callejón...", Conversaciones..., p. 60).

El Estado constitucional crea condiciones marco para el crecimiento de la riqueza: las libertades económicas de los empresarios, pero también la libertad de asociación de los trabajadores, cuya fuerza deriva sólo de su organización colectiva en sindicatos ("Entrevista de Héctor Fix-Fierro y Diego Valadés”, Conversaciones..., p. 176).

\section{Constitución, Estado y mercado}

El mercado es hasta hoy un ser desconocido. Necesitamos una teoría constitucional del mercado. Yo sostengo que el mercado no es el sentido último del Estado constitucional. La sociedad abierta no es un juego de ganancias económicas. Una república se basa en el trabajo, como dice la Constitución italiana de 1947, se fundamenta en la dignidad humana, descansa sobre la cultura, pero no se basa en los mercados. Desde 1989 observamos cómo va ganando terreno el pensamiento económico unilateral. El Estado social tiene que ser capaz de ofrecer prestaciones; tenemos que pasar de un entendimiento cuantitativo del Estado social a un entendimiento cualitativo ("Entrevista de Francisco Balaguer Callejón...”, Conversaciones..., p. 33).

La idea del mercado ha emprendido su grandiosa marcha triunfal en todo el planeta desde la derrota del marxismo-leninismo y de su economía planificada. Existe la amenaza de que hoy día se convierta en un fin en sí mismo sometiendo a las estructuras culturales ("Entrevista de Paolo Ridola", Conversaciones..., p. 98).

Desde la perspectiva del Estado constitucional es el mercado un simple instrumento y nunca la medida de todas las cosas. Economía de mercado refiere a economía social del mercado en el sentido que le ha dado Ludwig Erhardt. Debemos domar el capitalismo, acotarlo a través de derechos fundamentales culturales y sociales, a través de nuevas formas de democracia, también con desarrollo regional y mecanismos parecidos. En 1989 no era predecible la globalización ("Entrevista de Zvonko Posavec", Conversaciones..., p. 152).

¿Cuáles fueron los costos de la reunificación? El peligro de un nuevo economismo, una sobrevaloración de lo económico sin importar el significado del bienestar material para la democracia y sus ciudadanos. La valoración 
Este libro forma parte del acervo de la Biblioteca Juridica Virtual del Instituto de Investigaciones Juridicas de la UNAM

de cualquier cuestión humana en relación con el éxito económico muestra el infeliz curso que han tomado las cosas, contradiciendo el ideal de la antigua polis, así como también el idealismo alemán durante los clásicos de Weimar y la democracia plural. El materialismo poscomunista en Occidente, muestra un desarrollo que me hace dudar si la expresión annus mirabilis todavía es adecuada... Desde el punto de vista político, humano, científico sigue siendo para mí el año 1989 la experiencia más feliz, el comienzo de una nueva unidad europea y el reforzamiento del Estado constitucional y su modesta verdad para hacer coincidir justicia con bienestar general (ibidem, p. 153).

\section{Pluralismo y democracia}

Pluralismo: es la representación de una diversidad de intereses e ideas. La fundamentación teórica de la Constitución del pluralismo hay que buscarla en Popper. La idea de la sociedad abierta podemos tomarla de él. Lo que en Popper falta, sin embargo, es el principio científico-cultural: toda sociedad abierta necesita un consenso cultural fundamental, que hace posible la apertura y la cohesiona ("Entrevista de Francisco Balaguer Callejón...", Conversaciones..., p. 48).

El precio de la democracia consiste precisamente en que tengamos libertad de expresión y de prensa tan amplia como sea posible, aun cuando ocasionalmente los sacrificios sean altos. No existe, en principio, alternativa (ibidem, p. 66).

Una palabra sobre el posible fortalecimiento de los instrumentos de democracia directa en la Unión Europea. La tesis dice que en el nivel de desarrollo en que se encuentran los Estados constitucionales nacionales son igualmente valiosas ambas variantes de democracia: la directa e indirecta. Suiza es el país que a la fecha ha logrado la "combinación" más exitosa, porque se practica la "medio-directa democracia". También en las nuevas provincias federales alemanas se "arriesga más democracia". Esto, por cierto, en concordancia con la pacífica revolución de octubre de 1989 que se abanderó con la divisa: "nosotros somos el pueblo", y que finalmente en nuestra historia constitucional significó la reunificación ("Entrevista de Paolo Ridola", Conversaciones..., p. 107).

En la historia del pensamiento alemán podría estar relacionado el dogma de la separación dualista del derecho y la política con la separación del Estado y la sociedad. Sin embargo, yo tengo otra opinión. El Estado y la sociedad coinciden en parte. En el Estado constitucional sectores de la sociedad están estructurados y constituidos. Por eso desde 1978 yo hablo de la "sociedad constituida", piénsese como ejemplo en los efectos indirectos de los derechos fundamentales frente a terceros (G. Dürig, uno de mis mentores). Se puede hablar de "sociedad civil" en lugar de sociedad. Con ello están comprendidos 
Este libro forma parte del acervo de la Biblioteca Juridica Virtual del Instituto de Investigaciones Juridicas de la UNAM

desde el principio el ciudadano y los grupos pluralistas. Algunas constituciones nuevas textualmente emplean ya el concepto "sociedad civil", por lo que están un paso adelante de la literatura científica. Esto es un testimonio de mi paradigma de las etapas textuales de 1989 (Revista Peruana de Derecho Constitucional, 2014, p. 161).

\section{Teoría constitucional}

La teoría de las formas de gobierno debe ser revisada a la luz de una teoría constitucional. Debemos persistir en esta pluralidad de formas de gobierno, sobre todo cuando cada una de ellas tienen algo que aprender de las otras ("Entrevista de Paolo Ridola", Conversaciones..., p. 107).

He concebido a la Constitución como legítimo orden del Estado y sociedad ("Entrevista de Zvonko Posavec", Conversaciones..., p. 139).

La Constitución debe organizar la comunidad diferenciando las funciones del Estado, creando órganos y procesos para cumplir con su finalidad de hacer realidad la cláusula del Estado social, la protección del medio ambiente o el Estado cultural. Pero la Constitución tiene, además de eso, una función simbólica, a saber; simboliza la relativa unidad de la comunidad política, incluso en Europa. Esto significa que posee una función integradora que cumple junto con una función pedagógica, y esta es la idea más audaz que causa rechazo por muchos de mis colegas. Función pedagógica que se realiza cuando nosotros, partiendo de la Constitución, extraemos algunas metas educativas, como he expuesto en otro lugar, para los jóvenes escolares... He olvidado una función más, se trata de la clásica función que limita y controla el poder (ibidem, p. 141).

Mi concepción de Constitución no pretende eliminar la función y conceptos clásicos de la Constitución, sino que sólo pretende ser un complemento de aquello que desarrollaron los gigantes de Weimar y otros más (ibidem, p. 143).

Constitución entendida como lo público y Constitución entendida como proceso público, indican que la Constitución se desarrolla a través de la interpretación viva de todos los ciudadanos y de aquellos profesionales ocupados con la interpretación constitucional, como juristas (ibidem, p. 147).

La calidad de una Constitución en el Estado constitucional se mide por las funciones que aquélla debe desempeñar y por la posición y el valor reales y vividos que ha adquirido en una sociedad civil abierta ("Entrevista de Héctor Fix-Fierro y Diego Valadés", Conversaciones..., p. 165).

La Constitución no es sólo un conjunto de reglas jurídicas, sino también una guía cultural para el ciudadano (ibidem, p. 166).

Constitución que no es sólo un conjunto de reglas jurídicas, sino también expresión de la herencia cultural de un pueblo, fundamento de sus esperanzas y espejo de su identidad. La encuesta es consecuencia de la teoría de la 
Este libro forma parte del acervo de la Biblioteca Juridica Virtual del Instituto de Investigaciones Juridicas de la UNAM

sociedad abierta de los intérpretes de la Constitución (1975); es decir, de la idea de que cualquiera que viva la norma contribuye en primera y última instancia a su interpretación. La concepción de la sociedad abierta de los intérpretes de la Constitución vive de dos preocupaciones: por un lado, de la democratización de la interpretación constitucional y, por el otro, del impulso teórico que deriva del ejercicio práctico de los derechos fundamentales para la comprensión jurídica de estos derechos (ibidem, p. 174).

El concepto de derecho eclesiástico del Estado tiene que ser reemplazado por el de derecho constitucional de la religión, si tomamos en cuenta que en Francia el Islam es ya la segunda religión en importancia, y entre nosotros la tercera (ibidem, p. 170).

\section{Colofón}

Las páginas que preceden ofrecen una especie de autorretrato del profesor Häberle. Seleccioné párrafos de sus entrevistas que considero una buena muestra de sus ideas. Son sólo, como en las representaciones que hacen de sí mismos los grandes maestros, trazos aislados que no sustituyen la lectura de la gran obra que ha venido escribiendo a lo largo de su fructífera vida, pero presentan una imagen general de sus múltiples contribuciones a la ciencia jurídica.

En varias de sus conversaciones declara, con la modestia espontánea que siempre lo ha caracterizado, que no es más que un enano a quien le fue dado contemplar el mundo jurídico desde los hombros de gigantes. Tal vez así comenzó, al asomarse al mundo jurídico en su etapa de estudiante; pero sin duda hoy, él mismo es un gigante que con su inteligencia y erudición ayuda a ver más lejos a quienes emprenden la grata y enriquecedora tarea de estudiarlo a fondo.

Como en toda selección dejé otras muchas páginas brillantes fuera de este texto; tuvo que ser así por razones naturales, pues de otra manera habría reproducido íntegras las entrevistas. Aquí, insisto, sólo ofrezco unas pinceladas con el ánimo de inducir al lector a la lectura completa de sus entrevistas y, por supuesto, de sus obras.

Este texto lo preparé gracias a las cordiales exhortaciones de mi admirado y querido amigo Domingo García Belaunde, por quien el profesor Häberle también profesa genuino afecto. Rindo así un nuevo homenaje a uno de los pensadores más sobresalientes del mundo jurídico contemporáneo. 
Este libro forma parte del acervo de la Biblioteca Juridica Virtual del Instituto de Investigaciones Juridicas de la UNAM

\section{Referencias}

AbIGnente, Angelo, "Il contributo di Rudolf Smend ed Hermann Heller al dibattito weimariano su diritto e Stato", Quaderni fiorentini per la storia del pensiero giuridico moderno, Milán, Giuffrè, 1992.

AlExy, Robert, Teoría de los derechos fundamentales, Madrid, Centro de Estudios Constitucionales, 1997.

ARminjon, P. et al., Traité de droit comparé, París, LGDJ, 1950-1952.

Balaguer Callejón, Francisco, "Un jurista europeo nacido en Alemania", Anuario de Derecho Constitucional, Universidad de Murcia, núm. 9, 1997.

BilbaO UBiLlos, Juan María, Los derechos fundamentales en la frontera entre lo público y lo privado, Madrid, McGraw-Hill, 1997.

BRZEZINSKi, Zbigniew, Out of Control, Nueva York, Macmillan, 1993.

CARPIZO, Jorge, Estudios constitucionales, México, UNAM, Instituto de Investigaciones Jurídicas, 1980.

Carbonell, Miguel, "Estudio introductorio", en JellineK, Georg, La Declaración de los Derechos del Hombre y del Ciudadano, México, UNAM, Instituto de Investigaciones Jurídicas, 2000.

Concha, Hugo A. et. al., Cultura de la Constitución en México. Una encuesta nacional de actitudes, percepciones y valores, México, UNAM-TEPJF-Cofemer, 2004.

DAVID, René, Tratado de derecho civil comparado, Madrid, Revista de Derecho Privado, 1953.

Estévez ARAujo, José Antonio, La Constitución como proceso y la desobediencia civil, Madrid, Trotta, 1994.

ESTRADA, Alexei Julio, Eficacia de los derechos fundamentales entre particulares, Bogotá, Universidad Externado de Colombia, 2000.

FOUCAUlT, Michel, La verdad y las formas jurídicas, Barcelona, Gedisa, 1980.

Fueter, E., Historia de la historiografia, Buenos Aires, Nova, 1953.

Gaos, José, Historia de nuestra idea del mundo, México, Fondo de Cultura Económica, 1973.

García Belaunde, Domingo, "Los gigantes de Weimar", De la jurisdicción constitucional al derecho procesal constitucional, Lima, Instituto Iberoamericano de Derecho Constitucional (sección peruana), 2000.

García Torres, Jesús y Jiménez Blanco, Antonio, Derechos fundamentales y relaciones entre particulares. La Drittwirkung en la jurisprudencia del Tribunal Constitucional, Madrid, Civitas, 1986.

Goethe, J. Wolfgang, Prométhée, en Théatre, París, Pleiade, 1942. 
Este libro forma parte del acervo de la Biblioteca Juridica Virtual del Instituto de Investigaciones Juridicas de la UNAM

, Egmont, en Théatre, París, Pleiade, 1942.

Gomes Canotilho, José Joaquim, "A mais recente obre de Peter Häberle", ponencia presentada en el homenaje a Peter Häberle, Universidad de Granada, Facultad de Derecho, marzo de 2000.

- Constituiçao dirigente e vinculaçao do legislador, Coimbra, Coimbra Editora, 1994.

GonzÁLez PÉREz, Jesús, La dignidad de la persona, Madrid, Civitas, 1986.

HÄBERLE, Peter, "Problemi attuali del federalismo tedesco", Giuriprudenza Costituzionale, año XXXVII, núm. 4, Milán, Giuffrè, julio-agosto de 1992. , "Recientes desarrollos sobre derechos fundamentales en Alemania", Derechos y Libertades, Revista del Instituto Bartolomé de las Casas, Madrid, Universidad Carlos III, febrero-octubre de 1993.

—_, "Unitá politica e pluralismo culturale in Germania", en SABELLA, Marco y URbaniti, Nadia, Quale federalismo, Florencia, Vallecchi, 1994.

,, "El concepto de los derechos fundamentales", en SAUCA, José Ma. (ed.), Problemas actuales de los derechos fundamentales, Madrid, Universidad Carlos III, 1994.

-, "Avances constitucionales en Europa Oriental desde el punto de vista de la jurisprudencia y de la teoría constitucional", Pensamiento Constitucional, Lima, Pontificia Universidad Católica del Perú, s. n., 1995.

, "Derecho constitucional común europeo", en PÉREz LuÑo, A. E. (coord.), Derechos humanos y constitucionalismo ante el tercer milenio, Madrid, Marcial Pons, 1996.

-, "Elementos teóricos de un modelo general de recepción jurídica", en PÉrez Luño, A. E. (coord.), Derechos humanos y constitucionalismo ante el tercer milenio, Madrid, Marcial Pons, 1996.

-, "La sociedad abierta de los intérpretes constitucionales. Una contribución para la interpretación pluralista y procesal de la Constitución”, en HäBerle, P., Retos actuales del Estado constitucional, Oñate, Gobierno Vasco, 1996. constitucional y como máxima de la política del derecho europeo", en HäBERLE, P., Retos actuales del Estado constitucional, Oñate, Gobierno Vasco, 1996.

, "Programas sobre Europa en Constituciones y proyectos constitucionales recientes. El desarrollo del «derecho constitucional nacional sobre Europa»", en HÄBERLE, P., Retos actuales del Estado constitucional, Oñate, Gobierno Vasco, 1996. 
Este libro forma parte del acervo de la Biblioteca Juridica Virtual del Instituto de Investigaciones Juridicas de la UNAM

, "El fundamentalismo como desafío del derecho constitucional: consideraciones desde la ciencia del derecho y la cultura", en HÄBERLE, P., Retos actuales del Estado constitucional, Oñate, Gobierno Vasco, 1996.

- "La ética en el Estado constitucional. La relación de reciprocidad y tensión entre la moral y el derecho", Direito, Santiago de Compostela, vol. 5, núm. 2, 1996.

—, "El recurso de amparo en el sistema germano-federal de jurisdicción constitucional", en García Belaunde, D. y Fernández SEgado, F. (coords.), La jurisdicción constitucional en Iberoamérica, Madrid, Dykinson, 1997.

análisis comparativo", Revista Española de Derecho Constitucional, Madrid, vol. 18, núm. 54, 1998.

- Libertad, igualdad, fraternidad. 1789 como historia, actualidad y futuro del Estado constitucional, Madrid, Trotta, 1998.

-, "Teoria de la Constitució com a ciéncia de la cultura en lexemple dels 50 anys de la llei fonametal”, Revista de Llengua i Dret, Barcelona, núm. 32, diciembre de 1999.

_- "Colloquio sulla Costituzione europea", Diritto romano attuale, Roma, ESI, 1999.

, "El eterno combate por la justicia. La ciencia jurídica en el camino hacia Europa", Revista General de Derecho, núms. 652-653, Valencia, enerofebrero, 1999.

, "Los derechos fundamentales en el espejo de la jurisprudencia del Tribunal Constitucional Federal alemán. Exposición y crítica", Revista de la Facultad de Derecho de la Universidad de Granada, Granada, tercera época, núm. 2, 1999.

tad de Derecho de la Universidad de Granada, Granada, tercera época, núm. 3, 2000.

- Teoría de la Constitución como ciencia de la cultura, Madrid, Tecnos, 2000.

-, Diritto e veritá, Turín, Einaudi, 2000.

__ , "El Estado constitucional europeo", Cuestiones Constitucionales. Revista Mexicana de Estudios Constitucionales, México, núm. 2, enero-junio de 2000.

Pensamiento Constitucional, Lima, núm. 7, 2000. 
Este libro forma parte del acervo de la Biblioteca Juridica Virtual del Instituto de Investigaciones Juridicas de la UNAM

- "La revisión 'total' de la Constitución federal suiza de 1999/2000”, Revista Peruana de Derecho Público, Lima, núm. 1, 2000.

—_ "Problemas fundamentales de una teoría constitucional del regionalismo en perspectiva comparada", s. p. i.

Habermas, Jürgen, Teoría de la acción comunicativa, Madrid, Taurus, 1987, t. II. HALE, John, La civilización del Renacimiento en Europa (1450-1620), Barcelona, Crítica, 1996.

HayeK, Friedrich A., The Road to Serfdom, Chicago, The University of Chicago, 1944.

Hegel, G. W. F., Fundamentos de la filosofia del derecho, Madrid, Prodhufi, 1993. Heller, Hermann, Teoría del Estado, México, Fondo de Cultura Económica, 1961.

Las ideas políticas contemporáneas, Madrid, s. p. i., 1977.

Jaeger, Werner, Paideia: los ideales de la cultura griega, México, Fondo de Cultura Económica, 1962.

JASPERs, Karl, La filosofia, México, Fondo de Cultura Económica, 1953.

JellineK, Georg, Teoría general del Estado, Buenos Aires, Albatros, 1954.

, Reforma y mutación de la Constitución, Madrid, Centro de Estudios Constitucionales, 1991.

KANT, Immanuel, Fundamentación de la metafisica de las costumbres, Madrid, Santillana, 1996.

-, La metafisica de las costumbres, Madrid, Tecnos, 1989.

KELSEN, Hans, "El problema del parlamentarismo", Escritos sobre la democracia y el socialismo, Madrid, Debate, 1988.

KNOLLES, Richard, The Generall Historie of the Turkes, Londres, Adam Islip, 1621.

LANDA, César, "El rol de los tribunales constitucionales ante los desafíos contemporáneos", entrevista con Peter Häberle, en Pensamiento Constitucional, Lima, núm. 3, 1997.

-, "Reforma de la enseñanza del derecho constitucional", entrevista con Peter Häberle, en Pensamiento Constitucional, Lima, núm. 6, 1999.

LarenZ, Karl, Derecho justo, Madrid, Civitas, 1985.

Lassalle, F., ¿Qué es una Constitución?, Buenos Aires, Siglo Veinte, 1964.

LEÓn Portilla, Miguel, "Encuentro de dos mundos", En torno al 12 de octubre de 1492, México, Instituto Matías Romero, 1992. 
Este libro forma parte del acervo de la Biblioteca Juridica Virtual del Instituto de Investigaciones Juridicas de la UNAM

LiNZ, Juan, El factor tiempo en un cambio de régimen, México, Instituto de Estudios para la Transición Democrática, 1994.

Loewenstein, Karl, Teoría de la Constitución, Barcelona, Ariel, 1964.

Lutero, Martín, "Charlas de sobremesa", Obras, Salamanca, Sígueme, 1977.

MÂRTIRes Coelho, Inocêncio, "Konrad Hesse/Peter Häberle: um retorno aos fatores reais de poder", Notícia do Direito Brasileiro, Brasilia, Universidad de Brasilia, núm. 5, primer semestre de 1998.

MAX-MÜLLER, F., Origen y desarrollo de la religión estudiados a la luz de la religión de la India, Madrid, La España Moderna, s. f.

Mommsen, Hans, The Rise and Fall of Weimar Democracy, Chapell Hill, The University of North Carolina Press, 1996.

Mikunda Franco, Emilio, Fillosofia y teoría del derecho en Peter Häberle, Madrid, Dykinson, 2009.

MORA, Juan Miguel de, Tantrismo, México, UNAM, 1988.

Mortati, Costantino, La Constituzione in senso materiale, Milán, Giuffrè, 1998.

Nietzsche, F., Humano, demasiado humano, Madrid, Aguilar, 1932.

NozICK, Robert, Anarchy, State and Utopia, Nueva York, Basic Books, 1974.

Ovalle, Alfonso de, Histórica relación del reino de Chile, Roma, F. Cavallo, 1646.

Peukert, Detlev J. K., The Weimar Republic, Nueva York, Hill and Wang, 1989.

Pico Della Mirandola, Giovanni, Oration on the Dignity, Chicago, Gateway Edition, 1956.

StAMmLER, Rudolf, Tratado de filosofia del derecho, Madrid, Reus, 1930.

RANKe, Leopold von, Historia de los papas, México, Fondo de Gultura Económica, 1943.

Revista Peruana de Derecho Constitucional, Lima, 2014.

RoEHrssen, Carlo, "La Integrationslehre di Rudolf Smend: un sintomo significativo della patogenesi del nazismo", Materiali per una storia della cultura giuridica, Boloña, Il Mulino, vol. XII, núm. 1, 1982.

RODRÍGuez Olvera, Óscar, Teoría de los derechos sociales en la Constitución abierta, Granada, Comares, 1998.

Rousseau, J. J., Discours sur lorigine et les fondements de linégalité parmi les hommes, en Oeuvres politiques, París, Garnier, 1989.

-, Du contrat social, en Oeuvres politiques, París, Garnier, 1989.

SchmitT, Carl, Sobre el parlamentarismo, Madrid, Tecnos, 1990. 
Este libro forma parte del acervo de la Biblioteca Juridica Virtual del Instituto de Investigaciones Juridicas de la UNAM

, Legalidad y legitimidad, Madrid, Aguilar, 1971.

SMEND, Rudolf, Constitución y derecho constitucional, Madrid, Centro de Estudios Constitucionales, 1985.

Tachibana, S., The Ethics of Buddhism, Londres, Oxford University Press, 1926.

TAJADURA TEJADA, Javier, El preámbulo constitucional, Granada, Comares, 1997.

, "Exposiciones de motivos y preámbulos", Revista de las Cortes Generales, Madrid, núm. 44, 1998.

, "La Constitución cultural", Revista Furídica del Perú, Lima, año XLVIII, núm. 17, octubre-diciembre de 1998.

—_ "La función política de los preámbulos constitucionales", Cuestiones Constitucionales. Revista Mexicana de Estudios Constitucionales, México, núm. 5, julio-diciembre de 2001.

Troeltsch, Ernst, El protestantismo y el mundo moderno, México, Fondo de Cultura Económica, 1951.

TunG, André, "Standars juridiques et unification du droit", Revue Internationale de Droit Comparé, París, abril-junio de 1970.

VALADÉs, Diego, El control del poder, México, Porrúa-UNAM, 2000.

- (comp.), Conversaciones académicas con Peter Häberle, México, UNAM, 2006.

VEGA, Pedro de, La reforma constitucional y la problemática del poder constituyente, Madrid, Tecnos, 1985.

Diego VALADÉS 
Este libro forma parte del acervo de la Biblioteca Juridica Virtual del Instituto de Investigaciones Juridicas de la UNAM

\section{PRÓLOGO DEL AUTOR}

Es una gran satisfacción y un gran honor que el Instituto de Investigaciones Jurídicas de la Universidad Nacional Autónoma de México, bajo la dirección del doctor Diego Valadés, se haga cargo de la edición española del presente volumen. Mi segundo agradecimiento es para el doctor Héctor Fix-Fierro por la excelente traducción al español de un texto que con seguridad no es sencillo. El suscrito sabe muy bien cuánta capacidad de comprensión creativa se requiere para realizar una buena traducción, y él mismo conoce lo suficiente el español como para juzgar con cuánto cuidado, con cuánta paciencia y fantasía ha trabajado el doctor Fix-Fierro para lograr esta traducción de primer nivel.

La ciencia, en general, y la doctrina del derecho del Estado, en particular, viven del impulso material que da la "eterna" búsqueda de la justicia y la verdad, $y$ también del elemento personal de la comunidad nacional e internacional de los científicos como parte de la "sociedad abierta de los intérpretes de la Constitución".

La lucha por la justicia y la verdad hoy, después del "annus mirabilis" de 1989, ha entrado en una nueva fase en relación con el tipo del Estado constitucional. En estos procesos están incluidos creadoramente, desde el inicio, los países latinoamericanos, sobre todo porque se encuentran específicamente ligados a Europa a través de España y su ejemplar Constitución de 1978. Los procesos de producción y recepción entre Europa y Latinoamérica no se asemejan a una calle de sentido único. Precisamente el constitucionalista europeo haría bien en respetar la diversidad constitucional latinoamericana (también con vistas a un "derecho constitucional común latinoamericano"), y observar de manera sensible la respectiva cultura constitucional nacional de países como México y Perú (por ejemplo, especial respeto merece la innovadora institución de la Comisión de la Verdad en El Salvador). El suscrito menciona aquí a esos dos países como pars pro toto, porque desde hace algunos años ha tenido la fortuna de construir puentes hacia la comunidad científica local, ya sea como editor del Fahrbuch des öffentlichen Rechts (cfr. García Belaunde, D., "The New Peruvian Constitution (1993)", 
Este libro forma parte del acervo de la Biblioteca Juridica Virtual del Instituto de Investigaciones Juridicas de la UNAM

FöR, vol. 43, 1995, pp. 651 y ss.; también Landa, C., "Constitutional Justice in Peru", föR, vol. 44, 1996, pp. 583 y ss.), ya sea como autor (La libertad fundamental en el Estado constitucional, Lima, 1997), ya sea como entrevistado de Landa (cfr. Pensamiento constitucional, año III, núm. 3, 1996, pp. 3279-289). García Belaunde ha descrito su visita a Bayreuth con el sugestivo título "Los gigantes de Weimar (a propósito de una visita a Peter Häberle)", en Ius et veritatis, Lima, año IX, núm. 17, noviembre de 1998, reimpreso en Entre abogados, San Juan, Argentina, año VII, núm. 1, 1999. El autor está orgulloso de ser miembro de la Asociación Peruana de Derecho Constitucional desde 1998, y tiene la esperanza de que, gracias a todos estos contactos, en los próximos años pueda apoyar académicamente a algunos jóvenes científicos de Perú o de México que lo visiten en su Instituto de Derecho Constitucional Europeo en Bayreuth.

Además de lo anterior, en la madre patria española han aparecido no escasas publicaciones suyas (por ejemplo: Retos actuales del Estado constitucional, Bilbao, 1996; Libertad, igualdad, fraternidad. 1789 como histórica actualidad y futuro del Estado constitucional, Madrid, 1998). Sobre todo la Facultad de Derecho de la Universidad de Granada se ha convertido para él, en los últimos años, casi en una "segunda patria", gracias a la hospitalidad de los profesores F. Balaguer-Callejón y G. Camarra ( $c f r$. también la entrevista por F. Balaguer, "Un jurista europeo nacido en Alemania", Anuario de Derecho Constitucionaly Parlamentario 1997, núm. 9, pp. 9-49).

El discurso científico vive también del trato personal - en casos afortunados será amistad - entre los participantes. Así tuvo el suscrito la fortuna de conocer personalmente al doctor Valadés en junio de 1999 en Granada, durante el coloquio realizado con motivo de su aniversario, y también de haber tenido un intercambio científico con él al finalizar su brillante ponencia. En esa ocasión surgió el plan de publicar la presente obra en México. Se trata de una "suma", quizá más bien de un "concentrado", del trabajo del autor en los últimos quince años: así, en los libros Verfassung als öffentlicher Prozeß (La Constitución como proceso público), 3a. ed. 1998; Europäische Rechtskultur (Cultura jurídica europea), 1994; Wahrheitsprobleme im Verfassungsstaat (Problemas de la verdad en el Estado constitucional), 1995, y por último, Europäische Verfassungslehre in Einzelstudien (Estudios de teoría constitucional europea), 1999. La Enciclopedia Treccani que aparece en Roma le solicitó al autor la presente obra en 1995, y ahí deberá publicarse en algunos años más una versión o variante italiana de este libro.

El autor une a su agradecimiento personal el deseo de que el Instituto de Investigaciones Jurídicas en México logre convertirse en foro vivo en la 
Este libro forma parte del acervo de la Biblioteca Juridica Virtual del Instituto de Investigaciones Juridicas de la UNAM http://www.juridicas.unam.mx

lucha en torno al tipo del Estado constitucional, "en clave cosmopolita", como quería I. Kant, y con responsabilidad latinoamericana, en el espíritu de A. von Humboldt.

Profesor Dr. Dr. h.c. mult. Peter Häberle

(Bayreuth/St. Gallen) 
Este libro forma parte del acervo de la Biblioteca Juridica Virtual del Instituto de Investigaciones Juridicas de la UNAM

\section{ABREVIATURAS}

AöR

BRD

BT-Drs.

BVerfG

BVerfGE

GE

CEDH

cit.

DDR

DÖV

DVBl.

$\mathrm{E}$

ed.

EG

EuGRZ

EUA

FAZ

FS

Ged. Schrift

GG

GG AK
Archiv des öffentlichen Rechts

Bundesrepublik Deutschland (República Federal de Alemania)

Bundestag-Drucksache (Publicación del Parlamento Federal alemán)

Bundesverfassungsgericht (Tribunal Constitucional Federal alemán)

Entscheidungen des Bundesverfassungsgerichts (Sentencias del TFCA)

Comunidad Europea

Convención Europea para la Protección de los Derechos Humanos y las Libertades Fundamentales citado

Deutsche Demokratische Republik (República Democrática Alemana)

Die Öffentliche Verwaltung

Deutsches Verwaltungsblatt

Entscheidung (sentencia)

edición, editor

Europäische Gemeinschaft (Comunidad Europea)

Europäische Grundrechte-Zeitschrift

Estados Unidos de América

Frankfurter Allgemeine Zeitung

Festschrift (Obra de homenaje)

Gedächtnisschrift (Obra en memoria)

Grundgesetz (Ley Fundamental de Bonn)

Alternativkommentar zum Grundgesetz (Comentario alternativo a la $\mathrm{LF}$ ) 
Este libro forma parte del acervo de la Biblioteca Juridica Virtual del Instituto de Investigaciones Juridicas de la UNAM

GVK

HdBStKirchR

HdBStR

HdBVerfR

JöR

$\mathrm{JZ}$

LF

n.

N. del T.

NJW

NZZ

OCDE

OEA

OSGE

OTAN

RDA

sc.

SED

TFCA

ONU

UE

UEO

UNESCO

VRÜ

VVDStRL
Gemeinsame Verfassungskommission von Bundestag und Bundesrat (Comisión conjunta de Constitución del Parlamento y el Consejo Federales de Alemania)

Handbuch des Staatskirchenrechts (Manual del Derecho eclesiástico del Estado)

Handbuch des Staatsrechts (Manual del Derecho del Estado)

Handbuch des Verfassungsrechts (Manual de Derecho constitucional)

Jahrbuch des öffentlichen Rechts

Juristenzeitung

Ley Fundamental de Bonn (GG)

nota a pie de página

Nota del traductor

Neue Juristische Wochenschrift

Neue Zürcher Zeitung

Organización para la Cooperación y el Desarrollo Económico

Organización de Estados Americanos

Organización para la Seguridad y la Cooperación en Europa, antes CSCE

Organización del Tratado del Atlántico Norte

República Democrática Alemana (DDR)

scilicet

Sozialistische Einheitspartei Deutschlands (Partido Socialista Unificado de Alemania)

Tribunal Constitucional Federal alemán (BVerfG)

Organización de las Naciones Unidas

Unión Europea

Unión de Europa Occidental

United Nations Educational, Scientific and Cultural Organization (Organización de las Naciones Unidas para la Educación, la Ciencia y la Cultura)

Verfassung und Recht in Übersee

Veröffentlichungen der Vereinigung der Deutschen Staatsrechtslehrer 
Este libro forma parte del acervo de la Biblioteca Juridica Virtual del Instituto de Investigaciones Juridicas de la UNAM

WRV

ZaöRV

ZfP

ZGB

ZHR

ZSR
Weimarer Reichsverfassung (Constitución de Weimar)

Zeitschrift für ausländisches öffentliches Recht und Völkerrecht

Zeitschrift für Politik

Schweizerisches Zivilgesetzbuch (Código Civil suizo)

Zeitschrift für das gesamte Handelsrecht und Wirtschaftsrecht

Zeitschrift für Schweizerisches Recht 
Este libro forma parte del acervo de la Biblioteca Juridica Virtual del Instituto de Investigaciones Juridicas de la UNAM

\section{GAPÍTULO PRIMERO. CONGEPTO, FUNDAMENTAGIÓN DEL OBJETO Y MÉTODOS DE TRABAJO}

\section{EL TIPO DEL ESTADO CONSTITUGIONAL COMO CONQUISTA CULTURAL}

La teoría de la Constitución tiene por objeto el tipo de las Constituciones democráticas, tal como se han implantado tanto en el mundo libre - no sólo en el occidental por sus contenidos y procedimientos esenciales, sino también por la profundidad de sus manifestaciones particulares y evolución en el curso de la historia-, como en el espacio planetario, al menos desde el "annus mirabilis" de 1989. Este tipo se compone de elementos ideales y reales - referidos al Estado y a la sociedad - los cuales no se han alcanzado al mismo tiempo en prácticamente ningún Estado constitucional, pero que apuntan tanto a una situación óptima de lo que debe ser como a una situación posible de lo que es.

Tales elementos son: la dignidad humana como premisa, realizada a partir de la cultura de un pueblo y de los derechos universales de la humanidad, vividos desde la individualidad de ese pueblo, que encuentra su identidad en tradiciones y experiencias históricas, y sus esperanzas en los deseos y la voluntad creadora hacia el futuro; el principio de la soberanía popular, pero no entendida como competencia para la arbitrariedad ni como magnitud mística por encima de los ciudadanos, sino como fórmula que caracteriza la unión renovada constantemente en la voluntad y en la responsabilidad pública; la Constitución como contrato, en cuyo marco son posibles y necesarios fines educativos y valores orientadores; el principio de la división de poderes tanto en sentido estricto, relativo al Estado, como en el sentido amplio del pluralismo; los principios del Estado de derecho y el Estado social, lo mismo que el principio del Estado de cultura (“Kulturstaat")1 abierto; las garantías de los derechos fundamentales; la independencia de la

1 El concepto alemán de "Kulturnation" se traduciría habitualmente como "nación civilizada", no obstante la referencia explícita a la "cultura" y no a la "civilización". Por ello, "Kulturstaat" tendría que traducirse como "Estado civilizado". Sin embargo, dada la importancia tan particular que tiene el concepto de cultura en la presente obra, el término "Estado 
Este libro forma parte del acervo de la Biblioteca Juridica Virtual del Instituto de Investigaciones Juridicas de la UNAM

jurisdicción, etcétera. Todo esto se incorpora en una democracia ciudadana constituida por el principio del pluralismo.

Esta descripción esquemática pretende poner en claro que este tipo, en sus elementos centrales, es una conquista cultural de la civilización occidental. Es resultado y aportación de procesos culturales, del mismo modo como se transmite y es apropiado renovadamente el "patrimonio cultural" de los textos clásicos. Sin embargo, también plantea hacia el futuro la pretensión de que el nivel cultural alcanzado por el Estado constitucional ya no se pierda, sino que se conserve y que incluso se acreciente (en la medida en que los "enanos" encaramados a hombros de gigantes son capaces de ver más lejos). ${ }^{2}$

Toda teoría de la Constitución debe intentar capturar algo del "espíritu de las Constituciones"; tendría que orientarse por "El espíritu de las leyes" de Montesquieu, si tal pretensión no fuera tan inmodesta. Sin embargo, algo del "espíritu de las Constituciones" resulta palpable en los textos constitucionales, sobre todo en su "evolución", concebida contemporánea e históricamente como proceso de etapas textuales. Este "espíritu" actúa también en los contextos culturales que debe desentrañar la ciencia cultural, para lo cual debe distinguirse entre dos planos: hay un "espíritu de las Constituciones" (del Estado constitucional) general y orientado al tipo, y existe un "espíritu", de configuración muy individual, de los diversos "pueblos" que viven en, conforme a y "bajo" las Constituciones. Estos planos no se encuentran desvinculados entre sí; por el contrario, existen múltiples contactos e interacciones entre la nación constituida concretamente y el tipo general del "Estado constitucional". Estos contactos e interacciones solamente pueden mostrarse en relación con problemáticas particulares y en términos por lo general muy fragmentarios. En la medida en que es universal el tipo del "Estado constitucional", en esa misma medida es individual su respectiva configuración nacional, al punto que no serían capaces de describirla ni un equipo enciclopédico de estudiosos ni una computadora universal.

civilizado" no siempre transmite el matiz deseado, en este y en otros contextos. Por ello hemos preferido la traducción aquí utilizada (N. del T.).

2 Merton, R. K., A hombros de gigantes, 1990 (1a. ed. norteamericana 1965). 
Este libro forma parte del acervo de la Biblioteca Juridica Virtual del Instituto de Investigaciones Juridicas de la UNAM

\section{El CONCEPTO DE CONSTITUCióN. "CONCEPCIÓN MIXTA DE LA CONSTITUCiÓN"}

1. El Estado constitucional de cuño común europeo y atlántico se caracteriza por la dignidad humana como premisa antropológico-cultural por la soberanía popular y la división de poderes, por los derechos fundamentales y la tolerancia, por la pluralidad de los partidos y la independencia de los tribunales; hay buenas razones entonces para caracterizarlo elogiosamente como democracia pluralista o como sociedad abierta. Su Constitución, entendida como orden jurídico fundamental del Estado y de la sociedad, posee una validez jurídica formal de naturaleza superior. La Constitución es creadora del momento de la estabilidad y la permanencia; el ejemplo más impresionante lo ofrece la Constitución de los Estados Unidos con sus más de dos siglos de vigencia. No obstante, en virtud de esta duración - la Ley Fundamental alemana (en adelante LF) incluso plantea una " pretensión de eternidad" a favor de los principios fundamentales de su artículo 79, inciso 3 , en forma análoga a algunas Constituciones anteriores y a otras que le han seguido - se requieren instrumentos y procedimientos gracias a los cuales la Constitución se adapte en forma flexible, como "proceso público", ${ }^{3}$ a los acontecimientos de la época, sin detrimento de su sentido: a saber, como "estímulo y límite", en los términos de R. Smend, también como " norma y tarea" (U. Scheuner), lo mismo que como "limitación y racionalización" del poder del Estado (H. Ehmke), pero también del poder de la sociedad. Precisamente la Constitución de los Estados Unidos, además de las muy escasas enmiendas (actualmente 28) que ha sufrido en doscientos años, conoce el procedimiento del cambio, especialmente a través de la jurisprudencia constitucional.

2. Constitución quiere decir orden jurídico fundamental del Estado y de la sociedad, es decir, incluye a la sociedad constituida, aunque ciertamente no en el sentido de nociones de identidad, es decir, no sólo es el Estado el constituido (la Constitución no es sólo Constitución "del Estado"). Este concepto amplio de Constitución comprende las estructuras fundamentales de la sociedad plural, como por ejemplo, la relación de los grupos sociales entre sí y de éstos con el ciudadano (¡tolerancia!). Las estructuras constitutivas a este respecto, como la "eficacia frente a terceros" de los derechos fundamentales, los principios del orden jurídico general o las instituciones para prevenir abusos de poder (¡derecho de la competencia económica o an-

3 Sobre todas estas cuestiones: Häberle, P., Verfassung als öffentlicher Prozeß, 1978 (3a. ed. 1998). 
Este libro forma parte del acervo de la Biblioteca Juridica Virtual del Instituto de Investigaciones Juridicas de la UNAM http://www.juridicas.unam.mx

timonopolios!), se encuentran, sin duda, apenas en sus comienzos, pero ya existen. La división de poderes como principio constituyente ${ }^{4}$ se convierte en tarea de la política jurídica. De ninguna manera se hace referencia exclusiva al "esqueleto de las normas", sino que hay que incluir a la cultura ${ }^{5}$ y al ambiente políticos (D. Schindler), las opiniones y prácticas, que no son jurídicas en sentido estricto, en la "sociedad" constitucional. Piénsese en los buenos o malos usos parlamentarios, en las críticas de políticos y periodistas a las sentencias de los tribunales, en la autorregulación de los medios de comunicación o en el código de conducta de 1976 para las empresas multinacionales. Todo esto contribuye a la estructuración de la sociedad abierta como lo hacen los textos de los clásicos (v. gr. Montesquieu), los logros de una vida (como los de T. Heuss), los preámbulos de las Constituciones y sus contenidos pedagógicos.

Siguiendo a la filosofía del "espíritu abierto" (Popper), la Constitución permite la apertura hacia adelante, hacia el futuro; institucionaliza las experiencias (apertura hacia atrás) y abre espacio para el desarrollo del espíritu humano y su historia. ${ }^{6}$ En favor de la dignidad de la persona obliga al grado máximo de tolerancia - la que permite la plenitud de la interpretación- claro está con ciertos "límites de tolerancia", que se hacen tanto más indispensables cuanto más se convierte la tolerancia en parte integrante del consenso constitucional básico, el cual difícilmente se puede formalizar como tal en términos jurídicos (constitucionales). ${ }^{7}$

3. Frente a este trasfondo debe concebirse a la Constitución como un estadio cultural. Toda Constitución de un Estado constitucional vive en última instancia de la dimensión de lo cultural. La protección de los bienes culturales, las libertades culturales especiales, las cláusulas expresas sobre el "patrimonio cultural" y los artículos generales sobre el Estado de cultura no

4 Sobre la "desdogmatización" de la teoría de la división de poderes véase: Kägi, W., Von der klassischen Dreiteilung zur umfassenden Gewaltenteilung, 1961; Hesse, K., Grundzüge des Verfassungsrechts der Bundesrepublik Deutschland, 20a. ed., 1995, pp. 207 y ss., con mayores referencias; Seiler, H., Gewaltenteilung, Allgemeine Grundlagen und schweizerische Ausgestaltung, 1994.

5 Sobre las "condiciones naturales y culturales de la unidad del Estado" véase Heller, H., Staatslehre (1934), 4a. ed., 1970, pp. 139 y ss. (trad.: Teoría del Estado, 2a. ed., 1998, pp. 106 y ss.); sobre la "comunidad cultural activa" en el contexto de la integración material: Smend, R., Verfassung und Verfassungsrecht (1928), p. 45 (trad.: Constitución y derecho constitucional, Madrid, 1985, p. 93).

6 Sobre la vinculación de la ciencia del derecho constitucional democrática con la ciencia "general" del ser humano: Häberle, P., "Demokratische Verfassungstheorie im Lichte des Möglichkeitsdenkens", Archiv des öffentlichen Rechts, 1977, pp. 27 y ss. (67 y ss.).

Véase al respecto: Podlech, A., "Wertentscheidungen und Konsens" , en Jakobs, G. (ed.), Rechtsgeltung und Konsens, 1976, pp. 9 y ss. (25). 
Este libro forma parte del acervo de la Biblioteca Juridica Virtual del Instituto de Investigaciones Juridicas de la UNAM

constituyen sino las manifestaciones particulares de la dimensión cultural general de la Constitución. ${ }^{8}$ Cuando en su etapa evolutiva actual el Estado constitucional da efectividad, refina y desarrolla en forma especial su protección de los bienes culturales, lo hace, en suma, al servicio de su identidad cultural. Al mismo tiempo la concepción culturalista (kulturwissenschaftlich) de las Constituciones gana en capacidad de convicción: la Constitución no es sólo un ordenamiento jurídico para los juristas, los que tienen que interpretarla conforme a las antiguas y las nuevas reglas de la profesión, sino que actúa esencialmente también como guía para los no juristas: para el ciudadano la Constitución no es sólo un texto jurídico o un "mecanismo normativo", sino también expresión de un estadio de desarrollo cultural, medio para la representación cultural del pueblo ante sí mismo, espejo de su patrimonio cultural y fundamento de sus esperanzas.

4. La Constitución escrita constituye un óptimo regulador variable. La lista de temas del Estado constitucional está abierta. Ciertamente, en dicho Estado deben satisfacer un "mínimo" tanto los textos constitucionales como los temas que deben tratarse en ellos en una cierta época, del mismo modo como debe existir un inventario básico de las tareas necesarias del Estado. Así como hablamos de un "bloc des idées incontestables", siguiendo a M. Hauriou, podemos también partir de un "bloc des textes incontestables", entre los que se encuentran textos clásicos, como el de Montesquieu sobre la división de poderes, que corresponden a cada ejemplo del "tipo Estado constitucional”, pero también el principio del Estado de derecho. Este principio ha hecho carrera en todo el mundo, en parte en los textos constitucionales, en parte como tema, incluso en las nuevas Constituciones de Europa oriental y en África del Sur, en conexión o en correspondencia con el "rule of law" angloamericano. A los constituyentes hay que recomendarles que regulen expresamente algunos aspectos del principio del Estado de derecho, no todos, para abrir espacio a la evolución futura. El principio como tal pertenece hoy al "bloc des textes incontestables", aunque sus configuraciones individuales puedan variar de país a país. ${ }^{9}$ Sin embargo, un inventario en el tiempo y el

8 Desarrollada en Häberle, P., Verfassungslehre als Kulturwissenschaft, 2a. ed. 1998; id., Europäische Rechtskultur, 1994; id., "Altern und Alter des Menschen als Verfassungsproblem” , FS Hans Lerche, 1993, pp. 189 y ss.; id., "Das Staatsgebiet als Problem der Verfassungslehre", FS G. Batliner, 1994, pp. 397 y ss.

9 Véase también Hofmann, R., Merli, F., Marko, J. et al. (eds.), Rechststaatlichkeit in Europa, 1996. En Turquía, el Tribunal Constitucional ha logrado una notable efectividad del principio del Estado de derecho en dirección a las medidas provisionales. Al respecto véase Gören, Z., "Die einstweilige Anordnung in der Rechtsprechung des türkischen Verfassungsgerichts", EuGRZ 1994, pp. 597 y ss. Véase también el alto nivel del principio del Estado de derecho en 
Este libro forma parte del acervo de la Biblioteca Juridica Virtual del Instituto de Investigaciones Juridicas de la UNAM

espacio, pero también en la concepción evolutiva del Estado constitucional como tipo y como ejemplo individual, llevarían a la conclusión de que la lista de temas está abierta en lo demás. Una y otra vez se agregan nuevos temas: en la parte orgánica de la Constitución, por ejemplo, el "plebiscito consultivo" (Suecia, Finlandia), la "publicidad de los actos administrativos" (artículo 30 de la Constitución de Guatemala), las "relaciones con Estados afines" (artículo 151 de la misma Constitución), las agendas de un "cooperative government" (artículo 40 de la Constitución de Sudáfrica, de 1996/97). Suiza ha elaborado, a nivel de los cantones, refinadas máximas para el proceso constituyente. ${ }^{10}$ Recientemente aparecen cada vez más, en casi todo el mundo, artículos sobre el pluralismo (por ejemplo, España, África, algunos países de Europa oriental; cláusulas anti-ideológicas, como por ejemplo, el artículo 6o. de la Constitución de Rusia), mientras que la protección de las generaciones hace también una carrera similar como tema ( $c f r$., el temprano artículo 11 de la Constitución de Japón de 1946: se confieren, a esta generación y las futuras, "derechos humanos básicos" como "derechos eternos inviolables"). Las cláusulas de verdad se encuentran sobre todo ahí donde la fase anterior en la vida de los pueblos se caracterizaba por la mentira difundida por el Estado (así, en los nuevos Länder alemanes: por ejemplo, el artículo 22, inciso 2, de la Constitución de Turingia). En el apartado de derechos fundamentales, el artículo 39, inciso 2, de la Constitución de Azerbaiyán (1995) garantiza un derecho a la información "sur l'état veritable de l'environnement'.

En resumen: en un mundo en transformación cambian también los temas constitucionales. Mientras más antiguas las Constituciones, tanto más la ciencia y la práctica complementan los textos escritos mediante reglas no escritas, lo que puede ser motivo, más tarde, para que otros constituyentes, próximos o lejanos, traduzcan su "quintaesencia" en nuevos textos, y la teoría constitucional puede acompañar estos procesos, descubrir sus interrelaciones e incluso reforzarlas (de manera limitada). Así leído, el paradigma de las etapas textuales no sobrestima ni subestima los textos constitucionales.

5. El tema del Estado constitucional toca al mismo tiempo a la ratio y la emotio, e implica al principio esperanza. Tanto la teoría de la Constitución como el tipo del "Estado constitucional" deben conceder al ser humano espacio para un "quantum de utopía", no sólo en forma de la ampliación de los límites de las libertades culturales y su promoción (¡también de las reli-

el artículo 141, inciso 3, de la Constitución de Turquía (1982): "Fundamentación forzosa de todas las resoluciones judiciales".

10 Máximas que podrían ser reconocidas, pero no estar escritas en otros países. 
Este libro forma parte del acervo de la Biblioteca Juridica Virtual del Instituto de Investigaciones Juridicas de la UNAM http://www.juridicas.unam.mx

giones!), sino incluso de una manera más intensa, en la medida en que los textos constitucionales normen esperanzas (por ejemplo, antiguamente la unidad de Alemania o ahora la de Irlanda), ${ }^{11}$ que constituyan por lo menos "deseos de utopía" concretos. El "principio esperanza" (E. Bloch), el "principio responsabilidad" (H. Jonas), como por ejemplo, en la protección del ambiente, estimulan una fructífera evolución constitucional, porque el ser humano necesita la esperanza como el aire que respira y porque la comunidad vive en libertad responsable. En la medida en que los textos constitucionales se encuentren fundamentalmente apartados de las utopías en su dimensión jurídica, y por su naturaleza propia así deban mantenerse, pueden, no obstante, ser "utopía" en algunas de sus partes:" El principio del Estado social era un pedazo de utopía en la época de H. Heller (1930) y también lo fue inicialmente en 1949 la Ley Fundamental de Bonn. ${ }^{13}$

\section{LA INCLUSIÓN DE LOS ESTADOS REFORMADOS, LOS MICRO ESTADOS Y LOS PAÍSES EN DESARROLLO}

El concepto de "micro Estado" es controvertido. De manera lapidaria se dice en la Enciclopedia Brockhaus:" "Micro Estado, concepto político de significado variable, frecuentemente aplicado a los Estados que no se encuentran entre las principales potencias mundiales, pero también a los Estados de tercero o cuarto rangos". La doctrina señala la falta de una definición de autoridad ${ }^{15}$ y considera los máximos o mínimos de población, de extensión del territorio, o bien, la medida efectiva del poder estatal, como más o menos arbitrarias. Habría que proceder entonces de manera pragmática, por ejemplo, en el sentido de una "unidad política muy pequeña" y tomar

11 Véase, para mayor precisión, Häberle, P., "Neues Kulturverfassungsrecht in der Schweiz und in der Bundesrepublik Deutschland”, ZSR, vol. 105, 1986, p. 195 (227 y s.).

12 Véase también Maihofer, W. "Ideologie und Naturrecht", en id. (ed.), Ideologie und Recht, 1968, pp. 121 (141 y s.), y las pp. 135 y ss. En lo relativo al "derecho natural moderno como utopía". Notable también Hommes, U., "Brauchen wir eine Utopie? Plädoyer für einen in Mißkredit geratenen Begriff”, Aus Politk und Zeitgeschichte, B 20/77, del 21 de mayo de 1977.

13 Pionero para la realización: Ipsen, H. P., "Über das GG", discurso rectoral en Hamburgo, 1950. Una etapa esencial en la concretización del principio del Estado social lo constituye la ponencia de O. Bachof, "Begriff und Wesen des sozialen Rechtsstaates", VVDStRL vol. 12, 1954, pp. 37 y ss.

14 Enciclopedia Brockhaus, 17a. ed., 1970, t. 10, p. 251.

15 Así Kokott, J., "Micro-states”, en Encyclopedia of Public International Law, núm. 10, 1987, pp. 297 y ss. 
Este libro forma parte del acervo de la Biblioteca Juridica Virtual del Instituto de Investigaciones Juridicas de la UNAM

la población como "elemento primario", por más importancia que el territorio y el espacio puedan tener o adquirir más tarde en la perspectiva de la teoría constitucional. En vista de la victoria mundial tanto de la idea de los derechos humanos y ciudadanos como del Estado constitucional, resulta natural tomar al ser humano en cuanto punto de partida ideal del derecho y el Estado, del derecho constitucional y del derecho internacional. Si bien la dignidad humana como premisa antropológico-cultural, la idea kantiana del Estado como "conjunto de hombres sometidos a los preceptos del derecho" y de una sociedad civil que administra justicia "de manera general", ya ponen en cuestión la idea del pueblo en tanto "elemento del Estado", el ser humano tampoco puede cuantificarse y agregarse matemáticamente para constituir el "pueblo". Por lo pronto, el concepto de "micro Estado" puede hacerse practicable a través del número máximo de habitantes, y con apoyo en la doctrina ${ }^{16}$ se propone aquí, como índice, la cifra de 500,000.

Sin embargo, el concepto de "micro Estado" no debe ajustarse al lecho de Procusto de las cifras y los datos fijos, sino que debe pensarse más en el sentido de una escala abierta hacia arriba y hacia abajo ("Estados enanos"), en el espíritu de una reflexión global que ponga en primer plano lo material, en lugar de pensar en términos del esquema de poder y tamaño, de conceptos terminados, de "elementos" espaciales y cuantificables fijos como elementos dados de la naturaleza del Estado más allá de los criterios materiales de la Constitución y el derecho, así como de los sujetos personales como el ciudadano y el ser humano. Así visto, el "micro Estado" es un punto imaginario, una marca o unidad en una escala con transiciones hacia el Estado "menor", etcétera. El concepto se relativiza. Sobre todo se vuelve evidente qué tanto se modifican los criterios de valoración en el curso de la historia regional y universal.

\section{Palabra clave: los Estados reformados de Europa oriental}

El micro Estado tiene gran actualidad en estos momentos. Si bien no en sentido técnico, bajo la forma de los Estados pequeños se anuncia actualmente una tendencia hacia esta variante del Estado constitucional en el marco de los fenómenos de desintegración del bloque de Europa oriental. Piénsese en la separación de las tres repúblicas bálticas, Lituania, Letonia y

16 Cfr. Von Wedel, H., "Der sog. 'Mikrostaat' im internationalen Verkehr", Verfassung und Recht in Übersee, vol. 5, 1972, pp. 303 (304 y s.), con mayores referencias. 
Este libro forma parte del acervo de la Biblioteca Juridica Virtual del Instituto de Investigaciones Juridicas de la UNAM

Estonia, de lo que entonces era todavía la URSS ${ }^{17}$ y la secesión de Eslovenia y Croacia, así como de Macedonia (1991) y Bosnia y Herzegovina (1996) de Yugoslavia. La esperanza es que los pequeños Estados constitucionales que surgen de este modo puedan construirse duraderamente sobre el tesoro de experiencias de los verdaderos "micro Estados", y que la teoría constitucional del "micro Estado" incluya a estos "pequeños Estados". Incluso debemos preguntarnos si a mediano plazo se anuncia una escala, en cuyo extremo inferior se encuentre el "micro Estado" (ya diferenciado), los "Estados pequeños", como Suiza y Luxemburgo, estén a la mitad, y los Estados nacionales, tanto los clásicos como los mayores, en el extremo superior.

\section{Los países en desarrollo en el campo de fuerzas de los procesos de crecimiento del Estado constitucional}

En lo que sigue se establece, en forma general y profundizada, el puente hacia los países en desarrollo. ¿Es posible incluirlos en los contextos de producción y recepción del tipo del "Estado constitucional"? Y esto, ¿también como contribuyentes activos y no sólo como receptores pasivos? ¿Es posible integrar ya ahora al Tercer Mundo en el "mundo único" de la "familia" de los Estados constitucionales, con todas las particularidades de su especial situación cultural y las siempre presentes asincronías? ¿O simplemente "persigue" el Tercer Mundo la evolución constitucional europea y angloamericana, sin la "esperanza" de poder alcanzarla jamás? La modestia científica y el abandono de un "eurocentrismo" autocomplaciente inducen a evitar pensar en "vías de un solo sentido", sin "tráfico en sentido contrario".

A) En el espejo de sus recientes textos constitucionales, pueden observarse procesos de aprendizaje recíproco entre los países en desarrollo y los Estados constitucionales "desarrollados".

B) Los países en desarrollo, lo mismo que la labor científicamente asesorada y comparativa de sus constituyentes, no sólo asimilan los textos constitucionales europeos, sino que además condensan la realidad constitucional y administrativa de los "antiguos" países modelo en nuevas y diferenciadas formas y etapas textuales, lo que en sí mismo ya constituye una aportación codificadora. En todo caso, tal conquista comunitaria universal respecto del

17 Estonia $\left(45,000 \mathrm{~km}^{2}\right)$, tiene 1.6 millones de habitantes; Letonia $\left(64,500 \mathrm{~km}^{2}\right), 2.7 \mathrm{mi}$ llones de habitantes; Lituania (66,000 km²), 3.7 millones de habitantes; Armenia (30,000 $\mathrm{km}^{2}$ ), 3.3 millones de habitantes (datos del Frankfurter Allgemeine Zeitung del 28 de agosto de 1991, p. 16). Gagausia en Moldavia pretende convertirse en micro Estado (FAZ del 3 de septiembre de 1991, p. 2). 
Este libro forma parte del acervo de la Biblioteca Juridica Virtual del Instituto de Investigaciones Juridicas de la UNAM

tipo del "Estado constitucional" es un logro que posee tanto mayor valor, por cuanto es frecuente que los países en desarrollo se atrevan más a enfrentar la "pobre" realidad, que los viejos países, que viven en un elevado bienestar. Los altos riesgos que corren aquéllos son evidentes, ya que los textos constitucionales pueden ser descartados por su falta de credibilidad, como simples promesas o incluso utopías, lo que dañaría a la idea misma del Estado constitucional. El texto constitucional se convierte entonces en hoja de parra para una "mala" realidad.

C) Son grandes y no deben subestimarse las - posibles - repercusiones, sobre el continente europeo y sus variantes del Estado constitucional, de los procesos y contenidos constitucionales vaciados en nuevas formas textuales por el Estado constitucional en "ultramar". Estas repercusiones consisten frecuentemente en temas nuevos, según se manifiestan en cláusulas sobre la dignidad humana o en cláusulas sobre el patrimonio cultural y, en general, en el derecho constitucional de la cultura (por ejemplo, en una búsqueda más intensa en torno a las cláusulas de identidad cultural), pero también en nuevos derechos fundamentales o en una más elaborada definición de las tareas estatales, así como en cuanto a los problemas jurídicos que suscitan la técnica y el medio ambiente, o bien, en forma de nuevos conjuntos textuales (por ejemplo, los preámbulos).

D) "País en desarrollo": una definición provisional de este concepto, en términos de las ciencias de la cultura, en el contexto presente sería la ofrecida por la Comisión Norte-Sur que presidiera el ex canciller alemán Willy Brandt (1977):18

El desarrollo es más que el paso de la pobreza a la riqueza, de una economía agraria tradicional a una comunidad urbana compleja. El desarrollo implica no sólo la idea del bienestar material, sino también la idea de mayor dignidad, seguridad, justicia e igualdad de los seres humanos.

De este modo, los elementos del tipo del "Estado constitucional" se incorporan de entrada al horizonte de los conceptos de "desarrollo" y "país en desarrollo", por más importantes que sigan siendo los criterios económicos del "ingreso real per cápita" de la población.

18 Citada en Andersen, U., "Begriff und Situation der Entwicklungsländer", Informationen zur politischen Bildung, Entwicklungsländer, núm. 221 (1988), p. 2. 
Este libro forma parte del acervo de la Biblioteca Juridica Virtual del Instituto de Investigaciones Juridicas de la UNAM

\section{LA TEORÍA DE LA CONSTITUGIÓN COMO CIENGIA JURÍDICA DE LOS TEXTOS Y LA CULTURA}

1. En la ciencia histórica hay un esfuerzo por llegar a un "manual europeo de historia"; los congresos sobre libros escolares, por ejemplo, entre Alemania y Polonia, o entre la República Checa y Francia, ofrecen los primeros trabajos al respecto. La bibliografía sobre las diversas artes poseen desde hace tiempo sus ediciones europeas: ya está escrita la historia europea de la literatura y la música; la historia europea de la pintura y la arquitectura cuenta con grandes autores. ¿No sería el momento de trabajar en un "manual europeo común de derecho constitucional"? En él debería haber espacio tanto para el "acervo europeo común" en materia del Estado constitucional como para los procesos de oferta y recepción de las naciones participantes, y además para las variantes y desviaciones respecto del tipo común del Estado constitucional, que han sido y son propias de las diversas culturas jurídicas nacionales y que éstas también necesitan. Habría que empezar con que cada país abordara la cuestión de cuáles sean los respectivos contextos en que haya surgido su propia Constitución junto con otras, en cuáles se encuentra y sigue evolucionando.

Para tal efecto, podrían servir de modelo los volúmenes publicados en Alemania sobre los "cuarenta años de la Ley Fundamental" (1989), y podrían ser completados por "obras paralelas", como las relativas a los "veinte años de la Constitución española" (1998), los "cincuenta años de la Constitución italiana" (1997), y otras similares. Entonces quedará libre la visión para todo el rico acontecer en materia del "Estado constitucional europeo", quedando de manifiesto las diversas olas de recepción, los procesos de recepción o reproducción indirectas, hasta los procesos, difícilmente apreciables, de la recepción informal. Entonces podrá observarse de qué manera un texto, recibido desde Italia por ejemplo, se transforma paulatinamente en el campo de fuerzas de la sociedad abierta de los intérpretes constitucionales, como el de España, y qué tan productiva es una incorporación en apariencia puramente pasiva. También podrían aclararse las consecuencias concretas que resultan de los diversos modos de la recepción. Por ejemplo, ¿la recepción de una parte del texto de la Ley Fundamental alemana implica que deban asumirse también la posterior jurisprudencia del Tribunal Constitucional Federal y la doctrina anterior (por ejemplo, de la época de Weimar)? ¿O será mejor que el Estado constitucional extranjero se refrene y actúe en el plano de la interpretación de manera más creativa que "repetitiva”, a fin de fundir así lo extraño con lo propio? 
Este libro forma parte del acervo de la Biblioteca Juridica Virtual del Instituto de Investigaciones Juridicas de la UNAM

Esto no significa que los contextos especiales de producción y recepción se igualen y se nivelen: los "vínculos especiales" que existen, por ejemplo, entre Italia, de un lado, y Portugal y España, del otro, como países romanistas, deben permanecer, y quizá en el futuro deban ampliarse a Bulgaria, Rumania y Albania. Los tres países de lengua alemana, Austria, Suiza y Alemania, deberían conservar, como lo han hecho hasta ahora, el "taller" común en el terreno de los derechos fundamentales, el federalismo y la jurisdicción constitucional. La competencia es deseable; conocida es la lucha de la influencia alemana con la competencia francesa en la doctrina y la jurisprudencia iuspublicistas de Grecia. La "casa constitucional europea" común puede tener muchas habitaciones; lo determinante es que se mantenga abierta dentro y fuera y que conozca su fundamento común.

La "doctrina del derecho constitucional como literatura" aporta en tal sentido una función integradora, en todos los géneros literarios, ${ }^{19}$ siempre que trabaje en el plano europeo. Los trabajos previos pueden consistir en monografias, comentarios y memorias de tipo comparativo entre las diversas naciones o entre varias de ellas, ${ }^{20} \mathrm{y}$ constituyen etapas en el camino hacia un "manual constitucional europeo común" en el que tendrían que trabajar varias generaciones de juristas europeos, esto es, en el horizonte de un jus publicum europeum. España ha trabajado desde 1978 de manera ejemplar y por todos nosotros, no sólo en cuanto a la transición pacífica de la dictadura a la democracia, sino también en cuanto al modo en que establece constantemente puentes, a través de la fusión creativa de lo mejor de la evolución constitucional, por ejemplo de Italia y Alemania, en los textos, la jurisprudencia y la doctrina, gracias a nombres como los de P. Cruz Villalón, F. Rubio Llorente, A. López Pina, F. Balaguer y otros. Sin darse cuenta, España se ha convertido así en la vanguardia. La temida "germanización" de la doctrina iuspublicista española desemboca en la europeización, como tarea para todos las doctrinas nacionales en nuestro continente, si su pretensión es la de afirmarse en el concierto europeo.

2. La relación entre naturaleza y cultura, entre teoría general del Estado y teoría de la Constitución, requiere un examen especial. La relación entre Estado y Constitución debe reconceptualizarse. El concepto de "Estado constitucional" ("Verfassungsstaatlichkeit") vincula al Estado y la Constitución sin especificar tal relación. En mi opinión, en la tradición de los clásicos

19 Claves en Häberle, P., "Verfassungslehre im Kraftfeld rechtswissenchaftlicher Literaturgattungen", Festschrift für O. K. Kaufmann, 1989, pp. 15 y ss.

20 Ejemplos en Häberle, P., "Gemeineuropäisches Verfassungsrecht", EuGRZ 1991, pp. 261 (272 y s.). 
Este libro forma parte del acervo de la Biblioteca Juridica Virtual del Instituto de Investigaciones Juridicas de la UNAM

como R. Smend y A. Arndt — todos estamos encaramados a "hombros" de estos "gigantes", seguimos siendo "enanos", pero ocasionalmente vemos más lejos que ellos - hay tanto Estado como el que constituya la Constitución. El Estado no es, como gusta postularlo la tradición monárquicaconservadora, lo dado de manera primaria (natural), el objeto al que se refiere la Constitución, al que ésta configura en mayor o menor medida. En el Estado constitucional democrático, los ciudadanos y los seres humanos, su dignidad humana, constituyen la "premisa antropológico-cultural"; ellos se "dan" la Constitución a sí mismos, como lo indican apropiadamente algunos de los nuevos textos constitucionales alemanes (véase, por ejemplo, el preámbulo de la Constitución de Brandemburgo de 1992).

3. En tanto cultura, la Constitución debe ser concebida, ya de modo real, ya de modo ficticio, como contrato. ¿Qué significa esto? Las doctrinas del contrato social, sobre todo en la variante kantiana de la "piedra de toque de la razón", más allá de los hechos reales, pero también la versión de Rawls ("velo de ignorancia"), siguen siendo útiles precisamente en el Estado constitucional. Debemos concebir a la Constitución, lo mismo que al derecho y al Estado como partes de ella, "como si" se fundara en un pacto de todos con todos (en el sentido de John Locke). El pacto constitucional de los peregrinos ingleses en el "Mayflower", el juramento de Rütli en Suiza (1291) y el pacto de prórrogas subsecuentes (por ejemplo, el "Stanzer Verkommnis"), son afortunados eventos reales, los que debemos actualizar, (re)pensar, e incluso incorporar ficticiamente, en el concepto de la Constitución como " avenencia y tolerancia siempre renovados de todos". Claro está que el recurso al modelo contractual es más fácil en la democracia concordataria suiza o en el federalismo que en los Estados nacionales centralistas. Sin embargo, si hay una idea que haya impregnado como chispa el annus mirabilis de 1989 fue el paradigma de la "mesa de negociación" (Runder Tisch). Inventada desde el "Solidarnosc" de Walesa (¿o quizá debiera decirse " descubierta"?), la "mesa de negociación" ha " hecho" historia, tanto universal como constitucional, en la transición de los sistemas totalitarios hacia la sociedad abierta del Estado constitucional. En todas partes se hicieron mesas de negociación, por último en la "Codesa" en Sudáfrica.

Es posible dar un fundamento teórico-constitucional a las "mesas de negociación", clasificarlas desde el punto de vista de la ciencia cultural, y legitimarlas desde la perspectiva de la teoría del consenso y del discurso. La "mesa de negociación" simboliza la coexistencia y la convivencia en igualdad de muchos en una comunidad política. La misma distancia y la misma proximidad hacia todos los participantes, la reconstrucción del diálogo y la convivencia, rompen con las estructuras del dominio totalitario. Es la mejor, 
Este libro forma parte del acervo de la Biblioteca Juridica Virtual del Instituto de Investigaciones Juridicas de la UNAM

más visible y plástica traducción de la igualdad en "la avenencia y la tolerancia", que caracteriza a la negociación de las Constituciones pluralistas. El círculo y la "mesa (de negociación)", esta metáfora podría ser o convertirse en algo así como un "gen cultural" de la humanidad.

4. Por último, la Constitución es un "pacto de las generaciones", a través del cual se realiza la constitución del pueblo de una manera tangible para la ciencia cultural. Lo que la teoría clásica del Estado ha examinado, y la praxis política hizo realidad en 1989 con la "mesa de negociación" de L. Walesa en Polonia, o a través de la figura argumentativa del "consenso básico" utilizado en Alemania en los años setenta, y que también regresa a la política del día de hoy con nombres diversos ("pacto de solidaridad", "alianza para el trabajo", "pacto con América", etcétera) - a saber, el "contrato social" - se presentan como "pacto de las generaciones" en la dimensión temporal. Ciertamente, hasta ahora la idea del pacto de las generaciones no es, ni de lejos, comparable con el esfuerzo de fundamentación que se ha puesto en el "tema y las variaciones" del contrato social; piénsese solamente en John Rawls. ${ }^{21}$ Sin embargo, es posible utilizar algunas palabras clave de este último debate también para el pacto de las generaciones. Este pacto debe concebirse, en el sentido de la filosofía contractualista de I. Kant, en parte como ficción ("piedra de toque de la razón"), en parte como fundado en eventos reales (no solamente la "confederación" suiza desde 1291; como "consenso básico", "bargaining", "consenso sobre las pensiones").

El pueblo, que en la época del pacto de las generaciones es concebido como magnitud "prorrogante" y viviente, es por su parte, de entrada menos una magnitud biológica que cultural. Sobre todo, no se trata simplemente de un "elemento del Estado" en el sentido que le daba G. Jellinek a este concepto, ${ }^{22} \mathrm{o}$ de la suma biológica de los "nacionales", sino que se mantiene unido y organizado en su identidad y pluralidad por relaciones culturales; es, pues, el resultado de procesos de socialización cultural que frecuentemente se prolongan por varias generaciones. Si la cultura es concebida, desde la ciencia cultural, como "cuarto" elemento del Estado, aunque no como el "primero", tal concepción debe referirse también, y de manera intensiva, al pueblo, del mismo modo como la libertad del individuo se cumple

${ }_{21}$ Rawls, J., Teoría de la justicia, 1979. De la doctrina iuspublicista casi inmediata: Saladin, P., "Verfassungsreform und Verfassungsverständnis", Archiv des öffentlichen Rechts, vol. 104, 1979, pp. 345, 272 y ss.; Häberle, P., Kommentierte Verfassungsrechtsprechung, 1979, pp. 438 y ss.; más tarde Kersting, W., Die politische Philosophie des Gesellschaftsvertrags, 1994.

22 Jellinek, G., Allgemeine Staatslehre, 3a. ed., 1959, pp. 183, 406 y ss. (hay trad.: Teoría general del Estado, varias ediciones). En contraposición, correctamente: Heller, H., op. cit., pp. 158 y ss.: "El pueblo como formación cultural" (trad. cit.: pp. 205 y ss.). 
Este libro forma parte del acervo de la Biblioteca Juridica Virtual del Instituto de Investigaciones Juridicas de la UNAM

no como libertad "natural", sino cultural, ya que la investigación genética muestra que no somos de ningún modo "esclavos de los genes" (libertad a partir de la cultura, en especial la educación). Ciertamente, las tendencias hacia la "sociedad multicultural", la admisión de la doble nacionalidad en varios países de Europa, la intensificación de los derechos (colectivos) de protección a las minorías y el alegato a favor de un concepto "abierto" de la cultura, plantean problemas básicos que no es posible examinar aquí.

\section{LA TRIADA DE LOS ÁMBITOS REPUBLICANOS: PRIVADO-PÚBLICO-ESTATAL}

\section{Planteamiento del problema}

El concepto de "triada de los ámbitos republicanos" intenta vincular, en el foro de la teoría constitucional, los tres ámbitos, el privado, el público y el estatal, con la "república", y al mismo tiempo, permitir que estos tres ámbitos actúen en lo que les es propio y en su diferencia cultural. La res publica como marco significa también una referencia a otros conceptos "republicanos" como los de "libertad pública", "bien público", "derecho público", en un sentido más profundo, no técnico. La comunidad política del Estado constitucional consiste en una pluralidad de ámbitos diferenciados, y de ellos vive, todos los cuales tienen su carácter propio y sin los cuales no puede haber "pluralismo". La frase de J. Habermas sobre el "kantianismo republicano", que coloca en términos de igualdad el compromiso ciudadano, la constitución colectiva de un espacio público autónomo al lado de la libertad privada, es una "acción paralela" de la filosofía política. Aquí podría estar incluido el emergente "espacio público mundial", en temas como los de la "cosmovisión del Estado constitucional" y el "status mundialis hominis", y en Europa se plantea la cuestión de en qué medida existe un "espacio público europeo", que, por ejemplo, se alimente de las ciencias y las artes y qué tanto posee ya formas de manifestación concretas en el derecho constitucional común europeo. En lo que sigue, lo privado y lo público se tratan solamente en el marco del Estado constitucional en lo individual, a pesar de la diversidad de interacciones que hay entre el espacio público "constitucional interno del Estado" y el espacio público mundial o regional. Por lo demás, la triada de ámbitos debería corresponder a la doctrina de las tareas del Estado, en la medida en que se distinga con precisión entre las privadas, las públicas y las estatales. 
Este libro forma parte del acervo de la Biblioteca Juridica Virtual del Instituto de Investigaciones Juridicas de la UNAM

\section{Lo privado, protección de la privacía}

Lo privado no debe concebirse primariamente como ámbito excluido y alejado de los contextos comunicativos de los seres humanos en una comunidad política. Sin embargo, también habría que reconocer esta posibilidad del "sin mí", ciertamente en la conciencia de que el ámbito privado constituye también un pedazo de "libertad cultural" y de que se constituye "en" la comunidad, y no en una esfera de una supuesta libertad "natural" fuera de ella. Bajo esta reserva, deben tomarse con la mayor seriedad las disposiciones del texto constitucional respecto del ámbito privado como zonas de protección de la identidad y la libertad individuales, precisamente también frente al trasfondo de los regímenes totalitarios derrocados en 1989, los cuales ocupaban todos los ámbitos como potencialmente públicos y "sociales".

Una mirada a la evolución de las etapas textuales resulta reveladora. Mientras que la Ley Fundamental alemana de 1949 no conoce, en su texto, una protección fundamental a la privacía, y por ello tal protección ha tenido que ser desarrollada por la doctrina y la jurisprudencia, ${ }^{23}$ otras Constituciones y otros textos sobre derechos humanos se muestran, prima facie, más productivos. Ya el artículo 8o. de la Convención Europea de Derechos Humanos de 1950 formula un "derecho al respeto de la vida privada y familiar" de todos. El artículo 26 de la Constitución de Portugal (1976-1992) protege el derecho de todos "a la identidad personal... a la reserva de la intimidad de la vida privada y familiar...". El artículo 18, inciso 1, de la Constitución española (1978) habla de manera similar del derecho a la "intimidad personal y familiar y a la propia imagen". Una nueva etapa textual se refleja ya en el artículo 10, inciso 2, de la Constitución de los Países Bajos (1983-1995), en la medida que ahí se dispone: "Una ley del Parlamento establecerá normas para la protección de la vida privada en relación con el registro y la difusión de datos personales". Esta reserva de desarrollo elabora los problemas que en Alemania ha tratado de manera pretoriana el Tribunal Constitucional Federal a través del "derecho a la autodeterminación informacional" (BVerfGE 65,1$)$ y que, a través de reformas constitucionales, se han formulado textualmente como protección de datos personales (Datenschutz) (por ejemplo, el artículo 21 b de la Constitución de Berlín de 1950-1994; el artículo 11 de la Constitución de Brandemburgo de 1992; el artículo 6o. de la Constitución de Mecklemburgo-Antepomerania de 1993; los artículos 4o., 77a de la Constitución de Renania del Norte-Westfalia de 1950-1992). Nuevamente

23 De la jurisprudencia del Tribunal Constitucional Federal alemán véase $B V \operatorname{Ver} f G E, 65$ 1, y por último $B \operatorname{VerfGE}, 89,214$ y 90, 255. 
Este libro forma parte del acervo de la Biblioteca Juridica Virtual del Instituto de Investigaciones Juridicas de la UNAM

se ve confirmado el paradigma de las etapas textuales, en la medida, por ejemplo, que la jurisprudencia constitucional conduce frecuentemente a enmiendas constitucionales.

\section{Lo público}

Redescubierto por R. Smend, ${ }^{24}$ incorporado tempranamente por K. Hesse a la dogmática del artículo 21 de la LF, ${ }^{25}$ más tarde lo público fue abordado plenamente por J. Habermas en su filosofía social. ${ }^{26}$ No obstante las dificultades de entonces y ahora para definirlo, el concepto de "espacio público" (Öffentlichkeit) ha encontrado un lugar permanente en el marco de las cuestiones relativas a los derechos fundamentales, la democracia y la oposición.

Lo público y el espacio público se refieren, en el sentido que aquí se les da, a dos cosas: en el marco de la triada de ámbitos republicanos, se refieren, en lo espacial, a un cierto campo de la res publica, al ámbito intermedio entre lo estatal y lo privado, lo que frecuentemente se llama también la "sociedad". En este ámbito actúan fuerzas diversas, como los partidos políticos, con su propio estatus público ( $c f r$. el artículo 21, inciso 1, frase 4, de la LF), las iglesias, como "potencias públicas" (A. Hollerbach) más distanciadas del Estado, pero también la televisión pública y, a la cabeza de los medios de comunicación, la televisión privada. De manera tan temprana como frecuente se le ha atribuido una función pública a la prensa en Alemania; en todo caso, ésta influye en la "opinión pública". También los sindicatos y los empresarios se sitúan en este ámbito social-público, como grupos plurales poderosos a los que hay que equilibrar constantemente. "Público" significa también una dimensión sustantiva y valorativa: se trata de la salus publica, del "paralelograma de las fuerzas" de una comunidad política, a partir del cual se unen de manera pluralista las fuerzas, luchan entre sí en disenso y consenso, para finalmente tomar forma, por ejemplo, de ley aprobada en la publicidad del parlamento. El ciudadano también toma parte en lo público, tanto en lo espacial como en lo valorativo, cuando ejerce el lado público de

24 Cfr. Smend, R., "Zum Problem des Öffentlichen und der Öffentlichkeit", Ged. Schrift für. W. Fellinek, 1955, pp. 13 y ss. (trad.: "Sobre el problema de lo público y la «cosa pública»", Constitución y derecho constitucional, cit., pp. 269 y ss.).

25 Hesse, K., "Die verfassungsrechtliche Stellung der politischen Parteien im modernen Staat", VVDStRL 17 (1959), pp. 11 (41 y ss.).

26 Habermas, J., Strukturwandel der Öffentlichkeit, 8a. ed., 1976, 12a. ed. 1980 (hay trad.: Historia y crítica de la opinión pública, 1981). 
Este libro forma parte del acervo de la Biblioteca Juridica Virtual del Instituto de Investigaciones Juridicas de la UNAM

sus derechos fundamentales, por ejemplo, a través de la libertad de manifestación como "libertad de expresión del hombre común", o cuando ejerce su libertad religiosa al tomar parte en una procesión. Por lo tanto, resulta consecuente que muchas de las garantías contenidas en la libertad religiosa protejan expresamente también su ejercicio público (así, por ejemplo, el artículo 9o., inciso 1, de la GEDH). Hay razón para hablar entonces de "libertades públicas", uso que es común en la Francia republicana ("libertés publiques"; cfr. también el título I, capítulo segundo, sección la. de la Constitución española).

\section{Lo estatal en el Estado constitucional}

De acuerdo con la doctrina ya clásica de R. Smend y A. Arndt, en el Estado constitucional habrá tanto Estado como se encuentre constituido en la Constitución, lo que, en todo caso, es válido en el marco de una teoría constitucional democrática. Esto no significa un viraje contra el Estado constituido, el cual resulta indispensable precisamente en la protección de los derechos fundamentales y los privados, sino que significa simplemente que se toma en serio a la "Constitución" y que no se reconocen supervivencias feudales o monarquistas, ya sea en la dogmática o en la realidad. Si todo el poder del Estado proviene de los ciudadanos que se "encuentran" en la comunidad ciudadana, no queda entonces ningún espacio para un poder estatal extra o preconstitucional. La Constitución debe concebirse como "previa" al Estado, a pesar de la importancia que éste pueda tener o conservar.

La comunidad política (lo mismo de una república que de una monarquía constitucional), concebida como marco general y constituida por la Constitución concreta, conoce, al lado del ámbito privado descrito, así como junto al ámbito y las funciones de lo público, también lo "estatal constituido". Este concepto se refiere a los órganos del Estado, a las competencias y funciones estatales (por ejemplo, las del parlamento, el gobierno, la administración y la jurisdicción). Si bien se encuentran articuladas de diversas maneras con lo público "social", lo que se advierte, por ejemplo, en cuanto a la labor de comunicación social de los parlamentos y gobiernos, o incluso del Tribunal Constitucional federal, tales funciones y competencias han sido establecidas "para sí" y en tal sentido son indispensables. Los 
Este libro forma parte del acervo de la Biblioteca Juridica Virtual del Instituto de Investigaciones Juridicas de la UNAM

órganos del Estado no son "virtual" o realmente omnicompetentes, en el sentido de contar con un "poder general y en blanco", ${ }^{27}$ sino que, de inicio, sus funciones están circunscritas y vinculadas funcionalmente por el derecho. La teoría de las tareas del Estado constitucional tiene que "manifestarse" también en la concepción de los órganos del Estado. Del mismo modo debemos desprendernos del antiguo concepto de la "soberanía estatal": por el lado externo, al reconocer el "condicionamiento supraestatal del Estado" (W. v. Simson), aunque también existe un condicionamiento estatal de lo supraestatal, ya que solamente los Estados constitucionales "sostienen" a la comunidad de las naciones; en el lado interno, por el reconocimiento de que los ordenamientos de protección a la libertad, de competencias y funciones de una Constitución en el Estado constitucional, no tienen espacio para la soberanía de cualquiera.

El término de la "triada de ámbitos republicanos" pretende ver juntos los tres "lados", privado, público y estatal, a pesar de los numerosos conflictos y roces que pueda haber entre ellos (por ejemplo, muchos órganos del Estado funcionan públicamente, pero no todos). Cada generación está obligada a vivirla y configurarla de nuevo, $v$. gr., en materia de protección de los datos personales o del medio ambiente, de la libertad económica y la privatización, incluso en materia de "protección a las generaciones".

\section{Una revisión de los "elementos del Estado"; la cultura como "cuarto" elemento; el ejemplo del territorio y los símbolos del Estado}

\section{A. Los llamados tres elementos del Estado, y el "cuarto" elemento: la cultura}

Entre los capítulos tradicionales de la teoría general del Estado ${ }^{28}$ se encuentran los tres "elementos del Estado": el pueblo, el poder, el territorio. Típicamente, en esta triada (todavía) no tiene un lugar la "Constitución", y esto caracteriza a las teorías generales del Estado, pero también las hace cuestionables. Una "teoría de la Constitución" que merezca tal nombre tiene que buscar el modo de incorporar a la Constitución, en el sentido de

27 Véase, en cambio, el enfoque de Krüger, H., Allgemeine Staatslehre, 1964, pp. 196, 940 y ss.

28 Véase la opinión parcialmente crítica de Pernthaler, P., Allgemeine Staatslehre und Verfassungslehre, 1986, pp. 82, 35 y ss.; 111 y ss. Véase también la crítica de Saladin, P., Wozu noch Staaten?, 1995, pp. 16 y ss. 
Este libro forma parte del acervo de la Biblioteca Juridica Virtual del Instituto de Investigaciones Juridicas de la UNAM

que ésta sea, si no el "primer" elemento del Estado, al menos un elemento esencial. Dicho en términos concretos: la teoría de los elementos del Estado tiene que ser plenamente declinada (conjugada) a partir del citado elemento de la cultura. La Constitución es una parte de la cultura; forma, si se quiere (o más bien, debe formar) un "cuarto" elemento. G. Dürig propuso tempranamente esto de manera tendencial (1954), pero no lo desarrolló más. ${ }^{29}$ Cuanto antes, ahora hay que atreverse a dar este paso en la teoría de la Constitución. Esto significa que también los demás elementos del Estado tienen que ser "llenados" desde la perspectiva de la ciencia cultural, empezando por el pueblo como "conjunto de hombres sometidos a los preceptos del derecho" (I. Kant), pero por lo mismo en el "status culturalis". La diversidad de identidades de los pueblos de Europa es de naturaleza cultural, y eso es lo que constituye la diversidad de Europa.

El territorio del Estado es territorio culturalmente formado, un "espacio cultural", no un factum brutum. ${ }^{30}$ El concepto de la historia de J. G. Herder como "geografía puesta en movimiento" pudiera ser útil en este sentido. El poder del Estado, por su parte, debe concebirse como determinado de manera cultural, no actuando de manera natural, ya que, en el Estado constitucional, se encuentra fundado y limitado normativamente, y se halla al servicio de la libertad cultural. La guerra civil en Yugoslavia muestra de manera dramática hasta qué punto es indispensable tal poder.

\section{B. El ejemplo del "territorio del Estado"}

\section{a. Introducción y planteamiento del problema}

No solamente en los micro Estados se destacan actualmente los aspectos suprarregionales e inclusive globales; no sólo en Europa surgen en 1997 grandes mercados, sino que gracias a la movilidad multimedial surge mundialmente una comunidad comunicativa de alcance global, de modo que la cuestión del territorio del Estado podría parecer pasada de moda y superada. ¿Acaso el territorio del Estado (y con él la "estática" que implica) no se ha desvanecido desde hace tiempo, incluso disuelto, en los procesos dinámicos de una sociedad mundial de los medios, multinacional y abierta, en la cual todo parece moverse, extenderse y se encuentra menos "fijo" de manera

29 "Der deutsche Staat im Jahre 1945 und seither", VVDStRL 13 (1955), pp. 27 (37 y ss.).

30 Véase Häberle, P., "Das Staatsgebiet als Problem der Verfassungslehre", FS G. Batliner, 1993, pp. 397 y ss. 
Este libro forma parte del acervo de la Biblioteca Juridica Virtual del Instituto de Investigaciones Juridicas de la UNAM

permanente? En vista de la articulación supranacional del Estado constitucional de la actualidad, no podría quedar intocado por estos procesos el elemento del Estado llamado "territorio".

Sin embargo, esto constituye solamente una faceta de eventos que se aceleran visiblemente. En contraste, hay una vuelta a lo "pequeño" en la localidad, una retirada hacia un espacio visible, a la "región" y la "patria": Estados nacionales verdaderos o supuestos se descomponen en "micro Estados"; grupos étnicos exigen derechos de minoría; el regionalismo se convierte gradualmente en principio estructural de muchos Estados constitucionales que hasta ahora habían sido centralistas (desde España hasta la Gran Bretaña); el federalismo continúa su marcha victoriosa por el mundo. Todo ello remite a lo específicamente territorial. Al mismo tiempo se adquiere conciencia de la ambigüedad del término "frontera": por un lado, significa limitación, a la propia identidad; por el otro, a partir del espacio delimitado es posible extenderse hacia lo ajeno, lo nuevo, lo lejano. Precisamente los micro Estados (como Liechtenstein) tienen gran conciencia de esta dialéctica, pues reciben e integran mucho que viene de "fuera", para así mejor afianzarse. Quizá pudiéramos dar una variación territorial y espacial al verso de Goethe: "La ley sola puede darnos libertad": el ser humano, en su libertad fundamental, se precipitaría literalmente al vacío si no hubiera un terreno "seguro", culturalmente conformado, desde el cual pudiera extenderse al entorno. El Estado constitucional crea actualmente el marco óptimo para una libertad cultural ligada así al terreno, y su territorio constituye un "elemento cultural" específico en el conjunto de sus valores fundamentales.

b. La constitucionalización del territorio en el Estado constitucional; el enfoque culturalista de la teoría constitucional

i) El punto de partida es un "concepto básico" y distinto del territorio del Estado. Ya sea que esté ubicado en general (y formalmente) en el contexto de los artículos tradicionales sobre el Estado o (modernamente) en el contexto de las cláusulas relativas a los valores materiales fundamentales, tales como la libertad y la democracia, ya sea que se trate de manera esporádica o se encuentre sujeto a reserva de ley: en la actual etapa evolutiva del Estado constitucional el territorio constituye un fundamento de su identidad cultural y de su individualidad histórica. La Constitución entera es su "contexto". Todo ello se manifiesta en algunos textos mediante la atribución y descripción históricas de sus fronteras, pero también se expresa 
Este libro forma parte del acervo de la Biblioteca Juridica Virtual del Instituto de Investigaciones Juridicas de la UNAM

de otras maneras: por ejemplo, en las Constituciones que lo declaran como inalienable e indivisible, o que lo convierten en límite absoluto de la revisión constitucional, así como en los casos, en los que se requiere una enmienda constitucional formal para modificar las fronteras. Si J. G. Herder podía hablar de la historia como "geografía puesta en movimiento", ${ }_{31}$ en todos estos casos el territorio se presenta a la vista en el horizonte del tiempo. ${ }^{32}$ Cada Estado constitucional se apropia internamente, una y otra vez, de su propio territorio, que se convierte en cultura. Solamente en un sentido secundario es el territorio "fundamento del Estado"; lo es, pero de la Constitución. No es "elemento del Estado", sino valor constitucional.

Es posible poner de manifiesto vínculos con los derechos fundamentales ahí donde el territorio se encuentra implícito en el supuesto de hecho de uno o varios de ellos. Si la garantía del derecho de asilo acepta al "solicitante" cuando éste ha sido un luchador por la "libertad, los derechos humanos, la democracia y la paz entre las naciones", lo que se manifiesta aquí es que el Estado abre su territorio a favor de estos valores fundamentales generales. Muchos Estados constitucionales, sobre todo los alemanes, norman, por ejemplo, la paz entre las naciones como fin de la educación (desde el artículo 148, inciso 1, de la Constitución de Weimar, de 1919, pasando por el artículo 26, número 1, de la Constitución de Bremen de 1947, hasta el artículo 28 de la Constitución de Brandemburgo de 1992). Cuando el Estado desarrolla la protección de los derechos fundamentales de los extranjeros en el ámbito interno, entonces también pone su "territorio" al servicio de los demás derechos fundamentales protegidos. Inclusive ahí donde el Estado constitucional pone el territorio a disposición de sus ciudadanos y existe, prima facie, solamente una relación "negativa" entre territorio y derechos fundamentales - en la libertad de emigrar - se puede descubrir también un vínculo positivo, pues solamente el ciudadano libre y en libertad de transitar es capaz de identificarse con su país, en la medida y en tanto que desee permanecer en él. Por lo demás, los textos constitucionales más recientes ponen de manifiesto la instrumentalización del territorio al servicio de los derechos fundamentales como valores básicos del mismo, al darles prioridad sistemática sobre aquél.

El territorio puede concebirse como función plural del Estado, lo que es posible fundarlo en no pocos textos constitucionales positivos: primeramen-

31 Al respecto, véase más ampliamente Häberle, P., "Der Kleinstaat als Variante des Verfassungsstaates", en A. Waschkuhn (ed.), cit., 1993, pp. 121, 170 y ss.

32 Si Richard Wagner decía filosóficamente en el Parsifal: "En espacio se torna aquí el tiempo": desde el punto de vista de la teoría constitucional, el territorio en particular del Estado se presenta como valor constitucional "en el curso del tiempo". 
Este libro forma parte del acervo de la Biblioteca Juridica Virtual del Instituto de Investigaciones Juridicas de la UNAM

te, de manera más bien externa, ahí donde se atribuye a los órganos del Estado la salvaguarda de la integridad del territorio soberano, por ejemplo, en situaciones de emergencia o de guerra, en las cuales se puede recurrir también a las disposiciones protectoras internacionales ( $f f r$. el artículo 2o., inciso 4, de la Carta de la ONU), si bien la concepción de la soberanía distorsiona, en cuanto al objeto, las relaciones aquí expuestas. Desde una perspectiva material, se trata sobre todo de los nuevos artículos, arriba analizados, sobre protección de la naturaleza, el ambiente y la cultura, los que muestran de qué manera "trabaja" el Estado en y con su territorio, y de qué modo es responsable de su conservación como "base de la existencia", incluso para las generaciones futuras. Este constituir al territorio es también un pedazo de Constitución vivida. De ahí el término de la concepción "constitucional" del territorio del Estado. Este razonamiento recibe mayor impulso gracias a dos aspectos más: la protección de la naturaleza, el ambiente y la cultura, se encuentra, en última instancia, vinculada a los derechos fundamentales (como tarea del Estado relativa a estos derechos); se le ha atribuido al Estado constitucional en favor del ser humano. Por otro lado, hay que recordar los artículos relativos a la reorganización territorial (en los Estados federales) y a la división en regiones y otras formas de descentralización (en los Estados unitarios). En sus "conceptos rectores" sustantivos se manifiestan valores constitucionales (por ejemplo, rasgos comunes históricos, étnicos, culturales, económicos) que, por su parte, establecen un puente hacia otros valores fundamentales postulados en diversas partes del documento constitucional. Por lo demás, conviene recordar la clásica función estatal que ha sido normada en el artículo 1o., inciso 2, de la Constitución de Baden-Württemberg: reunir "en una comunidad ordenada a los seres humanos que habitan su territorio" y "otorgarles protección y estímulo".

En suma: la teoría de las tareas del Estado debe "prolongarse", en el sentido apuntado, hacia el territorio, en el tiempo, en la naturaleza y el espacio, y así también en tanto cultura: el listado preciso de las referencias ya existentes a los valores fundamentales del Estado constitucional como tipo - las que no están todas normadas al mismo tiempo en una Constitución concreta, pero que se pueden conjuntar a partir de varias Constitucionespuede dar un impulso a esta teoría constitucional del territorio del Estado que se pueda transformar, desde el punto de vista de la política constitucional, en nuevos textos. El "territorio se convierte en espacio", el "ambiente y la naturaleza, en cultura". De este modo, el territorio del Estado incrementa su primera y última significación en el Estado constitucional, todo ello gracias a una teoría constitucional alimentada por los textos y la ciencia cultural. Dicho en otras palabras: a través de la proyección de los valo- 
Este libro forma parte del acervo de la Biblioteca Juridica Virtual del Instituto de Investigaciones Juridicas de la UNAM

res constitucionales fundamentales hacia el territorio, se convierte éste mismo en un "valor fundamental" de la Constitución. El territorio se presenta como "base" espacial para la realización de los valores fundamentales de la Constitución. El análisis de los artículos constitucionales relativos al territorio en los micro Estados demuestra ser especialmente fértil. Todas las disposiciones constitucionales en las que aparece el territorio, ya sea de forma general, especial o incluso puntual, constituyen una piedra de mosaico en la imagen global de esta "base de la existencia en el Estado constitucional".

ii) Existe una relación dialéctica entre la europeización y la globalización de los territorios de los Estados, por un lado, y la escasez del territorio, y por tanto, de la intensivización de su configuración por el Estado constitucional, por el otro. Este aspecto teórico se puede resumir brevemente. Observamos dos líneas de evolución aparentemente contrarias: por un lado, el territorio del Estado se relativiza por la penetración en regiones más amplias, incluso hacia lo global, estableciendo relaciones de responsabilidad que hacen que el "territorio del Estado" tradicional de cada país se contraiga de manera considerable, lo hagan parecer pequeño e incluso materialmente como "micro Estado". El "condicionamiento supraestatal del Estado moderno" (W. v. Simson) podría incluso provocar la cuestión de si todavía se justifica, en 1999, el esfuerzo que implica una teoría constitucional del territorio. De hecho, existe también un condicionamiento estatal de lo supraestatal, del mundo. Precisamente a partir de su territorio, por pequeño que sea, cada uno de los Estados constitucionales tiene que asumir su responsabilidad respecto de los derechos humanos y los valores fundamentales asociados con ellos. Debido a que ese único mundo, cada vez más estrecho, hace cada vez más escasos los territorios habitables, los Estados constitucionales deben configurar tanto más intensivamente el territorio que les corresponde. Lo uno condiciona a lo otro. El giro, hoy perceptible, hacia lo "pequeño, hacia la "patria", el surgimiento de nuevos micro Estados, no puede renunciar al "cultivo" de los territorios, sino que pretende "internalizarlos" de manera tanto más intensiva. El "entorno" de los diversos textos constitucionales es un pedazo del mundo que se ha hecho único, pero este mundo solamente puede sobrevivir si todos los Estados constitucionales que componen la "sociedad mundial", en el sentido de un contrato social mundial, cultivan su propio (y "pequeño" mundo) de manera fiduciaria, a través de la optimización de los valores fundamentales constitucionales, precisamente en el ámbito de su "territorio".

iii) Todo constituyente en el Estado constitucional, en su actual etapa de desarrollo, debería tratar al territorio en el contexto "correcto". Se recomienda situarlo en los artículos generales al inicio de la Constitución, en los 
Este libro forma parte del acervo de la Biblioteca Juridica Virtual del Instituto de Investigaciones Juridicas de la UNAM

cuales, junto con la libertad, la igualdad y la democracia, se habla también de la "protección de las bases naturales de la vida y de la cultura" como fines del Estado, pues ya está superada la etapa textual anterior, es decir, en la que dicho fin aparece sólo en el contexto de los elementos tradicionales del Estado, como el "pueblo" y el "poder", sin adiciones normativas. De ningún modo debería "estar" el territorio de manera aislada junto con los otros "elementos" o "símbolos" del Estado. Dicho en otras palabras: la teoría de la constitucionalización del territorio del Estado debe manifestarse textualmente en la medida en que dicho territorio se haya introducido visiblemente en el contexto de los valores fundamentales del Estado constitucional. El territorio es una base valiosa del Estado constitucional, no sólo del Estado; es un pedazo de la Constitución como cultura. Lo mejor sería que el territorio del Estado se abordara en la parte relativa a las bases de la Constitución, en la que se habla ya de los principales derechos fundamentales. Una variante consiste en la posibilidad de referirse a los derechos fundamentales en el primer apartado e iniciar la parte orgánica con preceptos sobre el territorio en sentido normativo y sustantivamente estructurado. El texto relativo al territorio del Estado de ningún modo debe quedar aislado, como en etapas anteriores, de los derechos fundamentales, por un lado, y de las tareas estatales, como la protección del ambiente, o la cultura, por el otro. Debe pensarse también en artículos que estructuren y utilicen al espacio mediante principios y objetivos. De ello ya hay ejemplos. Una posibilidad especial, pero solamente abierta al federalismo y al regionalismo, es la que plantean los artículos de distribución y redistribución espacial, como el artículo 29 de la LF, el artículo 227 de la Constitución de Portugal o el artículo 143, inciso 1, de la Constitución española.

El planteamiento específicamente constitucional adoptado aquí tiene consecuencias también para configurar los supuestos de cambios territoriales. El requisito mínimo es una ley del parlamento; el óptimo, una enmienda constitucional, ya que la modificación territorial significa, por su contenido, una modificación constitucional, consecuencia del enfoque culturalista que sostengo en la teoría constitucional.

Deben distinguirse las cláusulas generales sobre el territorio de las especiales, que se refieren a los contextos particulares en los que el territorio constituye un elemento del supuesto de hecho de un valor constitucional fundamental, como el derecho de asilo, la libertad de emigración, el estatuto fundamental de los extranjeros en el ámbito interno.

Tales máximas pretenden destacar que la "constitucionalización" del territorio del Estado que aquí se observa y se recomienda, no es una mera frase, sino una tendencia comprobable, y una consecuencia interna del tipo del Estado constitucional en su etapa actual de desarrollo. De ello hay más 
Este libro forma parte del acervo de la Biblioteca Juridica Virtual del Instituto de Investigaciones Juridicas de la UNAM

conciencia en los micro Estados, como Liechtenstein, que en los grandes Estados territoriales, en los que se encuentran tanto desiertos y lagos salados como "paisajes culturales". Examinada más de cerca la cuestión, tanto éstos como aquéllos constituyen también la identidad de una comunidad política, en sentido histórico, económico y cultural. Forman un pedazo del "paisaje interno" de todo Estado constitucional, de su entorno, de los seres humanos que constituyen su cultura. Desde esta perspectiva, el territorio obtiene varias dimensiones, a las que debe hacer justicia en lo posible el constituyente concreto. El valor constitucional del territorio tiene muchas facetas, como la Constitución misma, en cuyos principios y valores fundamentales se integra globalmente.

\section{La Constitución del pluralismo: formas de diferenciación cultural y de apertura externa del Estado constitucional}

Actualmente, la Constitución del pluralismo enfrenta desafíos especiales en tres campos: en el ámbito de lo nacional, en la exigencia de la federalización o regionalización, y en la apertura de todos los Estados constitucionales hacia la comunidad de las naciones (concepto clave: "Estado constitucional cooperativo").

a. Nación y Estado constitucional: normalización, relativización y normativización de la protección de minorías

El Estado constitucional, de tipo europeo, está obligado hoy, como nunca antes, a asegurarse del valor de lo nacional. ¿Dónde está la nación en la "Europa de los ciudadanos", de las "regiones", de las "patrias"? ¿Son nación y Estado constitucional parcial o totalmente idénticos? ¿Puede uno apoyarse en ideas como las de Sarah Kirsch, quien siempre ha "preferido las lenguas maternas a las patrias"? No es posible documentar totalmente aquí el debate actual sobre la "identidad nacional", pero sí podemos indicar algunas ideas clave. El Estado nacional clásico ya no puede ser el modelo obligatorio para el Estado constitucional. En la etapa actual de desarrollo es preciso que todos los Estados constitucionales, independientemente de lo mono o pluriculturales que puedan ser en la realidad, se conciban en todos sentidos como pluralistas: incluso Francia, que encuentra su identidad cultural y política en la "República", debe encontrar un refugio tolerante para el Islam, que ya es la segunda religión en importancia en el país. Desde hace 
Este libro forma parte del acervo de la Biblioteca Juridica Virtual del Instituto de Investigaciones Juridicas de la UNAM

tiempo, Suiza ha abierto caminos, como "nación de la voluntad", hacia el pluralismo, gracias, entre otras cosas, a su ejemplar libertad lingüística. Alemania lucha dolorosamente desde hace tiempo en torno a la protección expresa de las minorías culturales; la casi fracasada "comisión constitucional conjunta" trabajó sobre la protección de minorías (1993), pero las modificaciones constitucionales puntuales del otoño de 1994 no la hicieron realidad. ${ }^{33}$ Esto resulta tanto más extraño, porque varias Constituciones de los Länder alemanes, tanto occidentales como orientales, se han atrevido a incorporar ejemplares cláusulas sobre la protección de las minorías; así, el artículo 5o. de la Constitución de Schleswig-Holstein (1990), el artículo 25 de la Constitución de Brandemburgo (1992), y el artículo 5o. de la Constitución de Sajonia (1992). ${ }^{34}$

Aquí y ahora hay que atreverse a afirmar que la protección plena de las minorías étnicas, culturales, religiosas, pertenece, en mi opinión, a la actual "etapa de crecimiento" del tipo del Estado constitucional y que también tendría que expresarse en una etapa madura de desarrollo textual. El Consejo de Europa vigila debidamente a los países de Europa oriental respecto a cuán intensiva es su protección de las minorías, lo que resulta de actualidad para Letonia (en relación con los rusos).

\section{$b$. Federalismo y regionalismo (en formación) como principio estructural interno del Estado constitucional}

Ésta es la tesis: en la actualidad, el Estado constitucional, como tipo, debe estar estructurado de manera federativa o regionalista. Inclusive los Estados unitarios clásicos, como Francia o Italia, se encuentran en camino hacia la regionalización. Este proceso adquiere impulso desde Europa (en parte también desde "Maastricht": comité consultivo de las regiones, artículo 198 a) a c), reforzado en 1997 en el Tratado de Amsterdam). Los tiempos del Estado unitario centralista han concluido probablemente para el Estado constitucional como tipo. En la medida en que dicho Estado se conciba fundado en los derechos humanos y ciudadanos, en que descubra su pluralidad cultural interna, tome en serio la democracia en lo pequeño

33 La propuesta de artículo 20 b decía lo siguiente: "El Estado respeta la identidad de las minorías étnicas, culturales y lingüísticas" (citado en el Informe de la Comisión, en Zur Sache 5/93, 1993, p. 31); véase mi anterior propuesta de texto en "Aktuelle Probleme des deutschen Föderalismus", Die Verwaltung, vol. 24, 1991, pp. 169, 206 y s.

34 Véanse los textos y comentarios en Fahrbuch des öffentlichen Rechts, vol. 42, 1994, pp. 149 y ss. 
Este libro forma parte del acervo de la Biblioteca Juridica Virtual del Instituto de Investigaciones Juridicas de la UNAM

y local, y reconozca el valor de todos los tipos de división del poder, en tal medida se diversifica en sentido federal o regional.

c. La apertura del Estado constitucional hacia la comunidad de las naciones (el "Estado constitucional cooperativo")

El Estado abierto (K. Vogel), el "Estado constitucional cooperativo", constituyen otros tantos conceptos clave en la actual etapa de desarrollo de nuestro objeto (véase, infra, capítulo 2, VI, 2.). Los pactos internacionales de derechos humanos, pero también sus equivalentes regionales, como la Convención Europea de Derechos Humanos, constituyen un elemento de tal apertura del Estado constitucional hacia el exterior. Hoy se anuncia una "comunidad universal de los Estados constitucionales"; pensamos que desde un punto de vista "cosmopolita", en el sentido de I. Kant, a pesar de todos los retrocesos y las recaídas en la era nacional. El "condicionamiento supraestatal del Estado" (W. v. Simson), pero también el condicionamiento estatal de lo supraestatal, se vuelve tangible, tanto en lo próximo como en lo lejano.

\section{La verdad como problema en el Estado constitucional: la libertad a partir de la cultura}

El Estado constitucional europeo constituye un foro único para los problemas que plantea la verdad:35 no porque conozca "verdades terminadas, absolutas", que darían a conocer y aplicarían los juristas, sino porque permite, gracias a los derechos fundamentales en tanto libertades culturales y en virtud de la democracia como "gobierno" temporal en el sentido de Popper, destituir sin derramamiento de sangre a los gobernantes, y que "mueran las teorías en lugar de los seres humanos". El "racionalismo crítico" de Popper, apoyado, claro está, en el consenso cultural fundamental que se expresa en el eje temporal como "contrato de las generaciones", es, en mi opinión, la filosofía convincente del Estado constitucional europeo. Es decir, que sin duda existe la verdad, pero no podemos saber si la conocemos. Los procedimientos de ensayo y error, la formulación de hipótesis falsables y la prohibición de la mentira (I. Kant) nos auxilian, "hasta nuevo aviso", en nuestra aproximación a la verdad, tanto en el ámbito científico como en

35 Las particularidades sobre este tema pueden encontrarse en Häberle, P., Wahrheitsprobleme im Verfassungsstaat, 1995. 
Este libro forma parte del acervo de la Biblioteca Juridica Virtual del Instituto de Investigaciones Juridicas de la UNAM

el político. Pensamos en los correspondientes textos de Lessing y en la concepción de ciencia de W. von Humboldt. La "Constitución de la libertad" se encuentra aquí con la sociedad moderna hasta su aplicación práctica en la Europa de hoy; por ejemplo, en el "Open Society Fund" de G. Soros para Europa oriental. Sin duda hay que prevenirse de sostener una "filosofía de casa"; sin embargo, el pensamiento de Popper me parece especialmente adecuado para la "casa europea" abierta tanto como para su Estado constitucional.

\section{E. En particular: los llamados símbolos del Estado en el contexto de la nueva etapa de desarrollo textual}

a. Planteamiento del problema

Los así llamados "símbolos del Estado" "36 son, en la opinión tradicional, manifestación del "Estado", el cual se concibe frecuentemente como "previo" a la Constitución. La mayoría de las veces, los símbolos del Estado se conciben, o se norman, en los documentos constitucionales más antiguos, en el contexto de la lengua oficial, del territorio y de la nacionalidad, y se manifiestan bajo la forma de banderas, himnos, escudos e incluso ciudades capital, como "atributos", más aún, como "elementos" del Estado. Se trata de elementos fijos de los preceptos constitucionales iniciales o generales de las Constituciones de cuño antiguo y, de acuerdo con una rica tradición, deben "simbolizar" al Estado como tal. Sin embargo, tales símbolos deben admitir una interpretación distinta frente al trasfondo del enfoque culturalista aquí adoptado. Así como se reconceptualiza a los elementos del Estado, y del mismo modo como en la etapa textual más reciente el problema de la lengua es visto inevitablemente en relación con las minorías lingüísticas y la pluralidad cultural, resulta preciso cuestionarse nuevamente sobre la ubicación conceptual, y por lo tanto, el lugar sistemático, de los "símbolos estatales" en el Estado constitucional, ya que las banderas, los himnos, escudos, días festivos y también las ciudades capital ${ }^{37}$ no "simbolizan" al Estado, sino que apuntan a las dimensiones culturales de la comunidad política. En la so-

36 De la bibliografía: Klein, E., "Staatssymbole", HdbStR, vol. I (1987), pp. 733 y ss.; Badura, P., Staatsrecht, 2a. ed., 1996, pp. 251 y ss.

37 Véase al respecto Häberle, P., "Die Hauptstadtfrage als Verfassungsproblem", Die öffentliche Verwaltung, 1990, pp. 989 y ss. También los artículos 29 de la Constitución de Polonia (1997), 10 de la Constitución de Georgia (1995), 5o. de la Constitución de Madagascar (1995), 1o. de lan Constitución de Níger (1996), 8o. de la Constitución del Chad (1996). 
Este libro forma parte del acervo de la Biblioteca Juridica Virtual del Instituto de Investigaciones Juridicas de la UNAM http://www.juridicas.unam.mx

ciedad abierta del Estado constitucional constituyen contenidos fundantes, "soportan" funciones que se refieren a la sociedad civil.

\section{b. La evolución de la nueva etapa textual}

En la actual etapa textual del tipo del Estado constitucional, los artículos relativos a los símbolos del Estado pueden ser desentrañados con base en dos preguntas. Primera: ¿dónde se encuentran ubicados sistemáticamente dichos símbolos, por ejemplo, "ya” en el título preliminar? Segunda: ¿se encuentran en el contexto de cuáles otros temas constitucionales (últimamente, por ejemplo, en el contexto de las cláusulas relativas al Estado de derecho, de las garantías de los derechos fundamentales o de otros valores fundamentales - palabra clave: enriquecimiento normativo-)?

En lo particular: la Constitución de Francia (1958) ubica el idioma, la bandera, el himno y el "voto" en el título "De la soberanía" (artículo 2o.), ${ }^{38}$ con lo cual se toma en serio, en la sistemática del texto, la concepción clásica de los símbolos del Estado. También la Constitución de Irlanda (1937-1992) ubica la bandera y la lengua nacional en el capítulo sobre "El Estado" (artículos 7o. y 8o.). La Constitución de Italia (1948-1993) procede de manera diferente. En el apartado sobre los "Principios fundamentales" se encuentra también al final un artículo (12) sobre la bandera, después de que anteriormente se han abordado otros temas tan importantes como la protección de las minorías (artículo 6o.), la relación entre Iglesia y Estado (artículo 7o.) y se contiene una cláusula sobre el Estado de cultura (artículo 9o.). Algo del "espíritu" de la Constitución federal austriaca (1920-1994) se refleja en el modo en que el "Título Primero" se refiere al territorio, la capital federal, la lengua, la bandera y el escudo (artículos 3o., 5o., 8o. y 8o. a).

Las Constituciones de Portugal (1976-1992) y España (1978-1992) han sido concebidas y "cortadas" de modo distinto. Portugal incluye en los "Principios fundamentales" la norma sobre la estructura y los fines del Estado del artículo 2o.; luego se encuentra un artículo concentrado sobre las tareas del Estado en el artículo 9o., y sólo al final se define la bandera del país como "símbolo de la soberanía de la República, de la independencia, la unidad y la integridad de Portugal" (artículo 11) y se determina el himno nacional. Con ello queda en evidencia la vinculación con los valores funda-

38 También en forma similar los artículos 1o. de la Constitución de Benín (1990), lo. de la Constitución de Guinea (1991), 1o. de la Constitución de Níger (1992). También el Estatuto autonómico de Cantabria (citado en Bar Cendón, A. et al., Código Legislativo de Cantabria, 1994, pp. 17 y ss.), se ocupa en su artículo inicial de los símbolos, banderas e himnos del Estado. 
Este libro forma parte del acervo de la Biblioteca Juridica Virtual del Instituto de Investigaciones Juridicas de la UNAM

mentales. España incorpora en el "Título preliminar" la lengua, la bandera y la capital (artículos 3o. a 5o.) en el contexto de sus valores fundamentales (por ejemplo, la libertad, la igualdad y el pluralismo político (artículo 1o., inciso 1), así como del concepto de Estado de derecho (por ejemplo, artículo 9o.: supremacía de la Constitución, publicidad de las normas, etcétera).

Así, quedan presentadas los dos versiones típicas: por un lado, temas de rango simbólico concebidos a partir del Estado; por el otro, artículos sobre símbolos ubicados en el contexto de (otros) valores fundamentales, y, por tanto, concebidos normativamente. Las Constituciones recientes oscilan entre ambos tipos de regulación, lo cual se mostrará con base en más ejemplos:

La Constitución de Guatemala (1985) ubica el artículo relativo a los símbolos en el título III "El Estado". En esta parte hay disposiciones sobre el territorio, la lengua nacional y la ciudadanía (artículos 142, 147). En los artículos precedentes se abordaron el régimen de derecho, la obligación del Estado de procurar el bien común, los deberes del Estado (Preámbulo, artículos 1o., 2o.) y los derechos humanos, así como los derechos sociales fundamentales, junto con las tareas (ocasionalmente excesivas) del Estado (por ejemplo, artículos 102 y 119). ${ }^{39}$ La Constitución de Namibia ubica ya los "símbolos nacionales" en el artículo 2o., en el contexto del enriquecimiento sustantivo del concepto "República" (Article 1: "Principles of democracy, the rule of law and justice for all" ). Mientras que esto podría requerirse para la autoafirmación interna y externa, los países que todavía tienen que encontrar su identidad, al desprenderse, por ejemplo, de su época colonial o, como en Europa oriental, del marxismo-leninismo, pueden recurrir decididamente al potencial significativo que tienen las disposiciones relativas a los símbolos ubicados en un primer plano.

Así, la Constitución de Eslovenia (1991) aborda los temas del escudo, la bandera, el himno, la capital y la lengua en las "Disposiciones generales" (artículos 6o., 10, 11), no sin antes haber postulado los elementos del Estado constitucional, como el Estado social de derecho, también la democracia y la división de los poderes (artículos 1o. a 3o.). En adelante, procederemos de manera cronológica, de conformidad con la tesis del gran contexto de producción y recepción de los constituyentes contemporáneos. Así, la Constitución de Turkmenistán (1992) to trata a la bandera, los símbolos del Estado

39 La anterior Constitución del Perú (1979) relativiza el capítulo sobre el Estado, pero trata en él también los temas de la lengua oficial, la bandera (artículos 83 a 85), el escudo y el himno nacional como "símbolos de la patria".

40 La Constitución de Rusia (1993) trata los temas aquí discutidos apenas en el capítulo sobre la "estructura federativa". El territorio, la lengua oficial, la bandera, el himno así como la capital se tratan de una sola vez en el mismo contexto (artículos 67 a 70). 
Este libro forma parte del acervo de la Biblioteca Juridica Virtual del Instituto de Investigaciones Juridicas de la UNAM http://www.juridicas.unam.mx

y la capital al final del apartado sobre los "Fundamentos de la Constitución" (artículos 14 y 15), después de haber caracterizado suficientemente esta Constitución en sus elementos esenciales, como el Estado de derecho (Preámbulo), la supremacía de la Constitución (artículo 5o., inciso 2), la protección de la cultura y la naturaleza (artículo 10). La Constitución de Estonia (1992) ubica la lengua oficial y la bandera al final de las disposiciones generales (artículo 7o.), luego de que el Preámbulo y los artículos 1o. y 5 o. han fijado los valores fundamentales. La Constitución de Lituania (1992) también fija los temas correspondientes al final del capítulo inicial (artículo 14: lengua; artículo 15: bandera; artículo 16: himno nacional; artículo 17: capital). Con ello se convierte consecutivamente en texto una "cuadriga" de símbolos estatales como no podría hacerlo mejor la teoría constitucional. ${ }^{41}$

La Constitución de Ucrania (1996) se refiere al tema de los "state symbols" en el artículo 20, con el que se cierran los "principios generales" del primer capítulo. En éste se encuentran, de manera sumamente concentrada, los nuevos valores fundamentales, como los del artículo 3o., inciso 2 ("Individual rights and freedoms and the guarantee thereof determine the essence and aims of the activity of the state").

En Sudáfrica, en la Constitución por lo demás innovadora de la provincia de Kwazulu-Natal (1996), después de un sustancioso preámbulo (que se refiere, por ejemplo, a una "prosperous society for the present generation and posterity") y un buen artículo sobre valores fundamentales, se llega al capítulo sobre "Features of the Province", en el cual se tratan los "symbols", "territory", "language" (incisos 1 a 4 ). 42

${ }^{41}$ De manera similar los artículos 8o. a 10 de la Constitución de la República Eslovaca (1992) y 12 a 14 de la Constitución de Rumania (1992), la cual ha definido previamente (artículo 1o.) al Estado a través de los valores fundamentales como la justicia, la dignidad humana, el Estado de derecho. Ya las Constituciones de Croacia (1991), en sus artículos 11 a 13, y de Macedonia (1991), tratan los símbolos del Estado (artículo 5o.) en medio de los demás temas constitucionales como la democracia y el Estado social (artículo 1o.) y los valores fundamentales ( $c f r$ la lista en el artículo 8o.: entre otros, los derechos fundamentales, the rule of law, la economía de mercado libre, el humanismo, la protección del ambiente). Este artículo 8o. se lee casi como un manual sobre los valores fundamentales del Estado constitucional de hoy ("fundamental values of the constitutional order"). La lengua oficial, la capital y los símbolos estatales son regulados también en un texto y contexto similares en la Constitución de Azerbaiyán (artículos 21 a 23).

42 La Constitución de Uganda (1995) trata en el capítulo dos sobre "La República" los símbolos del Estado, la capital y la bandera (artículos 5o., 6o. y 8o.). De manera ejemplar procede el artículo 2o. inciso 4 de la Constitución de Sajonia (1992), relativo a la "capital, colores del Land, escudo", en la medida en que en la parte de los fundamentos concede a la minoría étnica de los sorbios en sus territorios el mismo derecho de portar sus "colores y escudos". 
Este libro forma parte del acervo de la Biblioteca Juridica Virtual del Instituto de Investigaciones Juridicas de la UNAM

En suma: los temas que la doctrina ha tratado tradicionalmente bajo el término de "símbolos del Estado" siguen siendo una preocupación importante del Estado constitucional, en vista tanto de la situación existente como desde la perspectiva de la teoría constitucional (deber ser). En la actual etapa evolutiva es posible observar significativas transformaciones de los contextos. Sólo muy pocos países se permiten iniciar su texto constitucional, a manera de redoble de tambor, con los "símbolos oficiales". La lengua, el territorio, la bandera, el himno y también la capital se trasladan hacia contextos diferenciados que los vinculan con los valores fundamentales del orden constitucional. Aquí encuentran su lugar, ya que justamente la Constitución del pluralismo requiere también contenidos fundantes, pero como comunidad en que el Estado existe "en razón del ser humano" (proyecto de Constitución alemana de Herrenchiemsee de 1948) y que no entiende los símbolos que unen al todo de la sociedad abierta "en y para sí" como parte del Estado, sino como elemento sustantivo del espacio público.

\section{6. "República"-"monarquía constitucional"}

\section{A. La nueva vida de la cláusula republicana: un ejemplo de procesos de crecimiento en la cultura constitucional}

El ejemplo del principio constitucional de la "República" (artículos 20, inciso 1, 28, inciso 2, de la LF) muestra con cuánta fuerza se encuentra inmerso el derecho constitucional en "procesos de crecimiento cultural", hasta qué punto los procesos de interpretación jurídica son dependientes, material y personalmente, de lo cultural, y no primariamente de lo jurídico, y de qué modo, "con el paso del tiempo", una disposición " jurídico-formal" poco tomada en cuenta adquiere (o recupera) vida, o bien es actualizada a partir del ambiente cultural, pero también se transforma, como parte de la (re)producción y recepción culturales.

La doctrina había desatendido la cláusula republicana desde la fundación de la República Federal de Alemania. Independientemente de varios intentos de reanimación a través de referencias a la "res publica" y la "salus publica", ${ }^{43}$ sigue predominando la definición puramente negativa tomada de

43 Hesse, K., Grundzüge des Verfassungsrechts der Bundesrepublik Deutschland, 20a. ed., 1995, pp. 56 y s., 1a. ed. 1967, pp. 50 y s.; Häberle, P., Öffentliches Interesse als juristisches Problem, 1970, pp. 708, 728. 
Este libro forma parte del acervo de la Biblioteca Juridica Virtual del Instituto de Investigaciones Juridicas de la UNAM http://www.juridicas.unam.mx

la teoría general del Estado: la república es la "no monarquía". ${ }^{44}$ En los años setenta se produjeron impulsos provenientes del ámbito político-cultural y literario, que se esforzaban por darle un nuevo y positivo significado y que pretendían "ocupar" el concepto; así, pensadores y poetas hicieron primeras contribuciones culturales. Recuérdense las "Cartas en defensa de la república" escritas por literatos, antes que por juristas (por ejemplo, H. Böll, N. Born, D. Kühn, H.-E. Nossack o M. Walser), o los "Discursos republicanos" de W. Jens (1979). Solamente después recordaron los juristas la plenitud de significados del concepto de república, ${ }^{45}$ trabajando así ex post, consciente o inconscientemente impulsados por la reproducción cultural. Por ello es tan importante el derecho constitucional de la cultura como cultivo de lo creativo. El concepto de "república" se entiende ahora en el sentido de "libertad", "democracia" y "responsabilidad". (Re)activada de tal modo, la "república" puede ser vivida por todos los intérpretes constitucionales de la sociedad abierta y puede ser realizada, jurídica y pedagógicamente en todas sus formas, como norma jurídica y objetivo de la educación.

Esta concepción material de la república ha superado ya una prueba en Europa: Pablo Picasso dispuso por testamento que su cuadro "Guernica" podría ser trasladado a España solamente hasta que se introdujera ahí la "República". Sin embargo, los albaceas y herederos de Picasso interpretaron correctamente la fórmula "cuando prevalezcan nuevamente condiciones de democracia y libertad" en el sentido de que tal también podría ocurrir en una monarquía parlamentaria, como es la España actual. Ahora sobre su contraparte "clásica", la monarquía.

\section{B. La "monarquía constitucional"}

Los siguientes renglones se refieren a un objeto que ha sido desatendido hasta ahora:46 los "residuos" de monarquía, que se encuentran, en los tér-

44 Véase, por ejemplo, Jellinek, G., Allgemeine Staatslehre, 5a. reimp. de la 3a. ed. de 1928, 1959, p. 711. Las 74 columnas del índice analítico de la Allgemeine Staatslehre de Herbert Krüger, 2a. ed., 1966 (1028 pp.) no conocen el término "república".

45 Cfr. por ejemplo Löw, K., "Was bedeutet 'Republik' in der Bezeichnung 'Bundesrepublik Deutschland', DÖV 1979, pp. 819 y ss.; J. Isensee, "Republik Sinnpotential eines Begriffs", en $7 Z 1981$, pp. 1 y ss.

46 De la bibliografía: Scheuner, U., Das Amt des Bundespräsidenten als Aufgabe verfassungsrechtlicher Gestaltung, 1966; Kaltefleiter, W., Die Funktionen des Staatsoberhaupts in der parlamentarischen Demokratie, 1979; Schlaich, K., "Der Status des Bundespräsidenten”, HdBStR, vol. II, 1987, pp. 529 y ss. (2a. ed., 1996). Sobre el presidente italiano, véase Luciani, M., Volpi, M. (a cura di), Il Presidente della Repubblica, 1997. 
Este libro forma parte del acervo de la Biblioteca Juridica Virtual del Instituto de Investigaciones Juridicas de la UNAM

minos y en el fondo, en no pocos Estados constitucionales europeos, a saber, en las Constituciones, no escrita de Gran Bretaña, y escritas de Noruega (1814), Bélgica (1831), Luxemburgo (1868), Liechtenstein (1921), Dinamarca (1953), Mónaco (1962), Suecia (1975), España (1978) y los Países Bajos (1983). En la teoría clásica del Estado se define a la república de manera tan formal como abreviada en cuanto "no monarquía" (G. Jellinek) y un número de Estados constitucionales en Europa son "repúblicas" en la realidad. Pero, ¿de qué manera se incorporan como tipo las monarquías "supervivientes" en el cuadro general del Estado constitucional europeo? ¿Cuál es la contribución específica de éstas en el proceso de unificación de Europa? ¿Son un elemento vivo de la "cultura jurídica europea" o un mero "adorno" puramente formal e histórico? ¿Constituyen una variante "superada", "superviviente", del tipo del Estado constitucional o hacen una contribución auténtica en la evolución de sus etapas textuales hasta la actualidad? Planteada la pregunta en otros términos: ¿son las monarquías solamente "malas" repúblicas? ¿O significan más que un "recordatorio" a la doctrina de las formas mixtas de Estado?

Lo que es imprescindible, en el concierto de los Estados constitucionales europeos cada vez más unidos, es preguntar por lo que une o separa al tercio aproximado que constituyen sus monarquías, y de qué manera debe tratarlas una teoría constitucional elaborada a nivel europeo:

Una mirada a la Constitución, correspondiente a una etapa textual muy antigua, del principado de Liechtenstein, por un lado, ${ }^{47}$ y a la muy moderna Constitución de los Países Bajos (1983), por el otro, revela una amplia banda de Estados constitucionales con elementos monárquicos en la Europa de 1997.

a) Es posible obtener algunos conocimientos teóricos a partir del material textual preparado sistemáticamente en otra parte, ${ }^{48} \mathrm{O}$ al menos plantear cuestiones básicas: ¿es la "monarquía parlamentaria" sólo un divertimento histórico, una supervivencia meramente aleatoria de antiguos periodos de la evolución del Estado constitucional como tipo? ¿Constituye la "república" una etapa evolutiva "superior" o solamente una modalidad más "mala"? ¿Es consecuencia necesaria de la democracia como "gobierno temporal", o bien, le proporciona al Estado constitucional elementos de una forma estatal "mixta", equivalentes, por ejemplo, a los que presentan modernamente

47 Entre la bibliografía sobre Liechtenstein, Kühne, J., "Zur Struktur des Liechtensteinischen Rechts", FöR 38 (1989), pp. 379 y ss.

${ }_{48}$ Cfr. al respecto Häberle, P., Verfassungslehre als Kulturwissenschaft, 2a. ed., 1998, pp. 1004 y ss. 
Este libro forma parte del acervo de la Biblioteca Juridica Virtual del Instituto de Investigaciones Juridicas de la UNAM

los Estados constitucionales con una jurisdicción constitucional fuerte (piénsese en el Tribunal Constitucional Federal alemán)? ¿Es la república solamente "sustituta" o "heredera" de la monarquía, así como en la República de Weimar se decía que O. von Hindenburg, presidente del Reich, era un "emperador sustituto"? La monarquía transmite quizá valores simbólicos que no puede satisfacer ni producir un presidente que cuando mucho puede ser reelecto una vez: la labor personal de integración del rey de Bélgica, Balduino I (que no se conoció apenas hasta su temprana muerte en 1993) o del rey de España, Juan Carlos I, el cual empleó exitosamente su reserva de legitimidad contra el intento de golpe de Estado de 1981, salvando así a la democracia. ¿No permanece la "res publica" como tal también en la monarquía parlamentaria, porque ésta no priva a la comunidad ni de la libertad pública ni de la salus publica?

b) En vista del hecho de que en Europa existen diez Estados constitucionales en cuya " cúspide" se encuentra un monarca y que prevén la sucesión dinástica del trono, una teoría de la Constitución que trabaje de manera comparativa debe ocuparse de estas estructuras monárquicas. ¿Es la monarquía hereditaria solamente "otra forma" del presidente republicano, que es electo o reelecto por periodos limitados? Si se examina esto a partir de las competencias previstas constitucionalmente, mucho habla a favor de que un presidente podría ocupar sin más el lugar del monarca, príncipe o duque, si bien respecto de la Gran Bretaña, en vista de las "prerrogativas reales", podría ser válida otra cosa. Se puede decir esto de otra manera: con el tiempo, el presidente republicano ha ido ocupando tendencialmente las competencias cada vez más débiles del monarca. Desde la perspectiva de la división de poderes, la institución del monarca o sus manifestaciones análogas, como el "principado" (en Liechtenstein), se presenta como uno entre varios "poderes" que están integrados en la sutil estructura de funciones del Estado constitucional. Pero no podemos quedarnos en este punto de vista más bien formal, ya que la monarquía hereditaria cumple funciones de representación e integración muy específicas. Después de que casi todos los Estados constitucionales europeos, con excepción de Liechtenstein, han abandonado el "principio monárquico", y de que han consagrado de manera más o menos expresa en los textos su contraparte, la soberanía del pueblo, se plantea la cuestión del modo en que se representa e integra al pueblo. Aquí es donde puede hacer mucho el monarca. Ciertamente también el presidente puede satisfacer la necesidad de integración y representación, piénsese en los presidentes de los Estados Unidos, de Francia o incluso de Austria, pero hay bastantes indicios de que el valor simbólico de una casa real o de una familia ducal es mayor simplemente por su duración. 
Este libro forma parte del acervo de la Biblioteca Juridica Virtual del Instituto de Investigaciones Juridicas de la UNAM

c) En los textos constitucionales se muestra cuán conscientes están los constituyentes del valor de representación e integración del elemento monárquico, así como de su fuerza simbólica, en el Estado constitucional respectivo. ${ }^{49} \mathrm{Y}$ los pasajes textuales relativos a la monarquía en las Constituciones escritas pueden ser atribuidos sin más a aquel grupo de artículos que penetra hasta las capas irracionales profundas de un pueblo: análogamente a las normas constitucionales sobre los días feriados, sobre la capital, la lengua, las fórmulas de juramento o protesta. ${ }^{50}$ Incluso los preámbulos que "enmarcan" y que de manera específica fundamentan a la Constitución, pertenecen a esta categoría. ${ }^{51}$ En suma: también en los Estados constitucionales las monarquías penetran hasta la capa profunda de las "fuentes irracionales del consenso" (K. Eichenberger) del Estado. El Estado constitucional depende en buena medida de ellas, y en ellas tiene, literalmente, que "enraizar", en tanto y en la medida que en lo demás dependa de la racionalidad. Como ciudadano, el ser humano tiene sus lados racionales y emocionales. El momento "litúrgico", para no decir "ritual", puede ser satisfecho de modo específico en una res publica monárquica. Ciertamente, las monarquías modernas (parlamentarias) asumen también la función de una "empresa de servicios", como se sabe por las revelaciones sobre la casa reinante española. Pero precisamente la moderna monarquía de España demuestra la manera tan capaz y efectiva con la que una figura (el rey Juan Carlos I) puede "representar" y, literalmente, "encarnar" a la nación en los eventos culturales, las olimpiadas, las exposiciones universales (como la de 1992), pero también en lo pequeño, en las regiones y las provincias.

Ciertamente deben recordarse los "costos" de las estructuras monárquicas en el Estado constitucional, y con ello no nos referimos a los costos financieros ${ }^{52}$ sino a otra cosa: por ejemplo, al surgimiento de elites privilegiadas e improductivas, de entramados de relaciones e influencias que no

49 Cfr. el artículo 56, inciso 1, de la Constitución española: el Rey como "símbolo de su unidad y permanencia" (del Estado).

50 Al respecto Häberle, P., Rechtsvergleichung im Kraftfeld des Verfassungssaates, 1992, pp. 199 y ss., 297 y ss., id., Feiertagsgarantien als kulturelle Identitätselemente des Verfassungsstaates, 1987.

51 Véase al respecto mi lección inaugural en la Universidad de Bayreuth: "Präambeln im Text und Kontext von Verfassungen” (1982), Rechtsvergleichung..., cit., pp. 176 y ss.

52 Los cuales se encuentran previstos en la forma de una "lista civil" ( $c f r$. el artículo 77 de la anterior Constitución de Bélgica, el artículo 43 de la de Luxemburgo, el 10 de la Constitución de Dinamarca, el 40 de la Constitución de los Países Bajos, el artículo 40 de la Constitución de Mónaco). En la Constitución de Liechtenstein no se encuentra la correspondiente regulación. El príncipe "cubre los costos derivados de su función de su patrimonio privado", lo cual hizo notar expresamente el príncipe Hans Adam II en su discurso de acceso al trono en otoño de 1992. 
Este libro forma parte del acervo de la Biblioteca Juridica Virtual del Instituto de Investigaciones Juridicas de la UNAM http://www.juridicas.unam.mx

generan responsabilidad pública (palabra clave: “cortesanos"). Si bien esto también existe en las sedes presidenciales, la duración ilimitada de tales "subestructuras" crea, en las "no repúblicas", peligros de tipo propio. El "gobierno temporal" sigue siendo un aspecto irrenunciable del Estado constitucional, y las monarquías parlamentarias ejercen también un pedazo de "gobierno", sin importar que tan "meramente representativas" sean.

Es en esta medida que subsiste un problema residual insoluble en todos los Estados constitucionales europeos que mantienen elementos monárquicos. Sin embargo, es posible recordar, con D. Sternberger, que "no todo el poder del Estado dimana del pueblo"; ténganse presentes ciertos elementos aristocráticos que se encuentran en países que poseen una poderosa jurisdicción constitucional o que cuentan con "senados", a fin de poder encuadrar las estructuras y funciones monárquicas de hoy en el conjunto del tipo del "Estado constitucional"; 53 no obstante, las tensiones y contradicciones subsisten. Por lo tanto, estas reflexiones no deben considerarse como contribución a una propia "teoría constitucional de la monarquía", sino como intento de explicar las estructuras monárquicas existentes en diversos Estados constitucionales de Europa, de encuadrarlas en el sistema de coordenadas teóricas del tipo del Estado constitucional y de mostrarlas como variante posible, que se deja "ver" y que no constituye una mera "degeneración" o un modelo anacrónico o una supervivencia ridícula de una época pasada. Dependiendo de la historia, la concepción que tenga de sí mismo un país y de su cultura, las monarquías (parlamentarias) se presentan como variante legítima y alternativa a la "república". ${ }^{54}$ No constituyen una forma contraria al tipo del Estado constitucional, a pesar de que frecuentemente lo hayan sido en la historia, y no obstante la intensidad con la que tuvieron que "constitucionalizarse" en el transcurso del tiempo ("monarquías constitucionales").55

53 Sobre la "posición del monarca en la Constitución moderna": Schmitt, C., Verfassungslehre (1928), pp. 288 y ss. (hay trad.: Teoría de la Constitución) quien encuentra en la historia comparada de las Constituciones y los Estados, términos para caracterizar al monarca como "representante" (pp. 205, 211), como "de Dios" (p. 282), como "padre" (p. 293), como "jefe del Ejecutivo" (p. 286), como "pouvoir neutre" (p. 287), como "sujeto del poder constituyente" (pp. 80 y s.). Loewenstein, K., Verfassungslehre, 2a. ed. 1969, p. 58, nota 9 (hay trad.: Teoría de la Constitución, Barcelona, 1965), le atribuye "a la monarquía todavía considerable importancia el día de hoy".

54 Resulta notable la opinión de Loewenstein, K., Staatsrecht und Staatspraxis von Grossbritannien, vol. I, 1967, p. 530, para quien las monarquías, como forma de Estado, parecen tanto más sólidas (excepción: Grecia) en los otros países de Europa occidental, en los cuales "ha podido resistir el tormentoso impulso hacia la republicanización".

55 Sobre el constitucionalismo en Alemania: Huber, E. R., Deutsche Verfassungsgeschichte seit 1789, vol. I, 2a. ed., 1967, pp. 652 y ss.; Stolleis, M., Geschichte des öffentlichen Rechts in Deutsch- 
Este libro forma parte del acervo de la Biblioteca Juridica Virtual del Instituto de Investigaciones Juridicas de la UNAM

d) En general, resulta oportuno despedirse del concepto de la "monarquía constitucional", pues se encuentra históricamente lastrado y ya superado en la actualidad, pues recuerda al Estado monárquico "original" que después fue constitucionalmente limitado. Actualmente sólo existen Estados constituidos. El lugar de la "monarquía constitucional" lo ha ocupado, en la evolución constitucional de Europa, el Estado constitucional monárquico, como posibilidad dentro del tipo del Estado constitucional. En el Estado constitucional, una monarquía prevista constitucionalmente es uno de los "órganos constitucionales" más allá de una "soberanía" propia de la forma que sea. ${ }^{56}$ Liechtenstein constituye la excepción atípica pues este país está todavía por sufrir una "revolución retardada" (mejor: una evolución), si no es que ya se ha iniciado con su incorporación a la Convención Europea de Derechos Humanos y a la Conferencia (hoy Organización) sobre Seguridad y Cooperación Europea. El concepto y la materia de la "soberanía del príncipe" han sido desprendidos de la soberanía popular, en su texto o contenido, también en los Estados constitucionales monárquicos (así, de manera expresa, en España). Hoy incluso hay que preguntarse si la "soberanía del pueblo" ha sido superada en el ámbito estatal interno, ya que la dignidad humana de los ciudadanos es una premisa antropológico-cultural de la democracia. ${ }^{57}$

El concepto de "Estado constitucional monárquico" describe solamente el modelo básico. Como lo demuestra el análisis de los textos, existen diversas variantes sobre la posición, competencias y funciones del monarca; téngase presente el rango que hay entre Bélgica y España, pasando por Dinamarca y Suecia. Cada país puede configurar "su” monarquía en el derecho y la realidad constitucionales, con sus formas y colores propios: así, con vistas a Bélgica se ha acuñado la afortunada imagen de la "monarquía federativa" (R. Senelle), ${ }^{58}$ la cual remite a la tarea y la contribución específicas del rey belga (Balduino I) en el surgimiento y conservación del Estado federal en Bélgica (función de unión entre flamencos y valones), por la que

land, vol. 2, 1992, pp. 103 y ss.

56 Más bien retrospectivas resultan las palabras del presidente de la Cámara de representantes belga, C.-F. Nothomb, después de la entronización del nuevo rey, Alberto II (1993): "Majestad... de este modo se ha sellado la unión entre el rey y la nación, y se ha confirmado el pacto constitucional entre el país y la dinastía" (citado en el Nordbayerischer Kurier del 10 de agosto de 1993, p. 3). Un vocero de palacio negó que hubiera sido una "coronación" con las siguientes palabras: "Una corona es un símbolo de tiempos antiguos y no es adecuada para una monarquía relativamente joven" (ibidem).

57 Véase al respecto Häberle, P., "Die Menschenwürde als Grundlage der staatlichen Gemeinschaft”, HdbStR, vol. I, 1987, pp. 815 (846 y ss.).

58 Cfr. FöR 36, 1987, pp. 121, 133 y ss. 
Este libro forma parte del acervo de la Biblioteca Juridica Virtual del Instituto de Investigaciones Juridicas de la UNAM http://www.juridicas.unam.mx

aquí resultaría insuficiente el conocido concepto del monarca como "pouvoir neutre". ${ }^{59}$ Otros Estados constitucionales monárquicos, como el sueco, pueden caracterizarse como puramente "representativos", ya que no es posible ninguna participación activa del monarca en el "gobierno supremo del Estado". Al igual que con los presidentes,${ }^{60}$ en el ejercicio de las funciones constitucionales mucho depende de la persona del monarca y de su autoridad.

e) Pocas cosas encuentran sus raíces en la historia de un país como la monarquía, por lo que resulta casi imposible fundarlas en el foro de la obra constitucional de un constituyente concreto y mucho menos en nuestros días. España constituye una excepción, porque ahí, a partir de 1975, la monarquía se convirtió en pilar de transición entre el sistema autocrático de Franco y un Estado constitucional; afortunadamente ha permanecido como tal, y fue posible fundarla en los derechos al trono de una dinastía. Sin embargo, puede recordarse también que en Italia se suprimió a la casa reinante después de la segunda guerra mundial (1946) y que Grecia optó por la república en un plebiscito (1974). En Liechtenstein se vive una crisis constitucional desde 1992, que puede poner en cuestión a la casa reinante misma; en todo caso, resulta improbable que Liechtenstein quiera y pueda vivir por tiempo indefinido bajo "dos soberanos" (príncipe y pueblo representado en el parlamento). En general, resulta difícil esperar que un Estado constitucional quiera regresar a la "forma de Estado" de la monarquía parlamentaria. Y esto resulta cierto para Grecia, Rumanía, Albania, Serbia y Bulgaria. ${ }^{61}$

Sin embargo, la monarquía podría tener oportunidades futuras con vistas al proceso de unificación europea. ¿Necesita la Unión Europea una cúspide monárquica? ¿Podría ser la monarquía uno de los temas de la "Constitución de Europa” en formación? En mi opinión, la única respuesta posible es: ¡no! Si bien la teoría constitucional tiene que pensar también en la di-

59 Véase al respecto Kimminich, O., op. cit., VVDStRL, vol. 25, 1967, pp. 2 (38 y ss), así como Pernthaler, P., ibidem, pp. 95 (146 y ss.).

60 Véase al respecto Hesse, K., Grundzüge des Verfassungsrechts der Bundesrepublik Deutschland, 20a. ed., 1995, p. 275.

${ }_{61}$ La actuación ejemplar del "buen rey" y "buen ser humano" Balduino I tuvo consecuencias políticas poco antes de su muerte: el ex rey griego Constantino dijo (según el Nordbayerischer Kurier del 10 de agosto de 1993, p. 3): "Si el pueblo griego desea tener una monarquía constitucional y me desea para tal fin, estoy a su disposición". La fuerza unificadora de Balduino podría ser también una lección para algunos nacionalismos separatistas en Europa. El nuevo rey belga, Alberto II, en su discurso de entronización, tomó como punto de partida el último discurso de Balduino y habló de la tolerancia y el espíritu ciudadano, con el cual deberían acercarse los flamencos y los valones (Frankfurter Allgemeine Zeitung del 10 de agosto de 1993, p. 5). 
Este libro forma parte del acervo de la Biblioteca Juridica Virtual del Instituto de Investigaciones Juridicas de la UNAM

mensión de la "política científica de las existencias", por lo que la pregunta planteada es legítima, un examen más cuidadoso habla totalmente en contra de la idea "sensacional", que con gusto se discute en algunos medios, de una "monarquía europea". Las monarquías solamente pueden surgir de las profundidades de la historia de los diversos pueblos, por lo que no es posible crearlas de un día para otro. No obstante lo queridas que puedan ser las casas reinantes en los Estados constitucionales europeos mencionados, ninguna podría satisfacer las funciones de integración y representación respecto de "toda Europa". Tampoco ninguna asamblea constituyente europea tendría poder suficiente para convertir a alguna de las casas existentes en "casa reinante europea". En un sentido profundo, la "casa europea" debe constituirse en forma republicana. En el "concierto europeo" las diversas monarquías de algunas casas y países se consideran como un bienvenido toque de color y como prueba de la diversidad de las culturas constitucionales nacionales, pero en el plano de Europa debería establecerse, en la medida en que fuera necesaria, una representación republicana. En primer plano subsiste la supresión del muy lamentado déficit democrático y esto debe remediarse en el foro del Parlamento Europeo y por el "espacio público" europeo. El presidente del Parlamento Europeo debería adquirir las funciones de integración y representación que requiere actualmente. La "Constitución de Europa" debería ser, formal y materialmente, republicana. 
Este libro forma parte del acervo de la Biblioteca Juridica Virtual del Instituto de Investigaciones Juridicas de la UNAM

\section{CAPÍTULO SEGUNDO. LA EVOLUCIÓN HISTÓRICA. LA DIMENSIÓN DEL TIEMPO}

\section{GRANDES FECHAS Y GRANDES PERSONAJES}

Entendido como tipo, en un nivel medio de abstracción, y tangible concretamente en sus variantes nacionales, incluidos los países en desarrollo y los micro Estados, el Estado constitucional es, respectivamente, una suma parcial de filosofias políticas, ${ }^{62}$ textos de los clásicos, programas de partidos políticos, saber derivado de la experiencia, incluso de las "heridas", de numerosas generaciones, así como de utopías concretas; es también una suma parcial de procesos revolucionarios y evolutivos. Esto se hace palpable en las grandes fechas, como las de los años de 1776 (Virginia Bill of Rights), 1787 (Federalist Papers), 1789 (Declaración francesa de los Derechos del Hombre y el Ciudadano), 1848 (Constitución federal suiza), 1849 (Convención constituyente alemana en la Iglesia de San Pablo, en Francfort), 1947 (Constitución italiana), 1948 (Declaración Universal de los Derechos del Hombre de las Naciones Unidas), 1968 y siguientes (Constituciones cantonales suizas), 1976 (Constitución de Portugal), y "1989". Se hace visible también en los textos de los clásicos; por ejemplo, en el de Aristóteles sobre la relación entre igualdad y justicia, de Montesquieu sobre la división de poderes (1748), de I. Kant sobre la dignidad humana, de J. Rawls sobre la justicia (1971), de H. Jonas sobre el "principio responsabilidad" (1964). Estos textos de los clásicos, entendidos como esencia del valor y el éxito, ${ }^{63}$ transportan el desarrollo del Estado constitucional. No obstante lo abierto que pueda estar su futuro, en retrospectiva es posible aplicarle el modelo general de la evolución, a pesar de los déficits conocidos, los peligros permanentes, también los dolorosos retrocesos y debilidades. ${ }^{64}$

62 El volumen editado por Brugger, W., Legitimation des GG aus der Sicht von Rechtsphilosophie und Gesellschaftstheorie, 1996, aborda algunos aspectos relativos a la LF alemana. Véase al respecto mi reseña en $A \ddot{o} R$, vol. 123, 1998, pp. 476 y ss.

$63 \mathrm{Al}$ respecto véase Häberle, P., Klassikertexte im Verfassungsleben, 1981.

64 Sobre el "Estado constitucional desde la perspectiva evolutiva", véase Häberle, P., "Der Verfassungsstaat in entwicklungsgeschichtlicher Sicht", FS K. Stern, 1996, pp. 143 y ss. 
Este libro forma parte del acervo de la Biblioteca Juridica Virtual del Instituto de Investigaciones Juridicas de la UNAM

II. LOS TEXTOS DE LOS CLÁSICOS EN LA VIDA CONSTITUCIONAL. SIETE TESIS INICIALES DESDE LA PERSPECTIVA DE LA CIENCIA CULTURAL

En varias ocasiones hemos hecho ya referencia puntual a los "textos de los clásicos", y algunos de dichos clásicos fueron citados como tales. En este apartado formularemos siete tesis iniciales:

1. No es casualidad que los textos de los clásicos, como son los escritos de J. Locke y Montesquieu, los de Sieyès e I. Kant, incluso los de los "contra clásicos" como T. Hobbes, J. J. Rousseau o K. Marx, influyan "fácticamente" en el proceso de formación, y más tarde de interpretación, de las Constituciones del Estado constitucional; estos textos tienen, pues, una validez de tipo normativo, legítima aunque limitada. Su validez en el contexto de las Constituciones es culturalmente específica y debe desentrañarse con auxilio de los métodos de trabajo de la ciencia cultural.

2. Mientras que los grandes nombres y los grandes textos se citan constantemente, con excesiva naturalidad e incluso "ingenuidad", hasta donde puede verse no se ha planteado hasta ahora la cuestión de qué es lo que verdaderamente legitima su utilización en la vida constitucional: desde el proceso político, por ejemplo, un debate en el Parlamento federal sobre la noción "correcta" de la Constitución o la democracia, hasta la sentencia del Tribunal Constitucional Federal; desde un discurso solemne del presidente federal hasta las resoluciones de los congresos de los partidos. Solamente cuando tengamos presentes la amplitud y la profundidad de la materia y el proceso de la "vida constitucional", en el sentido de la amplitud del pluralismo de los intérpretes constitucionales y la profundidad de una cultura, será posible distinguir la multiplicidad de formas en que se manifiestan los (textos de los) clásicos jurídicos. A la vida constitucional pertenecen las personas y las instituciones, detrás de las cuales se encuentran, naturalmente, siempre otras personas.

3. Los textos de los clásicos son "textos constitucionales" en sentido amplio, es decir, actúan como "contexto escrito" en relación con un texto constitucional que requiere ser interpretado, del mismo modo como se requieren otros medios auxiliares, en tanto métodos de la interpretación, concepciones previas (Vorverständnisse), teorías adicionales, otros contextos. En particular, los textos de los clásicos son fundadores de paradigmas en el sentido que da a este término T. Kuhn, ${ }^{65}$ ya que designan los problemas y

Un texto clásico en esta perspectiva es el de Maine, H. S., Ancient Law, 1861 (nueva traducción 1997).

65 Kuhn, T., La estructura de las revoluciones cientificas (1962). 
Este libro forma parte del acervo de la Biblioteca Juridica Virtual del Instituto de Investigaciones Juridicas de la UNAM

proporcionan aspectos parciales para su solución. ${ }^{66}$ Una directriz sustantiva, como la división de poderes de Montesquieu actúa a través de su ampliación y renovación (por ejemplo, gracias a W. Kägi). ${ }^{67}$ Los clásicos auxilian al "intérprete constitucional en sentido amplio", es decir, al ciudadano, en su trato con la Constitución. Toda Constitución en un Estado constitucional tiene sus textos clásicos indispensables. La imagen del contrato social o de la "mesa de negociación" forman parte de ellos.

4. En vista de que no pocas veces los textos de los clásicos absolutizan verdades parciales, y en virtud de que las Constituciones tienen el carácter de compromiso y de que se transforman, resulta necesario preguntar constantemente por las posiciones "alternativas" a los clásicos, o por su reinterpretación, antes de intentar cualquier solución concreta a un problema. ¡Los clásicos tienen sus contraclásicos!

5. En la medida apuntada, los textos de los clásicos enriquecen la vida constitucional y constituyen un "concepto en crecimiento" (J. Kuhn);68 soportan y modifican ciertos institutos del derecho positivo y sus dogmáticas altamente ligadas a la época. Los textos de los clásicos permiten la racionalización de la vida constitucional, en la medida en que se mencionan posibles peligros.

6. Los textos de los clásicos son un modo y una figura especialmente cercanos al ciudadano, por la cual éste puede conocer "su" Constitución. Una frase de Montesquieu o de J. Locke, o bien de Friedrich Schiller, sobre la división de poderes o la libertad, o de G. E. Lessing sobre la tolerancia, comunican mejor al ciudadano su Constitución y le dan un fundamento más profundo que el que pueda proporcionarle un manual especializado, por importante que sea. Los textos de los clásicos convierten a las Constituciones en herencia cultural y en tarea para todos nosotros, en "posesión viva". Son parte de nuestra imagen cultural y se almacenan en la "memoria colectiva" de nuestro pueblo. En la sociedad abierta de los intérpretes constitucionales determinamos en última instancia todos nosotros, incluso en la sucesión de las generaciones, quién es un clásico o se convierte en tal. Nosotros somos el sujeto de referencia de los clásicos.

66 La imagen de la "mesa de negociación"se remite quizá a la instrucción pastoral Communio et Progressio de 1971 del papa Paulo VI, la "Magna Charta"de la ética, la educación y la política eclesiásticas de los medios de comunicación. La mesa de negociación hizo historia universal del Estado constitucional en la Polonia de 1989. Desde entonces ha habido nuevas "mesas de negociación", la más reciente en Albania.

67 Kägi, W., Von der klassischen Dreiteilung zur heutigen Gewaltenteilung (1961).

68 Lo clásico como concepto histórico en Jaeger, W. (ed.), Das Problem des Klassischen und die Antike, 1931, p. 112. 
Este libro forma parte del acervo de la Biblioteca Juridica Virtual del Instituto de Investigaciones Juridicas de la UNAM

7. Los textos de los clásicos, es decir, las obras políticas, jurídicas y constitucionales de los grandes escritores, son una forma de comunicación de la experiencia y, fundadas antropológicamente, se encuentran también abiertas en la dimensión temporal. La calidad de clásico no es exclusivamente retrospectiva, sino que tiene también futuro. No existe una sociedad cerrada de los clásicos en el Estado constitucional.

\section{EL PENSAMIENTO DE LAS POSIBILIDADES GOMO PARTE DE UNA TRIADA (JUNTO CON EL PENSAMIENTO DE LA REALIDAD Y LAS NEGESIDADES)}

\section{Introducción, problemática, tesis inicial}

El pensamiento y la acción constitucionales están obligados a analizarse a sí mismos una y otra vez, a fin de investigar sus posibilidades y sus límites, las oportunidades y peligros que existen para su "causa", que es el orden fundamental de libertad y democracia en consonancia con la dignidad humana. A ello se dirigen las siguientes reflexiones. El pensamiento de las posibilidades (Möglichkeitsdenken), situado en el marco de la realidad y las necesidades, debe ser examinado de manera más central para la teoría constitucional de lo que ha sido hasta ahora, a saber, con base en ejemplos sacados de la legislación, la administración, la jurisprudencia y la política, así como en otros provenientes de la dogmática o el periodismo, es decir, ejemplos tomados de la vida pública y de la realidad de una Constitución viva. El pensamiento de las posibilidades podría ser relativamente desconocido como problema de la teoría constitucional. Por el contrario, el pensamiento de la realidad es casi popular (por ejemplo, mediante referencias al "imperativo de los hechos"). A H. Lenz debemos el concepto del "hombre de la realidad". El pensamiento de las necesidades adopta una posición intermedia (que se encuentra presente en la "prohibición del exceso" ["Übermaßverbot"] y que hoy se vuelve especialmente relevante para la cuestión de cuáles sean las tareas "necesarias" del Estado, claro está que sujetas a la reserva de lo posible). Las tres formas de pensamiento son indispensables en el Estado constitucional. 
Este libro forma parte del acervo de la Biblioteca Juridica Virtual del Instituto de Investigaciones Juridicas de la UNAM http://www.juridicas.unam.mx

\section{Del pensamiento de las posibilidades (pensamiento pluralista de las alternativas) en lo particular}

\section{A. Explicación del concepto}

El pensamiento de las posibilidades es el pensamiento de y en las alternativas. Sin embargo, no se le denomina "pensamiento de las alternativas" porque es frecuente asociarlo con el razonamiento en términos de "esto o lo otro", ${ }^{69}$ que se apoya en posibilidades que se excluyen mutuamente. Por el contrario, el pensamiento de las posibilidades debe estar tan abierto hacia terceras y cuartas posibilidades como hacia los compromisos. Si bien es posible llevarlo retóricamente a una fórmula de "esto o lo otro" "EntwederOder"), no hay que absolutizarlo al grado de que no admita ninguna alternativa, ya que el pensamiento de las posibilidades es un razonamiento inquisitivo. Es la búsqueda de lo que es también posible, preguntando: “¿qué podría ocupar el lugar de lo que es?”. En la res publica del Estado constitucional hay un ethos jurídico específico del pensamiento mediante alternativas, de la búsqueda de alternativas, que incluye la mirada hacia la realidad y las necesidades, sin dejarse gobernar por ellas. El pensamiento de las posibilidades se hace tanto más necesario cuanto más elabore la ciencia del derecho constitucional conceptos fundamentales como espacio público, tolerancia, pluralismo, derechos de las minorías, representación de intereses no organizados, derechos fundamentales sociales y culturales.

El pensamiento de las posibilidades como razonamiento de las alternativas se hace especialmente evidente a partir del racionalismo crítico. ${ }^{70}$ Podemos encontrar además elementos más recientes del pensamiento clásico de las posibilidades en R. Musili1 y E. Bloch. Esto lo demuestra no sólo el temprano concepto de "pensamiento fabulador" en Bloch (1930), sino

69 Sobre los diversos significados del concepto de alternativa, cfr. Rödig, J., Die Denkform der Alternative in der Furisprudenz, 1969, pp. 99 y ss.

70 Enfatiza que siempre vale la pena "buscar alternativas, otras teorías que posiblemente sean mejores..." (subrayados en el original): Albert, H., Traktat über kritische Vernunft, 1968, p. 49. La "dogmatización" revela su "función protectora" a través de la "difamación de las alternativas", ibidem, p. 97.

71 Musil, R., Der Mann ohne Eigenschaften, 1970-1972, p. 16: "Empero si existe el sentido de la realidad, y ninguno dudará que tiene su derecho a existir, entonces debe haber algo que podamos llamar sentido de las posibilidades... Así podría definirse el sentido de las posibilidades como la capacidad de pensar todo aquello que también podría ser, y de no dar a lo que existe mayor importancia que a lo que no es". Sobre la historia del concepto de posibilidad, véase Hartmann, N., Möglichkeit und Wirklichkeit, 1937, 2a. ed., 1949. 
Este libro forma parte del acervo de la Biblioteca Juridica Virtual del Instituto de Investigaciones Juridicas de la UNAM

sobre todo su "principio esperanza", bajo el apartado "hacer realidad la posibilidad". ${ }^{72}$ En la teoría de sistemas se define la contingencia, en el sentido de la tradición de la teoría modal, como "posibilidad no necesaria". ${ }^{73} \mathrm{El}$ concepto de contingencia de N. Luhmann representa una clara referencia al pensamiento de las posibilidades. O. von Bismarck se refería a la relevancia de este pensamiento en su frase sobre la política como "arte de lo posible" (ipero también la política se refiere a lo necesario!).

\section{B. Inventario}

En un orden jurídico pluralista y abierto de la libertad existe un amplio espectro de formas diversas que han sido institucionalizadas jurídicamente como alternativas. Estas formas abren espacio a las decisiones, a la libertad individual y a la razón general. Presuponen, en lo posible, comunicación sin violencia, en el sentido de J. Habermas.

a) El pensamiento de las posibilidades no se introduce en la Constitución desde afuera o desde arriba. La noción de Constitución de U. Scheuner como "proyecto" ${ }_{74}$ apunta hacia el pensamiento de las posibilidades. La multiplicidad de las distintas Constituciones posibles es lo que confiere su importancia a disciplinas como la teoría y la comparación constitucionales. Esto significa que el pensamiento mediante alternativas que aquí se propone no está solamente orientado hacia el futuro, pues dejar fuera las posibilidades y experiencias de la historia constitucional estrecharía la visión. Precisamente en el "tesoro de la historia" hay material para la solución de problemas que ha sido frecuentemente olvidado y desplazado por la posibilidad hecha realidad. Pero hay también renacimiento y regeneración de las disposiciones constitucionales. Un ejemplo lo ofrecen los derechos fundamentales sociales en las Constituciones de los Länder a partir de 1945,75 y en general su derecho constitucional de la cultura, así como los deberes

72 Das Prinzip Hoffnung, vol. 1, Suhrkamp, 1974, pp. 284 y ss.

73 Luhmann, N., en Habermas, J. y Luhmann, N., Theorie der Gesellschaft oder Sozialtechnologie, 1971, p. 310. La contingencia se define como "categoría heurística, estratégica y comparativa" que mantiene abierto el acceso a otras posibilidades. Cfr. Luhmann, N., "Soziologie als Theorie sozialer Systeme”, Kölner Zeitschrift für Soziologie und Sozialpsychologie, 1967, pp. 615 (637).

74 Scheuner, U., voz "Verfassung", Staatslexikon, vol. 8 (1963), col. 117 (118).

75 Al respecto, Beutler, B., Das Staatsbild in den Länderverfassungen nach 1945, 1973, y mi reseña en AöR, vol. 100, 1975, pp. 520 y s.; Mangoldt, H. V., Die Verfassungen der neuen Bundesländer, 2a. ed. 1997; Starck, Ch., "Die Verfassungen der neuen Länder”,HdbStR, vol. IX (1997), pp. 353 y ss. 
Este libro forma parte del acervo de la Biblioteca Juridica Virtual del Instituto de Investigaciones Juridicas de la UNAM http://www.juridicas.unam.mx

fundamentales. La idea de hacer posibles las alternativas subyace especialmente al procedimiento de enmienda constitucional: jel artículo 79, incisos 1 y 2, de la LF, y normas análogas en otros países, constituyen la más audaz institucionalización de las alternativas en la comunidad política! En la dogmática de los derechos fundamentales se ha vuelto necesaria la "reserva de lo posible" en la dimensión de la participación. ${ }^{76}$

b) Mantener abiertas las posibilidades dentro del orden constitucional vigente es un contenido central de importantes principios jurídico-constitucionales. La democracia que no se funda en la idea de una voluntad popular única y "verdadera" en el sentido de Rousseau, debe dar oportunidad a la minoría, como alternativa a la mayoría, de convertirse ella misma en mayoría. Según K. Hesse, la democracia consiste en iniciativas y alternativas pluralistas. ${ }^{77}$ En las teorías norteamericanas, la democracia se identifica prácticamente con el pluralismo y la competencia. ${ }^{78}$ La apertura hacia las alternativas debe existir efectivamente, por lo que en este punto los ordenamientos democráticos han de someterse continuamente a la crítica. La apertura a las alternativas puede peligrar por las cláusulas del $5 \%{ }^{79}$ o por un modo determinado de financiamiento de los partidos, ${ }^{80}$ por la "tecnoestructura" (M. Duverger), ${ }^{81}$ por la desigualdad de oportunidades económicas y por la consolidación de posiciones elitistas. Incluso resulta necesario preguntarse si la idea experimental de la democracia, que convierte en principio la revisión de los pequeños pasos, no excluye alternativas más fundamentales.

Los derechos fundamentales constituyen también un vehículo y una reserva de alternativas e innovaciones, sobre todo ahí donde hacen posible la "democracia pluralista" ( $f f r$. el preámbulo de la Constitución de Gabón de

$76 \mathrm{Al}$ respecto véase Häberle, P., "Grundrechte im Leistungsstaat", VVDStRL, vol. 30, 1972, pp. 43 (107, 139 LS 40); BVerfGE 33, 303 (333).

77 Hesse, K., Grundzüge des Verfassungsrechts der Bundesrepublik Deutschland, 20a. ed. 1995, p. 62 .

78 Al respecto véase Narr, W. D. y Naschold, F., Theorie der Demokratie, 1971, pp. 137 y ss., 205 y ss., y Scharpf, F., Demokratietheorie zwischen Utopie und Anpassung, 1970, pp. 29 y ss.

79 Forsthoff, E., Der Staat der Industriegesellschaft, 1971, p. 87; al respecto véase también Häberle, P., "Retrospektive Staats(rechts)lehre oder realistische 'Gesellschaftslehre'?" ZHR, vol. 136, 1972, pp. 425 (431 y s.); Grimm, D., "Politische Parteien", HdbVerfR, 2a. ed., 1994, pp. 599 (627 y s.). [La cláusula citada hace referencia al umbral de votación que un partido debe alcanzar en Alemania para tener derecho a representación en el Parlamento Federal. N. del T.]).

${ }^{8}$ Cfr. Hesse, K., "Die verfassungsstaatliche Stellung der politischen Parteien", VVDS$t R L$, vol. 17, 1959, pp. 11 (37, nota 69): "Premio a la posesión del poder político"; véase más tarde BVerfGE 41, 399 (411 y ss.; sentencia Daniels); E 85, 264.

${ }_{81}$ Duverger, M., Demokratie im technischen Zeitalter, 1973, pp. 149 y ss. 
Este libro forma parte del acervo de la Biblioteca Juridica Virtual del Instituto de Investigaciones Juridicas de la UNAM

1994): los artículos 4o., 5o., incisos 1 y 3, 7o., inciso 4, 9o., incisos 1 y 3, de la LF. Los típicos derechos fundamentales " $a$ " las alternativas son aquellos que garantizan una posibilidad de elección: la libertad del sufragio (artículo 38, inciso 1 frase 1, de la LF), la libertad de elección de la profesión, del puesto de trabajo, de la institución educativa (artículo 12, inciso 1, frase 1, de la LF); también podría designarse al artículo 11, inciso 1, de la LF como derecho fundamental a elegir libremente el lugar de estancia.

Libertad no es sino otra palabra para las alternativas, dondequiera que aparezca constitucionalmente; en las libertades fundamentales (incluyendo la libertad económica); en la libertad creadora del legislador y la administración, pero también del juez, en la libertad de fundar partidos. Libertad significa esencialmente posibilidades.

c) De entrada parece banal la constatación de que en el plano de la legislación existe la posibilidad de varias alternativas. Las leyes "correctas" solamente pueden deducirse de manera parcial de la Constitución y de la "realidad"; tampoco son siempre expresión de las "necesidades", el legislador tiene libertad de crear. Las alternativas no existen per se; la legislación no es solamente un acto de selección, sino que más bien es necesario organizar procedimientos que sirvan a la formulación de alternativas que aumenten el margen de las posibilidades. La deliberación parlamentaria de las leyes debe tener esta función, por lo que aquí son importantes las garantías de su publicidad. ${ }^{22}$ Es necesario que en el procedimiento legislativo se desarrollen más los "métodos de la invención" que hacen posible "la obtención de ocurrencias para encontrar nuevas soluciones a los problemas". ${ }^{83}$ El legislador debería en cierto modo poder experimentar con alternativas. En la medida que no apruebe la ley misma como experimento, o incluya cláusulas experimentales, puede considerar al derecho comparado como prueba de diversas posibilidades. La "audiencia" legislativa, una forma de la pluralización del derecho, ${ }^{84}$ tiene por objetivo no sólo la obtención de material fáctico, sino que es también un "test" de las reacciones de los círculos afectados a las distintas alternativas de la regulación. ${ }^{85}$

${ }^{82}$ Sobre tales garantías, véase Häberle, P., Öffentliches Interesse als juristisches Problem, 1970, pp. 103 y s.

83 Noll, P., Gesetzgebungslehre, 1973, pp. 113. Cfr. también la referencia de la p. 114 a la "ars combinatoria" de Leibniz como "ars inveniendi".

${ }_{84}$ Sobre las leyes del pluralismo véase Häberle, P., "Leistungsrecht im sozialen Rechtsstaat”, en FS Küchenhoff, 1972, pp. 453 (465, 472 y s.).

${ }_{85}$ Hopt, K., "Finale Regelungen, Experiment und Datenverarbeitung in Recht und Gesetzgebung", fZ 1972, pp. 65, 69. 
Este libro forma parte del acervo de la Biblioteca Juridica Virtual del Instituto de Investigaciones Juridicas de la UNAM

d) Las alternativas como posibilidades del pensamiento en el proceso jurídico se vuelven relevantes en el proceso de la interpretación, en la elección de métodos. Esto quedó comprobado, de diversas formas, en el debate sobre el pensamiento tópico como "fuerza productiva de la interpretación". La tópica busca los posibles criterios de interpretación. El voto particular en los tribunales constitucionales es la manifestación, institucionalizada procesalmente, de la idea de que las normas jurídicas dejan abiertas diversas posibilidades y alternativas de interpretación, y de que la alternativa que hoy se escoge no puede excluir otras alternativas en el futuro.

\section{Requisitos teórico-constitucionales del pensamiento de las posibilidades - límites de este pensamiento}

El pensamiento jurídico de las posibilidades y las alternativas (pluralistas) no es un fin en sí mismo, sino que se trata de un medio para mantener y recrear la libertad de la comunidad, para lograr el equilibrio justo y razonable de los intereses, la conservación de la Constitución en el tiempo, el desarrollo de la res publica del ser humano y para el ser humano. Los pensamientos de la realidad y de las necesidades guardan al pensamiento de las posibilidades frente las utopías que buscan la salvación en el futuro y descuidan el presente. El pensamiento de las posibilidades es un medio para acceder al potencial innovador de las normas jurídicas (o para crear normas nuevas). Claro está que las normas jurídicas también imponen límites al pensamiento de las posibilidades, los que se examinarán más adelante. Precisamente en la res publica democrática el pensamiento de las alternativas seguirá siendo realista y estará dispuesto al compromiso en virtud de la protección que corresponde a las minorías. Es muy posible que el pensamiento de las posibilidades conduzca, a fin de cuentas, a la confirmación de lo ya probado, por ejemplo, para argumentar que una interpretación alternativa es insostenible por los costos excesivamente altos que traería por consecuencia. Tal pensamiento es evolutivo, no revolucionario, en el sentido admitido aquí. La virtud democrática del "esto pero también lo otro" ("Sowohl-Als-Auch"), como expresión de la tolerancia y el pluralismo, debe seguir siendo directiva para el pensamiento de las alternativas. El pensamiento en términos de "esto o lo otro" puede ser una forma de intolerancia intelectual, porque amenaza con bloquear la vía del equilibrio del "esto, pero también lo otro" y, por lo tanto, para el compromiso democrático, del cual debería ser etapa previa. En esta medida, el pensamiento de las posibilidades y las alternativas es una manifestación específica del racionalismo crítico, con su postulado de la 
Este libro forma parte del acervo de la Biblioteca Juridica Virtual del Instituto de Investigaciones Juridicas de la UNAM

falsabilidad, de las "conjectures and refutations". El pensamiento de las posibilidades presupone apertura de la Constitución, del Estado, de la sociedad, del pensamiento, y crea al mismo tiempo dicha apertura. Su padrino es el racionalismo crítico, el pensamiento liberal (transformado) en alternativas. Donde sea necesario, hay que cuestionar paso a paso las "alianzas sagradas" de lo existente y sobre lo existente. Una teoría constitucional de la "sociedad abierta" vive de este pensamiento realista de las posibilidades. Así, por ejemplo, a través de las garantías de los derechos fundamentales, en especial en los ámbitos económico y artístico, se institucionalizan numerosas posibilidades (jincluso utopías concretas!).

Así puede hablarse de la fuerza del pensamiento de las posibilidades (y de las necesidades y la realidad) que abren las normas jurídicas. El pensamiento jurídico de las posibilidades es expresión y consecuencia, presupuesto y límite, de la interpretación constitucional abierta.

\section{La integración de la realidad, las posibilidades y las necesidades en el proceso}

(del pensamiento y la acción) de la interpretación y la politica constitucionales abiertas

\section{A. La relación de las tres formas de pensamiento entre sí (competencia y cooperación, confrontación e integración)}

La tesis es la siguiente: el contenido, la validez y el cambio de las normas jurídicas, pero también sus límites, sólo pueden desentrañarse plenamente a través de la triada abierta del pensamiento de las posibilidades, la realidad y las necesidades. Y estas tres formas del pensamiento también actúan conjuntamente en la creación de las normas. Existen relaciones de competencia, pero también, y ante todo, de cooperación. La dosis "correcta" de los estilos de razonamiento se convierte en problema del pensamiento jurídico.

Desde un punto de vista analítico, la cooperación entre los pensamientos de las posibilidades, la realidad y las necesidades tendrían que proceder "uno tras otro". Primeramente hay que investigar la realidad, después hay que buscar las posibilidades alternativas; éstas deben ser valoradas, a fin de poder identificar las necesidades. Desde este punto de vista, no se trata de estilos sino de etapas del pensamiento que se suceden unas a otras. Por lo tanto, se presupone una separación estricta de los modos de pensamiento que ocurren en cada una de las etapas, la cual difícilmente puede sostenerse en la práctica. Si, por el contrario, se escoge un enfoque, basado en las más re- 
Este libro forma parte del acervo de la Biblioteca Juridica Virtual del Instituto de Investigaciones Juridicas de la UNAM

cientes reflexiones sobre la tópica, entonces se advierte que no hay sucesión lineal de pasos, sino una relación, de múltiples dimensiones y de alta complejidad, de conjunción, cooperación y contradicción. La "relación de mezcla" entre los estilos de razonamiento habrá de ser distinta, dependiendo de la función de que se trate: la "política", la legislación, la jurisdicción, la administración, y los diversos acentos son una característica de la distinción (¡no separación!) de las diversas funciones del Estado. La combinación jurídico-funcional de los diversos modos de pensamiento y su organización se convierten en problema central de una teoría constitucional de la práctica.

Las tres formas del pensamiento se limitan mutuamente. Así, por ejemplo, el pensamiento de la realidad previene a la dogmática del predominio del pensamiento derivado del status quo, pero también de su extremo contrario, las ideologías de la transformación. ${ }^{86}$ La concepción de la Constitución, como teoría constitucional referida destacadamente a la práctica y guía de una "buena" interpretación constitucional, especialmente dispuesta al compromiso, despliega su fuerza directiva con relación al proceso de la confrontación e integración de los resultados, mejor dicho, de los resultados provisionales de los tres pasos del pensamiento. Producen selección a través de la proyección de objetivos, "recogen" el material de los tres pasos del pensamiento, establecen acentos entre ellos, lo cual pueden realizar porque la triada se mantiene abierta, su integración es "floja" y el "paralelograma de las fuerzas" de las posibilidades y necesidades, que frecuentemente son en sí antagónicas, se mantiene flexible gracias a la acción de los objetivos normativos. Del "conjunto de las posibilidades" hay que escoger aquellas que llevan a la realidad "existente" a un mejor desarrollo y que evitan los peligros de un retroceso hacia una realidad más mala. Por tanto, la colaboración de los tres pasos del pensamiento presupone "insumos y preceptos" (el "input normativo").

\section{B. La valoración de lo real, lo posible y lo necesario en el horizonte de lo normativo}

Aquí se plantea la pregunta crucial: en vista del pensamiento jurídico sobre la realidad, las posibilidades y las necesidades, ¿dónde queda lo propiamente normativo? ¿Acaso se disuelve? ¿O no es más bien que hasta ahora ha quedado empobrecido y reducido por no haber sido situado consecuentemente, ab initio, en el horizonte de lo posible, lo real y lo necesario?

${ }_{86}$ Véase la opinión crítica de Lerche, P., "Stiller Verfassungswandel als aktuelles Politikum”, FS Maunz, 1971, pp. 285 (289 y ss.). 
Este libro forma parte del acervo de la Biblioteca Juridica Virtual del Instituto de Investigaciones Juridicas de la UNAM

La respuesta es que lo normativo, el deber ser, no se "pierde" en la triada de las posibilidades, las necesidades y la realidad. De entrada, el pensamiento de las posibilidades, las necesidades y la realidad no puede ser aplicado de manera "independiente" frente la norma jurídica. Se trata de la "valoración" de lo real, de las posibilidades y de la incorporación de lo necesario; se trata de una tarea de delimitación a partir de lo normativo. ¡No es que la realidad, las posibilidades y las necesidades existan sin valoración y sin supuestos previos! Sería ilusorio suponer que una "buena" política constitucional podría ser la resultante de factores que no contuvieran ya el "input" normativo que determina el "buen" resultado. Las valoraciones ya están en juego, incluso cuando se trata de diagnosticar empíricamente la realidad, y aun tratándose de las posibilidades libres, "desencadenadas", frente a toda norma. Y la renuncia, tan amplia como sea posible, a la apresurada limitación normativa de las posibilidades, hasta llegar a lo "absurdo", debe liberar la fuerza productiva e innovadora del pensamiento de las posibilidades. Finalmente, el pensamiento de las necesidades, concebido "realistamente", se funda siempre en objetivos y "datos" normativos; lo que hay que hacer es sacarlos a la luz.

\section{Limites}

En relación con el problema de la normativización, hay que ver también los límites que la norma jurídica impone a los tres estilos de pensamiento: la selección que hace la norma consiste en que pretende precisamente excluir ciertas posibilidades "malas"; en que pueda imponerse incluso contra las "necesidades del bien común", la "razón de Estado" y conceptos similares, por presuntamente urgentes que sean; en que se oponga a una determinada realidad pública "mala". Aunque la triada mencionada "abra" a las normas jurídicas, en la misma medida hay que tener presentes los límites del proceso. Las normas jurídicas tienen que enfrentarse y afirmarse contra realidades, posibilidades y necesidades determinadas. La relación es ambivalente, pero fructífera. Sin pensamiento de la realidad, de las posibilidades y las necesidades, sin su confrontación e integración, no existe una adecuada interpretación y desarrollo de las normas jurídicas en la libertad, así como tampoco hay creación de tales normas en procedimientos libres. Pero sin normas jurídicas no es posible el pensamiento jurídico de las posibilidades, las necesidades y la realidad. Las normas son, por tanto, el vehículo de un pensamiento tridimensional y como tales resultan imprescindibles. 
Este libro forma parte del acervo de la Biblioteca Juridica Virtual del Instituto de Investigaciones Juridicas de la UNAM http://www.juridicas.unam.mx

\title{
IV. El Estado GONSTITUCIONAL DESDE LA PERSPECTIVA EVOLUTIVA; LAS DOS DIMENSIONES DE ESTA PERSPECTIVA:
}

\author{
EL TIEMPO Y EL ESPACIO
}

\section{La comparación jurídica en el tiempo: la historia constitucional}

La "evolución" corre, por un lado, en la "vía" o la "escala" temporal. En este sentido se ha formado, respecto del Estado constitucional, una disciplina científica propia, la "historia constitucional", la cual se encuentra presente hoy en las grandes obras de E. R. Huber, ${ }^{87}$ O. Kimminich, ${ }^{88}$ D. Willoweit, ${ }^{89}$ y M. Stolleis. ${ }^{90}$ Ciertamente, esta disciplina no ha podido todavía fijar de manera "clásica" su objeto y sus métodos, del mismo modo como lo ha logrado la "historia del derecho privado moderno" de un F. Wieacker, ${ }^{91}$ la cual contiene también elementos de la constitución de la libertad, ${ }^{92}$ pero tal vez esto no sea siquiera posible. E. R. Huber tiene la esperanza, ${ }^{93}$

de al menos ofrecer un reflejo de qué modo el ser real todavía no configurado y la estructura ordenada de las instituciones del derecho del Estado y de las normas; de qué manera las grandes corrientes de las ideas y la agitada marea de los intereses; cómo la subjetividad de las fuerzas actuantes y la objetividad del espíritu de una época que se realiza a sí mismo en la lucha, plena de crisis, por la Constitución, se encuentran inseparablemente ligadas, pero no sin que no puedan distinguirse.

Este autor sostiene un "concepto sustancial de Constitución" ${ }_{94}$ y se propone una "historia constitucional de toda Europa" (intención parcialmente satisfecha por H. Hattenhauer). ${ }^{95}$ M. Stolleis ${ }^{96}$ habla de la "transformación evolutiva" y ocasionalmente "revolucionaria" de las reglas jurídicas "que constituyen a la comunidad y que ordenan la relación interna entre gobernantes y gobernados, así como las relaciones externas con otras comunida-

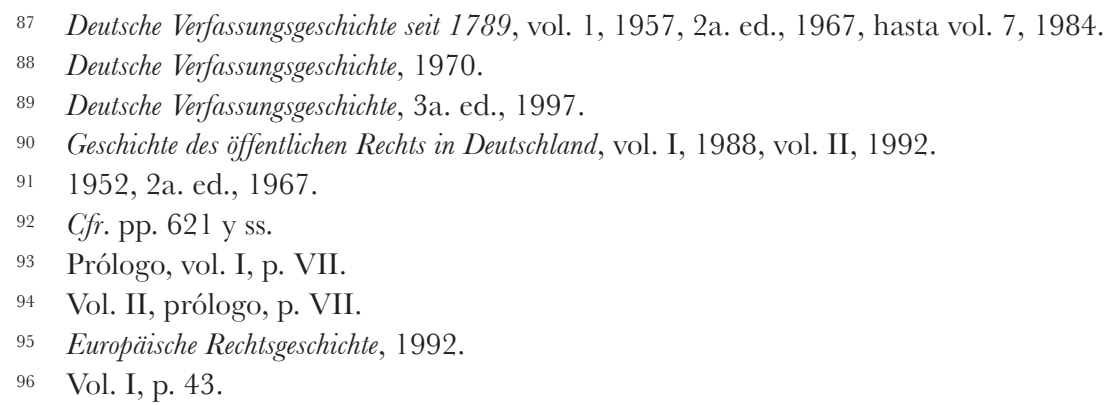


Este libro forma parte del acervo de la Biblioteca Juridica Virtual del Instituto de Investigaciones Juridicas de la UNAM

des", y pide una "analogización", es decir, la constatación de similitudes entre el ahora y el entonces. ${ }^{97}$ Se trata pues de una comparación en el tiempo, a través de la cual podemos reconstruir "procesos evolutivos" (Entwicklungen), explicar lo nuevo y lo otro como cosas diferentes. Toda lucha por elaborar una historia constitucional se revela como comparación en el tiempo, como extensión de lo próximo hacia lo lejano: del Estado constitucional nacional hacia el Estado constitucional regional europeo, y desde ahí hacia procesos evolutivos universales, según la época. En lo particular, la reconstrucción de la evolución histórica (constitucional) es sin duda dificil, ya que "concepción previa (Vorverstädnis) y elección del método" se encuentran históricamente condicionadas.

\section{La comparación jurídica en el espacio: comparatística contemporánea, comunidad universal de producción y recepción en materia del Estado constitucional}

La comparación jurídica en el espacio es la "otra" dimensión - correlativa del derecho comparado en el tiempo, es decir, de la historia - que nos permite "perseguir" los procesos evolutivos. Tiempo y espacio son dos las dimensiones correlativas, "hermanas", que requiere la comprensión histórico-evolutiva del Estado constitucional. Aquí podríamos invocar, o no, al "Parsifal" de Richard Wagner ("Aquí se torna en espacio el tiempo"), pero lo que sí hace falta es una teoría constitucional del espacio. ${ }^{98}$ Con ello no queremos proponer un retorno a las funestas ideologías del espacio de la época nazi; por fortuna, después de su "Ser y tiempo" (1927), M. Heidegger no escribió un libro con el título "Ser y espacio". Más bien se trata de reconocer que los procesos de desarrollo del Estado constitucional en última instancia solamente pueden entenderse si se toma en cuenta el espacio, hoy Europa o incluso el mundo. No es sólo a partir de 1989 que podemos observar procesos de producción y recepción en materia del Estado constitucional a través del espacio y por encima de los continentes. Esto lo veíamos ya respecto de elementos que hoy son clásicos, como la división de poderes de Montesquieu, y su "ignición" en los jóvenes Estados Unidos de América; una recepción inversa se presenta en el "salto" del federalismo desde ese país hacia Europa. Sin embargo, a partir de 1989 es visible una comunidad de producción y recepción mundial, que abarca a Europa oriental y a par-

\footnotetext{
97 Ibidem, p. 54.

$98 \mathrm{Al}$ respecto, Häberle, P., Kulturpolitik in der Stadt - ein Verfassungsauftrag, 1979, pp. 38 y ss.; id., Rechtsvergleichung im Kraftfeld des Verfassungsstaates, 1992, pp. 778 y ss.
} 
Este libro forma parte del acervo de la Biblioteca Juridica Virtual del Instituto de Investigaciones Juridicas de la UNAM

tes de Asia, en la que los textos constitucionales, los paradigmas científicos, las resoluciones judiciales, se vuelven objeto de los "procesos de globalización", es decir, son intercambiados y también "transformados". Con ello también hay recepción de una "realidad constitucional", en el sentido de que los Estados constitucionales más jóvenes convierten en conceptos y en texto lo que se ha desarrollado paulatinamente en los más antiguos. Así, Italia discute actualmente en su sistema de coordenadas, como "regionalismo cooperativo", elementos del "federalismo cooperativo"; de este modo incorporó España, a partir de 1978, mucho de lo que se había desarrollado en el federalismo alemán. El ejemplo más espectacular de un intercambio de experiencias a través del espacio en el marco del Estado constitucional (sobre todo respecto del federalismo y la jurisdicción constitucional) lo ofrece actualmente Sudáfrica. ${ }^{99}$ Esta constatación tiene consecuencias: la entronización de la comparación jurídica como "quinto método de interpretación" 100 (ya K. Zweigert se había atrevido a hablar de un método de interpretación "universal"), que se agrega al "histórico". En el ámbito de los derechos fundamentales se produce su integración en el tipo del Estado constitucional, por ejemplo, a través del postulado de una "interpretación conforme a los derechos humanos" y su condensación en "principios generales del derecho", como lo ha demostrado el Tribunal de Justicia europeo, mientras que en el plano de Europa madura la idea del "derecho constitucional común europeo". Puesto que el "taller" del Estado constitucional se vuelve cada vez más global en el espacio (lo que se compensa en parte por nuevas fragmentaciones), las "piezas" deben ser examinadas de manera correlativamente amplia, como contraparte de la amplitud y profundidad de la investigación histórico-constitucional. El tiempo y el espacio trabajan en el tipo del "Estado constitucional" como "proyecto de desarrollo". La metodología constitucional se hace correlativamente extensa.

En resumen: el Estado constitucional asegura su continuidad y supervivencia en el curso del tiempo a través de instrumentos y procedimientos "grandes" (de "malla gruesa") y "finos", en un equilibrio entre constancia y cambio. El tiempo y la cultura constitucional ${ }^{101}$ constituyen un modo de existencia de este tipo. Sin embargo, aun la citada escala de procedimientos

99 De la bibliografía: Karpen, U., "Südafrika auf dem Weg zu einer demokratischenrechtsstaatlichen Verfassung", FöR, vol. 44, 1996, pp. 609 y ss. El principal manual es el de Rautenbach, I. y Malherbe, E., Constitutional Law, 2a. ed., 1996.

100 Propuesto inicialmente por el autor en su ensayo: "Grundrechtsgeltung und Grundrechtsinterpretation im Verfassungsstaat", 72 1989, pp. 913 y ss.

101 Al respecto véase Häberle, P., mismo título (“Zeit und Verfassungskultur”), en Peisl, A. y Mohler, A. (eds.), Die Zeit, 3a. ed., 1991, pp. 289 y ss. 
Este libro forma parte del acervo de la Biblioteca Juridica Virtual del Instituto de Investigaciones Juridicas de la UNAM

no lo hacen inmune contra errores y desviaciones, como tampoco lo está ninguna obra humana. Sin embargo, en el marco de una "teoría de la Constitución como ciencia cultural", el Estado constitucional se "conecta" de manera diferenciada con el paradigma de la "evolución" que quizá caracteriza actualmente a todas las ciencias naturales y culturales. (Palabra clave más reciente: "la computadora como «máquina evolutiva»"). ¡En un sentido más profundo, todos los Estados constitucionales son "países en desarrollo"!

\section{TIEMPO Y GULTURA CONSTITUCIONAL: INSTRUMENTOS Y PROCEDIMIENTOS PARA EL PROCESAMIENTO DEL FACTOR TIEMPO EN EL PRESENTE Y EN EL FUTURO}

Los instrumentos y procedimientos para el procesamiento constitucional del factor tiempo con vistas al presente y al futuro son múltiples y de ellos se ocupa principalmente una concepción más "dinámica" de la Constitución. Escalonados de acuerdo con su grado de formalización se obtiene la relación que sigue.

\section{Cláusulas relativas al futuro y al progreso}

Una forma especial de reivindicación del futuro por el texto constitucional se encuentra en diversas variantes: en la fijación absoluta, "eterna", de ciertos principios, en forma similar a lo dispuesto por el artículo 79, inciso 3, de la LF; ${ }^{102}$ en la formulación de una "pretensión de validez perenne" 103 o en la negación duradera de situaciones jurídicas anteriores especialmente reprochables, como la servidumbre y los títulos. La elaboración rigurosa del pasado (Vergangenheitsbewältigung) se convierte aquí en elevada exigencia para el futuro. Otra tematización más del futuro se encuentra en las Constituciones que expresamente hablan de un "futuro benéfico", ${ }^{104}$ que se dirigen a las

102 Cfr. el artículo 16 de la Declaración francesa de 1789; el artículo 110, inciso 1, de la Constitución de Grecia (1975); el artículo 130 de la Constitución de Bélgica; el artículo 9o. de la Constitución de Turquía (1961); el artículo 89, inciso 5, de la Constitución de Francia (1958); el artículo 75, inciso 1, frase 2 de la Constitución de Baviera (1946).

103 Cfr. el artículo 25, inciso 2, de la Constitución de Grecia (1975): "derechos fundamentales e inalienables del hombre".

104 Preámbulo del documento constitucional de Hesse de 1831. Véase también el "futuro” en el preámbulo de la Constitución de Hesse (1946). 
Este libro forma parte del acervo de la Biblioteca Juridica Virtual del Instituto de Investigaciones Juridicas de la UNAM http://www.juridicas.unam.mx

futuras generaciones alemanas, ${ }^{105}$ exigen de la república la promoción del desarrollo cultural ${ }^{106}$ o invocan el "progreso": en cláusulas que se refieren a la fiesta del 1o. de mayo, como profesión de fe en el progreso (artículo 32 de la Constitución de Hesse de 1946) o en forma bastante más general. ${ }^{107}$ Aquí se manifiestan claramente los dos lados de una cultura, el tradicional y el prospectivo. ${ }^{108}$

\section{Mutación constitucional a través de la interpretación}

La mutación constitucional ${ }^{109}$ a través de la interpretación, es decir, sin modificación expresa del texto de la Constitución, se produce de manera relativamente discreta y sin formalización. Por la sola vía de la interpretación, ya sea la de los tribunales, la de la práctica estatal, la de la opinión pública o la doctrina, o como producto de la combinación de ellas, es que una norma constitucional puede adquirir un significado nuevo o diferente. Así, por ejemplo, la propiedad reconocida por el Código Civil alemán (BGB) de 1900 se ha visto sometida a una profunda transformación. También pertenecen aquí los procesos de crecimiento que han afectado a los diversos principios constitucionales, con resultados fenomenales. Así, la concepción del "Estado social de derecho" en 1999 tiene muy poco en común con la interpretación de la LF en 1949.

Dependiendo del método, la interpretación de la Constitución es en parte retrospectiva y en parte prospectiva. ¡Los diversos métodos de interpretación no hacen otra cosa que "organizar" el tiempo! La interpretación histórica incorpora los orígenes; el método objetivo, el presente, el método orientado a las consecuencias y el pronóstico, el futuro. Quizá la “imprede-

105 Preámbulo orientado a las generaciones de la Constitución de Baviera (1946); ahora el preámbulo de la Constitución de Ucrania: "past, present and future generations". Véase también el preámbulo de la Constitución de Kwazulu-Natal (1996): "present generation and posterity". En forma similar los preámbulos de las Constituciones de Kazajstán (1995), Armenia (1995) y Azerbaiyán (1996).

106 Artículo 9o., inciso 1, de la Constitución de Italia (1947).

107 Preámbulo de la Constitución española (1978): "promover el progreso de la cultura y de la economía". Véase también el artículo 41, inciso 2, de la Constitución de Turquía.

108 De manera precisa el artículo 9o. de la Constitución de Italia: la República promueve el desarrollo de la cultura (primer párrafo); tutela el paisaje y la herencia histórica y artística de la nación (segundo párrafo).

$109 \mathrm{El}$ autor utiliza aquí, con la opinión dominante (Jellinek, G., Verfassungsänderung und Verfassungswandel, 1906, reimp. 1996), el concepto de "mutación constitucional", a pesar de que, en su opinión, deberíamos "despedirnos" de él; cfr. Häberle, P., "Zeit und Verfassung" (1974), id., Verfassung als öffentlicher Prozess, 1978 (3a. ed., 1998), pp. 59 (82 y ss.). 
Este libro forma parte del acervo de la Biblioteca Juridica Virtual del Instituto de Investigaciones Juridicas de la UNAM

cibilidad" general de los procesos temporales sea la razón por la cual, hasta ahora, ninguna metodología ha sido capaz de ponderar entre sí los diversos métodos de interpretación. Presumiblemente, su interrelación es una función del tiempo, o sea, es flexible.

\section{Votos particulares}

Los votos particulares de los jueces constitucionales que sostienen interpretaciones alternativas pueden convertirse en una forma especial de anunciar y promover, e incluso de acelerar, la "mutación constitucional". La historia de la jurisdicción constitucional en los EUA ofrece ejemplos sorprendentes al respecto, ${ }^{110}$ por ejemplo, en relación con la observancia de la legislación del New Deal de Roosevelt. Entre nosotros ya también es posible identificar signos de tales efectos en la "jurisprudencia alternativa" de los votos particulares, en la evolución de la jurisprudencia del Tribunal Constitucional Federal. ${ }^{111}$

\section{Mandatos al legislador}

La actividad del legislador puede concebirse como procesamiento permanente del cambio social en el tiempo y ofrece una variedad de procedimientos y técnicas pertinentes. En la primera época de la LF, se intentaba "cumplir" los mandatos constitucionales, abiertos (u ocultos), por ejemplo, sobre la igualdad de los sexos (artículo 3o., inciso 2, de la LF), de los hijos nacidos fuera de matrimonio (artículo 6o., inciso 5 de la LF) o sobre la democracia interna de los partidos (artículo 21, inciso 1, frase 3, de la LF) (cfr. también los artículos 95, inciso 3, y 117, inciso 2, de la LF).

\section{Efectos anticipados de las leyes}

Mencionemos brevemente dos formas más de incluir el tiempo en el desarrollo constitucional, formas de las que se tiene más conciencia recientemente: en primer lugar, el efecto anticipado (Vorwirkung) de las leyes y tra-

$110 \mathrm{Al}$ respecto véase Haller, W., Supreme Court und Politik in den USA, 1972.

111 Ejemplos en Häberle, P., Kommentierte Verfassungsrechtsprechung, 1979, pp. 24 y ss. Recientemente Schlaich, K., Das Bundesverfassungsgericht, 4a. ed., 1997, pp. 38 y ss. 
Este libro forma parte del acervo de la Biblioteca Juridica Virtual del Instituto de Investigaciones Juridicas de la UNAM

tados. ${ }^{112}$ Los efectos anticipados de leyes todavía no vigentes formalmente es tan comprobable como admisible, aunque en forma diferenciada. En el ámbito internacional llaman la atención los efectos anticipados del Tratado SALT II, pues durante mucho tiempo los EUA y la entonces URSS se apegaron tácitamente al proyecto de tratado. Los efectos anticipados no son otra cosa que la aceleración del factor tiempo.

\section{Cláusulas de experimentación y de experiencia}

Por último, echemos una mirada a las cláusulas legales de experimentación y de experiencia, las cuales aparecen sobre todo en tiempos reformistas y se muestran como intento de anticiparse al futuro de manera temporalmente limitada. En los años setenta estas cláusulas fueron tema de discusión en Alemania. Un ejemplo es el $\S 5$ b de la Ley sobre la Judicatura Alemana (DRiG) en relación con la educación jurídica de una sola etapa. No podemos discutir aquí en lo particular ${ }^{113}$ estas cláusulas, que ya había advertido Montesquieu, ${ }^{114}$ pero deben considerarse como forma de "prueba anticipada" del futuro. Actualmente el interés se dirige a la evaluación de las leyes: la investigación de la implementación, por ejemplo, trata a una ley en su conjunto como si fuera un experimento, a fin de preparar iniciativas de reforma que posiblemente la mejoren (sobre todo en la protección del ambiente y el derecho de la planeación); también se discute la "legislación temporal", por ejemplo, en el derecho alemán de la educación superior o de los municipios (por último, su "fecha de caducidad").

\section{Modificaciones constitucionales}

La institución clásica encaminada a formalizar lo nuevo y darle entrada directa en la Constitución es la modificación o reforma constitucional, es decir, el cambio del texto de la Constitución a través de determinados procedimientos que requieren, por lo común, mayorías calificadas como base de un consenso más amplio (cfr. el artículo 79, inciso 2, de la LF). Todos

112 Sobre los efectos anticipados de las leyes véase Häberle, P., Öffentliches Interesse als juristisches Problem, 1970, p. 396, nota 148; véase pp. 486 y ss.; "Zeit und Verfassung" (1974), ibidem, Verfassung als öffentlicher Prozess, 1978 (3a. ed. 1998), pp. 59 (83 y ss.).

113 Más detalles en Häberle, P., Verfassung als öffentlicher Prozess, 1978 (3a. ed. 1998), pp. 85 y ss.

114 Cfr. Montesquieu, El espiritu de las leyes, libro II, cap. 2, al final. 
Este libro forma parte del acervo de la Biblioteca Juridica Virtual del Instituto de Investigaciones Juridicas de la UNAM

los Estados constitucionales que cuentan con un documento constitucional conocen esta posibilidad de incorporar al texto el cambio en el tiempo, aunque los supuestos puedan ser diferentes en lo particular (por ejemplo, la mayoría requerida).

Las modificaciones constitucionales pueden servir para adaptarse a cambios que ya han ocurrido en los hechos, pero también pueden tratar de producirlos. Así, hay que distinguir entre modificaciones de "adaptación" y de "creación". En principio, la duración y la estabilidad de la Constitución parecen hablar en contra de las modificaciones constitucionales, pero éstas pueden contribuir precisamente a la duración y la estabilidad de una comunidad cuando son "oportunas". Que esto sea así sólo puede señalarse en el caso particular y en ámbitos específicos.

Lo anterior es cierto con mayor razón respecto de aquel paquete de modificaciones constitucionales que debe conducir a la "revisión total" de una Constitución. La discusión alemana en y acerca de la Comisión de investigación del Parlamento federal alemán en los años setenta demostró evidentemente que era inoportuna en su momento, ${ }^{115}$ ya que ni en lo político-constitucional ni en lo científico llegó prácticamente a ningún resultado. La labor de la Comisión conjunta de Constitución (1993) fue apenas poco más exitosa. En cambio, la discusión suiza ${ }^{116}$ podría mostrarse más eficaz en el mediano y largo plazos: esto lo demuestra la discusión actual sobre una Constitución federal "por crear". Especialmente fructíferas fueron y son las revisiones totales de las Constituciones cantonales suizas, siendo la más reciente la de Appenzell A. Rh. en 1995 (véase, infra, capítulo cuarto, IV, 2.).

\section{LA EUROPEIZACIÓN Y LA INTERNACIONALIZACIÓN - EL "ESTADO CONSTITUCIONAL COOPERATIVO"-. LA VISIÓN DEL MUNDO DEL ESTADO GONSTITUCIONAL}

\section{La europeización del Estado constitucional}

La europeización del derecho en general, pero también de sus disciplinas, se ha convertido en lugar común. El "derecho civil común euro-

115 Sobre la Comisión: Enquete-Kommission Verfassungsreform, Schlußbericht, 1976 (BTDrs. 7/5924). Sobre la Comisión conjunta de Constitución: Berlit, U., "Die Reform des Grundgesetzes nach der staatlichen Einigung Deutschlands", fö R, vol. 44, 1996, pp. 17 (27 y ss.).

116 Cfr. el proyecto de Constitución federal suiza de 1977, reproducido en AöR, vol. 104, 1979, pp. 475 y ss. 
Este libro forma parte del acervo de la Biblioteca Juridica Virtual del Instituto de Investigaciones Juridicas de la UNAM

peo", concebido quizá por primera vez por H. Kötz, ${ }^{117}$ encuentra su equivalente en el "derecho constitucional común europeo" (gemeineuropäisches Verfassungsrecht). ${ }^{118}$ Otros términos clave provienen de H. Coing y su frase "desde Bolonia hasta Bruselas", así como de sus investigaciones sobre la historia del derecho en Europa, pero también de los esfuerzos en torno al derecho europeo laboral o social o también el penal. Estos procesos generales de desarrollo, que no deben perderse en lo indeterminado, se vuelven tangibles para la teoría de la Constitución en tres campos que penetran en las dimensiones culturales profundas y respecto de los cuales es válida la siguiente proposición: la cultura y el derecho "hacen" la cultura del derecho de Europa.

\section{A. La europeización a través del derecho europeo en sentido amplio y restringido}

El derecho europeo (Europarecht) en "sentido restringido" es el derecho de la Unión y las Comunidades Europeas. En el campo de la ciencia, este derecho ha llevado a extraordinarias contribuciones como la del "derecho administrativo europeo" (J. Schwarze, 1988), a través del descubrimiento del derecho privado europeo en la CE (P.-G. Müller-Graff, 1989), a las obras pioneras como el Derecho comunitario europeo de H. P. Ipsen (1970). El Tribunal de Justicia europeo ha hecho contribuciones equivalentes, por ejemplo, en relación con los derechos fundamentales como "principios generales del derecho", que hacen aparecer al derecho europeo casi como derecho pretoriano, similar al derecho de los juristas en Roma. El derecho europeo en sentido amplio es el derecho del Consejo de Europa que encuentra sus puntos culminantes en diversas sentencias de la Corte Europea de Derechos Humanos. Austria y Suiza se han adelantado a algunos otros miembros del Consejo de Europa al haber otorgado jerarquía constitucional a la Convención Europea de Derechos Humanos. ${ }^{119}$ La teoría constitucional europea debiera poner mucha atención en este derecho europeo en sentido amplio, pues constituye una etapa de crecimiento del Estado constitucional europeo mismo.

117 Kötz, H., "Gemeineuropäisches Zivilrecht”, FS K. Zweigert 1981, pp. 481 y ss.

118 Häberle, P., "Gemeineuropäisches Verfassungsrecht”(1991), en id., Europäische Rechtskultur, 1994, pp. 33 y ss.; id., Gemeineuropäisches Verfassungsrecht, 1997.

119 Bleckmann, A., "Verfassungsrang der Europäischen Menschenrechtskonvention?", EuGRZ, 1994, pp. 149 y ss. 
Este libro forma parte del acervo de la Biblioteca Juridica Virtual del Instituto de Investigaciones Juridicas de la UNAM http://www.juridicas.unam.mx

\section{B. El "derecho constitucional común europeo"}

El "derecho constitucional común europeo", introducido en la discusión en 1991, ${ }^{120}$ circunscribe un aspecto parcial del Estado constitucional europeo, el cual se alimenta del pensamiento del derecho común y de los principios (en el sentido de J. Esser), sin pretender nivelar la pluralidad de culturas jurídicas nacionales.

\section{G. "Derecho constitucional nacional de Europa"}

Una dimensión de la europeización, hasta ahora poco estudiada por la doctrina, la denominamos aquí "derecho constitucional nacional de Europa" (nationales "Europaverfassungsrecht").121 Con este concepto nos referimos al aumento, cuantitativo y cualitativo, de los artículos sobre Europa que se encuentran en los distintos Estados constitucionales. Recientemente se añadieron a la LF bastantes "artículos sobre Europa" (artículos 23, 24 a, inciso 1 a, 28, inciso 1 , frase $3,45,50,88$, frase 2).

Del surgimiento y desarrollo del "derecho constitucional nacional de Europa”, en sus diversas manifestaciones, se derivan también consecuencias respecto de los problemas constitucionales concretos, por ejemplo, en relación con las cuestiones particulares que plantea el artículo 32 de la LF, cuyo inciso 1 debe ser reinterpretado, "europeizado", en lo particular. Cuando ahí se disponía, desde 1949, que "corresponde a la Federación conducir las relaciones con los Estados extranjeros", hay que preguntarse ahora, a partir del nuevo artículo 23 de la LF, de 1992, si los Estados constitucionales que actúan en el contexto de Europa son todavía "Estados extranjeros"; en otras palabras: el esquema interno-externo se cuestiona fundamentalmente en relación con Europa. Los Estados de la Unión Europea no son entre sí ya "extranjeros", sino que existe sobre todo el "Euroland".

120 Véase Häberle, P., mismo título ("Gemeineuropäisches Verfassungsrecht”), EuGRZ 1991, pp. 261 y ss.; reproducido en Häberle, P., Europäische Rechtskultur, 1994, pp. 33 y ss.

121 Véase al respecto Häberle, P., "Europaprogramme neuerer Verfassungen und Verfassungsentwürfe für den Ausbau von nationalem 'Europaverfassungsrecht'”, FS Everling, 1995, pp. 355 y ss. 
Este libro forma parte del acervo de la Biblioteca Juridica Virtual del Instituto de Investigaciones Juridicas de la UNAM

\section{El Estado constitucional cooperativo}

\section{A. Causas y trasfondo}

Las causas y el trasfondo de la evolución hacia el Estado constitucional cooperativo son complejas. Dos factores ocupan particularmente el primer plano: el lado sociológico-económico, y el lado ideal-moral.

Factor destacado y motor de la tendencia hacia la cooperación es la interdependencia económica de los Estados (constitucionales). Si se puede decir que el "Estado europeo" viene de la economía, con mayor razón es esto válido para el Estado constitucional cooperativo, que es efecto de las interrelaciones económicas y es causa de éstas mismas. La actual "globalización" intensifica estos procesos.

El reconocimiento de las formas de cooperación económica y su "conversión" en conceptos, procedimientos y competencias jurídicos adecuados, requiere vincularse a los métodos y al objeto de las "ciencias del Estado".

El trasfondo ideal-moral de la evolución hacia el Estado constitucional cooperativo solamente puede ser esbozado: es, por un lado, resultado del estar constituido a través de los derechos fundamentales y humanos. La "sociedad abierta" merece tal calificativo solamente si es una sociedad abierta hacia lo internacional. Los derechos fundamentales y humanos remiten al Estado y a "sus" ciudadanos también hacia lo "otro", lo "extraño", es decir, a otros Estados con sus sociedades y a los ciudadanos "extranjeros". El Estado constitucional cooperativo vive de necesidades de cooperación económica, social y humanitaria, así como, en lo antropológico, de la conciencia de la cooperación (internacionalización de la sociedad, de la red de datos, de la esfera pública mundial, de las manifestaciones con temas de política exterior, de la legitimación proveniente del exterior; regionalmente: el espacio público europeo).

\section{B. Limites y peligros}

Hasta 1989, el Estado constitucional occidental era, numéricamente hablando, un tipo de Estado relativamente infrecuente. Por un lado, se hallaba en competencia con los llamados Estados "socialistas", y, por el otro, con los Estados autoritarios y totalitarios de Europa, África, América Latina y Asia. Por ello, sería miope, incluso peligroso, que la teoría de la Constitución, entusiasmada por su propio "modelo", no recordara hoy este hecho 
Este libro forma parte del acervo de la Biblioteca Juridica Virtual del Instituto de Investigaciones Juridicas de la UNAM

al construir las formas de cooperación europea, las que abren a los Estados europeos de tal modo que quedan expuestos a los riesgos provenientes de los Estados "salvajes" (que son, por su lado, sujetos del derecho internacional; los ejemplos se encuentran en la ex Yugoslavia). Ciertamente, la "fuerza de atracción" (y el tesoro de experiencias) del Estado constitucional (occidental) es grande, y debiera crecer en el espacio público mundial en la medida en que se tome más en serio la cooperación. Sin embargo, no hay que perder de vista que las conquistas de este Estado, así como los elementos formales del Estado de derecho o el concepto mismo de derecho, se encuentran amenazados constantemente, y que la estructura de valores (y la identidad), en parte muy diversas, de terceros Estados (como los islámicos), no puede ni desea adaptarse al modelo del Estado constitucional. Pero también con ellos debe ser posible una cooperación (limitada).

Por lo tanto, hay una cierta ambivalencia en el tema "Estado constitucional y relaciones internacionales". Por un lado, la posibilidad de la cooperación encubre grandes oportunidades y desafios: los elementos constitutivos del Estado constitucional (como los procedimientos democráticos, la independencia de la jurisdicción, los derechos humanos) pueden ser "exportados", a fin de constituir a la comunidad de los Estados (así por ejemplo, actualmente en dirección a Europa oriental o el sudeste asiático). Por otro lado, son evidentes los peligros que derivan de la "importación", pues se producen procesos de retroalimentación y situaciones obligadas: el Estado constitucional como tipo, en lo que concierne a sus elementos dogmáticos como Estado de derecho, corre el riesgo de caer en zonas en que peligre su identidad, aunque abierta al cambio, por ejemplo, en cuestiones monetarias: la interrelación con Estados que no son constitucionales (todavía), como lo son algunos países en desarrollo, pero también con organizaciones no gubernamentales multinacionales o privadas, puede conducir a un efecto negativo de atracción. Se producen así roces entre el Estado constitucional y el concepto de Estado que postula el derecho internacional, ${ }^{122}$ entre los diversos modelos económicos (por ejemplo, en los países en desarrollo o en Cuba o Corea del Norte), a procesos de retroalimentación entre las economías nacionales. El Estado constitucional puede erosionarse, contra lo cual deberán imaginar algo la dogmática y la política del Estado constitucional. Pero también es posible una "balanza activa", en el sentido de una competencia de los Estados en relación con los elementos de su carácter constitucional que, de manera condicionada, se pueden intercambiar y transmitir, en camino hacia un "modelo" óptimo de Estado constitucional cooperativo.

$122 \mathrm{Al}$ respecto, Kriele, M., Einführung in die Staatslehre, 1975, pp. 81 y ss. 
Este libro forma parte del acervo de la Biblioteca Juridica Virtual del Instituto de Investigaciones Juridicas de la UNAM

\section{Derecho internacional de la coordinación y la cooperación: elementos constitucionales de la comunidad de naciones}

a) La organización de la comunidad de los Estados puede desentrañarse mejor desde el punto de vista histórico. Ya en los Estatutos de la Sociedad de Naciones (1919), la "Constitución" de la primera organización política amplia de la comunidad de los Estados, se habla de la "promoción de la cooperación entre las naciones", objetivo de la Sociedad de Naciones junto con la "garantía de la paz y la seguridad internacionales". Sin embargo, los medios dispuestos en el Preámbulo y en los siguientes 26 artículos para la realización de la paz como objetivo son las obligaciones típicas de un orden jurídico internacional entendido como derecho coordinador (desarme, protección de las posesiones, prohibición de la guerra y solución pacífica de los conflictos). La creación de las Naciones Unidas (1945), al igual que la de la Sociedad de Naciones, fue una reacción a los sacudimientos y sufrimientos de la guerra anterior. A diferencia de los Estatutos de la Sociedad de Naciones, se señala en la Carta de las Naciones Unidas que la colaboración entre las naciones no es un objetivo sino un medio "en la solución de problemas internacionales de carácter económico, social, cultural o humanitario, y en el desarrollo y estímulo del respeto a los derechos humanos y a las libertades fundamentales de todos, sin hacer distinción por motivos de raza, sexo, idioma o religión" (artículo 1o., inciso 3, de la Carta de las Naciones Unidas).

b) Es posible observar variadas formas regionales de cooperación más intensa. La constitucionalización de la comunidad jurídica de las naciones ha avanzado más en el plano regional que en el universal. Además de las organizaciones y sistemas regionales de seguridad colectiva, establecidos conforme al capítulo VIII de la Carta de las Naciones Unidas, como la OEA, la UEO, la OTAN, esto resulta especialmente cierto de la Comunidad Europea, cuya "Constitución" 123 son los tratados de París y de Roma. Una renuncia parcial a la soberanía en favor del "poder comunitario" de la $\mathrm{CE}$ en relación con el deber fundamental de solidaridad de los Estados miembros establecido en el artículo 5o. del Tratado de la CE, ha sido y es

${ }^{123}$ Ipsen, H. P., Europäisches Gemeinschaftsrecht, 1972, pp. 64 y ss.; cfr. BVerfGE 22, 296; "El Tratado de la CEE constituye en cierto modo la Constitución de esta Comunidad". Sobre la discusión actual $c f r$. S. Oeter, "Souveranität und Demokratie als Problem in der 'Verfassungsentwicklung' der Europäischen Union”, ZaöRV, vol. 55, 1995, pp. 659 y ss.; RodríguezIglesias, G. C., "Zur 'Verfassung' der Europäischen Gemeinschaft”, EuGRZ, 1996, pp. 125 y ss. 
Este libro forma parte del acervo de la Biblioteca Juridica Virtual del Instituto de Investigaciones Juridicas de la UNAM

el presupuesto para la realización de los objetivos del mismo, en particular de la integración económica, de la política regional y social a través de órganos independientes de creación y aplicación del derecho. La legitimación inmediata de los órganos comunitarios a través de un Parlamento Europeo de elección directa podría hacer retroceder, paulatinamente, el dogma de la soberanía nacional en favor de una distribución de funciones, justificada materialmente, entre el Estado y la organización supranacional. La adopción de una nueva identidad "europea" 124 abre la vía para el ejercicio de la "responsabilidad social" de las regiones ricas frente a las más pobres y a la elevación general del nivel de vida. ${ }^{125}$ La integración como forma más elevada de la cooperación puede ser vista, por tanto, como perspectiva de los esfuerzos internacionales de cooperación. El "sistema de Estados" de la UE (TCFA), o mejor dicho, el "sistema constitucional" de la UE (I. Pernice), ha llevado hoy la cooperación a una integración más estrecha.

La integración europea se inició con la creación del Consejo de Europa (1949), cuyos estatutos se adoptaron en la convicción "de que la consolidación de la paz sobre la base de la justicia y la cooperación internacional es de interés vital para la conservación de la sociedad humana y de la civilización".

El Convenio de la Organización para la Cooperación y el Desarrollo Económicos (OCDE) de 1960, tiene por objetivo particular la colaboración económica entre los Estados europeos, incluyendo también a algunos países no europeos, como los EUA y el Japón. De acuerdo con el preámbulo del Convenio, la Organización fue creada en la convicción "de que una cooperación más amplia contribuirá de manera vital a las relaciones pacíficas y armónicas entre los pueblos del mundo", y de que "las naciones económicamente más avanzadas deben cooperar, en la medida de sus capacidades, para ayudar a los países en vías de desarrollo".

Entre las formas de cooperación más intensa, aunque limitada regionalmente, se encuentra el Acta Final de la Conferencia sobre Seguridad y Cooperación en Europa de 1975 (CSCE, hoy OSCE). Aquí lo determinante no es tanto la forma jurídica y la posible obligatoriedad internacional de las declaraciones, sino que el Acta pone al descubierto la relación interna que existe entre la seguridad militar y la general respecto de una cooperación

${ }_{124}$ Cfr. el artículo 128, inciso 2 del Tratado de la CE: "Conservación y protección del patrimonio cultural de importancia europea”. El artículo 7o., inciso 5 de la Constitución de Portugal (1976/92) habla de "identidad europea".

125 Cfr. el artículo 2o. del Tratado de la CE, así como el inciso 5 del preámbulo: "Con el propósito de unir sus economías nacionales y promover su desarrollo armónico, reduciendo la distancia entre las distintas regiones y el atraso de los territorios menos favorecidos...". 
Este libro forma parte del acervo de la Biblioteca Juridica Virtual del Instituto de Investigaciones Juridicas de la UNAM

más intensa en el terreno económico, social, científico, técnico, cultural, etcétera. El Acta Final, en la cual también participaron los Estados de Europa oriental, documenta la conciencia de los Estados en favor de la cooperación, a través de sus declaraciones de principios e intenciones, que es esencial para el desarrollo futuro del derecho internacional y de la protección internacional de los derechos humanos, lo que se ha profundizado desde "1989".

c) De ahí se derivan puntos de partida para un derecho internacional "humanitario" y "social" y, a escala universal, para el sistema comercial mundial institucionalizado desde 1994 en la Organización Mundial de Comercio $(\mathrm{OMC})$. El desplazamiento del centro de gravedad de la labor de la ONU, desde el mantenimiento de una paz simplemente negativa (en el sentido de ausencia de violencia militar) hacia la creación de la infraestructura económica, social y cultural de una "paz positiva" a través de una mayor justicia social, conduce la evolución del derecho internacional hacia un derecho cooperativo en sentido material. Así, en la declaración aprobada el 24 de octubre de 1970 por la Asamblea General de la ONU sobre los principios fundamentales del derecho internacional en relación con las relaciones amistosas y la cooperación entre los Estados, se dice que éstos, independientemente de sus diferencias de sistema político, económico y social, están obligados a la cooperación en los diversos planos de las relaciones internacionales, a fin de mantener la paz y la seguridad internacionales, la estabilidad y el progreso económicos, así como el bienestar general de los Estados y la colaboración internacional, libres de toda discriminación que pueda basarse en tales diferencias.

\section{Del Estado nacional soberano al Estado constitucional cooperativo}

En la medida en que, desde la perspectiva internacional, la cooperación entre los Estados ocupe el lugar de la mera coordinación y del simple ordenamiento de la coexistencia pacífica (es decir, de la delimitación de los ámbitos de la soberanía nacional), en el campo del derecho constitucional nacional pueden advertirse tendencias que apuntan hacia un debilitamiento de la distinción estricta entre lo interno y lo externo a favor de una apertura hacia el exterior. He aquí algunos ejemplos de la evolución de las etapas textuales.

Un aspecto importante es la cuestión de la apertura de los textos constitucionales hacia el derecho internacional. Siendo la Constitución escrita más antigua todavía vigente, la Constitución de los EUA del 17 de septiembre de 1787 no contiene, aparte de algunas disposiciones sobre el poder ex- 
Este libro forma parte del acervo de la Biblioteca Juridica Virtual del Instituto de Investigaciones Juridicas de la UNAM http://www.juridicas.unam.mx

terior (artículo I, sección 8, incisos 3 y 10, así como el artículo II, sección 2, inciso 2), ${ }^{126}$ enunciados sobre la relación de los Estados Unidos con otras naciones. Otras Constituciones antiguas, como la de Noruega de 1814,127 la de los Países Bajos de 1815, la de Bélgica de 1831 y la de Luxemburgo de 1868, han abandonado su introversión original y se han abierto al derecho internacional mediante reformas constitucionales muy recientes. Los nuevos artículos constitucionales, al permitir la transmisión de poderes soberanos a organizaciones e instituciones supraestatales o internacionales, documentan una disposición a renunciar a la soberanía que era ajena al derecho internacional tradicional. Disposiciones equivalentes se establecieron por primera vez en la Constitución de Italia de 1947 (artículo 11) y en la Ley Fundamental de la República Federal de Alemania de 1949 (artículo 24, inciso 1). La nueva Constitución griega de 1975 las contiene en su artículo 28, inciso 2. ${ }^{128}$ Que aquí pueda estar anunciándose un cambio fundamental general en la concepción que de sí mismos tienen los Estados soberanos lo permite suponer la Constitución de Suecia de 1975, que al contrario de la Constitución de 1809, a pesar de seguir vigente la neutralidad, dispone en su capítulo $10 \S$ 5 , inciso 2, que las funciones de la jurisdicción y la administración "pueden ser transferidas a otro Estado, a una organización internacional, o a una institución o comunidad extranjeras o internacionales"(véase ahora el capítulo $10, \S 5$ inciso 3). A nivel regional se vuelven comunes los "artículos sobre Europa" (por ejemplo, el nuevo texto del artículo 23 de la LF).

El reconocimiento de la cooperación internacional amistosa se encuentra predominantemente en las Constituciones recientes. Así, Irlanda afirma, conforme al artículo 29 de su Constitución de 1937, "su entrega al ideal de la paz y de la cooperación amistosa entre las naciones sobre la base de la justicia y la moral internacionales". El pueblo japonés se declara decidido, según el preámbulo de su Constitución de 1946, a "conservar los frutos de la cooperación pacífica con todos los pueblos".

Este breve paseo por las Constituciones europeas y algunas fuera de Europa permite reconocer el giro en la tendencia de muchos Estados (constitucionales) hacia la cooperación internacional. El análisis de las más de

126 El texto en Franz, G. (ed.), Staatsverfassungen, 1964, pp. 10 y ss.

127 El texto en Mayer-Tasch, P. G. (ed.), Die Verfassungen der nicht-kommunistischen Staaten Europas, 2a. ed., 1975, pp. 404 y ss.

128 "To serve an important national interest and to promote cooperation with other States, competences under the Constitution may be granted by treaty or agreement to organs of international organizations..." "Las competencias conforme a la Constitución podrán ser otorgadas mediante tratado o convenio a los órganos de organismos internacionales cuando tengan el propósito de contribuir a un interés nacional importante y de promover la cooperación con otros Estados"). 
Este libro forma parte del acervo de la Biblioteca Juridica Virtual del Instituto de Investigaciones Juridicas de la UNAM

100 Constituciones vigentes hoy en día de los países en desarrollo debería confirmar esta tendencia. ${ }^{129}$ Finalmente, debe hacerse referencia a las cláusulas especiales de apertura o cooperación que se basan en última instancia en características culturales comunes, como el mismo idioma ( $c f r$ el artículo 15, inciso 3, de la Constitución de Portugal de 1976/92 en relación con ciudadanos extranjeros de "países de lengua portuguesa", así como el artículo 11, inciso 3, de la Constitución española de 1978-1992 en relación con los tratados sobre doble nacionalidad con "países iberoamericanos").

\section{La imagen del mundo del Estado constitucional: "comunidad universal de los Estados constitucionales"}

Dicha imagen constituye una primera palabra clave. Como un elemento de la imagen del mundo del tipo del "Estado constitucional" nos atrevemos a afirmar que los diversos Estados constitucionales no existen más "para sín", sino que de entrada constituyen una comunidad universal abierta. La referencia al mundo y a sus semejantes en dicho mundo (la humanidad) es un pedazo de su noción de sí mismos, ya sea que se manifieste en forma de referencia a principios generales del derecho o a la internalización de derechos humanos universales (incluso en forma de una política exterior en favor de los derechos humanos), en forma de objetivos educacionales equivalentes, en la normación de valores fundamentales como la política por la paz mundial, la amistad y la cooperación internacionales, o en la obligación de proporcionar ayuda al desarrollo y ayuda humanitaria ("ayuda mundial contra el hambre"). Ciertamente, aquí hay siempre motivo para el desánimo. Sin embargo, si quiere conservar su credibilidad en sí, el Estado constitucional no puede desentenderse de representar "hacia fuera" los mismos valores que considera en lo interno como elementos de su identidad y de su concepción de sí mismo. Aunque pueda haber aquí y allá Estados autoritarios y totalitarios en el mundo, el Estado constitucional se encuentra en una comunidad responsable hacia sus semejantes con respecto al mundo y sus

129 Cfr. la Constitución de la República de Níger (1960), preámbulo, inciso 2: "They affirm their determination to cooperate in peace and friendship with all peoples who share this ideal of Justice, Liberty, Equality, Fraternity and Human Solidarity" (Afirman su determinación de cooperación en paz y amistad con todos los pueblos que compartan este ideal de Justicia, Libertad, Igualdad, Fraternidad y Solidaridad Humana"). En sentido amplio el artículo 145, inciso 1, de la Constitución del Paraguay: "La República del Paraguay, en igualdad de condiciones con otros Estados, acepta un sistema jurídico supranacional que garantice el cumplimiento de los derechos humanos, la paz, la justicia, y la cooperación, así como el desarrollo político, socio-económico y cultural". 
Este libro forma parte del acervo de la Biblioteca Juridica Virtual del Instituto de Investigaciones Juridicas de la UNAM http://www.juridicas.unam.mx

seres humanos, que debe cumplirse, por ejemplo, en materia del derecho internacional del ambiente o del espacio exterior. Algunos textos apuntan hacia esta responsabilidad. En todo caso, la "perspectiva cosmopolita" de I. Kant es actualmente un elemento del principio "esperanza" y del principio "responsabilidad" en el Estado constitucional. Los derechos humanos y el derecho de la humanidad van juntos. ${ }^{130}$ El nuevo "imperativo categórico" de H. Jonas ("Actúa de tal manera que las consecuencias de tu acción sean compatibles con una futura existencia humanamente digna, es decir, con el derecho de la humanidad a subsistir por tiempo indeterminado")'131 está en camino de convertirse en un texto clásico del Estado constitucional, con referencia mundial.

Frecuentemente, la comunidad universal de los Estados constitucionales en la responsabilidad puede exigirles demasiado o algo que solamente pueda cumplirse de manera puntual. La cuestión es si el Estado constitucional, en su etapa actual de desarrollo, tiene un deber de solidaridad regional; esto no en sentido de una hegemonía con vistas a dominar un pedazo del mundo, esto es, una región, sino en el de una asociación en igualdad de derechos. Así lo indican, por el lado de los textos constitucionales, las cláusulas de identidad mencionadas, referidas a las regiones, y los artículos relativos a competencias transfronterizas, incluyendo las comunidades de las Convenciones Europea y Americana sobre Derechos Humanos, quizá también la OSCE desde 1995. Precisamente, a partir de 1989 el Consejo de Europa ha exigido, con bastante éxito, a los países post-socialistas de Europa oriental, numerosos elementos constitucionales como condición para su adhesión (derechos humanos, protección de minorías, etcétera). Una asociación regional, políticamente vivida, de los Estados constitucionales se anuncia también con vistas a la responsabilidad, aunque erróneamente asumida, de los Estados de la UE por los países de los Balcanes como parte de Europa. Esto se manifiesta no solamente en el intento de fomentar la paz, sino también en los "requisitos constitucionales" que se pactaron, en calidad de "convenio marco", para Bosnia y Herzegovina (1995). Ya que aquí se "exigen" los elementos que caracterizan al Estado constitucional, como los derechos

130 En el sentido de Kant, I. (1795): "El derecho del ciudadano cosmopolita", "el ciudadano de un Estado universal del hombre" como "complemento necesario del derecho del Estado y del derecho internacional para formar el derecho público del hombre". Véase también la fórmula de Kant sobre "el derecho que corresponde a todo hombre en razón de su humanidad".

131 Cfr. sus conceptos clave (en Jonas, H., Das Prinzip Verantwortung, 1979): "La tecnología como vocación de la humanidad", "El primer imperativo: que haya humanidad", "La humanidad no tiene derecho al suicidio", "Futuro de la humanidad y futuro de la naturaleza". 
Este libro forma parte del acervo de la Biblioteca Juridica Virtual del Instituto de Investigaciones Juridicas de la UNAM

fundamentales (libertad de tránsito, libertades de opinión y de prensa) o los derechos humanos reconocidos internacionalmente; también se pactaron las elecciones, la aplicación del principio de mayoría y la creación de un "tribunal constitucional". La tarea de la "constitucionalización" de una región que así se anuncia podría convertirse en un anillo de crecimiento de las competencias y funciones, y aun de la legitimación, del Estado constitucional de hoy, lo que resultaría quizá más fácil de transmitir al ciudadano constitucional que un deber general, universal. Quizá sea demasiado pedirle, en "perspectiva cosmopolita", el "derecho ciudadano cosmopolita" de I. Kant; pero quizá pueda "pedírsele" hoy al menos una ciudadanía regional, porque está al alcance de la vista. 
Este libro forma parte del acervo de la Biblioteca Juridica Virtual del Instituto de Investigaciones Juridicas de la UNAM

\title{
GAPÍTULO TERGERO. TRATAMIENTO POR LA GIENGIA GULTURAL
}

\author{
I. EVOLUCIÓN DE LAS ETAPAS TEXTUALES \\ EN EL ESPACIO Y EL TIEMPO
}

La tesis inicial postula lo siguiente: en términos generales, el análisis de etapas textuales se manifiesta fructífero en el marco de la teoría de la Constitución como disciplina jurídica, y resulta sustantivamente indicado en la medida en que trabaje con las tipologías de manera consecuente y piense en el "eje del tiempo". En conjunto, tal análisis busca la variable del "cuadro textual" ("Textbild") de los diversos campos problemáticos de las Constituciones del Estado constitucional, en la medida en que sean "escritas", y pretende convertirla en el "camino real" (sit venia verbo) de un examen material y científico de la realidad de su objeto. ${ }^{132}$ Lo típico para el respectivo ámbito material puede ser captado de manera muy precisa gracias a un análisis textual sensible (en el cual resulte palpable la "realidad" a mediano plazo y de manera mediata). Más aún, solamente con auxilio de esta labor con los textos podrá la teoría constitucional ser "ciencia jurídica de los textos y la cultura", y vaciar en conceptos y principios "provisionales" al tipo, evolutivamente abierto, del "Estado constitucional".

Tomar los textos constitucionales positivos como punto de partida comparativo, y regresar una y otra vez a ellos, conjunta las nociones imprescindibles de un "positivismo ilustrado", es decir, que toma en serio los textos jurídicos, y la dimensión histórica profunda hasta la que puede penetrar una teoría de la Constitución en tanto "ciencia cultural" que trabaje de manera comparada e histórica.

La comparación constitucional, o de manera más precisa, la comparación de los textos constitucionales, es "vehículo" en el desarrollo del Estado constitucional y de su observación. Sin embargo, la comparación consti-

132 En esta medida sigue debiéndose a Heller, H., Staatslehre (1934) (la teoría del Estado como "ciencia cultural" y como "ciencia de la realidad", pp. 32 y ss., 37 y ss.; trad. cit.: pp. 57 y ss., 63 y ss. 
Este libro forma parte del acervo de la Biblioteca Juridica Virtual del Instituto de Investigaciones Juridicas de la UNAM

tucional no debe agotarse en lo textual, sino que el "constitutional law in the books" debe avanzar hacia un "law in public action". Empero, puesto que gracias a la comparación es frecuente que un "law in action" más antiguo adquiera forma textual en un "law in the books" más reciente, en la perspectiva del desarrollo histórico no son los textos sólo "superficie", sino también una pieza de la dimensión profunda del derecho constitucional viviente. Todos los esfuerzos de "reforma de los derechos fundamentales", por ejemplo, en Austria, ${ }^{133}$ o de una "revisión total" en Suiza, ${ }^{134}$ se apoyan en la comparación de textos en forma más o menos reconocible.

Hoy en día trabajan comparativamente todas las funciones estatales (desde el constituyente hasta el órgano que revisa de manera puntual o "total" la Constitución), ciertamente de manera más o menos intensa y abierta. Respecto de todas ellas cumple una especial función de proveedora la ciencia del Estado constitucional, es decir, la teoría de la Constitución. Hay, no obstante, una función estatal que en lo particular no debiera subestimarse en sus tareas y contribuciones jurídico-comparadas al desarrollo del Estado constitucional: la jurisprudencia constitucional, incluyendo los votos particulares. Su labor respecto del texto constitucional concreto de un Estado constitucional implica que donde el texto constitucional de su país no alcance, eche un "vistazo" comparativo a su alrededor. ¡En la jurisprudencia del TCFA ${ }^{135}$ hay ejemplos, precisamente en las sentencias de principio (Grundsatzentscheidungen), de este proceso de labor comparativa de los textos! La división del trabajo en el desarrollo progresivo del Estado constitucional a través de estos procesos de dar y recibir dentro de un país en lo particular, pero también por encima de sus fronteras con vistas a otros Estados constitucionales, siempre tiene que habérselas, visto así, con un conjunto de textos constitucionales. Quizá no todo el patrimonio de ideas y realidades que un tribunal constitucional nacional o la doctrina propongan como derecho constitucional material "cuaje" en textos constitucionales, pero en la "familia" de los Estados constitucionales pueden convertirse potencialmente en tales, unas veces más temprano, otras más tarde. Así miradas las cosas, la interpretación constitucional es frecuentemente una forma previa a las etapas

133 Cfr. Rack, R. (ed.), Grundrechtsreform, 1985, passim, especialmente el anexo, pp. 242 y ss.; véase también Wahl, R., ibidem, pp. 223, 224 y ss.; Holzinger, G., "Grundrechtsreform in Österreich", föR, vol. 38, 1989, pp. 325 y ss.

134 Véase al respecto el Bericht der Expertenkommission für die Vorbereitung einer Totalrevision der Bundesverfassung, 1977; actualmente Hangartner, Y. y Ehrenzeller, B. (ed.), Reform der Bundesverfassung, 1995.

135 Cfr. BVerfGE: 7, 198 (208); 19, 342 (348); 39, 68 (71, 73 y s.): voto particular de Ruppv. Brünneck/Simon; E. 69, 315 (343 y s.). 
Este libro forma parte del acervo de la Biblioteca Juridica Virtual del Instituto de Investigaciones Juridicas de la UNAM

de desarrollo de "textos constitucionales" y etapas textuales que se prolongan. El derecho constitucional consuetudinario no escrito puede orientarse, aquí, por los textos escritos de allá. ${ }^{136}$ Incluso el texto de los programas de los partidos políticos puede actuar a mediano plazo como "proveedor" de textos constitucionales nuevos, elaborados por el constituyente o por el poder revisor. Piénsese, por ejemplo, en los temas del Estado social o del medio ambiente, formulados primeramente por los partidos, o en las demandas de política cultural o en las aspiraciones de política de los medios.

La clave de la comparación de las etapas textuales consiste en que comprende también, de manera mediata, a la realidad constitucional, porque los textos de otros países que son recibidos o reelaborados convierten ahora en conceptos lo que la práctica (por ejemplo, la jurisprudencia constitucional), la doctrina y la docencia han desarrollado en otras partes. La evolución constitucional no escrita, ajena, concretamente de los Estados constitucionales occidentales, es literalmente prorrogada, por ejemplo, en las nuevas Constituciones de Europa oriental. Esto no significa que los textos constitucionales de Europa oriental, ya sean nuevos o revisados, prendan inmediatamente y creen ya una realidad constitucional conforme con la Constitución. Pero los nuevos textos reflejan el estadio de desarrollo de los Estados constitucionales en Occidente. Concretamente: no son la LF de 1949 ni la Constitución golista de 1958 las que actúan como modelos para algunos de los Estados constitucionales en Europa oriental, sino que son la LF de 1999, vivida en la jurisprudencia del TFC, en la doctrina y en la práctica, así como la Constitución de la Quinta República en 1999, desarrollada por el Conseil Constitutionnel, el Conseil d'État y la doctrina francesa, las que actúan como ejemplo para los jóvenes constituyentes en Europa oriental.

Ciertamente, a la larga no es suficiente la simple comparación de textos, sino que ésta constituye una primera fase de preparación científica, a la que debe seguir una fase más de comparación constitucional sustantiva que proceda conforme a los métodos, la sistemática y las funciones e incluya a las fuerzas que contribuyen a determinar el con-texto de los textos. Tratándose precisamente de nuevos textos, la ciencia depende por lo pronto de la

136 La categoría de "derechos fundamentales no escritos" (como las libertades de expresión, personal, lingüística y de asamblea; de la bibliografía: Müller, B. y Müller, S., Grundrechte. Besonderer Teil, 1985, pp. 97 y ss.; Müller, J. P., Elemente einer schweizerischen Grundrechtstheorie, 1982, pp. 23 y ss.) desarrollada en el derecho federal suizo por el Tribunal Federal en Lausana, es derecho constitucional material que posee en otros Estados constitucionales forma textual desde hace tiempo. Resulta consecuente entonces que en el marco de las revisiones totales o parciales se pida su garantía escrita. 
Este libro forma parte del acervo de la Biblioteca Juridica Virtual del Instituto de Investigaciones Juridicas de la UNAM http://www.juridicas.unam.mx

PETER HÄBERLE

comparación textual; lo demás se produce más adelante, "en el curso del tiempo".

\section{RIQUEZA DE LAS ESPECIES Y DIVERSIDAD DE FUNCIONES \\ DE LOS TEXTOS CONSTITUCIONALES EN EL ESPEJO DE UNA CONGEPCIÓN “MIXTA” DE LA CONSTITUCIÓN}

\section{Riqueza de las especies y multiplicidad de estratos de los textos constitucionales}

\section{A. Planteamiento del problema}

Las Constituciones más recientes en el mundo occidental, sobre todo en Europa a partir de 1975, han creado numerosos textos nuevos, o bien, modificado los antiguos. Puesto que precisamente la teoría constitucional, entendida como ciencia cultural, debe tomar en serio los textos constitucionales, resulta necesario hacer un inventario de la riqueza formal de estos textos, de sus múltiples estratos, que resultan palpables ya desde el punto de vista lingüístico, y de la diversidad de sus funciones; al respecto, el oficio y el arte de la interpretación constitucional han producido bibliotecas en el último decenio y medio. ${ }^{137}$ La teoría de la Constitución debe incluir su objeto, la diversidad de los textos, en sus planteamientos. Ya una mirada somera a las Constituciones más recientes de los Estados constitucionales muestra hasta qué punto esas han "crecido" y se han diferenciado, formal y sustantivamente, frente al tipo del antiguo Estado constitucional.

\section{B. Inventario en la selección; la diversidad de los ejemplos}

El inventario propugna por el tratamiento de los textos constitucionales bajo el criterio de la diversidad de lenguas, técnica y dogmática jurídicas, así como de funciones. Estos aspectos deben ir juntos, pero por lo pronto hay que desentrañarlos de manera separada. Hay que partir de la congruencia de las formas y los contenidos textuales. La teoría constitucional como

137 Documentados en parte en el volumen, editado por R. Dreier y F. Schwegmann, Probleme der Verfasunsinterpretation, 1976; véase además: Hesse, K., Grundzüge des Verfasungsrechts der Bundesrepublik Deutschland, 20a. ed., 1995, pp. 19 y ss.; Stern, K., Das Staatsrecht der Bundesrepublik Deutschland, vol. I, 2a. ed., 1984, pp. 123 y ss. (hay trad.: Derecho del Estado de la República Federal Alemana, Madrid, 1987). 
Este libro forma parte del acervo de la Biblioteca Juridica Virtual del Instituto de Investigaciones Juridicas de la UNAM

"ciencia jurídica de los textos y la cultura" toma a los textos como punto de partida, de manera precisa, pero recurre también a los "contextos" culturales presentes (!) en el proceso de creación, a fin de extraer todo el contenido, de estratos múltiples, de los textos. Esto no constituye una relativización de los textos, sino su fundamentación. Habrá de mostrarse que las formas textuales indican el uso altamente diferenciado de contenidos, los que hay que interpretar en consecuencia. El "microcosmos" de los diversos pasajes textuales es un elemento en el "macrocosmos" del conjunto total de la Constitución. Esto conduce a la existencia de un uso diferenciado de los métodos de interpretación constitucional. La diversidad del "ropaje" textual, sólo en apariencia externo, de los contenidos constitucionales, apunta hacia una diversidad de los contenidos y las funciones de las disposiciones constitucionales.

\section{a. La diversidad lingüística}

Muchos textos constitucionales se distinguen de los textos del derecho ordinario ya por su lenguaje, además de que ofrecen un cuadro en sí altamente diferenciado. Piénsese en el "lenguaje festivo" (sobre todo en los preámbulos) y en las normas orgánicas y competenciales que se mantienen más bien técnicas y racionales (por ejemplo, en las Constituciones federales). Los contenidos y funciones específicos de los preámbulos (la "sintonización" de los ciudadanos, los grupos y el pueblo pluralista con la Constitución; la "elaboración" de la historia, la fundamentación del texto constitucional como "concentrado") exigen un lenguaje "propio" con un "timbre" específico.

La amplitud e indeterminación, incluso la "apertura" de las disposiciones constitucionales, son prácticamente un lugar común. Sin embargo, un examen más próximo muestra cuán diferente es el "carácter de cláusula general" que poseen las disposiciones constitucionales (que va incluso hasta las normas especiales con efectos técnicos) y cuánto varía el texto literal en términos de su determinación.

Desde el punto de vista lingüístico, es posible distinguir los textos constitucionales que son de contenido más bien simbólico-retórico, educativo, incluso irracional ("de fe") de los que son más fuertemente " positivistas", jurídico-dogmáticos y racionales, con todas las transiciones y las formas mixtas. Los campos en los que el constituyente trabaja de forma simbólicaretórica, incluso teatral y sugestiva, son, además de los preámbulos, otras partes de la Constitución: sobre todo los artículos relativos a la bandera, los 
Este libro forma parte del acervo de la Biblioteca Juridica Virtual del Instituto de Investigaciones Juridicas de la UNAM http://www.juridicas.unam.mx

colores nacionales, los himnos, las lenguas, los fines de la educación, incluso los días festivos, como "fuentes irracionales del consenso" (K. Eichenberger). Ejemplos de ello son: el artículo 131 de la Constitución de Baviera de 1946-1984 ("Las escuelas no deben transmitir sólo el saber y la capacidad de hacer, sino también formar el corazón y el carácter...". "Los fines supremos de la educación son el temor de Dios... la apertura hacia todo lo verdadero, bueno y bello, así como la conciencia de la responsabilidad hacia la naturaleza y el ambiente..."); el artículo 32 de la Constitución de Hesse de 1946 ("El 1o. de mayo es día festivo oficial para todos los trabajadores. Este día simboliza el reconocimiento de la justicia social, el progreso, la paz, la libertad y el entendimiento de los pueblos"); el artículo 139 de la Constitución de la República de Weimar, ahora artículo 140 de la LF ("El domingo y las fiestas reconocidas por el Estado quedan protegidos por ley como días de descanso del trabajo y para la elevación espiritual"); y el artículo 56 de la Constitución española de 1978 ("El Rey es el Jefe del Estado, símbolo de su unidad y permanencia, arbitra y modera el funcionamiento regular de las instituciones..."). Es posible incluso encontrar un elemento "retórico" en algunas partes de los artículos, hoy tan refinados, sobre las (crecientes) tareas del Estado. ${ }^{138}$ Por último, este "espíritu" y este lenguaje penetran también en las garantías de los derechos fundamentales. ${ }^{139} \mathrm{El}$ prototipo de un preámbulo de lenguaje "cultivado" y rico contenido es el de la Constitución española de 1978. La Constitución de Portugal (de 1976/92) inicia su preámbulo con las siguientes frases grandilocuentes:

El 25 de abril de 1974, el Movimiento de las Fuerzas Armadas derribó el régimen fascista, coronando la larga resistencia del pueblo portugués y reflejando sus sentimientos más profundos. Liberar Portugal de la dictadura, la opresión y el colonialismo supuso una transformación revolucionaria y el comienzo de un cambio histórico de la sociedad portuguesa. La Revolución restituyó a los portugueses los derechos y libertades fundamentales.

138 Artículo 29, inciso 1, de la Constitución de Brandemburgo (1992): "La protección de la naturaleza, del ambiente y del paisaje cultural histórico como fundamento de la existencia actual y futura, es deber del Land y de todas las personas".

139 Ejemplos: artículo 22, inciso 3, de la Constitución de los Países Bajos de 1983 (citado en föR, vol. 32, 1982, pp. 277 y ss.): "El Estado y las demás corporaciones públicas crean las condiciones para el desenvolvimiento social y cultural y para el desarrollo de la libertad". Artículo 19, inciso 1, de la Constitución del Cantón del Jura de 1977: "Le droit au travail est reconnu". Artículo 25, inciso 2, de la Constitución de Grecia de 1975: "El respeto y la protección de la dignidad del ser humano es obligación fundamental del Estado" (citado en föR, vol. 32, 1983, pp. 355 y ss.). 
Este libro forma parte del acervo de la Biblioteca Juridica Virtual del Instituto de Investigaciones Juridicas de la UNAM http://www.juridicas.unam.mx

Aquí se vuelven tangibles el pathos y el ethos en el lenguaje. Es evidente la influencia de los preámbulos español y portugués en las Constituciones latinoamericanas recientes: compárese, por ejemplo, el preámbulo de la Constitución de Guatemala de 1985: "hemos sido impulsados por los ideales de nuestros antepasados y reconocemos nuestras tradiciones y nuestro patrimonio cultural...", y el de la Constitución de Perú de 1979. ${ }^{140}$

Un preámbulo que por su ritmo, contenido, lenguaje y forma "destinados" especialmente al ciudadano y que se "sintoniza" con él, es el logrado por la Constitución del Cantón de Basilea, de 1984:

El pueblo de Basilea, consciente de su responsabilidad ante Dios respecto del hombre, la comunidad y el ambiente; deseoso de proteger la libertad y el derecho en el marco de su tradición y su orden democráticos; en la certidumbre de que la fuerza del pueblo se mide por el bienestar de los débiles; con el propósito de facilitar el desenvolvimiento del hombre como individuo y como miembro de la comunidad; resuelto a consolidar al Cantón como estamento soberano en la confederación y a mantenerlo en su diversidad...

El lenguaje y la cultura festivos de los preámbulos posee larga tradición, así que no representan una etapa evolutiva nueva del Estado constitucional. Esto lo demuestran los antiguos preámbulos en Suiza (por ejemplo, de la Constitución federal: "¡En nombre de Dios Omnipotente! La Confederación Suiza, queriendo afirmar el vínculo entre los confederados, mantener y aumentar la unidad, la fuerza y el honor de la Nación Suiza..."). ${ }^{141}$ Sin embargo, la cultura del preámbulo sufre hoy un fuerte "empujón de crecimiento", sobre todo con vistas a los enriquecimientos valorativos, totalmente en el sentido del "pensamiento en términos de tareas" ("Aufgabendenken") que incluye a los derechos fundamentales.

$140 \quad$ El preámbulo de la Constitución de Perú de 1979 se inicia así: "Nosotros, diputados de la Asamblea Constituyente, sometidos a la protección de Dios y en ejercicio del poder soberano, que nos ha conferido el pueblo del Perú; en la convicción de la primacía de la persona humana y en que todos los hombres poseen dignidad y derechos de validez universal, anteriores al Estado y superiores a éste...”.

141 Cfr. también el preámbulo de la Constitución irlandesa de 1937: "En el nombre de la Santísima Trinidad, de quien proviene toda autoridad... reconociendo humildemente todas nuestras obligaciones hacia nuestro Divino Señor, Jesucristo... Recordando con gratitud su heroica [sic. de nuestros padres] e incansable lucha por recuperar la legítima independencia de nuestra Nación, y con el propósito de promover el bien común, observando debidamente la Sabiduría, la Justicia y la Caridad, de modo que pueda quedar asegurada la dignidad y libertad del individuo...". 
Este libro forma parte del acervo de la Biblioteca Juridica Virtual del Instituto de Investigaciones Juridicas de la UNAM

Esto queda de manifiesto incluso en Austria, ${ }^{142}$ a pesar del trasfondo de su tradición constitucional acentuadamente "formal" y enemiga de los preámbulos (véase la Constitución federal de 1920). El preámbulo de la Constitución de Bremen de 1947 es representativo de las tres características de los preámbulos orientados a valores de los Estados constitucionales (lenguaje festivo, "elaboración" de la historia y "anticipación" de los contenidos sustantivos de la Constitución, sobre todo de la parte relativa a los derechos fundamentales y a las funciones del Estado):

Sacudidos por la destrucción causada por el gobierno autoritario de los nacionalsocialistas, con desprecio de la libertad humana y de la dignidad del hombre en la centenaria ciudad libre y hanseática de Bremen, los ciudadanos de este Land están dispuestos a crear un orden de la vida social en la que se guarden la justicia social, la humanidad y la paz, en el que el débil económico sea protegido de la explotación y a todos los dispuestos al trabajo se les asegure una existencia digna.

Bastante afortunados son también las Constituciones y los preámbulos de los cinco nuevos Länder alemanes, de 1992-1993, el preámbulo de la Constitución de Polonia (1997), así como el de las Constituciones de Madagascar (1995) y de Togo (1992).

\section{b. La diversidad de técnica y dogmática jurídicas}

Las diferencias lingüísticas y la "diversidad de figuras" de las disposiciones constitucionales, las que se incrementan en el curso del proceso de crecimiento del tipo del Estado constitucional a partir de 1975, no son un fin en sí mismas. Los constituyentes las han creado para los propósitos de ciertos contenidos y funciones. Ciertamente, la dogmática "desarrolla", en el marco de sus métodos y a partir de textos gruesos y todavía poco diferenciados, una diversidad de contenidos más allá y por encima del texto. Pero seguramente no hay ni una figura de la dogmática que, hoy día, no haya adoptado ya forma en algún texto constitucional positivo, de tan intensa que se ha vuelto la cooperación internacional en materia del Estado constitucional.

142 Cfr. el preámbulo inserto en 1980 a la Constitución del Tirol de 1953: "conscientes, de que la fidelidad a Dios y a la herencia histórica, la unidad espiritual y cultural de todo el Land, la libertad y la dignidad del hombre, la familia ordenada como célula básica del pueblo y el Estado son los fundamentos espirituales, políticos y sociales del Land del Tirol, por lo que es deber supremo del legislador y el ejecutivo del Land su conservación y protección...”. 
Este libro forma parte del acervo de la Biblioteca Juridica Virtual del Instituto de Investigaciones Juridicas de la UNAM

Es posible distinguir una rica escala, que va desde la norma competencial formal, pasando por los principios constitucionales "objetivos" y el mandato constitucional, hasta el derecho fundamental subjetivo. Con frecuencia, estas dimensiones se encuentran contenidas en las mismas disposiciones constitucionales o en los mismos complejos normativos constitucionales, o bien, han sido desarrollados por la doctrina y la jurisprudencia. Piénsese en la multicitada "multidimensionalidad" de los derechos fundamentales como normas objetivas, "principios", derechos públicos subjetivos, mandatos constitucionales, contenidos protegidos, derechos de participación, o en los múltiples estratos del principio del Estado social, desde la proposición programática hasta el topos interpretativo, desde el derecho subjetivo mínimo (a la asistencia social) hasta el mandato legislativo. Es evidente que en la actualidad existe una tendencia a diseñar e interpretar las normas en tantos estratos como sea posible, de desentrañar en ellas no una sola dimensión de validez ("optimización"). ${ }^{143}$ Este refinamiento, particularmente visible en Alemania y Suiza, ${ }^{144}$ es de saludarse. También "el tiempo" es procesado de diversas maneras en los textos: desde la cláusula de recepción conservadora hasta el mandato constitucional dinámico. En suma, la doctrina de las "fuentes" del derecho se vuelve cuestionable ya desde el punto de vista conceptual-gráfico.

Desde un punto de vista "típico-ideal", pueden apreciarse dos modelos básicos. El modelo de facultamiento y delimitación (Ermächtigungsund Grenzziehungsmodell) y el de valores fundamentales (Grundwertemodell).

i) El modelo de facultamiento y delimitación se refiere a las normas orgánicas y sustantivas clásicas, en las cuales se encuentra en primer plano el carácter de facultamiento y delimitación. Por un lado se crean órganos estatales (“normas de creación”), se establecen competencias y distribuyen funciones; se reconocen facultades, se fijan los procedimientos y delimitan los ámbitos de competencia (por ejemplo, entre la Federación y los Länder, entre los diversos órganos del Estado, entre Estado e iglesias); por el otro lado, se separa sustantivamente del estatal el ámbito social-privado de los ciudadanos y los grupos a través de los derechos fundamentales (las "limitaciones" y "afectaciones" son excepciones). Este tipo formal y textual se ha realizado de la manera más pura en la Constitución bismarckiana de 1871, pues casi toda ella se parece a un "estatuto orgánico". Los catálogos

143 Son representativas de ello las sentencias del TCFA en BVerfGE 6, 55 (72); 7, 198 (203 y ss.); 39, 1 (38); 95, 193 (209).

${ }_{144}$ Cfr. por ejemplo, la doctrina de J. P. Müller sobre los "contenidos parciales" de los derechos fundamentales (en Elemente einer schweizerischen Grundrechtstheorie, 1982); Hesse, K., Grundzüge, cit., p. 28 (“optimización”). Cfr. también BVerfGE 81, 278 (292): “optimización”. 
Este libro forma parte del acervo de la Biblioteca Juridica Virtual del Instituto de Investigaciones Juridicas de la UNAM http://www.juridicas.unam.mx

de derechos fundamentales en el estilo de la Declaración francesa de 1789145 o de Bélgica (1831) representan el modelo clásico para la parte sustantiva o dogmática. El "dualismo" entre parte orgánica y parte de derechos fundamentales era la expresión dogmática de este estilo de normación, así como el razonamiento en términos de "afectaciones" y "limitaciones" "Eingriffsund Schrankendenken"), ${ }^{146}$ o el énfasis exagerado en lo formal y lo técnico. No hay normas que definan funciones o tareas, o sólo de manera muy aislada; así, por ejemplo en el preámbulo de la Constitución bismarckiana de 1871 ("unión eterna para la defensa del territorio de la Federación y del derecho vigente en el mismo, así como para promover el bienestar del pueblo alemán”) o a través de los fines de la Federación en el artículo 2o. de la Constitución federal suiza de 1874 ("La Confederación tiene por objeto asegurar la independencia de la Patria frente al extranjero, mantener la tranquilidad y el orden en el interior, proteger la libertad y los derechos de los confederados y acrecer su prosperidad común"). ${ }^{147}$ En pocas palabras, el tipo de la Constitución como "facultamiento y delimitación" puede caracterizarse a través de las partes orgánica y de derechos fundamentales, de la limitación en la relación del ciudadano hacia el Estado, pero también por la relación del segundo hacia el primero, en la cual éste delimita la libertad fundamental (en interés de los demás), así como mediante la delimitación entre el Estado central y las entidades federativas (en los Estados federales). ${ }^{148}$

ii) El segundo "modelo" es el modelo de valores fundamentales, un tipo de Constitución en cuyo texto, además de facultamientos y delimitaciones, se expresan contenidos, valores, fundamentos, pero sobre todo "tareas" ("Aufgaben"). La idea de Constitución de R. Smend como "estímulo y limitación" comprende ambos aspectos, pero el aspecto del "estímulo" puede

145 A diferencia del preámbulo de 1789 (“declaración solemne”, "sagrados derechos del hombre").

${ }_{146} \mathrm{Al}$ respecto véase la crítica de Häberle, P., Wesensgehaltsgarantie, cit., pp. VII y s., 136 y ss. Véase también el informe de la comisión suiza de expertos, 1977, p. 14: "El Estado gendarme del siglo XIX, dirigido sólo a la defensa del Estado, podría salir adelante con las normas de facultamiento y limitación".

147 Cfr. también la forma festiva, la estructura confesional y el contenido de la Bill of Rights de Virginia (1776): "I. Que todos los hombres son por naturaleza igualmente libres e independientes y que poseen ciertos derechos innatos, de los cuales no pueden privar o desposeer a sus descendientes cuando aceptan unirse en un estado; a saber, el derecho al disfrute de la vida y de la libertad".

148 La Constitución de Austria de 1920 permanece también en el contexto del positivismo jurídico de H. Kelsen, en la tradición del tipo constitucional que se encuentra más bien formal técnica, en el sentido de un pensamiento en términos de delimitación y distribución de competencias. 
Este libro forma parte del acervo de la Biblioteca Juridica Virtual del Instituto de Investigaciones Juridicas de la UNAM

manifestarse en las formas, etapas de intensidad y abstracción, así como "grados de densidad" más diversos, llegando hasta la obligación normativa. Si las Constituciones francesas a partir de 1791 recorrieron esta vía del enriquecimiento sustantivo, ${ }^{149}$ las nuevas Constituciones en Europa y América, a partir de 1975, siguen de manera más acentuada la tendencia hacia una "carga" material. Esto tiene un trasfondo político (partidista), ya que todos los participantes en el proceso constituyente y en los compromisos pluralistas desean introducir "su" parte, su "política", pero también hay una razón científica. La "idea material de Constitución" empieza a influir en el redactor del texto. La fórmula de U. Scheuner sobre la Constitución como "norma y tarea" 150 ofrece una expresión concisa sobre esta tendencia evolutiva. La conducción y el procesamiento, incluso la "reivindicación" de la realidad, es ya un particularidad textualmente visible de los constituyentes modernos (son pioneros la forma y el "espíritu" de la segunda parte de la Constitución de Weimar de 1919, en especial los artículos 119 a 122, 139, 148, 151, 155; cfr. ahora, respecto de la "naturaleza y el ambiente", los artículos 39 a 40 de la Constitución de Brandemburgo de 1992).

Llama la atención el enriquecimiento material de la Constitución en todos los ámbitos problemáticos y en toda clase de normas constitucionales, si bien hay diferencias tanto entre países como en el eje temporal: unas veces se enriquece ya el preámbulo con tareas; otras se da a la parte competencial (no sólo en los Estados federales) la forma de tareas; en otras más los derechos fundamentales se presentan como tareas del Estado o en ropaje procesal, o bien se crean tipos de normas completamente nuevos (por ejemplo, en las cláusulas sobre "el espíritu" o sobre el "patrimonio cultural", o artículos de reconocimiento o normas de bases). Al respecto también hay formas mixtas.

Esta "doctrina de los modelos" tiene que relativizarse, pues dependiendo del "estilo de codificación", y esto quiere decir también de la "antigüedad" de un documento constitucional o de sus modificaciones, tiene una importancia mayor o menor (en Europa) lo formal y lo técnico; las Constituciones más recientes son habitualmente más "ricas" en lo material y lo textual, sin prescindir de los textos más antiguos. Pero aun ahora hay diferencias. Así, por ejemplo, la Constitución de los Países Bajos de 1983 es más bien reservada y parca respecto de los "grandes" contenidos y programas,

149 Compárense sus textos. Los puntos son: Constitución de 1848 (por ejemplo, preámbulo y artículo 13), artículos 22 a 39 de la Constitución de 1946.

150 Scheuner, U., voz "Verfassung" (1963), ahora en Staatstheorie und Staatsrecht. Ges. Schriften, 1978, pp. 171 (172). 
Este libro forma parte del acervo de la Biblioteca Juridica Virtual del Instituto de Investigaciones Juridicas de la UNAM http://www.juridicas.unam.mx

mientras que las nuevas Constituciones de los dos países ibéricos, Portugal y España, prefieren proposiciones barrocas, materiales, que sugieren numerosas diferenciaciones. Y en general, casi ningún tema constitucional se encuentra fijado en una sola forma textual. En los apartados orgánicos de las Constituciones pueden encontrarse fuertes elementos materiales, así como puede haber elementos formales-orgánicos en la parte de los derechos fundamentales. Las partes se unifican. Finalmente, existen múltiples "formas mixtas", como normas sobre tareas casuísticas, normas sobre tareas relativas a los derechos fundamentales ("derechos fundamentales sociales y culturales"), cláusulas limitativas especiales, mandatos dirigidos únicamente al legislador (artículos programáticos).

En este sentido, los textos pueden haber sido "trabajados" de manera diversa. En ocasiones, el constituyente los formula como cláusulas generales abiertas; en otras los redacta de manera especial y casuista; al respecto, constituyen una forma mixta las disposiciones constitucionales "redactadas" en estilo de "en particular" o "por ejemplo" (tratándose de los derechos fundamentales y sus limitaciones, o de normas generales o detalladas sobre las tareas del Estado).

La riqueza de formas se manifiesta en la utilización alternada del "catálogo" de ciertos derechos fundamentales o bienes constitucionales. La lista puede actuar "compresoramente", pero también puede convertirse en una sobrecarga de los textos constitucionales. Unas veces se encuentran catálogos que se pretenden abiertos, es decir, no exhaustivos, en otras se pretenden "cerrados", exhaustivos. 151

Las definiciones legales constitucionales, es decir, la definición de conceptos a nivel constitucional, son un instrumento de uso frecuente. En estos casos la Constitución se esfuerza por lograr un máximo de precisión, y los procesos de concretización de la misma se simplifican. Los ejemplos los ofrecen Constituciones pertenecientes a etapas evolutivas muy diversas, y en ámbitos problemáticos muy distintos. ${ }^{152}$

151 He aquí algunos ejemplos: el artículo 40, inciso 6, núm. 1, de la Constitución de Irlanda de 1937 lista los derechos de los ciudadanos (a la libertad de expresión asamblea y asociación). El artículo 45, inciso 2, se refiere a los fines políticos ("en particular"). Cfr. también el capítulo 2o. § 1 de la Constitución sueca de 1974.

152 El artículo 81, inciso 1, de la Constitución española de 1978: "Son leyes orgánicas las relativas al desarrollo de los derechos fundamentales y de las libertades públicas...". Véase también los artículos 121 de la LF (concepto de mayoría); 22, inciso 1, de la Constitución de Irlanda de 1937 (definición de "proyecto de ley financiera"); 154 de la Constitución de Hesse de 1946 ("nacionales"); 51 de la Constitución de Schleswig-Holstein de 1949 ("mayoría"). 
Este libro forma parte del acervo de la Biblioteca Juridica Virtual del Instituto de Investigaciones Juridicas de la UNAM http://www.juridicas.unam.mx

Un grupo especial de normas constitucionales lo constituyen las normas de reconocimiento (Bekenntnis-Normen), las cláusulas sobre símbolos y valores fundamentales, los artículos "en el espíritu" y sobre el "patrimonio cultural”, las cláusulas sobre identidad, principios y primacía. Estas cláusulas son formas de expresión y vehículo de un enriquecimiento, incluso de una "carga" sustantiva y orientada a valores, de las Constituciones. Se presentan en numerosos sitios, potencialmente en cualquier parte del documento constitucional; en sí mismas se encuentran diferenciadas, asumen incluso formas mixtas, e impregnan con grados variables las Constituciones de los distintos países. En general, hoy tienden más a incrementarse que a disminuir y se proyectan hacia el grupo de las normas de tareas (por ejemplo, en el artículo 3o., incisos 1 y 2, de la Constitución de Baviera o en la fórmula del "Estado social de derecho" de la LF), pero siguen distinguiéndose de éstas. En las Constituciones anteriores se encuentran solamente de manera muy fragmentaria, o sólo en sus comienzos, pero en las más recientes, como las de los países ibéricos, se muestran al mismo tiempo y en forma "masiva". Si se presentan al mismo tiempo con el grupo de las normas de tareas y con las normas relativas a los derechos fundamentales, convertidas en estratos múltiples, nos hallamos ante el prototipo de una Constitución "material".

Las "normas de reconocimiento" se encuentran en varios ámbitos. En las Constituciones más recientes ocupan un lugar más prominente: por ejemplo, en los preámbulos, ${ }^{153}$ en los artículos de bases, ${ }^{154}$ en las garantías sobre los días festivos, ${ }^{155}$ pero también en otras partes de la Constitución. ${ }^{156}$ La "forma del reconocimiento" es una indicación de la gran importancia de los contenidos, de su calificación como valores fundamentales, que trata de vincular el pensamiento objetivamente existente con el grado más alto

153 Véase el preámbulo de la Constitución francesa de 1958: "El Pueblo francés proclama solemnemente su adhesión a los Derechos del Hombre y a los principios de la soberanía nacional...”. En términos similares la Constitución de Benin (1990).

154 Constitución española de 1978, título preliminar, artículo 1o., inciso 1; artículo 1o., inciso 2 de la LF de 1949: "El pueblo alemán reconoce por tanto, que los derechos inviolables e inalienables del hombre son el fundamento de toda comunidad humana, de la paz y de la justicia en el mundo".

155 Por ejemplo, el artículo 3o., inciso 2, frase 2, de la Constitución de Baden-Württemberg de 1953: "El primero de mayo tiene por propósito el reconocimiento de la justicia social, la paz, la libertad y el entendimiento de los pueblos".

156 Por ejemplo, el artículo 69, inciso 1 de la Constitución de Hesse de 1946 en el apartado sobre "Vínculos internacionales": "Hesse reconoce la paz, la libertad y el entendimiento entre los pueblos". El artículo 2o., inciso 3, de la Constitución de Brandemburgo (1992): Reconocimiento de los derechos fundamentales de la CEDH, de la Carta Social Europea, etc. Véase también el artículo 1o., inciso 2, de la Constitución de Turingia. 
Este libro forma parte del acervo de la Biblioteca Juridica Virtual del Instituto de Investigaciones Juridicas de la UNAM http://www.juridicas.unam.mx

de identificación del sujeto del poder constituyente, el pueblo o el individuo (casi en el sentido de artículos "confesionales"). La racionalidad y los contenidos subjetivos-irracionales establecen la vinculación más estrecha posible. El constituyente crea en realidad aquí una cláusula de identidad; hace una afirmación sobre su concepción de sí mismo.

Los artículos simbólicos ${ }^{157}$ se encuentran estrechamente emparentados con las normas de reconocimiento. Un buen ejemplo es el artículo 2o., segundo párrafo, de la Constitución francesa de 1958 (similarmente, el artículo 1o. de la Constitución de Benín): "L'Emblème national est le drapeau tricolore, bleu, blanc, rouge. L'hymne national est 'la Marsellaise'. La devise de la République est: 'Liberté, Egalité, Fraternité'. Son principe est: gouvernment du peuple, par le peuple et pour le peuple"; ${ }^{158}$ pero también el juramento del presidente de la República de Irlanda. ${ }^{159}$ Por ello, no es casualidad que figuren la mayoría de las veces en los artículos de bases de la Constitución. ${ }^{160}$ España (Constitución de 1978) ubica sus artículos sobre las lenguas y la bandera también en el título preliminar (artículos 3o. y 4o.), y respecto del Rey utiliza incluso, de manera expresa, el concepto de "símbolo". 161

También se aproximan a los artículos símbolicos y de reconocimiento a las cláusulas sobre valores fundamentales. Un ejemplo preciso es el artículo 12, inciso 6, de la Constitución de Renania del Norte-Westfalia: "En las escuelas de la comunidad se instruirá en común a los niños sobre la base de los

157 Sobre los símbolos, por ejemplo, los "colores del Reich" (artículo 3o. Constitución de Weimar); Smend, R., "Verfassung und Verfassungsrecht" (1928), en Staatsrechtliche Abhandlungen, 3a. ed., 1994, pp. 162, 260 y ss.

158 "El emblema nacional es la bandera tricolor: azul, blanco, rojo. El himno nacional es 'La marsellesa'. El lema de la República es: 'Libertad, igualdad, fraternidad'. Su principio es: gobierno del pueblo, por el pueblo, para el pueblo" (N. del T.).

159 Artículo 12, inciso 8, de la Constitución de Irlanda.

160 Así, en la Constitución de Italia (1947), principios fundamentales, artículo 12: "La bandera de la República es la tricolor italiana...". Artículo 11 de la Constitución de Portugal (bandera e himno); artículo 5o. de la Constitución de Berlín de 1950: símbolos del Land: "La bandera, el escudo y el sello de Berlín llevarán un oso...". Véase por último los artículos 161 y siguientes de la Constitución de Angola (1992).

161 Artículo 56, inciso 1: "El Rey es el jefe del Estado, símbolo de su unidad y permanencia...”. La Constitución de Japón procede de manera semejante en su artículo 1o. (citado en Neumann, R., Änderung und Wandlung der Japanischen Verfassung, 1982, pp. 185 y ss.): "El Tenno es el símbolo de Japón y de la unidad del pueblo japonés". El artículo 85 de la Constitución peruana de 1979 señala a las banderas, el escudo y el himno nacional como "símbolos de la patria". Artículo 11 de la Constitución de Georgia (1995): "The State Symbols of Georgia are determined by organic law". Artículo 34 de la Constitución de Burkina Faso (1997): "Los símbolos de la nación". 
Este libro forma parte del acervo de la Biblioteca Juridica Virtual del Instituto de Investigaciones Juridicas de la UNAM

valores culturales y formativos cristianos en apertura hacia las confesiones cristianas y hacia otras convicciones... religiosas...".

Quizá el artículo de valor fundamental más conciso lo haya creado el constituyente español (1978) en su artículo lo., inciso 1:162 "España se constituye en un Estado social y democrático de derecho, que propugna como valores superiores de su ordenamiento jurídico la libertad, la justicia, la igualdad y el pluralismo político".

Un tipo de texto constitucional, no infrecuente en la actualidad, son los artículos "en el espíritu". Se encuentran en varios campos de la regulación, así por ejemplo, en los preámbulos, ${ }^{163}$ en los fines de la educación, ${ }^{164}$ en fórmulas de juramento ${ }^{165} \mathrm{y}$ al servicio de la descripción de la función de la jurisdicción. ${ }^{166}$ Las cláusulas "en el espíritu" 167 reflejan el intento del constituyente de capturar y fijar lo fundamental de sus contenidos, de su estado de conciencia. La referencia a los valores fundamentales es tan evidente, como difícilmente comprensible y aplicable resulta la positividad jurídica o incluso la justiciabilidad de tales normas. Sin embargo, esta técnica de normación y (tendencialmente también) de positivización podría tomarse como importante instrumento en el arsenal de los constituyentes más recientes, dirigido hacia las tres funciones estatales y en ocasiones como obligatorios también para el ciudadano.

Las "cláusulas sobre el patrimonio" cultural son de la misma materia y espiritu. Se encuentran en las Constituciones recientes, por ejemplo, en el preámbulo de la Constitución de Guatemala de 1985: "somos impulsados por los ideales de nuestros antepasados y reconocemos nuestras tradiciones

162 Cfr. el artículo 8o. de la Constitución de Macedonia (1991): "fundamental values"; artículo 3o. de la Constitución de Croacia (1991); "valeurs suprêmes", artículo 1o., inciso 1 de la Constitución de Guinea Ecuatorial (1991): "valores supremos".

163 Preámbulo de la Constitución de Hamburgo de 1952. Preámbulo de la Constitución de Brandemburgo (1992): "En el espíritu de las tradiciones de derecho, tolerancia y solidaridad...".

164 Artículo 133 de la Constitución de Renania-Palatinado de 1947.

165 Por ejemplo, el artículo 111 de la Constitución de Hesse de 1946 ("así como obedecer y defender la Constitución y las leyes en el espíritu democrático").

166 Artículo 62 de la Constitución de Berlín (1950-1994): "La administración de justicia se ejercerá en el espíritu de esta Constitución y de la comprensión social".

167 El Tribunal Constitucional Federal alemán las empleó en la célebre sentencia Lüth: E 7, 198 (205): "toda... disposición debe ser interpretada en su espíritu (sic. del sistema de valores)". "Texto clásico" es el § 112, inciso 1, de la Constitución de Noruega de 1814: "espíritu de esta Constitución". 
Este libro forma parte del acervo de la Biblioteca Juridica Virtual del Instituto de Investigaciones Juridicas de la UNAM http://www.juridicas.unam.mx

y nuestro patrimonio cultural...". ${ }^{168}$ Remitimos a otros ejemplos textuales ${ }^{169}$ (cfr. solamente el artículo 34, inciso 2, de la Constitución de Brandemburgo: "Se promueven públicamente la vida cultural en su diversidad y la transmisión del patrimonio cultural"; preámbulo de la Constitución de Polonia de 1997: "comprometidos a transmitir a las nuevas generaciones todo lo valioso de una herencia de más de mil años").

Estas cláusulas se encuentran emparentadas con la célebre frase del maltés A. Pardo (1967) sobre el "patrimonio común de la humanidad" y constituyen un enriquecimiento del cuadro textual de las Constituciones del Estado constitucional, por lo que podemos hablar de "patrimonio cultural".

Las normas sobre principios constituyen una forma paralela. ${ }^{170}$ Así, al apartado sobre el "trabajo", la Constitución de Guatemala de 1985 antepone la siguiente frase: "La vida laboral del país debe organizarse de conformidad con los principios de la justicia social" (artículo 101, frase 2). ${ }^{171}$ La antigua Constitución de Perú de 1979 procede en su texto de manera similar (artículo 110): "El orden económico de la República se funda en los principios de la justicia social". ${ }^{172}$

168 Véase también el preámbulo de la antigua Constitución de Perú de 1979: "así como de la herencia célebre de Sánchez Carrión, fundador de la República...”. También el preámbulo de la Constitución del Tirol de 1980 ("herencia histórica"); Constitución de Níger (1996).

169 Por ejemplo, al artículo 46 de la Constitución española: "Los poderes del Estado garantizarán la conservación y promoverán el enriquecimiento del patrimonio histórico, cultural y artístico de los pueblos de España y de los bienes que lo integran...". Artículo 78, inciso 2c de la Constitución de Portugal: "Fomentar y proteger el patrimonio cultural, a fin de que se convierta en un elemento renovador de la identidad cultural común". Artículo 36 de la Constitución de Perú: "Los sitios arqueológicos declarados como patrimonio cultural de la nación, y las ruinas, construcciones, monumentos, objetos artísticos y testimonios de valor histórico se encuentran bajo protección del Estado". Artículo 61 de la Constitución de Guatemala: "Protección del patrimonio cultural". Véase también el artículo 60 de la misma Constitución. Cfr. el preámbulo de la Constitución de Hamburgo: "Como ciudad portuaria cosmopolita, misión que le es atribuida por su historia y ubicación...”. Quizá la descripción más amplia, que va más allá de lo jurídico, sobre el patrimonio cultural se encuentre en la Convención Europea de los Derechos Humanos de 1950: "resueltos como gobiernos de los Estados europeos, imbuidos del mismo espíritu y que poseen una herencia común de bienes espirituales, tradiciones políticas, respeto ante la libertad y el gobierno de las leyes...".

170 Cfr. el artículo 101 inciso 2 de la Constitución del Sarre: "La modificación (de la Constitución) no puede contrariar los principios del Estado social y democrático de derecho". Véase también el artículo 129, inciso 2 de la Constitución de Renania-Palatinado; el artículo 56, inciso 3, de la Constitución de Mecklemburgo-Antepomerania.

171 El artículo 118 de la misma Constitución señala: "El orden económico y social de la República de Guatemala se basa en los principios de la justicia social".

172 Véase también el artículo 30 de la misma Constitución: "Toda persona natural o jurídica tiene el derecho... de fundar establecimientos educativos respetando los principios constitucionales". 
Este libro forma parte del acervo de la Biblioteca Juridica Virtual del Instituto de Investigaciones Juridicas de la UNAM http://www.juridicas.unam.mx

Y con toda la intención de la "defensa" de la Constitución se dice en el artículo 277, inciso 1, de la Constitución de Portugal: "Son inconstitucionales las normas que infrinjan lo dispuesto en la Constitución o los principios establecidos en ella".

En el ámbito de los fines de la educación utiliza la Constitución española de 1978 la figura de los principios. ${ }^{173}$ La forma más amplia es la empleada por la Constitución portuguesa (1976/92): "Portugal es una República soberana, basada en la dignidad de la persona humana y en la voluntad popular...".

La teoría de H. Heller sobre los "principios del derecho" es el marco clásico para la comprensión de este tipo de artículos.

Las referencias de la Constitución a sí misma constituyen una nueva forma característica de disposición constitucional, que se encuentra, por ejemplo, en las "cláusulas de eternidad", ${ }^{174}$ así como en otros campos problemáticos; por ejemplo, al formular el deber de lealtad del maestro. ${ }^{175}$ Con mucha frecuencia se trata de grupos de artículos sobre la "defensa de la Constitución" en sentido profundo y amplio. Esto se vuelve especialmente claro en la Constitución de Hesse de 1946. ${ }^{176}$ Las Constituciones extranjeras aplican esta forma de artículo a ámbitos amplios, como el artículo 30, párrafo tercero, de la anterior Constitución de Perú, de 1979, ${ }^{177}$ el artículo 39 de la Constitución de Georgia de 1995 a la cláusula de desarrollo de los derechos fundamentales.

173 El artículo 27, inciso 2 señala: "La educación tendrá por objeto el desarrollo pleno de la personalidad humana en el respeto a los principios democráticos de convivencia y a los derechos y libertades fundamentales".

174 Artículo 75, inciso 1, frase 2, de la Constitución de Baviera de 1946: "No se admitirán las iniciativas de reforma constitucional que contraríen los principios democráticos fundamentales de la Constitución". Artículo 20, inciso 1, de la Constitución de Bremen de 1947: "Son inadmisibles las modificaciones constitucionales, que violen las nociones fundamentales de los derechos universales del hombre". En forma similar el artículo 150, inciso 1, de la Constitución de Hesse de 1946 ("nociones fundamentales democráticas de la Constitución"); artículo 64 de la Constitución de Camerún (1996).

175 Artículo 36 de la Constitución de Renania-Palatinado de 1947.

176 Véase los artículos 146, inciso 2, y 150, inciso 1, en el marco del apartado "La defensa de la Constitución".

177 Véase el artículo 277, inciso 1, de la Constitución de Portugal (1976/82): "Son inconstitucionales las normas que infrinjan lo dispuesto en la Constitución o los principios establecidos en ella". Artículo 288 de la misma Constitución: "Las leyes de revisión constitucional deberán respetar: a) La independencia nacional y la unidad del Estado; b) La forma republicana de gobierno; c) La separación de las Iglesias y el Estado; d) Los derechos, libertades y garantías de los ciudadanos...”. En forma similar el artículo 159 de la Constitución de Angola (1992). 
Este libro forma parte del acervo de la Biblioteca Juridica Virtual del Instituto de Investigaciones Juridicas de la UNAM

Cada vez se hacen más frecuentes los "artículos de primacía", es decir, las normas constitucionales que destacan especialmente un bien jurídico y le confieren una especial jerarquía de valor; el parentesco con las cláusulas de defensa ${ }^{178}$ es evidente. También la jurisprudencia constitucional postula frecuentemente la "primacía", ${ }^{179}$ un paralelismo que con seguridad no es accidental.

Ejemplos antiguos son el artículo 125, inciso 1, de la Constitución de Baviera de 1946 ("Los niños sanos son el bien más preciado de un pueblo"), también el artículo 12, inciso 1, de la Constitución de Bremen de 1947 ("El ser humano es más valioso que la técnica y la máquina"), o el artículo 24, inciso 1, frase 2, de la Constitución de Renania del Norte-Westfalia de 1950 ("La protección de su fuerza de trabajo - del ser humano - tiene primacía ante la protección de las posesiones materiales"). ${ }^{180}$ Sobre todo las nuevas cláusulas de protección del ambiente se atreven a utilizar este estilo codificatorio, que es prueba, por un lado, de la necesidad e indispensabilidad de los procesos de ponderación en la concretización de las normas constitucionales, y por el otro, revela inseguridades o conduce a las mismas. Resulta característico el artículo 141 de la Constitución de Baviera: "También corresponde a las funciones primordiales del Estado, de los municipios y las corporaciones públicas, la protección del suelo, el agua y el aire como bases naturales de la vida". ${ }^{181}$

En el extranjero llama la atención la cláusula unilateral de primacía del artículo 44, inciso 2, de la Constitución de Guatemala (1985): "El interés social prima sobre el interés individual", claro está que en el contexto de un artículo sobre "los derechos naturales de la persona". Y ya en el preámbulo hay una anticipación, aunque cae en alguna contradicción: "Nosotros, los

178 Por ejemplo, el artículo 166, inciso 1, de la Constitución de Baviera de 1946: "El trabajo es la fuente del bienestar del pueblo y se encuentra bajo la especial protección del Estado". Artículo 40, inciso 2, frase 2, de la Constitución de Brandemburgo: "En consecuencia se dará especial peso al interés público en el uso cuidadoso del suelo".

179 Por ejemplo, BVerfGE 39, 1 (142): "La vida humana constituye un valor supremo dentro del orden de la Ley Fundamental". E 33, 23 (29): la dignidad humana como "bien supremo”. Igualmente E 54, 341 (357). Véase también E 89, 28 (35); 95, 220 (241).

180 Artículo 53, inciso 1, de la Constitución de Renania-Palatinado de 1947: "La fuerza de trabajo humana debe protegerse contra la explotación como contribución personal y como bien económico valioso del pueblo".

181 En forma similar el artículo 11 a, inciso 1, frase 2, de la Constitución de Bremen. El artículo 29 a, inciso 2, de la Constitución de Renania del Norte-Westfalia ha encontrado una cláusula compensatoria ("Las obligaciones y deberes necesarios se determinan en compensación de los intereses públicos y privados de que se trate"). Artículo 59, inciso 1, frase 2, de la Constitución del Sarre: "Corresponde por tanto a las funciones primordiales del Estado la protección del suelo, el agua y el aire como bases naturales de la vida...”. 
Este libro forma parte del acervo de la Biblioteca Juridica Virtual del Instituto de Investigaciones Juridicas de la UNAM

representantes del pueblo guatemalteco... afirmamos la primacía de la persona humana como sujeto y objeto del orden social".

La problemática de tales cláusulas de primacía es evidente, pues amenazan con relativizarse o incluso anularse mutuamente, o bien, a caer en contradicción. Guatemala ofrece un ejemplo especial al respecto. La anterior Constitución de Perú (1979) señala en su preámbulo: "en la creencia de la primacía de la persona humana...", y esta valoración se repite en un artículo de bases (artículo lo., frase 1) con las palabras: "La persona humana es el fin supremo de la sociedad y el Estado".

La Constitución de Portugal (1976-1992) recurre varias veces a la figura de la primacía: por ejemplo, en el artículo 68, inciso 2 ("La maternidad y la paternidad son valores sociales eminentes"), una cláusula que provoca incertidumbres, ya que no menciona los valores concurrentes, y tampoco puede hacerlo, pues las reglas de preferencia solamente pueden desarrollarse paulatinamente en el proceso de la interpretación. Por tanto, desde el punto de vista de la política constitucional, este tipo de cláusulas debería utilizarse de manera muy reservada.

De las anteriores hay que distinguir las normas de tareas ("Aufgaben-Normen"). Estas normas constituyen hoy día quizá el campo más rico en la innovación y la fantasía, la diversidad de textos y la capacidad de diferenciación, incluso ambivalencia, de los constituyentes. Tales normas conquistan todas las partes y los campos problemáticos de la Constitución: desde el preámbulo, pasando por los derechos fundamentales, hasta la parte orgánica. Se dirigen a los destinatarios más variados (funciones del Estado, ámbitos de la sociedad o la economía), y van desde las cláusulas de "preocupación", pasando por los artículos de "protección" y "promoción", hasta el mandato constitucional justiciable o el mandato legislativo. Se conocen en la dogmática como "disposiciones sobre los fines del Estado" (U. Scheuner) ${ }^{182}$ o como "normas estructurales del Estado", ${ }^{183}$ y su grado de obligatoriedad normativa es variable. En el umbral inferior se encuentra la competencia o facultamiento meramente formal, incluso la garantía receptora del status quo. Su forma más fuerte es el "mandato constitucional". Su frecuente carácter como principio rector la emparenta con los artículos de identidad y principios. Por su contenido, son muy diversas: van desde el "bien común"

182 Scheuner, U., Staatszielbestimmungen (1972), reproducido más tarde en id., Staatstheorie und Staatsrecht, 1978, pp. 223 y ss.

183 Cfr. Stern, K., Das Staatsrecht der Bundesrepublik Deutschland, vol. I, 2a. ed., 1984, pp. 551 y ss. 
Este libro forma parte del acervo de la Biblioteca Juridica Virtual del Instituto de Investigaciones Juridicas de la UNAM http://www.juridicas.unam.mx

como fin amplio del Estado, hasta un fin particular (como el de protección a la familia o el ambiente).

La creciente utilización de normas de tareas es una característica de la actual etapa evolutiva del Estado constitucional, y expresa una concepción diferente del Estado y de la Constitución ("Estado y Constitución como tarea", o también como "proceso"), pero por su parte también la alimentan. La figura del "mandato o encargo constitucional" ("Verfassungsauftrag") 184 es sólo un ejemplo, aunque el más frecuente. Ciertamente nos lo encontramos en diversas variantes, pues puede tener como destinatario al Estado o a alguna de sus funciones particulares, o bien a otros sujetos, como la "economía" o el individuo. ${ }^{185}$ Llama la atención la creciente interrelación e intercambiabilidad entre los derechos fundamentales y las tareas del Estado, pues los derechos fundamentales se presentan como tales, pero también con el "ropaje" de tareas del Estado. ${ }^{186}$ Inversamente, éstas se manifiestan como contenidos objetivados de los derechos fundamentales. ${ }^{187}$

Ciertamente que entre las distintas naciones hay grandes diferencias en esta materia: $c f r$. los artículos de "preocupación" más bien reservados de la Constitución de los Países Bajos (1983), por un lado, con las numerosas

184 Véase, de la bibliografía, Lerche, P., "Das Bundesverfassungsgericht und die Verfassungsdirektiven", AöR, vol. 90, 1965, pp. 241 y ss.

185 Como "deberes fundamentales", véase por ejemplo el artículo 120, incisos 2 y 4, de la Constitución de Grecia de 1975. En forma similar el artículo 10, inciso 1, frase 1, de la Constitución de Sajonia (1992): "La protección del medio ambiente... es obligación de todos en el Land". En forma similar el artículo 86 de la Constitución de Polonia (1997); artículo 50 de la Constitución de Usbekistán.

186 Por ejemplo, el artículo 9o. de la Constitución de Portugal: "Son misiones fundamentales del Estado: ... 2. Garantizar los derechos y libertades fundamentales y el respeto a los principios del Estado democrático de derecho...". Una estrecha fusión de derechos fundamentales y tareas del Estado se encuentra en la nueva Constitución del Vorarlberg de 1984: "Artículo 7o. Objetivos y principios de la acción estatal (1) El Land tiene la tarea de asegurar el libre desarrollo de la personalidad del individuo, así como el desarrollo de la vida comunitaria según los principios de subsidiariedad y solidaridad de todos los grupos sociales. Se promoverán la autonomía y autoayuda de los ciudadanos. (2) Toda acción estatal en el Land debe respetar la dignidad del ser humano, la igualdad ante la ley, la proporcionalidad de los medios empleados y los principios de la buena fe".

187 Cfr. el capítulo 1, § 2, inciso 2, de la Constitución de Suecia de 1974: "El bienestar personal, económico y cultural del individuo será objetivo fundamental de la actuación pública. En particular, corresponderá a la administración pública asegurar el derecho al trabajo, la vivienda y la educación, y promover la previsión y la seguridad sociales, así como un buen ambiente para la vida”. 
Este libro forma parte del acervo de la Biblioteca Juridica Virtual del Instituto de Investigaciones Juridicas de la UNAM

normas de tareas de Portugal y España, por el otro. ${ }^{188}$ Suiza sigue una línea intermedia en las Constituciones, totalmente revisadas, de los cantones. ${ }^{189}$

Quizá el constituyente esté retornando hoy a la concepción clásica, conforme a la cual el Estado y todas sus competencias se encuentran situadas instrumentalmente al servicio de los derechos fundamentales, como lo estipula el artículo 2o. de la Declaración francesa de los Derechos del Hombre: "El fin de toda asociación política es la conservación de los derechos naturales e imprescriptibles del hombre. Estos derechos son la libertad, la propiedad, la seguridad y la resistencia a la opresión".

El Estado no posee valor propio; las tareas del Estado son, a final de cuentas, "tareas de los derechos fundamentales". 190

Una norma sobre los fines del Estado, audaz para Austria, lo intenta el nuevo artículo 4o. de la Constitución de la Baja Austria de 1979 (más tarde en forma similar el artículo 7o. de la Constitución del Tirol): "Condiciones de vida: El Land de la Baja Austria deberá ocuparse, en su ámbito de acción, de que estén garantizadas las condiciones de vida de la población en las diversas regiones del Land, tomando en cuenta las necesidades económicas, sociales y culturales que se aprecien".

Las tareas del Estado se encuentran en la forma más concentrada posible en los preámbulos, incluso en la Constitución bismarckiana de 1871, concebida en forma tradicional y orgánica, y en la Constitución suiza de 1874, y con mayor razón en las Constituciones más recientes.

Algunas Constituciones escogen los artículos de bases como ubicación sistemática de las tareas del Estado o de los derechos fundamentales; así, por ejemplo, el artículo 1o., inciso 1, de la Constitución de BadenWürttemberg de 1953: "El Estado tiene la misión de servir al ser humano para tal fin (el desenvolvimiento de su libertad). El Estado reúne a los seres humanos que habitan en su territorio en una comunidad ordenada, les otorga protección y estímulo y promueve a través de las leyes y los mandamientos una compensación de los derechos y deberes mutuos".

Un ejemplo conciso más es el del artículo 2o., inciso 1, de la Constitución de Grecia de 1975: "El respeto y la protección de la dignidad del ser humano es obligación fundamental del Estado".

188 Por ejemplo, artículos 9o. (fines fundamentales del Estado), 60 inciso 2, 63 inciso 2, 81 de la Constitución de Portugal; artículo 9o., inciso 2 de la Constitución española.

189 Artículo 41, inciso 1, frase 1, de la Constitución de Berna de 1993: "El cantón y los municipios protegen y fomentan la salud".

190 Véase al respecto Häberle, P., "Grundrechte im Leistungsstaat", VVDStRL, vol. 30, 1972, pp. 43, en especial 103 y ss. 
Este libro forma parte del acervo de la Biblioteca Juridica Virtual del Instituto de Investigaciones Juridicas de la UNAM

(El "padrinazgo" del artículo 1o., inciso 1, de la LF es evidente, como también lo es respecto del artículo 30 de la Constitución de Polonia.)

El pensamiento en términos de tareas conquista, textualmente, incluso derechos fundamentales clásicos, como la libertad de prensa, ${ }^{191}$ también el matrimonio y la familia, ${ }^{192}$ el principio de igualdad, ${ }^{193}$ o nuevos derechos de participación cultural. ${ }^{194}$ Se encuentran próximos a los "deberes fundamentales", ${ }^{195}$ y se hallan incluso en los fines de la educación. ${ }^{196}$ Por la vía (el rodeo) de estos últimos, el pensamiento en términos de tareas llega incluso hasta el ser humano individual. ${ }^{197}$ Destinatario puede ser el Estado, pero también la economía. ${ }^{198}$ Los artículos de promoción son una variante en la evolución de la competencia puramente formal hacia la tarea (estatal). ${ }^{199}$

En forma paralela al terreno que han ganado los mandatos constitucionales corre la penetración de las cláusulas de defensa (Schutzklauseln), frecuentemente referidas a derechos fundamentales, las cuales se conquistan cada vez más temas y campos problemáticos, sobre todo en relación con el

191 Cfr. por ejemplo, el artículo 111 de la Constitución bávara de 1946: "La prensa tiene la tarea de informar... sobre sucesos de la vida pública al servicio de la idea democrática". Artículo 67 de la Constitución de Usbekistán (1992): "responsibility for trustworthiness".

192 Artículo 41, inciso 3, núm. 1, de la Constitución de Irlanda de 1937.

193 Cfr. por ejemplo el preámbulo de la Constitución de Guatemala de 1985.

194 Cfr. el artículo 34, inciso 2, frase 2, de la Constitución del Sarre: "Deberá facilitarse a todas las capas del pueblo la participación en los bienes de la cultura".

195 Por ejemplo, el artículo 59a, inciso 1, frase 1, de la Constitución del Sarre: "La protección de las bases naturales de la vida está encomendada al cuidado especial del Estado y de cada individuo". Artículo 12, inciso 3, de la Constitución de Mecklemburgo-Antepomerania: "Todos están obligados a contribuir a la realización de los fines indicados en los incisos 1 y 2". Artículo 82 de la Constitución de Polonia (1997): "Es deber de todo cuidadano polaco la lealtad hacia la República de Polonia y la preocupación por el bien común".

196 Artículo 101, inciso 1, de la Constitución de Sajonia (1992): "La juventud deberá educarse... en la conservación del ambiente, el amor a la patria...".

$197 C f r$. el artículo 26 de la Constitución del Sarre: "La docencia y la educación tienen el fin de formar a los jóvenes, de modo que puedan cumplir con su tarea en la familia y la sociedad".

198 Por ejemplo, el artículo 51, inciso 1, de la Constitución de Renania-Palatinado: "La economía tiene la tarea...”.

199 Artículo 41, inciso 3, frase 1, de la Constitución de Berna (1993): "El cantón y los municipios promueven la ayuda y los cuidados en casa". Artículo 34, inciso 1, de la Constitución de Georgia (1995): "The state promotes the development of culture...". 
Este libro forma parte del acervo de la Biblioteca Juridica Virtual del Instituto de Investigaciones Juridicas de la UNAM

medio ambiente ${ }^{200}$ y la cultura, ${ }^{201}$ el trabajo ${ }^{202}$ y la economía. ${ }^{203}$ Cada vez se utiliza más al Estado al servicio de fines más detallados. Remitimos por ello al socorrido modo indicativo y al tiempo presente ("se encuentra bajo protección del Estado"). ${ }^{204}$ Una categoría propia (aunque más débil) del pensamiento en términos de tareas son las cláusulas sobre el "cuidado", como el artículo 21, inciso 3, de la Constitución de Grecia de 1975 ("El Estado velará por la salud de los ciudadanos..."; véase también el inciso 4, ahí mismo: "El otorgamiento de vivienda para las personas que carezcan de ella o vivan en condiciones inadecuadas es objeto de especial cuidado por el Estado").205 Se trata de un elemento estructural esencial en los textos de la Constitución de los Países Bajos de 1983.206 Sobre todo los "derechos fundamentales sociales" (derechos de participación) se presentan en esta forma, con lo cual se

200 Por ejemplo, el artículo 9o., inciso 2, de la Constitución de Italia de 1947. Artículo 39, inciso 3, de la Constitución de Brandemburgo de 1992: "Los animales y las plantas son respetados como seres vivos. Deben conservarse y protegerse las especies y su hábitat".

201 Artículo 9o. de la Constitución del Vorarlberg de 1984: "Educación y cultura. El Land reconoce el cultivo de la ciencia, la educación y el arte, así como de la patria. Respeta la libertad, independencia y diversidad de la vida cultural, así como el derecho de cada quien de participar en ella". Véase también el artículo 10 de la Constitución de Benín (1990).

202 Artículo 49, inciso 1, de la Constitución de Bremen (1947): "El trabajo humano goza de la protección especial del Estado". Artículo 40 de la Constitución de Renania-Palatinado de 1947: "Protección del trabajo intelectual". En forma similar el artículo 28 de la Constitución de Burkina Faso (1997).

203 Artículo 45, inciso 4, núm. 1, de la Constitución de Irlanda: "El Estado se compromete a promover con especial cuidado los intereses económicos de los grupos económicamente más débiles...".

204 Artículo 21, inciso 1 de la Constitución de Grecia: "La institución de la familia, en cuanto fundamento de la preservación y mejoramiento de la nación, así como el matrimonio, la maternidad, y la infancia, serán protegidos por el Estado". Artículo 24, inciso 6, de la misma Constitución: "Los monumentos y sitios históricos serán protegidos por el Estado". Artículo 40, inciso 3.2, de la Constitución de Irlanda: "El Estado protege a través de sus leyes, en particular y de la mejor manera que le sea posible, contra ataques injustos, y en el caso de que se haga injusticia, reivindicará la vida, la persona, el buen nombre, y los derechos de propiedad de cada ciudadano". Artículo 30, inciso 3, de la Constitución de Turingia de 1993: "El deporte goza de protección y promoción por el Land y sus corporaciones territoriales".

205 Véase también la Constitución de Luxemburgo, artículo 11, inciso 5: "La ley tendrá cuidado de la seguridad social, de la protección de la salud y del descanso de los trabajadores y garantiza las libertades sindicales".

206 Artículo 19, inciso 1. "La creación de empleos suficientes es objeto del cuidado de las autoridades...". Artículo 20, inciso 1, ahí mismo: "Será objeto del cuidado de las autoridades asegurar los medios de subsistencia de la población y lograr la distribución de la riqueza". Artículo 21: "Será objeto del cuidado de las autoridades mantener el país habitable, así como la protección y el mejoramiento del ambiente". Artículo 22, inciso 2: "Será objeto del cuidado de las autoridades la provisión de suficiente espacio para vivir". 
Este libro forma parte del acervo de la Biblioteca Juridica Virtual del Instituto de Investigaciones Juridicas de la UNAM http://www.juridicas.unam.mx

debilita su contenido como derechos públicos subjetivos y son reducidos a lo objetivo, lo puramente programático. Una forma paralela la constituyen los giros desarrollados en Suiza: "El Estado adopta medidas..." (v. gr., para la promoción de la familia ${ }^{207}$ o de los derechos sociales).

El cambio en el estilo de la normación así como la tendencia hacia el "pensamiento en términos de tareas" puede advertirse incluso en el mismo documento constitucional, modificado en forma especialmente concisa en Suiza, aunque pueden constatarse formas mixtas entre las simples normas competenciales y las de tareas (ocasionalmente en el mismo artículo (!)). Una característica del proyecto de revisión total de la Constitución federal de 1977208 es que el pensamiento en términos de tareas se encontraba fuertemente (ien exceso?) en primer plano, lo que trata de corregir el nuevo proyecto de 1995.

Muchos temas que eran normados como simple competencia en las anteriores etapas evolutivas del Estado constitucional adoptan actualmente la forma de cláusulas de tareas. La Constitución federal austriaca de 1920 es típica de la etapa textual anterior. En cambio, la Constitución de Portugal inventa un nuevo terreno para el pensamiento en términos de tareas al formular la función de la jurisdicción. ${ }^{209}$

Los programas clásicos y (en retrospectiva) la normatividad "unidimensional" de la Declaración de los Derechos del Hombre de 1789 se han transformado en la pluralidad y diversidad de estratos de los contenidos de los derechos fundamentales en las Constituciones más recientes. Los derechos fundamentales se presentan ya en su texto no sólo como derechos públicos subjetivos, en el sentido del "statusnegativus", sino como conjunto pluridimensional con múltiples "contenidos parciales" (aparte de que sus "temas" se han incrementado numéricamente hablando). ${ }^{210}$ La política de los derechos fundamentales es la finalidad del constituyente. En interacción con la dogmática común europea de los derechos fundamentales, que se ha diferencia-

\footnotetext{
207 Cfr. el § 38 de la Constitución del Cantón de Aaargau de 1980.

208 Citado en $F \ddot{0} R$, vol. 34, 1985, pp. 536 y ss.

209 Artículo 202, inciso 2: "En la administración de la justicia corresponde a los tribunales asegurar la defensa de los derechos e intereses legalmente protegidos de los ciudadanos, reprimir la violación de la legalidad democrática y dirimir los conflictos de intereses públicos y privados".

210 Un derecho fundamental "nuevo" era y es, por ejemplo, la libertad de manifestación. Cfr. El artículo 8o., lit. g, de la Constitución del Cantón del Jura, el artículo 45, inciso 2, de la Constitución de Portugal, el artículo 33, de la Constitución de Guatemala, el artículo 29, inciso 1, lit. d, de la Constitución de Uganda (1995), el artículo 32 de la Constitución del Paraguay (1992), y también el derecho de "ejercer el periodismo" (artículo 29, incisos 1 a 3 de esta última Constitución).
} 
Este libro forma parte del acervo de la Biblioteca Juridica Virtual del Instituto de Investigaciones Juridicas de la UNAM

do, los textos constitucionales mismos se han vuelto pluriformes, mientras que, a la inversa, los textos recientes incitan a la dogmática a un mayor refinamiento.

Antes como ahora, es frecuente que las diversas capas, dimensiones y tareas (también "temas") de los derechos fundamentales aparezcan de modo fragmentario en el texto de las Constituciones, hasta que la evolución de la jurisprudencia, la dogmática y la realidad de los derechos fundamentales "lleven andando" varios años. Sin embargo, el cuadro textual es suficientemente diverso. Los derechos fundamentales, o algunos momentos de ellos en particular, se extienden a todas las partes del texto del documento constitucional: desde sus preámbulos, pasando por la parte relativa a los derechos fundamentales hasta la parte orgánica, con lo cual ésta, en su materia, también "crece" textualmente para "encontrarse" con las tareas del Estado, o viceversa.

Antes como ahora subsisten grandes diferencias entre los distintos pueblos, de acuerdo con su propia cultura constitucional, pero tendencialmente puede observarse un fuerte incremento y refinamiento de los contenidos de los derechos fundamentales. El ropaje lingüístico va desde la consagración más bien simbólica de los derechos fundamentales en los preámbulos, hasta su garantía normativamente precisa como derechos subjetivos, como "principio" o institución, y como "realización" de tales derechos a través de la organización y el procedimiento. Rara vez se manifiestan textualmente en el derecho fundamental particular, al mismo tiempo, todas las capas y dimensiones posibles, pero siempre son posibles los préstamos interpretativos con el derecho fundamental vecino.

Ahora, por lo que se refiere a la ubicación sistemática. La idea de los derechos fundamentales se ha ubicado en el "corazón" de algunas Constituciones nuevas, en los preámbulos, y con ello se incrementa su valor. Nos encontramos varios ejemplos al hablar de los "textos funcionales". Con frecuencia, los derechos fundamentales se anticipan, en forma de principios, en los preámbulos, a pesar de que, o precisamente porque, a continuación se expone un catálogo detallado de derechos fundamentales; a menudo también son formulados de manera directa, o según su materia, en la parte sobre las competencias y tareas del Estado. En ocasiones los derechos fundamentales son trasladados, parcial o totalmente, a la parte relativa a las bases de la Constitución. ${ }^{211}$

211 Por ejemplo, el artículo 2o., inciso 1, de la Constitución de Grecia. "El respeto y la protección de la dignidad humana constituyen una obligación fundamental del Estado". 
Este libro forma parte del acervo de la Biblioteca Juridica Virtual del Instituto de Investigaciones Juridicas de la UNAM http://www.juridicas.unam.mx

Unas palabras sobre la creciente diversidad de capas, orientaciones y dimensiones: la forma del derecho clásico a la no interferencia (Abwehrrecht) también encuentra su lugar en los nuevos textos. ${ }^{212}$ El estilo de normación jurídica objetivo-institucional ${ }^{213}$ también se encuentra con frecuencia, pero unas veces se indica el elemento del derecho individual, y otras se encuentran entrelazados ambos aspectos. ${ }^{214}$ También son familiares para el constituyente los valores y los principios como forma. ${ }^{215}$ La versión social de los contenidos de los derechos fundamentales avanza visiblemente: en forma de derechos fundamentales sociales y culturales o de derechos de participación. ${ }^{216}$ La garantía de los derechos fundamentales bajo el "ropaje" de las tareas del Estado casi forman legión. 217 Incluso la dogmática de la realización de los derechos fundamentales "a través de la organización y el proce-

212 Por ejemplo, el artículo 5o., inciso 3, de la Constitución de Grecia: "La libertad de la persona es inviolable". Artículo 45, inciso 2, de la Constitución de Portugal: "Se reconoce a todos los ciudadanos el derecho de manifestación". Artículo 38 de la Constitución española: "Se reconoce la libertad de empresa en el marco de la economía de mercado". Artículo 10, inciso 1, de la Constitución de los Países Bajos: "Todos tienen derecho al respeto de su vida privada". Artículo 33 de la Constitución del Paraguay: "Derecho a la privacía".

213 Sobre la dogmática, veáse Hesse, K., op. cit., pp. 112 y ss.; Häberle, P., Das Wesensgehaltsgarantie des Art. 19 Abs. 2 GG, 3a. ed., 1983, pp. 70 y ss., 332 y ss.

214 Por ejemplo, el artículo 9o., inciso 1 de la Constitución de Grecia: "El domicilio de toda persona es inviolable". Artículo 16, inciso 1, frase 1: "El arte y la ciencia, la investigación y la docencia son libres; su desarrollo y promoción constituyen una obligación del Estado".

215 Por ejemplo, artículo 21, inciso 1, de la Constitución de Grecia: "La institución de la familia, en cuanto fundamento de la preservación y mejoramiento de la nación, así como el matrimonio, la maternidad y la infancia, serán protegidos por el Estado." Artículo lo., inciso 1, de la Constitución española: "España se constituye en un Estado social y democrático de derecho, que propugna como valores superiores de su ordenamiento jurídico la libertad, la justicia, la igualdad y el pluralismo político". Artículo 10, inciso 1, de la misma Constitución: "La dignidad de la persona, los derechos inviolables que le son inherentes, el libre desarrollo de la personalidad... son fundamentos del orden político y de la paz social".

216 Por ejemplo, artículo 16, inciso 4, de la Constitución de Grecia: "Todos los griegos tienen derecho a educación gratuita...", § 16 de la Constitución del Cantón de BasileaComarca: "Todos tienen derecho a la ayuda y protección en situaciones de necesidad y a los medios necesarios para una vida humanamente digna". Artículo 19, inciso 1, de la Constitución de los Países Bajos: "La creación de empleos suficientes es objeto del cuidado de las autoridades...".

217 Artículo 20, inciso 2, de la Constitución de los Países Bajos: "Las reglas relativas a los derechos a la seguridad social serán establecidas mediante ley del Parlamento". Artículo 72, inciso 1, de la Constitución de Polonia (1997): "La República de Polonia velará por la protección de los derechos del niño...". 
Este libro forma parte del acervo de la Biblioteca Juridica Virtual del Instituto de Investigaciones Juridicas de la UNAM http://www.juridicas.unam.mx

dimiento" ${ }^{218}$ ha dejado ya sus huellas en los textos. ${ }^{219}$ En ocasiones, los derechos fundamentales se incorporan textualmente ya en el canon de los fines de la educación ${ }^{220}$ y la transición hacia el tema de los "deberes de protección"221 del Estado es fluida. ${ }^{222}$

Resulta evidente que el constituyente moderno tiene presente el rico cuadro de los contenidos de los derechos fundamentales desarrollados por la dogmática y la jurisprudencia. La mayoría de las veces norma solamente algunas dimensiones de un derecho fundamental (por ejemplo, en el apartado mismo de los derechos fundamentales o en el de las tareas del Estado) y con frecuencia únicamente una de ellas. Esto no impide que la subsecuente "evolución" desenvuelva otras dimensiones, ya sea por la vía de la comparación jurídica interna (analogías con los derechos fundamentales vecinos) o por la de la diversidad de ejemplos que ofrecen otros Estados constitucionales.

La realidad, o más precisamente, la transformación de los contenidos normativos en la correspondiente realidad, es un tema que fascina a las Constituciones con posterioridad a la Segunda Guerra Mundial. En la medida en que la teoría del Estado ha descubierto su dimensión como "ciencia de la realidad", sobre todo gracias a H. Heller, ${ }^{223}$ el constituyente manifiesta en sus textos que para él no es suficiente su normatividad "ideal", sino que

218 Sobre la dogmática, veáse Hesse, K., Grundzüge, cit., pp. 160 y s.; Häberle, P., Grundrechte im Leisitungsstaat, cit., pp. 86 y ss., 121 y ss.

219 Por ejemplo, artículo 38, inciso 6, de la Constitución de Portugal; § 14, inciso 1, de la Constitución del Cantón de Basilea-Comarca: "Los derechos fundamentales deben aplicarse a todo el orden jurídico" (igualmente el artículo 27, inciso 1, de la Constitución de Berna de 1993). El artículo 24 del Proyecto de Constitución Federal de Suiza (1977): "Los derechos fundamentales deben aplicarse a toda la legislación, especialmente en las disposiciones orgánicas y procesales".

220 Por ejemplo, artículo 22, inciso 3, de la Constitución del Perú: "Las clases sobre la Constitución y los derechos humanos son obligatorias en las instituciones educativas civiles". Artículo 72, inciso 2, de la Constitución de Guatemala: "El Estado tiene un interés nacional en la educación... y en la introducción sistemática a la Constitución del Estado y los derechos humanos".

221 Sobre la dogmática Hesse, K., Grundzüge, cit., pp. 155 y s. Cfr. recientemente BVerfGE 89, 276; 90, 145 (195); 92, 26 (46); 95, 193 (209).

222 Por ejemplo, el artículo 43, inciso 1, de la Constitución española: "Se reconoce el derecho a la protección de la salud". Artículo 49 de la Constitución del Cantón de Uri: "El cantón y los municipios se ocupan en sus actividades de la protección del hombre, de su ambiente y de su espacio vital". Artículo 7o. de la Constitución del Perú: "La madre tiene derecho a la protección del Estado...". Artículo 3o. de la Constitución de Guatemala: "El Estado garantiza y protege la vida desde la concepción, así como la intangibilidad y la seguridad de la persona".

223 Heller, H., op. cit., pp. 63 y ss. 
Este libro forma parte del acervo de la Biblioteca Juridica Virtual del Instituto de Investigaciones Juridicas de la UNAM

quiere una "normalidad social" conforme con la Constitución, una realidad efectiva de los derechos fundamentales. Dos técnicas de normativización cristalizan en los cuadros textuales hoy día: por un lado, los cláusulas sobre la realización de los derechos fundamentales, ${ }^{224}$ y por el otro, los artículos en los que el constituyente pretende "reencontrar" en la realidad sus directivas normativas, sobre todo en relación con las tareas del Estado: como cláusulas de desarrollo.

Pionero en este sentido es el artículo 3o., segundo párrafo, de la Constitución italiana de 1947:

Es misión de la República suprimir los obstáculos de orden económico y social que, limitando de hecho la libertad y la igualdad de los ciudadanos, impidan el pleno desarrollo de la personalidad humana y la efectiva participación de todos los trabajadores en la organización política, económica y social del país.

El artículo 9o., inciso 2, de la Constitución española dispone:

Corresponde a los poderes públicos promover las condiciones para que la libertad y la igualdad del individuo y de los grupos en que se integra sean reales y efectivas; remover los obstáculos que impidan o dificulten su plenitud y facilitar la participación de todos los ciudadanos en la vida política, económica, cultural y social. ${ }^{225}$

Un antecedente de las cláusulas de realización de los derechos fundamentales es el artículo 42, inciso 3, núm. 2, de la Constitución de Irlanda de 1937.226

Las cláusulas de desarrollo se encuentran en el artículo 15, inciso 2, de la Constitución de Grecia de 1975 ("La radio y la televisión... procurarán... salvaguardar en sus emisiones, en todo caso, el nivel de calidad que resulte

$224 \mathrm{Al}$ respecto, Starck, C., "Europas Grundrechte im neuesten Gewand", FS H. Huber, 1982, pp. 467, 481 y ss.

225 El proyecto de revisión total de la Constitución federal suiza, de 1977 (citado en fö $R$, vol. 24, 1985, pp. 536 y ss.), también se guía por este estilo de razonamiento y normación orientado a la realización. Artículo 24: "Realización de los derechos fundamentales. Los derechos fundamentales deben aplicarse a toda la legislación, especialmente en las disposiciones orgánicas y procesales". Lo sigue, por ejemplo, el artículo 15 de la Constitución del Cantón de Uri (1984) (citado en föR, vol. 34, 1985, pp. 467 y ss.): "Realización de los derechos fundamentales".

226 "Sin embargo, el Estado, como guardián del bien común, debe exigir, con vistas a las condiciones existentes, que los niños reciban un cierto mínimo de educación moral, intelectual y social". 
Este libro forma parte del acervo de la Biblioteca Juridica Virtual del Instituto de Investigaciones Juridicas de la UNAM

necesario respecto de su función social y el desarrollo cultural del país") ${ }^{227}$ y se generaliza en el artículo 25, inciso 2, de la misma Constitución ("El reconocimiento y la protección de los derechos fundamentales e inalienables del hombre por el Estado tendrá por objeto lograr el progreso social en libertad y justicia").

\section{c. Procesos de diferenciación y transformación}

La riqueza formal de los textos constitucionales y la "correlativa" diversidad dogmática de los contenidos son grandes, cuando, como sucede aquí, se va más allá, de modo comparativo, de la respectiva Constitución de un pueblo, y se enriquece la diversidad de ejemplos con los provenientes de tantas democracias occidentales como sea posible.

Lo que se puede observar es una diferenciación progresiva, a la que apunta ya incluso la cantidad creciente de los artículos de las diversas Constituciones; y esta observación se deriva con mayor razón del análisis cualitativo. Los "procesos de crecimiento" y las "etapas evolutivas" del tipo del Estado constitucional se manifiestan en un refinamiento de los medios y las posibilidades del texto. Cuando el texto es insuficiente o fragmentario, la interpretación constitucional posterior asume la tarea de "hacer" una diferenciación con base en otros ejemplos textuales. Aquí una constatación: si bien el texto del artículo 6o., inciso 1, de la LF está formulado como derecho objetivo, de él se han derivado tres dimensiones protectoras (BVerfGE $6,55): 228$ "derecho fundamental clásico", "garantía institucional" y "norma fundamental valorativa". Estas dimensiones también se han manifestado en alguna medida en otros derechos fundamentales. Es en esta medida que el material textual de diferenciación del constituyente actúa potencialmente de modo universal, porque está presente para el intérprete incluso donde el constituyente (todavía) no lo ha introducido. ¡La idea de la efectivización de los derechos fundamentales ha desplegado una dinámica tal que se han desarrollado prácticamente todas las dimensiones y "estratos" imaginables!

Lo característico es que cada vez se interrelacionan más fuertemente, en sus elementos típicos, las partes dogmática y orgánica de la Constitución, a pesar de su separación externa ("bifurcación de la Constitución"), pues

227 Artículo 16, inciso 2, de la misma Constitución: "La educación constituye un objetivo fundamental del Estado y tiene por propósito la instrucción moral, intelectual, profesional y física de los griegos, el desarrollo de la conciencia nacional y religiosa, así como la formación de ciudadanos libres y responsables".

228 Véase al respecto Häberle, P., Verfassungsschutz der Familie, 1984, pp. 28 y ss. 
Este libro forma parte del acervo de la Biblioteca Juridica Virtual del Instituto de Investigaciones Juridicas de la UNAM

los elementos formal-orgánicos se encuentran también en el apartado de los derechos fundamentales ("protección de los derechos fundamentales a través de la organización y el procedimiento"), pero en las normas sobre los fines del Estado se esconden también derechos públicos subjetivos (derechos sociales derivados de las cláusulas sobre el Estado social). ${ }^{229}$ Los mandatos constitucionales y los elementos programáticos se encuentran también en el apartado de los derechos fundamentales, así como hay elementos eminentemente materiales que se encuentran asimismo en el derecho orgánico de apariencia puramente formal. La "unidad de la Constitución" realiza también aquí su obra: ambas partes de la Constitución sirven en última instancia a una sola res publica. A esto se agrega la creciente juridificación. Las tareas del Estado son (nuevamente) concebidas en última instancia en la perspectiva de los derechos fundamentales.

Si intentamos reducir a unos cuantos términos clave la creciente riqueza formal de la evolución más reciente de los textos constitucionales, y de dar nombre a las tendencias, tendremos la siguiente relación:

- La evolución de la competencia puramente formal hacia la tarea sustantiva.

- La utilización deliberada de normas de reconocimiento, valores fundamentales y estructurales, junto con garantías de identidad, en diversos ámbitos y variantes (por ejemplo, en las cláusulas "en el espíritu").

- El incremento en las cláusulas de protección en diversas variantes (incluyendo cláusulas sobre el "patrimonio cultural" y las normas de defensa de la Constitución).

- La incorporación de cláusulas de ponderación, jerarquía y compensación.

- El enriquecimiento de la Constitución en todas sus partes con numerosas normas de tareas (también e inclusive en el preámbulo).

- La ampliación de los derechos fundamentales a través de normas que establecen tareas relacionadas con ellos.

En resumen, esto conduce a una gran cantidad, ocasionalmente excesiva, de normas, valores y materiales de los nuevos textos constitucionales (ejemplos: Constitución de Portugal de 1976-1992, también la de Guatemala de 1985), lo que ya se manifiesta en el número de artículos (298 en

229 Cfr. § 16, inciso 1, de la Constitución del Cantón de Basilea-Comarca, y el artículo 102 de la Constitución de Guatemala ("derechos sociales mínimos”). 
Este libro forma parte del acervo de la Biblioteca Juridica Virtual del Instituto de Investigaciones Juridicas de la UNAM

Portugal). Las Constituciones incorporan cada vez mayor número de contenidos, y cada vez de manera más diferenciada, y amenazan en ocasiones con sobrecargarse y excederse en lo programático (y en lo político), dando lugar a la "retórica constitucional", la cual, usada de manera moderada, tiene su razón de ser. Las Constituciones "prometen" mucho (quizá demasiado), y a causa de ello se dan numerosos conflictos de objetivos. Aquí hay que hacer referencia al peligro del déficit de normatividad debido al exceso de contenidos, no en el sentido de una "vuelta" a la noción de Constitución y de Estado puramente instrumentales y formales que enfatiza su función limitativa, sino en el de una línea media del "no sólo esto, sino también lo otro" de directivas sustantivas y limitaciones más bien formales (la Constitución como "estímulo y límite" en el sentido de R. Smend), de normas que se refieren al status quo, pero que también "proyectan" ("pequeñas utopías"), de principios valorativos y delimitaciones "positivistas", de llamados del constituyente a la razón y al mundo de la emoción, a la ratio y la emotio, y por tanto, al hombre y al ciudadano en plenitud. Lo evidente es de qué modo las diversas funciones de la Constitución ejercen retroalimentación sobre su forma "externa" y cómo hay que trabajar en forma específica para cada ámbito.

\section{Consecuencias}

a. En el plano de la interpretación constitucional

¿Es posible entender los métodos de la interpretación constitucional de la manera tan "general" como se ha hecho hasta ahora? ¿Acaso no es preciso hacer una mayor diferenciación según el objeto y el ámbito de que se trate? Sin duda los preámbulos son derecho constitucional plenamente vigente (cfr. BVerfGE 36, 1, 16 y s.), pero con ello apenas comienzan los problemas. $\mathrm{Su}$ "interpretación" debe ser específica, debe desentrañar dimensiones culturales profundas, distinguirse de otros complejos de normas más formales; piénsese en las normas de competencia y en el derecho orgánico. O bien: los "programas constitucionales" como los de los deberes fundamentales ${ }^{230}$ o los mandatos constitucionales, como el del artículo 6o., inciso 5, de la LF, requieren métodos de interpretación altamente "productivos"; algo distinto sucede con las cláusulas de simple recepción, que recogen lo existente, por

230 Cfr. Hofmann, H., "Grundpflichten als verfassungsrechtliche Dimension", VVDStRL, vol. 41, 1983, pp. 42 (79 y s.); O. Luchterhand, Grundpflichten als Verfassungsproblem in Deutschland, 1988. 
Este libro forma parte del acervo de la Biblioteca Juridica Virtual del Instituto de Investigaciones Juridicas de la UNAM

ejemplo, conforme al artículo 68 de la Constitución de Bremen ("La Ciudad Libre Hanseática de Bremen tendrá el escudo y la bandera que ha tenido hasta ahora"), o también el artículo 140 de la LF. Su forma clásica, las garantías del status quo, ${ }^{231}$ si bien no deben interpretarse en el sentido de la "teoría de la petrificación" austriaca, pero aquí podría tener particular peso el método subjetivo-histórico de interpretación. En mi opinión, es preciso hacer una mayor diferenciación según la "materia de los objetos", los que, por su parte, asumen un ropaje lingüístico distintivo. La capacidad de concretización que se requiere del intérprete es muy diferente, dependiendo del grado de abstracción de las normas.

\section{b. En el plano de la teoría constitucional}

El reconocimiento de la diferenciación de los textos constitucionales en cuanto a su lenguaje, contenido y funciones, bien podría servir para moderar numerosos conflictos: por ejemplo, entre una concepción "instrumental" y otra "material" de la Constitución; entre la interpretación de la Constitución como "manual fundamental formal", "instrument of government" (W. Hennis), y su concepción como "plan estructural normativo" para la configuración jurídica de una comunidad (A. Hollerbach); ${ }^{232}$ entre su calificación como simple "ordenamiento marco" y un mayor contenido y extensión de su texto; entre las posiciones del decisionismo y la del énfasis en lo normativo; entre la "limitación" y la "tarea". La solución debe buscarse en un "esto y también lo otro". En efecto, existen normas y ámbitos de la Constitución que deben interpretarse de manera más bien "instrumental", y otros de modo más "material"; campos en los que la Constitución destaca, y así debe hacerlo, más la organización y el procedimiento, y otros en los que lo son los objetivos sustantivos; hay temas y ámbitos que la Constitución "excluye" (por ejemplo, el artículo 137, inciso 3, de la Constitución de Weimar/140 de la $\mathrm{LF})$, y aquellos que integra de manera deliberada. En el debate tradicional se trata frecuentemente de la absolutización de criterios particulares. Y no es ninguna casualidad que sea Suiza la que, desde los años sesenta y luego nuevamente en los noventa, haya creado, a nivel cantonal, muchos ejemplos

231 Por ejemplo, el artículo 150, inciso 2, de la Constitución de Baviera: "Se mantienen las facultades teológicas en las escuelas superiores".

232 Hollerbach, A., "Ideologie und Verfassung", Ideologie und Recht, ed. por W. Maihofer (1968), pp. 37 (46). 
Este libro forma parte del acervo de la Biblioteca Juridica Virtual del Instituto de Investigaciones Juridicas de la UNAM

afortunados de buenos textos constitucionales, ${ }^{233}$ y el que, en su "pragmatismo" frecuentemente citado, haya escogido numerosos tipos "mixtos" de textos, con lo cual no se fija en una sola concepción de Constitución. De este modo Suiza vuelve a convertirse en un ejemplo de "compromiso".

c. En el plano de la política constitucional

La política constitucional puede sentirse animada, ya que los diversos constituyentes nacionales (locales o cantonales) han elaborado un rico tesoro, incluso una rica fábrica de formas diversas.

Algunas cosas se vuelven borrosas en los compromisos políticos, en la medida en que el proceso constituyente en las democracias pluralistas es y debe ser un proceso de compromisos. Pero debe recomendarse al constituyente, como máxima, utilizar de manera consciente la distinción, pero también el contexto, en la diversidad lingüística de sus textos, así como la pluralidad teórico-dogmática y funcional. Lo técnico-jurídico y formal, por ejemplo, en el derecho parlamentario, tiene trasfondos sustantivos muy determinados. También las posibilidades irracionales del lenguaje deben utilizarse de modo muy dosificado, pero consciente. Finalmente, el político constitucional debe utilizar las modificaciones constitucionales de manera muy deliberada en su texto. ${ }^{234}$

\section{Perspectivas}

Sin importar cuántos estratos tenga una Constitución en su conjunto, o más bien la disposición constitucional particular, cuán "difusa" pueda ser ocasionalmente, qué tanta riqueza de formas y contenidos tenga, la Constitución manifiesta en esta diversidad creciente su vitalidad, su capacidad de evolucionar, su actualidad y su no disminuida fuerza vital, es decir, también,

233 Véase al respecto Häberle, P., "Neuere Verfassungen und Verfassungsvorhaben in der Schweiz, insbesondere auf kantonaler Ebene”, F̈̈R, vol. 34, 1985, pp. 303 y ss.

234 El tema "protección del ambiente" ha sido incorporado unas veces en los preámbulos (así, la Constitución de Hamburgo), en ocasiones como disposiciones sobre los fines del Estado (artículo 3o., inciso 2, de la Constitución de Baviera, en ocasiones como objetivos de la educación (artículo 131, inciso 2, de la Constitución de Baviera; artículo 30 de la Constitución del Sarre). Algo similar puede decirse de las Constituciones de los nuevos Länder (por ejemplo, la Constitución de Brandemburgo; el preámbulo y el artículo 28). Esto tiene "efectos lejanos" todavía no aclarados sobre otras partes de la Constitución, como los catálogos de derechos fundamentales. 
Este libro forma parte del acervo de la Biblioteca Juridica Virtual del Instituto de Investigaciones Juridicas de la UNAM

su normatividad y su proximidad a la realidad. La admonición de Georges Burdeau (de 1956) sobre "Une survivance: la notion de constitution", ${ }^{235}$ no se ha hecho realidad, sino que más bien aumenta a nivel mundial la fuerza de atracción del Estado constitucional, y esto significa también la res publica de los textos constitucionales escritos. Este Estado ha reaccionado a los nuevos procesos evolutivos en forma de una actualización y una diferenciación sensibles de sus textos, e incluso ha logrado actuar, es decir, regular la realidad. Las normas de todo tipo sobre las tareas del Estado lo demuestran, como también el catálogo de derechos fundamentales. El Estado constitucional ha procesado la "realidad" social (y también lo ha hecho la legislación), en textos nuevos o modificados. Sin importar que en toda democracia pluralista haya textos constitucionales que no se han cumplido en alguna medida, visto en conjunto el tipo del Estado constitucional atlántico/europeo común, en los textos constitucionales se refleja mucha realidad, configuradora y configurada. La realidad no "denuncia" a los textos, sino que los textos indican mucha realidad (constitucional). Independientemente de los déficit particulares, apenas puede sobreestimarse, en su importancia para la legitimación del Estado constitucional, la inventiva de los constituyentes en materia de diversidad de formas y riqueza de funciones, variabilidad del lenguaje y pluralidad de estratos de sus textos, así como la derivación de numerosas formas mixtas. Actualmente se espera más bien demasiado de las Constituciones, aunque con matices nacionales: en la República Federal de Alemania, la Constitución es casi un "sustituto de la religión", mientras que Inglaterra posee otras posibilidades de identificación, Austria le da a la Constitución más bien poco, Suiza mantiene el medio afortunado, no en último término gracias a su doctrina constitucional. Pero las diferencias son también prueba de la vitalidad de la Constitución y de sus textos.

\section{Diversidad de funciones de los textos constitucionales}

\section{A. Planteamiento del problema}

Todas las explicaciones antiguas y nuevas sobre la noción "correcta" de Constitución, Estado, derechos fundamentales, se refieren en el fondo a la función de las disposiciones constitucionales, a pesar del nivel de generalidad en que permanecen frecuentemente: ya sea en la concepción de

235 En L'evolution du droit public. Etudes en l'honneur d'Achille Mestre, 1956; también en Der Staat, vol. 1, 1962, pp. 389 y ss. 
Este libro forma parte del acervo de la Biblioteca Juridica Virtual del Instituto de Investigaciones Juridicas de la UNAM

H. Ehmke de la Constitución como limitación y racionalización del poder y como garantía de libertad en el proceso de la vida política; ${ }^{236}$ en la interpretación de W. Kägi de la Constitución como ordenamiento jurídico fundamental del Estado; ${ }^{237}$ o en el énfasis de H. Heller en el proceso de la interacción consciente, planeada y organizada. ${ }^{238}$ Así como K. Hesse ha conjuntado aspectos particulares de esta discusión en un conjunto teórico equilibrado, ${ }^{239}$ en lo que sigue nos referiremos concisamente a las diversas especies y grupos normativos de los textos constitucionales que corresponden a las diversas concepciones de Constitución. A la inversa, el proceso de transformación de la tipología de textos elaborada de manera comparativa debería conducir a una aproximación en la controversia sobre la noción "correcta" de Constitución, por ejemplo, en relación con el enfoque culturalista. ${ }^{240}$ La diversidad de los textos ofrece, en mi opinión, suficiente material probatorio para la correspondiente noción "mixta" de Constitución, que deje atrás las tradicionales posiciones enfrentadas.

\section{B. Las funciones particulares de los textos en el marco de una concepción antropocéntrica de la Constitución}

\section{a. La concepción antropocéntrica de Constitución}

Los textos clásicos, pero también los más recientes, sugieren una concepción antropocéntrica de Constitución. Esta noción se manifiesta tanto en la función, todavía importante, de la delimitación, sobre todo en los textos tradicionales sobre los derechos fundamentales, como también en la plenitud de los textos constitucionales más recientes comprometidos con el pensamiento funcional, ya que, en última instancia, estas funciones se encuentran plenamente al servicio del ser humano, de su dignidad y libertad, e incluso igualdad. El nuevo mandato protector en materia de dignidad humana (artículo 1o., inciso 1, de la LF; $§ 5$ de la Constitución del Cantón de Basilea-Comarca; artículo 31 de la Constitución de Polonia), y el texto clásico de la Declaración francesa de 1789 (artículo 2o.: "El fin de toda asocia-

\footnotetext{
236 Ehmke, H., Grenzen der Verfassungsänderung, 1953, pp. 88 y ss.

237 Kägi, W., Die Verfassung asl rechtliche Grundordnung des Staates, 1945, pp. 40 y ss.

238 Heller, H., Staatslehre (1934), pp. 228 y ss. (reimpr. 1963) (trad.: Teoría del Estado, 2a. ed., 1998, pp. 316 y ss.).

239 Hesse, K., Grundzüge des Verfassungsrechts der Bundesrepublik Deutschland, 20a. ed., 1995, pp.

$240 \mathrm{Al}$ respecto Häberle, P., Verfassungslehre als Kulturwissenschaft, 2a. ed., 1998.
} 3 y ss. 
Este libro forma parte del acervo de la Biblioteca Juridica Virtual del Instituto de Investigaciones Juridicas de la UNAM

ción política es la conservación de los derechos naturales e imprescriptibles del hombre"), todos los textos constitucionales, todo el Estado constituido y limitado por éstos, todas las normas de organización y procedimiento, así como todas las tareas del Estado, están ordenados en función del ser humano. Las nuevas "cláusulas de realización de los derechos fundamentales"241 tienen también esta intención, lo mismo que los fines de la educación (artículo 26, núm. 1, de la Constitución de Bremen: "Respeto a la dignidad de todos los seres humanos"), así como todas las nuevas dimensiones y funciones de los derechos fundamentales, incluyendo las estructuras, por ejemplo, de participación, que se desarrollan bajo el ropaje de las tareas (del Estado).

El todo constituido por la función delimitadora clásica de los textos relativos a los derechos fundamentales, su nueva estructura de funciones, y las competencias estatales, se encuentran al servicio del ser humano, lo mismo que las normas estructurales como la "democracia en libertad", el "Estado cultural y social de derecho". Esto es válido también, y precisamente, para los nuevos y variados textos sobre la protección del ambiente: ya que llevan a la dignidad humana, que es premisa del Estado constitucional, hacia un "antropocentrismo moderado"; en interés de un mundo futuro humanamente digno pretenden proteger hoy el ambiente. ${ }^{242}$ La dignidad humana es apreciada con vistas a las futuras generaciones en el horizonte del tiempo (véase el nuevo texto del artículo 141, inciso 1, frase 1, de la Constitución de Baviera: "conscientes también de su responsabilidad hacia las generaciones futuras").

En vista de la penetración de la idea de la protección del ambiente (mediada por la "naturaleza como cultura" o "la protección de la naturaleza como tarea cultural"), puede llegarse a un antropocentrismo "moderado", pero con ello no hemos encontrado todavía a un Kant "verde".

\section{b. Ratio y emotio}

Si los textos constitucionales cumplen con diversas funciones al servicio del ser humano, resulta evidente que aun cuando no puedan captar "total-

241 Ejemplo textual: artículo 3o., inciso 2, de la Constitución de Italia (1947). En forma similar, el artículo 9o., inciso 2, de la Constitución española.

242 Cfr. preámbulo de la Constitución del Cantón de Aargau de 1980: "Responsabilidad ante Dios respecto de los seres humanos, la comunidad y el ambiente". Preámbulo de la Constitución de Berna de 1993: "en la que todos convivan responsablemente ante la creación"; artículo 74, inciso 1, de la Constitución de Polonia de 1997: "Política que garantice a la presente generación y a las futuras seguridad ecológica". 
Este libro forma parte del acervo de la Biblioteca Juridica Virtual del Instituto de Investigaciones Juridicas de la UNAM

mente" a este ser humano en una Constitución de la libertad y el pluralismo, sí pretendan "abordar" los aspectos importantes para la comunidad política, por contrastantes que éstos sean. ${ }^{243}$ Este acercamiento al ser humano se produce, y se puede comprobar, en los textos constitucionales, sobre todo en dos campos: en el de la ratio y en el de la emotio.

Que el Estado constitucional se apoya en el ser humano como "ser racional", es un lugar común que es reconocible en muchos textos antiguos y más recientes: en el principio de la división de poderes, ${ }^{244}$ en la referencia a los mismos derechos fundamentales de los demás ("regla de oro" o "imperativo categórico" de I. Kant), incluso en la "construcción" de la "Constitución" misma, en la organización de sus procedimientos, en la "ficción" del contrato social (desde I. Kant hasta J. Rawls), y en la creación y la garantía del derecho constitucional y del Estado de derecho.

El lado de la "emotio" ha sido descuidado hasta ahora por la teoría constitucional; en todo caso, no ha sido elaborado de manera precisa y comparativa a lo "largo" de los textos constitucionales clásicos y más recientes. Por ejemplo, "tocan" a la estructura emocional que también tienen los seres humanos el grupo de normas constitucionales que pueden clasificarse como cláusulas de reconocimiento, simbólicas y de valores fundamentales. ${ }^{245} \mathrm{Su}$ función específica es captar la "conditio humana" desde el lado emocional y, por tanto, dar también más constitución a la res publica desde este lado. Ya sea en los preámbulos, en las garantías sobre días festivos o en los artículos relativos al idioma, la bandera y otros símbolos, los constituyentes configuran sus textos, en lenguaje y contenido, con vistas a esta función: dirigirse al ser humano desde el lado de lo irracional, de lo que "sobrepasa" a la razón, para hablar de lo importante de la Constitución, "ponerlos a tono", incluso "ganárselos".

Esta función se aprecia inclusive en los artículos "en el espíritu" y en las cláusulas sobre "el patrimonio cultural" y, en general, en los textos constitucionales sobre la cultura. La emotio a la que nos referimos aquí no sólo

243 Particularidades en Häberle, P., Das Menschenbild im Verfassungsstaat, 1988.

244 Cfr. el artículo 16 de la Declaración francesa de los Derechos del Hombre de 1789: "Toda sociedad en la que la garantía los derechos no esté asegurada, ni determinada la separación de poderes no tiene Constitución".

245 Ejemplos textuales: artículo 1o., inciso 2, de la LF (1949): "Por tanto, el pueblo alemán reconoce que los derechos humanos inviolables e inalienables son el fundamento de toda comunidad humana". Preámbulo de la Constitución francesa (1946): El pueblo francés proclama, además, "como particularmente necesarios" en nuestros días, los principios políticos, económicos y sociales siguientes: ... Artículo 1o., inciso 1, de la Constitución española: "la libertad, la justicia, la igualdad y el pluralismo político como valores superiores de su ordenamiento jurídico". 
Este libro forma parte del acervo de la Biblioteca Juridica Virtual del Instituto de Investigaciones Juridicas de la UNAM

se encuentra en una relación de tensión, frecuentemente fructífera, con la racionalidad del Estado constitucional, sino que es capaz de darle un fundamento más profundo, en el ciudadano como ser humano. De ahí los textos de algunas Constituciones que se refieren a "artículos de fe" y las declaraciones de derechos humanos (sobre todo en los preámbulos). El Estado constitucional democrático vive también del consenso sobre lo irracional, y no sólo del discurso o del consenso y el disenso en relación con lo racional.

\section{c. El "procesamiento" del tiempo}

La forma textual de las disposiciones constitucionales es tan diversa, entre otras razones, porque pretenden y deben procesar el tiempo en distintas maneras. En forma específica, se dirigen al pasado, al presente y al futuro, y aquí encuentra su fundamento la diversidad de funciones de la Constitución en general.

Ciertos textos constitucionales incluyen al pasado o se refieren de manera específica a él: las "garantías de institutos" y las "garantías institucionales" clásicas descubiertas por la dogmática de un C. Schmitt, las demás cláusulas de recepción (sobre el status quo) de tipo antiguo, pero también las nuevas cláusulas sobre el patrimonio cultural. ${ }^{246}$

Esto conduce al presente y al futuro como "fases" siguientes en el eje del tiempo: la diversidad de nuevas formas y tipos textuales, que son la expresión del pensamiento funcional programático, pretenden ganar el futuro para el respectivo Estado constitucional. Este aspecto y esta función se manifiestan ahí donde los textos garantizan a la Constitución como "proceso público", donde se organiza la "apertura de la Constitución" y se formulan (anticipadamente) los objetivos, proyectos, llamados, esperanzas, tareas. Esto sucede de manera muy diferenciada: desde el mandato de desarrollo en materia de los derechos humanos o de las tareas del Estado, pasando por el procedimiento de la modificación constitucional (revisión parcial o total), hasta el proceso constituyente en el marco del tipo del Estado constitucional.

Así alcanza la Constitución el "medio", frecuentemente aludido como indispensable, entre duración y cambio, entre estática y dinámica, entre regulación y adaptación, entre configuración creativa y vigorosa conservación. El "esto pero también lo otro" de "procesos y contenidos" se dis-

246 Por ejemplo, el artículo 3o., inciso 2, de la Constitución de Baviera: "El Estado protege las bases naturales de la vida y la tradición cultural", así como el artículo 9o., inciso 2, de la Constitución de Italia (1947). 
Este libro forma parte del acervo de la Biblioteca Juridica Virtual del Instituto de Investigaciones Juridicas de la UNAM

tribuye, con acentos diversos, entre las distintas especies de disposiciones constitucionales, pero frecuentemente se encuentran en un solo complejo normativo (así en los preámbulos o en las garantías, de múltiples estratos, de los derechos fundamentales). El presente recurre a "estímulos" y obligaciones provenientes del pasado; formula esperanzas para el futuro imaginado como abierto. Existen "garantías del status quo cultural" del Estado constitucional, como la dignidad humana y la democracia, los derechos fundamentales (clásicos) y la división de poderes desde 1776-1789, así como textos clásicos de I. Kant o las experiencias almacenadas aquí en los textos, pero existe también un "quantum de utopía". Así nos quedamos con la idea de que la Constitución es, en general, "estímulo y límite" (R. Smend), proceso público, y que es material, instrumental, valorativa, de principio y abierta. Sin embargo, los diversos textos constitucionales y los tipos de normas se distinguen más bien por ser lo uno o lo otro. Solamente su interrelación, su garantía al mismo tiempo en uno y el mismo documento constitucional de un pueblo, dicho en otras palabras, su "mezcla" en el Estado constitucional, es lo que les permite cumplir, en conjunto, con su función estabilizadora de ordenamiento y libertad, de crear unidad y diversidad plural, de poder actuar a la vez como fundamento y límite del poder.

\section{d. Consenso básico y pluralidad}

Los distintos textos constitucionales tienen la diversa función de crear, garantizar y desarrollar el consenso básico y la pluralidad en el Estado constitucional en su conjunto. Las cláusulas de reconocimiento, de valores fundamentales e identidad (por ejemplo, de "eternidad"), como en materia de "justicia social", orden económico conforme con la dignidad humana, democracia, fijan a la Constitución en sus principios, apoyados en un consenso básico, cuya pretensión es encontrarse bajo la idea de lo "correcto", ${ }^{247}$ es decir, realizar aspectos de la justicia y el bien común. ${ }^{248}$

Esta tarea de las Constituciones puede advertirse de manera precisa en los nuevos textos constitucionales y en sus funciones, y justamente en ellos. Las crecientes y diversificadas tareas del Estado (más recientemen-

\footnotetext{
247 Bäumlin, R., Staat, Recht und Geschichte, 1961, p. 24.

248 Cfr. el artículo 110, inciso 1, de la anterior Constitución del Perú (1979): "El orden económico de la República se apoya en los principios de la justicia social, los cuales están dirigidos hacia el trabajo digno como fuente principal de la riqueza y como medio de realización de la persona humana”. En términos similares, el artículo 151 de la Constitución de Weimar (1919) y el artículo 151 de la Constitución de Baviera (1946).
} 
Este libro forma parte del acervo de la Biblioteca Juridica Virtual del Instituto de Investigaciones Juridicas de la UNAM http://www.juridicas.unam.mx

te en materia de protección del ambiente) son derecho constitucional que tiene como objetivo al bien común. ${ }^{249} \mathrm{Y}$ el tipo del "Estado constitucional" intenta renovadamente organizar los elementos de la justicia desde el lado procesal y material, en el sentido de $\mathrm{H}$. Heller, mediante normas de tareas lo mismo que en los nuevos y clásicos contenidos de los derechos fundamentales (por ejemplo, en el "due process" o en las estructuras de participación).

La pluralidad, la "otra" función de garantía de los diversos principios constitucionales, lo mismo que de la Constitución en su conjunto, se encuentra detrás de las diversas "facetas" de los derechos fundamentales: de su función de límite (aseguramiento de un proceso abierto de la vida política), pero también de su estructura funcional ("tareas relativas a los derechos fundamentales" en interés de una óptima realidad de estos derechos para todos). Los "artículos del pluralismo" 250 formulados recientemente en forma general (por ejemplo, en España) o especial (por ejemplo, respecto de la libertad de los medios de comunicación), pero también respecto de la protección de minorías, cumplen esta función de garantía de la apertura de la Constitución, y ello equivale a decir también capacidad de evolución de sus textos. Particularmente en el Estado federal se resuelve de manera óptima el "esto pero también lo otro" de la pluralidad y el consenso básico (diversidad política, económica y cultural y cláusulas de homogeneidad).

Puede ser que las tensiones en la relación entre consenso básico y pluralidad varíen en el tiempo y el espacio; por ello, el tipo del "Estado constitucional" requiere una pluralidad de textos, que garanticen la "mezcla" de ambos, como marco para la "avenencia y tolerancia" renovadas de los ciudadanos.

249 Un panorama de las cláusulas constitucionales sobre el bien común puede encontrarse en Häberle, P., Öffentliches Interesse als juristisches Problem, 1970, pp. 39 y ss.

250 Ejemplos textuales: artículo 1o., inciso 1, de la Constitución española (1978): "España se constituye en un Estado social y democrático de derecho, que propugna como valores superiores de su ordenamiento jurídico la libertad, la justicia, la igualdad y el pluralismo político"; artículo 20, inciso 3, de la misma Constitución: "el acceso a dichos medios... respetando el pluralismo de la sociedad...". Véase también el artículo 2o. de la Constitución de Portugal (1976-1982): "pluralismo de expresión y organización política democráticas...". Las cláusulas contra la ideología de Estado en Europa oriental (por ejemplo, el artículo 15, inciso 2, de la Constitución de Ucrania de 1996) corresponden también aquí. Véase también el artículo 1o., inciso 2, de la Constitución del Paraguay (1992): "la democracia pluralista, la cual se funda en el reconocimiento de la dignidad humana”. En forma similar el preámbulo de la Constitución de Gabón (1997). 
Este libro forma parte del acervo de la Biblioteca Juridica Virtual del Instituto de Investigaciones Juridicas de la UNAM

\section{e. La función limitadora}

La función de establecer límites (incluso entre los ciudadanos, por ejemplo, a través de la eficacia frente a terceros de los derechos fundamentales), ${ }^{251}$ la limitación del poder (en la relación entre el Estado y el ciudadano), el impedir el abuso de poder (por el lado del Estado y la sociedad), sigue siendo propia de muchas disposiciones constitucionales, antiguas y nuevas, y continúa siendo, en general, irrenunciable. Y esto en nada es alterado por ningún pensamiento en términos de tareas, por ninguno de los textos constitucionales recientes orientados a tareas en la más reciente etapa evolutiva textual. El canon de los derechos fundamentales clásicos, la división de poderes, la democracia como confianza limitada en "el gobierno temporal", la organización precisa de los procedimientos, en los cuales se lucha por el bien común y se busca la justicia, todo esto puede tomarse con mucha precisión de los diversos tipos de texto, en su literalidad y en el fondo (por ejemplo, las normas sobre protección de minorías). Puede ser que aquí y allá el pensamiento en términos de tareas ahogue a los textos; no obstante, la doctrina del Estado constitucional debe aferrarse a esta función de los diversos textos constitucionales, así como de la Constitución como un todo. Las tareas permanecen limitadas. Bien entendidas, detrás de las crecientes normas de tareas (por ejemplo, tareas estatales referidas a las derechos fundamentales) se encuentra la preocupación por una libertad real en su dimensión "clásica" de no interferencia. El pensamiento en términos de tareas no es sino un elemento de "desarrollo y garantía de la vigencia de los derechos fundamentales", por ejemplo, bajo la forma de un "status activus processualis".

El artículo 1o., inciso 1, de la LF y el texto clásico del artículo 2o. de la Declaración francesa de 1789 "recuerdan" una y otra vez esta función de la fijación de límites, así como de su prórroga adecuada a la época.

f. Referencia a la realidad y configuración de la realidad

Se trata de la última función de las Constituciones y de sus diversos grupos y tipos de textos, y una que ha emergido al primer plano en la época más reciente. Hoy, la realidad no sólo es un tema principal de la ciencia

251 Cfr. $\S 14$, incisos 2 y 3 de la Constitución del Cantón de Basilea-Comarca (1984): "Quien ejerce sus derechos fundamentales debe respetar los de los demás. Nadie puede afectar los derechos fundamentales mediante el abuso de su posición de poder". Cffr. también el artículo 27, inciso 1, de la Constitución de Berna (1993): "Los derechos fundamentales deben manifestarse en todo el orden jurídico". 
Este libro forma parte del acervo de la Biblioteca Juridica Virtual del Instituto de Investigaciones Juridicas de la UNAM

jurídica (F. Wieacker), sino que también ha adquirido centralidad el campo de fuerzas de la doctrina del Estado constitucional. Esto se manifiesta de diversas maneras: en general, por las disposiciones sobre fines del Estado y las normas fundamentales sobre el Estado social de derecho, sobre la "justicia social"; en los textos sobre las tareas especiales del Estado, que pretenden hacer efectivos algunos o todos los derechos fundamentales (en el sentido de "libertades reales"); pero se manifiesta también en las nuevas dimensiones de los contenidos de los derechos fundamentales que se han vuelto complejos, ya sea gracias a la técnica de los mandatos de promoción y protección (por ejemplo, el artículo 6o., inciso 5, de la LF, el § 25 de la Constitución del Cantón de Aargau, el artículo 42, inciso 2, de la Constitución de Berna), a través de la dinamización del principio de igualdad ("igualdad de oportunidades"), o a través de otros textos constitucionales que se encuentran al servicio de la "optimización de los derechos fundamentales", como son las cláusulas relativas a su realización y desarrollo, o a su "protección a través de la organización y el procedimiento".

El Estado constitucional pretende que sus textos se hagan realidad, que se cumplan "socialmente"; "reivindica" la realidad para sí: su "normatividad" debe convertirse en "normalidad". Dicho Estado pretende regular y configurar la realidad en el sentido de sus textos, pero también guiarse por éstos. Los diversos grupos de artículos y tipos de textos constitucionales tienen esta función como propia, con intensidad variable, pero en conjunto, la tendencia de las Constituciones se dirige en dirección a una "mayor cantidad de realidad".

\section{LA RELEVANCIA POTENGIAL DE LOS PROYECTOS DE Constitución (EL MODELO SUIZO)}

Ya un "doble diagnóstico empírico", y dos ejemplos de la Europa de nuestros días, demuestran lo productivos que pueden ser los proyectos para la teoría constitucional comparativa, porque han sido "eficaces" tarde o temprano, y porque influyen en textos posteriores o en su "traducción" en la realidad constitucional. Un ejemplo proviene de Suiza, donde el impulso lo han dado el proyecto del basilense Max Imboden de 1959, con el título "La Constitución federal como podría ser", y el proyecto de Constitución de 1977 de la Comisión de expertos para la preparación de la revisión total de 
Este libro forma parte del acervo de la Biblioteca Juridica Virtual del Instituto de Investigaciones Juridicas de la UNAM

la Constitución federal. ${ }^{252}$ A pesar de toda la crítica que se les pueda hacer, podemos decir ahora, en lo particular, que dichos proyectos han influido mucho más allá de la comunidad científica de lengua alemana, en la formulación de problemas y en las variantes textuales, gracias a lo cual podrían ser de auxilio práctico para los constituyentes de Europa oriental (junto con las nuevas Constituciones cantonales de Nidwalden hasta Solothurn, Berna y Appenzell A. Rh.).253

Los proyectos de Constitución merecen también interés científico con toda independencia de que sean "exitosos". Lo merecen incluso cuando pueden considerarse como "fracaso" político y también lo son, pero deberían ser examinados científicamente por la doctrina del derecho del Estado, y no sólo por la historia constitucional, pues en sus textos se objetivizan y cristalizan, de manera singular, contenidos y procedimientos, ideas y realidad, esperanzas y deseos, así como la elaboración del pasado, pues el imperativo de tener que vaciar lo imaginado en formas textuales normativamente obligatorias induce a una labor de condensación que confiere contornos más claros al material difuso del que provienen. A pesar de que, en lo particular, sus autores manifiesten diversos grados de creatividad, los proyectos de Constitución reciben y combinan, ante todo, elementos muy dispersos y bastante heterogéneos: por ejemplo, sentencias constitucionales y prácticas del Estado, construcciones doctrinales y resoluciones judiciales, pero también elementos transformados en texto en otras partes, como los pactos regionales y universales de derechos humanos, incluso los programas de los partidos políticos, para no hablar de los modelos textuales que pueden hallarse en las Constituciones de otros países y Estados o en las Constituciones de la historia propia. Los textos, sobre todo los constitucionales, ejercen una fascinación peculiar, afín a las religiones del Libro, incluso cuando son "superadas" por la historia o cuando ellas mismas no han "alcanzado" a la historia.

252 Imboden, M., "Die Bundesverfassung, wie sie sein könnte" (1959), en id., Staat und Recht, 1971, pp. 219 y ss.; Bericht der Expertenkommission für die Vorbereitung einer Totalrevision der Bundesverfassung, 1977.

253 Todo esto está documentado (hasta 1985) en Häberle, P., "Neuere Verfassungen und Verfassungsvorhaben in der Schweiz, insbesondere auf kantonaler Ebene", JöR, vol. 34, 1985, pp. 303 y ss. Por último, véase fö $R$, vol. 47, 1999, pp. 149 y ss. 
Este libro forma parte del acervo de la Biblioteca Juridica Virtual del Instituto de Investigaciones Juridicas de la UNAM http://www.juridicas.unam.mx

\author{
IV. PROBlemas de las FUENTES DEL DERECHO EN EL ESTADO \\ CONSTITUCIONAL: UN PLURALISMO DE LO ESGRITO \\ Y LO NO ESCRITO DE MÚLTIPLES ESPACIOS Y ETAPAS
}

\title{
1. El cuestionamiento de la metáfora de la "fuente"
}

Tan cierto como es que la doctrina de las fuentes del derecho - hoy ya debido a los textos constitucionales positivos - debe constituir un capítulo central de toda teoría constitucional comparada, igualmente cuestionable parece la metáfora de la "fuente del derecho", porque sugiere que el derecho se deriva, más o menos "acabado", "presente" y dado, de "una" causa. Esto toma muy poco en cuenta que el derecho es "law in action" (J. Esser) y que "deviene" derecho apenas en y a través de la interpretación. ${ }^{254}$ La "metáfora de la fuente" difícilmente puede expresar la importancia constitutiva de la "sociedad abierta de los intérpretes de la Constitución". La metáfora "fuente del derecho" es criticada o corregida aquí y allá en la doctrina, pero no se cuestiona en forma radical. ${ }^{255}$ En mi opinión, en la actualidad sólo es posible utilizar el concepto de "fuente del derecho", si acaso, con muchos signos de interrogación y entre comillas, tan productivos son los intérpretes, tan plurívocos son los conceptos jurídicos que han de interpretarse, y tan abierto es el canon de posibles "fuentes del derecho" en el Estado constitucional. Esto no impide que ciertas afirmaciones sobre las "fuentes del derecho" aquí sistematizadas, se encuentren ya en los textos constitucionales. Su "buen" orden corresponde incluso a una Constitución escrita. Pero esto no puede ni pretende poner en cuestión la apertura y pluralidad de las fuentes del derecho en el Estado constitucional, en el que no hay un numerus clausus de "fuentes del derecho", sino que su listado solamente puede ser ejemplificativo.

Por otra parte, es más que dudoso que pueda sostenerse la distinción habitual entre "fuentes formales del derecho" y "fuentes de conocimiento del derecho". El "derecho de los jueces" se ha establecido desde hace tiempo

254 Ya clásica es BVerfGE 75, 223 (243 y s.): "así como no puede haber duda de que los Estados miembros desean dotar de un tribunal a la Comunidad, ante el cual estarán abiertas las vías jurisdiccionales tal como han surgido a través de las centurias en la tradición y la cultura jurídicas europeas comunes. El juez nunca fue en Europa simplemente 'la bouche qui prononce les paroles de la loi'; el derecho romano, el common law inglés, el derecho común, eran en buena medida una creación judicial... Los tratados comunitarios deben entenderse también a la luz de la tradición y la cultura jurídica común europea”.

255 Sin embargo, cfr. Michael, L., Der allgemeine Gleichheitssatz als Methodennorm komparativer Systeme, 1997, pp. 21 y ss. 
Este libro forma parte del acervo de la Biblioteca Juridica Virtual del Instituto de Investigaciones Juridicas de la UNAM

"entre" estas categorías. En el tipo del Estado constitucional la antigua alternativa entre derecho legislado y derecho de creación judicial se convierte en "tanto esto como lo otro" en las "fuentes del derecho".

\section{Apertura y pluralidad de las fuentes del derecho en el Estado constitucional}

Ya la comparación constitucional permite atreverse a hablar de la pluralidad y la apertura de las "fuentes del derecho". Nada menos que J. Esser se adelantó a esto cuando hablaba del "carácter pluralista (no la mera "estructura escalonada") de nuestras fuentes del derecho" y cuando andaba a la busca de una doctrina "realista" de las fuentes del derecho que superara el estatismo. ${ }^{256}$ Es cierto que en la actualidad las Constituciones nombran crecientemente determinadas fuentes del derecho, pero tampoco se fijan en un canon cerrado, sino que incorporan siempre fuentes abiertas, como los derechos humanos (internacionales), los principios generales del derecho, incluso las referencias generales al "derecho". Esto no es sólo un diagnóstico, sino que puede justificarse filosóficamente. El término clave "tiempo y Constitución" o "tiempo y cultura constitucional" apunta al trasfondo: la apertura y la pluralidad de las fuentes del derecho es un instrumento y un procedimiento, entre otros (desde la revisión parcial o total de las Constituciones pasando por las cláusulas legislativas experimentales hasta los votos particulares de los jueces constitucionales) que permiten al Estado constitucional mantener el equilibrio, en el tiempo, entre continuidad y cambio, entre estabilidad y flexibilidad. Precisamente las "mezclas" flexibles tanto de los métodos de interpretación como de las "fuentes del derecho" permiten la conservación del Estado constitucional "en el curso del tiempo".

\section{En particular sobre las "nuevas" fuentes del derecho}

Los nuevos constituyentes se caracterizan, entre otras cosas, porque se muestran, literalmente, "abiertos" hacia las nuevas fuentes del derecho. En parte lo que hacen es dar forma nueva a las "viejas" fuentes; por ejemplo, a través de cláusulas de primacía claramente expresas a favor de la Constitución; en parte nombran con mayor precisión las antiguas o las nuevas fuentes del derecho: a saber, principios generales del derecho, derechos humanos reconocidos internacionalmente, otros derechos fundamentales dis-

256 Grundsatz und Norm, 4a. ed., 1990, pp. 120 y ss., 241 y ss., 287 y ss. 
Este libro forma parte del acervo de la Biblioteca Juridica Virtual del Instituto de Investigaciones Juridicas de la UNAM

tintos de los "existentes" por escrito (cláusulas de desarrollo de los derechos fundamentales), ocasionalmente el derecho natural. Estas "nuevas" fuentes del derecho constituyen un enriquecimiento de los procesos de determinación del derecho; pero ciertamente también lo hacen más "complicado. Hacia fuera, acomodan al Estado constitucional en contextos regionales o universales de una "sociedad mundial" o de la humanidad, y hacia el interior permiten un refinamiento de los procesos de creación de derecho y así también una mayor medida de justicia. Además, permiten utilizar las experiencias jurídicas de otras comunidades, en particular de otros Estados constitucionales (vecinos), del mismo modo como puede ser una ganancia la comparación jurídica. Hay que elogiar a los constituyentes nacionales por haberse atrevido a llamar por su nombre y a integrar a la paleta de posibles fuentes del derecho, con lo cual han quebrado no sólo las doctrinas "clásicas" de la soberanía, sino también la idea simplista de la construcción escalonada del orden jurídico.

\section{Influencias recíprocas en lugar de la supra o subordinación de las fuentes del derecho}

Un aspecto más de la "revisión" de la doctrina clásica de las fuentes del derecho que proponemos se advierte menos en la evolución de etapas textuales de lo que puede observarse en la práctica. A él haremos al menos alusión aquí. Si bien es muy frecuente que los constituyentes más recientes, como se ha mostrado, normen la "supremacía de la Constitución", ${ }^{257}$ con ello no pretenden, ni pueden impedir, que la multicitada "construcción escalonada del orden jurídico" de la Escuela de Viena no sea sino sólo un aspecto de la acción de las "fuentes del derecho". En la práctica de la aplicación del derecho, en el "negocio hermenéutico de la interpretación", se producen frecuentemente la interacción creativa y la colaboración múltiple de los diversos "planos", lo que no es posible reducir a la imagen de la "jerarquía". Así, los principios constitucionales y las normas legislativas interactúan de múltiples formas en el ámbito de los derechos fundamentales, de modo que se produce no sólo la interpretación de las leyes conforme a la Constitución, sino también la "interpretación de la Constitución conforme a las leyes". ${ }^{258}$ Tampoco puede captarse mediante la imagen de la "jerarquía" la influencia de los "principios generales del derecho" que

257 En el mundo de habla inglesa son típicas frases como "Constitution to be supreme law" ( $c f r$. el artículo 6o., de la Constitución de Malta de 1964/92) o "This Constitution shall be the Supreme Law of Namibia" (artículo 1o., inciso 6, de la Constitución de Namibia de 1990).

${ }_{258} \mathrm{Al}$ respecto Hesse, K., Grundzüge..., cit., p. 33. 
Este libro forma parte del acervo de la Biblioteca Juridica Virtual del Instituto de Investigaciones Juridicas de la UNAM

trascienden al Estado constitucional nacional, por ejemplo, en el sentido del derecho europeo. Lo mismo vale para la eficacia, interna o de otro tipo, de los derechos fundamentales, pues su "universalismo" relativiza su nacionalismo.

\section{Despedida del estatismo nacional de la doctrina de las fuentes del derecho; la "europeización" de las fuentes del derecho}

Las reflexiones hechas hasta el momento sugieren, en el contexto de los enunciados textuales de las Constituciones recientes, despedirse declaradamente del estatismo nacional de las doctrinas tradicionales sobre las fuentes del derecho. Esta idea cruza la obra pionera de J. Esser, "Grundsatz und Norm" ("Principio y norma"), en el campo del derecho civil, pero puede y debe ser un modelo también para la teoría constitucional. Aquí ofrecemos solamente unas cuantas palabras clave. La penetración de la categoría de los "principios generales del derecho" quiebra el carácter estatal de las fuentes del derecho lo mismo que lo hacen las referencias, expresas de manera más o menos clara, a los principios del derecho "pre-estatales" o "pre-positivos", en la forma que sea: como "derechos humanos universales", como "derecho", por la vía de las "cláusulas de realización de los derechos fundamentales", etcétera. Sobre todo resultan relevantes aquí los procesos que, por ejemplo, permiten pensar en el surgimiento de un "derecho común" en Europa. En la medida en que la teoría constitucional nacional y la jurisdicción constitucional se "europeícen", se enriquecerá el "corpus iuris" nacional, se pluralizarán las fuentes nacionales del derecho, se abrirá el canon interno hacia "fuera". En lo particular, todos los procesos evolutivos que permiten calificar a la comparación jurídica como "quinto" método de interpretación, además de los cuatro clásicos de F. C. von Savigny, constituyen una despedida, o al menos una decisiva relativización, del estatismo nacional en la doctrina sobre las fuentes del derecho. Este proceso evolutivo caracteriza al Estado constitucional en su actual etapa textual, la que no ha permanecido sólo en el "papel", sino que también impregna la realidad constitucional. 
Este libro forma parte del acervo de la Biblioteca Juridica Virtual del Instituto de Investigaciones Juridicas de la UNAM

\section{CAPÍTULO GUARTO. PROGESO CONSTITUYENTE. MODIFICACIÓN E INTERPRETACIÓN DE LA CONSTITUCIÓN. JURISDIGCIÓN CONSTITUGIONAL}

\section{Proceso CONSTITUYENTE}

\section{Un catálogo de problemas, preguntas y respuestas}

\section{A. Planteamiento de la cuestión}

El Estado constitucional democrático de la actualidad se entiende y se vive a partir del poder constituyente del pueblo. Por un lado, este poder se deriva expresamente como tal de los textos constitucionales - en la historia constitucional del tipo del "Estado constitucional" ha prevalecido unas veces de manera "revolucionaria" y en otras de modo evolutivo (sobre todo en contra del poder constituyente del monarca) - ; por el otro, dicho poder fue desarrollado de manera "no escrita" por la doctrina y la práctica, vaciado en conceptos, refinado y traducido, de manera parcial o plena, en textos constitucionales. Lo característico en "materia de proceso constituyente" (Verfassunggebung) para el Estado constitucional se deduce, como no lo es casi ningún otro aspecto, de un conjunto y un "paralelograma de las fuerzas" compuesto por ideas políticas, doctrinas científicas, textos constitucionales escritos y prácticas no escritas. Sin importar qué tan grandes sean, también hoy en día, las diferencias entre países - como consecuencia de su historia constitucional nacional-, se ha desarrollado un concentrado de "doctrinas" y de la práctica relativas al poder constituyente del pueblo, el cual, a pesar de las "variaciones", permite identificar un tipo básico. Este tipo debe ser desentrañado primordialmente a partir de los textos constitucionales, cambiantes en la historia y diversos entre las naciones según su estadio cultural, pero para tal fin se requiere tomar en cuenta la historia (constitucional) de las "doctrinas políticas" (sin que éstas puedan ser expuestas en lo particular); porque han conducido a determinados textos constitucionales y los han desarrollado, del mismo modo como, a la inversa, estos textos han actuado, y deberían actuar, en cuanto "material" y 
Este libro forma parte del acervo de la Biblioteca Juridica Virtual del Instituto de Investigaciones Juridicas de la UNAM http://www.juridicas.unam.mx

desafío para la subsecuente elaboración de teorías. De manera particular, en la Alemania del siglo XIX se produjeron, además, formas de "pacto" entre los "sujetos" que influían en el proceso constituyente (monarca y estamentos o pueblo) que recuerdan a la idea, hoy nuevamente de actualidad, de la "Constitución como contrato".259

\section{B. El catálogo de problemas: cinco conjuntos de cuestiones como continuum} en la transformación de los textos constitucionales

En lo particular, se deducen tipológicamente cinco conjuntos de cuestiones, con base en el examen histórico y actual de los textos constitucionales. Estos conjuntos permiten reconocer, por un lado, lo típico en materia de "poder constituyente del pueblo" en el Estado constitucional; por el otro, también el amplio espectro de posibles soluciones político-constitucionales:

a) ¿En qué "lugares" o apartados abordan los diversos textos constitucionales, desde el punto de vista de la sistemática textual, el problema del poder constituyente del pueblo? ¿"Ya" en el preámbulo ( $c f r$. la LF), en las disposiciones de bases o bien en las finales (así, en el artículo 146 de la LF y en el artículo 115 de la Constitución de Brandemburgo), o este problema no es abordado en absoluto (es decir, que se presupone y se practica como "inmanente al sistema", orientándose por la doctrina desarrollada a partir de 1789 (Sieyès), la cual gira alrededor de un tipo básico en nuevas variantes textuales)?

b) ¿Quién y en cuáles procedimientos interviene como "sujeto" en los procesos constituyentes? En este pluralismo actúan hoy día los partidos, asociaciones, iglesias, personajes (como N. Mandela en Sudáfrica), la doctrina (en España y Portugal de los años setenta; en Turquía de los años ochenta [también] los militares). ${ }^{260}$ En Brandemburgo (1992), fueron las "ciudadanas y los ciudadanos del Land", es decir, no el pueblo, los que se dieron "esta Constitución" (preámbulo; véase también el preámbulo de la Constitución de Mecklemburgo-Antepomerania, de 1993).

En la historia constitucional de Alemania, y esto puede leerse en el espejo de los textos constitucionales, los príncipes y los estamentos o las asam-

259 Sobre el particular véase Saladin, P., "Verfassungsreform und Verfassungsverständnis”, AöR, vol. 104, 1979, pp. 345 y ss.; Häberle, P., Kommentierte Verfassungsrechtsprechung, 1979, pp. 438 y ss.

260 Sobre el papel de las fuerzas armadas, $c f r$. los preámbulos de las Constituciones de Portugal (1976/82) y de Turquía (1982); en este último país, las fuerzas armadas volvieron a intervenir en 1997. 
Este libro forma parte del acervo de la Biblioteca Juridica Virtual del Instituto de Investigaciones Juridicas de la UNAM

bleas populares, lucharon por ser "sujetos" del proceso constituyente. Las Constituciones otorgadas (como la prusiana de 1848) fueron expresión del poder constituyente del monarca; las pactadas (como la Constitución prusiana revisada de 1850) constituyeron un pacto o compromiso entre el príncipe y los estamentos y el pueblo al que éstos representaban. Fue hasta más tarde, es decir, a partir de 1918, que en Alemania se reconoció al pueblo como único "sujeto" en materia de poder constituyente. ${ }^{261}$

c) $¿ E l$ poder constituyente del pueblo es fijado en el texto en determinados procedimientos o no? ¿Existen determinadas variantes procesales expresas en el texto? Por ejemplo: elecciones para una asamblea constituyente, con o sin referéndum subsecuente. O bien, ¿son requeridas éstas de modo inmanente por el tipo del Estado constitucional? También es posible la falta de toda legitimación democrática directa, ex ante, del constituyente (así para la LF de 1949). Suiza ha avanzado bastante en la "procesalización" del proceso constituyente, al haber desarrollado un canon fijo de reglas procesales escritas para la "revisión total", las cuales podrían pertenecer ya a la "sustancia" de este Estado constitucional, en el plano federal, tanto como en el cantonal (por último, en el artículo 129 de la Constitución de Berna de 1993, y en los artículos 83 a 90 del proyecto de Constitución de Tessin de 1995).

d) El poder constituyente del pueblo, ¿ise encuentra incorporado textualmente en un "contexto" de determinados contenidos normativos (como la dignidad humana, la justicia, los sucesos históricos), por ejemplo, y de manera especial, en los preámbulos o en los artículos de "reconocimiento"? o bien, ¿aparece como "poder" desvinculado, libre, que decide "normativamente a partir de la nada"?

e) En relación con lo anterior: ¿existen límites escritos o no escritos ("autoimpuestos" o culturalmente puestos) del poder constituyente del pueblo? Ya sea deducidos de los textos constitucionales (especialmente en los preámbulos), de las sentencias de los tribunales constitucionales (BVerfGE 1, 14, 61 y s.: iprimera sentencia sobre la reorganización territorial!), o desarrollados por la doctrina, la cual, por su parte, se orienta por los textos y por el concentrado del tipo del Estado constitucional en materia de proceso constituyente.

261 Stern, K., op. cit., p. 147, constata que la doctrina del pouvoir constituant constituye la más importante aplicación de la idea de la soberanía popular, y que resulta evidente en el Estado constitucional democrático, pero que "el camino para llegar a ella estuvo lleno de espinas". 
Este libro forma parte del acervo de la Biblioteca Juridica Virtual del Instituto de Investigaciones Juridicas de la UNAM

\section{Respuestas}

Una teoría que trabaje a la luz de las etapas de evolución textual y que "ofrezca" alternativas de regulación tomadas de la historia y del presente, es capaz de resolver el problema del poder constituyente del pueblo con mayor cercanía a la realidad de lo que son capaces muchas ideologías. De este modo, el tipo del Estado constitucional democrático puede llevar su reflexión un poco más allá de la respectiva Constitución concreta de un pueblo en particular, así como elaborar alternativas de acción que permitan la evolución abierta de esa Constitución concreta. Pero, en última instancia, no puede descartarse que al hacerlo, también evolucione el tipo del "Estado constitucional" mismo. Piénsese solamente en los catálogos de valores fundamentales en los que se enmarcan crecientemente, a partir de 1945, el Estado constitucional y el constituyente: se trata de una nueva etapa textual y de una ganancia para el Estado constitucional, como lo son también los instrumentos procesales suizos bajo el concepto de "revisión total" o la "revisión de conjunto" austriaca o el "modelo español". Tan pronto como una Constitución se hace realidad y continúa su desarrollo sobre los "rieles" del tipo del Estado constitucional, no puede haber sino procesos constituyentes evolutivos, precisamente porque una teoría de la Constitución de cuño culturalista elabora, más allá de los textos positivos, contenidos y procedimientos que abren la vía hacia una nueva Constitución ejemplar concreta. La teoría de la Constitución fracasa tan pronto como se producen revoluciones (culturales) que se apartan y se vuelven contra el Estado constitucional (bajo el signo del pensamiento del Estado totalitario, de derecha o de izquierda). El "gran salto" hacia atrás (mejor dicho: hacia adelante), hacia el tipo del "Estado constitucional", puede realizarse solamente a través de la argumentación arriba desarrollada, esto es, renuncia excepcional a elecciones previas para una asamblea nacional, pero elecciones o referéndum posteriores indispensables, porque el nuevo estadio se encuentra más "próximo" al tipo del Estado constitucional que el anterior (ejemplos: la LF de Alemania de 1949 y la Constitución turca de 1982).262

La tesis sobre el pueblo como "sujeto único" en los procedimientos materialmente preelaborados y normativos preestructurados de su poder constituyente no es contrariada por la sustitución de la tradicional "unidad de la voluntad popular" por el actual pluralismo del pueblo. ${ }^{263} \mathrm{El}$ derecho del

\footnotetext{
262 En analogía con BVerfGE 4, 157 (169 y s.): "más próximo a la Ley Fundamental".

$263 \mathrm{Al}$ respecto, Hesse, K., Grundzüge des Verfassungsrechts der Bundesrepublik Deutschland, 20a. ed., 1995, pp. 5 y ss., 62.
} 
Este libro forma parte del acervo de la Biblioteca Juridica Virtual del Instituto de Investigaciones Juridicas de la UNAM

pueblo, típico del Estado constitucional, a ser único sujeto o "titular" del poder constituyente, no hace incorrecta la idea de que el pueblo es una magnitud pluralista. En el Estado constitucional moderno contribuyen una diversidad de "factores" o "participantes" pluralistas en el consenso básico sobre el cual se "construye", en última instancia, la Constitución. Ya sea que se hable de un pluralismo "de los" constituyentes, de un compromiso o entendimiento de todos con todos: hoy en día "el pueblo" se encuentra "presente" y actúa a través de estos procesos y de estos participantes. El renacimiento de la idea de la Constitución pactada corresponde mejor al pluralismo de los contenidos y los participantes en el proceso constituyente que la ideología de la (ilimitada) voluntad "del" constituyente, el cual "se da" la Constitución. En todo caso, esta idea no significa un "retroceso" a las épocas del dualismo alemán entre príncipe y estamentos, así como tampoco un falso camino hacia el "Estado estamental", sin importar cuántos textos constitucionales se encuentren todavía impregnados por la ideología "del" constituyente.

Como consecuencia de lo dicho hasta ahora, se deducen también respuestas para la quinta cuestión del catálogo de problemas arriba citado, en relación con los posibles límites, escritos o no escritos, derivados del tipo del Estado constitucional o de cultura, al poder constituyente del pueblo. Tales consecuencias se deducen de que el "proceso constituyente" tiene que referirse a la Constitución de un ejemplo concreto respecto del tipo, más abstracto, del "Estado constitucional": de otro modo, el término y el concepto de "proceso constituyente" serían engañosos y triviales, un mero acto formal. Por razones que hoy todavía resultan convincentes, el artículo 16 de la Declaración francesa de los Derechos del Hombre y el Ciudadano de 1789 (la que se integró a la Constitución de 1791 y que todavía está vigente en Francia por obra del preámbulo de la Constitución de 1958) formula y dispone lo siguiente: "Toda sociedad en la que la garantía de los derechos no esté asegurada, ni determinada la división de poderes no tiene Constitución". Este es un enunciado válido de derecho constitucional en la Francia actual y, desde el punto de vista de la historia de la cultura, es también un "texto clásico" cultural del tipo del Estado constitucional. Los pueblos cuyo poder constituyente ha podido establecer una Constitución de este tipo se han decidido, cuando menos y de manera inmanente, en favor de este enunciado básico de 1789 . 
Este libro forma parte del acervo de la Biblioteca Juridica Virtual del Instituto de Investigaciones Juridicas de la UNAM http://www.juridicas.unam.mx

\section{Los dos planos: el proceso constituyente en el tipo del Estado constitucional y en un pueblo concreto en el contexto de su individualidad e identidad culturales}

Es preciso trabajar siempre en dos planos, que deben distinguirse entre sí (aunque en la evolución histórica influyan mutuamente uno en el otro): en el plano más abstracto del tipo del Estado constitucional, y en el más concreto de un pueblo constituido y que se constituye de manera individual concreta. Así, el principio del Estado federal no es (¿todavía?) parte inmanente de todo "proceso constituyente" del pueblo adecuado al tipo, porque existen grandes Estados constitucionales con tradición, como Inglaterra y Francia, que no son Estados federales, pero que han desarrollado formas previas (¡regiones!), pero también se encuentran algunos Estados constitucionales, como los Estados Unidos y Suiza, en los cuales el principio federativo constituye un principio estructural de toda especie de proceso constituyente o de revisión constitucional total por parte del pueblo, desde que dicho pueblo se encuentra constituido: lo que se presenta jurídicamente (como en Suiza) como "límite" de la revisión total o del proceso constituyente, es, en el fondo, mucho más: una manifestación viva y concreta de la "Constitución como estadio cultural", la cual no puede ser superada sin revolución ni pérdida cultural. Y en este estadio cultural, ni la nación ni el pueblo se encuentran en estado de naturaleza o de excepción, en el sentido de las doctrinas que van de Sieyès hasta C. Schmitt. ${ }^{264}$ Algo similar se aplica a la alternativa entre "monarquía parlamentaria (España) o "república" (Francia, la LF alemana) en la medida en que ambos Estados constitucionales solamente pueden ser monarquías o repúblicas constitucionales, de conformidad con su actual etapa de desarrollo cultural y constitucional.

\section{E. La normativización y constitucionalización del poder constituyente del pueblo}

La teoría y la práctica de la normativización y la constitucionalización, aquí propugnadas, del poder constituyente del pueblo ${ }^{265}$ sobre la hoja de

\footnotetext{
${ }_{264}$ Cfr. Schmitt, C., Verfassungslehre (1928), p. 79: "El poder constituyente es siempre estado de naturaleza, cuando se presenta en esta calidad inalienable".

265 Kriele, M., Einfïhrung in die Staatslehre, 1975, ofrece un impresionante esbozo del Estado constitucional democrático. Sin embargo, en última instancia elimina la soberanía popular y el poder constituyente del pueblo mediante las siguientes frases (p. 226): "La soberanía popular aparece al principio o al final del Estado constitucional, cuando es constituido
} 
Este libro forma parte del acervo de la Biblioteca Juridica Virtual del Instituto de Investigaciones Juridicas de la UNAM

los artículos de reconocimiento que lo "rodean" como contexto en materia de valores fundamentales y sus "textos clásicos" de 1789 y 1776-1787, así como los textos suizos sobre las máximas procesales para la "revisión total", no pueden ser descalificadas con el argumento de que se trata sólo de una "autobligación" (frente al trasfondo de un "poder ilimitado por principio") del respectivo constituyente concreto y no de la normalidad y la normatividad de un principio constitucional inmanente al tipo del Estado constitucional. Sólo desde la perspectiva externa y formal "se" obligan "a sí mismos" el constituyente o el pueblo (pluralista): en el fondo, y desde la óptica de la historia cultural, vota a favor de contenidos y procedimientos que están dados e impuestos de manera bastante más "objetiva" de lo que quiere reconocer un decisionismo ahistórico. ${ }^{266}$ La vinculación a un determinado estadio de desarrollo cultural crea "realidades" e "idealidades" para las que no resulta adecuada la teoría de la mera "autoobligación" subjetiva y la "autolimitación" voluntarista. La "internalización" intensiva de determinados valores fundamentales como los "derechos humanos", la "paz", etcétera, que se revela en los elementos textuales de los preámbulos como el "propósito", la "conciencia", "animados por la voluntad", se convierte en algo objetivo, en determinantes culturales.

\section{Consideraciones de política constitucional}

Las reflexiones teóricas esbozadas hasta el momento, y los análisis comparativos de los textos constitucionales, así como de la práctica del poder constituyente del pueblo, que les acompañan, quedarían a medias si no desembocaran en consecuencias de política constitucional, ya que la teoría de la Constitución no excluye, sino que, en un "último paso", incluye la dimensión de la política constitucional. La ciencia puede y debe ofrecer a los futuros constituyentes apoyos prácticos en la elaboración de sus textos, y donde sea posible, también en el sentido de alternativas, como las que se han hecho habituales, como "variantes", en los proyectos de revisión total en Suiza. ${ }^{267}$

o cuando es suprimido". "La soberanía democrática descansa, mientras subsiste el Estado constitucional".

266 Véase también Stern, K., Staatsrecht..., cit., p. 149: "Un elemento básico de esta idea (es decir, del proceso constituyente europeo-atlántico) posee una objetividad que se puede fundamentar racional e históricamente: derechos humanos, orden fundamental de libertad y democracia, Estado de derecho".

267 Cfr. las "variantes" en el Proyecto de revisión total de la Constitución federal (1977), así como para las Constituciones cantonales de Solothurn (1985) y Glarus (1977), reproducidos en $\mathcal{f o ̈} R$, vol. 24, 1985, pp. 536 y ss, 497 y ss., 480 y ss., respectivamente. 
Este libro forma parte del acervo de la Biblioteca Juridica Virtual del Instituto de Investigaciones Juridicas de la UNAM

Frente a este trasfondo se recomienda lo siguiente:

A) Los constituyentes nacionales (o a nivel de entidades federativas, provincias o cantones) deberían abordar como tal la competencia constituyente del pueblo, tanto en los preámbulos como en los artículos finales:268 dando, en cierto modo, un "marco" a su obra constitucional. Al hacerlo, debe describirse el proceso histórico-cultural constituyente, en el sentido del postulado de la verdad y claridad del texto constitucional, como se haya producido en la realidad, incluso cuando "instancias en realidad no competentes", como las "fuerzas armadas" y las "potencias de ocupación" (así, en Portugal en 1976, en Turquía en 1982 o en Alemania Occidental en 1949), hayan intervenido y se hayan apropiado de un pedazo de la competencia que reside exclusivamente en el pueblo.

B) El poder constituyente del pueblo, de conformidad con el tipo del "Estado constitucional", debería enriquecerse en el texto constitucional desde dos ángulos: por una parte, desde el lado sustantivo de los valores fundamentales (ejemplo de ello son las Constituciones de los Länder alemanes a partir de 1945, pero también las Constituciones de Portugal de 1976 y España de 1978), es decir, a través de "artículos de reconocimiento" o de "conciencia" o mediante elementos de los preámbulos; por la otra, desde el lado procesal (ejemplos de ello son las disposiciones suizas, austriacas y españolas sobre la "revisión total" o "general").

C) También son recomendables los apartados propios sobre la revisión total o general de la Constitución (en lo posible, en "tres tiempos" procesales: iniciativa del pueblo, votación en los parlamentos y promulgación por el pueblo; el pueblo debería tener "después", ya sea a través de elecciones o de un referéndum, la palabra final). Desde el punto de vista de la redacción, pueden ubicarse junto con las disposiciones relativas a la revisión total y la reforma constitucional bajo el "techo" de uno y el mismo apartado (hay ejemplos en Suiza a nivel federal y cantonal). Con ello se da a entender textualmente que la "revisión total" es plenamente un proceso posible y normal (del proceso constituyente) junto con la mera revisión parcial o la "modificación constitucional". De este modo también se manifiesta que el poder constituyente del pueblo tendencialmente se ha normalizado, nor-

268 Así se dice en el preámbulo de la Constitución francesa de 1946: "le peuple français proclame à nouveau... Il réaffirme solennellement les droit et les libertés"; al final, en el artículo 106: "La présente Constitution, déliberée et adoptée par l'Assemblée nationale constituante, approuvée par le peuple français...”. Se cita según Godechot, J. (ed.), Les Constitutions de la France depuis 1789, 1979, pp. $389,410$. 
Este libro forma parte del acervo de la Biblioteca Juridica Virtual del Instituto de Investigaciones Juridicas de la UNAM

mativizado y constitucionalizado en el tipo del Estado constitucional en la etapa evolutiva actual. ${ }^{269}$

D) No es necesario suprimir ni despedirse del concepto de "proceso constituyente" o de poder o competencia constituyentes del pueblo en los textos constitucionales ni en la teoría, tan sugestivo es el efecto de los textos clásicos de 1776-1778 y 1789-1791-1792 que lo soportan culturalmente hasta la actualidad. Sin embargo, tendría que imponerse el reconocimiento de que el "proceso constituyente por el pueblo" y la "revisión total" o "general" por el pueblo en el tipo del "Estado constitucional" son idénticos entre sí. Las Constituciones que hablan de "proceso constituyente" en los preámbulos o en los artículos finales, deberían ser consecuentes terminológicamente e intitular a un posible apartado sobre la "revisión general" también textualmente como "proceso constituyente". Para poner en claro que en la aproximación, típica del Estado constitucional, entre modificación de la Constitución (revisión parcial) y "proceso constituyente" (revisión total), es recomendable reunir ambos tipos de "reforma constitucional" en lo sistemático bajo un solo "techo" o apartado.

\section{El proceso constituyente como proceso pluralista, normación de lo "políticamente significativo"}

Finalmente, el enfoque jurídico tradicional tampoco es suficiente en el campo del proceso constituyente, ya que aquí no hay todavía un texto positivo "vigente". Solamente un enfoque más amplio y profundo, de tipo cultural, es capaz de tematizar y conceptualizar determinados movimientos, sus "promotores" y actores. Los procesos constituyentes recientes de Portugal (1976), Grecia (1975) y España (1978), pero también en Canadá (1981), así como la discusión suiza alrededor de la "revisión total" de la Constitución federal (Proyecto de 1977, reintroducido posteriormente en 1995) no pueden describirse y explicarse únicamente en términos económicos y políticos, es decir, sin tomar en cuenta el trasfondo cultural.

Antes de la elaboración textual, existen "en la plaza" una pluralidad de elementos diversos de construcción para la nueva Constitución. Los textos de los clásicos, los programas de partidos y asociaciones, las conocimientos de la ciencia, fragmentos de textos constitucionales antiguos, pero también los logros de algunos personajes (por ejemplo, N. Mandela) luchan

269 Cfr. también el artículo 196 de la Constitución de Costa Rica: "La reforma general de esta Constitución, sólo podrá hacerse por una Asamblea Constituyente convocada al efecto". 
Este libro forma parte del acervo de la Biblioteca Juridica Virtual del Instituto de Investigaciones Juridicas de la UNAM

sustantivamente entre sí. Las esperanzas y experiencias políticas penetran en los procesos constituyentes tanto como los elementos provenientes de Constituciones extranjeras en cuanto ejemplos del tipo del Estado constitucional. De este modo, los modelos alemanes de Estado federal y de jurisdicción constitucional, pero también de la relación entre Estado e iglesias, así como el catálogo de derechos fundamentales, influyen hoy de manera creciente en algunas nuevas Constituciones de Europa. Los procesos de recepción cultural, como por ejemplo de la garantía del contenido esencial del artículo 19, inciso 2, de la LF, pueden reconocerse no solamente con vistas a la revisión total en Suiza sino incluso hasta África del Sur (anteriormente hasta Bophuthatswana, hoy Sudáfrica). Pero antes de que todo esto "cuaje" en un texto constitucional, hay mucha lucha, mucha toma de partido y mucha defensa de intereses.

Vale la pena echar una mirada a la normación de lo "políticamente significativo":

La primera función de los constituyentes consiste en traducir, de manera formalizada en un texto constitucional, lo que para ellos sea "políticamente significativo" en la dimensión del tiempo, es decir, en el pasado, el presente y el futuro (carácter de la Constitución como ordenamiento fundamental). Lo que en la experiencia histórica ha dado resultado hay que unirlo con el "espíritu del tiempo", en particular, con la realidad, de tal modo que también al respecto se expresen en el texto constitucional esperanzas hacia el futuro, posibilidades de conformarlo, y criterios (objetivos). Lo específico en este sentido es el momento de la duración y ello legitima la normación de una idea jurídica, una institución o un procedimiento a nivel constitucional. En otras palabras: un tema debe parecerle suficientemente duradero al constituyente para hacerlo objeto de regulación textual en la nueva Constitución. No cualquier cosa que se encuentre en la evolución social y estatal respectiva merece la distinción de contener un proceso de desarrollo constitucional, sino que debería dar buen resultado esta vinculación entre tradición y apertura hacia el futuro, entre estabilidad y dinámica, entre reproducción de lo existente y orientación prospectiva, entre recepción y producción.

Lo que el constituyente considere como "políticamente significativo" e incorpore en su texto varía en el tiempo y el espacio, de país en país. Pero se plantea la pregunta sobre cuáles criterios debería poner a su disposición la doctrina en funciones de asesoría, a fin de describir temáticamente y traducir jurídicamente, de manera óptima, lo políticamente significativo. Estos criterios deben obtenerse de un panorama empírico de las Constituciones más importantes de la actualidad (inventario de lo que es típico-real), complementado por los requerimientos "ideales" que hasta ahora no pertenecen, 
Este libro forma parte del acervo de la Biblioteca Juridica Virtual del Instituto de Investigaciones Juridicas de la UNAM

de facto, al contenido típico, pero que merecen ser tomados en cuenta por tantas Constituciones como sea posible (requisitos del deber ser típico-ideales). En este sentido, el punto de orientación es la buena Constitución del Estado constitucional. La política constitucional y la doctrina del derecho del Estado deben colaborar, a pesar de lo inevitables que sean los elementos decisionistas, en la decisión sobre lo "políticamente significativo".

\section{MODIFICACiÓN DE LA CONSTITUCiÓN}

\section{Preguntas iniciales}

La institución clásica para formalizar lo nuevo y darle entrada directa en la Constitución es la modificación constitucional (Verfassungsänderung), es decir, la modificación del texto constitucional, a través de determinados procedimientos y mediante una mayoría casi siempre calificada que amplíe la base del consenso ( $c f r$. el artículo 79, inciso 2, de la LF). Todos los Estados constitucionales que poseen un documento constitucional conocen esta posibilidad de ajustarse también textualmente al cambio en el tiempo, aunque en lo particular puedan ser diferentes los supuestos (por ejemplo, la magnitud de la mayoría).

Las modificaciones constitucionales pueden servir para adaptarse a procesos evolutivos que ya se han producido en los hechos; pero también pueden pretender inducir tales procesos. Deben distinguirse pues la "modificación de adaptación" y la "modificación de creación". En principio, la duración y la estabilidad parecen hablar en contra de la modificación de la Constitución, pero esta modificación también puede ser útil para la duración y estabilidad de una comunidad, cuando son "oportunas". Que esto sea así, sólo puede decirse en el caso particular y en ámbitos específicos.

\section{Un catálogo de problemas de política constitucional en materia} de modificación de la Constitución

La modificación constitucional es el procedimiento institucionalizado para la adaptación de la Constitución al cambio cultural y para la iniciación activa de medidas para dicho cambio. Por razones derivadas del principio del Estado democrático de derecho, dicha modificación sólo es parcialmente sustituible o intercambiable con la "mutación constitucional" (G. Jellinek), es decir, con la modificación del contenido constitucional sin cambio 
Este libro forma parte del acervo de la Biblioteca Juridica Virtual del Instituto de Investigaciones Juridicas de la UNAM

del texto constitucional, por sorprendente que resulte la diferencia entre 43 modificaciones de la LF en sólo 47 años (1949 a 1996), por un lado, y sólo 6 modificaciones de la Constitución bávara en 50 años, de 1946 a 1996, o las 28 enmiendas a la Constitución federal de los Estados Unidos (gracias también a la "broad interpretation") desde 1787. En su idea, la modificación constitucional es expresión de los procesos normales de crecimiento y desarrollo de una Constitución y en algunos casos incluso puede ser necesaria a favor de la idea de Constitución misma. No es un "accidente de trabajo", sino que constituye más bien un sector dentro del tema más amplio de "tiempo y cultura constitucional" y "el Estado constitucional desde la perspectiva de la evolución histórica".

En lo que sigue se señalarán tipológicamente los ámbitos problemáticos que el constituyente de la actualidad tiene que tomar en cuenta al normativizar los procesos de modificación de la Constitución, y los que de hecho sigue, de acuerdo con la observación de muchos años, de la práctica comparada en el tiempo y el espacio. En este sentido, llama la atención que la problemática de la modificación constitucional se caracterice por numerosas variantes y diferenciaciones progresivas (sobre todo en dirección hacia criterios materiales, pero también temporales). En la medida en que la teoría de la Constitución sea también una teoría de la "buena" Constitución y que pueda, e incluso deba, incorporar de entrada y de manera consecuente las cuestiones de la política constitucional en su horizonte de análisis, es posible distinguir los siguientes ámbitos problemáticos:

A) La cuestión de quién es "sujeto" de la competencia o la función modificatoria de la Constitución. Por ejemplo, solamente los cuerpos parlamentarios, como en la LF (artículo 79) o también (adicionalmente) el pueblo (cfr. el artículo 75, inciso 2, frase 2, de la Constitución de Baviera; el artículo 46, inciso 2, de la Constitución de Irlanda; el artículo 51, inciso 2, de la Constitución de la República de Guinea de 1991, así como las Constituciones suizas, tanto a nivel federal como cantonal; cfr. el artículo 135 de la Constitución del Cantón del Jura de 1977; véase además el referéndum requerido por el artículo 168, inciso 3, de la Constitución española, así como el artículo 152 de la Constitución de Azerbaiyán de 1995). El artículo 138 de la Constitución de Italia (1947/93) contiene disposiciones particulares para la intervención del pueblo; el artículo 89, incisos 2 y 3, de la Constitución de Francia de 1958/96 prevé alternativas.

B) La cuestión de la naturaleza y el alcance de los obstáculos procesales a las modificaciones constitucionales (por ejemplo, mayoría de dos tercios en el Parlamento y el Consejo Federales de Alemania, conforme al artículo 79, inciso 2, de la LF), llamando la atención las disposiciones en cuyo marco 
Este libro forma parte del acervo de la Biblioteca Juridica Virtual del Instituto de Investigaciones Juridicas de la UNAM

son posibles mayorías especiales adicionales, con consecuencias particulares (disolución de las cámaras) respecto de modificaciones constitucionales especiales desde el punto de vista de su contenido (así el artículo 168, inciso 1, de la Constitución española de 1978/92).270

C) La cuestión de si existen disposiciones formales adicionales, por ejemplo, el mandato de modificación expresa del texto de la Constitución, como lo establece el artículo 79, inciso 1, frase 1, de la LF, esto es, la documentación y visibilidad de la modificación constitucional, ${ }^{271}$ un principio que es manifestación del carácter público formalizado de la Constitución. La carencia de una disposición como la del artículo 79, inciso 1, frase 1, de la LF, ha provocado por ejemplo que la Constitución federal de Austria se haya deformado hasta la "ruina". ${ }^{272}$

D) La cuestión de otros límites (v. gr., de carácter temporal) impuestos al procedimiento. Así, el artículo 110, inciso 6, de la Constitución de Grecia de 1975 regula la prohibición de toda modificación constitucional "antes del transcurso de un periodo de cinco años a partir de la conclusión de la precedente revisión", lo que es manifestación de la idea de la Constitución como orden fundamental. Un límite temporal análogo se encuentra en el artículo 284, inciso 1, de la Constitución de Portugal. Así, el 88 de la Constitución de Dinamarca (1953) exige, en su caso, una nueva elección del Folketing, cuando éste haya llevado a cabo previamente una nueva votación constitucional. También el capítulo 8, 15 de la Constitución de Suecia (1975-1980) exige una segunda resolución que confirme las modificaciones de la Ley Fundamental, lo cual solamente puede realizarse cuando previamente se hayan llevado a cabo elecciones al Parlamento "en todo el reino". El artículo 114, inciso 2, de la Constitución de Luxemburgo (1868-1996) declara disuelta de jure la Cámara cuando ésta se haya pronunciado previamente a favor de una modificación constitucional.

E) Límites de la modificación constitucional mediante "cláusulas de eternidad" (como las que contienen, recientemente, el artículo 56, inciso 3,

270 Cfr. también el 79, inciso 1, frase 1, de la Constitución de Islandia (1944/68). En un sistema presidencial puede ser también conveniente prever límites especiales en materia de reelección o prolongación del mandato del presidente en funciones (así, en el artículo 129, inciso 2, de la Constitución de Corea del Sur de 1980, citada en Fö R, vol. 35, 1986, pp. 604 y ss.).

271 Véase al respecto Stern, K., Das Staatsrecht..., cit., vol. I, 2a. ed., 1984, p. 159.

272 Véase al respecto Österreichische Parlamentarische Gesellschaft (ed.), 75 Fahre Bundesverfassung, 1995, passim, por ejemplo, pp. 12 y s., 160. 195 y ss. Véase también la prohibición del "quebrantamiento de la Constitución" ("Verfassungsdurchbrechung") en el artículo 64, inciso 4, de la Constitución de Baden-Württemberg de 1953. 
Este libro forma parte del acervo de la Biblioteca Juridica Virtual del Instituto de Investigaciones Juridicas de la UNAM

de la Constitución de Mecklemburgo-Antepomerania de 1993, el artículo 78, inciso 3, de la Constitución de Sajonia-Anhalt de 1993, el artículo 83, inciso 3, de la Constitución de Turingia de 1993).

F) La cuestión de si en determinadas épocas, como en tiempos de guerra o situaciones de emergencia, no están permitidas las modificaciones constitucionales ( $c f r$. el artículo 289 de la Constitución de Portugal, el artículo 169 de la Constitución española; véase también el artículo 115e, inciso 1, frase 1, de la LF; el artículo 196 de la Constitución de Bélgica de 1994; el artículo 148, inciso 3, de la Constitución de Rusia de 1993). La contestación afirmativa de esta cuestión debería convertirse, en mi opinión, en elemento independiente de toda reflexión sobre las modificaciones constitucionales, y donde no esté regulada expresamente, deberá fundamentarse de manera no escrita ("inmanente") mediante la interpretación constitucional (comparada).

G) Desde el punto de vista de la política constitucional se plantea la cuestión de la "ubicación" de la regulación de la modificación constitucional por el constituyente: por ejemplo, solamente en las disposiciones finales o transitorias, como en el § 95 de la Constitución de Finlandia (1991-1995), en el artículo 152, incisos 1 y 2, de la Constitución de la República Eslovaca de 1992; véase también el artículo 116 de la Constitución de Turkmenistán de 1992, así como la Parte séptima de la Constitución de Turquía de 1982 (artículo 175), o por el contrario, en el apartado de las "disposiciones de bases" (así, en el artículo 9o. de la Constitución de la República Checa de 1992), en el apartado sobre la legislación federal, como en Austria (artículo 44 de la Constitución federal de 1920-1994) o en apartados propios (como el artículo 110 de la Constitución de Grecia de 1975; el artículo 46 de la Constitución de Irlanda de 1937-1992), o la "legislación" (como en Brandemburgo, según el artículo 79 de la Constitución de 1992, o el artículo 74 de la Constitución de Sudáfrica de 1996), o en el contexto del proceso constituyente como procedimiento más fuerte, pero próximo (así, en el capítulo IX de la Constitución de Bulgaria de 1991; $c f r$. especialmente el artículo 158). Las transiciones entre (varias) revisiones parciales y (una) revisión total (proceso constituyente) pueden ser fluidas. El artículo 44 de la Constitución federal austriaca distingue entre modificación de conjunto y modificación parcial. ${ }^{273}$ Hay bastantes elementos que hablan a favor de que ambos procedimientos se regulen en un solo apartado conjunto (así, el

273 De la bibliografía véase al respecto: Huber, H., "Die Gesamtänderung der Verfassung", FS Scheuner, 1973, pp. 183 y ss. 
Este libro forma parte del acervo de la Biblioteca Juridica Virtual del Instituto de Investigaciones Juridicas de la UNAM

capítulo XIII de la Constitución de Nicaragua de $1986^{274}$ y el título X de la Constitución de Venezuela de 1961).

Particularmente lograda parece ser la vinculación de la revisión de la Constitución con un apartado sobre "vigilancia de la constitucionalidad" (en una parte común: "Garantía de la Constitución y revisión": así, en los artículos 277 a 289 de la Constitución de Portugal de 1976-1992), porque de este modo se pone de manifiesto que se toma en serio a la Constitución, que su garantía se puede manifestar también en una (prudente) revisión. El término "defensa de la Constitución", tal como aparece en la Constitución de Renania-Palatinado de 1947-1993, no es entonces un eufemismo, pues así se indican claramente determinados obstáculos procesales y materiales.

En general, no es recomendable regular la modificación de la Constitución "sólo" en las disposiciones transitorias, por importantes que éstas puedan ser (al respecto, véase capítulo sexto, VIII, 15, infra). También hay que discutir si es preciso escoger el concepto de "reforma constitucional" que recientemente se utiliza (así, el artículo 138 de la Constitución de los Países Bajos de 1983; similarmente los artículos 191 a 195 de la Constitución de Nicaragua de 1986); o bien, si hay que prevenirse de utilizar la distinción entre "modificación" y "adición" de la Constitución (así, empero, la Constitución de Azerbaiyán de 1995: artículos 162 y ss., 156 y ss.).

\section{Los límites a la modificación de la Constitución: las cláusulas de eternidad como garantías de la identidad del Estado constitucional}

En lo que sigue es posible solamente bosquejar una teoría en materia de "cláusulas de eternidad": en el sentido de una propuesta teórica, referida al Estado constitucional como tipo. Así como varían ampliamente las cláusulas de eternidad que pueden identificarse en el derecho positivo, tanto en la historia como en el presente, así de evidente es también que muchas Constituciones quieren y pueden arreglárselas sin tales cláusulas (por ejemplo: ¡Suiza en la actualidad!): en la medida en que se logre decir algo "típico" en relación con los diversos "temas", principios y procedimientos del Estado constitucional, debe ser posible también elaborar algo de "principio" sobre un "elemento" muy tradicional y no infrecuente de tal Estado constitucio-

274 De manera similar ya el título XVII de la Constitución de Costa Rica de 1949, con normas desusadamente detalladas en el artículo 195 y la "reforma general de la Constitución", que presupone una asamblea constituyente (artículo 196). También los artículos 373 y ss. de la Constitución de Honduras de 1982 hablan de la "reforma de la Constitución". Igualmente el título XIII de la Constitución de Colombia de 1991. 
Este libro forma parte del acervo de la Biblioteca Juridica Virtual del Instituto de Investigaciones Juridicas de la UNAM

nal, la cláusula de eternidad, y a saber, en el foro de una teoría constitucional (comparada). Ciertamente, la diversidad en el cuadro de presentación de las "cláusulas de eternidad", que en lo particular son muy diversas, hace dificil decir algo general y, al mismo tiempo, hacer justicia a la individualidad de los Estados constitucionales particulares. Así, existe el peligro de que la teoría de la Constitución se haga tan abstracta en sus métodos y contenidos, que en última instancia permanezca como formal. Sin embargo, con ello se le haría un flaco servicio, especialmente en la época actual, en la que el tipo del "Estado constitucional" se ve desafiado a escala mundial y, por ejemplo, los derechos humanos, en cuanto elemento clásico y vivo del tipo del Estado constitucional, se han convertido, al menos verbalmente, en una prueba universal de legitimidad. La teoría de la Constitución debe más bien intentar desarrollar métodos y contenidos que, no obstante la lucha por el tipo del "Estado constitucional", dejen margen de configuración para lo "histórico-individual" de los diversos ejemplos de este tipo: el concepto de "cultura constitucional" y el método de la teoría constitucional como ciencia cultural pueden llenar de manera positiva este margen.

La perspectiva teórico-constitucional sobre las cláusulas de eternidad aquí esbozada da por sentados numerosos resultados de la discusión científica hasta la actualidad, sin examinarlos en lo particular. Lo que hay que enfatizar más de lo que lo hace la doctrina tradicional es la tarea de la integración del material normativo, ejemplar y textual, de las cláusulas de eternidad que pueden identificarse hasta ahora en la historia y en el presente. Estos textos son "teóricamente" mucho más fructíferos para la clasificación científica y la configuración político-constitucional de las cláusulas de eternidad de lo que hasta ahora se ha "hecho" de ellas. Sin embargo, no se desconoce que estas cláusulas son, por su parte y en alguna medida, el resultado de discusiones científicas precedentes y altamente productivas. ${ }^{275}$

Las siguientes consideraciones constituyen criterios de solución de la cuestión teórico-constitucional de la noción de "cláusulas de eternidad" en este sentido:

- Las cláusulas de eternidad son parte integrante inmanente, escrita o incluso no escrita, de las Constituciones del Estado constitucional,

275 Ejemplos de ello son la distinción francesa entre contenidos constitucionales básicos y de otro tipo, las ideas de Schmitt, G., Verfassungslehre (1928) (hay trad: Teoría de la Constitución) y su influencia en las Constituciones de los Länder alemanes después de 1945 y en la LF de 1949. 
Este libro forma parte del acervo de la Biblioteca Juridica Virtual del Instituto de Investigaciones Juridicas de la UNAM

en la medida en que sean interpretadas desde un enfoque material. 276

- Tales cláusulas son de naturaleza declarativa, en la medida en que definan, total o parcialmente, elementos de la "sustancia" de estas Constituciones.

- Esta sustancia de las Constituciones comprende, tipológicamente hablando, los siguientes contenidos: los derechos fundamentales, con la dignidad humana en su vértice, porque ésta constituye la base antropológica; la democracia y la división de poderes. ${ }^{277} \mathrm{La}$ cláusula republicana (entendida sólo formalmente como "no monarquía") ya no es, considerada a partir del tipo del Estado constitucional, una "características esencial" necesaria (ejemplos: ¡Suecia, Noruega, Dinamarca!); lo mismo puede decirse de la estructura federativa (ejemplo: ¡el Estado unitario francés!). Esto no impide que dentro del margen que deja abierto el tipo del Estado constitucional para ejemplos particulares de este Estado, se convierta la cláusula republicana (Francia) y la fórmula federativa (Suiza), con base en la cultura constitucional particular, en "elemento sustancial" individual de una cláusula de eternidad escrita o no escrita, o interpretarla como tal (por la doctrina o incluso pretorianamente).

- Las cláusulas de eternidad deben desentrañarse en el sentido de un pensamiento positivo, de "contenido esencial" o de identidad ${ }^{278}$ y solamente a partir de este marco también en el sentido del "pensamiento en términos de limitaciones" ("Schrankendenken"). En la medida en que se encuentren normadas por el derecho positivo, no ofrecen per se indicios exhaustivos de lo que es "esencial" en una Constitución concreta, y esta "sustancia", que es históricamente variable, se aprehende mediante una interpretación integral.

- Esta noción de las cláusulas escritas y no escritas de eternidad vive de un panorama de las formas típicas en que hasta ahora se han presentado tales cláusulas en los textos constitucionales y de aquello que ha elaborado la doctrina: en especial, deben verse en conjunto las cláusulas clásicas "en el espíritu de esta Constitución", según el modelo noruego (1814) y la "cláusula fundamental" emparentada con aquélla (por ejemplo, el artículo 75, inciso 1, frase 2, de la

276 Sobre este enfoque véase, sobre todo, Ehmke, H., op. cit., pp. 99 y s., 136 y ss.

277 Cfr. Hesse, K., op. cit., p. 293. Cfr. también el artículo 17 de la Constitución de Gabón de 1994.

278 Sobre la "identidad" de la Constitución como límite para su modificación, véase Bryde, B.-O., Verfassungsentwicklung, 1982, pp. 232 y ss., 236. 
Este libro forma parte del acervo de la Biblioteca Juridica Virtual del Instituto de Investigaciones Juridicas de la UNAM

Constitución de Baviera de 1946), así como el "pensamiento sustancial" de un C. Schmitt, junto con los contenidos típicos que el Estado constitucional ha producido paulatinamente en las diversas naciones en los distintos "empujones de crecimiento".

- Contenidos típicos del "Estado constitucional común" constituyen en particular: la dignidad humana y los derechos humanos; el principio democrático, la división de poderes ( $c f r$. el artículo 16 de la Declaración francesa de 1789), el Estado social de derecho. Este "panorama" significa prácticamente que los Estados constitucionales que cuentan con cláusulas simples y no especificadas sobre el "espíritu", los "principios" o las "ideas fundamentales" de su Constitución, pueden y deben ser enriquecidos en cuanto a su contenido con los "elementos indispensables de una (!) Constitución democrática" (en el afortunado giro lingüístico del artículo 92, inciso 3, de la Constitución de Baden de 1947), tal como se encuentran, de manera ejemplar pero no exhaustiva, en otras Constituciones. A la inversa, los ejemplos expresos en tales Constituciones ofrecen indicios de lo que consideran una ilustración del tipo del Estado constitucional, como parte de su "identidad". Esto no tiene que ser exhaustivo, puesto que el "espíritu" de una Constitución es intangible per se para el legislador constitucional; siempre habrá que examinar si la Constitución concreta, en correspondencia precisamente con su "espíritu" particular, a su individualidad histórica concreta, hay que agregar elementos adicionales (como el Estado federal en la RFA o el "pacifismo" en Japón) como parte de su "sustancia". Nuevamente se demuestra qué tanto puede lograr la interpretación, cuando se trata de la comprensión "general" y "especial" de las cláusulas de eternidad.

Así visto, el desentrañamiento de las cláusulas de eternidad, escritas y no escritas, constituye una prueba de rendimiento y un "hic Rhodus hic salta" de la teoría de la Constitución, tanto en su pretensión de circunscribir un tipo, como también en su función de hacer justicia a la individualidad respectiva de un Estado constitucional concreto.

Este enfoque muestra la proximidad específica de las cláusulas de eternidad, escritas y no escritas, con lo que está contenido en los preámbulos, los que en múltiples ocasiones esbozan, como una especie de "Constitución de la Constitución", los principios sustantivos de la misma. Y no es accidente, sino una demostración jurídico-positiva de esta idea, que algunas cláusulas 
Este libro forma parte del acervo de la Biblioteca Juridica Virtual del Instituto de Investigaciones Juridicas de la UNAM

de eternidad positivas incluyan, en todo o en parte, a los preámbulos. ${ }^{279}$ En otras palabras: al lograr el desentrañamiento interpretativo de las cláusulas de eternidad escritas y no escritas, deben tomarse en cuenta, integralmente, los posibles contenidos del preámbulo de la Constitución concreta y los contenidos esenciales típicos de los preámbulos de las Constituciones del Estado constitucional.

\section{LA “SOCIEDAD ABIERTA DE LOS INTÉRPRETES \\ DE LA CONSTITUCiÓN"}

\section{Tesis básica, estado de la cuestión}

\section{A. El planteamiento de la teoría de la interpretación constitucional hasta el momento}

Hasta ahora, la teoría de la interpretación constitucional se ha planteado, en lo esencial, dos cuestiones:

- La cuestión de las funciones y los objetivos de la interpretación constitucional, y

- La cuestión de los métodos (procedimientos) de la interpretación constitucional (reglas de interpretación).

En cambio, se ha descuidado el problema de la ubicación sistemática en que se encuentra la tercera (y nueva) cuestión de los participantes en la interpretación constitucional, pregunta provocada por la práctica: un diagnóstico da por resultado un círculo muy amplio, pluralista, incluso difuso, de participantes; éste es motivo suficiente para que la teoría tematice de manera explícita y central esta cuestión, sobre todo desde la perspectiva de la teoría de la ciencia y de la democracia. La teoría de la interpretación constitucional estaba demasiado centrada en la "sociedad cerrada" de los intérpretes jurídicos de la Constitución, y su ángulo de visión se estrechaba todavía más, porque observaba primordialmente la interpretación por el juez constitucional y el procedimiento formalizado.

279 Así probablemente el artículo 176, inciso 1, en relación con el artículo 4o., de la Constitución de Turquía (1982); de manera clara, el artículo 129 de la Constitución de RenaniaPalatinado (1947). 
Este libro forma parte del acervo de la Biblioteca Juridica Virtual del Instituto de Investigaciones Juridicas de la UNAM

Si una teoría de la interpretación constitucional pretende tomar en serio el tema "Constitución y realidad constitucional" (piénsese aquí en la exigencia de la inclusión de las ciencias sociales en las ya conocidas teorías jurídicas funcionalistas, ${ }^{280}$ así como en los métodos más recientes de la interpretación referida al espacio público y al bien común) entonces hay que plantear de manera más decidida la cuestión de quién configura la realidad constitucional.

\section{B. Nuevo planteamiento y tesis}

En este sentido se plantea ahora la cuestión de los participantes, es decir, la cuestión de quiénes intervienen en la interpretación de la Constitución bajo la siguiente fórmula clave: de la sociedad cerrada de los intérpretes constitucionales hacia la interpretación por y para la sociedad abierta.

La tesis es la siguiente: en los procesos de la interpretación constitucional están incluidos potencialmente todos los órganos del Estado, todos los poderes públicos, todos los ciudadanos y los grupos. ¡No hay un numerus clausus de intérpretes de la Constitución! Hasta ahora, la interpretación constitucional ha sido en exceso, de manera consciente y menos realiter, un asunto de una "sociedad cerrada": la de los intérpretes constitucionales jurídicos y de quienes participan formalmente en el proceso constitucional, pero en la realidad es más un asunto de una sociedad abierta, es decir, la de todos los poderes públicos en tanto participen materialmente, porque la interpretación constitucional participa una y otra vez en la constitución de esta sociedad abierta y es constituida por ésta. Sus criterios serán tan abiertos como pluralista sea la sociedad.

\section{Explicación de la tesis, concepto de interpretación}

El concepto de interpretación aquí utilizado requiere una explicación. Dicho concepto dice: quien "vive" la norma, también la interpreta. Toda actualización de la Constitución (por cualquiera) es, cuando menos, un pedazo de interpretación constitucional anticipada. Tradicionalmente se entiende por "interpretación" una actividad que está encaminada, consciente e intencionalmente, a la comprensión y explicación de una norma (un texto). La utilización de un concepto de interpretación así definido también

$280 \mathrm{Al}$ respecto Ehmke, H., VVDStRL, vol. 20, 1963, pp. 53 (73 y ss.); Hesse, K., Grundzüge, cit., pp. 31 y ss. 
Este libro forma parte del acervo de la Biblioteca Juridica Virtual del Instituto de Investigaciones Juridicas de la UNAM

tiene sentido, ya que la cuestión del método, por ejemplo, solamente puede plantearse ahí donde se interpreta de manera consciente. Sin embargo, un examen realista del surgimiento de la interpretación constitucional puede requerir un concepto de interpretación más amplio, para el cual los ciudadanos y los grupos, los órganos del Estado y la opinión pública (Öffentlichkeit), son "fuerzas productivas de la interpretación", es decir, intérpretes de la Constitución en sentido amplio. Estos intérpretes actúan al menos como "intérpretes previos" ("Vorinterpreten"); la responsabilidad permanece en la jurisdicción constitucional como intérprete de "última instancia" (a reserva de la fuerza normativa de los votos de minoría). Si se quiere, se trata de la democratización de la interpretación constitucional, en la medida en que la teoría de la interpretación tenga que obtener respaldo en la teoría democrática y viceversa. No hay interpretación de la Constitución sin los ciudadanos activos y los poderes públicos citados.

Todo el que vive en y con las situaciones de hecho reguladas por la norma es intérprete de la misma de manera indirecta, e incluso directa. El destinatario de las normas participa más vigorosamente en el proceso interpretativo de lo que comúnmente se acepta. Puesto que no sólo los intérpretes jurídicos de la Constitución viven las normas, tampoco son los únicos y ni siquiera los intérpretes primarios.

\section{La sociedad abierta de los intérpretes de la Constitución}

Esta relevancia del concepto de sí mismos de los individuos y los grupos, así como de su correspondiente actuación, pero también el de los órganos estatales, es una destacada y fructífera forma de la vinculación de la interpretación constitucional en sentido amplio y en sentido estricto. La concepción de sí mismo (Selbstverständnis) se convierte así en un "elemento material iusfundamental". ${ }^{281}$ Aquí pertenece también la función realiter cointerpretadora del experto y del perito en los procedimientos legislativo y judicial. Esta colaboración de los intérpretes en sentido amplio y en sentido estricto no sólo se realiza donde ésta ya se encuentra institucionalizada, como en la inclusión de los representantes de trabajadores y empresarios en los tribunales laborales del Estado. "Expertos" e "interesados" provenientes de la sociedad pluralista se convierten en intérpretes del derecho estatal. Esto se pone de evidencia no sólo en el proceso de creación, modernamente tam-

281 Sobre el concepto de concepción de sí mismo o de sí propio véase BVerfGE 83, 341 (356). 
Este libro forma parte del acervo de la Biblioteca Juridica Virtual del Instituto de Investigaciones Juridicas de la UNAM

bién en el ulterior desarrollo en forma pluralista: la teoría de la ciencia, de la democracia y de la interpretación (constitucional) conducen aquí a una mediación específica entre Estado y sociedad.

\section{Los participantes en la interpretación constitucional}

\section{A. Cuadro sistemático}

El intento de lograr una presentación sistemática de los participantes en la interpretación constitucional ofrece la siguiente relación provisional:

a) Las funciones estatales:

i) Decisión de última instancia: el Tribunal Constitucional Federal alemán (claro está que "relativizada" y, por lo tanto, "abierta" por el voto minoritario).

ii) Sujetos llamados por la LF a producir decisiones obligatorias, pero revisables: la jurisdicción, el legislador (en medida variable, según la materia:) el ejecutivo, sobre todo en la formulación (previa) de los intereses públicos.

b) Los participantes, no necesariamente de carácter estatal, en los procedimientos de las decisiones a que se refieren los incisos a) i) y ii), es decir:

i) Peticionario y contraparte, recurrente (por ejemplo, en el recurso constitucional), demandante y demandado, que fundamentan su instancia y obligan al tribunal a adoptar una posición (“diálogo jurídico").

ii) Otros participantes en el procedimiento, legitimados para pronunciarse o adherirse conforme a la Ley del Tribunal Constitucional Federal alemán (BVerfGG: por ejemplo, §§ 77, 85, inciso 2, 94, incisos 1 a 4, así como los $\S \S 65,82$, inciso $2, \S 83$, inciso 2 , $\S \S 88,94$, inciso 5) o que son "convocados" por el Tribunal (por ejemplo, § 82, inciso 4, de la Ley citada).

iii) Dictaminadores (por ejemplo, de las comisiones parlamentarias; $\S 73$ del Reglamento Interior del Parlamento Federal alemán).

iv) Expertos y representantes de intereses en las audiencias (\$73, inciso 3, del Reglamento Interior del Parlamento Federal alemán, § 40, inciso 3, del Reglamento Interior del Consejo Federal alemán), peritos judiciales, 
Este libro forma parte del acervo de la Biblioteca Juridica Virtual del Instituto de Investigaciones Juridicas de la UNAM

asociaciones (Anexo la del Reglamento Interior del Parlamento Federal alemán: registro de asociaciones y de sus representantes), partidos políticos (sus fracciones): participan también, especialmente a través del "brazo largo" de la designación de los jueces.

v) Cabilderos, "delegaciones" (§ 10 del Reglamento Interior del Gobierno Federal alemán).

vi) Participantes en procedimientos administrativos, configurados de modo participativo.

c) El espacio público democrático-pluralista, el proceso político como "gran excitador": medios de comunicación (prensa, radio, televisión), que no participan en procedimientos en sentido estricto, por un lado el periodismo profesional, expectativas y cartas de los lectores, por el otro lado, iniciativas ciudadanas (Bürgerinitiativen), asociaciones, partidos políticos fuera de su participación orgánica ( $c f r .2$ d), iglesias, teatros, casas editoriales, instituciones de extensión cultural (Volkshochschulen), pedagogos, asociaciones de padres de familia.

d) La teoría del derecho constitucional (la que debe incorporarse entre los apartados a), b) y c), de un modo todavía por aclararse); esta teoría ocupa un lugar especial, porque tematiza la participación de las demás fuerzas, y ella misma participa también en los diversos planos.

\section{B. Explicación del cuadro sistemático}

En este panorama queda de manifiesto que la interpretación constitucional no es, ni en la teoría ni en la práctica, un proceso de naturaleza exclusivamente estatal, sino que potencialmente tienen acceso a él todas las fuerzas de la comunidad política. El ciudadano que interpone un recurso constitucional es tan intérprete de la Constitución como el partido político que plantea una acción orgánica (Organklage) 282 o contra el cual se inicia un procedimiento de prohibición (Parteiverbotsverfahren). Hasta ahora ha dominado un estrechamiento demasiado fuerte de la interpretación constitucional en los órganos estatales o en los participantes procesales inmediatos, una fijación en el "oficio" de la interpretación constitucional, en la colaboración de las funciones del Estado, por importantes que éstas sean. Sin embargo, la interpretación es un "negocio" que interesa potencialmente a cada uno y

${ }_{282}$ En el sentido de BVerfGE 4, 27 (30); 20, 56 (113 y ss.); 73, 40 (65 y ss.), jurisprudencia constante. 
Este libro forma parte del acervo de la Biblioteca Juridica Virtual del Instituto de Investigaciones Juridicas de la UNAM

a todos. Los citados grupos, individuos, etcétera, pueden ser denominados intérpretes "mediatos" o a largo plazo, de la Constitución. La configuración de la realidad de la Constitución se convierte en un pedazo de la interpretación de las "respectivas" normas constitucionales.

El multicitado "proceso político", el cual es mencionado sub specie su libertad frente a la interpretación constitucional, es, de constitutione lata y de facto, mucho más un pedazo de interpretación constitucional de lo que comúnmente se piensa (la "política como interpretación constitucional"). Este proceso no se encuentra excluido por la Constitución, sino que constituye uno de sus ámbitos vitales y funcionales más esenciales, es el "corazón", en el sentido auténtico del término, comparable a una bomba. Aquí se producen movimientos, innovaciones, cambios, pero también "confirmaciones", que son más que un mero "material objetivo" para la interpretación constitucional (futura); son un pedazo de interpretación de la Constitución, porque en su marco se crea una realidad pública y en ocasiones se modifica inadvertidamente. La libertad creadora de que goza el legislador "en cuanto" intérprete de la Constitución se distingue cualitativamente del margen interpretativo que corrresponde al juez constitucional, porque el margen respectivo se delimita técnicamente de modo muy diferente. Empero, esto no significa que también deba haber una considerable diferencia cuantitativa.

El proceso político no es un espacio exento de la Constitución; este proceso formula criterios, inicia procesos que también son constitucionalmente relevantes allá, cuando el juez constitucional dice que es asunto del legislador decidir así o de otro modo en el marco de las alternativas que estén conformes con la Constitución. ${ }^{283}$

\section{Valoración del inventario}

\section{A. Posibles objeciones, crítica}

Una objeción podría ser la siguiente: la interpretación constitucional se "disuelve" tanto en una multiplicidad de diversas interpretaciones como de intérpretes, dependiendo de la función que esté actuando. Precisamen-

283 Sobre la figura argumentativa de la "alternativa" en el proceso de la interpretación: Esser, J., Vorverständnis, cit., pp. 65 y ss., 132, 151 (con referencia a Popper); de manera más general, BVerfGE 24, 300 (348). Entre las funciones de los partidos políticos se encuentra la de "ofrecer alternativas políticas a todos los ámbitos vitales susceptibles de configuración por parte del Estado"; véase también el caso especial respecto de la "alternativa": interpretación judicial-proyecto de ley (¿deber de espera?), BVerfGE 34, 269 (291 y ss.). 
Este libro forma parte del acervo de la Biblioteca Juridica Virtual del Instituto de Investigaciones Juridicas de la UNAM

te una teoría de la Constitución que considere como misión la creación de unidad política y que enfatice el principio de la unidad de la Constitución, tiene que enfrentar esta crítica, aunque no ahí donde "solamente" intente un inventario realista. Las objeciones tienen que ser examinadas en el marco de una valoración diferenciada, la cual debe preguntarse primariamente por la legitimación de los diversos intérpretes de la Constitución.

La cuestión de la legitimación se plantea respecto de todas las fuerzas que no han sido "designadas formal u oficialmente" o en "virtud de su competencia" como intérpretes de la Constitución. Poseen competencia formal a través de la Constitución solamente los órganos (cargos) que están "sujetos" a la Constitución y que deben "hacerla cumplir" en un procedimiento reglado - legitimación a través del procedimiento (constitucional), ${ }^{284}$ es decir, los órganos del Estado (artículo 20, incisos 2, 3, de la LF: sujeción al orden constitucional, a la ley y al derecho)-. Pero también los diputados (artículo 38, inciso 1, de la LF) están sujetos a la Constitución, en tanto no pretendan modificarla. Asimismo están sujetos a la Constitución los partidos políticos, los grupos y los ciudadanos, aunque en distinta medida y de manera más o menos "directa"; la mayoría de las veces dando un rodeo por el poder estatal sancionador. Aquí parece que una medida más reducida de sujeción corresponde por lo pronto a una medida más reducida de legitimación.

\section{B. Legitimación proveniente de los criterios de la teoría del derecho, de la norma y de la interpretación}

Sin embargo, la relación de correspondencia entre sujeción (a la Constitución) y legitimación (de la interpretación constitucional) pierde fuerza expresiva cuanto más se tomen en cuenta las nuevas ideas de la teoría de la interpretación: la interpretación es un proceso abierto, no una sumisión pasiva, ni la aceptación de una orden, ${ }^{285}$ sino que conoce posibilidades alternativas. La sujeción se convierte en libertad en la medida en que una concepción más nueva de la interpretación ha refutado la ideología de la subsunción.

284 Tanto el concepto de legitimación como el de procedimiento deben ser entendidos en un sentido más material del que emplea N. Luhmann, Legitimation durch Verfahren, 1969.

285 Véase al respecto sobre todo la discusión de la interpretación iniciada por Esser, J., Vorverständnis und Methodenwahl, 1970, pero anteriormente ya en Grundsatz und Norm, 1956: Ehmke, H., "Prinzipen der Verfassungsinterpretation", VVDStRL, vol. 20, 1963, pp. 53 y ss. 
Este libro forma parte del acervo de la Biblioteca Juridica Virtual del Instituto de Investigaciones Juridicas de la UNAM

La ampliación del círculo de los intérpretes aquí postulada no es sino consecuencia de la inclusión, propuesta desde todos lados, de la realidad en el proceso de la interpretación, ya que los intérpretes en un sentido amplio constituyen un pedazo de esta realidad pluralista. Tan pronto como se reconoce que la norma no es un dato previo, simple, terminado, se plantea la cuestión de quiénes participan personal y funcionalmente en su "desarrollo", de las fuerzas activas del "law in public action" (personalización y pluralización de la interpretación constitucional).

La sujeción del juez solamente a la ley, y su independencia personal y material, no pueden ocultar el hecho de que los jueces interpretan dentro de la publicidad y la realidad de la Constitución. Sería erróneo considerar las influencias, las expectativas, los "imperativos" sociales, a los que se ven expuestos los jueces sólo bajo el aspecto de los riesgos que corre su independencia. Estas influencias contienen también un pedazo de legitimación e impiden la arbitrariedad en la interpretación judicial. La garantía de la independencia judicial solamente es soportable, porque otras funciones estatales y el espacio público pluralista proveen material "para" la ley.

\section{Legitimación proveniente de consideraciones de teoría constitucional}

La legitimación básica teórico-constitucional de la participación más o menos intensa de todas las fuerzas pluralistas en el "negocio" de la interpretación constitucional reside en el hecho de que estas fuerzas constituyen un pedazo del espacio público y de la realidad de la Constitución misma, no como "hecho aceptado", como factum brutum, sino en el marco de la Constitución: la inclusión mediata al menos de la res publica en la interpretación constitucional en conjunto es expresión y consecuencia de la concepción amplia de Constitución aquí defendida, abierta, puesta en el campo de tensión de lo posible, lo real y lo necesario. Una Constitución que no sólo estructura al Estado en sentido estricto, sino también al espacio público, y que constituye a la sociedad, incluyendo de manera inmediata el ámbito de lo privado, no puede hacer esto sólo de manera pasiva, esto es, tratar a las fuerzas sociales y a las privadas solamente como objeto, sino que también debe incorporarlos activamente en tanto sujetos.

Pensado desde la realidad y el espacio público constituidos en los que el "pueblo" actúa de diversos modos, de manera difusa en el punto de partida, pero "concertadamente" en el punto final, todas las fuerzas relevantes poseen también de hecho relevancia teórica para la interpretación constitucional. La práctica se convierte aquí en legitimación de la teoría, y no 
Este libro forma parte del acervo de la Biblioteca Juridica Virtual del Instituto de Investigaciones Juridicas de la UNAM

a la inversa. Puesto que estas fuerzas constituyen un pedazo de realidad y del espacio público constitucional, iparticipan también en la interpretación de la realidad y el espacio público de la Constitución! Incluso cuando son excluidas, como los partidos políticos prohibidos por el Tribunal Constitucional Federal alemán.

Estas fuerzas obligan precisamente a la reflexión sobre el contenido de la Constitución y, en virtud de su existencia, influyen en el desarrollo de la concepción de sí misma de la comunidad en libertad y democracia. Limitar la interpretación constitucional a los intérpretes constitucionales legitimados "gremialmente" y por el derecho funcional, significaría empobrecimiento y autoengaño, sobre todo porque una noción experimental de la ciencia del derecho constitucional como ciencia normativa y de la realidad no puede renunciar a la fantasía y a la fuerza creativa de los intérpretes "no gremiales" en el proceso de la interpretación constitucional.

La Constitución es, en este sentido, espejo del espacio público y de la realidad. Pero no es sólo espejo, sino también fuente de luz, si se nos permite esta comparación más bien plástica. Tiene función orientadora.

Una cuestión particular se refiere a la legitimación de la ciencia del derecho constitucional, la cual posee una función de catalizador e influye en grado especial en todos los ámbitos de la interpretación, debido a que reflexiona metódica y públicamente sobre la interpretación constitucional y, al mismo tiempo, configura la formación de los intérpretes "en razón de su cargo". ¿En qué podría fundarse una posible legitimación? Por la vía del artículo 5o., inciso 3, de la LF misma. La Constitución como objeto es (también) asunto de la ciencia. El ámbito de la ciencia debe ser considerado, en virtud del artículo 5o., inciso 3, de la LF, como parte integrante e independiente de la comunidad política.

\section{En particular: consideraciones de teoría democrática como legitimación}

En el Estado constitucional democrático debe plantearse nuevamente de manera especial la cuestión de la legitimación conforme a criterios democráticos (de teoría de la democracia). Ni la ciencia del derecho constitucional, ni las llamadas ciencias de la realidad que son sus "proveedoras", ni los ciudadanos o los grupos poseen una legitimación democrática, entendida en sentido tradicional, para la interpretación constitucional. Sin embargo, la democracia no se desenvuelve solamente a través de la relación de delegación y responsabilidad formalizada, canalizada, en sentido estricto, entre el pueblo y los órganos del Estado (legitimación a través de las elec- 
Este libro forma parte del acervo de la Biblioteca Juridica Virtual del Instituto de Investigaciones Juridicas de la UNAM

ciones) hasta el último intérprete "competente" de la Constitución, el TCF, sino que en una comunidad abierta se desenvuelve también en las formas mediatizadas, más "finas", del proceso público pluralista de la política y la práctica cotidianas, en especial, en la realización de los derechos fundamentales, frecuentemente abordada desde el "aspecto democrático" de estos derechos: a través de las controversias sobre las alternativas, las posibilidades y las necesidades de la realidad y mediante el "concierto" científico sobre las cuestiones constitucionales, en las que apenas hay "pausas" y "fermatas" y no hay director ni debe haberlo.

El "pueblo" no es solamente una magnitud uniforme que (solamente) "emana" el día de las elecciones, las cuales trasmiten legitimación democrática como tales. En tanto magnitud pluralista, el pueblo no se encuentra menos presente ni es menos legitimador en las interpretaciones del proceso constitucional: "como" partido político, opinión científica, grupo de interés, o bien, como ciudadanos, jsu competencia material para la interpretación constitucional es un derecho ciudadano en el sentido del artículo 33, inciso 1, de la LF! Así vistos, los derechos fundamentales son una pieza de la base legitimadora democrática para la interpretación constitucional que está abierta no sólo en cuanto a sus resultados sino también respecto del círculo de los que participan en ella. ${ }^{286}$ ¡En la democracia liberal el ciudadano es intérprete de la Constitución! Por ello se vuelven más importantes las medidas de garantía de la libertad real: política de bienestar, libertad de opinión, constitucionalización de la sociedad, por ejemplo, mediante una estructuración de división de poderes en el ámbito público y particularmente en el económico.

Esto no significa el "destronamiento" del pueblo, o en todo caso, lo sería solamente a partir de una concepción rousseauniana de la soberanía popular, en la que el pueblo se considera como absoluto y casi divino. El pueblo como magnitud constituida actúa "hacia todos lados", de manera universal, en múltiples planos, a partir de numerosos motivos y en muchas formas, incluso a través de la realización cotidiana de los derechos fundamentales. No se debe olvidar que el pueblo es, sobre todo, una reunión de ciudadanos. La democracia es el "gobierno de los ciudadanos", no del pueblo en el sentido rousseauniano. No hay vuelta hacia J.-J. Rousseau. La democracia ciudadana es más realista que la democracia del pueblo.

286 Sobre la interpretación constitucional abierta: P. Häberle, "Zeit und Verfassung", ZfP, vol. 21, 1974, pp. 111, 121 y ss; W. Höfling, Offene Grundrechtsinterpretation, 1987. 
Este libro forma parte del acervo de la Biblioteca Juridica Virtual del Instituto de Investigaciones Juridicas de la UNAM http://www.juridicas.unam.mx

\section{Consecuencias para la interpretación "jurídica" de la Constitución}

\section{A. Relativización de la interpretación jurídica; nueva noción de sus funciones}

Las reflexiones anteriores conducen a la relativización de la interpretación jurídica de la Constitución, en razón de lo siguiente:

a) El juez constitucional no es el "único" intérprete en el proceso constitucional: en el procedimiento hay varios participantes, y las formas de participación se amplían.

b) En el "campo previo" a la interpretación jurídica de la Constitución por los jueces hay numerosos intérpretes, es decir, potencialmente todas las fuerzas públicas pluralistas. En este sentido se relativiza el concepto de los "participantes en el proceso constitucional", en la medida en que se amplían los círculos de los participantes en la interpretación constitucional. El espacio público pluralista despliega fuerza normativa y el tribunal constitucional debe interpretar más tarde en correspondencia con ese espacio actual.

c) Muchos círculos problemáticos y ámbitos de la Constitución material no llegan al juez constitucional, por falta de competencia judicial o por ausencia de instancias ante el tribunal. Sin embargo, la Constitución material "vive" también aquí: sin interpretación constitucional por el juez (ipiénsese en los principios de los reglamentos parlamentarios!). Los participantes e intérpretes en sentido amplio desarrollan independientemente un derecho constitucional material. El derecho procesal constitucional no es el único acceso al procedimiento de la interpretación constitucional.

Visto en el tiempo, las instancias de la interpretación constitucional se prolongan hasta el infinito: el constitucionalista no es más que un sujeto intermediario. Los resultados de su interpretación están sujetos a la reserva de su éxito, la que en el caso particular se puede concretizar en el éxito, en "justificación de múltiples alternativas"287 o para su modificación mediante alternativas razonables. El procedimiento de la interpretación constitucional debe ser extendido hacia delante y mucho más allá del proceso constitucional concreto mismo; el radio de interpretación de la norma se amplía

287 Esta expresión se encuentra en Habermas, J., Legitimationsprobleme im Spätkapitalismus, 1973, p. 148 (hay trad.: Problemas de legitimación en el capitalismo tardío, 1975). 
Este libro forma parte del acervo de la Biblioteca Juridica Virtual del Instituto de Investigaciones Juridicas de la UNAM

gracias a todos los "intérpretes de la Constitución de la sociedad abierta". Se trata de participantes esenciales en el proceso de "ensayo y error" que es el proceso de determinación del derecho (Rechtsfindungsprozess). ${ }^{288}$ La sociedad se hace libre y abierta en virtud de las aportaciones que todos pueden hacer, potencial o actualmente, a la interpretación constitucional. La interpretación jurídica de la Constitución trasmite (solamente) el espacio público y la realidad pluralistas, las necesidades y posibilidades de la comunidad que se encuentran ante, en y detrás de los textos constitucionales. Las doctrinas de la interpretación sobreestiman siempre la importancia del texto.

\section{B. De la extensión e intensidad del control judicial, en particular; diferenciación en vista del grado de participación}

Una teoría de la interpretación constitucional que reúna en un contexto sistemático la cuestión de los objetivos y métodos con la cuestión de los participantes, debe sacar de ahí conclusiones concretas para el método de la interpretación constitucional.

Un tribunal como el TCFA, el cual revisa la interpretación constitucional de otros órganos, debe emplear métodos diversos, según quien haya intervenido en la primera interpretación, la que será revisada. Esto ya había sido advertido, inicialmente, por el pensamiento jurídico-funcional, señalando que en la revisión de las decisiones del legislador democrático los tribunales deben ejercer especial reserva, y algo similar se aplica a la revisión del derecho local (Landesrecht) por el Tribunal Constitucional Federal. En prosecución de este enfoque, habría que considerar que hay leyes (leyes de educación superior, reformas al Código Penal, como el § 218, relativo al aborto, leyes que establecen los horarios comerciales) en las cuales la opinión pública muestra un enorme interés, que se encuentran permanentemente a discusión, y que se han aprobado con amplia participación y bajo un control alerta de la opinión pública pluralista. Al revisar una ley de esta especie, el TCFA debería tomar en consideración que esta ley se encuentra especialmente legitimada, porque fueron particularmente muchos los que participaron en el proceso democrático de la interpretación constitucional. Tratándose de leyes que no son impugnadas en lo fundamental, esto significaría que éstas no deben revisarse con excesivo rigor, a diferencia de las leyes que se encuentran menos expuestas a la discusión pública, porque apa-

$288 \mathrm{Al}$ respecto véase Esser, J., Vorverständnis, cit., pp. 23, 151 y ss. 
Este libro forma parte del acervo de la Biblioteca Juridica Virtual del Instituto de Investigaciones Juridicas de la UNAM http://www.juridicas.unam.mx

rentemente no son interesantes (por ejemplo, regulaciones de oportunidad técnicas) o ya se han olvidado.

\section{Consecuencias para la configuración y aplicación del derecho procesal constitucional}

De ello derivan consecuencias para la configuración y aplicación del derecho procesal constitucional: los instrumentos de información del juez constitucional ${ }^{289}$ deben ampliarse y refinarse, no a pesar sino en razón (!) de la sujeción a la ley, en especial las formas y posibilidades escalonadas de participación en el proceso constitucional mismo (sobre todo "audiencia" y "participación"); deben desarrollarse nuevas formas de participación de las potencias públicas (öffentliche Potenzen) como intérpretes de la Constitución en sentido amplio. El derecho procesal constitucional se vuelve un pedazo del derecho de la participación democrática. La interpretación de la Constitución por el juez constitucional se puede volver correlativamente elástica y expansiva, sin que se llegue, ni se deba llegar, a una identidad con el legislador. También debe hacerse flexible la aplicación concreta del derecho procesal constitucional por el TCFA, de acuerdo con las cuestiones materiales planteadas y los participantes materiales (interesados). Aquí se manifiesta también la vinculación intensiva entre Constitución material y derecho procesal constitucional.

\section{LA COMPARACIÓN JURÍDICA COMO “QUINTO” MÉTODO DE INTERPRETACIÓN Y COMO GOMPARACIÓN CULTURAL}

Sin importar lo que se piense de la sucesión de los métodos tradicionales de la interpretación, en el Estado constitucional de nuestra etapa evolutiva la comparación de los derechos fundamentales se convierte en "quinto" e indispensable método de la interpretación. Como se sabe, la LF no contiene reglas de interpretación. Sin embargo, debe considerarse si, en el fondo, no resulta posible trasladar el $\S 1$ del Código Civil suizo de 1911, que es la gran

\footnotetext{
289 Ejemplar resulta el instrumento de información del § 82, inciso 4, de la Ley del TCFA, así como la oportunidad que el Tribunal otorga a las "dependencias y organizaciones" interesadas de manifestarse, la mayoría de las veces en los "grandes" procesos: E 35, 202 (213 y s.); 35, 78 (100 y ss.); 33, 265 (322 y s.); 31, 306 (307 en el apartado 4); 30, 227 (238 y s.); 89, 214 (223 y ss.); 92, 53 (64 y ss.); 95, 267 (293). Esta oportunidad transmite un pedazo de "representación social" pluralista hacia el proceso constitucional.
} 
Este libro forma parte del acervo de la Biblioteca Juridica Virtual del Instituto de Investigaciones Juridicas de la UNAM http://www.juridicas.unam.mx

obra de Eugen Huber (en parte, en el espíritu de Aristóteles), a la interpretación de la Constitución y de los derechos fundamentales. ${ }^{290}$

En todo caso, la comparación jurídica debe ser incorporada de manera decidida y abierta en la interpretación de los derechos fundamentales. El TCFA trabaja sin duda, solitariamente, en esta dirección. ${ }^{291}$ Son dos las razones que animan a este postulado: por un lado, la doctrina y la práctica del Tribunal de Justicia europeo en Luxemburgo sobre los derechos fundamentales, obtenidos de "una comparación jurídica valorativa", como "principios generales del derecho";292 por el otro lado, existen algunas nuevas Constituciones, en cuyas garantías de los derechos fundamentales se hace remisión expresa a algunos de los grandes textos de los derechos fundamentales. El artículo 10, inciso 2, de la Constitución española dispone: "Las normas relativas a los derechos fundamentales y a las libertades que la Constitución reconoce se interpretarán de conformidad con la Declaración Universal de Derechos Humanos y los tratados y acuerdos internacionales sobre las mismas materias ratificados por España". ${ }^{293}$ Cuando en Suiza la Convención Europea de Derechos Humanos ha adquirido jerarquía constitucional gracias a la interpretación constitucional(!!), ${ }^{294}$ esto no es sino un signo de la integración entre Estado constitucional y derechos humanos.

Lo que se dispone expresamente en estos textos puede reclamar vigencia general. En la "Internacional del Estado constitucional", en la "familia" de los Estados constitucionales, el intérprete de los derechos fundamentales tiene que tomar en consideración siempre los textos universales y regionales sobre los derechos humanos. La apertura de los contenidos y las dimensiones de los derechos fundamentales "hacia fuera" es consecuencia de la evolu-

290 El $§ 1$ del Código Civil suizo (ZGB) dispone: "La ley se aplica a todas las cuestiones jurídicas para las cuales contenga una disposición según el texto o la interpretación. Si no es posible obtener ningún precepto de la ley, el juez debe resolver conforme al derecho consuetudinario, y si tampoco éste existe, debe resolver conforme a la regla que establecería si fuera el legislador. En tal sentido deberá seguir la doctrina y la tradición probadas".

291 Referencias en Häberle, P., Wesensgehaltgarantie, 3a. ed., 1983, pp. 408 y ss.

$292 \mathrm{Al}$ respecto véase Bleckmann, A., Europarecht, 4a. ed., 1985, pp. 104 y ss.

293 Véase también el artículo 16, inciso 2, de la Constitución de Portugal; además, el preámbulo de la Constitución del Cantón del Jura (1977), citada en Fö R, vol. 34, 1985, pp. 425 y ss.: "Le peuple jurassien s'inspire de la Déclaration des droits de l'homme de 1789, de la Déclaration universelle des Nations unies proclamée en 1948 et de la Convention européenne des droits de l'homme de 1950".

294 Véase al respecto Müller, J. P., Elemente einer Schweizer Grundrechtstheorie, 1982, p. 177. También es notable el artículo 46 de la Constitución de Guatemala de 1985: "Se establece el principio general de que en materia de derechos humanos, los tratados y convenciones aceptados y ratificados por Guatemala, tienen preeminencia sobre el derecho interno". 
Este libro forma parte del acervo de la Biblioteca Juridica Virtual del Instituto de Investigaciones Juridicas de la UNAM

ción hacia el "Estado constitucional cooperativo". De este modo surge una "comunidad de interpretación de los derechos fundamentales". O bien: la sociedad abierta de los intérpretes de los derechos fundamentales se hace internacional, y se diferencia, inclusive de acuerdo con las convenciones regionales de derechos humanos (como la CEDH y la CE) y la afinidad cultural, por ejemplo, en los espacios europeo, latinoamericano o africano. La pretensión universal de las Naciones Unidas también actúa en materia de derechos fundamentales (Declaración Universal de 1948, Pactos de 1966). Es motivo de ánimo la orientación más reciente de los Estados orientales y socialistas hacia las garantías de los derechos fundamentales del tipo del Estado constitucional (piénsese en la nueva y vieja libertad de asociación en Polonia y Hungría, en otros derechos fundamentales políticos de reciente reforzamiento, desde la libertad de manifestación hasta las formas previas de derechos electorales que conocen alternativas).

En mi opinión, la "canonización" de la comparación jurídica como "quinto" método de la interpretación, al menos en el derecho constitucional del tipo del "Estado constitucional", no sería sino consecuente con la historia de la doctrina de la interpretación jurídica. En el "sistema" de F. C. v. Savigny, como fundador de la "escuela histórica del derecho", era natural que tuviera un lugar preeminente la interpretación histórica. En el marco de una teoría sobre el tipo del "Estado constitucional" le toca ahora a la comparación constitucional un lugar "paralelamente" importante. Llevado más adelante, de la dimensión histórica se deriva, aquí y ahora, la comparación de la dimensión contemporánea: la "comparatística constitucional". En todo caso, la comparación constitucional es la vía mediante la cual pueden "comunicarse" entre sí las diversas Constituciones. De este modo adquiere la más alta eficacia la fuerza conformadora del único tipo del Estado constitucional. Aunque a la "escuela histórica del derecho" pudiera parecerle que la interpretación histórica era importante e incluso el "primer" método clásico, en la doctrina de la interpretación del Estado constitucional de hoy el método comparativo debe ocupar, cuando menos y en todo caso de manera tendencial, un "quinto" lugar, si no es que el preeminente.

En resumen: los procesos de creación y recepción no se realizan por sí solos. Se requiere que los receptores (mejor dicho: los actores) en el procedimiento de recepción "busquen" de manera abierta y sensible, observando y elaborando lo típico y lo individual propio del Estado constitucional "vecino" en sentido estricto o amplio; "adquirir para poseer". De este modo surge o se confirma el "derecho constitucional común europeo", o con mayor alcance, el derecho constitucional común europeo-atlántico, y en parte también el derecho "emparentado". En otras palabras, los procesos de recep- 
Este libro forma parte del acervo de la Biblioteca Juridica Virtual del Instituto de Investigaciones Juridicas de la UNAM

ción requieren comparación jurídica, la cual solamente puede tener éxito como comparación cultural. En la comparación, los receptores laboran en parte en la política jurídica (como constituyentes o legisladores), en parte de manera interpretativa, aunque los límites pueden ser fluidos: en la interpretación por los jueces constitucionales o por la doctrina del derecho constitucional; por esta razón, y en el campo de fuerzas del Estado constitucional, corresponde a la comparación jurídica el rango de un "quinto" método de la interpretación, al lado de los cuatro métodos clásicos de Savigny. ${ }^{295}$

\section{INCURSO: JURISDICGIÓN CONSTITUCIONAL INSTITUGIONALIZADA EN EL ESTADO CONSTITUCIONAL}

\section{El Tribunal Constitucional Federal alemán como tribunal constitucional - como "tribunal social" de naturaleza propia, su función en la garantía y el desarrollo del contrato social (del contrato de las generaciones)}

\section{A. El TCFA como "tribunal constitucional" - como "tribunal social" de naturaleza propia}

Desde la perspectiva formal, el TCFA posee todas las características de un tribunal "estatal", dicho en su propia terminología (al respecto E 18, 241), es decir, se funda en una ley estatal y el Estado regula e influye en la designación de los jueces. Sin embargo, es mucho más que eso: es un tribunal constitucional, es decir, tiene competencia respecto de una lista enumerativa de controversias constitucionales materiales. El peso pleno de esta afirmación se ilustra primeramente a partir de una aclaración del concepto de Constitución. La "Constitución" es el orden jurídico fundamental del Estado y la sociedad; no es sólo limitación del poder del Estado, sino que también autoriza a dicho poder. La Constitución abarca al Estado y a la sociedad, y por ello, la jurisdicción constitucional como fuerza política actúa de entrada más allá del dogma de la separación entre Estado y sociedad.

Que el TCFA sea "tribunal constitucional" de toda la res publica tiene efectos concretos en cuestiones de detalle, por ejemplo, en la recusación de los jueces (al respecto BVerfGE 35, 171 (246); 89, 28); tiene además la consecuencia de que el tribunal no puede fijarse en una teoría o "escuela", sino que debe esforzarse por lograr la integración pragmática de elementos

$295 \mathrm{Al}$ respecto Häberle, P., "Grundrechtsgeltung und Grundrechtsinterpretation im Verfassungsstaat", fZ, 1989, pp. 913 y ss. 
Este libro forma parte del acervo de la Biblioteca Juridica Virtual del Instituto de Investigaciones Juridicas de la UNAM

teóricos. Por ello, los jueces constitucionales de origen académico deberían evitar fijar en sus resoluciones "sus" teorías.

Esta referencia constitucional material de la jurisdicción constitucional tiene implicaciones materiales y procesales, por ejemplo, en el compromiso con el modelo del pluralismo y en la exigencia de desarrollo del derecho procesal constitucional con vistas a los instrumentos pluralistas de información y participación.

En este contexto debe verse la creciente política de obtención de información pluralista por parte del TCFA. La selección de los jueces constitucionales a partir del espectro de todos los partidos políticos, y esperemos que en el futuro todavía más allá de ellos, incorpora de manera efectiva el pluralismo en el procedimiento constitucional (e influye en él). Este es un supuesto para la orientación de la sociedad por el tribunal constitucional y "su" derecho. Aquí se produce una interacción: cuanto más interviene el TCFA en los procesos de orientación de la sociedad abierta, tanto más se dirige esta sociedad hacia él, también quiere que la "oigan en Karlsruhe". ${ }^{296}$ Qué tanto esto es así se demuestra por la audiencia en materia de codeterminación (de los trabajadores en las empresas) en 1978: en la sala de sesiones del tribunal se podían percibir auténticamente las líneas de fuerza de la opinión pública.

Este enfoque conduce a una nueva "etapa". El TGFA debe verse en su relación intensiva con la sociedad entera, pues se trata de un "tribunal social" de naturaleza propia y en un sentido amplio. A través de su jurisprudencia se abre hacia la diversidad de ideas e intereses y los incorpora; a la inversa, dirige a la sociedad. En vista de la designación de los jueces, de la aplicación del derecho procesal constitucional y de los resultados materiales de la interpretación (por ejemplo, en la estructuración de algunos aspectos de la sociedad a través de la "eficacia frente a terceros" de los derechos fundamentales; más recientemente E 95, 28 (37)), se trata más de un tribunal de toda la sociedad que de un tribunal "estatal". ¡Esto tiene consecuencias en un plano más alto, incluso para las labores cotidianas del tribunal!

\section{B. La jurisdicción constitucional "en" el contrato social: el TCFA como regulador} en los procesos continuos de la garantía y el desarrollo de la Constitución como contrato social

La tesis estipula: el TCFA posee una responsabilidad plena en la garantía y desarrollo de la Constitución como contrato social; participa en la

296 Ciudad alemana que es sede del TCFA (N. del T.). 
Este libro forma parte del acervo de la Biblioteca Juridica Virtual del Instituto de Investigaciones Juridicas de la UNAM

orientación de sus procesos continuos; al hacerlo, está comprometido con el principio del pluralismo.

El modelo del contrato social, como clásico patrimonio común europeo, es, en el sentido aquí empleado, un modelo intelectual, un principio heurístico para fines de la consagración de la libertad personal y la justicia pública. No se trata, sin duda, de una "horma" dentro de la cual hubiera que acomodar a la realidad completa de una Constitución como proceso público; pero puede ofrecer auxilio para la solución adecuada de algunas cuestiones básicas políticas y jurídico-constitucionales, libre de las "ideologías" unilaterales. Tan antiguo como es el modelo contractual, tan relativamente joven es la jurisdicción constitucional (independizada). Quizá todavía (y por ello) no han sido puestas todavía en relación el uno con la otra. Esta puede ser una oportunidad que debe ser aprovechada. La doctrina clásica del contrato social ha servido en el curso de la historia y en los contextos más diversos, como modelo de explicación y de justificación (desde J. Locke hasta J.-J. Rousseau, desde I. Kant hasta la discusión en torno al consenso básico). ¿Por qué no habría de poseer ahora todavía validez para nuestros problemas, para las cuestiones de la jurisdicción constitucional, para el desarrollo progresivo de la Constitución?

\section{Posibilidades y limites de la capacidad de acción del TCFA —el TCFA en el marco de la cultura política del orden fundamental de libertad y democracia de la $L F$}

En última instancia, ¡la jurisdicción constitucional no es un seguro de vida jurídico o político! Su desarrollada concepción política y pluralista está ligada a la cultura general de nuestra república. Esto le trasmite funciones positivas, pero también conduce a límites. (Un límite de la jurisdicción constitucional se deriva también del hecho de que solamente actúa a petición de parte, no de oficio. Debe ser "impulsada" por el ciudadano o por las fuerzas políticas.)

La función de la jurisdicción constitucional consiste en la limitación, la racionalización y el control del poder estatal y social; se trata de una colaboración sustantiva con el consenso básico; reside en la nueva protección de las minorías y los débiles, en la reacción oportuna a los nuevos peligros para la dignidad humana, en su carácter no impolítico de orientación y respuesta. 
Este libro forma parte del acervo de la Biblioteca Juridica Virtual del Instituto de Investigaciones Juridicas de la UNAM

\section{Política constitucional en materia de jurisdicción constitucional}

La marcha triunfal de la jurisdicción constitucional tiene hoy alcance mundial. A partir de la obra pionera de Austria y de Hans Kelsen (1920), esta jurisdicción forma parte de los elementos del Estado constitucional que, en numerosas ocasiones, han sido recibidos, desarrollados, también modificados y probados una y otra vez. La Suprema Corte de los Estados Unidos actúa también, a su modo, como ejemplo, ya sea en la política jurídica, en la medida, por ejemplo, en que en Alemania se está examinando actualmente (1997-1998) la posibilidad de adoptar un procedimiento discrecional para la admisión de los recursos constitucionales, a fin de evitar la sobrecarga del TCFA, ya sea a través de la discusión permanente de sus doctrinas (por ejemplo, la doctrina de la "preferred freedom").

Resulta evidente que no se pueden adoptar simplemente los "modelos" ni los textos ajenos. La cultura constitucional particular de un país se ha desarrollado de manera "individual" y su "autonomía" debe ser respetada. Así, Francia no podría simplemente adoptar el modelo de los EUA; su Conseil Constitutionnel ya hace bastante a favor de la prudente ampliación de sus competencias. Del mismo modo hay que exhortar a la precaución en Europa oriental, pues la era constitucional que ahí emerge, que es también al mismo tiempo época de una nueva jurisdicción constitucional (a la que Polonia ya había precedido antes del cambio de 1989),,297 sigue siendo precaria. Por otro lado, resulta satisfactorio oír que en 1996 los jueces sudafricanos buscaron asesoría en Karlsruhe con el TFCA y que incluso se incorporó al Tribunal Constitucional africano al proceso constituyente, a fin de insistir en el cumplimiento de todos los "constitutional principles" de la Constitución provisional de 1993 en la definitiva de 1996 ( $c f r$. capítulo 5o., artículo 66, incisos 2 a 4).

297 Al respecto véase Garlicki, L., "Vier Jahre Verfassungsgerichtsbarkeit in Polen (19851989)", fö R, vol. 39, 1990, pp. 285 y ss. 
Este libro forma parte del acervo de la Biblioteca Juridica Virtual del Instituto de Investigaciones Juridicas de la UNAM http://www.juridicas.unam.mx

\title{
GAPÍTULO QUINTO. MANIFESTACIONES PARTICULARES
}

\author{
I. LA DIGNIDAD HUMANA COMO "PREMISA ANTROPOLÓGICO- \\ GULTURAL” DEL ESTADO CONSTITUGIONAL, LA DEMOCRAGIA \\ COMO "CONSEGUENCIA ORGANIZATIVA"
}

\section{La dignidad humana como "premisa antropológico-cultural"}

\section{A. Planteamiento del problema}

A pesar de la gran tradición jurisprudencial del Tribunal Constitucional Federal alemán, ${ }^{298}$ no se advierte ninguna fórmula que pueda considerarse suficiente, "manuable", de lo que es la dignidad humana. De las diversas cláusulas sobre la dignidad humana de las Constituciones se llega a percibir, "entre líneas", que aquéllas están referidas a una concepción culturalmente específica de la dignidad humana. Esto plantea la cuestión de la dependencia cultural (y sobre todo, de la dependencia religiosa) de las concepciones de la dignidad humana. ${ }^{299}$ Así, por ejemplo, la posición de la mujer en el Islam, ¿es contraria a un contenido de la dignidad humana válido en todo el mundo ("universal") e irrenunciable? ¿O más bien se aplica la famosa frase: "The mores can make anything right" (William G. Sumner)? ¿Existe un "núcleo"de la dignidad humana que sea independiente del ámbito cultural?

Esta pregunta solamente puede responderse en forma específica respecto de los derechos fundamentales. ${ }^{300}$ Hay que partir de la tesis de que el conjunto de los derechos de tipo personal, por un lado, y los deberes, por

298 Referencias en Häberle, P., "Die Menschenwürde als Grundlage der staatlichen Gemeinschaft", HdBStR vol. I (1987), 2a. ed., 1995, pp. 815 (820 y ss.); por último Dreier, H., en id. (ed.), Grundgesetz-Kommentar, vol. I, 1996, artículo 1o., inciso 1, núms. marginales 81 a 86. Por último, BVerfGE 89, 28 (35); 93, 266, en relación con la protección del honor personal. Véase también E 94, 12 (24); 95, 96 (130); 97, 391 (399 y ss.).

299 Cfr. BVerfGE 12, 1 (4): "actuales pueblos civilizados", "piso de ciertas concepciones morales básicas coincidentes en el curso de la evolución histórica"; cfr. también BVerfGE 23, 236 (246).

300 Véase ya BVerfGE 12, 45 (50 y ss.); más tarde, E 54, 341 (357). 
Este libro forma parte del acervo de la Biblioteca Juridica Virtual del Instituto de Investigaciones Juridicas de la UNAM

el otro, deben permitir al ser humano llegar a ser persona, ${ }^{301}$ serlo y seguir siéndolo. En esta garantía jurídica, específica de los ámbitos vitales, del ser persona, de la identidad, encuentra la dignidad humana su lugar central: el cómo es que el ser humano llega a ser persona nos ofrece indicios de lo que sea la "dignidad humana". Aquí deben distinguirse dos cuestiones: cómo se forma la identidad humana en una sociedad, y en qué medida puede partirse de un concepto de identidad válido entre culturas (y por tanto, universal).

\section{B. Algunas consecuencias}

Si se observan los conceptos de identidad sicológicos y científico-sociales, se advierte una similitud material (no terminológica): la identidad parece realizarse en una libertad contenida por un "marco" determinado; dicho marco es, en parte, también la "superestructura" jurídica de la sociedad, y en él, el principio de la dignidad humana transmite al individuo determinadas "concepciones normativas de la persona", las cuales se hallan marcadas por la cultura en la que han surgido. ${ }^{302}$

Sin embargo, la dignidad humana no sólo es analizable en términos culturalmente específicos. Ya una mirada a los conceptos de identidad válidos entre culturas muestra que ciertos componentes fundamentales de la personalidad humana deben ser tomados en cuenta en todas las culturas, con lo cual se convierten en contenido de un concepto de dignidad humana que no sea reductible a una cultura específica.

Más allá de lo anterior, no es estático en lo absoluto el marco de orientación frente al cual llega a ser persona el ser humano, desenvolviéndose de manera libre pero orientada. Las posibilidades garantizadas, es decir, socialmente aceptadas, de desenvolvimiento y comunicación por ejemplo, en forma de roles estabilizados, como los "modelos" de una profesión, se convierten en parte del marco de orientación (que no es sólo jurídico); la especificidad cultural de las concepciones sobre la dignidad humana se convierte así en especificidad cultural en el tiempo, y el marco de orientación se hace más flexible y diferenciado gracias al creciente número de sus posibi-

301 Así ya Wintrich, J. M., Zur Problematik der Grundrechte, 1957, especialmente la p. 6: le corresponde al ser humano su dignidad, porque "en esencia es" persona.

302 Véase también Zippelius, R., Bonner Kommentar (Zweitbearbeitung), artículo 4 de la LF (1996), número marginal 4: "El segundo concepto capital de las concepciones vivientes en nuestra comunidad cultural (!) sobre la dignidad humana es la autonomía moral". 
Este libro forma parte del acervo de la Biblioteca Juridica Virtual del Instituto de Investigaciones Juridicas de la UNAM http://www.juridicas.unam.mx

lidades de orientación, ${ }^{303}$ por lo que se vuelve difícil, si no es que imposible, el regreso a las tradicionales concepciones estáticas.

Dicho en otras palabras: la fórmula del objeto de Dürig se convierte en fórmula del sujeto; el Estado constitucional realiza la dignidad humana haciendo a los ciudadanos sujetos de su actuación. ${ }^{304}$ En este sentido, la dignidad humana es la biografía desarrollada y en desarrollo de la relación entre el ciudadano y el Estado ${ }^{305}$ (y con la desaparición de la separación entre Estado y sociedad, de la relación Estado/sociedad-ciudadanos). Aquí reside la justificación (parcial) de destacar a la dignidad humana como autopresentación exitosa de una persona constituida en individuo y, por tanto, como logro propio de cada ser humano en lo individual, ${ }^{306}$ la que, por ejemplo, resulta evidente, en términos prácticos, como "derecho a la autodeterminación informacional". ${ }^{307}$ El concepto (de la percepción y el logro) de la identidad se entiende aquí, en virtud de la apertura de aquel marco orientador para la dignidad humana, en un sentido amplio que incluye las condiciones de posibilidad sociales y jurídicas. ${ }^{308}$

\section{La dignidad humana en relación con el tú $y$ en la solidaridad de las generaciones}

Los conceptos científico-sociales de la identidad comprueban además otra idea jurídica: en la dignidad humana se concibe de entrada también la relación con el tú. El reconocimiento de la "igual dignidad humana del otro" ${ }_{309}$ constituye el puente dogmático hacia la adecuación relativa al tú de

303 Por lo tanto, también es funcionalmente "correcto"normar un derecho fundamental "residual" o general ("Auffang-Grundrecht"), como el artículo 2o., inciso 2, de la LF, que en unión con el artículo 1o., inciso 1, puede actuar hacia el futuro.

304 De manera clara BVerfGE 38, 105 (114 y ss.); 9, 89 (95); E 87, 209 (228); véase también E 89, 28 (en especial la p. 35). Fundamental el trabajo de Dürig, G., Der Grundrechtssatz von der Menschenwürde (1956), recogido más tarde en id., Gesammelte Schriften, 1984, pp. 127 y ss.

305 El artículo 79, inciso 3, de la LF no se refiere tanto a conceptos abstractos éticofilosóficos de dignidad, sino más bien a la biografía desarrollada de la relación Estado/ (sociedad)-ciudadanos.

306 Luhmann, N., Grundrechte als Institution, 1965, 2a. ed., 1974, pp. 68 y ss.; Podlech, A., $G G-A K, 2$ a. ed., vol. I, 1989, artículo 1o., inciso 1, número marginal 11.

307 Cfr. BVerfGE 65, 1 (41 y ss.). Badura, P., Staatsrecht, 2a. ed., 1996, pp. 112 y ss.

308 Un concepto más estricto en Podlech, A., Alternativ- $K$. GG, artículo 1o., inciso 1 (1989), números marginales 34 y ss.

309 Cfr. sobre los derechos de igualdad: HdBStR, vol. V (1992), pp. 837 y ss. (en especial Kirchhof, P.); Hesse, K., "Der Gleichheitssatz in der neuen Rechtsprechung des Bundesverfassungsgerichts", FS Lerche, 1993, pp. 121 y ss. 
Este libro forma parte del acervo de la Biblioteca Juridica Virtual del Instituto de Investigaciones Juridicas de la UNAM

la dignidad humana "del uno", tal como lo han concretizado de manera especial la jurisprudencia del Tribunal Constitucional Federal sobre la imagen del hombre ${ }^{310} \mathrm{o}$ el catálogo de los derechos fundamentales, en particular los artículos 6o. y 140, 9o. y 21, o el artículo 28, inciso 2, de la LF. ${ }^{31}$ La referencia al "otro", al "prójimo", al "tú" y al "hermano" (en el sentido de la fraternidad de 1789), hoy también a la "hermana", es una parte integral del principio jurídico-fundamental de la dignidad humana.

\section{La dignidad humana en el cambio cultural}

El enunciado constitucional sobre la dignidad humana trae consigo un grado mínimo de capacidad de desarrollo y, con ello, también de transformación de la dignidad humana que es "absoluta" en apariencia. De este modo, los peligros en el campo ambiental entran apenas recientemente en la conciencia general, o bien, sólo en época próxima se tiene percepción de algún grupo social marginal (como el de los transexuales): las cláusulas sobre la dignidad humana se encuentran en el contexto de la cultura constitucional, la cual apunta más allá de lo jurídico en la Constitución, hacia lo cultural, es decir, hacia los textos clásicos lo mismo que hacia utopías concretas (por ejemplo, la de los ecologistas), hacia las experiencias de un pueblo (por ejemplo, con las tiranías), así como hacia las esperanzas (hasta 1990, unidad de Alemania, hoy, la de Europa).

\section{La vinculación entre dignidad humana y democracia}

\section{A. El pensamiento "clásico" de la separación y su crítica}

El fundamento del Estado constitucional es doble: la soberanía del pueblo y la dignidad humana. En la historia de las ideas, la soberanía popular y la dignidad humana fueron concebidas y "organizadas", la mayoría de las veces, en forma separada. La soberanía popular era la contrapartida

$310 \mathrm{Al}$ respecto véase Häberle, P., Das Menschenbild im Verfassungsstaat, 1988, pp. 44 y ss. De la bibliografia: Bergmann, J. M., Das Menschenbild der Europäischen Menschenrechtskonvention, 1995.

311 Sobre el "status corporativus", Häberle, P., Die Wesensgehaltsgarantie des Art. 19 Abs. 2 GG, 3a. ed., 1983, pp. 376 y ss. 
Este libro forma parte del acervo de la Biblioteca Juridica Virtual del Instituto de Investigaciones Juridicas de la UNAM

político-polémica de la soberanía del príncipe o monarca. ${ }^{312}$ Su concepción clásica en la tradición de Rousseau ("toda la soberanía dimana del pueblo") impregna los textos constitucionales escritos y la tradición científica hasta la fecha. Su fuerza de convicción es tanta que las correcciones se toman en cuenta de manera periférica, los cuestionamientos fundamentales casi no lo son y muy rara vez se perciben las variantes sustanciales de los textos constitucionales. En la frase de Dolf Sternberger "no todo el poder del Estado dimana del pueblo" reside todavía una inclinación involuntaria frente a la posición de J.-J. Rousseau que se está combatiendo. En el postulado de la democracia con división de poderes o del Estado de derecho ${ }^{313}$ radica asimismo tanto una corrección de las doctrinas "absolutas" de la soberanía popular como una indicación de la fragmentación pluralista de la voluntad del pueblo. ${ }^{314}$ Sin embargo, sigue siendo una tarea pendiente la de desprender a la soberanía popular de su origen histórico polémico para verla en vinculación con la dignidad humana.

\section{B. Cambios en los textos constitucionales}

Una comparación de los textos constitucionales muestra, en el caso de las Constituciones más antiguas, al pueblo como elemento primario de la doctrina de los tres elementos de las teorías generales del Estado. Ocasionalmente se degrada al ciudadano a la calidad de "objeto" del poder estatal de manera textual, por un lado, en la tradición de la doctrina de la soberanía popular, es decir, según la fórmula "todo el poder del Estado dimana del pueblo", por el otro lado, llama la atención la figura codificadora del Estado nacional: el pueblo es postulado como unidad "nacional" (frente a las minorías étnicas), en el sentido de "pueblo alemán" y similares.

Algunos textos constitucionales más recientes recorren, casi sin que se advierta, una vía distinta, ${ }^{315}$ ya sea modificando la cláusula de la soberanía

312 Sobre la soberanía $c f r$. la exposición básica de Dagtoglou, P., voz "Souveranität", EvStL, 1966, cols. 2321 y ss. (ahora en 3a. ed., 1987, cols. 3155 y ss.).

313 Bäumlin, R., Die rechtsstaatliche Demokratie, 1954.

314 Hesse, K., op. cit., pp. 61 y ss.

315 De manera puntual se indica la relación entre pueblo y derechos humanos, por ejemplo, en el § 130 de la Constitución de la Iglesia de San Pablo (1849); véase también el artículo lo., frase 2, de la Constitución federal austriaca (1920): "Su derecho proviene del pueblo". El encabezado del apartado de derechos fundamentales de la Constitución de Japón (1946) reza: "Los derechos y deberes del pueblo"(citado en Neumann, R., Änderung und Wandlung der japanischen Verfassung, 1982, p. 187). 
Este libro forma parte del acervo de la Biblioteca Juridica Virtual del Instituto de Investigaciones Juridicas de la UNAM

popular, ${ }^{316}$ o bien, construyendo la parte de los derechos fundamentales de manera tan evidente a partir de la garantía de la dignidad humana, que esto no puede quedar sin efectos sobre la concepción de la tradicional cláusula de la soberanía popular, así por ejemplo, en el artículo lo. de la LF, que "corrige" al artículo 20, inciso 2. Si de acuerdo con el proyecto constitucional de Herrenchiemsee de 1948 (artículo 1o., inciso 1), "el Estado se encuentra al servicio del ser humano" (y no a la inversa), entonces bien puede ser que todo el poder del Estado "dimane" del pueblo, pero este enunciado ¡encuentra ya su "premisa primaria" en la dignidad humana! Es el "punto de referencia arquimédico" de todas las derivaciones y contextos del gobierno y de las "cadenas de legitimidad", que también son necesarias en el Estado constitucional. El "gobierno del pueblo" (por el pueblo y para el pueblo) es concebido apenas en una segunda etapa del razonamiento. Como principio jurídico, la protección de la dignidad humana (iy también su irradiación hacia los derechos fundamentales en lo particular!) es anterior al "Estado" y al "pueblo" y también a todas las derivaciones del gobierno y las vinculaciones de legitimación del pueblo hacia los órganos del Estado ( $c f r$. al respecto BverfGE 93, 37 (67 y s.)).

Un paralelismo entre dignidad humana y soberanía popular se advierte ya claramente en los artículos 1o. y 2o. de la Constitución de Grecia (1975). El artículo 1o., inciso 2, reza: "La soberanía del pueblo es el fundamento sobre el que descansa la forma de gobierno"; el inciso 3: "Todos los poderes emanan del pueblo, existen para su beneficio...", etcétera. Cuando el artículo 2o., inciso 1, norma la "obligación fundamental "del Estado de respetar y proteger la dignidad humana, de entrada se encuentran vinculados la soberanía popular y el concepto de la dignidad humana, pero el artículo 1o. de la Constitución de Portugal (1976-1992) formula todavía mejor esta vinculación. ${ }^{317}$

316 Cfr. el artículo 1o., inciso 2, de la Constitución del Burgenland: "El Burgenland se funda en la libertad y la dignidad del ser humano".

317 "Portugal es una República soberana, basada en la dignidad de la persona humana y en la voluntad popular, y empeñada en la construcción de una sociedad libre, justa y solidaria". 
Este libro forma parte del acervo de la Biblioteca Juridica Virtual del Instituto de Investigaciones Juridicas de la UNAM http://www.juridicas.unam.mx

\title{
3. Los derechos humanos fundamentales en el Estado constitucional
}

\author{
Referencias del Estado y los textos constitucionales a los derechos humanos \\ - una tipología comparativa: la progresiva "constitucionalización" \\ de los derechos humanos como positivización
}

Un primer conocimiento sobre la relación entre derechos humanos ${ }^{318}$ y Estado constitucional puede obtenerse de una comparación espacio temporal de los textos constitucionales mismos. La teoría de la Constitución, entendida como "ciencia jurídica de los textos y la cultura", toma los textos constitucionales positivos como punto de partida, los sitúa en sus contextos culturales y de este modo es capaz de reconstruir la evolución del tipo del Estado constitucional, porque los constituyentes de todos los tiempos y naciones se encuentran en un proceso intensivo de producción y recepción. De este modo ha surgido hoy día un espacio público mundial del Estado constitucional. Puesto que el constituyente más reciente no sólo "copia" los textos antiguos de los otros, sino que retoma en parte también la jurisprudencia y la doctrina constitucionales ajenas y las vacía en textos, y en virtud de que además de que trata de dar forma de texto nuevo en parte a la realidad constitucional ajena, y plenamente de su lado a la "Constitución no escrita", el Estado constitucional se vuelve tangible, como tipo ideal y real, en el "curso del tiempo", a través de la "evolución de etapas textuales". Independientemente de todas las variantes nacionales y de las diferencias contextuales de las diversas Constituciones, gracias al paradigma de las etapas textuales es posible dar un nombre y vaciar en conceptos a la dinámica y la estática, lo común y lo distinto, lo nuevo y lo viejo, del tipo del "Estado constitucional" y sus temas. Por ejemplo, los dos países ibéricos y el contexto

318 La bibliografía ya es inabarcable: por ejemplo, Schwartländer, J. (ed.), Menschenrechte: Aspekte ihrer Begründung und Verwirklichung, 1978; id. (ed.), Menschenrechte und Demokratie, 1981; Kühnhardt, L., Die Universalität der Menschenrechte, 1987; Mensen, B. (ed.), Grundrechte und Menschenrechte in verschiedenen Kulturen, 1988; Maier, H., "Überlegungen zu einer Geschichte der Menschenrechte", FS Lerche, 1993, pp. 43 y ss.; id., Wie universal sind die Menschenrechte?, 1997. De la bibliografía estadounidense sobre los derechos fundamentales: Abernathy, G. M. y Perry, B. A., Civil Liberties Under the Constitution, 6a. ed., 1993; Dworkin, R., Taking Rights Seriously, 1977 (hay trad. Los derechos en serio); Vieira, N., Civil Rights in a Nutshell, 2a. ed., 1989; véase también Brugger, W., Grundrechte und Verfassungsgerichtsbarkeit in den Vereinigten Staaten, 1987. Sobre Francia: Itin, M., Grundrechte in Frankreich, 1993; Gicquel, J., Droit constitutionnel et institutions politiques, 1 la. ed., 1991, pp. 87 y ss. Sobre Italia: Pace, A., Problemática delle libertà costituzionali, 2 partes, 2a. ed., 1990 y 1992; Ridola, P., Diritti di libertà e costituzionalismo, 1997; Modegna, F., I "nuovi diritti"nella giurisprudenza costituzionale, 1995. 
Este libro forma parte del acervo de la Biblioteca Juridica Virtual del Instituto de Investigaciones Juridicas de la UNAM http://www.juridicas.unam.mx

cultural especial en que se encuentran con América Latina, para gran utilidad de toda Europa (hay que mencionar el gran arco que va de la Constitución de Cádiz de 1812 a la nueva Constitución de Colombia de 1991), abre perspectivas especiales a la teoría comparada de la Constitución.

\section{a. Los derechos humanos como parte integrante} de las cláusulas generales de reconocimiento

Un elemento textual ya clásico lo constituyen las cláusulas generales de reconocimiento de los derechos humanos, ya sea en los preámbulos o en los artículos de bases. Su modelo estilístico es el preámbulo de la Declaración francesa de los Derechos del Hombre y el Ciudadano de 1789 ("derechos naturales, inalienables y sagrados del hombre"); ya la Declaración de Derechos de Virginia (1776), contiene la frase (en I.) de que "todos los hombres son por naturaleza igualmente libres e independientes". Más tarde reza el preámbulo de la Constitución francesa (1958-1976): "El pueblo francés declara solemnemente su adhesión a los Derechos del Hombre... tal como fueron definidos por la Declaración de 1789...". ${ }^{319}$ Quizá el giro lingüísticamente más bello sea el logrado por el preámbulo de la Constitución del Cantón suiza del Jura (1977): "Le peuple jurassien s'inspire de la Déclaration des droits de l'homme de 1789, de la Déclaration universelle des Nations unies proclamée en 1948 et de la Convention européenne des droits de l'homme de 1950”. ${ }^{320}$ El preámbulo de la Constitución del Perú de 1979 se manifiesta resuelto a fundar un Estado democrático, que "garantice, a través de instituciones estables y legítimas, la plena vigencia de los derechos humanos".

En el artículo 2o. de los principios fundamentales de la Constitución de Italia (1947) se dice: "La República reconoce y garantiza los derechos inviolables del hombre, ya sea como individuo, ya sea en las formaciones sociales...". De acuerdo con el preámbulo de la Constitución española (1978), la

319 Por ejemplo, se dice en el preámbulo de la Constitución de Baden-Württemberg (1953): "en reconocimiento solemne de los derechos inviolables e inalienables del hombre y de los derechos fundamentales de los alemanes...".

320 ("El pueblo del Jura se inspira en la Declaración de los Derechos del Hombre de 1789, en la Declaración Universal de Naciones Unidas proclamada en 1948, y en la Convención Europea de los Derechos del Hombre de 1950".) Este texto es retomado por el artículo 2o., inciso 2, de la Constitución de Brandemburgo (1992): "El pueblo del Land de Brandemburgo reconoce los derechos fundamentales consagrados en la Ley Fundamental de la República Federal de Alemania, en la Convención Europea para la Protección de los Derechos Humanos y las Libertades Fundamentales, en la Carta Social Europea y en los Pactos Internacionales de Derechos Humanos". 
Este libro forma parte del acervo de la Biblioteca Juridica Virtual del Instituto de Investigaciones Juridicas de la UNAM http://www.juridicas.unam.mx

nación española proclama su voluntad de proteger "a todos los españoles y pueblos de España en el ejercicio de los derechos humanos...". Aquí podemos remitirnos a otros ejemplos. ${ }^{321} \mathrm{El}$ artículo 7o., inciso 1, de la Constitución de Sudáfrica (1996-1997) dispone plásticamente: "This Bill of Rights is a cornerstone of democracy in South Africa".

\section{b. Los derechos humanos como fines de la educación}

$\mathrm{Al}$ vincularse con los fines de la educación (Erziehungsziele), los derechos humanos establecen un vínculo bastante "nuevo" con temas constitucionales internos. El Estado constitucional "internaliza" los derechos humanos de un modo específico, porque, y en la medida en que los convierte en tema de los fines de la educación. En el fondo pretende educar a sus ciudadanos, desde la juventud, como "ciudadanos del mundo"; aquí se puede recordar el espíritu misionero de los EUA, quizá también el pathos universal de 1789 y el idealismo alemán.

El artículo 27, inciso 2, de la Constitución española es pionero en este sentido:322 "La educación tendrá por objeto el pleno desarrollo de la personalidad humana en el respeto a los principios democráticos de convivencia y a los derechos y libertades fundamentales". Esta idea es recibida en el artículo 22, tercer párrafo, de la Constitución peruana de 1979 con las siguientes palabras: "La enseñanza sistemática de la Constitución y de los derechos humanos es obligatoria en los centros de educación civiles y militares y en todos sus niveles". Más tarde se dice, y en forma mejorada, en el artículo 72, párrafo segundo, de la Constitución de Guatemala (1985): “Se

321 El artículo 2o. de la Constitución de Turquía (1982): Respeto de los derechos humanos. El artículo lo. de la Constitución de Baden (1947) pone los derechos humanos "inalienables y sagrados" bajo la protección de la Constitución. Véase también el artículo lo. de la Constitución de la República Checa de 1992 (citado en FöR, vol. 44, 1996, pp. 458 y ss.): "La República Checa es un Estado de derecho soberano, unitario y democrático fundado en el respeto de los derechos y las libertades del hombre y del ciudadano". Preámbulo de la Constitución de Bulgaria de 1991: "érigeant en principe suprême les droits de l'individu, sa dignité et sa securité...". Artículo 12, inciso 1, de la Constitución de la República Eslovaca de 1992 (citado en FöR, vol. 44, 1996, pp. 478 y ss.): "People are free and equal in their dignity and rights". Preámbulo de la Constitución de Georgia (1995): "The Citizens of Georgia... guarantee universally recognized human rights...".

322 Una formulación más temprana podría ser la de la Constitución de MecklemburgoAntepomerania de 1947, cuando exige que se eduque a la juventud en la "verdadera humanidad", o el artículo 131, inciso 2, de la Constitución de Baviera (1946), que eleva el respeto de la dignidad del hombre a la categoría de fin de la educación ( $c f r$. también ahora el artículo 28 de la Constitución de Brandemburgo de 1992). 
Este libro forma parte del acervo de la Biblioteca Juridica Virtual del Instituto de Investigaciones Juridicas de la UNAM

declaran de interés nacional la educación, la instrucción, formación social y la enseñanza sistemática de la Constitución de la República y de los derechos humanos".

\section{II. "ASPECTOS DE FILOSOFÍA DE LAS IMÁGENES": IMAGEN DEL HOMBRE, DEL ESTADO, DEL PUEBLO, DE DIOS, DEL MUNDO}

La teoría de la Constitución, entendida como ciencia jurídica de los textos y la cultura, puede asociarse con una "filosofia de las imágenes", ya que la teoría del derecho del Estado trabaja desde hace tiempo (siguiendo la jurisprudencia respectiva del TCFA) con la categoría de la "imagen del hombre" (Menschenbild), ${ }^{323}$ la cual es un aspecto de una triada, junto con la "imagen del Estado" y la "imagen del mundo". El hombre, el Estado constitucional y el mundo denotan cosas que van juntas, también, y precisamente, para el jurista, el cual ciertamente, tratándose de este tema, tiene todo el motivo de abrirse ampliamente a las otras disciplinas, ya que éstas participan en la constitución del "mundo" - al menos en la (re)construcción a través del ser humano-; piénsese en el "ethos mundial" entre los pueblos que propone el teólogo H. Küng, el cual pretende ser al mismo tiempo proyecto y patrimonio cultural. La teoría del Estado constitucional podría tener actualmente razones especiales para cuestionar sus competencias y funciones con vistas al mundo (no solamente porque la mayoría de los Estados sean Estados constitucionales o quieran serlo), ya que asume toda clase de responsabilidades que se refieren al mundo y es sujeto en forma especial del derecho internacional en desarrollo, en el plano universal en el marco de las Naciones Unidas, como también regionalmente por la vía de la ayuda al desarrollo, por ejemplo, para África, o también en forma de exigencias e intervenciones, como la de la Unión Europea en los Balcanes.

Ciertamente son otras ciencias y las artes las que, mucho antes que la teoría constitucional, han escogido como su objeto al "mundo" o, desde el punto de vista humano, a la "humanidad". Así tenemos la gran obra de J. G. Herder "Ideas para una historia de la filosofia de la humanidad"(1785), o las "Ideas para una historia universal en clave cosmopolita" de Kant (17751795); también conocemos así las "reflexiones sobre la historia universal" de J. Burckhardt (1905). ${ }^{324}$ Antes que ellos ya hablaba G. W. F Hegel del "es-

${ }^{323}$ Véase al respecto Häberle, P., Das Menschenbild im Verfassungsstaat, 1988 (pp. 12 y ss.), donde se aborda por primera vez la cuestión de la "imagen del mundo".

324 Cfr. Burckhardt, J., La cultura del Renacimiento en Italia (1860), cuarta parte: "El descubrimiento del mundo y del hombre". 
Este libro forma parte del acervo de la Biblioteca Juridica Virtual del Instituto de Investigaciones Juridicas de la UNAM

píritu universal" y del "juicio universal" (1821). La ciencia histórica ha intentado siempre escribir una "historia universal". Un A. Heuss no deseaba estudiar sino altas culturas que poseyeran una cierta "vocación universal" ("Welthaftigkeit"), que durante cierto tiempo hubieran ejercido una influencia en el mundo. Esta "vocación universal" podría atribuírseles a las altas culturas china, hindú, árabe-musulmana, y sobre todo, a la europea. Es esta última la que hoy en día marca a la humanidad, contra la creciente resistencia del "mundo" islámico, por ejemplo, en materia de derechos humanos, democracia y economía social de mercado. De este modo podríamos considerar, con H. Freyer, que la historia universal del siglo XX ha sido una "historia universal de Europa", ${ }^{325}$ pero ciertamente no sería cinismo constatar que las primeras "guerras mundiales" calificadas como tales, empezaron en Europa. Ciertamente, a la búsqueda de la "imagen del mundo" europea, tendremos particular éxito en encontrarla en las artes (plásticas), por ejemplo, de la Edad Media y después de 1492. Y J. W. v. Goethe hizo su aportación anticipada en el verso: "De Dios es el Oriente, de Dios es el Occidente, en la paz de sus manos descansan las tierras del norte y del septentrión".

¿Cómo se constituye este mundo único, esta "sociedad mundial" (N. Luhmann) desde la perspectiva de la teoría comparada de la Constitución? ¿Acaso no se excede en vista de la diversidad de culturas y del "choque de las civilizaciones”? ¿O no tendrá más bien que ocuparse de elementos de su imagen del mundo precisamente a causa de su derecho constitucional, altamente desarrollado, de la tolerancia y en virtud del derecho internacional de la coexistencia y la cooperación? Aquí le corresponde un lugar al proyecto de J. Habermas: ${ }^{226}$

Sólo una ciudadanía democrática que no se cierre en términos particularistas puede, por lo demás, preparar el camino para un status de ciudadano del mundo o una cosmociudadanía, que hoy empieza ya a cobrar forma en las comunicaciones políticas que tienen un alcance mundial.

Y:

El Estado cosmopolita ya ha dejado de ser un simple fantasma, aun cuando nos encontremos todavía bien lejos de él. El ser ciudadano de un Estado y el ser ciudadano del mundo constituyen un continuum cuyos perfiles empiezan ya al menos a dibujarse.

325 1954, 3a. ed., 1969; Heuss, A., Zur Theorie des Weltgeschichte, 1968.

326 Habermas, J., Faktizität und Geltung, 1992, pp. 659, 138 y ss.: "supuesta república de los ciudadanos del mundo" (trad.: Facticidad y validez, Madrid, 1998, citas en p. 643). 
Este libro forma parte del acervo de la Biblioteca Juridica Virtual del Instituto de Investigaciones Juridicas de la UNAM

En el idioma alemán, la palabra "mundo" ("Welt") aparece también en aquella palabra o término que se desarrolla vertiginosamente como "derecho ambiental" ("Umweltrecht"), incluyendo el "derecho ambiental internacional" ("Umweltvölkerrecht"). Podrá haber controversia sobre la "imagen del mundo" antropocéntrica o fisiocéntrica, pero el entorno ("Umwelt") es un pedazo del "mundo" ("Welt") y en la suma constituyen al mundo en su conjunto. El mandato de orden, protección y configuración con vistas al ambiente exige plantear la cuestión de la "imagen del mundo" del Estado constitucional.

\section{III. "LIBERTAD GULTURAL", LIBERTAD A PARTIR DE LA GULTURA, LOS DERECHOS HUMANOS FUNDAMENTALES EN EL ESTADO CONSTITUCIONAL}

\section{Libertad cultural}

En la dimensión cultural es preciso considerar a la libertad fundamental, así como a la democracia en la libertad (y la cultura), también a partir de sus resultados. Tan arbitrario como puede y debe ser lo que el individuo hace (o no) con o de su libertad, así estará orientada al resultado, vista en conjunto, la garantía de la libertad de todos y como tal. La libertad cultural es, considerada en el eje del tiempo, una conquista de muchas generaciones; vista en un "corte transversal", es el producto de diversos círculos y grupos de un pueblo o de los intérpretes constitucionales. A partir de la estatura individual de un pueblo, se garantiza esencialmente la libertad en función de sus "objetivaciones" y "materializaciones", es decir, de los resultados que su ejercicio particular pueda producir; las luchas por lograr formas culturales "alternativas" y su consecuente reconocimiento (por ejemplo, The Beatles) confirman la vinculación entre cultura y libertad.

El concepto de "libertad cultural" pretende, pues, enriquecer la libertad a partir del objeto, no en el sentido de un requisito normativo obligatorio, sino a partir del resultado esperado, aunque éste sea frecuentemente erróneo. Así vista, toda libertad es "libertad cultural": como libertad que, conforme a una apreciación realista, está incorporada en una red de fines educativos y valores orientadores, parámetros culturales y obligaciones materiales, en suma, que tiene literalmente a la "cultura" como "objeto", incluso como función. En esta forma la cultura es objeto tanto de la libertad del individuo y en lo particular como también de la libertad como "situación global" de un pueblo. Esta libertad "cuaja" o se objetiva en elementos culturales; se 
Este libro forma parte del acervo de la Biblioteca Juridica Virtual del Instituto de Investigaciones Juridicas de la UNAM

producen cristalizaciones culturales sobre las cuales puede construirse más tarde el ejercicio individual y el colectivo de la libertad. Los procesos de crecimiento cultural se desenvuelven a través del juego recíproco que va desde la libertad "potencial", pasando por la libertad "realizada" y los resultados culturales de la libertad, hasta las obras a partir de las cuales es posible, pero también es necesaria e incluso debe arriesgarse (con la posibilidad del fracaso), la nueva libertad individual: la libertad de opinión y de prensa conducen a opiniones y obras impresas que benefician al proceso cultural y político; la libertad del arte y de la ciencia conduce a obras científicas y artísticas, incluyendo a la teoría del derecho constitucional como ciencia y como literatura, las cuales pueden ser de auxilio en futuros procesos interpretativos; la libertad de credo religioso conduce a contenidos y orientaciones religiosos que pueden influir en el concepto de sí mismos de los grupos religiosos; algo similar puede decirse de todos los aspectos corporativos de las libertades fundamentales. Los derechos fundamentales son normados, configurados y desarrollados en beneficio de estos "resultados globales" individuales y colectivos. Y lo que su ejercicio produce en lo político, lo económico y lo cultural influye también a largo plazo en los derechos fundamentales, en su configuración normativa y en las vías de su realización. Los citados procesos de producción y recepción toman precisamente el camino que pasa a "través" de los derechos fundamentales.

\section{En particular: los "derechos fundamentales", la distinción entre "derechos humanos"} $y$ "derechos ciudadanos", y en particular: el "status mundialis hominis"

A) Los "derechos fundamentales" ("Grund-Rechte") constituyen hoy en día el concepto que engloba a los derechos humanos universales y los derechos ciudadanos nacionales. Ambas clases de derechos fundamentales ${ }^{327}$ son, aunque con diversa intensidad, parte integrante necesaria de la cultura jurídica de todo "Estado constitucional" que merezca tal nombre.

B) El marco teórico de los derechos fundamentales, fundado en la doctrina del contrato social (en el sentido de J. Locke, enfocado a la libertad y la propiedad; con base en T. Hobbes: la vida y la seguridad) y el que hoy ha de entenderse como "contrato constitucional", debe extenderse del nivel nacional al universal: al lado de la sociedad particular de cada Estado y su "sta-

327 Ya la bibliografía alemana sobre la dogmática de los derechos fundamentales resulta inabarcable; aquí sólo unas cuantas referencias: Hesse, K., Grundzüge des Verfassungsrechts der Bundesrepublik Deutschland, 20a. ed., 1995, pp. 125 y ss.; Lerche, P., Übermass und Verfassungsrechts, 1961; Dürig, G., Gesammelte Aufsätze, 1964. 
Este libro forma parte del acervo de la Biblioteca Juridica Virtual del Instituto de Investigaciones Juridicas de la UNAM

tus civilis", surge de manera complementaria la "sociedad mundial", con la consecuencia de un status mundialis fundamental de cada ser humano; en su campo de fuerzas debe "imaginarse" un "contrato social mundial", cuando menos como ficción en el sentido de I. Kant. No sólo en el interior de los Estados ha logrado el ser humano la transición del "status naturalis" al "status civilis"; también a nivel mundial, visto globalmente, se ha producido, al menos de manera ficticia, el paso del "status naturalis" al "status civilis": los contratantes son todos los seres humanos, todos los Estados constitucionales y todos los pueblos, incluso hasta llegar a la perspectiva de las generaciones futuras. Todos ellos se garantizan mutuamente los derechos humanos de cada uno. Puede ser que la ciencia del derecho internacional todavía se encuentre algo atrasada en el reconocimiento de los derechos humanos, así como de la capacidad internacional de los seres humanos; sin embargo, es asunto de la teoría constitucional fundar una teoría de los derechos humanos mediante figuras intelectuales, como la del contrato social, que sean generales y se proyecten con un parámetro mundial. La tradición del idealismo alemán nos proporciona las palabras clave necesarias ("en clave cosmopolita", la "paz perpetua", de Kant en 1795, etcétera), y el pensamiento anglosajón que va desde el Bill of Rights de Virginia (1776) hasta la Declaración Universal de los Derechos Humanos de las Naciones Unidas (1948) y la política de los derechos humanos de un J. Carter, ofrecen la necesaria práctica de la teoría.

C) Los derechos humanos, entendidos como derechos de todo ser humano de todas las naciones, incluyendo los llamados "apátridas", tienen su raíz al mismo tiempo en el Estado constitucional nacional de la actual etapa evolutiva y en la "humanidad" universal. Los elementos textuales se encuentran ya en la formulación del preámbulo de la Declaración Universal de los Derechos Humanos de la ONU (1948): "Considerando que la libertad, la justicia y la paz en el mundo tienen por base el reconocimiento de la dignidad intrínseca y de los derechos iguales e inalienables de todos los miembros de la familia humana"; más adelante se habla de la "conciencia de la humanidad". También ahí se hace referencia a la "fe" de los pueblos de las Naciones Unidas en los "derechos fundamentales del hombre". La Ley Fundamental de 1949 se atrevió ya a disponer en su artículo 1o., inciso 2: "El pueblo alemán reconoce por tanto los derechos inviolables e inalienables del hombre como fundamento de toda (i) comunidad humana, de la paz y de la justicia en el mundo". De manera congenial se dice en el preámbulo de la Convención Europea de Derechos Humanos de 1950: "Reafirmando su profundo apego a estas libertades fundamentales, que constituyen las bases mismas de la justicia y de la paz en el mundo...”. Y en el preámbulo de la 
Este libro forma parte del acervo de la Biblioteca Juridica Virtual del Instituto de Investigaciones Juridicas de la UNAM

Convención Americana sobre Derechos Humanos (1969) se encuentra la siguiente frase: "Reconociendo que los derechos esenciales del hombre no nacen del hecho de ser nacional de determinado Estado, sino que tienen como fundamento los atributos de la persona humana...". ${ }^{228}$ Es asunto de la teoría de la Constitución, como doctrina del tipo del Estado constitucional, desarrollar más los elementos teóricos y textuales (por ejemplo, apartados propios sobre "derechos fundamentales de los extranjeros" o artículos que mejoren su posición, según el modelo del artículo 13, inciso 1, de la Constitución española; esto tendría que ser parte de la revisión de la LF alemana).

D) Así como hay derechos humanos "en" el Estado constitucional (por ejemplo, para los extranjeros; pero también para los nacionales, en virtud de su naturaleza humana), así también hay elementos de un derecho humano a la nacionalidad: una prueba de la vinculación ideal, aquí propugnada, entre los derechos humanos y los derechos ciudadanos como "dos manifestaciones" de los "derechos fundamentales"; la palabra "fundamento" debe ser agotada, se refiere a lo pre-estatal, a lo pre-positivo, a lo que está antes del derecho secundario, justamente a lo "fundamental". También se puede formular de la siguiente manera: el ser humano posee ciertos derechos "por naturaleza", y al mismo tiempo es precisamente el Estado constitucional (como cultura) el que le asegura, como tal, justamente, estos derechos humanos y ciudadanos (“derechos culturales"). De manera significativa se dice en el artículo 15 de la Declaración Universal (1948): "Toda persona tiene derecho a una nacionalidad. A nadie se privará arbitrariamente de su nacionalidad ni del derecho de cambiar de nacionalidad". ${ }^{329}$ La dificultad teórica reside en el intento de concebir al Estado, que resulta indispensable para los derechos fundamentales, dentro del campo pre-estatal de los derechos humanos, si se quiere: en el "status naturalis", para lo cual, en última instancia sólo puede auxiliarnos el enfoque culturalista. Esto quiere decir: si bien la libertad como derecho humano existe "por naturaleza", es "innata" (el artículo 1o. de la Declaración Universal dispone: "Todos los seres humanos nacen libres e iguales en dignidad y derechos..."), en última instancia se "cumple" culturalmente, es un "derecho cultural". La cadena del razonamiento va del status naturalis hacia el status civilis como status culturalis (cfr. el artículo 58 de la Constitución de Guatemala de 1985: derecho a

328 En el preámbulo del Pacto Internacional de Derechos Civiles y Políticos se dice: "Considerando que... la libertad, la justicia y la paz en el mundo, tienen por base el reconocimiento de la dignidad inherente a todos los miembros de la familia humana y de sus derechos iguales e inalienables".

329 Cfr. también el artículo 24, inciso 3, del Pacto Internacional de Derechos Civiles: "Todo niño tiene derecho a adquirir una nacionalidad". 
Este libro forma parte del acervo de la Biblioteca Juridica Virtual del Instituto de Investigaciones Juridicas de la UNAM

la identidad cultural). Esto se manifiesta en el artículo 26, inciso 2, de la misma Declaración: "La educación tendrá por objeto el pleno desarrollo de la personalidad humana y el fortalecimiento del respeto a los derechos humanos y a las libertades fundamentales...". La educación y la formación deben entenderse como "segundo nacimiento" del hombre (Hegel), los derechos humanos y fundamentales como fines educativos, aun cuando hoy en día (1996-1997) se reconozca con cuánta rapidez amenaza la recaída en el status naturalis de T. Hobbes (la exYugoslavia, atentados contra extranjeros en Alemania, Italia y Francia). Dicho de otro modo: los derechos humanos universales son actualmente los elementos de la "cultural universal" como sociedad mundial, ipero sin un Estado mundial! A su lado permanece, empero, la identidad nacional o regional como cultura. La cultura es aquí la "otra", la "segunda" creación, la de los seres humanos.

En seguida los principios que varían el tema de la "buena disposición hacia los derechos humanos" ("Menschenrechtsfreundlichkeit"). Dicho en otros términos: los catálogos nacionales de derechos fundamentales, y precisamente también donde garantizan derechos humanos y derechos ciudadanos, deben ser interpretados de manera conforme con los derechos humanos. Un ejemplo de ello se encuentra en el artículo 10, inciso 2, de la Constitución española. ${ }^{330}$ Algunas nuevas Constituciones y proyectos constitucionales en Europa oriental contienen sorprendentes "continuaciones"(por ejemplo, el artículo 10 de la Constitución de la República Checa de 1992: "Los tratados internacionales sobre derechos humanos y libertades fundamentales ratificados y promulgados que sean obligatorios para la República Checa, son directamente eficaces y tienen primacía frente a la ley").

Si hasta ahora se hablaba, sobre todo gracias a Suiza, de la "interpretación conforme a la Constitución" de las leyes ordinarias, ${ }^{331}$ hoy nos encontramos ante el mandato de la "interpretación de los derechos fundamentales conforme a los derechos humanos" y del principio "en formación" de la buena disposición hacia los derechos humanos. ${ }^{332}$

La etapa "más alta" de desarrollo sería el enunciado: "los derechos humanos internacionales prevalecen sobre los derechos fundamentales nacionales", cuando estos últimos se encuentren por debajo del estándar global

330 "Las normas relativas a los derechos fundamentales y a las libertades que la Constitución reconoce se interpretarán de conformidad con la Declaración Universal de Derechos Humanos y los tratados y acuerdos internacionales sobre las mismas materia ratificados por España”.

$331 \mathrm{Al}$ respecto véase Hesse, K., Grundzüge..., cit., pp. 30 y ss.

332 Cfr. el artículo 12, inciso 2, de la Constitución de Angola (1992); el artículo 29, inciso, de la Constitución de Guinea-Bissau. 
Este libro forma parte del acervo de la Biblioteca Juridica Virtual del Instituto de Investigaciones Juridicas de la UNAM

de los derechos humanos ( $c f r$. el artículo 142 de la LF). Aquí se manifiesta cuán confusa es todavía la terminología. Desde el punto de vista constitucional interno, la expresión "derechos fundamentales" se refiere siempre a las dos manifestaciones: los derechos humanos y los derechos ciudadanos. Es del todo concebible que un Estado constitucional nacional otorgue muy pocos "derechos fundamentales" a sus ciudadanos, lo cual puede corregirse, en la medida que pueda compensarse a través de la interpretación, por las garantías internacionales de los derechos humanos (y en su caso, también los regionales). Dicho en términos de la teoría de los derechos fundamentales: el status mundialis hominis (universal) de los derechos fundamentales irradia hacia el status civilis y culturalis. Al respecto ya hay ejemplos textuales. El marco teórico hay que crearlo de la manera arriba sugerida, del mismo modo como hoy, en absoluto, en la "hora mundial" del Estado constitucional, surge la tarea de que las teorías de los derechos fundamentales desarrolladas en el marco nacional se continúen desenvolviendo en términos de la teoría de los derechos humanos, y viceversa, que los derechos humanos universales se incorporen a las teorías nacionales de los derechos fundamentales. Resulta evidente, pues, que esto sólo es posible en forma de un "concierto" multinacional y multicultural de muchas, incluso todas las culturas y dogmáticas nacionales de los derechos fundamentales. ${ }^{333}$ El postulado de la comparación de los derechos fundamentales como "quinto método de la interpretación" encuentra aquí su "lugar", con motivo del artículo 10, inciso 2, de la Constitución española y disposiciones equivalentes, pues solamente a través de la comparación, que vaya de las garantías de los derechos fundamentales nacionales hacia las "universales" y que regrese enriquecida de aquí hacia allá, es posible lograr esta obra. ${ }^{334} \mathrm{~A}$ la inversa, se requiere una teoría universal de los derechos humanos que, según parece, no existe hasta ahora, que dé fundamento, brazo a brazo, con las doctrinas de los derechos fundamentales del Estado constitucional nacional. Este último, por su lado, ya no puede ver, crear, interpretar y desarrollar los "derechos fundamentales propios" sin los derechos humanos universales. El conflicto con la declaración musulmana "particular" de los derechos humanos de El Cairo (1990) es grave y con ello se cuestiona la imagen universal del hombre. 335

333 No se niegan las dificultades de la comprensión intercultural de los conceptos de "dignidad humana", "igualdad", "libertad".

334 Sobre la comparación jurídica como "quinto" método de la interpretación: Häberle, P., "Grundrechtsgeltung und Grundrechtsinterpretation", fZ, 1989, pp. 913 y ss.

335 Cfr. la Declaración de El Cairo sobre los Derechos Humanos en el Islam (1990), en: Gewissen und Freiheit, vol. 19, 1991, pp. 93 y ss. De la bibliografía: Bielefeldt, H., "Menschenrechte und Menschenrechtsverständnis im Islam”, EuGRZ, 1990, pp. 489 y ss. 
Este libro forma parte del acervo de la Biblioteca Juridica Virtual del Instituto de Investigaciones Juridicas de la UNAM

El derecho de asilo para los perseguidos políticos y la configuración efectiva de su estatus conforme a los derechos humanos (es conocido el debate alemán en torno al artículo 16 de la LF, su europeización, es decir, su limitación conforme al artículo 16a) en forma especial en favor de los perseguidos por causa de la idea de los derechos fundamentales ( $c f r$. el artículo 105 de la Constitución de Baviera de 1946) es una forma más, muy general, del pathos de los derechos fundamentales, que radica en la garantía incondicional que le dieron los "padres" y las "madres" de la LF, se encuentra en peligro en vista del actual abuso de este derecho fundamental por los refugiados económicos. El artículo 14, inciso 1, de la Declaración Universal dispone: "En caso de persecución, toda persona tiene derecho a buscar asilo, y a disfrutar de él, en cualquier país". Tengamos presentes los ejemplos constitucionales que este derecho humano ha encontrado mientras tanto en diversos países y sus Constituciones: artículo 10, inciso 3, de la Constitución italiana (1947), artículo 33, inciso 6, de la Constitución de Portugal (1976), artículo 56 de la Constitución de Polonia (1997).

\section{FiNES DE LA EDUCACIÓN (LOS DERECHOS HUMANOS COMO FINES EDUCATIVOS), "PEDAGOGÍA CONSTITUCIONAL" Y VALORES ORIENTADORES}

\section{Fines de la educación}

A. Los fines de la educación como elementos formadores de consenso en el Estado constitucional

Los fines educativos y los valores orientadores tienen una función específica como texto constitucional en sentido amplio, ${ }^{336}$ pues se trata de elementos formadores de consenso en el Estado constitucional y constituyen un pedazo de su identidad cultural y su vida pública. Son fines de la educación, por ejemplo, la tolerancia y la dignidad humana (o también la "imagen del ser humano"), la legalidad, la honestidad y la aceptación de la responsabilidad, la apertura hacia el mundo y el sentido del deber (deberes fundamentales): cfr. los artículos 131, 136, inciso 1, de la Constitución de Baviera; el artículo 26 de la Constitución de Bremen, pero también los artículos 1 o. y 20, inciso 1 ("república") o el 12 de la LF (libertad de profesión, el "traba-

$336 \mathrm{Al}$ respecto véase de manera detallada Häberle, P., Erziehungsziele und Orientierungswerte im Verfassungsstaat, 1981. 
Este libro forma parte del acervo de la Biblioteca Juridica Virtual del Instituto de Investigaciones Juridicas de la UNAM

jo" o el "ethos del trabajo" como fin educativo), interpretados desde "su otra cara": dicha "interpretación constitucional pedagógica" es fructífera, por ejemplo, para la ética social en los artículos económicos de las Constituciones de los Länder alemanes (por ejemplo, los artículos 27, 30, 38 de la Constitución de Hesse de 1946; los artículos 51, 52-56 de la Constitución de RenaniaPalatinado de 1947), por ejemplo, como deberes fundamentales de los empresarios. Los fines de la educación constituyen condiciones de base para la Constitución de la libertad; se trata de derecho constitucional material y dentro del pluralismo de los sujetos de la educación son interpretados y realizados en parte de manera privada por los padres, por el Estado a través de las escuelas, así como de manera pública por la sociedad. Los fines de la educación constituyen una especie de "profesión de fe" cultural del Estado constitucional.

En algunos Estados constitucionales de Europa, pero también más allá de ellos, entre los países en desarrollo, se encuentran significativos procesos de crecimiento y evolución a través del medio de la recepción. Alemania se encuentra en primer plano allá (pero también Portugal y España), y países en desarrollo como Perú (antigua Constitución) y Guatemala aquí. No es reconocible (¿todavía?) un inventario común europeo de fines de la educación en textos constitucionales; en este sentido, este tema es tratado también como ejemplo de que hay campos en el Estado constitucional como tipo en el cual hay "carencia total", mientras que algunos miembros de su "familia" han desarrollado elementos estructurales muy intensos y consecuentes en sí. "Texto clásico" en materia de fines de la educación es el artículo 148, incisos 1 y 2, de la Constitución de Weimar de 1919:

En todas las escuelas se buscará la instrucción moral, la conciencia ciudadana, la capacidad personal y profesional en el espíritu del pueblo alemán y de la reconciliación de los pueblos. La docencia en las escuelas públicas tendrá cuidado de que no se ofendan los sentimientos de quienes piensen de manera diferente.

\section{B. Los fines de la educación como condiciones de base de la Constitución del pluralismo}

Los fines de la educación se constituyen en condiciones de base de la Constitución del pluralismo y de la libertad. La Constitución de la libertad depende de que se pongan al descubierto los contenidos de la educación, 
Este libro forma parte del acervo de la Biblioteca Juridica Virtual del Instituto de Investigaciones Juridicas de la UNAM

ya que la apertura de la sociedad y la Constitución solamente pueden sostenerse frente al trasfondo de sustancias educativas y culturales. Ambos se condicionan mutuamente, del mismo modo como la libertad y la obligación se corresponden. Las democracias en libertad requieren de un "soporte" interno material, a través de fines educativos fundamentales, que se orientan por los derechos humanos, la tolerancia, la solidaridad, la responsabilidad, la humanidad, el trabajo, etcétera. Éstos permanecen precarios, "formales" y, por tanto, están amenazados, si solamente se ven constituidos jurídicamente en sentido tradicional, y si no provocan, en la práctica pedagógica, la profundidad y amplitud de la "internalización en la libertad" de sus contenidos fundamentales, que prefiguran jurídicamente sus Constituciones, y no se viven de manera cotidiana en su trasfondo cultural.

En primer término, la Constitución debe educar para ella misma. La "voluntad de Constitución" (K. Hesse) exige contribuciones educativas en la escuela, por ejemplo, comprensión de la Constitución, conocimientos cívicos mínimos, criterios de valoración. Las "condiciones de base" para el pluralismo deben ser transmitidas a cada nueva generación.

Con ello no se espera de todos los ciudadanos la "fidelidad constitucional", en el sentido de una religion civile, pues transferir a todos las exigencias que se imponen a los servidores públicos sería contrario al sistema. La sociedad abierta de los intérpretes constitucionales libres, que también es la sociedad abierta de los constituyentes, se cerraría; el pensamiento de las posibilidades como razonamiento alternativo pluralista se convertiría en vía de un solo sentido y en callejón sin salida; el ciudadano perdería su libertad.

La Constitución del pluralismo trae consigo los límites mismos del mandato educativo del Estado. Sus fines educativos están limitados tanto en su contenido como en los medios para su realización, pues las dictaduras educativas que se presumen en posesión de la verdad absoluta son contrarias a la Constitución. Incluso un fin educativo básico, como el de la tolerancia, normado en los "artículos sobre la tolerancia" de las Constituciones de los Länder, tiene sus límites, como los que se derivan de los "artículos del pluralismo";337 la Constitución debe (poder) ser autocrítica respecto de sus propios fines educativos.

337 Por último, el artículo 2o. de la Constitución de Angola (1992), el artículo 1o. de la Constitución de Guinea Ecuatorial (1991), los preámbulos de las Constituciones de Benín (1990) y Chad (1996), así como el artículo 15 de la Constitución de Ucrania (1996). 
Este libro forma parte del acervo de la Biblioteca Juridica Virtual del Instituto de Investigaciones Juridicas de la UNAM

\section{Los fines de la educación como medios para una "pedagogía constitucional"}

El mandato constitucional de la LF exige no tanto la transmisión de conocimientos jurídicos teóricos, pues esto es cosa del "gremio" de los juristas. Se trata más bien de comunicar a la Constitución como marco y afirmación de los ideales de la educación: la Constitución es texto escolar y docente. Su realidad comienza en los salones de clase: jla escuela de la Constitución es la escuela! Lo que ésta logre beneficia a la cultura constitucional.

Esta vía pedagógica hacia la LF como Constitución vivida no puede ser sobreestimada en su relevancia jurídica mediata y su eficacia a largo plazo. La escuela y la universidad, las escuelas profesionales y la enseñanza para los adultos, forman a los intérpretes constitucionales en sentido amplio, pues en la medida en que éstos adquieran conciencia de sí, pueden convertirse en intérpretes constitucionales activos. La relación entre los planes de estudio y la Constitución se hace lo más estrecha posible; en sentido amplio se trata de "clases de Constitución".

Los "principios constitucionales como fines de la educación", esto es menos una obligación jurídica que un mandato educativo: la Constitución como ética social ("pedagogía constitucional"). La Constitución debe ser desentrañada en su significado para los pedagogos y sus tareas, lo cual también beneficia a los juristas. Esta concepción "pedagógica" de la Constitución es una consecuencia de la teoría de los intérpretes constitucionales en sentido amplio: una característica de la sociedad abierta y de sus fundamentos de ética social. La Constitución no es sólo un ordenamiento jurídico para los juristas (y los políticos), sino que en lo esencial es también una "guía” para los no juristas, los ciudadanos.

\section{La educación de la juventud: un mandato de la "Constitución como contrato"}

La educación de la juventud es un mandato constitucional, el cual se lleva a cabo mediante la división del trabajo entre los padres, el Estado y la escuela, así como otros sujetos de la educación en forma optativa (como las iglesias) y también es ejercido de manera diversa en cuanto a sus objetivos sustantivos. La Constitución no puede sustraerse a estas funciones diferenciadas de la educación para los niños hasta la enseñanza de los adultos, sino que los norma en favor de su propia permanencia. Se garantiza a sí misma como comunidad libre en la sucesión de las generaciones, de la "Constitución como contrato", a través de sus fines educativos, en llamados a 
Este libro forma parte del acervo de la Biblioteca Juridica Virtual del Instituto de Investigaciones Juridicas de la UNAM

la juventud como nuevo socio contractual. Los objetivos como la tolerancia, la democracia, la dignidad humana, la reconciliación de los pueblos o el "espíritu de la democracia", son directivas abiertas para un proceso en el que siempre debe ser posible un entendimiento mutuo y siempre renovado entre las generaciones: ¡la educación no es una calle de sentido único! Sólo de este modo es posible amortiguar el cambio general de los valores. Los fines de la educación son de cierto modo "objetivos contractuales", con vistas al contrato de las generaciones entre jóvenes y viejos. El educador debe comprender que una generación joven tiene que buscar primero su propio futuro, y tiene que hacer plausible que este futuro se encuentra también en el patrimonio cultural del pasado, encarnado en los correspondientes fines educativos. $\mathrm{Al}$ mismo tiempo, los fines educativos son en mucho un proyecto anticipado del ser humano, que habrá de vivir y configurar la Constitución en el porvenir. Así vista, la Constitución se reencuentra en los fines educativos. ¡Su presente se encuentra con su futuro en forma pedagógica!

\section{Valores orientadores}

Los valores orientadores son, por ejemplo, concepciones morales, los programas de los partidos políticos o de los sindicatos, los estatutos de una asociación, los modelos familiares y otros modelos y ejemplos sociales (por ejemplo, los textos clásicos de un F. Schiller o B. Brecht, J. Locke o Montesquieu, las concepciones de sí mismas y las memorias de las iglesias y las comunidades religiosas). Éstas son realizadas, desarrolladas pero también incumplidas, en el Estado constitucional por el ciudadano capaz. Así tendría pleno sentido en la LF alemana (preámbulo), como se propone ocasionalmente, el valor orientador de la "solidaridad y el sentido de comunidad". El fracaso de la reforma constitucional plantea de manera tanto más urgente la cuestión: "¿qué tanto sentido de comunidad requiere la sociedad liberal”? (A. Hirschmann).

Los fines educativos y los valores orientadores se distinguen entre sí, pero también se encuentran en interrelación que genera cambios. Muchos valores orientadores no se encuentran formulados en los textos jurídicos, ni siquiera en calidad de esbozo. Lo son parcialmente en los fines educativos y por ello su fuerza y validez son sólo limitadas. En cambio, los fines educativos esenciales se encuentran al menos formulados como principios en los textos constitucionales y otros textos jurídicos culturales. Su fijación jurídica es necesaria, aunque sea solamente "como" soft law del derecho constitucional de la cultura, ya que habrán de ser transmitidos mediante la educación 
Este libro forma parte del acervo de la Biblioteca Juridica Virtual del Instituto de Investigaciones Juridicas de la UNAM

al ciudadano adolescente en el estatus especial de la "escuela". Los valores orientadores son "pluralistas", incluso antagonistas; se contradicen, compiten entre sí, en parte son excluyentes. Entre ellos puede escoger libremente el ciudadano adulto; pueden hacerse jurídicamente obligatorios de manera muy limitada, su realización apenas puede ser forzada por el Estado. Otra cosa sucede con los fines educativos, pues caracterizan obligatoriamente a la enseñanza que imparte el Estado en las escuelas. Aquí el pluralismo es un "objetivo de aprendizaje", vía la tolerancia. Aquí se trasmiten los valores y los textos de la época clásica y de la moderna, se exponen los derechos y los deberes, se enseña la dignidad humana y la tolerancia, la libertad y la igualdad. Esta diferencia (más bien formal) en el grado de su obligatoriedad jurídica corresponde a una diferencia de contenido: los fines educativos se incorporan en última instancia en un todo equilibrado: la dignidad humana y la tolerancia se corresponden, así como la honestidad, la legalidad y la responsabilidad, la educación para el acceso o la participación en los bienes de la cultura, así como la protección del ambiente, por un lado, la apertura al mundo, la "paz en la coexistencia de las culturas y los pueblos"(artículo 22, inciso 1, de la Constitución de Turingia), por el otro ( $c f r$. ya el artículo 26 de la Constitución de Bremen), aunque haya algunas tensiones en lo individual. Los valores orientadores son muy diferentes: lo que se "ofrece" en la sociedad abierta se excluye entre sí de muchas maneras, y en todo caso no se encuentra en una relación tendencialmente equilibrada. Los partidos políticos buscan atraer al ciudadano capaz a través de programas encontrados, las iglesias y las comunidades ideológicas se excluyen mutuamente, las "tablas de valores" de muchos grupos plurales viven precisamente del conflicto entre ellos. Por lo demás, los valores orientadores trasmiten aquello que se ha formado en la evolución cultural, religiones, sistemas de la moral, patrimonio cultural, etcétera.

\section{LA DEMOGRACIA COMO CONSECUENCIA ORGANIZATIVA DE LA DIGNIDAD HUMANA}

\section{Variantes de la democracia}

En el Estado constitucional, el principio organizativo fundamental es la división de poderes, el cual se deriva directamente, en la actual etapa evolutiva del Estado constitucional, de la garantía de la dignidad humana. Se trata de una premisa antropológico-cultural, cuya consecuencia organizativa es la 
Este libro forma parte del acervo de la Biblioteca Juridica Virtual del Instituto de Investigaciones Juridicas de la UNAM

democracia. Sin embargo, no resulta evidente esta vinculación interna entre democracia y dignidad humana, ni entre aquélla y los derechos humanos que derivan de ésta. En Alemania se acostumbra hacer una distinción entre la garantía "no política" de la dignidad humana y la democracia política. En realidad, el núcleo del ser humano como ciudadano se ve afectado si no tiene la posibilidad de ejercer en la práctica su derecho al voto o de utilizar efectivamente su libertad de opinión y de manifestación también para fines políticos ("democracia de los ciudadanos").

Hoy se considera a la "democracia" casi en todo el mundo como quintaesencia de un "buen" ordenamiento estatal, con lo cual se olvida frecuentemente que se requiere una caracterización más próxima: como democracia "con división de poderes", "vinculada a valores", "en libertad", "pluralista". Con ello se desechan todas las formas de democracia "totalitaria", como las llamadas "democracias populares" en los regímenes socialistas, como el vigente en Alemania oriental hasta 1989. Al mismo tiempo en ello se manifiesta que existen numerosas variantes de la democracia entre las diversas naciones, que existen igualmente ante el foro del Estado constitucional como tipo. La concepción de la democracia también cambia en el curso de la historia (constitucional), así como en el espacio y el tiempo. La democracia del Estado constitucional requiere constantemente de reformas, por ejemplo, a través del mejoramiento de la protección de minorías, mediante el fortalecimiento de los derechos de la oposición en la democracia parlamentaria, a través del impedimento de que un poder económico muy grande se transforme en poder político, o mediante la limitación del financiamiento público a los partidos, así como a través del desarrollo de competencias de control de la jurisdicción constitucional.

Estas variantes de la democracia se reflejan en la distinción entre democracia presidencial y parlamentaria (como entre los EUA y Francia, por un lado, y Gran Bretaña y Alemania, por el otro), o en la diferencia entre democracia representativa (indirecta) y directa (plebiscito, referéndum, iniciativa popular) y sus formas mixtas. Así, la Ley Fundamental alemana de 1949 se decidió por principio en favor de la democracia representativa, apartándose conscientemente de las formas de democracia directa ("plebiscitaria") de la Constitución de Weimar de 1919. El pueblo alemán ni siquiera participó, vía referéndum, en la expedición de la LF, así como tampoco en el marco de la reunificación en 1990. Esta "exclusión del pueblo" se encuentra en notorio contraste con los elementos de democracia directa en varias de las Constituciones de los Länder alemanes después de 1945 (por ejemplo, la Constitución de Hesse de 1946 en su artículo 124); también resulta difícilmente comprensible en vista del lema victorioso de la revolución pacífica 
Este libro forma parte del acervo de la Biblioteca Juridica Virtual del Instituto de Investigaciones Juridicas de la UNAM

de octubre de 1989 en el ocaso de la "RDA": "nosotros somos el pueblo". Consecuentemente, todas las Constituciones de los nuevos Länder han incorporado elementos de democracia directa (por ejemplo, los artículos 76 a 78 de la Constitución de Brandemburgo de 1992; los artículos 71 a 73 de la Constitución de Sajonia de 1992). Suiza puede enorgullecerse de practicar una democracia "semi-directa" tanto a nivel federal como cantonal, la cual mantiene a raya algunas de las manifestaciones negativas de la "democracia de partidos". También otros Estados constitucionales, como los EUA, conocen, por ejemplo en California, formas mixtas afortunadas de las ya clásicas variantes de la democracia.

Textos de los clásicos sobre la democracia hay muchos, pero la frase de mayor "impacto" ha sido de Rousseau: "Todo el poder del Estado dimana del pueblo", la cual se encuentra tanto en Constituciones antiguas como recientes (por ejemplo, el artículo 20, inciso 2, de la LF de 1949; el capítulo $1 \S 1$ de la Constitución de Suecia de 1975; el artículo 3o., inciso 1, de la Constitución francesa de 1958; los artículos 1o. a 3o. de la Constitución de Portugal de 1976; el artículo 6o., inciso 1, de la Constitución de Ruanda de 1991-1996). El poeta B. Brecht sigue preguntando irónicamente: "pero ¿hacia dónde va?", lo que equivale sobre todo a una invitación a los juristas para preguntarse constantemente por las zonas de peligro del poder fundado democráticamente. También la frase de D. Sternberger - "no todo el poder del Estado dimana del pueblo"- puede recordarnos los límites de la democracia. Por último, siempre hay que agregar a la respectiva configuración jurídica positiva de la "democracia"en un Estado constitucional concreto un pedazo del pensamiento de Montesquieu, es decir, su imagen escéptica pero "realista" del ser humano, la cual lo llevó a la idea de la división de poderes. Dicho en otras palabras: la soberanía popular "pura" ha sido sustituida en el Estado constitucional de la actualidad por la competencia, jurídicamente definida, del pueblo.

En lo que sigue se ilustrará, mediante ejemplos, la pluralidad de posibles enunciados sobre la democracia concretizados en los textos constitucionales; después se expondrán los elementos de la democracia en libertad, también llamada "burguesa", tal como han sido desarrollados por la doctrina y la jurisprudencia de muchas naciones. Muchos de ellos resuenan cuando hoy día se invoca, en casi todo el mundo, la idea del Estado "ideal" bajo los términos clave de los "derechos humanos y la democracia".

Las siguientes Constituciones, antiguas y recientes, pero también los textos sobre derechos humanos (como la Convención Europea) pretenden captar en sus textos la democracia, o pueden caracterizarse como "artículos sobre la democracia": 
Este libro forma parte del acervo de la Biblioteca Juridica Virtual del Instituto de Investigaciones Juridicas de la UNAM http://www.juridicas.unam.mx

- Las cláusulas sobre la forma de Estado (por ejemplo, artículo 1o. de la Constitución de Austria de 1920; el artículo 2o. de la Constitución de Angola de 1992).

- En el contexto de los derechos fundamentales (por ejemplo, el artículo 21 de la Constitución de Brandemburgo de 1992; el artículo 6o. de la Constitución de la República de Sao Tomé y Príncipe, de 1990).

- Los artículos sobre los partidos (por ejemplo, el artículo 21 de la LF, el artículo 4o. de la Constitución de Francia).

- Los fines de la educación (por ejemplo, el artículo 131 de la Constitución de Baviera de 1946).

- Los artículos sobre la oposición (por ejemplo, el artículo 23a, inciso 1, de la Constitución de Hamburgo de 1952-1972).338

- Otras formas (por ejemplo, el capítulo 1 § 2, inciso 3, de la Constitución de Suecia de 1975, el artículo 14 de la Constitución de Guinea de 1991).

Permítansele al autor alemán también algunas destacadas descripciones tomadas de la jurisprudencia del TCFA. En el procedimiento para la prohibición del partido SRP,339 el TCFA desarrolló (E 2, 1) los principios de mayoría, de la soberanía popular y de la pluralidad de los partidos y de la oposición como elementos del orden fundamental de libertad y democracia en el sentido del artículo 21, inciso 2, de la LF, relativo a los partidos y, por tanto,

338 "La oposición es parte integrante esencial de la democracia política”. El trabajo preparatorio para el "artículo de la oposición" en la Constitución de Hamburgo (artículo 23a) lo realizaron varios, sobre todo la jurisprudencia constitucional ( $c f r$. BVerfGE 2, 1 (13): "Derecho, conforme a la Constitución, de crear y ejercer la oposición”; E 5, 85 (199): "Crítica de la minoría opositora") y la doctrina del derecho del Estado (de la bibliografía: Schneider, H.-P., Die parlamentarische Opposition im Verfassungsrecht der Bundesrepublik Deutschland, vol. I, 1974; Haberland, S., Die verfassungsrechtliche Stellung der Opposition nach dem Grundgesetz, 1995). Quizá la constitucionalización más temprana de la oposición en el plano textual se encuentre (respecto de los partidos) en el artículo 120, inciso 3, frase 1, de la Constitución de Baden de 1947: "Cuando se encuentren (sc. los partidos) en oposición al gobierno, tendrán la obligación de dar seguimiento a la actividad del gobierno y de los partidos que en él participen, y en caso necesario, de ejercer la crítica". En el Estado constitucional, como tipo, y en la República Federal de Alemania, la oposición es ciertamente parte del derecho constitucional material, independientemente del documento constitucional formal. Pero ha llegado a serlo gracias a la colaboración de muchos elementos: desde la "adelantada" Constitución local (Baden), pasando por la jurisprudencia y la doctrina, hasta llegar al poder revisor de la Constitución que va "detrás”(Hamburgo: artículo 23a). Cfr. por último el artículo 26 de la Constitución de Mecklemburgo-Antepomerania.

339 Partido de tendencia neonazi (N. del T.). 
Este libro forma parte del acervo de la Biblioteca Juridica Virtual del Instituto de Investigaciones Juridicas de la UNAM

como "valores fundamentales supremos del Estado constitucional y democrático" (E, 2, 1 (12)). Para su realización se requieren también principios democráticos en el orden interno de los partidos (ibidem, p. 14). En la sentencia sobre el Partido Comunista Alemán declara el TCFA que el consenso fundamental de todos los partidos en relación con estos principios es un presupuesto del "tipo de democracia" establecido en la LF (E 5, 85 (141)).

Con vistas al desarrollo del procedimiento electoral (artículo 38, inciso 3, de la LF), el TCFA le reconoce al legislador un margen de desarrollo amplio, aunque cuestionado en lo particular (BVerfGE 95, 335 (349 por un lado, 367 y ss., por el otro). El sufragio, y la cláusula del umbral del 5\%, no están sujetos a parámetros estáticos, sino que tienen que adaptarse siempre a las condiciones políticas concretas (BVerfGE 6, 84 (89 y ss.), por un lado, y E 82, 322 (337 y ss.) por el otro).

En la dogmática del derecho constitucional puede contarse con los siguientes elementos como "lineamientos" del orden democrático del Estado constitucional: 340

A) El pluralismo significa diversidad de intereses e ideas. Se trata de un "dato" en el Estado constitucional, es decir, existe previamente, su historia constitucional la ha generado, pero también le plantea tareas, por ejemplo, para fines del éxito de las "leyes del pluralismo"(como las leyes sobre fusión de medios impresos o las leyes sobre cárteles) o la preocupación por las estructuras pluralistas en los medios de masas como la radio y la televisión ("pluralismo interno y externo"; cfr. BVerfGE 57, 295 (325 y s.). La filosofia del pluralismo es la concepción de la "sociedad abierta" (la filosofía del "espíritu abierto"), en oposición a la sociedad cerrada, que esbozó Sir Karl Popper en su crítica a Marx, Hegel y Platón. ${ }^{341}$ De manera congenial también adoptan estas ideas algunas Constituciones recientes (por ejemplo, la anterior Constitución peruana de 1979), y la misma idea se encuentra después de 1989 bajo la forma de cláusulas contra las ideologías de Estado en las Constituciones de Europa oriental, como la de Ucrania (artículo 15, incisos 1 y 2) o Rusia (artículo 13). Una forma de expresión del pluralismo es también la tolerancia como principio constitucional y como fin de la educación (por ejemplo, el artículo 131 de la Constitución de Baviera). Ciertamente hay límites para el pluralismo en el Estado constitucional (los cuales residen en sus valores fundamentales irrenunciables), pero en principio constituye su elíxir de la vida. El Estado constitucional desarrolla sus propias fuerzas

340 Sobre lo que sigue, en relación con la LF alemana: Hesse, K., Grundzüge, cit., pp. 63 y ss.; véase también Badura, P., Staatsrecht, 2a. ed., 1996, pp. 230 y ss.

341 Popper, K. R., La sociedad abierta y sus enemigos. 
Este libro forma parte del acervo de la Biblioteca Juridica Virtual del Instituto de Investigaciones Juridicas de la UNAM

a partir del paralelograma de las fuerzas que resulta de numerosas ideas e intereses. La consecuencia es una "teoría pluralista del bien común", así como el reconocimiento de los grupos de interés y las asociaciones, religiones, iglesias y partidos pluralistas.

La idea del pluralismo nos recuerda que el Estado constitucional no es una "asociación de dominación" que flota por "encima" de los ciudadanos, sino que se constituye una y otra vez a partir de los ciudadanos y los grupos, y que se encuentra a su servicio. La Constitución escrita y no escrita es a tal efecto un "ordenamiento marco", con aspectos "inductores" y limitantes, como ya se ha demostrado. La diversidad de ideas e intereses en lugar de la unidad "por decreto" es lo que hace al Estado constitucional superior frente a todas las formas de dominio totalitario, como ha quedado nuevamente de manifiesto en 1989. El pluralismo es expresión y condición de la libertad tanto individual como colectiva de los ciudadanos y los seres humanos.

B) El principio de mayoría se encuentra en una tensa relación con la protección de las minorías. Algunas Constituciones prevén expresamente el principio de mayoría (como el artículo 121 de la LF), pero al mismo tiempo regulan múltiples formas de protección a las minorías (por ejemplo, bajo la forma de derechos de petición de la oposición parlamentaria para la instalación de una comisión investigadora, según el artículo 44 de la LF, o mediante el acceso al TCFA, conforme al artículo 93, inciso 1, subinciso 2 de la LF). El arma contundente del principio de mayoría es, en general, "tolerable", porque existe una protección (escalonada) de las minorías (primordialmente a través de la "supremacía de la Constitución" y la protección de los derechos fundamentales). La justificación interna de la democracia como "gobierno de la mayoría" ${ }_{342}$ es difícil: se puede lograr gracias a la idea de la libertad y la igualdad y de la necesidad de llegar a una decisión funcional. El principio de mayoría siempre ha encontrado sus ("contra") clásicos, por ejemplo, en la frase de F. Schiller: "la mayoría de los votos no es la prueba del derecho...", Demetrius). En el Estado constitucional de hoy llama la atención el inteligente escalonamiento de las mayorías: por ejemplo, mayorías de dos tercios o mayorías todavía más amplias para las reformas constitucionales; un cuarto de la mayoría para las comisiones de investigación, etcétera. Tan cierto como es que el arte del proceso político cotidiano radica en encontrar y configurar mayorías en la publicidad del parlamento, igualmente evidente resulta también recordar una y otra vez los límites constitucionales del prin-

342 Véase al respecto Scheuner, U., Das Mehrheitsprinzip in der Demokratie, 1973; Häberle, P., "Das Mehrheitsprinzip als Strukturelement der freiheitlich-demokratischen Grundordnung", en id., Verfassung als öffentlicher Prozess, 3a. ed., 1998, pp. 565 y ss. 
Este libro forma parte del acervo de la Biblioteca Juridica Virtual del Instituto de Investigaciones Juridicas de la UNAM

cipio de mayoría. Estos límites se encuentran, por ejemplo, bajo la forma de "cláusulas de eternidad", en las garantías de identidad del Estado constitucional. ${ }^{433}$ Por lo demás, debe existir la posibilidad de relaciones de mayoría diversas y cambiantes, de modo que los perdedores en una decisión tengan la oportunidad igual y real de ganar la mayoría en una oportunidad futura. ${ }^{344}$ La interacción entre mayoría y minoría presupone un consenso fundamental que permite a la parte perdedora ad hoc reconocer el voto de la mayoría. La posibilidad del voto particular en algunos tribunales constitucionales (Estados Unidos, Alemania, España) es la forma más sutil de la protección de la minoría, detrás de la cual se hace visible un pedazo de "publicidad de la Constitución", pues el voto particular de hoy puede ser el voto mayoritario de mañana (así en los casos de BVerfGE 32, 129 (141 y ss.) "casos austriacos" y E 53, 257 (289 y ss.), "compensación alimentaria en «matrimonios antiguos»").

En el Estado constitucional es preciso recordar siempre los límites de la democracia. A pesar de que es indispensable la disposición del ciudadano a participar "activamente" como tal, también es legítima la posición del ciudadano no político en el sentido del "sin mí", del ciudadano que, por ejemplo, no acude a votar (por ello resulta cuestionable la obligatoriedad del sufragio en algunos países, como Bélgica). El "comportamiento no político" está garantizado constitucionalmente de varias maneras: a través del status negativus fundamental del ciudadano y los grupos, a través de la protección de la vida privada, el cual limita dialécticamente el principio democrático de la publicidad, y por el simple conocimiento de la naturaleza del ser humano, el que no vive nada más de la democracia y que también quiere que lo "dejen en paz". En el Estado constitucional la democracia no es la única forma de vida del ser humano.

La necesidad de los límites de la democracia puede ilustrarse mediante ejemplos negativos: el lema del movimiento del 68 sobre la "democratización" de todos los ámbitos vitales, incluso la economía, ha llevado a manifestaciones totalitarias; por ejemplo, en Alemania se propagó la "codeterminación" del personal no científico en la docencia y la investigación (véase, por el contrario, los límites marcados por el TCFA en E 35, 79). También la irrenunciable autonomía del arte (hasta llegar a la "anarquía" de muchos artistas) se pierde cuando sus ámbitos vitales son "democratizados" o son hechos públicos. La votación democrática prácticamente no es secreta en los Estados

343 Al respecto véase Häberle, P., Verfassungslehre als Kulturwissenschaft, 2a. ed., 1998, pp. 267 y ss.

344 Así Hesse, K., Grundzüge, cit., p. 64. 
Este libro forma parte del acervo de la Biblioteca Juridica Virtual del Instituto de Investigaciones Juridicas de la UNAM

totalitarios. Los niveles de participación electoral del 99\% despiertan dudas sobre la libertad de un régimen político. Por lo demás, algunos Estados constitucionales establecen límites jurídicos positivos a la democracia, por ejemplo, al institucionalizar la prohibición de los partidos políticos contrarios a la Constitución (artículo 21, inciso 2, de la LF) y cuando recuerdan, mediante el concepto de la democracia "sujeta a valores", "dispuesta a la defensa", los valores fundamentales previos al Estado que también obligan al pueblo activo políticamente (como los derechos humanos).

\section{Reflexiones de teoría democrática como legitimación}

En el Estado constitucional democrático es preciso plantear de manera especial la cuestión de la legitimación conforme a criterios democráticos (esto es, de la teoría democrática). La ciencia del derecho constitucional, las llamadas ciencias de la realidad que son sus "proveedores", los ciudadanos y los grupos, no tienen una legitimación democrática, entendida en sentido tradicional, para la interpretación constitucional. Pero precisamente la democracia no se desenvuelve sólo a través de la relación de delegación y responsabilidad formalizada, canalizada y constituida en sentido estricto, del pueblo hacia los órganos del Estado (legitimación a través de las elecciones), 345 hasta llegar al intérprete constitucional "competente" en última instancia, el TCFA. En una comunidad abierta se desenvuelve también a través de las formas mediatizadas "más finas" del proceso público pluralista de la política y la práctica cotidianas, especialmente mediante la realización de los derechos fundamentales, la que se aborda frecuentemente en la "faceta democrática" de tales derechos: a través de las controversias sobre las alternativas, las posibilidades y necesidades de la realidad, y también mediante el "concierto" científico sobre cuestiones constitucionales, en el cual apenas hay "pausas" y "fermatas" y no hay directores ni debe haberlos.

El "pueblo" no es una magnitud unitaria que "emana" (solamente) el día de las elecciones, y que como tal otorgue legitimación democrática. ${ }^{346}$ Como magnitud pluralista, el pueblo no se encuentra menos presente respecto de las interpretaciones en el proceso constitucional ni tampoco es me-

345 Cfr. también BVerfGE 33, 125 (158) (sentencia sobre los médicos especialistas), por último E 93, 37 (67 y ss.).

346 Sobre la relación entre democracia e independencia judicial, $c f r$. Eichenberger, K., Dierichterliche Unabhängigkeit als staatsrechtliches Problem, 1960, pp. 103 y ss. 
Este libro forma parte del acervo de la Biblioteca Juridica Virtual del Instituto de Investigaciones Juridicas de la UNAM

nos legitimador: "como" partido político, ${ }^{347}$ como opinión científica, como grupo de intereses, como ciudadano; isu competencia material para participar en la interpretación constitucional es un derecho ciudadano en el sentido del artículo 33 de la LF! Así vistos, los derechos fundamentales son una pieza de la base de la legitimación democrática para la interpretación constitucional que es abierta no sólo por sus resultados sino también por el círculo de sus participantes. ¡En la democracia en libertad el ciudadano es intérprete de la Constitución! Tanto más importantes se hacen las medidas para la garantía de la libertad real: política de derechos fundamentales prestacionales, ${ }^{348}$ libertad en la formación de la opinión, constitucionalización de la sociedad, por ejemplo, a través de la separación estructural de poderes en el ámbito público, y en particular en el económico.

No se trata de "destronar" al pueblo; pues lo sería solamente a partir de una concepción rousseauniana de la soberanía popular, en la cual el pueblo es absoluto y divino. El pueblo como magnitud constituida actúa "omnidireccionalmente", de manera universal, en numerosos planos, a partir de múltiples motivos y en muchas formas, e incluso a través de la realización cotidiana de los derechos fundamentales. No se olvide que el pueblo es ante todo una reunión de ciudadanos. La democracia es el "gobierno de los ciudadanos", no del pueblo en sentido rousseauniano. No hay vuelta hacia J.-J. Rousseau. La democracia ciudadana es más realista que la democracia popular.

La democracia ciudadana se encuentra próxima a un pensamiento que concibe a la democracia a partir de los derechos fundamentales, no de concepciones en las que el pueblo, como soberano, simplemente ha ocupado el lugar del monarca. ¡Esta perspectiva es consecuencia de la relativización del concepto, fácilmente malentendido, del pueblo a partir de los ciudadanos! La libertad fundamental (el pluralismo), no el "pueblo", se convierte en punto de referencia para la Constitución democrática. Esta capitis diminutio de la concepción criptomonárquica del pueblo se encuentra bajo el signo de la libertad ciudadana y del pluralismo.

Una vez que uno se ha liberado del pensamiento lineal y "eruptivo" de las concepciones tradicionales de democracia, se advierten numerosas formas de legitimación democrática, entendida en este sentido amplio. A

347 En este sentido hay coincidencia con la doctrina del Estado de partidos de Leibholz, G. (Strukturprobleme der modernen Demokratie, 3a. ed. 1967, especialmente pp. 78 y ss.): el pueblo adquiere capacidad de actuación y articulación solamente en determinadas formas de organización. Pero esto no autoriza la identificación entre pueblo y partidos (populares), pues la comunidad pluralista se encuentra mucho más diferenciada.

348 Véase al respecto Häberle, P., "Grundrechte im Leistungsstaat", VVDStRL, vol. 30, 1972, pp. 43 y ss. (69 y ss.). 
Este libro forma parte del acervo de la Biblioteca Juridica Virtual del Instituto de Investigaciones Juridicas de la UNAM http://www.juridicas.unam.mx

través del desarrollo interpretativo de la norma constitucional se llega hacia un pedazo de democracia ciudadana. ${ }^{349}$ La posibilidad y la realidad de la libre discusión de los individuos y los grupos "sobre" y "por debajo" de las normas constitucionales y su acción pluralista "en "ellos se introduce de manera múltiple en el proceso de la interpretación. (Hay que hacer notar expresamente que este proceso, realiter, también se ve amenazado con frecuencia desde dentro, y que nuestro orden fundamental de libertad y democracia muestra en realidad déficit respecto del tipo ideal.) La teoría de la democracia y la teoría de la interpretación se convierten en consecuencia de la teoría de la ciencia. La sociedad es libre y abierta en la medida en que se abra el círculo de los intérpretes de la Constitución en sentido amplio.

\section{LA DIVISIÓN DE PODERES EN SENTIDO ESTRICTO Y EN SENTIDO AMPLIO - CONSTITUCIÓN DE LOS ÓRGANOS Y DIVISIÓN DE FUNCIONES EN INTERÉS DE LA REALIZACIÓN DE TAREAS}

\section{La división de poderes en sentido amplio y en sentido estricto}

A) El principio de la división de poderes es tanto "texto clásico" desde Montesquieu (1748) como también principio constitutivo en la triada del Legislativo, el Ejecutivo y el Judicial, del tipo del "Estado constitucional", y viene a ser derecho constitucional positivo en todos los ejemplos y variantes nacionales. Entre los tres planos y formas de manifestación hay múltiples traslapes y fecundaciones mutuas. El derecho constitucional positivo de muchos países ha creado en la actualidad algunos órganos constitucionales nuevos (como el comisionado ciudadano o el ombudsman), el cual debe ser incorporado en el cuadro conjunto del equilibrio de poderes, del mismo modo que la jurisdicción constitucional, que se ha fortalecido, ha encontrado paulatinamente su "lugar correcto" en el cuadro conjunto de un Estado constitucional. El texto clásico inspirador sigue siendo la obra de Montesquieu

349 No es posible exponer aquí las particularidades de la concepción de democracia de Popper y el contexto que la justifica (!) a través de su teoría de la ciencia y el conocimiento (referencias a la democracia en: Die offene Gesellschaft und ihre Feinde, vol. I (1957), en especial pp. 25, 156 y ss., 170 y ss.; vol. II (1958), pp. 157, 159 y ss., 186 y ss., 293 y ss.; hay trad: $L a$ sociedad abierta y sus enemigos). Baste decir que el concepto de ciencia de Popper es fructífero para la teoría de la democracia y de que el concepto de democracia pluralista, basado en la división de poderes, la Constitución y la libertad ciudadana, que se sostiene en el texto puede remitirse a Popper en la medida en que éste desarrolla su teoría de la democracia, sin e incluso en contra, de los dogmas "clásicos" de la soberanía popular. 
Este libro forma parte del acervo de la Biblioteca Juridica Virtual del Instituto de Investigaciones Juridicas de la UNAM

De l'esprit des lois, en cuyo libro XI, capítulo 4, se lee: "La experiencia eterna enseña, sin embargo, que todo hombre que tiene poder se ve impulsado a abusar de él".

Esta imagen realista del ser humano en relación con el agudo peligro permanente de que los hombres abusen del poder no sólo en los cargos políticos o del Estado conduce actualmente a la lucha constitucional por una división óptima de los poderes, y el renovado retorno creador al "texto original" de Montesquieu (y de J. Locke) puede reconocer y combatir nuevas zonas de peligro del abuso de poder. Dicho en otras palabras: la división de poderes es un principio relativamente abierto, con constantes y variantes. Mientras que el peligro del abuso de poder permanece constante, porque el ser humano y el ciudadano al que se refiere el Estado constitucional siguen siendo quizá "el mismo" en todas las épocas y todos los espacios (en sus fortalezas y debilidades), varían las manifestaciones particulares de la división de poderes entre épocas y países. En este sentido hay que distinguir entre división de poderes en sentido estricto y en sentido amplio. La división de poderes en sentido estricto significa la división de los poderes estatales; en sentido amplio se refiere además a todo el ámbito social. Así, por ejemplo, en Alemania se habla de una "división de los poderes comunicativa" entre la prensa privada y la radio y la televisión públicas; por ejemplo, también hay que respetar un equilibrio de poderes entre las partes en las negociaciones colectivas laborales (sindicatos y asociaciones de empresarios). ${ }^{350}$ En el caso particular esto es tanto cuestión sobre todo de los tribunales constitucionales, pero también, en última instancia, del proceso social en su conjunto y del proceso político. Incluso en el derecho privado puede ser de utilidad la imagen del equilibrio, por ejemplo, entre las partes de un contrato; en especial hay que tomarla en cuenta en los contratos de arrendamiento ( $c f r$. BVerfGE 89, 1) y en las garantías de deudas civiles (cfr. BVerfGE 89, 214). El derecho de la competencia económica también está fundamentalmente al servicio de la idea del equilibrio de poderes en el mercado "abierto", y algún desequilibrio grave es eliminado, por ejemplo, por las cláusulas generales del derecho civil (prohibición de negocios jurídicos contrarios a las buenas costumbres o al principio de la buena fe). También debe pensarse en la relación de fuerzas entre los trabajadores y los empleadores dentro de la empresa, que de manera significativa se regula en la ley alemana de las empresas ("Betriebverfassungsgesetz").

En lo que sigue se desarrollará con más detalle la división de poderes en sentido estricto, es decir, la que se refiere al Estado. Hay que distinguir aquí

350 Cfr. Badura, P., Staatsrecht, 2a. ed., 1996, p. 268. 
Este libro forma parte del acervo de la Biblioteca Juridica Virtual del Instituto de Investigaciones Juridicas de la UNAM

entre la división "horizontal" de poderes y la "vertical". La división horizontal de poderes se refiere, de manera clásica, a los tres poderes: Legislativo, Ejecutivo y Judicial; referida a los órganos, alude al parlamento, el gobierno y la administración, y los tribunales ( $c f r$. el artículo 20, inciso 2, frase 2, de la LF). Debe hacerse notar que se ha multiplicado el número de poderes en el marco de los procesos sociales de crecimiento del Estado social. Así, en numerosos Estados constitucionales hay tribunales de cuentas ${ }^{351}$ (también el Banco Federal Alemán, ahora el Banco Central Europeo), que se aproximan a los tribunales en su estatus independiente ( $c f r$. el artículo 100, incisos 1 y 2 , de la Constitución de Italia); así se han desarrollado "ombudsman" o formas próximas como los comisionados para las fuerzas armadas (Wehrbeauftragte; artículo 45b de la LF), comisionados para la protección de datos personales (por ejemplo, el artículo 21b de la Constitución de Berlín de 1950/1994) o los “comisionados para los derechos de los niños"(artículo 72, inciso 4, de la Constitución de Polonia de 1997). El que en ocasiones se llame a la prensa el "cuarto poder" indica que la división de poderes en sentido estricto y en sentido amplio deben ser conceptuadas de manera conjunta. Dicho en otras palabras: el canon de los poderes y de las funciones que ejercen está abierto, como la historia evolutiva del Estado constitucional misma.

En el ámbito estatal debe distinguirse la división de poderes vertical respecto de la horizontal. En el Estado federal corresponde aquélla a la división de poderes entre la Federación y las entidades federativas. Desde la perspectiva alemana, dicha división garantiza adicionalmente (junto con los derechos fundamentales) la libertad política y justifica de manera especial al federalismo. Pero también los Estados constitucionales que "solamente" se han decidido en favor del regionalismo (desde Italia hasta España) o que se encuentran en vías de hacerlo (en Gran Bretaña, como "devolution" para Escocia y Gales, y desde 1998 también en Irlanda del Norte) aprovechan igualmente en lo fundamental la idea de la división vertical de los poderes; con mayor razón cuando se concibe al regionalismo como variante independiente del tipo del Estado constitucional, pero asimismo como "hermano menor" del federalismo.

B) Las variantes nacionales del "principio de la división de poderes" son grandes. La Constitución federal de los Estados Unidos de 1787 desarrolló el sistema de "checks and balances", el cual enfatiza la separación de los poderes, mientras que las democracias con sistemas de gobierno parlamentarios, en los cuales el gobierno depende de la confianza del Parlamento, conocen

351 Al respecto Schulze-Fielitz, H., "Kontrolle der Verwaltung durch Rechnungshöfe", VVDStRL, vol. 55, 1996, pp. 231 y ss. 
Este libro forma parte del acervo de la Biblioteca Juridica Virtual del Instituto de Investigaciones Juridicas de la UNAM

elementos de múltiples intersecciones entre el primero y el segundo poder (entrecruzamiento de los poderes). Claro está que en ellos la jurisdicción independiente se encuentra fuertemente separada y es autónoma, si bien también hay aquí influencias (por ejemplo, elección o nombramiento de los jueces, ya sea por el Parlamento o por los gobiernos). Como quiera que se encuentre constituida una democracia nacional con división de poderes, lo determinante es que quede garantizada la idea fundamental de la división de poderes, el impedimento al abuso de poder.

En este sentido hay que tomar en cuenta la regulación de las incompatibilidades ( $f f r$. los artículos 94, inciso 1, frase 3, 137, inciso 1, y 55, inciso 1, de la LF, así como el § 2 del Reglamento Interior del Consejo Federal)..352 Así, desde 1998 se empeña Francia en expedir una ley de incompatibilidades, la que, por ejemplo, impedirá la membresía en el Parlamento al mismo tiempo que se desempeña el cargo de alcalde. A la idea de la separación de poderes hay que agregar el equilibrio de poderes, del control y limitación mutuos. ${ }^{353}$

Visto desde el punto de vista histórico y comparativo, la acumulación de poderes ("concentración de poderes") es el temido modelo contrario: se ha practicado tanto en el marxismo-leninismo y su ideología del centralismo socialista ("legalidad socialista"), también en la "parcialidad del derecho", como en el nacionalsocialismo alemán ("principio del Führer", el "mandato secreto del Führer" como fuente suprema del derecho). También el gobierno del SED (Partido Socialista Unificado) en la República Democrática Alemana produjo perversiones aleccionadoras bajo la forma de la orden de disparar (secreta) junto al "muro" o la frontera alemana interna hasta 1989.

De modo que no es ningún accidente que los numerosos Estados reformados de Europa oriental hayan recurrido nuevamente a la división de poderes como principio constitutivo director después del "annus mirabilis" de 1989 (por ejemplo, el artículo 10, inciso 1, de la Constitución de Polonia de 1997: "El sistema de gobierno de la República de Polonia se fundará en la separación y el equilibrio entre los poderes Legislativo, Ejecutivo y Judicial").

También las Constituciones de ultramar reconocen la división de poderes y realizan así un pedazo de "Montesquieu" en su Constitución (por ejemplo, el preámbulo de la de Madagascar de 1992-1995). Montesquieu es en

352 Véase el respecto Hesse, K., Grundzüge..., cit., p. 212, número marginal 489; sobre lo último Tsatsos, D. Th., Die Unzulässigkeit der Kumulation von Bundestags- und Bundesratsmandat, 1965.

353 Hesse, K., op. cit., p. 207, número marginal 476. 
Este libro forma parte del acervo de la Biblioteca Juridica Virtual del Instituto de Investigaciones Juridicas de la UNAM http://www.juridicas.unam.mx

la actualidad un texto clásico universal de la única humanidad de nuestro "planeta azul la Tierra".

El Tribunal Constitucional Federal alemán ha desarrollado constantemente el principio de la división de poderes en una dogmática finamente cincelada y definida. El texto de la LF, incluido el artículo 20, inciso 2, frase 2 , no contiene un reconocimiento unívoco y expreso de la división o la separación de poderes, como tampoco del equilibrio de poderes, ${ }^{354}$ sino que únicamente está implícita la distribución de poderes, su articulación. ${ }^{355}$ Pero detrás de la parca formulación se encuentra el patrimonio intelectual suprapositivo de los clásicos Montesquieu y Locke. De acuerdo con la jurisprudencia del TFCA, la división de poderes es un principio de organización en que se sustenta la LF (E 3, 225 (247); jurisprudencia constante; por último 95, 1 (15)). Si queremos "interpretar" esto en la LF, también hay que tomar en cuenta que la LF "en ninguna parte ha realizado de manera pura", en su configuración particular, el principio de la división de poderes (BVerfGE 3, 225 (247); jurisprudencia constante; por último E 95, 1 (15)).

Este enfoque diferenciador ha llevado al TCFA a una jurisprudencia casuística específica para cada ámbito y cada caso, la cual se encuentra marcada, metódicamente hablando, por tres ideas. En primer lugar, el tribunal argumenta de modo teleológico, al referirse al fin de la división de poderes, a saber, "el control mutuo de los órganos del Estado y con ello la moderación del gobierno del Estado" (E 95, 1 (15); jurisprudencia constante, con mayores referencias). En segundo lugar, el TCFA propone reflexiones funcionales en el sentido de que "las decisiones estatales deben ser correctas en lo posible, es decir, ser adoptadas por los órganos que por su organización, composición, función y modo de proceder cuenten con las mejores condiciones" (E 68, 1 (86); por último E 95, 1 (15). En tercer término, el Tribunal recurre a la idea del "contenido esencial", el cual puede apoyarse dogmáticamente en el artículo 79, inciso 3, de la LF,356 al declarar como inmodificable un núcleo de cada poder y que protege las "funciones que típicamente" le confiere la LF (E 34, 52 (59); por último E 95, 1 (15)). Por ejemplo, esto no impide la planeación estatal a través de una ley federal, en todo caso cuando "existan buenas razones para tal efecto en el caso particular" (E 95, 1 (15)), es decir, razones para el "bien común" (idem). Por tanto, el TCFA considera a la división de poderes no sólo como un mecanismo protector negativo contra el abuso de poder, sino también, positivamente, como elemento constitutivo del

354 Ibidem, número marginal 477.

355 Schmidt-Aßmann, E., "Der Rechtsstaat", HdBStR I, 2a. ed., 1995, 24 RN 47, p. 1010.

356 Ibidem, número marginal 56, p. 1016. 
Este libro forma parte del acervo de la Biblioteca Juridica Virtual del Instituto de Investigaciones Juridicas de la UNAM

poder estatal, como elemento de optimización funcional y de "responsabilidad de los poderes". ${ }^{357}$

Las necesidades de otros países en relación con la división de poderes pueden ser distintas. Lo que importa es solamente que se impida de manera efectiva el abuso de poder. En conjunto, la división de poderes se muestra como pieza central de todo Estado constitucional. Se trata de una de las más felices "invenciones" de la historia del espíritu y la cultura y es equivalente a los diez mandamientos de la Biblia, junto con la dignidad humana y la democracia, los derechos humanos y el Estado social y ecológico de derecho, también el Estado de cultura, el federalismo y el regionalismo, la protección jurídica por tribunales independientes y la jurisdicción constitucional. Quizá podría hablarse incluso de un "derecho fundamental a la división de poderes", ya que en última instancia ésta se encuentra al servicio de los derechos humanos, de la protección de la "libertad del individuo" (BVerfGE 9, 268 (279)). El artículo 16 de la Declaración de los Derechos del Hombre y el Ciudadano, expedida por la Asamblea Nacional francesa en 1789, menciona conjuntamente dichos derechos con la división de poderes y señala que ambos elementos son sencillamente constitutivos: "Toda sociedad en la que la garantías de los derechos no esté asegurada, ni determinada la separación de los poderes, no tiene Constitución”. De este modo, la división de poderes pertenece a los elementos capitales del Estado constitucional moderno. ${ }^{358}$

\section{Constitución de los órganos y división de funciones en interés del cumplimiento de las tareas estatales}

La división de poderes en el Estado constitucional se refiere, en su sentido estricto, a determinados órganos del Estado, órganos constitucionales o instituciones, entre los cuales se distribuyen equilibradamente las funciones estatales en cuanto cometidos. En esta exposición podríamos comenzar con estos órganos, porque se encuentran articulados entre sí por la división de poderes. Sin embargo, en el Estado constitucional todos los "órganos" están constituidos por la Constitución y el principio transtemporal, el texto clásico que "divide" a todo Estado constituido, que equilibra y articula entre sí sus formas de manifestación, es precisamente la división de poderes de Montesquieu. La división de poderes es "de inicio constitución de poderes

357 Ibidem, número marginal 50, p. 1012.

358 Cfr. Badura, P., Staatsrecht, 2a. ed., 1996, p. 267. 
Este libro forma parte del acervo de la Biblioteca Juridica Virtual del Instituto de Investigaciones Juridicas de la UNAM

diversos" 359 y se encuentra - intelectualmente próxima a la doctrina clásica de la "Constitución mixta" - el "principio organizativo fundamental de la Constitución" (K. Hesse).

Las tres funciones clásicas de la legislación, la ejecución de las leyes y la jurisdicción, así como las tareas que se encuentran detrás de ellas, resultado de los derechos fundamentales, de los llamados objetivos del Estado y de las tareas del bien común, por un lado, y los órganos y las competencias, por el otro, deben ser concebidos conjuntamente e interrelacionados de entrada, aunque en la presente exposición tengan que ser examinados por separado.

En este caso también se trabaja comparativamente en el tiempo y el espacio, y ponemos atención a los textos constitucionales positivos y a su evolución por etapas. De conformidad con el programa de la teoría de la Constitución como "ciencia cultural" hay que agregar siempre los contextos culturales, la cultura política, aquello que la doctrina y la jurisprudencia han "hecho" de los textos, el cómo la viven en la práctica. Resulta evidente que esto sólo puede lograrse de forma muy fragmentaria y puntual, en vista del sinnúmero de Constituciones de todo el mundo que habría que analizar, e independientemente de que hoy ningún estudioso tiene ya el panorama de todos los textos y los contextos. Esto quizá lo podría sólo un Aristóteles o un Montesquieu de nuestros tiempos.

En lo que sigue se tratan primero las tres "típicas" funciones clásicas del Estado, después los órganos estatales típicos, a saber, el Parlamento (y, en su caso, también las segundas cámaras), el jefe de Estado (presidente o monarca), el Ejecutivo (es decir, el gobierno y la administración), así como los tribunales, en especial la jurisdicción constitucional; las instancias independientes relacionadas, como los tribunales de cuentas o los comisionados parlamentarios, sólo pueden ser "puntos" a tomar en cuenta.

En un apartado propio se tratarán los "fines del Estado", los cuales, en cuanto "bien común" o "tareas del Estado", tienen una denominación más bien abstracta, pero que en los diversos Estados nacionales se hacen concretos a través de los principios como el del "Estado social y ecológico de derecho", el "Estado de cultura" y también a través de los derechos del hombre y el ciudadano. Así como los órganos estatales o constitucionales adquieren su perfil a partir de las funciones, así también hay que entender a los "órganos" y sus funciones a partir del cumplimiento de ciertos objetivos de bien común o tareas del Estado.

Las tres típicas funciones del Estado están al servicio de ciertas tareas fijadas en las Constitución de manera sustantiva o procesal. Por su parte, son

359 Hesse, K., Grundzüge..., cit., p. 210. 
Este libro forma parte del acervo de la Biblioteca Juridica Virtual del Instituto de Investigaciones Juridicas de la UNAM

instrumentos del Estado constitucional sometidos al cambio histórico. A pesar de la diversidad nacional y de la multiplicación de tareas, la que ciertamente hoy se pretende reducir a través de la privatización, es posible distinguir, antes como ahora, tres funciones del Estado: legislación, ejecución de las leyes y jurisdicción.

La constitución de ciertos "órganos" así como el establecimiento de competencias se produce en el Estado constitucional en función de ciertas tareas delimitadas. La "primacía del derecho", la función de la Constitución como "orden jurídico fundamental" del Estado y la sociedad, se manifiesta en que los "órganos" del Estado solamente pueden actuar con un fundamento jurídico. Aquí también actúa la división de poderes como sistema de control en el sentido de checks and balances. Ningún órgano del Estado posee "plenos poderes en blanco" en el sentido de las doctrinas absolutistas tardías o postabsolutistas. La diversidad de modelos es amplia en la comparación temporal y espacial, por lo que la teoría constitucional solamente puede proceder aquí de manera tipificadora.

\section{A. El Parlamento}

En el Estado constitucional democrático se encuentra en primer lugar el Parlamento, ya que se trata del "principal órgano" legitimado democráticamente de manera directa. Inclusive en una democracia presidencial le corresponde una especial legitimación, ya que "representa" "360 la diversidad de un pueblo dividido pluralistamente y en cierto modo es un "espejo", un foro amplio de la nación, inclusive con un sistema electoral "puro" de mayoría (merecen preferencia los sistemas electorales "mixtos", con elementos de elección por mayoría y de representación proporcional, como en Alemania y también Italia, debido a su amplia "representatividad")..361 Que el Parlamento como órgano y la legislación como función estatal no se corresponden plenamente, lo demuestra la distinción entre ley formal y ley material, conforme a la cual no todas las normas generales abstractas que son expedidas por el Parlamento y no todas las leyes parlamentarias son normas jurídicas. 362

360 Sobre la representación $c f r$. Hofmann, H., Repräsentation, 3a. ed., 1998.

361 De la literatura, Stern, K., Staatsrecht I, 2a. ed., 1984, p. 301.

362 Hesse, K., Grundzüge..., cit., p. 216. 
Este libro forma parte del acervo de la Biblioteca Juridica Virtual del Instituto de Investigaciones Juridicas de la UNAM

Sigue siendo clásica hasta nuestros días la distinción de W. Bagehot. ${ }^{363}$ Las tareas del Parlamento residen en su función "electiva" ("elective"), "expresiva" ("expressive"), "educativa" ("teaching") e "informativa" ("informing"), así como en la "función legislativa" ("function of legislation"). Los diversos países toman muy diversas vías. Algunos poseen un verdadero sistema bicamaral (en los Estados Unidos Cámara de Representantes y Senado), lo cual está condicionado de manera primaria por el federalismo (véase también el Parlamento y el Consejo federales en Alemania). Pero hay también Estados centralistas que poseen un "Senado" (República Checa, Eslovenia, Polonia). En la medida en que avanza el regionalismo, se llega también a la representación de las regiones en cámaras propias, o por lo menos en parlamentos regionales. En la LF le corresponden al Parlamento Federal alemán (Bundestag) al menos las siguientes funciones: la competencia legislativa (artículo 77, inciso 1, LF), incluyendo la aprobación del presupuesto (artículo 110, inciso 2, frase 1, LF), así como los asuntos europeos (artículo 23, incisos 2 y 3, LF) y exteriores (artículos 52, inciso 2, 115 a, inciso 1, 115 1, LF), la dirección política a través de la elección del canciller (artículo 63 LF) y el control (por ejemplo, artículos 43, inciso 1, y 44 de la LF). Entre las demás funciones ${ }^{364}$ mencionamos aquí solamente la elección de la mitad de los miembros del TCFA (artículo 94, inciso 1, frase 2 LF). A las funciones típicas pueden agregarse, conforme a la jurisprudencia del TCFA, también en el caso particular, funciones atípicas, como la planeación legal (E 95, 1).

Aunque sin duda existen algunas manifestaciones de crisis en relación con los parlamentos, ${ }^{365}$ las que pueden resolverse paulatinamente sólo a través de "reformas parlamentarias"(por ejemplo, mediante la introducción de la facultad de autodisolución, de los derechos de minoría de la oposición frente al gobierno, de mejoramiento del régimen de las comisiones investigadoras, por ejemplo, mediante votos particulares públicos, etcétera), siguen siendo el sitio representativo de las controversias políticas abiertas, por las cuales tienen que responsabilizarse los partidos políticos. A partir del Parlamento precisamente se crea un pedazo de la "publicidad de la Constitución". Las elecciones parlamentarias son todavía hoy un proceso unificador esencial para un pueblo, sobre todo cuando la democracia, como en la LF alemana, existe como democracia indirecta, no directa (como en Suiza: "democracia semidirecta"). Precisamente se manifiesta aquí la intensiva relación entre deter-

363 Bagehot, W., The English Constitution. The World Classics, 1928, pp. 117 y ss.

$364 \mathrm{Al}$ respecto Hesse, K., op. cit., pp. 252 y ss.

$365 \mathrm{Al}$ respecto Schneider, H.-P. y Zeh, W. (eds.), Parlamentsrecht und Parlamentspraxis in der Bundesrepublik Deutschland, 1989. 
Este libro forma parte del acervo de la Biblioteca Juridica Virtual del Instituto de Investigaciones Juridicas de la UNAM

minados derechos fundamentales con la democracia, pues las libertades de información, opinión y prensa son la "base funcional de la democracia". El ciudadano que se informa sobre la labor del Parlamento para evaluarla crea un pedazo de publicidad parlamentaria. Aun cuando se incremente el peso de las funciones de gobierno y administración, incluso en la Unión Europea (Comisión en Bruselas), la opinión pública ${ }^{366}$ que se forma en los Parlamentos o sobre ellos resulta indispensable para un Estado constitucional, pues actúa como un elixir, del mismo modo como la opinión pública es el "oxígeno de la democracia" (G. Heinemann).

Unas palabras sobre las segundas cámaras, aun cuando (como en varias naciones) tengan solamente una posición débil (sobre todo, de tipo consultivo): en el sentido de la doctrina de la "Constitución mixta" pueden otorgarle a la democracia un elemento aristocrático; en todo caso, son un elemento de la división de poderes en el sentido apuntado. Lo que parece perderse en "eficiencia" se revela en conjunto como ganancia para la libertad ciudadana y la pluralidad política.

El derecho parlamentario, muchas veces regulado de manera formal sólo en los reglamentos internos, es, en sus principios, derecho constitucional material: ${ }^{67}$ así de fundamental e importante es para la res publica en conjunto. De él forman parte también la división interna en fracciones ("partidos en el parlamento") y las comisiones.

Precisamente aquí se muestra, empero, que los parlamentos no son "órganos del Estado" en el sentido estricto del término, o en todo caso, no lo son solamente, ya que penetran también en el ámbito social-público, representan el pluralismo de la sociedad abierta; su organización como un pedazo del Estado constituido es un efecto secundario. En un cierto modo son "el pueblo" como conjunto de los ciudadanos y grupos. También los representantes en lo individual, que poseen un estatus de libertad, igualdad y publicidad, ${ }^{368}$ están referidos al bienestar de todo el pueblo y sujetos solamente a su conciencia ( $c f r$. artículo 38, inciso 1, LF). Del mismo modo, en el Estado constitucional los partidos políticos no son "instituciones estatales", como en los Estados monopartidistas, sino "formaciones" sociales libres, a

366 De la literatura: Kloepfer, M., "Öffentliche Meinung, Massenmedien”, HdBStR, vol. II, 1987, pp. 171 y ss.

367 Achterberg, N., Parlamentsrecht, 1984, pp. 39; Pietzker, J., "Schichten des Parlamentsrechts", en Schneider, H.-P. y Zeh, W. (eds.), Parlamentsrecht und Parlamentspraxis in der Bundesrepublik Deutschland, 1989, pp. 333 y ss.; en la página 354 se habla de derecho constitucional secundario.

$368 \mathrm{Al}$ respecto Häberle, P., "Freiheit, Gleichheit und Öffentlichkeit des Abgeordnetenstatus", $\mathcal{N} 7 W, 1976$, pp. 537 y ss. 
Este libro forma parte del acervo de la Biblioteca Juridica Virtual del Instituto de Investigaciones Juridicas de la UNAM

pesar del poder que pretendan o puedan acumular, de que influyan en el Estado, es decir, la legislación y el gobierno, y de que posean estructuras imperativas, que solamente puedan distenderse parcialmente por la democracia interna ( $c f r$. artículo 21, inciso 1, frase 3, LF); quizá una ventaja de la democracia "semidirecta" en Suiza sea el crear un contrapeso contra la "arrogancia del poder" de los partidos políticos. El unilateral "repudio a los partidos", que con frecuencia se escucha en Alemania 369 - palabra clave: el "Estado como botín" de los partidos - reconoce la indispensable función positiva de los partidos políticos, tal como se manifiesta en el derecho alemán: artículo 21, inciso 1, frase $1, \mathrm{LF}$ (participación en la formación de la voluntad política del pueblo), $§ 1$ de la Ley de Partidos ("elemento constitucional necesario del orden fundamental de libertad y democracia"). Aunque los países se distingan por su estructura o cultura partidaria (grupos más bien laxos en los Estados Unidos, más bien orientados ideológicamente en Alemania), el Estado constitucional pone de manifiesto cuán indispensable es su actuación en numerosos artículos sobre los partidos de las Constituciones recientes (por ejemplo, el artículo 11 de la Constitución de Polonia, el artículo 19, inciso 1, de la Constitución de Sudáfrica, el artículo 4o. de la Constitución de Angola de 1992, el artículo 138 c del Tratado de Maastricht). Debe hacerse notar de manera autocrítica que siempre existe necesidad de hacer reformas (debido al "patronazgo de los cargos", la acumulación de cargos, las incompatibilidades, la reducción de su influencia en los cuerpos de la radio y la televisión).

Por lo demás, hay que apostar al contrapeso que se obtiene a través de otros grupos plurales, como los medios masivos de comunicación, las iglesias y las asociaciones. Su "competencia" crea aquella pluralidad del Estado constitucional que establece la comunidad de la libertad en conjunto. De manera aislada las nuevas Constituciones se ocupan novedosamente de esta diversidad. Así encontramos crecientemente frases sobre los medios de masas (Portugal, artículo 38; España, artículo 20; artículos 183 a 187 de la Constitución del Chad de 1996), sobre las asociaciones (por ejemplo, el artículo 40, inciso 1, de la Constitución de Portugal); las religiones y los cultos son tomados en cuenta en una rica diversidad de formas por las Constituciones nacionales ("derecho constitucional de la religión", véase, infra, XIII). Las asociaciones y personas jurídicas son garantizadas por el lado de los derechos fundamentales (el artículo 9o. de la LF), ${ }^{370}$ y protegidos en su capaci-

369 De la literatura: von Arnim, H. H., Der Staat als Beute, 1993; pero véase también Huber, P. M., Möble, W. y Stock, M. (eds.), Zur Lage der parlamentarischen Demokratie, 1995.

370 Véase al respecto BVerwGE (Sentencias del Tribunal Administrativo Federal) 1, 184. 
Este libro forma parte del acervo de la Biblioteca Juridica Virtual del Instituto de Investigaciones Juridicas de la UNAM

dad como titulares de tales derechos (artículo 19, inciso 3 de la LF de 1949; artículo 3o. de la Constitución peruana de 1979). Pero también han sido tomados en cuenta en otros contextos (por ejemplo $§ 29$ de la Ley Federal alemana de Protección a la Naturaleza). Por ello se puede hablar en el tipo del Estado constitucional de un "status corporatious" que corrige en algunos aspectos la orientación individualista unilateral de los catálogos clásicos de los derechos fundamentales. ${ }^{371}$ En cuanto "grupos de presión", que sin duda también lo son, las asociaciones no deberían ser evaluadas sólo de manera negativa, pues en una Constitución del pluralismo son tan indispensables para el ser humano en lo individual, que se comunitariza en lo "pequeño" como en lo grande. No es sino una consecuencia de esto que el derecho parlamentario trate de crear publicidad y transparencia entre otras medidas, mediante "listas de cabilderos" ${ }_{372}$ y similares (para exponer los contratos de asesoría de los representantes)..373

\section{B. Excurso: el jefe de Estado: presidente o monarca}

Una pieza esencial del Estado constituido, con funciones casi indispensables de integración y representación, es - en el Estado constitucional- el llamado "jefe de Estado". Mientras que en la historia constitucional destacaba frecuentemente por su plenitud de competencias absolutas, el Estado constitucional de la más reciente etapa de desarrollo textual ofrece una imagen distinta: los presidentes — y en las monarquías constitucionales de Europa, que son todas democracias, los monarcas - poseen competencias jurídicamente limitadas, aunque su alcance sea diverso: piénsese en la posición fuerte del presidente de los Estados Unidos, o en la débil posición de los monarcas escandinavos (Suecia, Noruega y Dinamarca). Se trata de un "cargo" en la estructura de las funciones estatales, cumple con determinadas tareas y constituye una pieza en la diversidad de la división de poderes del Estado constitucional.

Los textos constitucionales han inventado formulaciones muy diversas para caracterizar al presidente o monarca. (La Constitución de Japón, de

$371 \mathrm{Al}$ respecto Häberle, P., Verfassungslehre als Kulturwissenschaft, 2a. ed. 1998, p. 965.

372 Regulado en el anexo 2 del reglamento interior del Parlamento Federal; $c f r$. al respecto Steinberg, R., "Parlament und organisierte Interessen", en Schneider, H.-P. y Zeh, W., op. cit., pp. 217 ss., 256.

373 Regulado en los $\S \S$ 1, inciso 2, núms. 5, 6 del anexo 1 al Reglamento interior del Parlamento Federal. 
Este libro forma parte del acervo de la Biblioteca Juridica Virtual del Instituto de Investigaciones Juridicas de la UNAM

1946, habla del "tenno" como símbolo de Japón y de la "unidad del pueblo japonés".)

El artículo 5o. de la Constitución golista de 1958 dispone: "El Presidente de la República vela por el cumplimiento de la Constitución... Es el garante de la independencia nacional...", un ejemplo que se encuentra nuevamente en algunas Constituciones reformadas de Europa oriental que tienen estructura presidencial, también en África (por ejemplo, el artículo 58 de la Constitución de Togo de 1992). En Italia, el debate relativo a la reforma constitucional gira actualmente en torno a la posición del presidente (¿electo por el pueblo? semipresidencialismo). Alemania ha recorrido diversas variantes en su historia constitucional, pues mientras que la Constitución de Weimar instituyó al presidente del "Reich", electo directamente por el pueblo, casi como "heredero" del monarca constitucional de la Constitución bismarckiana de 1871, creando así un dualismo frente al Parlamento ("Reichstag"), en cambio resultan modestas las competencias del presidente federal actual, electo por un cuerpo parlamentario ("Asamblea Federal": artículo 54 de la LF), pues no tiene participación independiente en la "dirección suprema del Estado". ${ }^{374}$ (Nuevamente se demuestra hasta qué punto las Constituciones son "reacciones" a las Constituciones que las precedieron y hasta qué grado la teoría constitucional es una ciencia de la experiencia). Sin embargo, el presidente federal, en cuanto instancia "separada" de los partidos políticos y de sus actividades cotidianas, puede, sobre todo a través de la "palabra", del discurso, "promover" algunas cosas, también criticar e impulsar reformas. Si bien no se trata de un "pouvoir neutre" en el sentido de B. Constant, satisface la necesidad humana de contar temporalmente, en el Estado constitucional, con una instancia lo más independiente, junto con los tribunales.

$\mathrm{Al}$ diseñarse una nueva Constitución, sobre todo en el proceso de " $n a$ tion building" y "Constitution making", como en Sudáfrica, pero también en las nuevas Constituciones de Europa oriental, hay que poner atención a la vinculación entre procedimiento electoral y competencias del "jefe de Estado". Mientras más amplias sean las competencias del presidente, tanto más hay que pensar en una elección popular directa ( $c f r$., por ejemplo, el artículo 59 de la Constitución de Togo, el artículo 61 de la Constitución del Chad de 1996). Si bien esto no es forzoso ( $c f r$. la Constitución de la República Eslovaca), un presidente puede ejercer mejores competencias - más ampliascuando cuenta con una legitimidad democrática directa (ejemplo: los EUA). Si bien esto puede conducir a "fricciones" frente al Parlamento, incluso a

374 Cfr. Hesse, K., Grundzüge..., cit., p. 274. 
Este libro forma parte del acervo de la Biblioteca Juridica Virtual del Instituto de Investigaciones Juridicas de la UNAM

situaciones de bloqueo, también puede significar una saludable pieza de los "checks and balances".

En cuanto institución del Estado constitucional, la monarquía no es una forma deficiente o una variante "degenerada" frente al presidente de una República ("monarquía constitucional"). El carácter hereditario del cargo mezcla, en el plano nacional, un elemento monárquico-aristocrático con el tipo del Estado constitucional. Los ejemplos actuales de Bélgica (rey Balduino) o España, muestran con cuánta intensidad pueden desempeñar funciones de integración y representación los jefes de Estado monárquicos respecto de "pueblos" que se encuentran divididos. En relación con el rey de España, don Juan Carlos I, se ha hablado también de que se trata del "rey de la República Española". Esto no es una "contradictio in adjecto", si se hace referencia a la "República" mediante conceptos como los de "libertad", "democracia", en la tradición de Cicerón con la res publica y la "salus publica res populi". Por lo demás, muchos ciudadanos se sienten más alentados en su "emotio" por la "tradición" de las "casas reinantes" que por la "ratio" en el caso de los presidentes temporales. Ambos caracterizan al ser humano - "ratio y emotio"- y el Estado constitucional hace bien en aprovechar también las fuentes irracionales del consenso, por ejemplo, bajo la figura de los llamados símbolos patrios o las festividades públicas o los días constitucionales (como el 14 de julio en Francia o el 4 de julio en los EUA) o por ejemplo en su nuevo día de "Martin Luther King".

En algunas nuevas Constituciones se encuentran notables catálogos de tareas, incluso en la delimitación respecto de las tareas del Parlamento y el gobierno (cfr. el artículo 106, números 1 a 30, de la Constitución de Ucrania, y los artículos 84 y 85 de la Constitución de Sudáfrica).

\section{El gobierno}

Gobierno en sentido institucional significa, en el Estado constitucional, la institución que, en principio, está encargada de la específica "función de gobierno" y que se compone del primer ministro y de los ministros. Si bien el concepto angloamericano de "government" es más amplio, porque se refiere al conjunto de las actividades del Estado, el concepto europeo continental de "gobierno" es más reducido: se refiere a la dirección política del Estado como liderazgo responsable del conjunto de la política interna y exterior. ${ }^{375}$ Con ello sin duda se producen intersecciones con las tareas y modos

375 Hesse, K., Grundzüge..., cit., pp. 226 y s., con referencia a Scheuner, U., "Der Bereich der Regierung", Staatstheorie und Staatsrecht, 1978, pp. 455 y ss. 
Este libro forma parte del acervo de la Biblioteca Juridica Virtual del Instituto de Investigaciones Juridicas de la UNAM

de actuación del presidente, por un lado (por ejemplo, en el sistema presidencial francés) y del Parlamento, por el otro (así en la Ley Fundamental de Bonn, la cual vincula estrechamente la función de gobierno con la función legislativa). Sin embargo, es posible desentrañar en el sentido funcional e institucional la relación específica de la función política del Estado constitucional - a diferencia de la función jurídica encarnada sobre todo por el Poder Judicial - respecto del gobierno: se hallan en primer término elementos de la dinámica y la actividad creativas, de la actividad por propia iniciativa, de la libertad flexible de configuración, del "conducir". Pero sin duda gobernar significa también ejercicio del poder; sin embargo, en el Estado constitucional dicho ejercicio se produce en función de ciertas tareas (del bien común) descritas en términos materiales y procesales por la Constitución. El gobierno controla hacia "abajo" o hacia lo interno a la "administración"; hacia fuera intenta influir, mediante su política de información, a la opinión pública, la cual, por su parte, controla al mismo tiempo al gobierno. En el Parlamento debe obtener mayoría y debatir con la oposición.

Las Constituciones harán bien si, en el texto, regulan en lo general, en sentido funcional e institucional, al gobierno, y dejan todo el resto al proceso político. De este modo, la Constitución no debería señalar el número y tipo de los ministerios, ya que, por ejemplo, en los gobiernos de coalición en los sistemas parlamentarios debe haber sitio para el "bargaining"; mucho depende de las personas y los partidos participantes. Un constituyente dificilmente puede prever todas las nuevas necesidades a las que debe enfrentarse rápidamente y de manera ad hoc un gobierno. Así, por ejemplo, en Baviera se creó en 1970 un ministerio del ambiente, mucho antes de que la Constitución bávara, a través de una reforma, reconociera la protección del ambiente como objetivo del Estado (1984).

Ciertamente llama la atención que las Constituciones recientes normen amplios catálogos de funciones en materia de gobierno, los que en ocasiones se vuelven muy detallados (ejemplos: artículos 40 y 41 de la Constitución de Sudáfrica de 1996; artículo 116 de la Constitución de Ucrania de 1995; véase también el artículo 146, inciso 4, de la Constitución de Polonia de 1997).

Es de suponerse que dichas "tablas de tareas" no solamente sirven de "incitación" sino también como limitación: en Sudáfrica el Estado del apartheid había abusado de la función de gobierno, en Europa del Este el todopoderoso Estado socialista, convertido en poder de gobierno sin límites, había degradado a los ciudadanos para convertirlos en súbditos. De esta manera quizá puedan explicarse las nuevas etapas textuales, tanto aquí como allá; sin embargo, hay que recordar que los catálogos de tareas referidos al gobierno no deben ser excesivos y "barrocos". 
Este libro forma parte del acervo de la Biblioteca Juridica Virtual del Instituto de Investigaciones Juridicas de la UNAM

\section{La administración}

La administración en el sentido institucional y funcional no es menos importante en el Estado constitucional. Esto queda ya de manifiesto en la frase que califica al derecho administrativo como "derecho constitucional concretizado" (F. Werner), pero también en una mirada a la normalidad de la vida cotidiana. Los altos fines del Estado señalados en la Constitución tienen que ser realizados, de manera práctica, en cada "lugar". Con razón se habla desde hace tiempo del "arte de administrar" y desde hace poco de la "cultura administrativa". ${ }^{376}$ Las diversas naciones se distinguen con bastante precisión en este aspecto: así, en Francia (que es un país centralista) se reconoce ampliamente la formación que otorgan las escuelas superiores de administración; la administración bávara goza de especial prestigio, en contraposición a algunos Länder del norte de Alemania. Los métodos del new public management, así como la tendencia a la privatización, indican de momento una "reestructuración" de la administración, la cual enfrenta a todo Estado constitucional a grandes desafíos. ${ }^{377}$ En los Estados federales y regionales se introduce también un pedazo de división de poderes garante de la libertad en la institución y la función administrativa, puesto que ésta se encuentra dividida en planos verticales. Por lo demás, en el Estado constitucional la administración se caracteriza por la "realización de las funciones estatales en lo particular y en especial por su vinculación a normas jurídicas". ${ }^{378}$ En lo particular resultan útiles los siguientes caracteres: la administración como actividad "dirigida", con la función de la concretización en el caso particular, en la que se requieren saber técnico y profesional. Sin embargo, en la realidad actual del Estado constitucional no puede describirse adecuadamente a la administración mediante el concepto de "ejecución dependiente" y la imagen de la "técnica avalorativa", ya que la sujeción al derecho es diferenciada: la administración pública tiene mayor margen de libertad en la aplicación de los conceptos constitucionales abiertos como "Estado social", "Estado ambiental" o "Estado de cultura", pero también en el ámbito

376 Häberle, P., Verfassungslehre als Kulturwissenschaft, 1a. ed., 1982, p. 20, nota 25; 2a. ed., 1998, p. 1079, p. 1344.

377 Mastronardi, P. y Schedler, K., New Public Management, 1998. Cfr. también Schuppert, G. F., Die Erfïllung öffentlicher Aufgaben durch verselbständigte Verwaltungseinheiten, 1981, pp. 24 y ss., sobre las "public corporations".

378 Hesse, K., Grundzüge..., cit., pp. 229 y ss., sobre lo que sigue. El artículo 195 de la Constitución de Sudáfrica de 1996 fija expresamente los objetivos de la administración, por ejemplo, "high standard of professional ethics", "transparency", "good human-resource management", etcétera. 
Este libro forma parte del acervo de la Biblioteca Juridica Virtual del Instituto de Investigaciones Juridicas de la UNAM http://www.juridicas.unam.mx

de los conceptos jurídicos indeterminados como el "bien común" o el "interés público", o bien también en el campo de la planeación y la prestación de servicios por la administración, así como en el ámbito discrecional. Pero siempre es directamente constitucional; tiene un mandato constitucional independiente ( $c f r$. BVerfGE 49, 89 (125 y ss.), sentencia Kalkar), le corresponden en sus campos nucleares una reserva de la administración protegida constitucionalmente. ${ }^{379}$ Por ejemplo, también tiene un mandato directo de proteger los derechos fundamentales y "contribuir" a su realización. Es en esta medida que la administración se afirma como poder, o mejor, como "función" independiente en el conjunto del Estado constitucional, a pesar de que sea "dirigida" por el gobierno político. Una función especial del Estado constitucional que se encuentra frecuentemente amenazada consiste en la configuración de garantías conexas de esta administración para el bien común sujeta al derecho. Aquí pertenece en época reciente cada vez más el principio de la publicidad de la administración (por ejemplo, bajo la forma de un derecho a la información ambiental, visible, por ejemplo, en el artículo 74, inciso 3, de la Constitución de Polonia de 1997); ya clásicos son los postulados, ligados al funcionariado profesional, de la "imparcialidad" y de la estricta "objetividad" ( $c f r$. el artículo 130, inciso 1, de la Constitución de Weimar: no "servidores de un partido"), los cuales se encuentran amenazados en varias democracias europeas por el patronazgo de los cargos.

$\mathrm{Al}$ segundo poder y a la administración les corresponde también la autonomía administrativa municipal (kommunale Serbstverwaltung), la cual muestra una especial vinculación con la democracia y el desarrollo de los derechos fundamentales en el Estado constitucional, ${ }^{380}$ lo que comenzó en Alemania con la reforma del Freiherr von Stein (1808). En este sentido es un texto constitucional afortunado el artículo 11, inciso 4, de la Constitución bávara de 1946: "La autonomía administrativa de los municipios sirve a la construcción de la democracia en Baviera de abajo hacia arriba". Ideas análogas se encuentran en la Carta Europea de la Autonomía Municipal de 1985 y en los nuevos textos constitucionales después de 1989 (por ejemplo, artículo 3o., inciso 2, de la Constitución de Mecklemburgo-Antepomerania de 1993).

También corresponde al segundo poder la "defensa militar", si bien ésta tiene sus rasgos "propios" en relación con las demás funciones de la adminis-

379 De la bibliografía, véase al respecto: Schmidt, W. Bartelsperger, R., "Organisierte Einwirkungen auf die Verwaltung", VVDStRL, vol. 33, pp. 183 y ss.; p. 306 (intervención de P. Häberle); $c f r$. también Schröder, M., "Die Bereiche der Regierung und der Verwaltung", HdBStR, vol. III, 1988, 67, núms. marginales 22 y ss.

380 Cfr. Häberle, P., Verfassungslehre als Kulturwissenschaft, 2a. ed., 1998, pp. 751 y ss. 
Este libro forma parte del acervo de la Biblioteca Juridica Virtual del Instituto de Investigaciones Juridicas de la UNAM

tración. Para el Estado constitucional resulta determinante la construcción de controles suficientemente efectivos respecto de la defensa y las fuerzas armadas, para que no se independicen y se conviertan en un "Estado dentro del Estado" (como en la República de Weimar). En este sentido hay necesidad de un control funcional mediante una opinión pública pluralista, pero también a través de mecanismos jurídicos de control: aquí se sitúa la pregunta de quién ejerce el poder de mando sobre las fuerzas armadas; frecuentemente corresponde al jefe de Estado, como el presidente de los Estados Unidos o el presidente de Francia (véase también el artículo 106.16 de la Constitución de Ucrania, el artículo 134, inciso 1, de la Constitución de Polonia) o al monarca (cfr. el artículo 62, literal h, de la Constitución española de 1978), en ocasiones al ministro de defensa y en caso de guerra al jefe de gobierno ( $c f r$. artículo 65 a, 115 b de la LF); aquí pertenece la creación de instituciones efectivas de control parlamentario (por ejemplo, un "comisionado parlamentario para la defensa": artículo 45 b de la LF). ${ }^{381}$ En los sistemas de seguridad colectiva, como la OTAN, se atribuye una competencia decisoria considerable a las instancias de la alianza, aunque en Alemania el TCFA creó una así llamada reserva parlamentaria ( $c f r$. E 90, 286). En el fondo nos encontramos aquí ante fenómenos de acción cooperativa de los Estados constitucionales que hacen cuestionables conceptos guías tradicionales como el de "soberanía". Esto es aplicable con mayor razón en la Unión Europea, donde ha surgido un "derecho administrativo europeo" (J. Schwarze).

Que las fuerzas armadas posean en algunas democracias una "función de guardianes" propia (así en Turquía por el Consejo Nacional de Seguridad; cfr. también el preámbulo y los artículos 118 y transitorio 15 de la Constitución de 1982) o que lo ejerzan en la práctica (así, quizá, en las Filipinas o en Indonesia) es una prueba de que estos países no son todavía Estados constitucionales plenamente "desarrollados".

\section{E. La jurisdicción}

La jurisdicción ha experimentado, como institución y como función en el Estado constitucional de hoy, una apreciación incomparable, lo cual se relaciona con las experiencias negativas en los Estados tiránicos socialistas y nacionalsocialistas, pero podría ser convergente con la destacada posición independiente de los jueces en los sistemas jurídicos angloamericanos (en la LF alemana el artículo 97, inciso 1). A esto se agrega que con frecuencia la

\footnotetext{
381 Cfr. al respecto Hartenstein, F.-H., Der Wehrbeauftragte des Deutschen Bundestages, 1977.
} 
Este libro forma parte del acervo de la Biblioteca Juridica Virtual del Instituto de Investigaciones Juridicas de la UNAM

"coronación" de la protección jurídica y el Estado de derecho se ve en una jurisdicción constitucional propia, la cual puede mostrar una historia de éxito sin paralelo, desde Austria (1920) hasta la lejana Sudáfrica (1996/97), desde Italia, Francia, Portugal y España hasta el TFG alemán (entre los Estados constitucionales clásicos solamente Grecia carece de una jurisdicción constitucional propia). A esto se agrega el modelo de la Suprema Corte de los Estados Unidos y el desarrollo de los "tribunales constitucionales europeos", como el Tribunal de Justicia Europeo y la Corte Europea de Derechos Humanos; también la actividad del tribunal constitucional interamericano y el de los países del Pacto Andino. No obstante las diferencias que pueda haber por la cultura jurídica en su desarrollo histórico, en todas partes el Estado constitucional se ha despedido de la idea de Montesquieu de que el juez es solamente la "bouche de la loi". Si bien se ha exagerado la imagen del "Estado judicial" (R. Marcic), crece cada vez más el reconocimiento de la función "pretoriana" del tercer poder, de que sus tareas también son creativas; la sola "defensa del derecho" (cfr. artículo 164 del Tratado de la Comunidad Europea) ${ }^{382}$ no es suficiente; también se trata de un prudente desarrollo del derecho hasta llegar al derecho judicial como "fuente del derecho" propia. En los Estados Unidos se habla plásticamente del "law in action", lo que hay que complementar con una palabra que designe lo público: "law in public action". Ciertamente, la legitimación democrática de los jueces es muy diversa en los países en lo particular: en Suiza, se elige directamente a los jueces a nivel de los cantones, asimismo en algunos estados de la Unión Americana; en Alemania lo son por los comités de selección judicial en unión de los gobiernos de los Länder. También hay que mencionar las reglas especiales que rigen para los jueces constitucionales, ya que algunos de ellos son nombrados por el presidente o por otros órganos (cfr. el artículo 135 de la Constitución de Italia, el 147 de la Constitución de Bulgaria de 1991). Ya que si bien el "tercer poder" se ha apreciado en el Estado constitucional actual, no es más que parte de las funciones estatales y permanece articulado en el sistema conjunto de la división de poderes y debe respetar el principio de los límites jurídico-funcionales de la actividad jurisdiccional, aunque éstos puedan variar en el tiempo, en el espacio y entre países (" judicial activism"-"judicial restraint").

El Estado constitucional bien haría en crear numerosas garantías conexas para la protección de la independencia personal y material de los jueces, en beneficio de la gran confianza que en casi todas partes se muestra al tercer

$382 \mathrm{Al}$ respecto véase I. Pernice en Grabitz, E. y Hilf, M. (eds.), Kommentar der Europäischen Union, Stand Mai, 1998, sobre el artículo 164, núms. marginales 7-19. 
Este libro forma parte del acervo de la Biblioteca Juridica Virtual del Instituto de Investigaciones Juridicas de la UNAM

poder. Su inamovilidad y intransferibilidad, su libertad frente a instrucciones, así como otras garantías desarrolladas como "derechos fundamentales judiciales", como el derecho de audiencia, la protección judicial efectiva, la prohibición de los tribunales especiales, los principios de "nulla poena sine lege"y "ne bis in idem", así como el de publicidad, son elementos indispensables para hacer realidad al "Estado constitucional" como tal. Ciertamente, existen siempre problemas con la "independencia interna"de los jueces, los que tienen que reconocer su "pre-juicio" cultural, mantenerse en lo posible libres de influencias partidistas y trabajar con ayuda de un canon de métodos racionalmente asegurado (a partir de F.-C. von Savigny, 1840), pero susceptible de ampliación (¡derecho comparado!), que permita orientar al resultado así obtenido mediante criterios de justicia "últimos" y "penúltimos". En ocasiones es necesario recurrir a un derecho natural preestatal (como en el juicio sobre la punibilidad de los "tiradores en el muro" en la frontera entre las dos Alemanias; $c f r$. sobre la punibilidad de sus instigadores BVerfGE 95, 96). Tanto en relación con las mencionadas garantías conexas como respecto de la "aplicación" y el desarrollo del derecho, existe actualmente un estándar de reglas y procedimientos, que caracterizan al Estado constitucional como tipo y con el cual tienen que trabajar todas las Constituciones nacionales. El TCFA (E 34, 269 (286), sentencia Soraya) ha fundado la función de desarrollo del derecho por los tribunales en la renuncia consciente de la LF al positivismo legalista en su artículo 20, inciso 3.

Si frente a este trasfondo nos preguntamos por el "tipo fundamental" de la jurisdicción, hay que hacer referencia, por un lado, a su amplia separación respecto de las demás funciones del Estado, y por el otro, a sus tareas de resolución "autoritativa, y por tanto, obligatoria e independiente, en los casos de derechos controvertidos o violados". ${ }^{383}$ En virtud de la "supremacía de la Constitución" que caracteriza al Estado constitucional (por ejemplo, artículo 8o., inciso 1, de la Constitución de Polonia de 1997, artículo 3o., inciso 2, de la Constitución de Benín de 1990), en particular de la sujeción de todos los poderes del Estado a la Constitución, son todos los tribunales, en un sentido más profundo y amplio, "tribunales constitucionales".

\section{EL ESTADO SOCIAL DE DERECHO}

1. Haber resumido en un principio constitucional único la fórmula del "Estado social de derecho" (cfr. artículo 28, inciso 1, frase 1, de la LF) es una

383 Así las opiniones en la doctrina alemana que resume Hesse, K., Grundzüge..., cit., pp. 234 y ss. 
Este libro forma parte del acervo de la Biblioteca Juridica Virtual del Instituto de Investigaciones Juridicas de la UNAM

conquista colectiva de la ciencia jurídica y la práctica constitucional alemanas. Sus clásicos son F. J. Stahl y R. v. Mohl, por un lado, en la medida en que fueron precursores científicos de la idea del Estado de derecho en el siglo XIX, ${ }^{384}$ H. Heller, por otro lado, porque propagó al "Estado social" en general y con vistas a la Constitución de Weimar. ${ }^{385}$ Nadie menos que Carlo Schmid, uno de los más influyentes "padres" de la Ley Fundamental de Bonn, hacía remontar expresamente, en los debates constituyentes, esta fórmula de H. Heller, propuesta por H. von Mangoldt,386 al "pathos social de la tradición republicana". ${ }_{387}$ Bien visto, el Estado social de derecho es una "prórroga" congenial, para el siglo XX, del antiguo concepto de Estado de derecho, y actualmente, es de preguntarse si no requiere una nueva prórroga, tomando en cuenta que el Estado constitucional es responsable también por las futuras generaciones y en tal medida se encuentra obligado a la protección del ambiente ("Estado constitucional o de derecho ecológico"). En todo caso, en la actualidad el "Estado social de derecho" es un elemento esencial ${ }^{388}$ en el conjunto del Estado constitucional, y su evolución de etapas textuales dan testimonio de ello. Así se encuentran ejemplos de textos en la mayoría de las Constituciones recientes, ya sea en los Estados reformados de Europa oriental (artículo 1o., inciso 1, de la Constitución e Macedonia de 1991: "social state"; artículo 2o. de la Constitución de Polonia de 1997: "Estado democrático de derecho que realiza los principios de la justicia social"; artículo 1o. de la Constitución de Ucrania de 1996: "social, law-based state") o en África (artículo 1o., inciso 1, de la Constitución de Guinea Ecuatorial de 1991: "Estado social y democrático"; preámbulo de la Constitución de Madagascar de 1995: "Estado de derecho"; asimismo el artículo 8o., inciso 1, de la Constitución de Níger de 1996: "Estado de derecho").

Las fórmulas varían, pero en el fondo quieren decir lo mismo: el Estado constitucional comprometido con la justicia social. Cierto es que ésta es una fórmula demasiado general y abstracta, por lo que es susceptible, y requiere, de una configuración (política) y de interpretación múltiple. En la comparación jurídica se producen ciertos "principios parciales" que son comunes a

384 De la bibliografía véase Stern, K., Staatsrecht, I, 2a. ed., 1984, p. 882.

385 Cfr. Heller, H., Rechtsstaat oder Diktatur, 1930, p. 11; véase al respecto, de la bibliografía Schluchter, W., Entscheidung für den sozialen Rechtsstaat. Hermann Heller und die staatstheoretische Diskussion in der Weimarer Republik, 1968; Denhard, A., Dimensionen staatlichen Handelns, 1996, pp. 33 y ss.

386 Cfr. Stern, K., op. cit., p. 878.

387 Consejo Parlamentario. Informe estenográfico, p. 172; al respecto, Stern, op. cit., p. 880.

388 Schmid, C., loc. cit., habla también del "contenido esencial". 
Este libro forma parte del acervo de la Biblioteca Juridica Virtual del Instituto de Investigaciones Juridicas de la UNAM

todos los Estados constitucionales. A ellos pertenecen, desde el lado formal, la "supremacía de la Constitución", 389 la sujeción a la ley (entre otros, la legalidad de la administración); por el lado material, un estándar europeo común de derechos humanos, la división de poderes, la responsabilidad del Estado, la protección jurídica por jueces imparciales, etcétera. Si la LF ya manifiesta, en su artículo 20, inciso 3, la tensión entre "ley y derecho" y mediante la positividad intermedia y la valoración, entonces el atributo "social" significa con mayor razón un recurso directo (Durchgriff) a los elementos de justicia (pre-estatales) como la compensación social, la ayuda para los débiles y su protección ("seguridad social"). Si la legislación social de Bismarck de 1881 inició tempranamente en la práctica un sistema de seguridad social, cuya "reestructuración" quizá esté pendiente en la actualidad, así también la cláusula del Estado social fue una vía para la integración de la clase trabajadora en el Estado constitucional y el sistema parlamentario. Lo que en el mundo angloamericano se discute como "welfare state", y que quizá resulte demasiado débil en los Estados Unidos, es hoy patrimonio común de los Estados constitucionales europeos (si bien la controversia actual sobre una "Carta Social Europea" de la UE permite apreciar que hay diferencias). Así, las Constituciones de Europa expedidas después de la segunda guerra mundial se caracterizan por fórmulas más o menos refinadas que se refieren en el fondo al "Estado social de derecho", por ejemplo en Italia (artículos 35, 36, 38 de la Constitución de 1947), pero también en Grecia (artículos 21 a 23 de la Constitución de 1975), España y la Constitución de Portugal de 1976 (artículo 1o.: "sociedad libre, justa y solidaria"; artículo 63, inciso 1: "Todos tienen derecho a la seguridad social"). También las Constituciones cantonales suizas contienen una rica paleta de textos normativos comprometidos con la idea del Estado social; así, la Constitución del Cantón del Aargau de 1980 ( 25 , inciso 1: "El Estado promueve el bienestar general y la seguridad social"); por último la Constitución de Berna de 1993 (artículo 29: "derechos sociales"; artículo 30: "Objetivos sociales").

Solamente en las Constituciones, como la de los Países Bajos de 1983, que son, en el conjunto de su programa regulador, más bien parcas y reservadas, es que se encuentran meros indicios (por ejemplo, el artículo 20, inciso 2: "Las reglas sobre los derechos a la seguridad social serán establecidas en ley del Parlamento"). Una mirada a Sudamérica y América Central es, por el contrario, muy productiva, llegando incluso hasta los esfuerzos excesivos en la materia por ejemplo en la Constitución de Brasil (1988), en parte también la anterior Constitución de Perú (1979). Buena parte del Es-

389 Cfr. Wahl, R., "Der Vorrang der Verfassung”, Der Staat, vol. 20, 1981, pp. 485 y ss. 
Este libro forma parte del acervo de la Biblioteca Juridica Virtual del Instituto de Investigaciones Juridicas de la UNAM http://www.juridicas.unam.mx

tado social es creada apenas en el proceso político por la vía de la legislación ordinaria; sin embargo, se requieren textos constitucionales "inductores". Dicho óptimo (o mínimo) de regulación de la justicia social corresponde hoy al estándar del tipo del "Estado constitucional", por ejemplo, mediante derechos justiciables a un mínimo económico existencial, a la protección de la salud, a la protección de la familia y a la garantía de condiciones de trabajo humanas.

Una teoría constitucional comparativa, que como la aquí esbozada, debe ser breve, solamente puede presentar algunas líneas de los contenidos del principio del "Estado social de derecho". En lo que sigue dichas líneas serán esbozadas con base en la doctrina y la jurisprudencia alemanas y requieren, naturalmente, de complementación por los estudiosos de otras culturas jurídicas, como la italiana. También tienen que examinarse las divergencias y las convergencias entre el "Estado de derecho" europeo continental y el "rule of law" angloamericano. Bajo las anteriores reservas se expone lo siguiente:

2. La configuración del principio del Estado de derecho en la Ley Fundamental alemana se compone de una multiplicdad de elementos que han encontrado precipitación textual distribuida en toda la LF: esto va desde los derechos fundamentales ${ }^{390}$ (artículos 1o. a 19 LF), incluyendo la reserva de ley, ${ }^{391}$ el principio de proporcionalidad ${ }^{392}$ y la garantía de la protección judicial 393 (artículo 19, inciso 4 de la LF), pasando por la división de poderes ( $c f r$. artículo 20, inciso 2, frase 2, LF), la primacía del derecho, ${ }^{394}$ la legalidad de la administración y la supremacía de la Constitución ${ }^{395}$ (artículo 20, inciso 3, de la LF), la responsabilidad del Estado ${ }^{396}$ (artículo 34 LF) y el derecho de revisión judicial, ${ }^{397}$ hasta llegar a las garantías de la justicia en los artículos 101 y siguientes de la LF.

Sin embargo, de acuerdo con la jurisprudencia del TCFA, el principio del Estado de derecho "se encuentra definido en la Constitución solamente

\footnotetext{
390 Hesse, K., Grundzüge..., cit., 20a. ed., 1995, p. 83.

391 Badura, P., Staatsrecht, 2a. ed., 1996, p. 276.

392 BVerfGE 23, 127 (133), con mayores referencias; cfr. Lerche, P., Übermaß und Verfassungsrecht, 1961, pp. 61 ss.; de manera diferenciada sobre ésta y otras derivaciones del principio de proporcionalidad Michael, L., Der allgemeine Gleichheitssatz als Methodennorm komparativer Systeme, 1997, pp. 267 y ss.
}

393 Schmidt-Aßmann, en Maunz y Dürig, sobre el artículo 19 IV LF, Rz. 15 y ss.

394 Hesse, K., Grundzüge..., cit., 20a. ed., 1995, pp. 86 y ss.

395 Hesse, K., Grundzüge..., cit., p. 88; Badura, P., Staatsrecht, 2a. ed., 1996, pp. 271 y ss.

396 Badura, P., Staatsrecht, 2a. ed., 1996, pp. 282 y ss.

397 Ibidem, pp. 271. 
Este libro forma parte del acervo de la Biblioteca Juridica Virtual del Instituto de Investigaciones Juridicas de la UNAM

de manera parcial". ${ }^{998}$ Por ello, el concepto del Estado de derecho se desarrolla en el derecho constitucional alemán a partir de su uso en la cláusula general del artículo 28, inciso 1, de la LF. El topos del Estado de derecho así utilizado "requiere de concretización dependiendo de las situaciones objetivas" ${ }_{999}$ y la doctrina y la jurisprudencia los han definido de manera diferenciada en múltiples ocasiones.

Pero en el centro de la discusión se encuentra siempre la seguridad jurídica. ${ }^{400}$ Bajo este concepto caen los siguientes subaspectos del problema de la retroactividad de las leyes, ${ }^{401}$ la cuestión de la certidumbre de las normas, la validez de los actos administrativos y la cosa juzgada de las sentencias, la autosujeción de la administración y los requisitos de publicidad. ${ }^{402}$ Lo que estos aspectos tienen en común es la función estabilizadora del principio del Estado de derecho, como "forma de producción de continuidad". ${ }_{403}$ El origen de todas estas garantías es la idea de la protección de la confianza, incluso en última instancia, la "idea de la justicia". ${ }^{404}$

Desde el punto de vista metódico es notable el hecho de que el principio del Estado derecho reúna en sí aspectos que en ocasiones son contradictorios entre sí, ${ }^{405}$ sobre todo en la oposición entre justicia formal y justicia material. Por ello se ha hablado de que el principio es como la "cabeza de Jano". ${ }^{406}$

3. El principio del Estado social (cfr. ya el artículo 20, inciso 1, de la LF) es mencionado en la LF de manera conjunta con el principio del Estado de derecho (el artículo 28, inciso 1, frase 1, de la LF habla de los principios del "Estado social de derecho"). Esto plantea la cuestión de la relación de ambos principios entre sí. Así como el principio del Estado de derecho incorpora en sí antinomias, también es frecuente que el principio del Estado de derecho y del Estado social hayan sido entendidos como un par opuesto. Sin embargo, la doctrina ha refutado o matizado ${ }^{407}$ poco a poco la incompa-

\footnotetext{
398 BVerfGE 65, 283 (290).

399 Idem.

400 Cfr. Schmidt-Aßmann, E., "Der Rechsstaat", HdBStR vol. I, 2a. ed., 1995, p. 1030;

Kunig, P., Das Rechtsstaatsprinzip, 1986, pp. 90 y ss.

${ }_{401} C f r$. al respecto BVerfGE 13, 261 (272), jurisprudencia constante, por último $v$. gr. E
} 88, 384 (403 y ss.).

402 Kunig, P., Das Rechtssaatsprinzip, 1986, pp. 394 y ss.

403 Hesse, K., Grundzüge..., cit., 20a. ed., p. 85.

404 BVerfGE 33, 367 (383), con mayores referencias.

405 BVerfGE 65, 283 (290).

406 Kunig, P., Das Rechtsstaatsprinzip, 1986, p. 378.

407 Hesse, K., Grundzüge..., cit., 20a. ed., 1995, p. 95, habla del Estado de derecho como límite del Estado social. 
Este libro forma parte del acervo de la Biblioteca Juridica Virtual del Instituto de Investigaciones Juridicas de la UNAM

tibilidad entre ambos que afirmaba E. Forsthoff. ${ }^{408}$ Pero con ello la idea del Estado social se ha convertido en un objetivo, sumamente indeterminado, del Estado ("norma en blanco"), ${ }^{409}$ para cuyo desarrollo el TFCA le ha conferido al legislador un "amplio margen para su libre configuración"..110 En todo caso, la garantía del mínimo existencial se ha fundado en el principio del Estado social en relación con el artículo 1o., inciso 1, de la LF (dignidad humana).411 Además de lo anterior, el principio del Estado social desempeña un papel como topos argumentativo en el marco del principio general de igualdad, ${ }^{412}$ de diversos derechos de libertad ${ }^{413} \mathrm{e}$ incluso del principio de la democracia. ${ }^{414}$

\section{ESTADO DE GULTURA Y DEREGHO CONSTITUCIONAL DE LA CULTURA: EL CONCEPTO ABIERTO DE GULTURA}

Un primer acceso a la relación entre Constitución y cultura lo da el derecho constitucional cultural como suma de las normas constitucionales que abarcan los asuntos culturales en sentido estricto en las Constituciones federal y de los Länder.

\section{1. Ámbitos materiales en Alemania}

$\mathrm{Al}$ igual que para el derecho administrativo de la cultura, nos referimos por lo pronto a los tres principales ámbitos materiales ya mencionados: educación (artículo 12, en relación con los artículos 3o., 20, inciso 1, de la LF, incluyendo la educación de los adultos, el artículo 139 de la Constitución de Baviera, y la libertad de las escuelas privadas, artículo 30 de la Constitución de Renania-Palatinado), el arte y la ciencia (artículo 5o., inciso 3, de la LF, artículo 18 de la Constitución de Renania del Norte-Westfalia). Los elementos comunes constitutivos de estos ámbitos culturales, que hablan en favor

408 Forsthoff, E., "Begriff und Wesen des sozialen Rechtsstaates", VVDStRL, vol. 12, 1954, pp. 8 y ss., 13.

409 Stern, K., Staatsrecht, vol. I, 2a. ed., 1984, p. 914.

410 BVerfGE 18, 257 (273).

411 Cfr. BVerfGE 1, 97 (104), por un lado, y E 40, 121 (133), por el otro; recientemente E 82, 60 (85). Una resolución temprana en BVerfGE 1, 159.

412 Zacher, H. F., "Das soziale Staatsziel”, HdBStR I, 2a. ed., 1995, p. 1068.

413 Ibidem, p. 1070.

414 Ibidem, pp. 1096 y ss. 
Este libro forma parte del acervo de la Biblioteca Juridica Virtual del Instituto de Investigaciones Juridicas de la UNAM

de la oportunidad del concepto de "Constitución cultural", son un particular grado de autonomía, de libertad y distancia hacia el poder coactivo del Estado, con la consecuencia de que la imagen propia de los participantes en el proceso cultural adquiere una particular importancia para la interpretación de la Constitución cultural; $; 15$ por esta razón es posible considerar al derecho eclesiástico del Estado (artículo 140 LF, artículos 132 y 150 de la Constitución de Baviera, artículos 41-48 de la Constitución de Renania-Palatinado, artículos 39-41 de la Constitución de Turingia), o mejor dicho, el "derecho constitucional de la religión", como derecho constitucional "especial" de la cultura. Los elementos comunes surgen de que el derecho constitucional de la cultura se refiere al mencionado concepto general cotidiano de la cultura en sentido estricto.

\section{Formas técnico-jurídicas de manifestación}

\section{A. Diversidad técnico-jurídica de las normas constitucionales de la cultura en los "viejos" Estados constitucionales}

Desde el punto de vista técnico-jurídico nos encontramos que las normas constitucionales de la cultura en los "viejos" Estados constitucionales asumen formas diversas:

a) En las cláusulas generales o especiales sobre el Estado de cultura (por ejemplo, artículo 3o. de la Constitución de Baviera: Baviera es un "Estado de cultura"; artículo 139 ibidem: mandato de educación de los adultos; artículo 1o., frase 2, de la Constitución de Sajonia de 1992: "Estado de derecho comprometido con la cultura"; artículo 24, inciso 2, frase 1, de la Constitución de Brandemburgo de 1992: "La vida cultural en su diversidad y la trasmisión del patrimonio cultural son promovidos por el poder público"; véase también el artículo 29, inciso 1, frase 2 de la LF: "contextos culturales");

b) En fines de la enseñanza y la educación (por ejemplo, artículo 56, inciso 3, 4 de la Constitución de Hesse: tolerancia) o artículo 27, inciso 1, de la Constitución de Sajonia-Anhalt de 1992: "asumir responsabilidad frente a las generaciones futuras");

415 Sobre la relevancia de la imagen propia, $c f r$. BVerfGE 24, 236 (247 y ss.). Véase también BVerfGE 54, 148 (155 y ss.), caso Eppler. En forma general Morlok, M., Selbstverständnis als Rechtskriterium, 1993. 
Este libro forma parte del acervo de la Biblioteca Juridica Virtual del Instituto de Investigaciones Juridicas de la UNAM

c) En catálogos de competencias (normas de tareas) de la Federación (artículo 74, numeral 57 13, 75 numeral 1 a de la LF) o de un Land (artículo 141 de la Constitución de Baviera; artículo 30 de la Constitución de Turingia de 1993);

d) En la consagración de derechos fundamentales (palabra clave: libertades (de no interferencia) culturales y su promoción por el Estado - concepto de derechos fundamentales en términos del derecho constitucional de la cultura, por ejemplo, artículo 5o., inciso 3, de la LF, artículo 7o. de la Constitución de Mecklemburgo-Antepomerania-);

e) En los preámbulos así como en fórmulas juramentales y garantías de los días festivos;

f) En el llamado "derecho constitucional municipal de la cultura" ${ }_{416}$ como parte del pluralismo de sujetos culturales ( $f f r$. los artículos 10, inciso 4, 83, inciso 1, 140 de la Constitución de Baviera, el artículo 36 de la Constitución de Sajonia-Anhalt).

Por lo demás, se puede estructurar el derecho constitucional de la cultura a través de la distinción entre derecho constitucional individual de la cultura (por ejemplo, libertad de artistas y científicos: artículo 5o., inciso 3, LF; artículo 10 de la Constitución de Hesse; derecho a la educación: artículo 27 de la Constitución de Bremen, artículo 29, inciso 1, de la Constitución de Brandemburgo), derecho constitucional de la cultura objetivo-institucional (por ejemplo, instituciones para la educación continua y de los adultos: artículo 32 de la Constitución del Sarre, artículo 17 de la Constitución de Renania del Norte-Westfalia; protección de los días festivos: artículo 22 de la Constitución de Berlín; atención espiritual en centros de reclusión: artículo 54 de la Constitución de Hesse; promoción del arte: artículo 7o. de la Constitución de Schleswig Holstein) y derecho constitucional de la cultura corporativo, como la garantía de la actividad de asociaciones socio-culturales (por ejemplo, artículo 37 de la Constitución de Renania del Norte-Westfalia), sobre todo de las iglesias y asociaciones religiosas (artículo 51 de la Constitución de Hesse, artículo 137 de la Constitución de Weimar en relación con el artículo 140 de la LF), así como derecho constitucional de la cultura de participación (por ejemplo artículo 11, inciso 1, de la Constitución de Sajonia: "La participación en la cultura en su diversidad y en el deporte debe

416 De manera detallada Häberle, P., Kulturpolitik in der Stadt ein Verfassungsauftrag, 1979, pp. $21 \mathrm{y}$ ss. 
Este libro forma parte del acervo de la Biblioteca Juridica Virtual del Instituto de Investigaciones Juridicas de la UNAM

ser posible para todo el pueblo"). Naturalmente hay aquí numerosas formas mixtas e intermedias, al igual que relaciones de complementariedad.

\section{B. Los países en desarrollo en el campo del derecho constitucional de la cultura}

Este campo se caracteriza por una especial densidad, alta diferenciación, mucha fantasía y algunas innovaciones, sin negar la pertenencia al tipo del "Estado constitucional". Esto no resulta sorprendente, ya que la cultura es el ámbito en que los Estados de ultramar deben encontrar, afirmar, proteger y desarrollar su identidad nacional. Sin querer subestimar el derecho constitucional económico como base económica, "material" para el proceso del desarrollo nacional de estos países, en vista del objetivo de la "nivelación" económica de los Estados bajo el término clave "desarrollo del bienestar", en la actualidad un país en lo particular solamente puede encontrar su individualidad, perfil e identidad, en lo cultural y a partir de lo cultural, a pesar de la "cultura intercontinental de la compensación" de nuestros días (H.-G. Gadamer). Proteger y desarrollar al mismo tiempo lo propio con apertura hacia la cultura mundial (resultan ejemplares en tal sentido los fines educativos del artículo 73 de la Constitución de Guatemala) es la "cuestión existencial" de los países en desarrollo. Por esta razón, el derecho constitucional de la cultura debe producir diferenciaciones textuales propias. El "desarrollo" puede ser "sostenido" por una nación en lo individual y por sus ciudadanos si, por un lado, se conserva retrospectivamente el patrimonio cultural, a través de las correspondientes cláusulas de protección e identidad (por ejemplo, de los bienes culturales nacionales), también por los artículos sobre la lengua; por el otro lado, de modo prospectivo, si se trabaja en el desarrollo (continuo) de lo cultural, a través de fines educativos, derechos de acceso y participación en la cultura, empezando con la eliminación del analfabetismo y terminando con un proyecto pluralista de cultura. ¡Aquí es donde puede y debe ponerse a prueba la tentativa de una teoría constitucional que se presenta como "ciencia de los textos y la cultura jurídicos"!

a. Cláusulas sobre patrimonio e identidad culturales en textos generales y especiales

Las cláusulas de patrimonio e identidad culturales son una característica de los países en desarrollo. Dichas cláusulas deben proteger de manera expresa lo que las naciones de los viejos Estados constitucionales toman de 
Este libro forma parte del acervo de la Biblioteca Juridica Virtual del Instituto de Investigaciones Juridicas de la UNAM

manera natural y no escrita como fundamento de su identidad y lo que en Europa puede considerarse "cultura constitucional" y que está conformado en el marco de la "unidad del orden jurídico" en muchos campos especiales del derecho ordinario. La riqueza de las variantes textuales es grande y merece nuestro respeto. Sin duda el artículo 48 de la Carta de la OEA actúa, como norma de reconocimiento y estímulo: "Los Estados miembros... se considerarán individual y solidariamente comprometidos a preservar y enriquecer el patrimonio cultural de los pueblos americanos". La anterior Constitución de Perú de 1979 disponía ya en su preámbulo: "Animados por el propósito de mantener y consolidar la personalidad histórica de la Patria, síntesis de los valores egregios de múltiple origen que le han dado nacimiento; de defender su patrimonio cultural; y de asegurar el dominio y preservación de sus recursos naturales...".

Las cláusulas especiales de protección se refieren a las "culturas nativas", al folklore nacional, al arte popular y la artesanía (artículo 34), el "patrimonio cultural de la nación" (artículo 36). Hay que agregar el artículo 100 sobre la integración: "El Perú promueve la integración económica, política, social y cultural de los pueblos de América Latina", así como el servicio y colaboración de los medios sociales y privados de comunicación en favor de la "educación y la cultura" (artículo 37).

La Constitución de Guatemala de 1985 recorre esta vía más lejos, al inventar alguna variante, por ejemplo en el preámbulo: "inspirados en los ideales de nuestros antepasados y recogiendo nuestras tradiciones y herencia cultural...".

Y en el artículo 58 sobre la "identidad cultural": "Se reconoce el derecho de las personas y de las comunidades a su identidad cultural de acuerdo a sus valores, su lengua y sus costumbres", así como otras normas sobre la protección de la "cultura nacional" (artículo 59), del "patrimonio cultural de la nación" (artículo 60, pero véase también el 61) y de los "grupos étnicos" (artículo 66).

La Constitución de Brasil (1988) formula una cláusula de protección en relación con "las manifestaciones de las culturas popular, indígenas y afrobrasileñas, así como las de los demás grupos que participan en el proceso civilizatorio brasileño" (artículo 215 1). El "patrimonio cultural brasileño" es protegido de manera muy detallada (artículo 216): desde las "formas de expresión", pasando por las formas de crear, hacer y vivir, hasta "otros espacios destinados a las manifestaciones artísticas y culturales". Lo último puede verse fácilmente como contribución a la controversia en torno al concepto de arte y cultura. 
Este libro forma parte del acervo de la Biblioteca Juridica Virtual del Instituto de Investigaciones Juridicas de la UNAM

\section{b. Artículos sobre la lengua}

Los Estados nacionales clásicos, en cuanto Estados constitucionales, tienen dificultades con la libertad lingüística, por ejemplo, en el sentido de la tradición y el presente ejemplares de Suiza. ${ }^{417}$ Tanta mayor atención merecen entonces algunos países en desarrollo. Aunque fijen una o varias lenguas como oficiales, permanecen preocupados por otras lenguas de sus ciudadanos, quizá en la conciencia de que las "lenguas indígenas" son un elemento esencial de su patrimonio "cultural" y "multicultural". Mientras más reconocen su patrimonio cultural, tanto más tienen que poner atención en la conservación y promoción de la diversidad de lenguas. Esto puede mostrarse con el ejemplo de Perú, cuya Constitución de 1979 disponía en su artículo 35: "El Estado promueve el estudio y conocimiento de las lenguas aborígenes. Garantiza el derecho de las comunidades quechua, aymara y demás comunidades nativas a recibir educación primaria también en su propio idioma o lengua".

Una correspondencia interna similar entre cláusulas sobre patrimonio cultural y sensibilidad a la diversidad de lenguas es la que logra la Constitución de Guatemala (1985). Sus ejemplares cláusulas sobre la identidad cultural en el artículo 58 (derecho de las "personas y de las comunidades a su identidad cultural de acuerdo con sus valores, su lengua y sus costumbres") encuentra su continuación en las palabras del artículo 66: "El Estado reconoce, respeta y promueve sus formas de vida"(de los diversos grupos étnicos), el uso de sus "idiomas y dialectos", así como en el artículo 76, párrafo segundo: "En las escuelas establecidas en zonas de predominante población indígena, la enseñanza deberá impartirse preferentemente en forma bilingüe".

Francia, el país de los derechos del hombre, podría aprender bastante de los países en desarrollo, por ejemplo, en relación con su política lingüística en Alsacia. Todavía en 1981 decía François Mitterrand, como candidato presidencial, en el sur de Bretaña:

Ha llegado el momento para un estatuto de las lenguas y las culturas en Francia que les conceda a éstas verdadera viabilidad. Ha llegado el momento de abrirles ampliamente las puertas en la escuela, la radio y la televisión, para que encuentren en la vida pública el espacio que requieren y que les corresponde.

417 Véase las particularidades en Häberle, P., "Sprachen-Artikel und Sprachenprobleme im Verfassungsstaat", FS Pedrazzini, 1990, pp. 105 y ss. 
Este libro forma parte del acervo de la Biblioteca Juridica Virtual del Instituto de Investigaciones Juridicas de la UNAM

Francia debería "dejar de ser por fin el último país de Europa que niega a sus pueblos derechos culturales elementales". ¡Hasta ahora Francia se ha mantenido en su tradición jacobina!

El respeto a la identidad cultural de los ciudadanos le vendría bien hoy día a todo Estado constitucional. Aunque haya quedado anclado en la anterior etapa del Estado nacional "egocéntrico", podría recuperar a nivel subconstitucional (mediante normas legislativas y administrativas) lo que hasta ahora se ha perdido. En este sentido, los países en desarrollo se encuentran más "adelantados" en su etapa de desarrollo textual, y sus ejemplares Constituciones podrían otorgar "ayuda al desarrollo" a algunos Estados constitucionales europeos, pues éstos se encuentran subdesarrollados en materia de libertad e identidad culturales de los ciudadanos dentro del campo de las lenguas. Ellos, los Estados constitucionales clásicos, deben volverse receptores, pues los países en desarrollo han creado "condiciones" altamente productivas. Pero en qué medida se ajustan a su realidad constitucional es una cuestión que queda abierta.

\section{c. Fines educativos}

"Artículo guía" de las posteriores codificaciones constitucionales culturales de los fines educativos (quizá también en los países en desarrollo) es el artículo 148 de la Constitución de Weimar:

En todas las escuelas debe lograrse educación moral, convicción ciudadana, capacidad personal y profesional en el espíritu del puebo alemán y de la reconciliación de los pueblos.

En las clases en escuelas públicas debe tomarse en cuenta que no sean lesionados los sentimientos de quienes piensan de manera diferente.

El civismo y la clase de trabajo son materias de las escuelas. Cada alumno recibirá un ejemplar de la Constitución al terminar la educación obligatoria.

Las Constituciones de los Länder de Alemania occidental impulsaron fuertemente, después de 1945, la etapa de desarrollo textual de los fines constitucionales de la educación, en disposiciones como: "Respeto de la convicción religiosa y de la dignidad del ser humano"(artículo 131, inciso 2 , de la Constitución de Baviera), preparación para "el servicio independiente y responsable al pueblo y la humanidad a través del respeto y el amor al prójimo"(artículo 56, inciso 4, de la Constitución de Hesse) y sobre todo a través del artículo 26, numeral 4, de la Constitución de Bremen: "La educación para la participación en la vida cultural del pueblo propio y de los 
Este libro forma parte del acervo de la Biblioteca Juridica Virtual del Instituto de Investigaciones Juridicas de la UNAM

pueblos ajenos". Qué tan fuertemente se encuentran integrados los objetivos educativos en la dinámica del desarrollo del tipo del Estado constitucional se muestra, por último, en que las Constituciones de los Länder alemanes occidentales han incorporado recientemente modificaciones en materia de la protección jurídica del medio ambiente (artículos 3o., inciso 2, 141 de la Constitución de Baviera; artículo 11 a de la Constitución de Bremen), lo que han "igualado" pedagógicamente en el "soft law" de los objetivos educativos ( $c f r$. el artículo 131, inciso 2, nuevo texto de la Constitución de Baviera: "Conciencia de la responsabilidad por la naturaleza y el ambiente", así como el artículo 26, inciso 5, de la Constitución de Bremen: "La educación para la responsabilidad por la naturaleza y el ambiente"). Todas las Constituciones de Alemania oriental han producido textos de "afinidad electiva"en 1992-1993.

Esta doble línea interna de desarrollo del Estado constitucional, es decir, apoyada jurídica y pedagógicamente, encuentra su contrapartida en elementos textuales de los convenios internacionales de derechos humanos, en la medida en que tematizan la educación en favor de dichos derechos. El "artículo guía" pionero es el artículo 26, inciso 2, de la Declaración Universal de los Derechos Humanos de la Naciones Unidas de 1948:

La educación tendrá por objeto el pleno desarrollo de la personalidad humana y el fortalecimiento del respeto a los derechos humanos y a las libertades fundamentales; favorecerá la comprensión, la tolerancia y la amistad entre todas las naciones y todos los grupos étnicos o religiosos; y promoverá el desarrollo de las actividades de las Naciones Unidas para el mantenimiento de la paz.

En el artículo 1o., inciso 1, de sus estatutos de 1945, la UNESCO creó igualmente una base textual para la educación en los derechos humanos y persigue este objetivo, entre otras formas, mediante la proclamación de un "día de los derechos humanos".

Es la contribución específica de los países en desarrollo haber creado recientemente una diferenciación en la etapa textual que combina los fines educativos constitucionales del tipo descrito con los textos internacionales sobre derechos humanos, en el sentido de una educación para la Constitución, así como para los derechos humanos y fundamentales. Los trasfondos son evidentes: los países en desarrollo deben fundarse también como Estados constitucionales a través de la socialización cultural y la educación; asimismo, la protección jurídica de los derechos humanos requiere urgentemente de un "flanqueo" mediante lo pedagógico. Los procesos de apren- 
Este libro forma parte del acervo de la Biblioteca Juridica Virtual del Instituto de Investigaciones Juridicas de la UNAM

dizaje que duran generaciones, por ejemplo en Francia desde 1789, deben ser recuperados de la manera más rápida posible a través de la educación.

La Constitución de Perú de 1979 logró todo esto en los siguientes puntos textuales: "La educación... [se] inspira en los principios de la democracia social" (artículo 21, segundo párrafo). "Promueve la integración nacional y latinoamericana, así como la solidaridad internacional" (artículo 22, primer párrafo), y: "La enseñanza sistemática de la Constitución y de los derechos humanos es obligatoria en los centros de educación civiles y militares y en todos sus niveles" (ibidem, tercer párrafo).

Igualmente enfático es el artículo 72 de la Constitución de Guatemala:

La educación tiene como fin primordial el desarrollo integral de la persona humana, el conocimiento de la realidad y cultura nacional y universal.

Se declaran de interés nacional la educación, la instrucción, formación social y la enseñanza sistemática de la Constitución de la República y de los derechos humanos.

Pensar las Constituciones del Estado constitucional, así como los derechos fundamentales y humanos como fines educativos - lo que en la doctrina alemana ha desarrollado hasta ahora bajo el término clave "principios constitucionales como fines educativos"- posee ahora, gracias a los países en desarrollo, una base textual de argumentación. A esto se agrega el compromiso en favor de la promoción de la idea de los derechos humanos, conforme al artículo 25 de la Carta africana de Banjul de 1982 ("comprometidos a promover a través de la enseñanza, la instrucción y las publicaciones el respeto frente a los derechos y libertades contenidos en esta Carta... y además velar por que las libertades y los derechos, así como las correspondientes obligaciones, sean comprendidos"). Futuras modificaciones constitucionales o procesos constituyentes en los Estados "desarrollados" deberían aprender de esto. ¡Piénsese en las nuevas Constituciones de Europa oriental, que han debido asegurar de manera doble en sus textos el estándar de derechos humanos que pretenden recuperar: jurídicamente a través de la protección de los derechos fundamentales, y pedagógicamente a través de los textos constitucionales (o por lo menos mediante leyes ordinarias) sobre los derechos fundamentales y humanos "como" fines educativos! Quizá podríamos atrevernos a decir "educación del género humano para el Estado constitucional". 
Este libro forma parte del acervo de la Biblioteca Juridica Virtual del Instituto de Investigaciones Juridicas de la UNAM

\section{d. Derechos fundamentales culturales}

La fundación de los países en desarrollo a partir de su cultura no excluye, sino que, por el contrario, incluye, en la actual etapa de la vida del Estado constitucional, los derechos fundamentales culturales. Mientras que en Alemania el derecho constitucional de la cultura se ha "explorado" sistemáticamente sólo desde finales de los setenta, es posible encontrar en las Constituciones recientes de los países en desarrollo elementos textuales que constituyen un gran enriquecimiento en el marco de una teoría del derecho constitucional de la cultura. Desde el punto de vista temático, hay que distinguir entre derechos fundamentales culturales nuevos y desarrollados y refinamientos de la dimensión de las libertades culturales (junto a los derechos de no interferencia, los objetivos y los prestacionales). He aquí algunos ejemplos:

Para empezar sobre los temas: en el artículo 21, párrafo primero, de la Constitución de Perú de 1979 se encuentra una cláusula general sobre el Estado de cultura en la figura de un derecho fundamental subjetivo: "El derecho a la educación y a la cultura es inherente a la persona humana". Una ejemplar precisión de los derechos fundamentales a la educación es la que logra el segundo párrafo del mismo artículo mediante las siguientes palabras: "La educación tiene como fin el desarrollo integral de la personalidad. Se inspira en los principios de la democracia social. El Estado reconoce y garantiza la libertad de enseñanza".

Los contenidos educativos en el artículo 22 ("conocimiento y la práctica de las humanidades, el arte, la ciencia y la técnica") no podrían ser formulados de manera más exacta en una Constitución europea. El derecho fundamental "congenial" a la identidad cultural en el artículo 58 de la Constitución de Guatemala ("Se reconoce el derecho de las personas y de las comunidades a su identidad cultural de acuerdo con sus valores, su lengua y sus costumbres") ya fue valorado. También resulta una precisión temática el artículo 2o., inciso 4, de la Constitución de Perú citada: "Los derechos de informar y opinar comprenden los de fundar medios de comunicación".

Una palabra sobre las diversas dimensiones de los derechos fundamentales culturales. Los jurídico-objetivos ya los encontramos en el contexto del análisis de las tareas culturales del Estado, debiéndose mencionar el artículo 63 de la Constitución de Guatemala ("El Estado garantiza la libre expresión creadora, apoya y estimula al científico, al intelectual y al artista nacional, promoviendo su formación y superación profesional y económica"), o el artículo 34 de la Constitución de Perú de 1979 ("El Estado preserva y estimula las manifestaciones de las culturas nativas...; artículo 38: "El Estado 
Este libro forma parte del acervo de la Biblioteca Juridica Virtual del Instituto de Investigaciones Juridicas de la UNAM

promueve la educación física y el deporte...), también el artículo 26 ("La erradicación del analfabetismo es tarea primordial del Estado...”).

La participación en los derechos prestacionales se condensa en el artículo 57 de la Constitución de Guatemala en un texto constitucional que se encuentra plenamente a la altura de la dogmática europea, pero que contiene un componente típico de los países en desarrollo: "Toda persona tiene derecho a participar libremente en la vida cultural y artística de la comunidad, así como beneficiarse del progreso científico y tecnológico de la nación".

El artículo 215 de la Constitución de Brasil de 1988 dispone: "El Estado garantiza a las personas el pleno ejercicio de sus derechos culturales, así como el acceso a las fuentes de la cultura nacional; y apoya y promueve la apreciación y difusión de las manifestaciones culturales".

Sin duda no estaremos escatimando el logro de los países en desarrollo si recordamos los textos ejemplares de los instrumentos internacionales sobre derechos humanos; por ejemplo, el artículo 27, numeral 1, de la Declaración Universal de los Derechos Humanos de Naciones Unidas de 1948 ("Toda persona tiene derecho a tomar parte libremente en la vida cultural de la comunidad, a gozar de las artes y a participar en el progreso científico y en los beneficios que de él resulten”). Ya la positivización jurídica y la consecuente integración en la sistemática y la forma típica de la propia Constitución individual es una contribución que merece respeto, con independencia de los refinamientos en contenidos y las adaptaciones a la biografía histórica de la propia nación. Finalmente, hay que recordar que los principios nacionales e internacionales sobre los derechos fundamentales trabajan de manera común e igualmente intensiva en las etapas evolutivas del tipo del "Estado constitucional". De este modo, el Estado constitucional - o al menos sus elementos textuales particulares-, se transforma verdaderamente en un proyecto universal de la comunidad de los pueblos, y los derechos humanos se convierten en la "religión civil universal" de nuestro tiempo.

\section{e. Cláusulas sobre el pluralismo cultural}

Ya la normación de las libertades culturales introduce el indispensable momento de la apertura en el derecho constitucional de la cultura de los países en desarrollo. Y la constatación del compromiso con el "patrimonio cultural" sería una infructuosa garantía historicizante del status quo si no se tomara en cuenta el aspecto de la diversidad de lo cultural en el pasado y el futuro. Desde el punto de vista de los textos constitucionales, los países en desarrollo recorren aquí el camino correcto entre la elaboración de la pro- 
Este libro forma parte del acervo de la Biblioteca Juridica Virtual del Instituto de Investigaciones Juridicas de la UNAM

pia historia cultural y la apertura hacia lo novedoso. La expresión clave del "concepto abierto de cultura", 418 de la "concepción pluralista de cultura", también puede mostrarse en relación con los países en desarrollo, aunque éstos tienen que luchar muy intensamente por su identidad cultural. He aquí algunos ejemplos textuales:

En su texto, el artículo 34 de la Constitución de Perú (de 1979) se basa ya en la diversidad cultural (protección de las "culturas nativas"), ya que la cultura aparece varias veces en plural. La pluralidad de los fines educativos está condensada de la mejor manera posible en el artículo 72, primer párrafo, de la Constitución de Guatemala ("La educación tiene como fin primordial... el conocimiento de la realidad y cultura nacional y universal"). Notable es el pluralismo de sujetos culturales que se abre paso en varios pasajes textuales, por ejemplo, en el artículo 85 de la misma Constitución (reconocimiento de las universidades privadas con el propósito de contribuir a la "investigación científica, a la difusión de la cultura y al estudio y solución de los problemas nacionales"), o bajo la figura del mandato constitucional para la promoción de la "iniciativa privada en el campo de la educación" (artículo 80 de la Constitución de Costa Rica). En lo demás, las cláusulas sobre el pluralismo consagran, en general, el pluralismo también en el campo cultural, a la manera de la Constitución de Perú (Preámbulo: "sociedad abierta"; en forma similar el preámbulo de la Constitución de Brasil: "sociedad civil, pluralista y libre de prejuicios"; véase también el artículo 1o., fracción V, de la misma Constitución: "pluralismo político").

Un texto "inspirador"puede verse en el artículo 3o., inciso m) de la Carta de la OEA: "La unidad espiritual del Continente se basa en el respeto de la personalidad cultural de los países americanos y demanda su estrecha cooperación en las altas finalidades de la cultura humana".

Por último recordemos una cláusula de Estado de cultura de tipo propio, que incluye a los países en desarrollo, pero también a los individuos. El artículo 17 de la Carta de la OEA dispone: "Cada Estado tiene el derecho de desenvolver libre y espontáneamente su vida cultural, política y económica. En este libre desenvolvimiento el Estado respetará los derechos de la persona humana y los principios de la moral universal".

418 Häberle, P., examinado por primera vez en id., Kulturpolitik in der Stadt ein Verfassungsauftrag, 1979, pp. 22, 34 y ss. 
Este libro forma parte del acervo de la Biblioteca Juridica Virtual del Instituto de Investigaciones Juridicas de la UNAM

\section{El concepto abierto de cultura como fundamento}

Independientemente de un concepto estricto en sí de cultura, el fundamento de los ámbitos materiales del derecho constitucional de la cultura es un concepto abierto de la misma, el que toma en serio - apartándose de una concepción (meramente) ilustrada de cultura - la "cultura para todos" $(\text { H. Hoffmann) })^{419}$ y la "cultura de todos" como magnitud empírica y como lineamiento normativo. El concepto amplio, diverso y abierto de cultura abarca la cultura de la tradición y la ilustración burguesas, así como la cultura "popular" y de masas, tanto como las culturas alternativas, las subculturas y las "contraculturas". La cultura y el concepto de cultura aquí sostenido actúan también en la vida diaria profesional, además de su tradicional situación - que debe conservarse - en el ámbito del tiempo libre. La convivencia, el intercambio y la competencia entre alta cultura, cultura popular y subcultura, de la cultura de consumo y la cultura activa, es una garantía de la diversidad cultural. Ésta vive del derecho constitucional de la cultura desarrollado "en" el Estado federal, con sus elementos de la libertad cultural, del pluralismo cultural, de la división cultural de los poderes: este concepto abierto de cultura es consecuencia de la estructura pluralista de la comunidad política.

Lo determinante sigue siendo el enfoque antropológico: el ser humano tiene distintas necesidades culturales, a las cuales debe dar un marco óptimo el derecho constitucional. En este sentido, el derecho, incluso el derecho constitucional de la cultura en el Estado federal, jes sólo un instrumento! El ser humano no vive sólo de la cultura, pero esencialmente vive hacia la cultura y de la cultura de generaciones pasadas y presentes (en el sentido de un contrato cultural de las generaciones, que en sí es una conquista cultural). La cultura es, y crea, la posibilidad y la realidad de dar sentido en una historia que se concibe abierta. Dicho en palabras de A. Gehlen: el ser humano es "por naturaleza un ser cultural".

\section{La relación con la teoría constitucional como ciencia cultural}

Lo que "norma" el derecho constitucional de la cultura no son sino sectores del objeto cultura. El texto constitucional los aborda de manera directa, sin "mediación", en la medida en que esto es posible, en general, en este sensible campo. Aquí se encuentran los sectores de la cultura en sentido

419 Hoffmann, H., Kultur für alle, 1979, 2a. ed., 1981. 
Este libro forma parte del acervo de la Biblioteca Juridica Virtual del Instituto de Investigaciones Juridicas de la UNAM

estricto, como la ciencia y el arte, la educación y la formación, también los objetivos educativos, días festivos, política cultural abierta y el deporte, en la relación más estrecha posible con el derecho. Se llega a una "simbiosis" entre derecho y cultura; se habla con razón de un "derecho de la cultura".

La relación entre Constitución y cultura en sentido más amplio, por el contrario, se encuentra mediatizada, aunque ello no la hace menos importante. Incluso son "cultura" el derecho constitucional económico, también la vida política, las actitudes valorativas de un pueblo, como objeto de investigaciones sobre su "cultura política". Mientras el derecho constitucional de la cultura en sentido más estricto puede ser captado jurídicamente, una concepción de la teoría constitucional como ciencia cultural requiere muchos eslabones intermedios y la contribución de muchos científicos.

\section{BIEN COMÚN Y TAREAS DEL ESTADO \\ (EL ENFOQUE MATERIAL Y PROGESAL)}

\section{Bien común}

A) El legislador, el gobierno, los funcionarios de la administración y los jueces tienen que trabajar día a día con el concepto de bien común; por ello no es posible evadirse hacia la "tesis de la fórmula vacía" en boga. En la democracia pluralista, el bien común -idéntico al interés público- es indispensable, aunque haya que desentrañarlo de modo diferenciado. La aportación parcial de la ciencia jurídica como ciencia práctica es labor previa para un foro de diálogo interdisciplinario.

B) El bien común se encuentra en todos los planos de la jerarquía de las normas y en todos los ámbitos del derecho, pero también en el contexto de todas las funciones del Estado, como principio, norma y topos jurídicos. A partir del material jurídico que en un primer momento aparece como difuso, es posible elaborar, en el plano de la legislación y la jurisprudencia, ciertas tipologías, es decir, constelaciones en las que el interés público cumple con determinadas funciones. A ellas pertenece, por ejemplo, el bien común como fundamento competencial y como título que limita los derechos fundamentales y crea obligaciones, como cláusula de excepción y título para los secretos del Estado (no publicidad). Pero de manera creciente se dibujan diferenciaciones e interrelaciones: el bien común se determina también a partir de intereses privados, entra en colisión con otros intereses públicos (plurales) ("conflictos en sí"); la libertad fundamental se convierte en parte 
Este libro forma parte del acervo de la Biblioteca Juridica Virtual del Instituto de Investigaciones Juridicas de la UNAM

integrante del interés público: así la libertad de opinión, prensa e información abre la vía para la "actualización de la publicidad y la concretización del bien común" en la res publica. El tercer poder se convierte, en la "jurisprudencia del bien común", gracias a sus sutiles técnicas pretorianas, en la concretización de los intereses públicos. Para la administración y la legislación, el bien común es, por su parte, un concepto guía abierto al desarrollo.

G) En el ámbito de lo social-público, los partidos políticos y otros grupos plurales - como las partes en las negociaciones laborales colectivas - formulan intereses públicos que, en la democracia pluralista, han perdido su referencia estatal y su carácter de previamente dados (más allá de las directivas constitucionales). La democracia, el pluralismo, la apertura y los derechos fundamentales, dan perfil sustantivo y procesal al bien común, el cual se encuentra situado, en el marco de las instituciones jurídicas - al igual que en el de la acción colectiva, como la de las asociaciones de protección del ambiente o la fauna - y bajo la responsabilidad del jurista.

D) La historia y la discusión teóricas — tangible en los textos de los clásicos lo mismo que en la vida diaria política - oscilan entre la hipostación acrítica del bien común en el concepto "supremo", no cuestionado, sino "creído", "ontológico" "bonum commune", "razón de Estado", "máxima arcana"), en cuyo nombre se han eliminado, e incluso reprimido, los intereses privados, como en las "sociedades cerradas", por un lado ("la utilidad común prevalece sobre la utilidad propia”, y similares), y la degradación hacia una simple "fórmula vacía", hacia un mero instrumento de poder, encubierto ideológicamente, por el otro. Por el contrario, en las sociedades abiertas (en el sentido de Popper), el bien común se revela como una fórmula que constituye a la convivencia humana. Sus contenidos históricamente cambiantes remiten a contextos de legitimación últimos o penúltimos, como la concepción del Estado y la forma de gobierno ("república", "democracia"), la ética social y la justicia, y tiene que ser transformado en la práctica en el caso particular del derecho positivo, a pesar de la tensión que pueda haber entre el bien común como postulado ideal y su realidad (no pocas veces deficiente).

E) En el Estado constitucional democrático de tipo occidental (con la dignidad humana como premisa, con legitimación democrática, derechos fundamentales y división de poderes, esfera pública pluralista y los "objetivos" del Estado social y cultural de derecho) es posible y necesaria una teoría jurídica del bien común. La Constitución, entendida como orden jurídico fundamental del Estado y la sociedad, ofrece directivas sustantivas para el bien común; también abre una diversidad de procedimientos para su concretización y revisión. 
Este libro forma parte del acervo de la Biblioteca Juridica Virtual del Instituto de Investigaciones Juridicas de la UNAM

F) Las palabras clave son "salus publica ex constitutione", "salus publica ex processu". El bien común republicano, en el marco de la LF, es menos un dato previo que una tarea conferida concretamente. Es el resultado de complejos procesos en la combinación de muchos miembros de las funciones estatales y los procesos públicos.

G) Numerosos impulsos para el bien común provienen, en el Estado constitucional, tanto de la sociedad abierta como de la constituida. Grupos plurales de todo tipo formulan, de manera agresiva o defensiva, de modo puntual o sectorial, aspectos del bien común que tratan de introducir en la determinación estatal del bien común.

H) A pesar, o quizá debido a sus manifestaciones jurídicas, requiere el bien común de investigación interdisciplinaria. Siendo desde la antigüedad una categoría del hombre que reflexiona sobre su res publica y que actúa en ella y para ella, el bien común se encuentra en un contexto cultural concreto. Los conceptos jurídicos básicos como el bien común no viven de sí mismos, sino que surgen de numerosos logros integradores de la cultura de un pueblo. El "bien común" debe ser determinado concretamente, y en tal medida es "relativo", pero también está dotado con contenidos y procedimientos clásicos, es un catalizador.

I) La Constitución del pluralismo descansa en contextos que en última instancia sólo pueden ser desentrañados por la ciencia cultural, y que el jurista no puede desentrañar solo (véanse también los fines educativos). Su consenso mínimo y básico (por ejemplo, de respeto al procedimiento del bien común, de la protección de las minorías, la prohibición de la violencia y la tolerancia) enraiza en estos ámbitos. En vista de crisis y peligros especiales, el actual concepto de bien común se ve sometido aquí a prueba.

J) Mientras que el concepto de bien común en el Estado constitucional debe elaborar cada vez nuevos instrumentos y procedimientos, para impedir los déficit del bien común (consumidores, contribuyentes, minorías de las minorías, acciones colectivas), la discusión interdisciplinaria del bien común tiene que prepararse para los enormes desafios de tipo ideal y material (por ejemplo, en materia de "desarrollo sustentable"). La concepción abierta del bien común surge y cae con la Constitución del pluralismo y con la fertilidad del diálogo entre las disciplinas particulares. 
Este libro forma parte del acervo de la Biblioteca Juridica Virtual del Instituto de Investigaciones Juridicas de la UNAM http://www.juridicas.unam.mx

\section{Tareas del Estado}

En lo que sigue se esbozará una teoría constitucional de las tareas del Estado. ${ }^{220}$ Dicha teoría se intersecta en parte con la cuestión del bien común, aun cuando los textos constitucionales recientes hablan hoy menos frecuentemente de "bien común". Mientras que las "tareas del Estado" (Staatsaufgaben) ${ }^{421}$ tienen un referente estatal directo, el bien común tiene un alcance más amplio, por ejemplo, que incluye a los ciudadanos y los grupos.

A) Una doctrina de las tareas del Estado constitucional debería adoptar de entrada un punto de vista interdisciplinario: la filosofía, la ciencia política, la economía política, la sociología e incluso la teología, están llamadas a manifestar sus contribuciones (limitadas y que deben ser limitadas) que desde hace tiempo hacen en materia de "tareas del Estado". La teoría constitucional tiene que integrarlas, del mismo modo que en otras ocasiones actúa como foro para las ciencias particulares. Así, hay que mezclar lo mismo los textos clásicos de la teoría del Estado que los de la economía política, ${ }^{422}$ o la doctrina social católica, la antigua tradición de la doctrina de los fines del Estado, ${ }^{423}$ la historia y el presente de las discusiones sobre el bien común, lo mismo que su perversión; así, el régimen nazi²4 (forma ejemplar de Estado totalitario) puede servir igualmente como material de enseñanza, a partir de lo negativo, para el tipo del "Estado constitucional".

B) Las "tareas del Estado" tienen que ser concebidas, de entrada, a partir del tipo del Estado constitucional, es decir, sobre todo a partir de la comunidad política constituida por la Constitución. Este tipo debe ser desentrañado en la comparación histórica y contemporánea de textos constitu-

420 Sobre lo que sigue, antecedentes ya en Häberle, P., "Verfassungsstaatliche Staatsaufgabenlehre", $A \ddot{o} R$, vol. 111, 1986, pp. 595 y ss.; también Isensee, J., "Gemeinwohl und Staatsaufgaben im Verfassungsstaat", HdBStR, vol. III, 1988, pp. 3 y ss.; Hebeisen, M. W., Staatszwecke, Staatsziele, Staatsaufgaben, 1996. El concepto de "public interest"se encuentra crecientemente en Europa oriental; por ejemplo, artículo 20, inciso 2, frase 1, de la Constitución eslovaca de 1992; artículo 59, inciso 3, de la Constitución de Polonia (1997), la cual utiliza de manera destacada la idea del bien común en su preámbulo ("common good of Poland").

${ }_{221}$ Aunque el término "Staatsaufgaben" podría traducirse como "funciones del Estado", hemos preferido el concepto de "tarea" que, si bien resulta menos usual en el contexto de la teoría constitucional, permite distinguir la actuación concreta del Estado frente al desempeño de funciones genéricas "funciones del Estado" por el autor (véase supra VI, 2.) (N. del T.).

422 Atinadamente al respecto: Starbatty, J., Die englischen Klassiker der Nationalökonomie, 1985.

${ }^{423} \mathrm{Al}$ respecto Hespe, K., Zur Entwicklung der Staatszwecklehre in der deutschen Staatsrechtswissenschaft des 19. Fahrhunderts, 1964.

${ }_{224} \mathrm{Al}$ respecto Stolleis, M., Gemeinwohlformeln im nationalsozialistischen Recht, 1974. 
Este libro forma parte del acervo de la Biblioteca Juridica Virtual del Instituto de Investigaciones Juridicas de la UNAM

cionales, también en su cambio. Esto significa concretamente un "adiós" a todos los "préstamos" abiertos o encubiertos al Estado por la "teoría general del Estado". Sobre todo, no hay que adoptar el concepto de las "tareas" "natas", "nucleares" o "primarias", así como tampoco el del "Estado industrial de regulación intensiva"(R. Zippelius). Es de rechazarse este último concepto porque encubre la diferencia fundamental entre el tipo del Estado totalitario y el Estado constitucional. Tampoco debe hablarse de tareas "natas" o "primarias", porque de este modo se desvalorizan indebidamente las nuevas tareas del Estado constitucional que lo legitiman en su actual etapa evolutiva y textual (tal como se manifiesta en las cláusulas sobre el Estado de cultura o social, así como en los artículos sobre el medio ambiente). Las tareas "clásicas" del Estado son también resultado de una evolución histórica; incluso las más recientes, en la fase evolutiva más próxima, han "nacido" y pueden modificarse en su desarrollo futuro. Cuando se introducen estas distinciones se manejan (inconscientemente) categorías de la teoría general del Estado surgida del "Estado" (absoluto). Sobre todo, en última instancia no se toma en serio la idea de que el Estado constitucional es constituido en todo por la Constitución, también en sus tareas. El Estado constitucional se distingue tanto del "Estado absoluto" como del totalitario en la concepción de las tareas estatales. De hecho, hay que trabajar primariamente en "el taller de la Constitución y no en el del Estado" (K. Stern), y contra él hay que llevar a término este enfoque en la "división" de las tareas del Estado. Las funciones clásicas del Estado se legitiman también por la Constitución y no por el "Estado". El Estado constitucional no se divide en un "nacimiento" o "naturaleza" estatal (o en tareas "natas" del Estado) y en historia o cultura jurídico-constitucionales ("tareas condicionadas a la situación"). En su concepción actual es un "resultado intermedio" o una etapa evolutiva, que reclama respeto, de los procesos culturales. En particular hay que desentrañar, mediante el pensamiento de las necesidades, cuáles tareas del Estado son "necesarias" y también "posibles". Al hacerlo hay que argumentar tanto a partir del tipo del Estado constitucional como de los ejemplos nacionales particulares.

C) Los contenidos, las divisiones y los límites de las tareas del Estado constitucional se desentrañan, por un lado, a través de la comparación de las etapas textuales de Constituciones antiguas y recientes. Por el otro lado, son necesarios los inventarios empíricos de lo que realmente se realiza. Por lo que toca a la comparación de textos constitucionales, aquí se presentan procesos de desarrollo notables. Las Constituciones recientes en Suiza, Por- 
Este libro forma parte del acervo de la Biblioteca Juridica Virtual del Instituto de Investigaciones Juridicas de la UNAM http://www.juridicas.unam.mx

tugal (1976-1992 ${ }^{425}$ y España (1978), se inclinan a normar expresamente una multiplicidad de "objetivos", "fines", etcétera, del Estado; se desconfía evidentemente de los "plenos poderes" o "poderes en blanco"(post)absolutistas en el sentido de H. Krüger. Dicho en otras palabras: se muestran procesos intensivos de crecimiento en materia de tareas del Estado; y puesto que éstas están fijadas o desarrolladas en los textos constitucionales, se trata al mismo tiempo de un proceso de normativización o constitucionalización del tema de las tareas de Estado.

D) Los catálogos de tareas del Estado se extienden tanto en lo textual como en lo científico hacia los apartados sobre derechos fundamentales, ${ }^{426}$ pero también a la inversa. En otros términos: ya no se puede sostener el terco dualismo entre tareas del Estado, por un lado, y derechos fundamentales, por el otro. Así, en los catálogos de tareas del Estado se encuentran en ocasiones temas típicos de los derechos fundamentales (por ejemplo, artículo 2o., inciso 2, del proyecto constitucional suizo de 1977: "El Estado protege los derechos y libertades del ser humano y crea las bases necesarias para su realización"); así, hay "teorías generales de los derechos fundamentales" que no solamente los entienden como "límite"(lo que no dejan de ser), sino también como tareas, ${ }^{427}$ es decir, las tareas del Estado y los derechos fundamentales se han "aproximado" también en el más antiguo tipo de Estado ("solamente liberal").428

425 Cfr. el artículo 9o. de la Constitución de Portugal: "Son misiones fundamentales del Estado: 1. Garantizar la independencia nacional y crear las condiciones políticas, económicas, sociales y culturales que la promuevan; 2. Garantizar los derechos y libertades fundamentales...; 3. Defender la democracia política...; 4. Promover el bienestar y la calidad de vida del pueblo y la igualdad real entre los portugueses, así como la efectividad de los derechos económicos, sociales, culturales... 5. Proteger y valorizar el patrimonio cultural del pueblo portugués, defender la naturaleza y el medio ambiente, preservar los recursos naturales...”. Otro catálogo de tareas en el artículo 5o. de la Constitución de Guinea Ecuatorial.

426 Por ejemplo, el artículo 19 de la Constitución de los Países Bajos de 1983, inciso 1: "La creación de suficientes plazas de trabajo es objeto de cuidado por las autoridades...". Inciso 3 del mismo artículo: "Se reconoce el derecho de todos los ciudadanos de los Países Bajos a la libre elección del trabajo...".

427 Sobre las "funciones de los derechos fundamentales" así entendidas véase mi ponencia presentada en Ratisbona VVDStRL, vol. 30, 1972, pp. 43 (103 y ss.).

428 Especialmente visible es la vinculación en la Constitución de Suecia (1974-76): "Principios básicos", 2: "El poder público se ejercerá con respeto al igual valor de todos y a favor de la libertad y la dignidad del individuo. El bienestar personal, económico y cultural del individuo será objetivo fundamental de la actuación pública; corresponderá a la administración pública asegurar el derecho al trabajo, la vivienda y la educación, y promover la previsión y la seguridad sociales, así como un sano ambiente para vivir." 
Este libro forma parte del acervo de la Biblioteca Juridica Virtual del Instituto de Investigaciones Juridicas de la UNAM http://www.juridicas.unam.mx

Desde el punto de vista dogmático se requiere tanto un "pensamiento de los límites" como de las "tareas". Antes y ahora, los derechos fundamentales norman los límites del Estado constitucional, así como sus "tareas", pero describen también de manera positiva tareas que le corresponden ("pensamiento competencial orientado a los derechos fundamentales").

E) Las clasificaciones de las tareas del Estado constitucional son recomendables por el lado temático: por ejemplo, la seguridad interior y exterior, ${ }^{429}$ la "economía", ${ }^{330}$ la "cultura", ${ }^{331}$ la "naturaleza" y el "medio ambiente", ${ }_{432}$ la "salud" y el "deporte". ${ }_{433}$ Puesto que muchos de estos temas afectan ámbitos de los derechos fundamentales, se dan algunas interseccciones (por ejemplo, el mandato cultural del Estado y las libertades culturales de los ciudadanos y grupos). ${ }^{434}$ Los conflictos de objetivos son palmarios: por ejemplo, entre economía y ecología. ${ }^{435}$

F) Hay que hacer una distinción entre tareas del Estado, tareas públicas y tareas privadas, en correspondencia con la "triada de ámbitos republicanos". Las tareas del Estado son cumplidas, con fundamento en una autorización constitucional, por el Estado; las "tareas públicas", por grupos, instituciones o individuos que no forman parte del Estado (por ejemplo, por la prensa, por las partes en las negociaciones colectivas laborales, por las iglesias).436 En qué medida pueden "estatizarse" las tareas públicas o incluso

429 Por ejemplo: artículo 2o. de la Constitución federal suiza: "La Confederación tiene por objeto asegurar la independencia de la Patria frente al extranjero, mantener la tranquilidad y el orden en el interior, proteger la libertad y los derechos de los confederados y acrecer su prosperidad común".

430 Por ejemplo, el artículo 40, inciso 1, de la Constitución española.

431 Por ejemplo, el artículo 44, inciso 1, de la Constitución española: "Los poderes públicos promoverán y tutelarán el acceso a la cultura, a la que todos tienen derecho”, o el artículo 7o., inciso 1, de la Constitución de Schleswig-Holstein (1949): "El Land promueve y protege el arte y la ciencia, la investigación y la docencia”.

432 Por ejemplo, el artículo 24 de la Constitución de Grecia. Cfr. también el octavo apartado de la Constitución de Brandemburgo de 1992: "Naturaleza y medio ambiente" (así como el apartado cuarto de la Constitución de Turingia de 1993).

433 Por ejemplo, el artículo 22, inciso 1, de la Constitución de los Países Bajos; el artículo 43 de la Constitución española; el artículo 68 de la Constitución de Polonia (1997). Artículo 30, inciso 3, de la Constitución de Turingia (1993): "El deporte goza de protección y promoción por el Land y sus corporaciones territoriales".

434 Por ejemplo, artículos 73 y 79 de la Constitución de Portugal.

435 Una máxima de armonización se encuentra en el 112 de la Constitución cantonal de Basilea-Comarca (1984): en su inciso 1: "El cantón y los municipios tienden hacia una relación, equilibrada en el largo plazo, entre las fuerzas de la naturaleza y su renovabilidad, por un lado, así como su utilización por el ser humano, por la otra”.

${ }_{336}$ También aquí son productivos los textos constitucionales recientes, por ejemplo, el artículo 15 de la Constitución de Grecia, inciso 2, in fine: "La radio y la televisión... procura- 
Este libro forma parte del acervo de la Biblioteca Juridica Virtual del Instituto de Investigaciones Juridicas de la UNAM http://www.juridicas.unam.mx

las privadas, es algo que decide la Constitución (limitándolas, por ejemplo, vía los derechos fundamentales), en el marco de su proceso político (por ejemplo, artículo 14, inciso 3, LF). Una teoría del Estado constitucional tendría que aclarar cuestiones particulares sobre lo privado.

G) En la democracia pluralista, la Constitución adopta enunciados materiales y procesales sobre las tareas del Estado: jurídico-materiales, en tanto menciona tareas sustantivas (de manera general, como en la cláusula del Estado social, o de modo especial). ${ }^{437}$ Numerosas tareas del Estado son tales, o se convierten en tales, primero vía un procedimiento (es decir, en el proceso político), porque el bien común pluralista se encuentra abierto. Aquí domina el indispensable margen de acción para una medida mayor o menor de "Estado" o de "lo privado", de "Estado" o de "más mercado", o de estatización o privatización (los ejemplos más recientes en Inglaterra y Francia, también en su "ir y venir", se mantienen dentro de una doctrina de las tareas del Estado constitucional; la actual euforia privatizadora en Alemania podría haber llegado a los límites del Estado social y de cultura). Frente a un posible "exceso" de tareas estatales, debe recordarse la función de límite de los derechos fundamentales; frente a una "carencia", su valor como fundamento competencial ("libertad a través del Estado constitucional"). La máxima orientadora es el principio de subsidiariedad (históricamente mudable). En el marco de la Constitución se puede hablar de una apertura de las tareas estatales; los límites los trazan, además de los derechos fundamentales, los conceptos generales o particulares, más o menos "determinados", que se emplean en la Constitución.

H) En la comparación histórica y contemporánea hay que examinar los procesos de expansión, intensivización y diferenciación, que crecientemente caracterizan a las tareas estatales del tipo del "Estado constitucional". ${ }_{438}$ Sobre todo hay que examinar bajo cuál ropaje textual pueden ser normadas tales tareas en el Estado constitucional. Aquí se revela una amplia variación, que va desde las normas expresas sobre tales funciones, pasando por

rán... salvaguardar en sus emisiones, en todo caso, el nivel de calidad que resulte necesario respecto de su función social y el desarrollo cultural del país". Artículo 46, inciso 1, de la Constitución de Berna (1993): "El cantón fomenta la independencia y la pluralidad de las informaciones".

437 Por ejemplo, artículo 9o., primer párrafo, de la Constitución de Italia: "La República promueve el desarrollo de la cultura y la investigación científica y técnica". Artículo 108, inciso 1, de la Constitución de Sajonia (1992): "Se promoverá la educación de los adultos". Similar el artículo 29 de la Constitución de Turingia de 1993.

$438 \mathrm{Al}$ respecto, con material comparativo sobre Suiza: Häberle, P., "Neuere Verfassungen und Verfassungsvorhaben in der Schweiz, insbesondere auf kantonaler Ebene", f̈öR, vol. 34, 1985, pp. 303 (31 y ss., 370 y ss.). 
Este libro forma parte del acervo de la Biblioteca Juridica Virtual del Instituto de Investigaciones Juridicas de la UNAM

las "simples" competencias, ${ }^{439}$ hasta los derechos fundamentales. ${ }^{40}$ Especialmente en éstos se esconden actualmente, apoyados por la doctrina y la jurisprudencia, "tareas estatales": recuérdese la concepción de las "tareas de los derechos fundamentales". Los derechos fundamentales y las tareas estatales se encuentran en una relación ambivalente. Por un lado, en los derechos fundamentales pueden estar "escondidos" mandatos constitucionales para el cumplimiento de tareas estatales activadas por el término del "aspecto prestacional" de los derechos fundamentales; por otro lado, hay que recordar una y otra vez la función limitadora de los derechos fundamentales respecto de las tareas del Estado. En la medida en que la dogmática de los derechos fundamentales complemente la dimensión clásica de no interferencia del Estado a través del aspecto jurídico-objetivo, prestacional, protector y procesal, se intensifican y se diferencian las funciones del Estado. El creador del texto constitucional sigue esto. Este es un motivo para la "multiplicación" de las tareas del Estado incluidas en textos constitucionales.

I) Hay que desarrollar, respecto el Estado constitucional, una doctrina que describa en qué procesos se desarrollan las tareas estatales como tales en la "Constitución del pluralismo". La "concepción procesal, pluralista, del bien común" representa una oferta teórica. La teoría constitucional puede, sin duda, mencionar criterios sustantivos generalizadores y, sobre todo, procedimientos diferenciados, en los cuales las tareas del bien común sean esbozadas en forma de tareas estatales y sean cumplidas en lo particular. En este sentido, siguen siendo notables las nuevas cláusulas sobre "state policy" en Sudáfrica.

J) Una doctrina de las tareas del Estado constitucional que se oriente por el tipo del "Estado constitucional", sobre todo en el modo en que éste se hace tangible en el espejo de sus textos, debería esbozar también directivas para la política constitucional, así como lo intenta la teoría constitucional para otros temas.

K) En suma: el tema de las "tareas del Estado" no puede ser olvidado ni por la teoría de la Constitución ni por los creadores de textos constitucionales. Es tan "importante" que asume el rango de derecho constitucional material y, por tanto, una configuración normativa variable en el texto constitucional (con nuevos temas como salud, medio ambiente, política de medios de comunicación, protección del consumidor, etcétera). ${ }^{411}$ Hay numerosas

439 Por ejemplo, el artículo 10 de la Constitución federal de Austria (1920): "Son materias federales...".

${ }_{440}$ Por ejemplo, el artículo 6o., inciso 5, de la LF.

441 En Constituciones recientes se convierte la protección del consumidor en tema de muchas maneras: Constitución española (1978), en el capítulo "De los principios rectores de la 
Este libro forma parte del acervo de la Biblioteca Juridica Virtual del Instituto de Investigaciones Juridicas de la UNAM http://www.juridicas.unam.mx

variantes de regulación; no es poco lo que habla en favor de poner sus "fundamentos" en el preámbulo o en los artículos iniciales (así en la Constitución de Sajonia-Anhalt de 1992 o el preámbulo de la Constitución de Mecklemburgo-Antepomerania de 1993: entre otros, protección de los "débiles").

Sin embargo, textualmente hay que dejar la "primacía" a los derechos fundamentales, también en lo externo, pues primero hay que "sentar" la "premisa" constitucional de la dignidad humana. Mucho es lo que habla en favor de un apartado propio sobre las "tareas del Estado" después de un apartado "clásico" sobre los derechos fundamentales. También puede pensarse en enriquecer deliberadamente los derechos fundamentales con tareas estatales, con lo cual podría renunciarse a un apartado propio de tareas estatales. En suma, hay que prevenir contra un "ramillete" excesivo de tareas estatales detalladas en la Constitución. La teoría constitucional no puede ser demasiado concreta en esas máximas político-constitucionales, porque no debe obstaculizar en exceso la innovación por parte del proceso político. Es precisamente un distintivo de la apertura de la Constitución recomendar "esto pero también lo otro": por un lado, textos "inductores", pero por el otro, límites en el tema "tareas estatales", reserva en lugar de "furia reglamentadora y normadora". Las citadas Constituciones recientes ofrecen mucho material de prueba sobre las soluciones logradas, pero también alguna exageración y motivo para la crítica. Aquí no hacen sino reflejar la urgencia de una doctrina más desarrollada de las tareas estatales. La elaboración de la referencia de las tareas estatales a los derechos fundamentales, pero también la referencia de éstos a aquéllas, sigue siendo un desiderato de la investigación. Ambos aspectos logran un pedazo esencial de legitimación del Estado constitucional tanto del tipo como de su configuración concreta.

Las tareas del Estado son elemento indispensable de la "imagen del Estado" (más precisamente: de la imagen del Estado constitucional) de una comunidad política. ${ }^{442}$ Esta "imagen" se basa en la "imagen del hombre" del

política social y económica", artículo 51: 1. "Los poderes públicos garantizarán la defensa de los consumidores y usuarios, protegiendo, mediante procedimientos eficaces, la seguridad, la salud y los legítimos intereses económicos de los mismos". 2. "Los poderes públicos promoverán la información y la educación de los consumidores y usuarios, fomentarán sus organizaciones y oirán a éstas en las cuestiones que puedan afectar a aquéllos, en los términos que la ley establezca". 3. "En el marco de lo dispuesto por los apartados anteriores, la ley regulará el comercio interior y el régimen de autorización de productos comerciales". Constitución del Cantón del Jura (1977): "III. Les Tâches de L'état... 10. La protection des consommateurs". Artículo 52: "L'État considère les interêts des consommateurs".

442 Sobre las cuestiones de la "imagen del Estado": Häberle, P., Die Wesensgehaltsgarantie des Art. 19 Abs 2 GG, 3a. ed., 1983, pp. 363 y ss. El artículo 3o. de la Constitución de Ucrania vincula imagen del Estado y del ser humano. 
Este libro forma parte del acervo de la Biblioteca Juridica Virtual del Instituto de Investigaciones Juridicas de la UNAM

Estado constitucional como tipo. Las tareas del Estado deben verse aquí, tanto en la Constitución como en su conjunto, en procesos de evolución cultural, y en las correspondientes "etapas textuales" (incluso hacia un futuro abierto). La riqueza de formas, procedimientos y contenidos es grande, porque el tipo del "Estado constitucional" ofrece bastante margen de configuración, pero norma también límites, los cuales deben buscarse, en última instancia, en la dignidad, libertad e igualdad de los ciudadanos. En este sentido, todo pensamiento y acción sobre las tareas estatales reconducen a la premisa antropológico-cultural del Estado constitucional; hacia la dignidad humana. Las cláusulas de state policy que en tiempos recientes se han vuelto más frecuentes y arbitrarias no deberían ser recibidas por la imagen constitucional de los Estados constitucionales europeos.

\section{TRABAJO Y PROPIEDAD, ECONOMÍA SOCIAL Y ECOLÓGICA DE MERCADO}

\section{Elementos de una "teoría constitucional del trabajo"}

La comparación jurídica histórica y contemporánea, bastante más allá del "derecho al trabajo", conduce, en el Estado constitucional, a las siguientes palabras clave:

A) Trabajo y propiedad se encuentran en una relación interna y externa, material y funcional, a pesar del antagonismo con el que frecuentemente se presentan en la historia constitucional y social. Culturalmente pertenecen ambos a un gran contexto, en parte en rivalidad, en parte en competencia, en parte en complementariedad. La historia de la cultura varía constantemente esta relación. Visto en conjunto con el derecho ordinario, el derecho constitucional refleja aspectos importantes de esta relación.

B) En un Estado constitucional como la República Federal de Alemania, esta relación se intensifica. La propiedad y el trabajo "en el sentido de la Constitución" se constituyen mutuamente. Las contraposiciones y "relaciones de competencia" entre propiedad y trabajo se reducen. Textualmente ambos van creciendo. Las vinculaciones se hacen visibles, por un lado, bajo la figura de la "nueva" propiedad o la "cuasi-propiedad", por el otro lado, por la protección constitucional especial a la propiedad "producto del trabajo". Las obligaciones sociales de la propiedad se intensifican en interés de los trabajadores, al mismo tiempo que se llega a formas de "más propiedad para todos" a partir del trabajo. Las Constituciones en el Estado constitu- 
Este libro forma parte del acervo de la Biblioteca Juridica Virtual del Instituto de Investigaciones Juridicas de la UNAM

cional expresan crecientemente esta relación entre trabajo y propiedad al regular a ambos en el mismo apartado; a veces, el artículo sobre la propiedad en el catálogo clásico de derechos fundamentales "emigra" hacia el derecho constitucional del trabajo. En otras ocasiones, la materia del trabajo figura, de manera incluso "apreciada", antes de la propiedad. El "derecho constitucional del trabajo" "crece", sin volverse "omnipresente", y sin poder hacerlo, como en las Constituciones socialistas, pues ello rompería con la "Constitución del pluralismo".

C) No sólo la propiedad, sino que también, y precisamente, al "trabajo" hay que ponerlo en conexión con las "disposiciones sobre la esencia humana". Ambos, propiedad y trabajo, pertenecen a la "conditio humana", a la libertad personal y a la dignidad de los derechos humanos (libertad de trabajar como "desenvolvimiento de la personalidad"), por lo que hay que buscar una "posible unidad" de ambos como derecho humano. El enfoque antropológico-cultural debe verse cumplido hoy, en última instancia, en el plano de una teoría de la Constitución desarrollada como ciencia cultural (pero distinta, en tanto tipo ideal y tipo real, de las Constituciones socialistas y las islámicas fundamentalistas). La "reconstrucción" de la agitada "historia constitucional del trabajo y la propiedad" sólo a través de las ciencias sociales sería demasiado estrecha, pues así tendrían muy escaso peso las concepciones, ricas en consecuencias, de vocación religiosa y teológica; se "explicaría" de manera demasiado unidimensional la "concepción de vocación idealista-holística" que ha influido en "todos los estratos educados de la sociedad alemana" y que actúa hasta ahora.

D) Si en la actualidad el trabajo, junto con la propiedad, está situado así en el centro de la identidad del ser humano y el ciudadano y su libertad, ello tiene, en el Estado constitucional, consecuencias para varios ámbitos parciales del texto constitucional en conjunto. No hay que preguntar sólo de modo puntual por la normación de un derecho al trabajo, sino integralmente (y por lo tanto, igualmente variados tendrán que ser las técnicas y los contenidos de la normación): el trabajo, que de entrada ha de verse en el "contexto" cultural con la dignidad humana, la libertad y la propiedad, tiene un sitio en el marco de los fines educativos y las tareas estatales, es decir, por un lado, desde el punto de vista competencial, y por el otro, en forma de un derecho fundamental al trabajo, de múltiples dimensiones, con "garantías conexas", como la protección de la salud, las condiciones justas de trabajo, etcétera. La concepción de un derecho fundamental al trabajo de estructura compleja relativiza la dicotomía (supuestamente "clásica") entre los derechos de libertad y los derechos fundamentales sociales, del mismo modo como el "trabajo" y la "protección del trabajo" penetran en 
Este libro forma parte del acervo de la Biblioteca Juridica Virtual del Instituto de Investigaciones Juridicas de la UNAM

las dimensiones de los derechos fundamentales. Esta concepción del derecho fundamental como "etapas" o "estadios" sobre una escala completa de contenidos y técnicas normativos permite, en última instancia, también un panorama diferenciado de la materia del trabajo junto con otros "temas" de las Constituciones del Estado constitucional (en especial, con la dignidad humana, la libertad y la propiedad), así como del trabajador como ser humano, con los "derechos fundamentales paralelos" suyos y de sus congéneres (por ejemplo, los del propietario). Esta "conexión" se produce y debe reproducirse constantemente, en primera y última instancia, en el contrato social dirigido hacia la propiedad y el trabajo. Así se cumple, desde el punto de vista de la ética social, con la muy invocada "solidaridad", tanto de manera "práctica" como "teórica".

E) No obstante la altura a la que se sitúa, en la teoría constitucional, a la materia trabajo y a la persona, y a pesar de la alta jerarquía en que están desarrollados actualmente los aspectos del derecho constitucional del trabajo, distribuidos en los diversos pasajes del texto constitucional (desde los préambulos, pasando por los fines educativos, que contienen el "ethos de la sociedad del trabajo", hasta los catálogos de derechos fundamentales, las normas sobre tareas estatales y los apartados sobre la economía y la cultura - esto tratándose de la propiedad y el trabajo "intelectuales"-), la prestación relativa a la propiedad y el trabajo en la cotidianeidad del Estado constitucional es aportada sobre todo por el derecho ordinario y sus intérpretes: las "concretizaciones del derecho al trabajo" se encuentran de manera muy diversa en el derecho del trabajo, pero también en otros ámbitos del derecho ordinario, como en el derecho social, el derecho fiscal, etcétera. Aquí participan todos en la "sociedad abierta de los intérpretes constitucionales". Se requiere un diálogo cultural de las diversas ciencias particulares sobre la materia "trabajo" y la persona del ser humano trabajador, también para reconocer lo que significa el desempleo.

Si este diálogo cultural conduce a encontrar una salida a la magnificación teórica, incluso la absolutización del trabajo, iniciada en el siglo XVII, que ahora encuentra sus límites en una "crisis de la sociedad del trabajo", ${ }_{433}$ es una cuestión que queda abierta aquí. Sin duda tiene que crecer la conciencia de que hay actividades "de altura" y "razonables" más allá del trabajo pagado (por ejemplo, los cargos honoríficos). El Estado constitucional occidental se encuentra aquí frente a desafíos apenas conocidos, pero también ante oportunidades. Un cambio culturalmente condicionado del concepto de trabajo podría volverse justamente agudo en este momento en que

${ }_{443} \mathrm{Al}$ respecto, Arendt, H., Vita activa, 1960, especialmente pp. 11 y ss. 
Este libro forma parte del acervo de la Biblioteca Juridica Virtual del Instituto de Investigaciones Juridicas de la UNAM

la teoría constitucional culturalista ha identificado al trabajo como uno de sus problemas.

F) El trabajo es un aspecto de la actualización culturalista del contrato social y constitucional. Sobre la triada de "libertad, propiedad y trabajo" se puede decir lo siguiente:

El "trabajo" asume actualmente una jerarquía tan alta, tanto en la perspectiva del ciudadano (especialmente el joven) como en la comunidad de los libres e iguales, que resulta necesario darle un sitio igualmente fundamental en la reconstrucción teórica del Estado constitucional. Esto puede ocurrir ampliando la famosa fórmula de "libertad y propiedad" mediante la dimensión del trabajo. Solamente así se toma en serio la idea filosófica de que el "trabajo es una condición existencial fundamental de la práctica del ser humano en sociedad", de que el "trabajo humano inalienablemente individual" es, al mismo tiempo, un factor de constitución de la sociedad. La concepción procesal de la Constitución como una convivencia y tolerancia constantes de todos pone en evidencia la continuación del modelo contractual clásico: protección de la libertad, la propiedad y el trabajo, como "norma fundamental y tarea", como consenso básico que tiene que reactualizarse constantemente, de la sociedad abierta del Estado constitucional, el cual requiere una fundamentación cultural a través de los contenidos que vaya más allá de los simples procedimientos. "Libertad, propiedad y trabajo" son, hoy día, tales contenidos legitimadores que están ligados de la manera más estrecha. Esto lo muestran fórmulas del tipo "propiedad y trabajo como libertad condensada", "propiedad a través del trabajo", "la propiedad es libertad" (G. Dürig), la frase de N. Blüm que parafrasea a K. Marx "el ser humano a través del trabajo", a la frase de A. Baruzzi "derecho humano al trabajo como realización de la libertad", ${ }^{44}$ así como a la sociedad entre patrones y trabajadores en el sentido de la doctrina social católica. El trabajador se convierte en con-ciudadano, así como en un sentido más profundo es co-propietario.

Tales modelos - en última instancia culturales - no pueden ser impuestos jurídicamente de manera repentina por el orden jurídico, ni siquiera por el orden constitucional "positivo", sino que, sobre todo, deben ser vividos a largo plazo y ser ganados duramente cada día, incluso en la perspectiva de las generaciones. El pacto de solidaridad social-ético que "armoniza" de nueva manera la "libertad, la propiedad y el trabajo" en la forma apuntada, y que constituye al "trabajo como cultura", puede ser modelo intelectual y marco de orientación científica: no más, pero tampoco menos.

444 Baruzzi, A., Recht auf Arbeit und Beruf?, 1983. 
Este libro forma parte del acervo de la Biblioteca Juridica Virtual del Instituto de Investigaciones Juridicas de la UNAM

No sólo la propiedad (como en el siglo XIX, pero también en el XX), sino que también el trabajo convierte (hoy) al ciudadano en ciudadano activo. Así como el siglo XIX tenía que solucionar, y trató de hacerlo, el problema de la autorrealización del ser humano a través de la propiedad, lo mismo debe ocurrir en el siglo XX con el trabajo, ya que en el eje del tiempo es el equivalente social de la propiedad. Una teoría constitucional científicamente probada y políticamente creíble no es posible hoy día sin la apuntada integración del "trabajo". No existe ya ningún concepto de dignidad humana ni teorías de los derechos fundamentales, concebidos en conjunto, así como tampoco ninguna doctrina de la democracia, de los fines estatales y el bien común, incluso ninguna teoría de la propiedad, sin el "trabajo como problema constitucional". Tomar en serio, en la teoría constitucional, al trabajador como con-ciudadano y como "co-propietario" será tanto más posible en la medida en que el derecho del trabajo (sobre todo gracias a la jurisprudencia y la doctrina laborales), en apariencia desde abajo, pero ya en el fondo, haya elaborado el tema del "trabajo" como "derecho constitucional en devenir", en forma adecuada a un Estado social y cultural de derecho. De este modo, las Constituciones del Estado constitucional aseguran un pedazo de su futuro propio, lo que ocurrirá también gracias a una "alianza" entre la ciencia laboralista y la ciencia constitucionalista. Y solamente de este modo puede ser y continuar siendo la Constitución del pluralismo una medida del ser humano: del ser humano como ciudadano y trabajador.

Pero con ello también queda en evidencia lo que significa el desempleo masivo en el Estado constitucional de hoy, pues lo afecta en su núcleo y le resta credibilidad cuando no es capaz de disminuirlo. Se trata de un cuestionamiento del descrito contrato social, similar a una emigración masiva. $\mathrm{Al}$ mismo tiempo hay que recordar que el ser humano no es solamente el "factor trabajo", un "factor de la economía" o una magnitud en el "lugar económico Alemania", por indispensable que resulte incorporar ahora a la economía en el sistema de coordenadas de esta teoría de la Constitución.

\section{Economía social y ecológica de mercado}

A) La "economía social de mercado"(a la que ocasionalmente se le completa con el apelativo de "ecológica"; $c f r$. el artículo 38 de la Constitución de Turingia) se ha convertido, entre tanto, en un elemento central del Estado constitucional de la actual etapa evolutiva: de manera escrita o no escrita. Por ello ya es el momento para contar con una teoría constitucional que integre al "mercado" en el sistema de coordenadas del pensamiento básico de 
Este libro forma parte del acervo de la Biblioteca Juridica Virtual del Instituto de Investigaciones Juridicas de la UNAM

la filosofía del Estado y el derecho. En este sentido, la discusión clásica sobre el contrato social y la imagen del ser humano se hacen tan relevantes como la interpretación del mercado desde la perspectiva culturalista.

El año de 1989 hizo sonar la "hora universal" del Estado constitucional: el fracaso casi global del marxismo-leninismo logró que muchos de los elementos estructurales de aquél, sobre todo los derechos humanos, la democracia, el Estado de derecho y también la economía (social) de mercado, entraran de manera positiva en la conciencia y lo legitimaran como gran meta de la reforma en Europa oriental. La exitosa historia de la "economía de mercado" ejerce también una fascinación que las diversas ciencias todavía no han analizado ni explicado, incluso ahora y precisamente en el año de 1997, en que en Europa del este se muestra de modo drástico cuán difícil resulta en la práctica la transición de la economía de comando a la economía social de mercado; en lo personal, lo institucional y lo jurídico, pero también en el aspecto sicológico-mental y "moral".

El surgimiento de un gigantesco y único mercado mundial por encima de todas las fronteras estatales ofrece una razón más para cuestionar, muy de principio, al mercado, que a pesar de su popularidad es un ser bastante "desconocido" en la amplitud de varias disciplinas y en la profundidad de cada una de ellas. El desafío a la teoría constitucional es tanto mayor por cuanto en Occidente se extiende un nuevo economicismo o materialismo (mercantilización de casi todos los ámbitos de la vida), en que deben ser vinculados la ecología ${ }^{45}$ y la economía, y que desde el punto de vista de la política constitucional, hay que decidir en todos los procesos constituyentes actuales (por ejemplo, en Europa oriental y anteriormente en Alemania del este) aquello que, en materia de mercado y economía de mercado, debe convertirse en textos constitucionales, y cómo debe hacerlo.

B) Mercado y economía de mercado constituyen hoy un problema constitucional central, "interno". Los textos clásicos, desde A. Smith hasta Sir K. Popper, considerados aquí como textos constitucionales en sentido amplio, ${ }^{446}$ y las etapas evolutivas de los textos constitucionales escritos en sentido estricto (con ellos frecuentemente vinculados), ofrecen más que meros indicios del problema. Vistos globalmente, muestran que la vida económica es un pedazo de libertad constituida y responsabilidad de un sector de la libertad cultural, del bien común y la justicia, y demuestran que el Estado constitucional no abarca espacios "naturales", sino que constituye ámbitos

445 De la bibliografía alemana: Berg, W., "Über den Umweltstaat", FS Stern, 1997, pp. 421 y ss.; M. Kloepfer, "Umweltschutz als Verfassungsrecht: Zum neuen Art. 20a GG", DVBl. 1996, pp. 73 y ss.

$446 \mathrm{Al}$ respecto Häberle, P., Klassikertexte im Verfassungsleben, 1981. 
Este libro forma parte del acervo de la Biblioteca Juridica Virtual del Instituto de Investigaciones Juridicas de la UNAM

culturales. Dicho en otros términos: la sociedad pluralista se constituye y reconstituye de tal modo que crea ordenamientos marco e institutos jurídicos para la actividad económica, con el consenso ético-jurídico (que también es un pedazo de "ética económica" indirecta), que toma en serio sobre todo en el derecho ordinario, y que realiza el principio del Estado social (por ejemplo, en el derecho laboral y social), de tal manera que la economía de mercado se convierta en economía social de mercado como aspecto del bien común. Mercado y competencia significan mucho para la sociedad abierta, aunque no todo. El "homo oeconomicus" constituye sólo una verdad parcial. La apertura, frecuentemente invocada, del procedimiento de la formación de la voluntad democrática no puede ser falsificada por los procesos de poder económico, ya que la sociedad abierta no es un "juego de ganancia económica". Las estructuras de la división de poderes, trasladadas del Estado a la economía (por ejemplo, leyes de competencia económica, leyes sobre fusiones en la prensa, o bien, topes en el ámbito de las fusiones de empresas televisoras privadas) son las que deben impedirlo. La política de competencia económica es, en este sentido, "política democrática", al mismo tiempo que un servicio a la economía social de mercado.

Una teoría constitucional del mercado enfrenta todavía hoy nuevos desafíos, a pesar de lo mucho que se ha logrado: la ecología debe desarrollar hacia la economía una relación de "concordancia práctica", del mismo modo que en ocasiones lo exigen programáticamente algunos objetivos del Estado (por último la Constitución de Turingia de octubre de 1993 en su artículo 38: "El ordenamiento de la vida económica debe corresponder a los principios de una economía social de mercado, comprometida con la ecología"). Y la democracia pluralista sobrevive únicamente cuando reconoce una disposición de responsabilidad hacia los Estados constitucionales "en devenir" de Europa del este y apoya los procesos de transformación que se llevan a cabo ahí. La teoría constitucional del mercado socialmente amortiguado y comprometido con la ecología debería convertirse en práctica constitucional vivida en todo el mundo. El Estado constitucional común europeo-atlántico habría demostrado así una vez más que tiene a la dignidad humana como premisa antropológico-cultural, que entiende a la democracia como su consecuencia y que colabora en el objetivo de la "riqueza de las naciones", orientados por la justicia y el bien común, sin caer presas del "economicismo". Éste queda ya excluido por la moral y la idealidad (relativas) que caracterizan a la convivencia republicana de los ciudadanos en un Estado constitucional y gracias a él. Dicho economicismo también despreciaría lo que los seres humanos en Europa oriental han intentado en 
Este libro forma parte del acervo de la Biblioteca Juridica Virtual del Instituto de Investigaciones Juridicas de la UNAM http://www.juridicas.unam.mx

las revoluciones, en su mayoría pacíficas, de 1989: quizá ya con "intención cosmopolita", pero al menos con consecuencias cosmopolitas.

En todo esto hay siempre que tomar en cuenta que la propiedad privada es un puntal del "mercado" enmarcado en el Estado constitucional, tanto en la evolución histórica como en la actualidad.

\section{FEDERALISMO Y REGIONALISMO COMO PLURALISMO TERRITORIAL Y DIVISIÓN GULTURAL DE PODERES}

\section{Federalismo: el "Estado federal cultural", la concepción culturalista del Estado federal - la teoría "mixta" del Estado federal}

\section{A. Fundamentación}

Además de algunos derechos fundamentales "culturales" en lo particular, al lado de los fines educativos y las garantías de ámbitos materiales y cláusulas de encargo cultural especiales, así como aparte del derecho constitucional cultural de los municipios, existe una estructura constitucional que frecuentemente es entendida como mero "principio de la organización estatal", pero que hoy constituye un principio material esencial de la Constitución de la cultura: el Estado federal (Bundesstaatlichkeit).

La teoría mixta del Estado federal solamente puede ser esbozada aquí respecto de la República Federal de Alemania, la ahora Alemania unificada, aunque en mi opinión, resulta relevante para los demás Estados federales del mundo. Sin embargo, la comprobación de esta tesis supone una elaboración amplia de los procesos y contenidos de las etapas textuales extranjeras, la cual no es posible aquí ni siquiera en su planteamiento. ${ }^{447}$ No obstante, hasta el momento ha sido posible mostrar que el "taller" mundial en materia de Estado federal y los procesos de producción y recepción que en él se dan, desde los clásicos "Federalist Papers" hasta el "cooperative federalism", no son sólo partes, sectores, piedras de mosaico de un todo: nunca se reciben,

${ }_{447}$ En particular de modo comparativo: Starck, G. (ed.), Zusammenarbeit der Gliedstaaten im Bundesstaat, 1988. Un acento propio sobre una base comparativa es el que propone Schindler, D., "Differenzierter Föderalismus", FS Häfelin, 1989, pp. 371 y ss. Véase también Münch, P. L., "Die Entwicklung des australischen Föderalismus", Der Staat, vol. 35, 1996, pp. 284 y ss.; Craven, G. (ed.), Australian Federation, 1992; Pernthaler, P., Der differenzierte Bundesstaat, 1992; Annaheim, J., Die Gliedstaaten im amerikanischen Bundesstaat, 1992; Pernthaler, P. (ed.), Bundesstaatsformen als Instrument der Verwaltungsreform und des europäischen Föderalismus, 1997; Palermo, F., Germania ed Austria: Modelli federale, 1997. 
Este libro forma parte del acervo de la Biblioteca Juridica Virtual del Instituto de Investigaciones Juridicas de la UNAM

ni se integran en una unidad sin contradicciones, una teoría en su totalidad, un modelo, tan diversos y plurales son los procesos de intercambio y las naciones en lo individual. Las teorías "puras" tampoco constituyen aquí ni la realidad entera, ni la controlan; los modelos de explicación del federalismo desarrollados a partir de "una" idea no ofrecen ganancia en el conocimiento.

A partir de esta (supuesta) "necesidad", hay que hacer una "virtud" de la carencia de una única teoría correcta del Estado federal, esto es, la teoría mixta del Estado federal, la que permite flexibilidad y crea apertura para el desarrollo, permite una integración pragmática de elementos teóricos y no corre peligro de violentar a la realidad en interés de una teoría ni impone pretensiones de verdad científica; por el contrario, integra la pluralidad de la lucha de muchos por lograr el "buen" Estado federal y quizá pueda invocar todavía el potencial argumentativo de la doctrina clásica de la "Constitución mixta". ${ }^{48}$ Si bien se puede criticar como "sincretismo" lo que aquí se propone como teoría "mixta" del Estado federal, este sincretismo, presunto o verdadero, no es, visto en términos positivos, sino una consecuencia de la "Constitución del pluralismo". La "pluralidad del poder de dirección política" en el Estado federal de la que habla K. Stern solamente puede ser captada también por un modelo de pluralismo en términos de teoría de la ciencia: la teoría mixta del Estado federal lo puede ser. Finalmente, la teoría mixta del Estado federal aquí esbozada es suficientemente flexible para captar las transformaciones en el tiempo y el espacio: en el espacio, en la medida en que los diversos Estados federales nacionales combinan de manera variable y completamente individual los elementos teóricos particulares; en el tiempo, en tanto la evolución constitucional y la historia de las etapas textuales de los diversos Estados constitucionales conocen fases en las que unas veces predomina en primer plano, y en otras se retrae, uno u otro elemento teórico. Apenas hay que señalar que la teoría "mixta" del Estado constitucional así esbozada se corresponde con la idea de la cultura abierta.

La estructura del Estado federal - de manera muy especial en la Alemania unificada - es parte integral del Estado constitucional. En el marco de una teoría de la Constitución como ciencia jurídica de los textos y la cultura, resulta evidente, por tanto, poner también el acento en lo cultural para efectos de la comprensión del Estado federal, a pesar de la importancia que pueda tener lo económico como sustrato y no obstante el derecho relativo que conservan otros modelos teóricos. Al respecto, resulta relevante tanto el concepto estricto (educación y formación, ciencia y arte, preservación de monumentos y medios de comunicación) como el concepto amplio de

${ }_{448} \mathrm{Al}$ respecto Stern, K., Staatsrecht, vol. I, 2a. ed., 1984, pp. 735 y ss. 
Este libro forma parte del acervo de la Biblioteca Juridica Virtual del Instituto de Investigaciones Juridicas de la UNAM

cultura (por ejemplo, arte popular y deporte). ${ }^{449} \mathrm{Y}$ precisamente el pragmatismo evidente en la evolución de cada Estado federal sugiere teóricamente el modelo mixto. El concepto de "federalismo de la cultura" es un término afortunado que refleja, respecto de Alemania, ya en su planteamiento y tanto en la historia como en la actualidad, la vinculación entre Estado federal y cultura. El "concepto abierto de cultura", el "pluralismo de los sujetos de la cultura" ${ }^{450}$ es la generalización jurídica de esta idea.

\section{B. El principio federativo en la LFy los elementos determinantes del tipo del Estado federal}

En siete concisas frases clave se puede caracterizar, siguiendo a $\mathrm{K}$. Stern, ${ }^{451}$ la manifestación del principio federativo en la Ley Fundamental alemana, siendo que esta serie de "normas constitucionales, principios e instituciones", se puede reconducir "a una cierta pluralidad del poder de dirección política"("two centres of government"):

a) El carácter estatal tanto de la Federación como de los Länder, que les confiere un "margen propio de configuración política" (cfr. BVerGE 1, 14 (34); 36, 342 (360 y s.)), en el que los espacios constitucionales de aquélla y de éstos coexisten independientemente (BVerfGE 4, 158 (189); 36 (342 (360 y s.)).

b) La distribución de competencias entre la Federación y los Länder como "importante manifestación del principio federativo... y al mismo tiempo como elemento de una división funcional adicional de los poderes. Dicha manifestación distribuye el poder político y establece un marco jurídico-constitucional para su ejercicio"(BVerfGE 55, 274 (318 y s.)). De acuerdo con la Ley Fundamental alemana, les han quedado todavía a los Länder: la organización de su ámbito estatal, los organismos municipales, la policía y los cuerpos de seguridad, el ámbito cultural (sobre todo, las escuelas e instituciones de educación superior) y la esfera de la planeación de sus propias tareas.

$449 \mathrm{Al}$ respecto Häberle, P., "Vom Kulturstaat zum Kulturverfassungsrecht", en $i d$. (ed.), Kulturstaatlichkeit und Kulturverfassungsrecht, 1982, pp. 1 (20) y ss.; véase también Steiner, U., "Kulturauftrag im staatlichen Gemeinwesen", VVDStRL, vol. 42, 1984, pp. 7 (8 y ss.); Grimm, D., ibidem, pp. 46 (60 y ss.).

${ }_{450} \mathrm{Al}$ respecto Häberle, P., "Kulturpolitik in der Stadt", op. cit., pp. 34 y ss., 37; id., Kultuverfassungsrecht im Bundesstaat, 1980, pp. 14 y ss. y passim.

451 Stern, K., Das Staatsrecht der Bundesrepublik Deutschland, vol. I, 2a. ed., 1984, pp. 667 y ss. 
Este libro forma parte del acervo de la Biblioteca Juridica Virtual del Instituto de Investigaciones Juridicas de la UNAM

c) Como "principio constitucional no escrito", la conducta favorable a la organización federativa (bundesfreundlich) tanto de la Federación frente a las entidades federativas, como de éstas frente a aquélla (BVerfGE 1, 299 (315); 8, 122 (138); 12, 205 (254); 31, 314 (354); 34, 9 (20); 43, 291 (348)), el cual debería aplicarse ahora específicamente, después de la reunificación, entre los Länder occidentales y la Federación respecto de los Länder orientales, apoyado en la garantía del "orden constitucional" por parte de la Federación conforme al artículo 28, inciso 3, de la LF (véase también la "obra comunitaria Auge del Este", por último: BVerfGE 92, 203 (230 y s.)).

d) El principio de homogeneidad (cfr. el artículo 28, incisos 1 y 3, LF), entendido como "estándar medio" de coincidencia tanto de las entidades entre sí como de éstas y la Federación. Por lo demás, este principio es equilibrado por la pluralidad y permite en el fondo concebir al Estado federal como pieza de la división pluralista de los poderes (nótese que en la "cláusula de garantía estructural" en el nuevo texto del inciso 1 del artículo 23 de la LF se encuentra una especie de principio de homogeneidad europeo).

e) Las posibilidades de intervención de la Federación en los Länder (por ejemplo, como vigilancia o como coacción federales), las que ciertamente se ven compensadas por las intervenciones de los Länder sobre la Federación (cfr. el Consejo Federal según el artículo 50 LF).

f) La primacía del derecho federal (conforme a la Constitución) sobre el derecho de un Land (artículo $31 \mathrm{LF}$ ).

g) La participación de los Länder en la formación de la voluntad de la Federación, ${ }^{452}$ del Consejo Federal como "órgano constitucional federativo".

Estos siete elementos son determinantes, en general, del tipo del Estado federal, aunque los ejemplos nacionales contienen numerosas variantes. Remitimos al efecto a ciertas posibilidades de analogía con su "hermano menor", el regionalismo. 
Este libro forma parte del acervo de la Biblioteca Juridica Virtual del Instituto de Investigaciones Juridicas de la UNAM http://www.juridicas.unam.mx

\section{El regionalismo desde la perspectiva culturalista y comparativa}

\section{A. El concepto constitucional de "región": un conjunto abierto de diversas magnitudes mixtas — lineamientos textuales, la imagen de la "escala"}

La estructura del regionalismo se encuentra en vía de convertirse en un elemento típico del Estado constitucional de la actual etapa de desarrollo textual. A pesar de la diversidad de formas de manifestación en los distintos países desde sus modestos inicios en la Gran Bretaña (ahora Escocia: 1997), pasando por ejemplos vitales en España hasta la "consumación” del regionalismo en el federalismo (en el sentido de una línea ascendente: Austria-Alemania-Suiza): toda doctrina moderna sobre el Estado constitucional debe plantearse de manera central el tema del "regionalismo". De qué modo el regionalismo "crece desde adentro" en el tipo del Estado constitucional, al menos en Europa occidental y, esperemos, también en Europa oriental, se revela también en que se constituye frecuentemente de los elementos que, por su lado, ya son elementos integrantes del Estado constitucional: la idea de la libertad cultural, la autonomía administrativa (que se manifiesta sobre todo en los municipios), de la descentralización y la subsidiariedad, de la democracia (también en lo pequeño), de la división de poderes y el control del poder. Esto hay que profundizarlo en el marco de los fundamentos de la legitimación. Aquí deberá bastar la referencia de que el regionalismo es hoy un elemento estructural "emergente" del Estado constitucional y que madura como máxima del derecho europeo. Aunque muchos Estados constitucionales no sean, entonces como ahora, Estados federales, o no deseen convertirse en tales: sin embargo, todos querrán trabajar más o menos, a mediano plazo, en el desarrollo de estructuras regionales constitucionales, y quizá tengan que hacerlo (como contrapeso a los vínculos supranacionales, a los grandes mercados, por razones de la protección de minorías étnicas, etcétera). Posiblemente ya nos encontremos en Europa en vías hacia estructuras regionales comunes europeas, aunque sean diversos los ejemplos nacionales, una vía en la que ya han avanzado los municipios; una expresión de ello es la Carta Europea de la Autonomía Municipal de 1985.

Este derecho constitucional regional común europeo sería entonces parte del "ius commune constitutionale", del derecho constitucional común europeo, tal como se ha consagrado en la doctrina jurídica antigua y reciente, inspirada en el derecho civil, al mismo tiempo que en la actual escena europea. ${ }^{453}$

${ }_{453}$ Häberle, P., “Gemeineuropäisches Verfassungsrecht”, EuGRZ, 1991, pp. 261 y ss. 
Este libro forma parte del acervo de la Biblioteca Juridica Virtual del Instituto de Investigaciones Juridicas de la UNAM

El tema "regionalismo" no debería ser fijado precipitadamente por definiciones y restricciones conceptuales. Si bien se trata de un elemento estructural emergente del tipo del Estado constitucional, actualmente se encuentra en una fase de desarrollo dinámico, con momentos y velocidades muy diversos. No obstante, debemos luchar por alcanzar un perfil del concepto de "región". También el federalismo ofrece, a escala mundial, una gran riqueza de ejemplos en las variantes nacionales, y a pesar de ello tiene que ser definido (aunque sea de manera provisional). Debemos, pues, proceder de manera paralela respecto de los caracteres constitutivos del "regionalismo". Los textos constitucionales y del derecho transnacional y europeo ofrecen importantes referencias, aun si a final de cuentas han de ser "leídos" en el sentido de una determinada teoría del regionalismo; esta teoría se aclara sobre todo en el contexto de la cuestión de la legitimación, a la luz de un enfoque culturalista y en el marco de la diversidad y la unidad de Europa.

El concepto de "región", que se encuentra en vía de convertirse en un concepto del Estado constitucional, obtiene su perfil sobre todo a partir de ciertos conceptos guía que le pertenecen. Una analogía constitucional hacia los conceptos guía del artículo sobre la nueva división territorial del artículo 29: "solidaridad de los coterráneos", "vínculos históricos y culturales", "oportunidad económica", "exigencias del ordenamiento espacial y territorial". De manera particular respecto de las regiones se encuentran conceptos orientadores y legitimadores paralelos, por ejemplo, en el artículo 143, inciso 1, de la Constitución española (1978) a través de las palabras "características históricas, culturales y económicas comunes", ${ }^{454}$ en el artículo 3o., incisos 2 y 3 , se pueden reconocer las diversas lenguas - en cuanto "patrimonio cultural" - como elementos de diferenciación regional. El artículo 147, inciso 2, literal a, permite reconocer la "identidad histórica" como tal. En el artículo 225 de la Constitución de Portugal (1976-1997) se encuentran elementos materiales del regionalismo que pueden ser aprovechables para dar contorno al concepto de la "unidad constitucional regional del Estado constitucional". Respecto de Madeira y las Azores se habla de "sus características geográficas, económicas, sociales y culturales", y en términos generales, la autonomía de las regiones tiene por objetivo, de acuerdo con la Constitución, "la participación democrática de los ciudadanos, el desarrollo económico-social y la promoción y defensa de los intereses regionales, así

${ }_{54}$ De la bibliografía sobre el regionalismo español véase Cruz Villalón, P., "Die Neugliederung des Spanischen Staates durch die «Autonomen Gemeinschaften»", FöR, vol. 34, 1985, pp. 195 y ss.; Balaguer-Callejón, F., "Die autonome Gemeinschaft Andalusiens", föR, vol. 47, 1999, pp. 109 y ss. 
Este libro forma parte del acervo de la Biblioteca Juridica Virtual del Instituto de Investigaciones Juridicas de la UNAM

como el refuerzo de la unidad nacional y de los lazos de solidaridad entre todos los portugueses" (iésta es la función de integración!). El artículo 115 de la Constitución de Italia contiene una definición más bien tecnocrática: ${ }^{455}$ "Las Regiones se constituyen en entes autónomos con poderes y funciones propias, conforme a los principios establecidos en la Constitución"; ;ise trata de una etapa textual temprana del regionalismo! En contraposición, en las más recientes modificaciones constitucionales en Bélgica (artículos 3o. bis y ter) se reconoce como elemento del regionalismo lo lingüístico y lo coterráneo (cuatro territorios lingüísticos, tres comunidades) (ahora artículos 3o. a 5o. de la Constitución de 1994).

Concebido a partir del tipo del Estado constitucional se plantean las siguientes "exigencias" a las estructuras regionales (también para efectos de distinguirlas de las meras estructuras de descentralización administrativa):

a) La estructura regional debe estar normada, en sus lineamientos, por el documento constitucional escrito y constituir una pieza de la Constitución en sentido material (Francia permanece a esto respecto claramente "subdesarrollada").

b) Debe haber una distribución efectiva de competencias en el plano de la legislación, el gobierno, la administración y la jurisdicción ("espejo"de la división de poderes).

c) Puede haber "formas previas" rudimentarias de un Estado propio (como los nombres y las banderas en España, artículo 4o., inciso 2, de la Constitución española).

d) Debe estar esbozada en sus principios la estructura orgánica de las funciones regionales (por ejemplo, los parlamentos).

e) Son posibles "pequeñas" cláusulas de homogeneidad (cfr. el artículo 152, inciso 1, de la Constitución española); sin embargo, debe hacerse visible el principio contrario de la pluralidad y la diversidad, lo "propio" de las regiones, con todas las formas posibles de cooperación ("regionalismo cooperativo"); también debe permanecer abierta la vía hacia un "derecho regional común"; la "lealtad regional", en analogía a la "lealtad federal", no debería ser una mera declaración. El regionalismo "diferenciado", o "asimétrico", como en España, encuentra sus límites en un mínimo de homogeneidad.

455 De la bibliografía italiana sobre el regionalismo italiano: Paladin, L., Diritto regionale, 5a. ed., 1992; Onida, V., "Landesbericht Italien", en Ossenühl, F. (ed.), Föderalismus und Regionalismus in Europa, 1990, pp. 239 y ss.; Cassese, S. y Serrani, D., "Moderner Regionalismus in Italien", fö R, vol. 27, 1978, pp. 23 y ss.; Martines, T., Diritto costituzionale, 6a. ed., 1990, pp. 757 y ss. 
Este libro forma parte del acervo de la Biblioteca Juridica Virtual del Instituto de Investigaciones Juridicas de la UNAM

f) Los derechos de participación de las regiones en el plano del Estado conjunto deberían estar determinados en forma de una "segunda pequeña cámara (regional)"o bajo la figura de requisitos de aprobación calificados.

g) Los procedimientos de solución de conflictos entre los Estados centrales y las regiones, así como de éstas entre sí, deben estar previstos y ser protegidos por una instancia independiente.

h) Debe otorgarse a las regiones autonomía presupuestal y financiera (asegurada por contribuciones propias), complementada por formas de compensación financiera.

Esta "lista de temas del Estado constitucional" para las regiones no tiene que ser agotada acumulativamente, ya que las diversas naciones pueden diferenciarse bastante; pero algunas partes deberían hacerse reales, pues sólo así se puede hablar de "regionalismo del Estado constitucional"; de otro modo el regionalismo se convertiría en un concepto indefinido e incoloro. Hay bastantes indicios de que Francia se mueve alrededor del límite inferior de estas exigencias, ${ }^{456}$ mientras que España ha llegado al límite superior.

En el marco de una teoría constitucional del regionalismo naturalmente también habría que elaborar tipológicamente las dos categorías del regionalismo "transfronterizo" (por ejemplo, Arge Alp o Euregio Egrensis) y el regionalismo "intrafronterizo" (regionalismo dentro de las entidades de un Estado federal, como Franconia dentro de Baviera en Alemania).

Sin importar cuál modelo básico de "regionalismo constitucional" se presente en una nación en particular: a semejanza del federalismo, en el caso del regionalismo hay que preguntar por sus condiciones y presupuestos no jurídicos. El regionalismo del Estado y del derecho constitucional requiere un determinado ambiente "cultural", exige datos previos sociales que lo "soporten", lo mantengan vivo y lo desarrollen, como los aspectos de la diversidad socio-cultural, la pluralidad lingüística, étnica o histórica. El regionalismo puede florecer donde existen estas condiciones, pues de otro modo se quedaría en el papel del texto constitucional y en realidad habría vencido en última instancia el Estado unitario.

456 Sobre Francia: Voss, D.-H., Regionen und Regionalismus im Recht der Mitgliedstaaten der Europäischen Gemeinschaft, 1989, pp. 365 y ss.; Héraud, G., "Die Regionalisierung Frankreichs", en Esterbauer, F. y Pernthaler, P. (ed.), Europäischer Regionalismus am Wendepunkt, 1991, pp. 79 y ss. 
Este libro forma parte del acervo de la Biblioteca Juridica Virtual del Instituto de Investigaciones Juridicas de la UNAM

\section{B. Las siete causas de legitimación (del federalismo y el regionalismo)}

La cuestión de la justificación interna y las causas de legitimación deben elaborar los fundamentos y las dimensiones de la región. En particular éstos pueden ser obtenidos de los principios del Estado constitucional de la actual etapa evolutiva, independientemente de que un país ya se haya decidido por el regionalismo o el federalismo. Debe distinguirse entre:

a) La legitimación a partir de la teoría de los derechos fundamentales (incluyendo la legitimación proveniente de las libertades culturales).

b) La legitimación derivada de la teoría de la democracia (incluyendo los aspectos étnicos).

c) La legitimación derivada de la división de poderes (argumento del control).

d) La legitimación económica y de política del desarrollo.

e) Las funciones de integración como argumento en favor del regionalismo.

f) La dimensión descentralizadora y distribuidora de funciones (el argumento de la subsidiariedad).

g) Particularmente en Europa, el argumento de política europea (palabra clave: "la cultura de Europa como diversidad y unidad").

Resulta evidente que existen muchas analogías respecto de la legitimación del federalismo, lo que sería consecuente si éste es entendido como "consumación" del regionalismo. En la concepción aquí desarrollada ciertamente no se afirma que el federalismo sea siempre la forma "ideal" y, por así decirlo, el "estadio final" de cualquier regionalismo. Esto puede ocurrir en los diversos países, pero no tiene por qué serlo. Es bien posible que los diversos Estados constitucionales se decidan, de manera consciente, a favor "sólo" del regionalismo realmente vigente, aunque al hacerlo se aproximen considerablemente a las fronteras del modelo del federalismo.

\section{MÁXIMAS DE JUSTICIA EN EL ESTADO GONSTITUCIONAL}

\section{Planteamiento del problema}

Mientras que las cláusulas sobre el bien común y los artículos sobre las tareas del Estado saltan a la vista en el texto constitucional, y además son 
Este libro forma parte del acervo de la Biblioteca Juridica Virtual del Instituto de Investigaciones Juridicas de la UNAM

muy tratados en las teorías del Estado y en el resto de la doctrina, ocurre algo diferente con el topos de la "justicia", el cual es examinado sobre todo en la filosofía del derecho, ${ }^{457}$ pero no es verdaderamente tomado en cuenta y ni elaborado cuando aparece en los textos constitucionales positivos. Por ello queremos iniciar aquí con un análisis tipológico de etapas textuales, el cual se integre luego, de manera muy esquemática, en la teoría de la Constitución. Todo ello no puede ser sino un primer paso para conjuntar la filosofía del derecho y del Estado con la teoría constitucional, del mismo modo como hoy en día no es posible practicar la filosofía del derecho sin una filosofía de la Constitución, no porque las Constituciones sean la "última palabra de la sabiduría", sino porque dichas Constituciones fijan, de acuerdo con el principio de "supremacía de la Constitución", el marco para todas las ramas del derecho, sin que puedan desatender sus caracteres propios, razón por la cual, por ejemplo, el derecho privado posee "su" justicia específica.

\section{Elementos de un inventario}

Un primer paso se refiere a los principios escritos sobre la justicia en la Constitución o a la "justicia de la Constitución". Un inventario sistemático de los textos resulta bastante fructífero. La "justicia" se encuentra:

- En los preámbulos (por ejemplo, la Constitución de Renania-Palatinado de 1947, de Baden-Württemberg, de 1953, de Guatemala de 1985, la anterior Constitución de Perú de 1979 - la "justicia como valor supremo", "sociedad justa"-; la Constitución de Irlanda de 1937-1992, la Constitución del Cantón del Jura de 1977 "justice sociale"), la Constitución española de 1978: "orden económico y social justo"; la Constitución de Turquía de 1982, la Constitución de Filipinas de 1986: "regime of truth, justice"; la Constitución de Corea del Sur de 1987, la Constitución de Uganda de 1995: "social justice and progress"; la Constitución de Mali de 1992: "respect de la justice"; la Constitución de Rusia de 1993: "clara creencia en la bondad y la justicia"; la Constitución de Mongolia de 1992: "justice and national unity"; la Constitución de Mecklemburgo-Antepomerania de 1993, la Constitución de Turingia de 1993; la Constitución del Cantón de Appenzell A. Rh. de 1995: "contribuir a configurar un orden de

457 Cfr. Hollerbach, A., voz "Gerechtigkeit und Recht", Staatslexikon, vol. 2, 7a. ed. 1986, cols. 898 y ss. 
Este libro forma parte del acervo de la Biblioteca Juridica Virtual del Instituto de Investigaciones Juridicas de la UNAM

vida justo"; la Constitución de Sudáfrica de 1996-1997: "social justice"; la Constitución de Estonia de 1992: "liberty, justice and law"; la Constitución de Polonia de 1997: "Dios como fuente de la verdad, la justicia, el bien y la belleza");

- Como objetivo o deber del Estado (artículo 1o. de la Constitución de Portugal de 1976; artículo 1o. de la Constitución de Rumania de 1991; artículo 2o. de la Constitución de Guatemala; artículo 2o., inciso a) de la Constitución del Cantón de Uri: "orden justo para la convivencia pacífica de los hombres");

- En el contexto de la "cláusula de desarrollo de los derechos fundamentales" (artículo 10 de la Constitución de Estonia);

- Como "derecho a condiciones justas de trabajo" (artículo 23, inciso 3, número 1 de la Constitución de Bélgica de 1994);

- Junto a los derechos humanos como fundamento de la paz y la justicia en el mundo (artículo 1o., inciso 2, de la LF);

- En la indemnización por expropiación (artículo 14, inciso 3, frase 2, de la LF);

- En el contexto del orden económico y social (artículo 118, párrafo primero, de la Constitución de Guatemala; artículo 110 de la antigua Constitución de Perú; artículo 45 de la Constitución de Irlanda; artículo 42, inciso 2, de la Constitución de Brandemburgo de 1992);

- En cláusulas de juramento (por ejemplo, artículo 56 de la LF; artículo 46 de la Constitución de la República de Weimar; artículo 81 de la Constitución de Turquía de 1982);

- En el contexto del deber de tributar (artículo 31, inciso 1, de la Constitución española; artículo 77 de la anterior Constitución de Perú de 1979);

- En el contexto de los fines de la educación (artículo 56, inciso 4, de la Constitución de Hesse de 1946: "justicia"; artículo 22, de la Constitución de Turingia: justicia social como obligación del tercer poder; artículo 20, inciso 3, de la LF: "derecho");

- Como máxima en las "relaciones entre los pueblos" (artículo 7o., inciso 2, de la Constitución de Portugal; de manera similar el preámbulo de la Constitución de Níger de 1992: "volonté de coopérer... avec tous les peuples épris de paix, de justice et de liberté"; análogamente el preámbulo de la Constitución de Burkina Faso (1997)).

El principio justicia se encuentra presente de manera directa en no pocos textos constitucionales. 
Este libro forma parte del acervo de la Biblioteca Juridica Virtual del Instituto de Investigaciones Juridicas de la UNAM

\section{Análisis, primeras conclusiones téorico-constitucionales}

Llama la atención que el principio "justicia" se encuentra consagrado de manera especialmente frecuente en los preámbulos, en el contexto de otros valores fundamentales del Estado constitucional ahí señalados. En tal medida participa de todos los contenidos y funciones específicas de la forma del preámbulo. Ciertamente por ello permanece en un plano bastante general y abstracto. Sin embargo, además de lo anterior, la máxima de la justicia se encuentra en los contextos más diversos: desde los objetivos del Estado hasta los derechos fundamentales, pasando por el orden económico y social, así como por los fines educativos y las fórmulas de juramento, incluso como elemento de relación con otros pueblos. Se podría hablar entonces de la justicia como "elemento vagabundo" en la estructura del Estado constitucional. Sin duda, además del principio general de justicia, con el que se compromete de manera explícita o no escrita el Estado constitucional, existen máximas de justicia específicas para distintos ámbitos, por ejemplo, la "compensación de las cargas familiares" ("Familienlastenausgleich") que se discute en el marco de la promoción de la familia conforme a la LF. Cuando no hay textos positivos sobre la justicia, los tribunales recurren a este tipos de manera pretoriana. También en la jurisprudencia del TCFA está presente el principio "justicia” (cfr. E 79, 106 (123); 80, 103 (108); 84, 90 (121); 86, 81 (87); 95, 96 (134 y s.)).

Desde el punto de vista de la política constitucional, hay que recomendar al constituyente incorporar al menos la justicia como valor fundamental en el preámbulo, ya sea de manera "apelativa", programática, quizá también como fin educativo (el joven ciudadano debe poder aprenderla), así también en el derecho constitucional del trabajo y la economía, sobre todo porque el término de justicia "ecológica" podría tener por delante una carrera como tema. Por lo demás, el ideal de la justicia no debería ser "textualizado" con demasiada frecuencia, sino que basta una cláusula general de reserva en el preámbulo, ya que son precisamente los principios y procedimientos concretos los que el Estado constitucional ha desarrollado durante largos periodos para crear justicia. Piénsese en las garantías constitucionales del debido proceso (justicia procesal) o en la libertad contractual como pilar del ordenamiento jurídico privado, en la libertad de coalición, pero también en los procedimientos parlamentarios.

Un desideratum sigue siendo combinar la doctrina clásica de la justicia de un Aristóteles (justicia conmutativa y distributiva) con la más reciente de un J. Rawls (“justicia como imparcialidad”), así como con el racionalismo críti- 
Este libro forma parte del acervo de la Biblioteca Juridica Virtual del Instituto de Investigaciones Juridicas de la UNAM

co de un Popper, para incorporarla en la teoría constitucional. En este sentido, la dignidad humana es un elemento de justicia material, los derechos humanos lo son bajo la figura de la fórmula de Radbruch; el "derecho de audiencia" remite a la fórmula clásica del "audiatur et altera pars" como parte de la cultura jurídica europea, y por último, también la equidad hace su contribución a la justicia de la Constitución. El tipo del Estado constitucional es, en la actualidad, el foro en el cual se puede transitar el camino hacia la justicia. Pero puesto que él mismo requiere siempre de reforma, hay un pedazo de justicia incluso "previo" o "superior" a la Constitución, a pesar del grado de justicia "constitucionalmente inmanente" que pueda haber. La necesidad que tiene el ser humano de justicia, es decir, el lado antropológico-cultural de la necesidad de este principio (expresado en la frase de B. Bohley: "Queríamos justicia y recibimos el Estado de derecho") lo caracteriza como ser cultural. Numerosos textos clásicos sobre la justicia hay que "leerlos conjuntamente" con esto, incluso cuando se trata de cuestiones especiales como la "justicia de transición" (presente, por ejemplo, en diversas disposiciones transitorias de las Constituciones) o de la "justicia del caso concreto".

\section{PREÁMBULOS, REFERENGIAS A DIOS, DERECHO GONSTITUCIONAL DE LA RELIGIÓN, ASÍ COMO EL DERECHO DEL DOMINGO Y LOS DÍAS FESTIVOS}

\section{Preámbulos}

\section{A. El preámbulo como fundamentación y profesión de fe}

Característica del contenido de los preámbulos es la formulación de posturas valorativas, ("altos") ideales, ${ }^{458}{ }^{458}$ convicciones, motivos, en suma, la imagen propia del constituyente. Esta confesión, la "fe" (así, expresamente, por ejemplo, la Convención de Derechos Humanos), se presenta ocasionalmente al lado de los "conocimientos". En ocasiones se encuentran caracteres rasgos, casi hímnicos, que trasmiten el carácter de un estado de ánimo y en general irradian "brillo". Cuando se tratan de este modo las cosas "primeras" y "últimas" es natural que de inmediato se establezca un aliento de pathos.

458 Constituciones de Japón (1946) y Francia (1958). 
Este libro forma parte del acervo de la Biblioteca Juridica Virtual del Instituto de Investigaciones Juridicas de la UNAM

La alta intensidad valorativa de los preámbulos también se muestra en que gustan remitir a realidades previas (ontológicas) como Dios o Cristo (por ejemplo, Australia 1900, Indonesia 1945, Argentina 1853) o las invocan (por ejemplo, Irlanda 1937). La casi sagrada autobligación hacia él, las ocasionales invocaciones o llamados ${ }^{459}$ son elementos y momentos formales y sustantivos recurrentes. Esto es, en parte se muestran los preámbulos como "proposiciones de fe" de una comunidad política, y no sólo en las referencias a Dios y a la responsabilidad ante él y los seres humanos, sino también en otras cláusulas de reconocimiento, que expresamente reafirman su "profunda fe en estas libertades fundamentales"(así, el preámbulo de la Convención Europea de Derechos Humanos de 1950), objetivizan ${ }^{460}$ declaraciones de voluntad próximas a tales reconocimientos o normativizan deseos y esperanzas subjetivos (por ejemplo, Constitución de Berlín de 1950: "Con el deseo de seguir siendo la ciudad capital de una nueva Alemania unida", lo que hoy es realidad) o las convicciones y declaraciones de voluntad.

El carácter de reconocimiento, en ocasiones ficticio, conduce a las capas profundas de un pueblo constituido, y en proceso de constituirse continuamente después del acto constituyente. Rudolf Smend las trató a su manera en su teoría de la integración. ${ }^{461}$ El Estado constitucional democrático no puede renunciar a estos vínculos más bien sentimentales de los ciudadanos hacia él, a la creación de posibilidades de identificación para el ciudadano y a su propia obligación y responsabilidad ante instancias y contextos más altos.

En todo caso, los preámbulos remiten a verdades básicas o de fe prepositivas de una comunidad política; en ocasiones reactualizan un pedazo de la "religion civile". Presumiblemente, las Constituciones sin preámbulo contienen también dichas "verdades de fe", que son previas a sus disposiciones jurídicas, pues todo orden jurídico positivo penetra en dichas capas profundas. Los preámbulos pretenden racionalizarlas y darles expresión, a veces en forma secularizada, otras en forma "todavía teológica". Estos fundamentos de la autocomprensión (en la identidad) de una comunidad política, el

459 Poco frecuente es la referencia al juicio de Dios, como en el preámbulo de la Constitución de Württemberg-Hohenzollern, en Dennewitz, B. (ed.), Die Verfassungen der modernen Staaten, vol. II 1948.

460 Como el prólogo a la Constitución de Renania-Palatinado de 1947: "Animados por la voluntad de asegurar la libertad y dignidad del ser humano..."; véase también el preámbulo de la CEDH de 1950: “...como gobiernos de Estados europeos animados del mismo espíritu...".

461 Smend, R., "Verfassung und Verfassungsrecht"(1928), ahora en id., Staatsrechtliche Abhandlungen, 3a. ed. 1994, pp. 119 (especialmente 160 y ss., 215 y ss.), sobre los préambulos por ejemplo las pp. 216 y ss. 
Este libro forma parte del acervo de la Biblioteca Juridica Virtual del Instituto de Investigaciones Juridicas de la UNAM http://www.juridicas.unam.mx

concentrado, es aquello que obliga a todos los ciudadanos, casi como una "profesión de fe", es aquello que es puesto "antes del paréntesis" y que con frecuencia es formulado en términos similares a un contrato (la Constitución como contrato).

\section{B. La función de puente en el tiempo}

Los elementos constructivos regulares de los preámbulos son expresiones de la dimensión temporal: por un lado, en el rechazo de un pasado determinado o en la vuelta o el "recuerdo"(por ejemplo, preámbulo de la Constitución de Irlanda) a determinadas tradiciones y periodos (referencia histórica, por ejemplo, Turquía: "en el curso de su historia": Baviera: "historia más que milenaria"; Constitución de Bremen de 1947: "centenaria Ciudad Libre Hanseática de Bremen"); pretenden invocar y elaborar el pasado de manera negativa (polémica) o positiva. ${ }^{462}$ Además, los preámbulos se pueden referir al presente, ocasionalmente en la orientación de deseos, por ejemplo Berlín: "Con el deseo de seguir siendo la ciudad capital de una nueva Alemania unida", lo que hoy se ha vuelto realidad. Por último, pueden referirse al presente y al futuro como tales, ${ }^{463}$ o incluso querer "ganar" el futuro.

En cuanto los préambulos cuentan la "historia" y hacen profesiones de fe en relación con ella, pretenden hacer justicia a la necesidad de identidad y de hacer presente la historia que tiene el ser humano, no en el sentido de un tratamiento científico para un público especializado, sino más bien en el sentido de una historia que "se sienta comprometida con el lego". Al respecto puede llegar a haber conflictos en los preámbulos entre los reconocimientos y los conocimientos: así, por ejemplo, el preámbulo de la Ley Fundamental alemana no resiste, en algunas de sus partes, una revisión histórica crítica.

En la medida en que los preámbulos se orientan hacia el futuro - así, por ejemplo, el modo como las futuras generaciones en la Constitución

462 Cfr. Baviera: "campo en ruinas" y la Constitución de Baden de 1947: "depositarios de la antigua tradición de Baden"; véase también el preámbulo de la CEDH de 1950: "patrimonio común en bienes y tradiciones espirituales. Respeto de la libertad y gobierno de la ley". Véase también la Constitución de Sajonia (1992): "apoyada en tradiciones de la historia constitucional sajona... consciente de la culpa propia en su pasado".

463 Así Renania del Norte-Westfalia: "superar con trabajo conjunto la necesidad del presente". Por último Turingia (1993): "superar aquello que es motivo de división en Europa y el mundo"; Mecklemburgo-Antepomerania (1993): "promover el progreso económico de todos". 
Este libro forma parte del acervo de la Biblioteca Juridica Virtual del Instituto de Investigaciones Juridicas de la UNAM

bávara (1946) encuentran en el círculo de la visión y la responsabilidad del constituyente - o expresan deseos y esperanzas, contienen un exceso concreto-utópico: en tal medida se encuentra en el preámbulo un bosquejo del futuro. El preámbulo introduce un pedazo de la fructífera tensión entre deseo y realidad en la Constitución (y la política), como se puede comprobar también en otras partes de los textos constitucionales, por ejemplo, en los mandatos constitucionales. Con frecuencia un pueblo tiene que tener paciencia con vistas a los deseos y esperanzas de los preámbulos. Un ejemplo afortunado es el del preámbulo de la LF de 1949 en relación con la reunificación alemana (1990): es al mismo tiempo muestra de una historia exitosa de la Ley Fundamental alemana.

\section{Referencias a Dios}

Conforme existen, las claúsulas constitucionales con referencias a Dios no constituyen, de ningún modo, una etapa evolutiva "superada", anacrónica o atípica, sino una posible variante cultural del Estado constitucional. Son expresión del "derecho constitucional de la religión" y, por tanto, de una imagen del ser humano que concibe a éste — y al pueblo - tanto en lo histórico como en la actualidad, como insertado en contextos de responsabilidad más altos: Estado y derecho son confirmados como ordenamientos limitados, fundados en la ética, lo que de por sí resulta característico del Estado constitucional. Así visto, existe una conexión interna entre las cláusulas de responsabilidad con referencias a Dios (o a la creación) y la dignidad humana, pero también con el principio constitucional de la tolerancia, como en lo absoluto tienen que integrarse los textos sobre Dios en la Constitución entendida como unidad. ${ }^{464}$ Con ello no se revierte la evolución histórica hacia el Estado constitucional secularizado, ya que el derecho constitucional no obliga a nadie al "culto religioso" a través de estos textos. Sin embargo, se toma culturalmente en serio al ser humano como homo religiosus, llegando hasta la garantía de comportarse de manera indiferente o contraria a la religión. Es este trasfondo cultural el que justifica, histórica y actualmente, a los textos sobre Dios en el Estado constitucional, aunque también los limita.

$464 \mathrm{Al}$ respecto, en general (es decir, sin citar los textos sobre Dios), Hesse, K., Grundzüge..., cit., p. 27. 
Este libro forma parte del acervo de la Biblioteca Juridica Virtual del Instituto de Investigaciones Juridicas de la UNAM http://www.juridicas.unam.mx

\section{3. "Derecho constitucional de la religión" en el Estado constitucional}

En lo que sigue se enuncia, a manera de términos clave, el modo como la teoría constitucional comparativa ha desglosado el tema "derecho constitucional de la religión". Merced al análisis de etapas textuales resultan ya aquí visibles, prima facie, intensos desarrollos que reflejan en Europa el largo camino desde el Estado de cuño cristiano hacia la sociedad secularizada (por tal motivo, la teoría constitucional debiera renunciar al concepto de "derecho eclesiástico del Estado")..465 En tal sentido se plantean las siguientes cuestiones:

¿De qué manera está ubicado sistemáticamente la relación entre Estado e iglesias y asociaciones religiosas? ¿Lo están en el inicio, en los artículos de bases de la Constitución, en apartados propios posteriores o solamente de modo puntual? He aquí una selección de ejemplos: al mero inicio, en el artículo 3o., la Constitución de Grecia (1975) establece un apartado sobre "relaciones entre la iglesia y el Estado". La Constitución de Portugal (1976) procede de modo diferente, al establecer en el artículo 41, en el marco del catálogo de derechos fundamentales, el principio de la separación (inciso 4), mientras que España (1978), si bien trata el tema también en la parte de los derechos fundamentales (artículo 16), a la frase "Ninguna confesión tendrá carácter estatal" agrega el siguiente enunciado: "Los poderes públicos tendrán en cuenta las creencias religiosas de la sociedad española y mantendrán las consiguientes relaciones de cooperación con la Iglesia Católica y las demás confesiones". La Constitución de Italia (1947) se estructura sistemáticamente de otro modo. Ya en los "principios fundamentales" se regula el aspecto corporativo de la libertad de religión (artículo 8o., segundo párrafo), también se abre la posibilidad de "acuerdos" (tercer párrafo 2). Dinamarca declara lapidariamente en el capítulo I § 4 de su Constitución de 1953: la iglesia evangélica luterana es la iglesia del pueblo danés, mientras que Finlandia (1919-1995) regula hacia finales de la Constitución un apartado IX: "Las comunidades religiosas". La Constitución de Irlanda (1937) encabeza el tardío artículo 44 con el título "Religión".

465 De la reciente bibliografía alemana básica sobre el derecho eclesiástico del Estado alemán: Hesse, K., "Das Selbstbestimmungsrecht der Kirchen und Religionsgemeinschaften", HdBStKiR, vol. I, 2a. ed., 1994, pp. 521 y ss.; Hollerbach, A., "Grundlagen des Staatskirchenrechts", en HdBStR, vol. VI, 1989, pp. 471 y ss.; Broglio, F. M., Mirabelli, C. y Onida, F., Religioni e sistemi giuridici, 1997. Cfr. ahora la Declaración al Acta Final de Amsterdam (1992): "La Unión respeta el estatus del que gozan la iglesias y asociaciones o comunidades religiosas en los Estados miembros de conformidad con sus disposiciones jurídicas, de modo que éstas no se vean perjudicadas". 
Este libro forma parte del acervo de la Biblioteca Juridica Virtual del Instituto de Investigaciones Juridicas de la UNAM

Este análisis muestra ya qué tan diversa es la "cultura religiosa" de las diversos Estados constitucionales y la diversidad de la "importancia" que se da a la "cuestión de la religión". ${ }^{466}$

Un análisis de las Constituciones más recientes, también en el contexto de sus posibles referencias a Dios, disposiciones sobre días festivos, cláusulas de juramento y fines educativos sigue siendo un desideratum, pero echaremos un breve vistazo a Europa oriental. La Constitución de Eslovaquia (1992) dispone ya en su artículo 1o., frase 2: "It is not tied to any ideology or religion". La Constitución de Bulgaria (1991) dispone lo siguiente en su parte de bases, en el artículo 13, inciso 2: "Les institutions religieuses sont separées de l'État". El artículo 14, inciso 1, de la Constitución de Rusia (1993) dispone también en su parte de fundamentos: "La Federación Rusa es un Estado laico". La Constitución del Chad (1996) garantiza la libertad de religión de manera individual y colectiva (artículo 35), sin perjuicio del reconocimiento de su responsabilidad ante Dios (preámbulo). Un "espíritu” propio se manifiesta en el proyecto de Constitución de "Solidaridad" en Polonia (1994), en cuanto se señala, en la parte de los fundamentos (artículo 6o., inciso 1): "The State shall guarantee the autonomy of churches and confessional organisations recognized by law". La Constitución de Polonia (1997) regula el estatus de las "iglesias y otras asociaciones religiosas" en el artículo 25 (parte de fundamentos).

Francia se define ya en el artículo 1o. de la Constitución de 1958 como "República laica”, ejemplo que es seguido por la Constitución de Mali ya en su preámbulo ("laïcitê"), lo mismo que por la Constitución de Guinea (1991) en su artículo 1o., inciso 1. En el resto de África dispone, por ejemplo, la Constitución de Níger (1992) la separación entre "Estado y religión" (artículo 4o.), igualmente el artículo 1o. de la Constitución del Chad (1996). La Constitución de Madagascar (1992) ratifica en su preámbulo su creencia en "Dieu Créateur", prohíbe ya en la parte de fundamentos toda discriminación por causa de religión (artículo 8o., inciso 2). El artículo II, sección 6, de la Constitución de Filipinas (1986) — que en algunos temas irradia intensamente hacia África - dispone: "The separation of Church and State shall be inviolable". El artículo 288 inciso c) de la Constitución de Portugal (1976-1992) incluye la "separación entre Iglesia y Estado" incluso en sus cláusulas de eternidad (igualmente el artículo 159 de la Constitución de Angola).

466 La Constitución de Suecia (1975) establece ejemplarmente ya en su capítulo I § 2 inciso 4 la protección de las minorías religiosas. 
Este libro forma parte del acervo de la Biblioteca Juridica Virtual del Instituto de Investigaciones Juridicas de la UNAM http://www.juridicas.unam.mx

\section{Días festivos-domingos}

\section{A. Días festivos}

\section{a. Planteamiento del problema}

Las garantías de los días festivos pertenecen a un "estrato" de normas constitucionales que frecuentemente se desatienden, pero que penetran hasta el centro de la identidad cultural del Estado constitucional respectivo y del Estado constitucional como tipo. Provienen de la "materia" de la que en ocasiones son los "sueños"(y primeramente sólo eso) — por ejemplo, la "unidad alemana", que se hizo realidad en 1990 - pero que sobre todo son o fueron valores fundamentales que se "dirigen", junto a la ratio, también a la emotio del ser humano y el ciudadano en el Estado constitucional: los himnos, banderas, ${ }^{467}$ los fines educativos como "el amor hacia el pueblo y la patria"(por ejemplo, artículo 33 de la Constitución de Renania-Palatinado (1947)) o la "reconciliación de los pueblos" (por ejemplo, artículo 25, inciso 2, de la Constitución de Renania del Norte-Westfalia), así como los monumentos. Los himnos nacionales significan, lo mismo que los días de fiesta nacional, un pedazo de memoria colectiva de un pueblo, en lo cual puede realizarse una transformación: prácticamente ningún francés piensa ahora en el sangriento contenido de "La Marsellesa". Estas "fuentes de consenso" más bien emocionales no deben ser subestimadas junto con el lado más bien racional (como la dignidad humana, la libertad, la democracia), pues ya lo impiden los mismos textos constitucionales positivos. En la garantía de los días festivos se refleja un pedazo de la concepción de sí mismo, propio del Estado constitucional, pero también un pedazo de la "imagen" que los ciudadanos pueden y deben hacerse de él y que él puede y debe hacerse de los ciudadanos. Solamente el enfoque culturalista puede iluminar las posibilidades y límites de los días festivos en el Estado constitucional, ya que el positivismo jurídico no sabe muy bien qué hacer con ellos. En un sentido más amplio y profundo son todos los días festivos vivos "días de la Constitu-

467 Cfr. Smend, R., "Integrationslehre"(1956), ahora en id., Staatsrechtliche Abhandlungen, 3a. ed., 1994, p. 475 (477): "Por tanto, es ésta (sc. la integración material), por ejemplo, la ubicación sistemática para la teoría de los símbolos del todo valorativo, las banderas, escudos, jefes de Estado, ceremonias políticas, fiestas nacionales, que hacen comprensible la totalidad del contenido de sentido del Estado y dan acceso a la vivencia". Por último sobre los "símbolos del Estado": Badura, P., Staatsrecht, 2a. ed., 1996, pp. 251 y ss. 
Este libro forma parte del acervo de la Biblioteca Juridica Virtual del Instituto de Investigaciones Juridicas de la UNAM

ción", porque pretenden traer a la conciencia elementos diversos del Estado constitucional en conjunto.

b. Las garantías de los días festivos como expresión de la integración, históricamente lograda, de las partes de la población en el Estado constitucional

Las garantías de los días festivos pueden ser expresión de la integración, lograda o sólo esperada, de un grupo poblacional en el pueblo en su conjunto.

Los ejemplos pueden ser, con vistas a la clase trabajadora, las garantías del 1o. de mayo, en lo que ocasionalmente se agregan grandes objetivos, de los que también impregnan a la Constitución (por ejemplo, como objetivo general del Estado o particular de la educación). Representativo en este sentido es aquí el artículo 3o., inciso 2, de la Constitución de Baden-Württemberg (1953): "El 1o. de mayo es, por ley, día festivo. Su propósito es reconocer la justicia social, la paz, la libertad y el entendimiento de los pueblos".

El ejemplo que quizá sea el más impresionante y al mismo tiempo más reciente de este tipo es el nuevo día festivo que los EUA han instituido, por primera vez en 1986, en honor del defensor de los derechos civiles Martin Luther King (15 de enero). Aunque ello no se haya producido bajo la figura de una reforma constitucional formal ("amendment"), en el fondo se trata de derecho constitucional material. El nuevo día festivo o día de Martin Luther King constituye la conclusión simbólica de la larga lucha del movimiento estadounidense de los derechos civiles en favor de la igualdad y la integración de la "gente de color". Cuando el gran Estado constitucional que son los Estados Unidos reconoce como día festivo el nacimiento de este representante de la resistencia no violenta, lo que anteriormente sólo se había hecho por G. Washington, ello significa lo siguiente: tal día de enero se convierte en una especie de "día de la Constitución"; constituye el foro en el que pueden encontrarse de manera ideal todos los ciudadanos de los EUA como ciudadanos libres e iguales. El día de Martin Luther King significa, por un lado, una "conmemoración" histórica de este gran ciudadano, pero al mismo tiempo la conciencia de las tareas del futuro: sobre el "camino eterno" hacia la eliminación de todas las formas sociales de discriminación racial que todavía puedan existir.

Una teoría del derecho del Estado desarrollada de manera puramente positivista no es capaz de desentrañar estos contextos y las dimensiones profundas. La fuerza simbólica, integradora de las garantías, sólo es capaz de 
Este libro forma parte del acervo de la Biblioteca Juridica Virtual del Instituto de Investigaciones Juridicas de la UNAM

revelarla una teoría constitucional que trabaje con el enfoque culturalista. Si se hace una comparación entre los objetivos declarados de los días festivos en las Constituciones de los Länder alemanes después de 1945 (sobre todo las de Baden-Württemberg, Bremen y Hesse) entre sí y con otros enunciados de sus textos, se producen relaciones sorpresivas: "justicia social", "paz", "libertad", "entendimiento de los pueblos" son "fines constitucionales" que también se presentan como fundamentales en otros pasajes, sobre todo como fines del Estado o de la educación. Así, en el artículo 12 de la Constitución de Baden-Württemberg se encuentra el fin educativo "fraternidad de todos los seres humanos y amor a la paz", así como la "fe en la democracia y la libertad", en el artículo 26 de la Constitución de Bremen la "voluntad de justicia social" y de "convivencia pacífica con otros hombres y pueblos", ahí mismo como "fines del Estado" en el artículo 65 ("justicia social, libertad, paz y entendimiento de los pueblos"), y el artículo 56 de la Constitución de Hesse postula como fin educativo el "servicio independiente y responsable al pueblo y a la humanidad a través del aprecio y el amor al prójimo, el respeto y la tolerancia". El "entendimiento de los pueblos" también está normado, como objetivo de la Constitución, en el artículo 69 del mismo documento.

En todo ello queda de manifiesto que algunas garantías de los días festivos están tejidas de la "materia prima" constitucional. Cuando el Estado constitucional festeja o "hace" festejar, lo hace al servicio de determinados fines. Y estos fines son de naturaleza fundamental, pues solamente de este modo puede legitimarse la exención del trabajo y la vida normal, el día de fiesta. La historia del 1o. de mayo enseña también que un día, frecuentemente de lucha sangrienta y que originalmente pertenecía sólo a una parte del pueblo, es "reconcebido" como día, ya pacífico, de todos los ciudadanos. Es un día que atestigua y ratifica la integración de los trabajadores (alemanes) en el Estado constitucional bajo el signo de las grandes ideas.

En particular el 1o. de mayo es un pedazo de "derecho constitucional laboral" desde el punto de vista material, porque permite a los trabajadores reencontrarse en la Constitución a través de "su" día; y desde la perspectiva formal, porque garantiza, en cuanto día feriado por ley, el "descanso del trabajo", pero manteniendo el derecho al salario. Al mismo tiempo constituye un pedazo de derecho constitucional de la cultura, porque vincula de manera específica a la Constitución con la cultura: el "descanso laboral" abre la posibilidad de reconocer el aspecto que como creador de sentido tiene el trabajo, al mismo tiempo que se puede dedicar a otras actividades culturales. El trabajo y el tiempo libre son igualmente un pedazo de cultura y, por lo tanto, también lo es el derecho que los desarrolla. 
Este libro forma parte del acervo de la Biblioteca Juridica Virtual del Instituto de Investigaciones Juridicas de la UNAM

\section{c. El ejemplo de "Europa oriental"}

Una palabra sobre la significación de símbolos como las banderas, los escudos y los himnos en Europa oriental. El comienzo y la transformación en Europa oriental (1989) fue acompañado, desde el principio, por el cambio de los símbolos del Estado. Si éstos habían sido otorgados desde arriba, literalmente "implantados", y visibles como "signos" socialistas en la hoz y el martillo, estrellas rojas y otros similares, los nuevos días festivos de la toma del poder o en los días festivos clásicos, ahora refuncionalizados, como el 10. de mayo, fueron modificados casi siempre desde el inicio al producirse la transición hacia el Estado constitucional, muchas veces a través de un recurso a la historia constitucional reprimida de la respectiva nación de Europa oriental. También en las democracias pluralistas, y particularmente en ellas, se requieren los símbolos del Estado como elementos de identidad cultural del Estado constitucional; incluso en las sociedades abiertas, y precisamente en ellas, necesita el ciudadano, en y para su comunidad política, signos de identificación y artículos de reconocimiento que generen consenso. La teoría de la integración de R. Smend ${ }^{468}$ ofrece palabras clave que siguen siendo válidas hasta hoy. Los símbolos deben hacer visible y comprensible para los contemporáneos lo acaecido y trasmitirlo a la "memoria colectiva" de la posteridad. Dichos signos dicen frecuentemente más sobre el "espíritu" de un pueblo que algunas normas jurídicas. De este modo se declaran los días festivos, se construyen monumentos, se nombran las calles, se crean y saludan las banderas, se cantan los himnos. De este modo se elabora la historia y arriesga el futuro.

Aquí los elementos de la evolución más reciente, los cuales demuestran que la caída de los símbolos estatales antecede la mayoría de las veces a las normaciones de detalle: tan sólida es la fuerza significativa de estos símbolos. Y tampoco es casualidad que los documentos constitucionales le concedan frecuentemente a los símbolos un lugar preeminente en los artículos de bases (por ejemplo, el artículo 3o. de la Constitución de la República de Weimar de 1919; el artículo 5o. de la Constitución de Venezuela de 1961; el artículo 11 de la Constitución de Portugal de 1976; el artículo 4o. de la Constitución española de 1978; el artículo 2o., incisos 2 y 3, de la Constitución francesa de 1958; el artículo 1o., incisos 2 y 3, de la Constitución de Baviera de 1946; ahora, el artículo 28 de la Constitución de Polonia de 1997;

468 Smend, R., "Verfassung und Verfassungsrecht"(1928), ahora en id., Staatsrechtliche Abhandlungen, 3a. ed., 1994, p. 119 (170). 
Este libro forma parte del acervo de la Biblioteca Juridica Virtual del Instituto de Investigaciones Juridicas de la UNAM

el artículo 1o. de la Constitución de la Costa de Marfil (1995), el artículo 4o. de la Constitución de Madagascar (1995)).

Polonia volvió a celebrar en 1990 su día de fiesta nacional y constitucional el 3 de mayo, en recuerdo de su primera Constitución de 1791. Al iniciarse 1990, el águila blanca recuperó su corona en el escudo nacional de armas de Polonia. ${ }^{469}$ En las modificaciones constitucionales se denomina a la "República de Polonia" como "Estado democrático de derecho" que se orienta por la justicia social. La Constitución regenerada y parcialmente revisada de Hungría de 1949-1989, una solución transitoria y más bien para salir de apuros, regula en el capítulo XIV la ciudad capital y los símbolos nacionales de la República de Hungría: el himno nacional (artículo 75). En el artículo 76 se dispone: "El escudo oficial y la bandera nacional de la República de Hungría, así como el uso de los símbolos nacionales, son regulados por una ley con contenido jurídico-constitucional". En el requisito formal de una "ley constitucional" se manifiesta la importancia del objeto. El 2 de mayo de 1990 expide el Parlamento húngaro una resolución en que se declara al levantamiento popular de 1956 como lucha revolucionaria de liberación. El 23 de octubre, aniversario del inicio de la revolución, será en adelante día festivo. Recientemente, al pretender Hungría combinar tres escudos - el "escudo de Kossuth" (1848-1849), el emblema socialista (1948) y el "escudo de la corona" (Reino de Hungría hasta 1945) - está luchando por una reconciliación consigo misma y con sus agitados periodos de la historia constitucional: por la vía de una "recepción productiva" que remite a su patrimonio cultural.

Ahora unas palabras sobre el domingo.

\section{B. Domingo y cultura dominical en el Estado constitucional, comportamiento dominical en la sociedad del tiempo libre, realidad del domingo}

El domingo exige un tratamiento separado de los días festivos, pues, no obstante la frecuencia con la que son reunidos en una "doble garantía", subsiste la diferencia, pues el "domingo" tiene más de mil años. Ni la Revolución Francesa de 1789 ni la Revolución Rusa de 1917,470 así como tampoco la China de Mao Zedong, pudieron suprimirlo o desplazarlo. Casi a escala mundial se afirma como tal.

469 Cfr. ahora el artículo 28, inciso 1, de la Constitución polaca de 1997.

470 De la bibliografia: Kunig, P., Der Schutz des Sonntages im verfassungsrechtlichen Wandel, 1989; Häberle, P., Der Sonntag als Verfassungsprinzip, 1989. 
Este libro forma parte del acervo de la Biblioteca Juridica Virtual del Instituto de Investigaciones Juridicas de la UNAM

En lo particular sobre los domingos y la cultura dominical en el Estado constitucional: la figura clásica se encuentra en el artículo 139 de la Constitución de Weimar, con su doble orientación hacia el "descanso laboral" y la "elevación espiritual". Desde el punto de vista dogmático se trata, primero, de una "garantía institucional" (C. Schmitt), y por tanto, protegida en su contenido esencial frente a todas las funciones estatales (a diferencia de las garantías "abiertas" de los días festivos, que pueden ser relativizadas por ley); y segundo, la garantía del domingo es un mandato de protección dirigido al Estado. El derecho ordinario le confiere perfiles más definidos en los conceptos clave: en principio, no hay ningún "trabajo que se perciba públicamente", protección de los servicios religiosos de los creyentes bajo la figura de ciertas prohibiciones en el marco del descanso laboral colectivo y un espacio público estructurado en este día en términos de descanso general, pero espacio para muy diversos comportamientos en el tiempo libre de los ciudadanos y grupos, en suma, del espacio público pluralista. De un modo que no siempre es comprensible en términos jurídico-positivos, sino que solamente puede profundizarse por la ciencia cultural, son los siguientes altos valores fundamentales constitucionales los que convierten al domingo en un multicitado "patrimonio cultural" o "patrimonio constitucional": estructuración tanto de la soledad como de la convivencia humanas en el ritmo semanal a través del descanso laboral colectivo, con ello tensión-distensión, trabajo-tiempo libre y obligación-ocio y con ello apertura hacia: valores fundamentales (ejercidos voluntariamente) como el matrimonio y la familia, la vecindad y la asociación, la amistad y las reuniones, la religión, la ciencia y el arte, como ejemplos de la posibilidad básica de la "elevación espiritual"(en tal sentido, "carácter de oferta" del domingo).

\section{Defensa de la Constitución}

En la democracia cívica pluralista, todos los ciudadanos son "guardianes" de la Constitución. Lo que las antiguas teorías del Estado concedían solamente como privilegio y predicado a un presidente, o las más recientes, al tribunal constitucional, ya no resulta ser, desde la perspectiva de la teoría constitucional de la actual etapa evolutiva, el monopolio de un solo poder o persona, sino asunto de todos: todos los ciudadanos y grupos, que por ejemplo interponen recursos constitucionales, todos los órganos estatales, que están sujetos a la Constitución, tienen que "defender" a la Constitución en el marco de sus competencias, y no sólo eso sino también continuar desarrollándola. Al respecto hay también una multiplicidad de competencias y 
Este libro forma parte del acervo de la Biblioteca Juridica Virtual del Instituto de Investigaciones Juridicas de la UNAM

procedimientos formalizados, de instituciones e instrumentos, que sirven a la protección de la Constitución. Visto comparativamente, el "arsenal" de medidas para la defensa de la Constitución en el espacio y el tiempo, es sumamente rico. De acuerdo con las diversas experiencias e incluso "temores" históricos, una Constitución nacional regula el ámbito problemático de la "defensa de la Constitución" de manera especialmente intensiva y extensiva (así la Ley Fundamental de Bonn de 1949, después de las experiencias negativas con los artículos de emergencia, formulados como cláusulas generales, de la Constitución de Weimar, o con el "poder dictatorial" del presidente del Reich y los enemigos de izquierda y derecha), o lo hace solamente al margen o no lo hace en absoluto (así, Suiza). La Ley Fundamental alemana es especialmente inventiva cuando se trata de la defensa de la Constitución. Incluso podría decirse que dispone, de manera potencial y actual, de casi todos los instrumentos imaginables para proteger a la Constitución. No obstante el perfeccionismo de estas buenas intenciones, es preciso recordar que, "en última instancia", una Constitución solamente puede ser protegida políticamente o en la profundidad cultural; si bien los instrumentos jurídicos son importantes, solamente son eficaces cuando todos poseen una "voluntad de Constitución" y ésta desenvuelve duraderamente su fuerza normativa (K. Hesse). Esto apunta, pues, a los "límites" de la defensa jurídica de la Constitución.

Bajo esta reserva cada constituyente nacional puede, y debe, hacer una selección entre la plenitud de posibles regulaciones que constituyan la mejor solución relativa para la cultura política de un pueblo, sus experiencias y esperanzas. Son imaginables los siguientes:

- La protección del contenido esencial o el núcleo de los derechos fundamentales en una garantía expresa (así, el artículo 19, inciso 2, de la LF de 1949; el artículo 28 de la Constitución del Cantón suizo de Berna de 1993; el artículo 31, inciso 3, frase 2, de la Constitución de Polonia de 1997); en ocasiones, los tribunales han desarrollado cláusulas no escritas sobre el contenido esencial (así, el Tribunal Constitucional austriaco y, en el plano europeo, el Tribunal de Justicia de la Unión Europea). ${ }^{471}$

- La prohibición de rupturas o quebrantamientos constitucionales (cfr. el artículo 49 , inciso 1 , frase 1 de la LF); se trata igualmente del intento de elaborar las experiencias negativas de Weimar; la práctica constitucional en relación con la LF ha impuesto, sin embargo, confor-

471 Häberle, P., Die Wesengehaltsgarantie des Art. 19, Abs. 2 GG, 3a. ed., 1983, pp. 264 y ss. 
Este libro forma parte del acervo de la Biblioteca Juridica Virtual del Instituto de Investigaciones Juridicas de la UNAM

me al artículo 79, inciso 1, frase 2, excepciones cuestionables. ${ }^{472}$ En Austria, la Constitución ha quedado desfigurada y convertida en "ruina" debida a la falta de una prohibición de esta naturaleza.

- La limitación de las modificaciones constitucionales: las así llamadas "cláusulas de eternidad" como garantías de identidad del Estado constitucional ( $c f r$. el artículo 79, inciso 3, de la LF); estas cláusulas se imponen cada vez con mayor frecuencia en las Constituciones recientes, ${ }^{473}$ pero todavía la Constitución de Weimar carecía de una semejante. Amplios catálogos se encuentran, por ejemplo, en el artículo 288 de la Constitución de Portugal; en otras ocasiones solamente se protege la forma de gobierno republicana (así, en África: artículo 142 de la Constitución de Madagascar de 1992), en otras más están protegidos varios principios constitucionales, los esenciales, frente al poder revisor de la Constitución (por ejemplo, artículo 118 de la Constitución de Mali de 1992; artículo 225 de la Constitución del Chad de 1996). En Suiza no existen "cláusulas de eternidad" como derecho positivo ni a nivel federal ni en el cantonal, aunque la doctrina se ocupa intensamente de las mismas. ${ }^{474}$

- Las limitaciones al proceso constituyente: para el político del poder o de la realidad no serán ningún tema, así como tampoco se plantea la cuestión de las límites al constituyente "todopoderoso" dentro de la cuestionable doctrina de que el constituyente decide "normativamente a partir de la nada" ("decisionismo"). Pero es diferente en la teoría del Estado constitucional, en el cual hay límites que se derivan de su tipo: dignidad humana, derechos humanos, democracia y división de poderes son (citados ya con frecuencia en el preámbulo) datos "ideales", que si no se respetan, conducen a que ya no se pueda hablar de "Estado constitucional". En Suiza el federalismo podría constituir un "límite inmanente" para cualquier constituyente. En la Europa en trance de unión, la pertenencia a ella, en la forma técnica que sea (Consejo de Europa o UE), constituye un límite para el constituyente nacional. Las "condiciones" que el Consejo de Europa fijó en los noventa en materia de protección de minorías a los Estados reformados de Europa oriental (por ejemplo, Estonia y Hungría) son también límites; dicho de otra manera: el Consejo de

472 Cfr. la posición crítica al respecto de Hesse, K., Grundzüge..., cit., pp. 291 y ss.

$473 \mathrm{Al}$ respecto Häberle, P., Verfassungslehre als Kulturwissenschaft, 2a. ed., 1998, pp. 267 y ss.

474 Müller, J. P., “Materiale Schranken der Verfassungsrevision?”, FS Haug, 1986, pp. 195 y ss.; Häberle, P., ibidem, pp. 81 y ss. 
Este libro forma parte del acervo de la Biblioteca Juridica Virtual del Instituto de Investigaciones Juridicas de la UNAM

Europa, pero de manera particular la UE, funcionan prácticamente respecto de los países que pretenden adherirse a ellos como un "constituyente mediato". ${ }^{475}$ De manera inversa, la LF intenta, a través de la llamada cláusula de aseguramiento estructural del artículo 23, inciso 1, frase 1, influir indirectamente en el proceso de unificación europea, lo que había logrado el Tribunal Constitucional Federal con la sentencia "Solange"(E 37, 271 y 73, 339). Visto en conjunto, e independientemente de los límites típicos apuntados, hay que buscar en la profundidad de la cultura constitucional de una nación los determinantes últimos que son dados previamente al constituyente, aún si no tienen que ser formulables jurídicamente. Así como va cambiando la comprensión del proceso constituyente en el proceso de etapas textuales, considerado comparativamente, en la misma medida es que, por ejemplo, ya no es una "nación" o el "pueblo" los que se "dan" una Constitución, sino que lo son los "ciudadanos y ciudadanas del Land de Brandemburgo"(así, el preámbulo de la Constitución de 1992), es así como el tipo del Estado constitucional ha comenzado a "institucionalizar" y a "constitucionalizar" el proceso constituyente, anteriormente concebido como "salvaje", "originario", que comenzaba explosivamente desde "cero". El mejor ejemplo a escala mundial son las Constituciones cantonales suizas, que fijan requisitos mínimos determinados al procedimiento constituyente (por ejemplo, los 121 a 125 de la Constitución de Aargau de 1980). También la Constitución de Brandemburgo (1992) establece, como única en Alemania, barreras procesales claramente definidas para una nueva Constitución del Land (artículo 115: entre otras, una mayoría de dos tercios de los miembros de la asamblea constituyente, aprobación por referéndum con la mayoría de los votantes). En Sudáfrica se establecen en la Constitución provisional de 1993 condiciones ("general principles") para la Constitución definitiva de 1996, cuyo cumplimiento fue revisado incluso en 1997 por el Tribunal Constitucional local, quizá el único ejemplo a nivel mundial, establecido por el derecho constitucional, de la participación de un tribunal constitucional en el proceso constituyente y una muestra de la historia exitosa del establecimiento de la jurisdicción constitucio-

475 Cfr. Streinz, R., Europarecht, 3a. ed., 1996, núm. 78. Normado de manera expresa en el artículo 6o., inciso 1, en relación con el artículo 49 del Tratado de la Unión Europea (Amsterdam). 
Este libro forma parte del acervo de la Biblioteca Juridica Virtual del Instituto de Investigaciones Juridicas de la UNAM

nal. El tema "límites del proceso constituyente" ya no es, desde hace tiempo, de naturaleza "platónica" o un mero juego teórico.

- Las garantías del "orden fundamental de libertady democracia" son una conquista particular de la Ley Fundamental de Bonn, las que, bajo el signo de los valores de la democracia "militante" o "dispuesta a la defensa", pretenden proteger a la Constitución contra posibles enemigos ("enemigos de la Constitución"), tempranamente identificados, para lo cual existe naturalmente el peligro de que los grupos gobernantes quieran excluir, como "enemigos de la Constitución", a los grupos de oposición que les desagraden, aunque éstos únicamente estén haciendo uso, en el marco de la Constitución, de sus derechos como oposición protegidos especialmente por los derechos fundamentales. En casos extremos, la Ley Fundamental alemana ha creado dos posibilidades de prohibición: la llamada "pérdida" ("Verwirkung") de derechos fundamentales, conforme al artículo 18 LF, y la prohibición de partidos, conforme al artículo 21, inciso 2, de la LF. De acuerdo con el artículo 18, pierde sus derechos fundamentales aquel que "abuse de ellos" (como las libertades de opinión o de asamblea, o el derecho de asilo) en su "lucha contra el orden fundamental de libertad y democracia". Solamente en muy pocos casos se ha aplicado hasta ahora el artículo 18. Algo diferente ocurre con la prohibición de partidos conforme al artículo 21, inciso 2, LF, según el cual "son inconstitucionales los partidos que por sus objetivos o por el comportamiento de sus adherentes tengan el propósito de dañar o suprimir el orden fundamental de libertad y democracia o poner en peligro la existencia de la República Federal de Alemania”. El TCFA dictó en 1952 y 1956, en virtud del privilegio de partidos, dos importantes sentencias (E 2, 1 y E 5, 85) que prohibían de manera constitutiva al Partido Socialista del Reich, radical de derecha, y al Partido Comunista de Alemania, haciendo profundas explicaciones sobre la "democracia en libertad" y la "democracia militante" ("process of trial and error", "síntesis entre el principio de tolerancia hacia otras opiniones políticas y el reconocimiento de ciertos valores fundamentales intangibles del orden estatal": E 5, 85 (135 y 139)). Lo que en otras partes se sanciona solamente a través del derecho penal político o por la opinión pública, trata de resolverlo jurídicamente la LF. Ciertamente hay que tener claridad sobre los límites de la prohibición del abuso, pues es más fácil neutralizar a los partidos políticos pequeños que a los que han sido legitimados con un mayor poder por el pueblo. En 1998, al prohibir el Tribunal Constitucio- 
Este libro forma parte del acervo de la Biblioteca Juridica Virtual del Instituto de Investigaciones Juridicas de la UNAM

nal al Partido islámico, que ya había participado en el gobierno, alcanzó quizá Turquía los límites de la prohibición de partidos ( $\mathrm{ffr}$. artículos 68 y 69 de la Constitución de Turquía de 1982, y 98 de la Ley sobre Partidos Políticos de 1983). En el fondo se muestra aquí también que la democracia en libertad debe ser asegurada, en última instancia, sólo por sus ciudadanos mismos.

- La finalidad del "estado de excepción" o la llamada "emergencia de Estado" es también la protección de la Constitución. Se trata de todos los peligros graves para la permanencia del Estado o de la seguridad y el orden públicos, lo que no puede resolverse mediante las vías normales previstas por la Constitución, sino que su defensa y medidas solamente son posibles con medios excepcionales. ${ }^{476}$ En la época anterior a la segunda guerra mundial, algunos países funcionaron con un derecho de emergencia de Estado no escrito, extra o supra constitucional (así, por ejemplo, Suiza). El Estado constitucional, que se caracteriza por el derecho escrito, aun cuando reconoce fuentes del derecho no escritas, como el derecho constitucional judicial o los principios generales del derecho, haría bien en establecer con claridad las competencias para el caso de excepción y señalarles límites claros. El objetivo de cualquier disposición sobre situaciones de emergencia debe ser el restablecimiento, tan pronto sea posible, de la "normalidad constitucional". La idea de la ultima ratio o de la prohibición del exceso debe guiar a todas las medidas de excepción, como el quebrantamiento (Durchbrechung) de las competencias normales de los parlamentos en favor del ejecutivo (concentración de poderes) o de la limitación o suspensión temporales de los derechos fundamentales. Bajo estas estrictas condiciones requiere la primacía de la Constitución escrita, suspender en partes la Constitución, "a fin de poder restablecer su vigencia ilimitada". ${ }^{477}$ Es en esta medida que el estado de excepción forma parte plenamente de las instituciones "normales" del Estado constitucional y no se encuentra, per se, en contradicción con él. En consecuencias, numerosas Constituciones antiguas y recientes conocen el estado de excepción o tradicionalmente el "estado de sitio". Su demonización por los ideologías de izquierda a fines de los años sesenta en Alemania (palabra clave: "Orwell") no se justificaba ni en la comparación jurídica ni en la historia constitucional.

476 Hesse, K., Grundzüge..., cit., p. 301.

477 Ibidem, p. 303. 
Este libro forma parte del acervo de la Biblioteca Juridica Virtual del Instituto de Investigaciones Juridicas de la UNAM

La teoría constitucional tiene que aclarar una serie de cuestiones fundamentales - también en vinculación con la política constitucional - que los diversos países pueden responder de manera distinta: ¿quién declara el estado de excepción (por ejemplo, el presidente, el Parlamento o el gobierno)? ¿cuáles son las condiciones y supuestos de hecho para declararlo (peligros para el orden y la seguridad públicos)? En este sentido hay que distinguir entre la "emergencia externa"(según la LF, el llamado "caso de defensa": artículo 155a, incisos 1 y 3) y la "emergencia interna" (catástrofes naturales, accidentes especialmente graves, peligros para la supervivencia del Estado o del orden fundamental de democracia: artículo 35, incisos 2 y 3,91 , inciso $1, \mathrm{LF})$; ¿se conforma con una cláusula general, como la de la Constitución de Weimar en su famoso artículo 48, o si se prefiere, tratar de resolver el problema a través de numerosas normas detalladas (como en la LF alemana a partir de 1968)? Si debido a la autorización general, como en Francia (artículo 16 de la Constitución de 1958) existe el peligro de un abuso, una regulación especial amenaza con conducir a la inefectividad (como sucede quizá con la LF alemana). Finalmente: ¿quién controla la proporcionalidad de la medidas (quizá un tribunal constitucional, como en el artículo $115 \mathrm{~g}$ de la LF) o quién decide sobre la duración del estado de excepción ( $c f r$. por ejemplo un comité especial: el "comité conjunto", artículo 53a de la LF)?

- El derecho de resistencia es el "último recurso del ciudadano" para la defensa de la Constitución. Algunos Estados constitucionales lo han positivizado, como la LF alemana en su artículo 20, inciso 4: "Contra todo aquel que se proponga suprimir este orden, tienen todos los alemanes el derecho a la resistencia cuando no sea posible otro remedio", y anteriormente ya las Constituciones de los Länder (el artículo 147, inciso 1, de la Constitución de Hesse abruma incluso a sus ciudadanos con un deber de resistencia). En África destaca la Constitución de Mali de 1992, en la medida en que otorga al pueblo "el derecho a la desobediencia civil... a fin de conservar la forma de Estado republicana"(artículo 121, inciso 2). Con ello encontramos una confirmación más del "paradigma de las etapas textuales". $\mathrm{Si}$ antiguamente el derecho de resistencia era abordado en las teorías generales del Estado bajo criterios de derechos humanos o de derecho natural, y tal derecho fue, por ejemplo, invocado por los hermanos Scholl en Alemania en 1944 contra el nacionalsocialismo, las Constituciones más recientes integran la discusión política y científica más reciente alrededor de la "desobediencia civil" que se debe al norteamericano Thoreau (1848) y que ha encontrado a 
Este libro forma parte del acervo de la Biblioteca Juridica Virtual del Instituto de Investigaciones Juridicas de la UNAM

sus testigos más convincentes en grandes figuras como M. Gandhi, Martin Luther King o Nelson Mandela. También grupos colectivos como "Amnesty International", "Robin Wood" o "Greenpeace" recurren a la doctrina de la "desobediencia civil" para justificar la "violación limitada de las reglas". ${ }^{478}$ El Estado constitucional posee varias posibilidades alternativas. Puede dejar sin regular el derecho de resistencia y esperar la "rebelión de las conciencias", recurriendo al derecho natural, o puede positivizarlo, a fin de dar a la conciencia individual siquiera un apoyo simbólico, o bien, puede prescribir la posible invocación de la desobediencia civil. ${ }^{479}$ En un orden democrático funcional sólo puede darse el derecho de resistencia en un "sentido conservador", de acuerdo con BVerfGE 5, 85 (376), mientras que el mandato de la ultima ratio sigue siendo irrenunciable: pero incluso el Estado constitucional desarrollado corre en ocasiones el peligro de no reconocer en absoluto abusos graves, o hacerlo demasiado tarde. Aquí se requiere un "sistema de alerta temprana", al que pertenece la desobediencia civil, que es capaz de sensibilizar a una comunidad política sobre eventos (como la contaminación del ambiente o la nuclear) que la opinión pública pluralista no toma suficientemente en serio. Bajo las condiciones que señala J. Rawls, aquí puede estar justificada la "desobediencia civil". Quien la ejerza tiene, empero, que aceptar las consecuencias para su persona, por ejemplo, un castigo, pues su justificación es ética, no jurídica. 
Este libro forma parte del acervo de la Biblioteca Juridica Virtual del Instituto de Investigaciones Juridicas de la UNAM

\title{
GAPÍTULO SEXTO. NEGESIDADES DE REFORMA EN EL ESTADO CONSTITUCIONAL DE LA ETAPA EVOLUTIVA ACTUAL
}

\author{
I. El ESTADO GONSTITUCIONAL EN LA PERSPECTIVA DE LA EVOLUGIÓN \\ HISTÓRICA. MÉTODOS DE SU COMPRENSIÓN CIENTÍFICA, \\ GARACTERIZACIÓN DE SUS CONTENIDOS ESENCIALES
}

\begin{abstract}
1. Métodos de comprensión científica: procesos mundiales de producción y recepción desde hace siglos, enfoque culturalista y empirico, textos clásicos, el paradigma de las etapas textuales, comparación jurídica "en clave cosmopolita"
\end{abstract}

La capacidad y la necesidad de desarrollo del Estado constitucional como tipo forma parte del credo de este trabajo, con lo cual no puede arriesgarse más que a un mínimo de indispensable optimismo científico. No podemos conocer el "sentido" de la historia (constitucional), pero sí quizá trabajar en el sentido de la técnica incremental de Popper, de modo que el Estado constitucional, que habrá de ser caracterizado con mayor detalle más adelante en sus contenidos y procedimientos específicos, sea entendido como "res publica semper reformanda" y siga desarrollándose como objetivo y foro de los "eternos" esfuerzos humanos en materia de dignidad humana, libertad y justicia social.

¿Cuáles son los métodos con los que se puede captar la evolución del Estado constitucional hasta la fecha? Los textos constitucionales, una vez que se encuentran en el mundo, en su caso incluso "sólo" como proyectos, desenvuelven en la sociedad abierta de los intérpretes constitucionales un potencial difícilmente predecible, sobre todo si ya el pluralismo de los métodos jurídicos de la interpretación conduce a dejar abierta la cuestión del modo como deben combinarse en el caso particular los cuatro métodos clásicos de la interpretación (desde F. C. von Savigny), que en mi opinión son cinco, si agregamos la comparación jurídica. ${ }^{400}$ Sin embargo, los textos constitu-

480 De la bibliografía, por último, Kramer, E. A., Furistische Methodenlehre, 1998. 
Este libro forma parte del acervo de la Biblioteca Juridica Virtual del Instituto de Investigaciones Juridicas de la UNAM

cionales, también en su intercambio a escala mundial hoy, pero también ya desde 1787 y 1789, son los "portadores" de las diversas partes integrantes del tipo del Estado constitucional. El "paradigma de las etapas textuales" puede y quiere demostrar que a través de los diversos procesos de recepción de textos constitucionales se transporta también, de manera indirecta, una realidad constitucional, porque, por ejemplo, una Constitución totalmente revisada convierte más tarde en texto y en conceptos aquello que se ha hecho realidad como práctica en otros Estados constitucionales (también gracias a la jurisprudencia y la doctrina). Es posible encontrar fácilmente ejemplos prácticos de esto en los textos normativos sobre los derechos fundamentales, los partidos políticos, el federalismo y el regionalismo. ${ }^{481}$

En rechazo al difundido "eurocentrismo": el Estado constitucional es en la actualidad una obra comunitaria de muchos tiempos y espacios - aunque históricamente haya sido un proyecto europeo-atlántico- por lo que hay que incluir en la comparación jurídica, de entrada y "en clave cosmopolita", a los países en desarrollo y los micro Estados. Tenemos que plantearnos la pregunta de si, y de qué modo, estos países pueden hacer contribuciones propias al tipo del Estado constitucional, y lo mismo resulta válido para los Estados reformados de Europa oriental. Así, por ejemplo, Madagascar (1992/1995) y Etiopía (1994) han convertido en texto constitucional el nuevo postulado de la "transparencia" de la vida política, pues el principio clásico de la publicidad ya no es suficiente. Así también se practica en los micro Estados, o en las ciudades-Estado en sistemas federales, la cercanía al ciudadano, la que puede resultar ejemplar para otros. ${ }^{482}$ Sudáfrica se atrevió a enriquecer en su Constitución de 1996 el canon de la interpretación, del modo como lo había requerido anteriormente la doctrina (artículo 39, inciso 1, literal c): "may consider foreign law"). Así también Polonia en 1997, en materia de referencias a Dios, creó un compromiso en su preámbulo a la Constitución que debería hacer historia (constitucional) en la sociedad plural, mientras que la Constitución del Cantón de Berna (1993) ha esbozado un artículo ejemplar (artículo 54) en materia de cooperación y ayuda internacionales, del mismo modo como, en el artículo 28, suaviza el debate (alemán) en torno al "contenido esencial" de los derechos fundamentales, a través de momentos absolutos y relativos y se atreve a ofrecer un catálogo de

481 Referencias en Häberle, P., "Theorieelemente eines allgemeinen juristischen Rezeptionsmodells", 7 Z, 1992, pp. 1033 y ss.

482 De la bibliografía sobre Liechtenstein, por último: Batliner, G., Aktuelle Fragen des liechtensteinischen Verfassungsrechts, 1998; sobre las ciudades-Estado, Häberle, P., "Die Zukunft der Landesverfassung der Freien Hansestadt Bremen”, fZ, 1998, pp. 57 y ss. 
Este libro forma parte del acervo de la Biblioteca Juridica Virtual del Instituto de Investigaciones Juridicas de la UNAM

ejemplos. ${ }^{483}$ Estas "etapas textuales" animan a captar y promover las ideas jurídicas a partir de los materiales constitucionales de todo el mundo, por ejemplo, para fines de la asesoría constitucional práctica local en Europa oriental.

\section{Caracterización de los contenidos esenciales (principios) del Estado constitucional}

Pasando ahora de los métodos a los contenidos, aunque ambos se vinculan: el Estado constitucional se caracteriza por un conjunto - realizadode principios que aquí mencionamos solamente a manera de términos clave, catálogo de principios que se encuentra abierto, a pesar de las llamadas "cláusulas de eternidad" en el sentido del artículo 79, inciso 3, LF, del mismo modo como la lista de temas del Estado constitucional en conjunto queda abierta hacia el futuro: así, la Constitución de Ucrania (1996) introdujo lo que hasta ahora es un singular artículo sobre Chernobil (artículo 16). De este modo también ha hecho carrera el tema de la "protección de las personas de edad y los discapacitados", primero en el curso de los últimos años, también gracias a los textos de la ONU de 1989, ${ }^{484}$ pero hoy a escala mundial; así empiezan a imponerse los derechos fundamentales de los niños (por ejemplo, artículo 28 de la Constitución de Sudáfrica, artículo 72 de la Constitución de Polonia). ${ }^{485}$

En Europa oriental se han creado, como resultado de las experiencias con el Estado totalitario del marxismo-leninismo, cláusulas contra las ideologías de Estado o sobre el pluralismo (por ejemplo, el artículo 11 de la Constitución de Bulgaria de 1991; artículo 1o., inciso 3, de la Constitución de Rumania de 1991; artículo 3o. de la Constitución de Croacia de 1991; artículo 9o. de la Constitución de Macedonia de 1991; artículo 13, incisos 1 y 2, de la Constitución de Rusia de 1993); también en los Estados africanos se encuentra un reconocimiento del pluralismo político (por ejemplo, preámbulo de la Constitución del Chad de 1996; artículos 2o. y 159 inciso c), de la Constitución de Angola de 1992).

483 De la bibliografía: Müller, J. P., Elemente einer schweizerischen Grundrechtstheorie, 1982, pp. 141 y ss.; Häberle, P., Die Wesensgehaltgarantie des Art. 19 Abs. 2 Grundegesetz, 1962, 2a. ed., 1972, pp. 39 y ss., 3a. ed., 1983, especialmente pp. 326 y ss.

${ }_{484} \mathrm{Al}$ respecto Hailbronner, K., "Der Staat und der Einzelne als Völkerrechtssubjekt", en Graf Vitzthum, W. (ed), Völkerrecht, 1997, p. 181 (245).

485 A petición del Consejo Nacional Suizo debe haber incluso en Suiza artículos sobre los derechos de los niños: $\mathcal{N} Z Z$ del 20 de marzo de 1998. 
Este libro forma parte del acervo de la Biblioteca Juridica Virtual del Instituto de Investigaciones Juridicas de la UNAM

Sin embargo, existe un inventario básico de principios constitucionales en la actual etapa evolutiva del Estado constitucional, por decirlo así, un "programa constitucional obligatorio", el cual comienza con la dignidad humana como premisa antropológico-cultural que conduce a la democracia como "consecuencia organizativa". Sin embargo, la comparación jurídica impide sostener la separación, muy alemana, entre dignidad humana y democracia, y la reducción de ésta a la democracia representativa como la "verdadera" democracia. Los "derechos del pueblo" en Suiza son la satisfacción de la dignidad humana, y también son entendidos así. Si agregamos las manifestaciones de la dignidad humana en los distintos derechos humanos, hasta el derecho al desarrollo (en este contexto, también el derecho a la paz discutido en el derecho internacional, como derecho de la "tercera generación"), y también el aseguramiento a través de derechos fundamentales sociales y libertades culturales, junto con una rica filigrana de varias "dimensiones", tendremos una "cultura de los derechos fundamentales" del Estado constitucional, la que naturalmente viven de manera bastante distinta los diversos Estados: Francia a partir de lo cultural, lo nacional-republicano ("libertades públicas"), Alemania en la actualidad más bien a partir de su autoimagen acentuadamente económica, pero en todo caso entendemos la "libertad alemana" como "libertad federativa", tan fuertemente enraizada está entre nosotros la cultura del federalismo. La división de poderes es otro elemento estructural indispensable, para la cual deberíamos considerar que la división de poderes clásica (horizontal y vertical), referida al Estado, fuera complementada por la división social de poderes en sentido amplio (por ejemplo, entre las partes de la negociación laboral colectiva o entre los medios de comunicación).

La propensión de los seres humanos que ocupan cargos públicos al abuso de poder le plantea una y otra vez al Estado constitucional la tarea de encontrar mecanismos de división de poderes (ejemplo: tribunales de cuentas, ombudsman u ombudswoman, consejos para los medios; son ejemplares los artículos 183-187 de la Constitución del Chad de 1996).

La obligación abstracta a favor del bien común debe ser satisfecha, de manera concreta, bajo la figura del Estado social de derecho y del Estado de cultura. Esto último tiene por resultado numerosas variantes textuales, especialmente en las cláusulas sobre el patrimonio cultural en los países en desarrollo (artículos 60 y 61 de la Constitución de Guatemala de 1985), así como en Europa oriental (por ejemplo, preámbulo y artículo 6o. de la Constitución de Polonia de 1997, artículos 11, 54 inciso 4, de la Constitución de Ucrania de 1996), pero también en el derecho constitucional de la cultura, ricamente articulado, de las Constituciones cantonales suizas o de los cinco 
Este libro forma parte del acervo de la Biblioteca Juridica Virtual del Instituto de Investigaciones Juridicas de la UNAM

nuevos Länder alemanes. ${ }^{486}$ El Estado de derecho, que de entrada debe ser considerado como social, plantea otras tantas tareas estatales, a pesar de todas las controversias sobre la "restructuración" del Estado social. Transfiere también el encargo constitucional a los "profetas del mercado", para luchar por la economía social de mercado y pensar en los límites del mercado (la "mano visible" del derecho constitucional). También existe quizá en las tareas culturales de las entidades federativas y los municipios (palabra clave: privatización, sponsoring cultural).

$\mathrm{Al}$ inventario típico de las Constituciones del Estado constitucional pertenece hoy la apertura hacia regiones más amplias: en Europa, los así llamados artículos sobre Europa, ${ }^{487}$ lo que tiene sus correspondencias en la península ibérica, así como en Sudamérica y África, cuando se habla expresamente, o por su sentido, de la unidad y la identidad iberoamericanas ( $c f r$. el artículo 7o., inciso 4, y el 15, inciso 3, de la Constitución de Portugal; el artículo 11, inciso 3, de la Constitución española), o de la unidad y la identidad africanas (por ejemplo, preámbulo y artículo 117 de la Constitución de Mali de 1992, artículo 122 de la Constitución de Níger de 1996, preámbulo de la Constitución de Senegal de 1992; artículos 146 y s. de la Constitución de Burkina Faso de 1991-1997). Aquí pertenece también la "imagen del mundo" propia de las Constituciones, ${ }^{488}$ pues encuadran a sus pueblos en la comunidad universal, se adhieren a los derechos humanos universales y aseguran la ayuda al desarrollo y otras formas de la cooperación. El lugar del Estado nacional introvertido lo ocupa el "Estado constitucional cooperativo". Se hacen visibles las tareas de la humanidad, la "imagen del ser humano" del Estado constitucional se convierte en la "humanidad" referida al mundo entero. ${ }^{489}$ La cláusula de eternidad del Estado constitucional, cuya carrera comienza en el artículo 112 de la Constitución de Noruega de 1814, encuentra una cima en el artículo 79, inciso 3, de la LF, el cual se prolonga en varias interpretaciones doctrinales y que desde entonces ha encontrado sucesores en diversas Constituciones en todos los continentes (por ejemplo,

486 Al respecto mi análisis en fö̈ $R$, vol. 40, 1991-1992, pp. 291 y ss.; vol. 41, 1993, pp. 69 y ss.; vol. 43, 1995, pp. 355 y ss. De la bibliografía general: para Suiza en föR, vol. 34, 1985, pp. 303 (320 y ss.; para Alemania oriental: v. Mangoldt, H., Die Verfassungen der neuen Bundesländer, 2a. ed., 1997.

487 Véase al respecto mi panorama comparativo en FS Everling, 1995, pp. 355 y ss.

${ }_{488} \mathrm{Al}$ respecto el ensayo 'Das 'Weltbild' des Verfassungsstaates — eine Textstufenanalyse zur Menschheit als verfassungsstaatlichem Grundwert und 'letztem' Geltungsgrund des Völkerrechts", FS Kriele, 1997, pp. 1277 y ss.

$489 \mathrm{Al}$ respecto, en relación con la idea del "Estado constitucional cooperativo" (1978), con todas las referencias textuales, Häberle, P., Verfassungslehre als Kulturwissenschaft, 2a. ed., 1998, pp. 175 y ss. 
Este libro forma parte del acervo de la Biblioteca Juridica Virtual del Instituto de Investigaciones Juridicas de la UNAM http://www.juridicas.unam.mx

artículo 159 de la Constitución de Angola; artículo 104 de la Constitución de Guinea Ecuatorial de 1991; artículo 64 de la Constitución de Camerún de 1996; artículo 157 de la Constitución de Ucrania de 1996), no son idénticos con el inventario mínimo aquí descrito. También y precisamente hay que pensar de manera nacional en este punto. Suiza no requiere semejante "cláusula de eternidad" escrita, pues su cultura constitucional se sostiene a sí misma y asegura "eternamente" sus elementos de identidad por sí mismos. ${ }^{490}$ Francia solamente garantiza la "eternidad" de la República (artículo 89, inciso 5, de la Constitución de 1958), mientras que Portugal creó un catálogo bastante amplio (artículo 228 de la Constitución de 1976), la Ley Fundamental alemana incorpora elementos del federalismo en el artículo 79, inciso 3, mientras que ambos Estados ibéricos, por lo que se refiere a la división vertical de los poderes, solamente conocen a su "hermano menor", el regionalismo, hacia el cual apenas se dirige ahora, de manera penosa, Gran Bretaña ("devolution" a Escocia y Gales, el estatuto de semiautonomía para Irlanda del Norte). Precisamente aquí se muestra que siempre hay que trabajar en dos planos: en el más abstracto del tipo del "Estado constitucional" y en el más concreto del ejemplo nacional, aunque ambos planos se interrelacionen en el largo plazo: el ombudsman de Escandinavia está en vías de convertirse en principio "normal" de las Constituciones del Estado constitucional (por ejemplo, Polonia 1997; veáse también los artículos 156 a 158 de la Constitución de Togo de 1992: "Comisión Nacional de Derechos Humanos"). A esto hay que agregar el derecho constitucional no escrito, el que, como sucede en Suiza en relación con algunos derechos fundamentales, es configurado por la doctrina y la práctica, "inducidos" frecuentemente por textos constitucionales de países extranjeros.

\section{Política constitucional y UTOPÍAS}

\section{Política constitucional ("pensamiento de las posibilidades")}

La política constitucional es la configuración consciente y el desarrollo progresivo de una Constitución que pertenece al tipo del "Estado constitucional": formalmente, esto puede producirse o funcionar de diversas mane-

490 De la bibliografía: Müller, J. P., "Materielle Schranken der Verfassungsrevision?”, FS Haug, 1986, pp. 81 y ss.; Häberle, P., "Verfassungsrechtliche Ewigkeitsklauseln als verfassungsstaatliche Identitätsgarantien", ibidem, pp. 81 y ss.; Kirchhof, P., "Die Identität der Verfassung in ihren unabänderlichen Inhalten"; HdBStR, vol. I, 1987, pp. 775 y ss. 
Este libro forma parte del acervo de la Biblioteca Juridica Virtual del Instituto de Investigaciones Juridicas de la UNAM

ras: como "expedición" original de una Constitución (como en 1787 en los Estados Unidos y en 1791 en Francia), como "revisión total" de Constituciones existentes (como ha ocurrido desde los años sesenta hasta la actualidad en varios cantones suizos), como "revisión parcial" (como ha ocurrido, hasta 1999, 44 veces con la LF alemana, o 28 veces desde 1787 en los Estados Unidos a través de los "amendments"), pero también a través de las formas más "finas" de la interpretación constitucional creativa de la Constitución vigente, hasta llegar al audaz voto particular (por ejemplo, de la señora von Brünneck E 32, 129). Desde el punto de vista de su contenido, la política constitucional se dirige hacia el todo o a partes del conjunto de una Constitución, en lo cual se orienta por otros tipos, pero también configura variantes nacionales (en el Estado federal, de las entidades federativas): dependiendo de la cultura constitucional individual, desarrollada históricamente (por ejemplo, en Suiza como democracia semidirecta, en los nuevos Länder alemanes vía la recepción y desarrollo de la doctrina y la jurisprudencia más recientes de Alemania occidental, o la incorporación de estándares europeos o mundiales).

Mientras que tanto las funciones estatales como el constituyente o el legislador ordinario que expide "leyes orgánicas"(ejemplo: España), pero también el órgano reformador de la Constitución, pueden "traerse" hoy sus "materiales", modelos, ejemplos e inspiraciones de toda la historia constitucional (tiempo) y comparación (espacio) accesibles a ellos en materia de Estado constitucional, a fin de crear nuevas Constituciones ("proceso constituyente") o reformar las existentes mediante algún procedimiento ("reforma constitucional"), y al hacerlo proceden de manera "política", es decir, que deben buscar un compromiso con otros grupos plurales en las asambleas constituyentes, el participante que es científico tiene más libertad, pues sirve directamente a la justicia (de la Constitución) y labora al servicio inmediato de la búsqueda de la verdad, precisamente como científico. Ante sus ojos se presenta directamente el ideal de una "buena" Constitución, se mueve libremente en el "taller" de la historia y la comparación constitucionales, que son dos lados de la misma cosa, mientras que el constituyente político está expuesto a las diversas condiciones de la negociación, de la acción con todos los participantes, hasta llegar a un compromiso "malo", pero inevitable. Estas vías y tareas distintas en materia de política constitucional, las directamente políticas y las primariamente científicas, tienen que ser distinguidas, aunque haya intersecciones: por ejemplo, cuando el constitucionalista debe dictaminar un proyecto concreto de Constitución, 
Este libro forma parte del acervo de la Biblioteca Juridica Virtual del Instituto de Investigaciones Juridicas de la UNAM

como ha sucedido a partir de 1990 hasta nuestros días en Polonia, ${ }^{491}$ o en Sudáfrica en 1996, con fuerte participación alemana, ${ }^{492}$ o bien, como pudo observarse en el proceso de elaboración de la Constitución provincial de Kwazulu Natal en 1996. Suiza ofrece también ejemplos de ello. La tarea de la ciencia consiste en proponer una paleta de posibles soluciones o normaciones, o bien, comentar las que ya estén vaciadas en forma de textos, y en su caso mejorarlas mediante variantes textuales. Previamente tendrá que realizar "politica científica de reservas", es decir, elaborar con independencia un espectro de varias alternativas que puedan ser de utilidad para quien haga política constitucional "en razón de su oficio", como por ejemplo, un órgano reformador de la Constitución. Un caso particular lo constituyen los proyectos científicos privados, que frecuentemente hay en Suiza, siguiendo una tradición clásica, más recientemente en el plano federal gracias a KölzMüller (1984), en Zürich gracias a T. Jaag. Se realizan sin encargo y pueden trabajar de manera "ideal", laborando por propia iniciativa sin estar sujetos a instancias, cuerpos y procedimientos concretos, así como tampoco a los partidos políticos.

Así entendida, la política constitucional debe convertirse en tarea natural de la doctrina constitucional. Sobre todo, no debe ser excluida por estar demasiado "próxima a la política", sino concebirse como parte integrante de la disciplina. Posee reglas manuales, y en caso afortunado, "reglas del arte", que se han formado en las largas tradiciones del Estado constitucional y que son especialmente demandadas hoy, en la "era de la Constitución”, después de 1989, para lo cual es conveniente mucha humildad. Por bueno que fuera un constituyente, en Sudáfrica quizá no hubiera logrado el "milagro" de la Constitución de transición de 1993 y la definitiva de 1996 sin un Nelson Mandela y sin un F. de Klerk que le abrieran el camino. Inversamente, quizá se haya perdido en Polonia en 1989-1990 la "hora de la Constitución", aunque había una personalidad carismática como la de L. Walesa (la Constitución se logró en 1997). Lo que el constitucionalista se imagina en materia del Estado constitucional más o menos desde la "mesa de discusión" no es necesariamente y per se adecuado para ser transformado de hecho en política constitucional práctica. Para ello se requieren las fuerzas políticas, una opinión pública dispuesta a aceptar, ciertas condiciones económicas y mucha buena voluntad. No obstante, el constitucionalista

491 Documentación en fö̈ $R$, vol. 43, 1995, pp. 184 y ss.

$492 \mathrm{Al}$ respecto Karpen, U., "Südafrika auf dem Wege zu einer demokratisch-rechtsstaatlichen Verfassung”, fö $R$, vol. 44, 1996, pp. 609 y ss. 
Este libro forma parte del acervo de la Biblioteca Juridica Virtual del Instituto de Investigaciones Juridicas de la UNAM

está llamado, en razón de su ciencia, a colaborar de acuerdo con sus (modestas) posibilidades.

\section{Utopias de todos los campos del arte}

Las "tesis sobre la utopía" de una teoría constitucional comparativa como ciencia jurídica de los textos y la cultura señalan:

A) Las utopías constituyen un género literario y una forma científica y artística indispensables con el fin de asegurarse a uno mismo, en parte como legitimación, en parte como crítica. Las utopías ofrecen a los seres humanos unas veces experiencias y otras esperanzas, pues están fundamentadas "antropológicamente".

B) Puesto que la historia enseña que el Estado constitucional, en especial, se ha convertido en "conquista cultural" también gracias a las utopías, las "fantasías", las visiones y "sueños" de sus clásicos, debe haber apertura en lo futuro para nuevas utopías o para las utopías clásicas transformadas como "catalizadores" o "fermentos". Piénsese en el "sueño" de la integración racial en los EUA de Martin Luther King, que en mucho se ha vuelto realidad y que ha asumido una forma constitucional, tanto jurídica como culturalmente, gracias a un nuevo día festivo a partir de 1986. En tal medida, la tesis del agotamiento de las energías utópicas, de ser cierta, apuntaría a un síntoma de crisis que no puede dejar indiferente al Estado constitucional democrático.

C) Lo anterior no impide que la teoría constitucional evalúe conscientemente y distinga entre las utopías "positivas" y las "negativas" (por ejemplo, las "historicistas" o "totalitarias"). El ejemplo más bello de una "utopía positiva", y hasta ahora solamente realizado de manera puntual, es el esbozo filosófico de I. Kant sobre "La paz perpetua" (1795), el de una utopía "negativa" es la de Orwell "1984"o el filme "Fahrenheit 451".

D) La teoría constitucional debería distinguir entre la indispensable función crítica de las utopías y su función admonitoria, y no tener miedo de señalar por su nombre los peligros de las utopías clásicas y las recientes, por ejemplo, el marxismo-leninismo o el anarquismo, hoy los "Estados de Dios" cerrados del Islam (Irán, Afganistán).

E) Esta apreciación diferenciada de las utopías significa una corrección del pensamiento de Popper, en la medida en que su "racionalismo crítico" 493 requiere de complementación sustantiva por el método de la ciencia cultural. Las utopías pueden crear "saber presuntivo" de manera anticipatoria y

493 Popper, K., Auf der Suche nach einer besseren Welt, 1984. 
Este libro forma parte del acervo de la Biblioteca Juridica Virtual del Instituto de Investigaciones Juridicas de la UNAM

creativa, el cual, realizado por la vía de la "reforma incremental", enriquece los procesos de desarrollo del Estado constitucional. Incluso las utopías de una "sociedad cerrada", como la de Platón o del marxismo, pueden mostrar efectos positivos en cuanto tipos contrarios al modelo del Estado constitucional. Esta apreciación diferenciadora, sin embargo, se apoya en Popper en cuanto cree, con él, en el "curso abierto de la historia" y en la posibilidad de que el individuo le confiera un sentido, y por ello se opone al marxismo o a los sistemas deterministas. Su fundamento es la "imagen moderadamente optimista del ser humano" y el "optimismo científico", lo que debería caracterizar a la teoría de la Constitución en cuestiones particulares (por ejemplo, en los fines educativos o en el derecho penal resocializador), así como también en su conjunto.

F) La teoría constitucional y el tipo del "Estado constitucional" han de dar espacio al ser humano para un "quantum de utopía", esto no solamente en forma de la ampliación y promoción de las libertades culturales (¡también de las religiones!), sino de una manera mucho más intensiva, por la cual los textos constitucionales normen esperanzas (por ejemplo, anteriormente la unidad de Alemania o ahora la de Irlanda) que sean al menos "deseos utópicos" concretos. El "principio esperanza" (E. Bloch), el "principio responsabilidad"(H. Jonas), por ejemplo, en la protección del ambiente, estimulan desarrollos constitucionales fructíferos, porque el ser humano necesita la esperanza como el aire que respira y la comunidad vive de una libertad responsable. En la medida en que las Constituciones se encuentren alejadas fundamentalmente de las utopías en su dimensión jurídica, y que por su naturaleza propia deban permanecerlo, en algunas de sus partes pueden ser "todavía" utopías - ¡también el principio del Estado social era, en la época de H. Heller (1930), y después en 1949, con la LF, un pedazo de utopía!- .

G) El arte y los artistas se anticipan no pocas veces a aquello que más tarde la realidad política pone en el "orden del día": piénsese en la "Guerra de las Galaxias" como película de los años setenta y como concepción (¿peligrosa?) de una política internacional de defensa en los años ochenta, o en la filosofía de la verdad del checo V. Havel con vistas al año de 1989.

H) En la medida en que tanto la teoría constitucional como la ciencia, en conjunto, deban "atender" al arte y los artistas, para ganar sensibilidad sobre los nuevos problemas, debe otorgarle en su marco un alto valor declarado a la utopía, pero ciertamente marcarle también sus límites, los cuales existen sobre todo donde la violencia y la falta de libertad se convierten en medios para lograr coercitivamente situaciones ideales que se han prometido "para más adelante". El postulado de Popper de la "reforma incremental" sigue siendo una máxima de política constitucional. Bajo estas condiciones 
Este libro forma parte del acervo de la Biblioteca Juridica Virtual del Instituto de Investigaciones Juridicas de la UNAM

pueden ser los textos utópicos textos clásicos y convertirse en textos constitucionales en "sentido amplio".

I) Así vistas, las utopías son un pedazo de "patrimonio cultural" del Estado constitucional como tipo, incluso donde aquéllas se le han adelantado o donde han sido escritas en su contra: de ellas y en parte contra ellas obtiene dicho Estado sus perfiles, el cual es "provocado" en parte por ellas, en parte tiene que afirmarse ante ellas, por ejemplo, en su trato con otros Estados en el derecho internacional en sentido de la "paz perpetua" de Kant: como "Estado constitucional cooperativo".

J) Las utopías pueden, e incluso deben, "desasosegar" a los seres humanos; y lo mismo es válido para el Estado constitucional. Pero también lo pueden "tranquilizar": porque — y en la medida que - sean satisfechos por él y lo confirmen en su libertad de pensamiento. Téngase presente el mandato de la "dignidad humana", alguna vez "utópico", así como su centenaria historia cultural ${ }^{494}$ y su actual idealidad y realidad en el Estado constitucional.

\section{CAMPOS EJEMPLARES DE LA POLÍTICA CONSTITUCIONAL: TAREAS ACTUALES DE LA POLÍTICA DE REFORMA EN EL ESTADO CONSTITUCIONAL}

\section{Reformas necesarias hoy, selección de un inventario}

Hay que distinguir entre dos especies de necesidades de reforma: entre aquellas cuyo referente primario es el Estado nacional y aquellas que superan a la forma de la comunidad política (nacional) y cuyo referente es mundial en última instancia. Ambos campos pueden estar articulados entre sí, pero hay que separarlos por lo pronto. Esto queda de manifiesto ya en las organizaciones e instituciones más o menos "informales", pero que no son primariamente de carácter estatal, como "Amnesty International", "Greenpeace" o "Robin Wood" o la organización internacional anticorrupción "Transparency International". Todas ellas tienen puesta la mira en los déficits nacionales y mundiales o públicos. Su operación óptima en el foro de los Estados constitucionales se da como "sistemas de alerta temprana", pero en conjunto son también indispensables, aunque también resulten dolorosas sus faltas a la verdad (así ocurrió con Greenpeace en relación con la

$494 \mathrm{Al}$ respecto Häberle, P., "Die Menschenwürde als Grundlage der staatlichen Gemeinschaft”, HdbStR, vol. I, 1987, pp. 815 y ss. (2a. ed., 1995). 
Este libro forma parte del acervo de la Biblioteca Juridica Virtual del Instituto de Investigaciones Juridicas de la UNAM

plataforma petrolera "Brent Spar" en 1995). No siempre la opinión pública pluralista es suficientemente sensible para reconocer con oportunidad los focos de peligro (por ejemplo, las "acciones de ocupación" de viviendas en Berlín, cuyo trasfondo eran las especulaciones inmobiliarias), aquí se puede recurrir a la doctrina de la "desobediencia civil" (Thoreau), que incluso una reciente Constitución africana ha recibido textualmente (artículo 121, inciso 2, frase 2, de la Constitución de Mali de 1992).

\section{A. Reformas necesarias referidas al Estado constitucional nacional}

Hay que distinguir entre las cuestiones de reforma planteadas respecto al tipo del Estado constitucional, es decir, de manera general, y las particulares referidas a las distintas naciones.

a) Quizá todas las naciones de ejemplo estén en cuestión, es decir, el tipo del Estado constitucional se ve desafiado en los siguientes temas:

- Reducción del desempleo masivo interior, cuyo trasfondo es el debate sobre la "correcta" delimitación entre Estado y economía (¿mercado contra el Estado, privatización? desregulación en vista de una "carga abrumadora" del Estado).

- Reforma de los sistemas de seguridad social para la vejez (restructuración de la seguridad social por la vía de un "tercer pilar").

— "Domesticación" del nuevo capitalismo (Gräfin Dönhoff).

- Reducción del endeudamiento (especialmente urgente en Bélgica e Italia, pero también en Alemania, reducción necesaria ya en razón del contrato de las generaciones como garantía de la justicia entre ellas, pero también en virtud de los criterios de estabilidad del euro).

- Reducción de las afectaciones al ambiente (depósito de basura nuclear, etcétera), el "desafío ecológico".

- Reducción de la burocracia del Estado (palabras clave: "Estado esbelto", "l'État modeste", "new public management").

- Lucha contra la delincuencia organizada (urgente no sólo en Italia y Rusia, sino también en Europa oriental, en Alemania la escucha de comunicaciones privadas ("grosser Lauschangriff"), abuso general en Internet - pornografía-).

- Lucha contra la corrupción (Francia, Italia, Bélgica, también Alemania).

- Sujeción pluralista de los medios de comunicación. 
Este libro forma parte del acervo de la Biblioteca Juridica Virtual del Instituto de Investigaciones Juridicas de la UNAM

- Peligro para la libertad de los periodistas (en muchos países de Asia y África).

- Solución de los desafíos que plantean las nuevas tecnologías (palabra clave: tecnología genética, bioética, moderna "sociedad de la información").

- Desafíos que plantea el fundamentalismo islámico, con diverso vigor en distintas naciones, pero en relación con la "sociedad multicultural".

- Crisis de la democracia de partidos (más fuerte en Alemania; palabra clave: "aburrimiento de la política", más débil en Suiza, gracias a la democracia semidirecta), brotes de la "democracia de la complacencia”.

- Reforzamiento jurídico y ético de la idea de los "deberes humanos" ("Declaración Universal de los Deberes Humanos", por ejemplo, gracias al ex canciller federal alemán Helmut Schmidt)

- Movimientos migratorios (lo que afecta tanto el plano regional como el mundial).

Detrás de muchos de estos temas de la reforma es posible descubrir eventos y conflictos más generales: algunos campos problemáticos se deben a la muy lamentada decadencia de los valores y a los déficits de la educación: así podría exigirse en Alemania un nuevo debate sobre los valores fundamentales, incluso un nuevo "contrato social". Otros permiten percibir, o al menos intuir, una conflicto, incluso lucha, de las generaciones (así, por ejemplo, la restructuración de los sistemas de seguridad social, el depósito de basura nuclear).

b) Solamente como "ejemplos" se ofrecen ahora algunos temas de reforma referidos primariamente a algunas naciones: Gran Bretaña debe buscar una división vertical de poderes más intensiva bajo la forma del regionalismo, aunque sea modesto. Italia está esperando desde hace tiempo una reforma constitucional; Bélgica ha logrado recientemente el paso al federalismo (Constitución de 1994). España lucha con una nueva formulación de su regionalismo. A pesar de que ha caracterizado ingeniosamente a las minorías como "factores formadores del Estado" (1989), Hungría tiene que trabajar más en la práctica (mediante la construcción de puentes) en la protección de las mismas. Alemania debería liberarse de las ideologías sobre su posición económica derivadas de la primacía de lo económico, a fin de contrarrestar la reducción de la cultura (por ejemplo, cierre de 
Este libro forma parte del acervo de la Biblioteca Juridica Virtual del Instituto de Investigaciones Juridicas de la UNAM

los institutos Goethe), mientras que Francia lleva adelante sin inmutarse su cultura política nacional en el extranjero (preferimos callar sobre la "obra maestra" de la reforma ortográfica alemana). Francia discute, en el marco de la "modernización de la vida política", sobre la prohibición de la acumulación de cargos. El debate sobre la inmigración y la "doble nacionalidad" seguirá siendo, a mediano plazo, un tema de reforma entre nosotros, así también el derecho de las fundaciones y la complementación de la economía social de mercado con la dimensión ecológica (reforma fiscal ecológica): el ser humano, no el mercado, es la medida de las cosas. En Alemania, precisamente después de la fortuna de la unificación, se empieza a apreciar un aburrimiento respecto del futuro que resulta de difícil comprensión. También hay necesidad de reducir el pensamiento en términos de derechos (reforma del derecho del servicio público). En el marco de la reforma alemana de la justicia están pendientes las nuevas formas de solución extra-judicial de conflictos ("mediación"). En Sudáfrica (también en los Estados Unidos) la superación de la discriminación racial sigue siendo un tema de la reforma ("affirmative action"). Suiza quizá tenga que resolver su relación con "Europa".

\section{B. Reformas necesarias referidas al mundo o a la humanidad}

Aquí también algunos términos clave: no se desconoce que no todos los Estados en este singular "planeta azul" son Estados constitucionales - sociedades abiertas - en el sentido apuntado. Algunos países en desarrollo en el África negra son miembros de la "familia de los Estados constitucionales" sólo sobre el papel. Otros países siguen siendo semiautoritarios. "Milagros" como el de la Sudáfrica de N. Mandela hablan por sí solos. Corea del Norte, Cuba y China siguen siendo naciones socialistas. Los Estados islámicos ni siquiera están recorriendo la vía hacia el tipo del "Estado constitucional". Sin embargo, nos atrevemos a sostener la tesis de que la comunidad jurídica internacional, en virtud de la Carta de la ONU y del compromiso con valores universales, como los derechos humanos, ${ }^{495}$ está fundada, en primero y en último término, en valores constitucionales.

Los temas de la reforma referidos al mundo y la humanidad en este sentido son:

${ }_{495}$ Kühnhardt, L., Die Universalität der Menschenrechte, 1987. 
Este libro forma parte del acervo de la Biblioteca Juridica Virtual del Instituto de Investigaciones Juridicas de la UNAM

- La preparación de los Estados constitucionales para enfrentar los retos de la globalización de los mercados, de los medios de comunicación (Internet), lo que recuerda naturalmente al Estado constitucional sus responsabilidades específicas que solamente él puede asumir; además, la "globalización" económica solamente es soportable por la regionalización cultural en lo pequeño, por el enraizamiento en la "patria": ¡de otro modo el ser humano caería en el vacío!

- Protección de los bienes culturales.

- Pensamiento subsidiario, no sólo en el marco de la UE, sino como principio estructural a escala mundial para la convivencia entre los "Estados constitucionales cooperativos".

- En vista de la escasez a nivel mundial que crece rápidamente en materia del ambiente-agua-aire (palabra clave: "desarrollo sustentable" de la conferencia de Río de Janeiro de 1992), se plantea la tarea comunitaria en materia de protección del ambiente, lo que da un impulso adicional al tema de los "deberes humanos"; la Convención para la Protección de la Biodiversidad es una etapa lograda (1996).

- Reducción de la pobreza, ayuda al desarrollo para la autoayuda (desendeudamiento de los países en desarrollo), lucha contra el analfabetismo y formas modernas del "tráfico de seres humanos"

- Entendimiento de los pueblos mediante el intercambio, a escala mundial, de alumnos, estudiantes y científicos.

- Institución de un Tribunal Permanente de Naciones Unidas para juzgar los crímenes contra la humanidad y el genocidio de acuerdo con el modelo del Tribunal de Naciones Unidas para la exYugoslavia y Ruanda.

- La realización de los derechos humanos universales, incluso paralos casos de desaparición de un poder estatal efectivo ("failed states").

\section{Perspectivas}

Las ideas reformistas acostumbran brincar por encima de las fronteras nacionales, los espacios y los continentes, como ha podido observarse en la recepción de algunas instituciones del Estado constitucional (ombudsman, jurisdicción constitucional, etcétera). ¿Cuáles son las condiciones culturales para las recepciones "exitosas"? Por ejemplo: ¿que sean desarrolladas de manera productiva en el Estado constitucional receptor? Para resolver este punto quizá habría que hacer primero un amplio inventario empírico (por 
Este libro forma parte del acervo de la Biblioteca Juridica Virtual del Instituto de Investigaciones Juridicas de la UNAM

ejemplo, de las reformas en Europa oriental a partir de 1989 y de las modificaciones constitucionales atoradas, por ejemplo, en los Estados de Europa occidental). ¿Es que hay naciones especialmente "dotadas" para las reformas, como los franceses para las revoluciones? Por conducto de los afectados, éstos introdujeron por primera vez de manera colectiva en la opinión pública y en el orden del día (1998) el tema del desempleo, con efectos sobre la opinión pública europea.

Como quiera que sea: en este punto solamente se pudieron indicar algunas de las necesidades de reforma referidas al Estado constitucional y la humanidad, para lo cual los valores orientadores significativos "últimos" son la dignidad humana y la democracia, los valores de la humanidad, así como la fe en el arte y la cultura. El "principio esperanza" y el "principio responsabilidad" siguen siendo las condiciones intelectuales previas de la reflexión sobre el Estado constitucional y sus necesidades y, esperemos, de sus posibilidades de reforma. 
Este libro forma parte del acervo de la Biblioteca Juridica Virtual del Instituto de Investigaciones Juridicas de la UNAM http://www.juridicas.unam.mx

\section{ADDENDUM: EL CONSTITUCIONALISMO UNIVERSAL DESDE LAS GONSTITUGIONES PARGIALES NAGIONALES E INTERNACIONALES. SIETE TESIS ${ }^{496}$}

Estas líneas son un recordatorio de nuestro amigo, recientemente desaparecido, Rafael Barranco. Su autor disfrutó de numerosas estancias en Granada de su extraordinaria hospitalidad y la de su mujer, Irene (desde 1994). En 2012 realizamos juntos un inolvidable viaje a Brasil como conferencistas invitados junto con los profesores F. Balaguer y J. Luther. Anteriormente, habíamos coincidido como invitados de una fundación científica en un seminario en St. Gallen (2005).

Rafael seguía los desarrollos científicos del derecho público en su conjunto con una perspectiva comparada y gran sensibilidad. Sus numerosos viajes a países muy diversos (incluso a China), enriquecieron la nueva escuela del derecho público en Granada. A su memoria están dedicadas las siguientes siete tesis.

1) El mundo del Estado constitucional (Die Welt des Verfassungsstaates) y La Constitución en el discurso global (Die Verfassung im Diskurs der Welt) fueron dos sugestivos títulos de dos libros homenaje de los años $1999{ }^{497}$ y $2004 .{ }^{498}$ Desde hace tiempo se habla en Alemania de "la constitucionalización del derecho internacional". El autor de este trabajo ha caracterizado siempre al derecho internacional como "derecho constitucional de la humanidad". D. Thürer acuñó el sugestivo título Derecho del Estado cosmopolita (2005). Últimamente, M. Kotzur ha realizado una aportación sobre El Estado de derecho en el derecho internacional (2013).

496 Traducción del alemán por Francisco Balaguer Callejón.

497 Morlok, M. (ed.), Die Welt des Verfassungsstaates, Bande-Banden, Nomos, 2001. El libro recoge las Actas del Congreso Die Welt des Verfassungsstaates. Wissenschaftliches Kolloquium zu Ehren von profesor de derecho, doctorado honoris causa Peter Häberle, organizado por FernUniversität Hagen, Forschungsstelle für Europäisches und Vergleichendes Verfassungsrecht (Universität Bayreuth) y Nomos Verlagsgesellschaft, celebrado en BadenBaden (Alemania), los días 13 y 14 de mayo de 1999 (nota del traductor).

498 Blankenagel, A. et al. (eds.), Verfassung im Diskurs der Welt, Liber Amicorum für Peter Häberle, Tubinga, Mohr Siebeck, 2004. 
Este libro forma parte del acervo de la Biblioteca Juridica Virtual del Instituto de Investigaciones Juridicas de la UNAM

2) En 1999 el autor de estas líneas propuso para Alemania, y para otras Constituciones de los Estados miembros de la Unión Europea, el concepto de "Constituciones nacionales parciales" que se complementan, se sobreponen y se ajustan como Constituciones parciales del derecho constitucional europeo. Elementos de conexión con el derecho internacional serían el "Estado constitucional cooperativo" (kooperative Verfassungsstaat) (1978), así como la "apertura al derecho internacional" (Völkerrechtsfreundlichkeit) (BVerfG). La Unión Europea es actualmente la comunidad regional de responsabilidades compartidas de los Estados de mayor densidad, pero también otros Estados nacionales tienen, como Estados constitucionales cooperativos en el contexto de la globalización, la característica de ser sólo constitucionales nacionales parciales. W. v. Simson habló ya, de manera temprana del "condicionamiento supraestatal de los Estados". Actualmente, el Estado constitucional cooperativo está condicionado por las Constituciones parciales del derecho internacional.

3) Muchos temas pasan total o parcialmente desde el Estado nacional al derecho internacional y sus sistemas fragmentarios. Como ejemplos tenemos en los pactos internacionales de derechos humanos de 1976, que recogen el espíritu de los grandes textos de 1776, 1789, etcétera, y el de muchos catálogos nacionales de derechos humanos codificados, en tiempos recientes, que constituyen las piezas de mosaico del Estado de derecho y, teniendo en cuenta el creciente número de tribunales internacionales, también elementos de la división de poderes (independencia judicial).

Desde esa perspectiva, podemos considerar Constituciones parciales la Carta de las Nacionales Unidas (1945) y sus numerosas convenciones. Podemos mencionar las convenciones de La Haya (1945) y la de Viena (1961 y 1969), la Convención sobre los Derechos del Niño (1989), la Convención sobre los Derechos de las Personas con Discapacidad (2006), la Convención contra la Tortura (1984) y la Convención contra la Discriminación Racial (1965). También los estatutos de los tribunales internacionales, como el Estatuto de la Corte Internacional de Justicia de La Haya (1945) o el del Tribunal Penal Internacional; además del de La Haya (1998), el Tribunal Europeo de Derechos Humanos en Estrasburgo y la Corte Interamericana de Derechos Humanos en Costa Rica.

4) Podemos hablar de algunos textos de derecho internacional como "Constituciones parciales" por los siguientes motivos:

Los tratados de larga duración son, sustancialmente, similares a las Constituciones. La importancia de los temas que las convenciones incorporan al espacio público mundial, como la Convención para la Prevención y la Sanción del Delito de Genocidio (1948); la de los Derechos del Niño 
Este libro forma parte del acervo de la Biblioteca Juridica Virtual del Instituto de Investigaciones Juridicas de la UNAM

(1989); el Convenio para la Protección de las Especies Amenazadas (1973); el derecho internacional humanitario; el derecho internacional del medio ambiente (1979, 1985. 1987, 1992 y 1997) y el derecho internacional del espacio exterior (1967), son evidentes.

Se trata de valores orientadores, ideales como "justicia", "paz mundial", "interés de la humanidad", "dignidad humana", que en parte proceden del derecho constitucional nacional. Podemos pensar, también, en elementos propios del Estado social de derecho en el estatuto internacional de los refugiados (1951 y 1967), así como en los principios generales del derecho en el derecho internacional. Por ejemplo, en el principio de buena fe que se recoge de manera expresa en algunos documentos internacionales (tal es el caso del artículo 2.2 de la Carta de las Naciones Unidas de 1945 o el artículo 31.1 del Convenio de Viena sobre el Derecho de los Tratados de 1961) y que es un principio clásico conocido desde los grandes procesos de codificación del derecho privado en los Estados nacionales. Estas normas tienen naturaleza constitucional, también, porque en su ámbito correspondiente están destinadas a limitar todo tipo de poder. Un elemento de la concepción constitucional de R. Smend era la de su condición de "estímulo y límite". Esto sirve también para muchos principios del derecho internacional. Lo mismo puede decirse del entendimiento de U. Scheuner de la Constitución como "norma y tarea", lo que quiere decir ahora: el derecho internacional como norma y tarea.

5) Es digna de mención la ósmosis entre las Constituciones parciales del derecho internacional y las Constituciones parciales nacionales. Podemos observar una articulación de principios jurídicos, una aportación y recepción recíproca entre el Estado constitucional cooperativo y el derecho internacional. Pensemos en las cláusulas de protección de los derechos del niño; de prohibición de esclavitud; de protección de la biodiversidad y del patrimonio cultural, que se pueden encontrar en ambos lados. Podemos ver una relativización del clásico esquema interior-exterior. Corresponde, también, con esto A. Peters en el descubrimiento del "derecho internacional subjetivo".

6) El pluralismo, por lo que se refiere a la pluralidad de los agentes que intervienen, es característico de estos procesos tan dinámicos. Agentes o actores en estos procesos son, entre otros, las organizaciones no gubernamentales; los tribunales nacionales; los tribunales internacionales; como los de la Organización de las Naciones Unidas, con el modelo de independencia del tercer poder; así como los Estados, las organizaciones internacionales y también los ciudadanos que reivindican y desarrollan sus derechos sociales y sus libertades fundamentales. Se trata de una combinación entre los nu- 
Este libro forma parte del acervo de la Biblioteca Juridica Virtual del Instituto de Investigaciones Juridicas de la UNAM

merosos derechos constitucionales nacionales y el derecho internacional. La ciencia se debe mencionar también; y no en último lugar, "las doctrinas de los publicistas de mayor competencia de las distintas naciones" (artículo 38.1.d del Estatuto de la Corte Internacional de Justicia, de 1945). Los internacionalistas son, a largo plazo, igualmente actores, como las comunidades científicas nacionales y supranacionales. Se trata también de "política del derecho internacional".

7) Con estas tesis sobre las limitaciones de las Constituciones parciales del derecho constitucional nacional y del derecho internacional podemos hablar sólo de un "constitucionalismo universal"; no de una "Constitución global" o de un "sistema jurídico global" ni tampoco de un Estado global o mundial. Sólo puntualmente debería utilizarse el concepto de "cultura jurídica mundial", acaso en relación con la Convención sobre la Protección del Patrimonio Cultural Mundial (1972) y la Convención sobre la Protección y la Promoción de la Diversidad de las Expresiones Culturales (2005) o con la prohibición de la esclavitud, la abolición de la pena de muerte (1989) y la lucha contra la piratería y la Convención sobre el derecho del mar (1982).

Las Constituciones parciales del derecho constitucional estatal y del derecho internacional mantienen una relación dinámica de interacción recíproca de agentes y temáticas. El tradicional planteamiento de separación está ya superado: el derecho internacional se enriquece con el derecho constitucional nacional y, recíprocamente, las temáticas del derecho internacional se desplazan al ámbito nacional interno, ante todo, a través del puente del "Estado constitucional cooperativo". 
Este libro forma parte del acervo de la Biblioteca Juridica Virtual del Instituto de Investigaciones Juridicas de la UNAM

\section{EPÍLOGO}

\section{OBSERVACIÓN PRELIMINAR: AGRADEGIMIENTO-BIBLIOGRAFÍA}

En primer lugar, debo expresar mi cordial agradecimiento a los profesores Diego Valadés y Héctor Fix-Fierro, así como a la casa editorial. Este libro apareció tanto en México (2001) como en Perú (2003) y Argentina (2007) por iniciativa del profesor Valadés. La traducción española de Héctor Fix-Fierro (Ciudad de México) ha sido y sigue siendo ejemplar. El autor nunca estará lo suficientemente agradecido por ello, ya que el libro ha tenido gran resonancia y ha encontrado un interés duradero en Latinoamérica (casi al mismo tiempo apareció una traducción en Croacia y otra en Italia, en la famosa Enciclopedia Treccani, en Roma).

Los "prólogos" y "epílogos" forman un género propio de la literatura científi$c a$. Son muy conocidos en Latinoamérica, pero también en Italia y España. Los estudiosos de edad escriben con frecuencia prólogos para sus discípulos. En la república de los académicos llega a ocurrir que los colegas amigos se obsequien mutuamente con prólogos o epílogos. El autor ha gozado de tal fortuna por parte de Diego Valadés. Así, no sólo hay un contrato de las generaciones entre maestros y discípulos, sino también entre amigos (una forma platónica del contrato social). En la ciencia, o al menos en el derecho constitucional comparado, las amistades que se establecen por encima de las fronteras constituyen un don especial, también en el aquí y el ahora. Rememoro aquí la obra de homenaje a Diego Valadés (2011), también Las cartas pedagógicas a un joven constitucionalista (2010, traducción española, 2a. ed., 2014), así como el prólogo de Francisco Fernández Segado a la nueva traducción española de la tesis doctoral friburguense del autor, sobre el contenido esencial de los derechos fundamentales (2003).

\section{PRIMERA PARTE: RESONANCIA EN LATINOAMÉRICA}

Las teorías del autor de este libro de 2001 han logrado considerable atención principalmente en Latinoamérica. Esto es cierto sobre todo del 
Este libro forma parte del acervo de la Biblioteca Juridica Virtual del Instituto de Investigaciones Juridicas de la UNAM

Brasil, donde el profesor G. Mendes ha traducido y presentado el concepto de la "sociedad abierta de los intérpretes constitucionales" (1997; palabras clave: audiencias públicas, amicus curiae). También lo es de Colombia, donde se publicó una obra del autor (La Constitución como cultura, Bogotá, 2002). Es cierto, además, de los dos volúmenes de conversaciones académicas, coordinados por el profesor Valadés (2006 y 2008), así como de los libros Verdad y Estado constitucional (1995/2006) y Estado constitucional cooperativo (Río de Janeiro, 1978/2007). Los "mediadores de la recepción" han sido, y siguen siendo hasta hoy, los profesores Domingo García Belaunde, César Landa, José F. Palomino Manchego (del Perú) e I. Sarlet (Porto Alegre), así como los colegas y amigos Raúl Gustavo Ferreyra y Eugenio Raúl Zaffaroni (ambos en Buenos Aires). El Tribunal Constitucional en Lima ha editado el volumen Poesía y derecho constitucional: una conversación (2015), realizada con Héctor López Bofill (y bajo la coordinación de G. R. Núñez). Asimismo, en Lima se publicará pronto la tesis doctoral hamburguesa de J. León: Teoría de la jurisdicción constitucional y del derecho procesal constitucional en Peter Häberle.

De manera expresa, algunos tribunales supremos en América Latina hacen referencia, en una o varias de sus sentencias, a las propuestas académicas del autor: así, el Tribunal Supremo Federal en Brasilia, los tribunales constitucionales en Bogotá y Lima, la Corte Suprema en Buenos Aires. Para el autor constituye un gran honor este "diálogo de las cortes", pues desde hace muchos años da seguimiento, con mucho interés, al constitucionalismo en Latinoamérica, al cual considera una "especie propia" en comparación con el de los Estados Unidos y Europa. Cabe mencionar, de manera particular, que precisamente en Perú se toma en cuenta al derecho procesal constitucional como "derecho constitucional concretizado".

En Europa ha llamado la atención la desafortunada reforma del derecho procesal constitucional en Polonia (2016) y provocado la intervención de la Comisión Europea. Un dictamen reciente de la Comisión de Venecia llama por su nombre las evidentes violaciones constitucionales en Varsovia. Lo cierto es que en Europa existe ya un "derecho procesal constitucional común" que se deriva de la comparación entre los ordenamientos procesales de los tribunales constitucionales nacionales y de los supranacionales que son el Tribunal Europeo de Justicia en Luxemburgo y el Tribunal Europeo de Derechos Humanos en Estrasburgo. En Varsovia, el gobierno nacionalconservador, a través de una reforma legislativa, violó sobre todo el principio de la división de poderes que subyace a las normas del derecho procesal constitucional, pero también la autonomía procesal del Tribunal Constitucional. El funcionamiento del Tribunal se vio afectado por la modificación 
Este libro forma parte del acervo de la Biblioteca Juridica Virtual del Instituto de Investigaciones Juridicas de la UNAM

de las normas del derecho procesal constitucional, que son un "instrumento muy fino y sensible".

Pero basta de "autocontemplaciones", que quizá en ocasiones sean de naturaleza subjetiva, cuando se trata de personalidades. Tal vez resulte algo más objetivo los textos recién publicados de R. Chr. V. Ooyen y M. H. W. Möllers (eds.), Verfassungs-Kultur, Staat, Europa und pluralistische Gesellschaft bei Peter Häberle ("Cultura constitucional, Estado, Europa y sociedad pluralista en Peter Häberle") (Berlín, 2016); y previamente de A. Blankenagel (ed.), Den Verfassungsstaat nachdenken. Eine Geburtstagsgabe ("Pensar el Estado constitucional. Un obsequio de cumpleaños") (Berlín, 2014).

\section{SEGUNDA PARTE: FASES EVOLUTIVAS POSTERIORES DE LA TEORÍA CONSTITUGIONAL GOMPARADA COMO GIENCIA DE LA GULTURA DE Peter HäBerLe (2001 A 2016)}

Una retrospectiva al día de hoy permite distinguir tres periodos evolutivos:

1) La teoría constitucional europea de 2001-2002 (7a. ed., 2011; 8a. ed., en preparación).

2) La "tetralogía" de la Teoría general de la Constitución como ciencia de la cultura (1982, 2a. ed., 1998), esto es, las cuatro monografias sobre temas particulares como los "días festivos" (1987; la traducción portuguesa para el Brasil a cargo de M. A. Maliska, 2008), los himnos nacionales como elementos de identidad cultural del Estado constitucional (2007, 2a. ed., 2013; traducción española de A. Oehling, 2012), las banderas, los elementos de identidad democrática ciudadana y los símbolos de la representación internacional (2008), la cultura de la memoria en el Estado constitucional (2011).

3) El Estado constitucional cooperativo desde la cultura y como cultura. Estudios preparatorios de una teoría universal de la Constitución (2013).

Como encore puede citarse el libro sobre el Domingo como principio constitucional (1988, 2a. ed., 2006), el volumen de ensayos Verfassungsvergleichung in europa- und weltbürgerlicher Absicht ("Comparación constitucional en perspectiva europea y cosmopolita"), 2009, así como Vergleichende Verfassungstheorie und Verfassungspraxis. Letzte Schriften und Gespräche ("Teoría constitucional comparada y praxis constitucional. Últimos escritos y entrevistas"), 2016. En lo particular:

La teoría constitucional europea trabaja con conceptos como el de "derecho constitucional común europeo" (1991) y "esfera pública europea" (algunos análisis previos ya desde 1998), así como "deferencia al derecho europeo". Estos conceptos pueden resultar fructíferos precisamente para la 
Este libro forma parte del acervo de la Biblioteca Juridica Virtual del Instituto de Investigaciones Juridicas de la UNAM

creación comunitaria en Latinoamérica. Piénsese en los países miembros del Mercosur o de la Convención Americana sobre Derechos Humanos, también del Pacto Andino. Hace tiempo que existe un "derecho constitucional común latinoamericano", tal como el autor lo había propuesto ya en la Ciudad de México (2003). De manera análoga existe también una esfera pública latinoamericana y un bien común latinoamericano.

La mencionada tetralogía de ensayos culturalistas se ubica también bajo el signo de nuevos paradigmas, como la tesis del contexto de 1979 ("interpretar mediante agregación mental", ningún texto sin contextos culturales, solamente existen textos interpretados), la concepción de la comparación jurídica como "quinto" método de la interpretación (1989) y la comparación constitucional cultural (1982). En este sentido, son los principios del derecho los que funcionan como vehículo. Recordemos las tres especies del pensamiento constitucional: el pensamiento de la realidad, el de la necesidad y el de la posibilidad. El paradigma de las etapas textuales (1989) se vuelve relevante también (palabra clave: la realidad constitucional correspondiente a los textos más antiguos se convierte frecuentemente en textos y conceptos en las Constituciones más recientes; como ejemplo: el derecho pluralista de los medios de comunicación elaborado por el Tribunal Constitucional Federal alemán, ahora tanto en los textos constitucionales nacionales de Europa como de la Unión Europea).

El libro de 2013 lucha por lograr una summa respecto del Estado constitucional cooperativo, a partir de la cultura y como cultura. De este modo se hace posible concebir una "ciencia jurídica universal", así como entender los tribunales internacionales como (fragmentos de) tribunales constitucionales. Piénsese en la Corte Interamericana de Derechos Humanos en San José, Costa Rica, y en el Tribunal Europeo de Derechos Humanos. Algunos instrumentos internacionales son "Constituciones parciales", como la Carta de las Naciones Unidas, las Convenciones de Ginebra, La Haya y Viena, la Convención sobre el Derecho del Mar, así como la Declaración de Naciones Unidas sobre los Derechos de los Pueblos Indígenas (2007), junto con la Conferencia Mundial sobre los Pueblos Indígenas (2014), porque se trata de fijar, de manera permanente, valores de elevado nivel. En lo particular, la Europa de la Unión Europea es una "comunidad constitucional". El enfoque a partir de la ciencia cultural se ve confirmado también por los "cascos azules de la cultura" de la UNESCO. El derecho internacional tiene que ser concebido a partir de la Humanidad. Los tribunales internacionales deberían pronunciar sus fallos "en nombre de la Humanidad". Su avance es una señal de aliento precisamente ante los apuros de la política mundial. 
Este libro forma parte del acervo de la Biblioteca Juridica Virtual del Instituto de Investigaciones Juridicas de la UNAM

\section{PERSPECTIVA Y CONGLUSIÓN: OPTIMISMO GIENTÍFICO}

Nunca antes se había hecho tan necesario, a nivel mundial, un grado mínimo de optimismo científico como el día de hoy. Si bien hay motivo para el pesimismo - piénsese en la ilegal invasión de los Estados Unidos a Irak en 2003 o la anexión de Crimea por parte de Rusia (2014), así como en las crisis de la Unión Europea-, la república universal de los estudiosos debe seguir luchando por lograr el optimismo científico. Piénsese en la paulatina aceptación de los derechos humanos, la prohibición universal de la tortura y los textos protectores del patrimonio cultural de la humanidad. El Estado constitucional cooperativo apuesta por una imagen del ser humano moderadamente optimista (al respecto véase mi monografía de 1988, 4a. ed. de 2008, traducción española de 2001); pero también toma en cuenta la culpa y el fracaso humanos. La idea de la división de poderes se hace cargo precisamente de esto último. Aparece bajo múltiples formas (por ejemplo, los Ombudsman en el espíritu de Héctor Fix-Zamudio, los tribunales de cuentas independientes, la estructuración pluralista de los medios de comunicación en el ámbito social) y constituye un texto clásico independiente desde Montesquieu. Los textos clásicos en la vida constitucional configuran un tema propio (el autor trabaja en él desde 1981, en un escrito que acaba de aparecer en Brasil, dedicado a Paulo Bonavides). Los textos clásicos, desde Aristóteles hasta John Rawls, pasando por Cicerón e Immanuel Kant, son textos constitucionales en sentido amplio.

Espero que la nueva edición de este libro encuentre lectores benévolos. $\mathrm{El}$ autor agradece nuevamente a todos aquellos que hacen posible su aparición. Quizá valga la pena citar el texto clásico del papa Gregorio Magno: scriptura cum legentibus crescit ("la escritura crece con los lectores").

Peter HÄBERLE

Bayreuth, primavera de 2016 
Este libro forma parte del acervo de la Biblioteca Juridica Virtual del Instituto de Investigaciones Juridicas de la UNAM

\section{FUENTES \\ (COLEGGIONES DE TEXTOS GONSTITUCIONALES)}

Baumann, H. y EBert, M. (eds.), Die Verfassungen der Mitgliedsländer der Liga der Arabischen Staaten, Berlín, 1995. Afrikas, Berlín, 1997.

BiscaretTI Di RUfFIA, P. (ed.), Costituzioni stranieri contemporanee, 3 vols., Milán, 1993-1996.

Blaustein, A. P. y Flanz, G. H. (eds.), Constitutions of the Countries of the World, Nueva York, 1971 (con actualizaciones sucesivas).

BRAZIER, R., Constitutional Texts, Oxford, 1990.

BRUnNer, G. y MEISSNER, B. (eds.), Verfassungen der kommunistischen Staaten, Paderborn, 1980.

Dennewitz, B. (ed.), Die Verfassungen der Modernen Staaten, vol. I, Hamburgo, 1947.

Di SUni PRAT, E. et al. (eds.), Le Costituzioni dei Paesi della Comunità Europea, 2a. ed., Padua, 1998.

DÜRIG, G. y RUDOLF, W. (eds.), Texte zur deutschen Verfassungsgeschichte, 3a. ed., München, 1996.

FranZ, G. (ed.), Staatsverfassungen, 2a. ed., München, 1964.

Godechot, J. (ed.), Les Constitutions de la France depuis 1789, París, 1979.

Guerra, Ll. y AGUiLAR, L. (eds.), Las Constituciones de Iberoamérica, Madrid, 1992 (nueva edición 1998).

HÄBERLE, P. (ed.), "Dokumentation von Verfassungsentwürfen und Verfassungen ehemals sozialistischer Staaten in (Süd)Osteuropa und Asien", fö $R$, Tübingen, vol. 43, 1995; vol. 44, 1996; vol. 45, 1997; vol. 46, 1998.

—, "Neuere Verfassungen und Verfassungsvorhaben in der Schweiz, insbesondere auf kantonaler Ebene", föR, Tübingen, vol. 34, 1985.

Huber, E. R. (ed.), Dokumente zur deutschen Verfassungsgeschichte, vol. 1: Stuttgart, 1961; vol. 2: Stuttgart, 1964; vol. 3: Stuttgart, 1966.

KIMMEL, A. (ed.), Die Verfassungen der EG-Mitgliedstaaten, 4a. ed., München, 1996. 
Este libro forma parte del acervo de la Biblioteca Juridica Virtual del Instituto de Investigaciones Juridicas de la UNAM http://www.juridicas.unam.mx

Klecatsky, H. R. y MORscher, S. (eds.), Die österreichische Bundesverfassung, 9a. ed., Viena, 1999.

Mayer-Tasch, P. G. (ed.), Die Verfassungen Europas, 2a. ed., München, 1995.

Peaslee, A. J. (ed.), Constitutions of Nations, 4 vols., 3a. ed., revisada, The Hague, 1970.

PestalozZa, G. (ed.), Verfassungen der deutschen Bundesländer, 5a. ed., München, 1995.

Reyntjens, F. (ed.), Constitutiones Africae, vol. I, Bruxelles, 1988.

Roggemann, H. (ed.), Die Verfassungen Mittel- und Osteuropas, Berlín, 1999.

Vedel, G. (ed.), Les Constitutions du Proche et du Moyen-Orient, París, 1957. 
Este libro forma parte del acervo de la Biblioteca Juridica Virtual del Instituto de Investigaciones Juridicas de la UNAM

\section{BIBLIOGRAFÍA GENERAL}

ARAGÓn, M., Constitución y democracia, Madrid, 1989.

Aubert, J. F. y EICHENBerger, K., La constitution, son usage - Sinn und Bedeutung einer Verfassung (Referate zum 125. Schweizerischen Juristentag), Basel, 1991.

BADURA, P., voz: "Verfassung", en Evangelisches Staatslexikon, 3a. ed., Stuttgart, 1987, cols. 3737 y ss.

BageHOT, W., The English Constitution, Londres, 1902 (2a. ed. 1983).

Balaguer Callejón, F. et al., Derecho constitucional, vols. I y II, Madrid, 1999.

Baldassare, A., "Costituzione e valori”, Politica del diritto, 1991.

BARILE, P., La costituzione come norma giuridica, Florencia, 1951.

BASTID, P., Lideé de constitution, París, 1985.

BERICHT DER GEMEINSAMEN VERFASSUNGSKOMMISSION, Zur Sache 5/93, Bonn, 1993.

vOn Beyme, K., Die verfassunggebende Gewalt des Volkes, Tübingen, 1968.

BIN, R., Capire la costituzione, Bari-Roma, 1998.

BLANCO VALDÉs, R., El valor de la Constitución, Madrid, 1994.

BobBiO, N., Liberalismo e democrazia, Milán, 1985.

BÖCKEnföRde, E. W., Staat, Verfassung, Demokratie, Frankfurt M., 1991.

BRYDE, B.-O., Verfassungsentwicklung, Baden Baden, 1982.

Buchanan, J. M. y Tullock, G., The Calculus of Consent, Ann Arbor, Mich., 1962.

BurdeaU, G., "Zur Auflösung des Verfassungsbegriffs", Der Staat, Berlín, vol. $1,1962$.

Compagna, L., Gli opposti sentieri del costituzionalismo, Bolonia, 1998.

Crisafuldi, V., Stato, Populo, Governo, Milán, 1985.

__, "Costituzione", Enziclopedia del Novecento, II, Roma, 1979.

Denninger, E., Menschenrechte und Grundgesetz, Weinheim, 1994.

DICEY, A. V., Lectures Introductory to the Study of the Law of the Constitution, 2a. ed., Londres, 1886 (8a. ed. 1923).

Dogliani, M., Potere costituente, Turín, 1986.

Duverger, M., Le système politique français, 20a. ed., París, 1990. 
Este libro forma parte del acervo de la Biblioteca Juridica Virtual del Instituto de Investigaciones Juridicas de la UNAM

EIDELberg, P., The Philosophy of the American Constitution, Nueva York, 1966.

ELIA, L., "Diritto costituzionale", Cinquant'anni di esperienza giuridica in Italia, Milán, 1981.

Elster, J. y Slagstad, R. (ed.), Constitutionalism and Democracy, Cambridge, 1988.

EsPosito, G., La Costituzione italiana, Padua, 1994.

FAVOREU, L. y RUBiO LlORENTE, F., El bloque de la constitucionalidad, Madrid, 1991.

FERnÁNDEZ SEGadO, F., El sistema constitucional español, Madrid, 1992.

FIORAVANTI, M., Stato e costituzione, Turín, 1993.

Fleiner-Gerster, T., Allgemeine Staatslehre, 2a. ed., Berlín-Heidelberg, 1995.

FORSTHOFF, E., Zur Problematik der Verfassungsauslegung, Stuttgart, 1961.

FRAENKEL, E., Das amerikanische Regierungssystem, 3a. ed., Opladen, 1976.

FrankenberG, G., Die Verfassung der Republik, Baden-Baden, 1996.

FRIEDRICH, C. J., Constitutional Government and Democracy, Boston, 1950. , Der Verfassungsstaat der Neuzeit, Berlín, 1953.

FRIEDRICH, M. (ed.), Verfassung, Darmstadt, 1978.

GARCíA BELAUNDE, D., De la jurisdicción constitucional al derecho procesal constitucional, 2a. ed., Lima, 2000.

Gomes Canotilho, J. J., Direito constitucional e teoria da Constituçao, Coimbra, 1998.

, Direito constitucional, 5a. ed., Coimbra, 1991.

GICQUEL, J., Droit constitutionnel et institutions politiques, 14a. ed., París, 1995.

Gough, J. W., Fundamental Law in English Constitutional History, Oxford, 1955.

Grewe, C. y RuIZ FABRI, H., Droits constitutionnels européens, París, 1995.

GrimM, D., Die Zukunft der Verfassung, 2a. ed., Frankfurt M., 1994.

HÄBERLE, P., Verfassung als öffentlicher Prozeß, 3a. ed., Berlín, 1998.

-, Verfassungslehre als Kulturwissenschaft, Berlín, 1982 (2a. ed., Berlín 1998).

-, Europäische Rechtskultur, Baden Baden, 1994.

-, Rechtsvergleichung im Kraftfeld des Verfassungsstaates, Berlín, 1992.

- Das Grundgesetz zwischen Verfassungsrecht und Verfassungspolitik, Baden Baden, 1996.

— Le libertà fondamentali nello Stato costituzionale, Roma, 1993.

—_, Europäische Verfassungslehre in Einzelstudien, Baden Baden, 1999.

Habermas, J., Faktizität und Geltung, Frankfurt M., 1992 (trad. española: Facticidad y validez, Madrid, 1998). 
Este libro forma parte del acervo de la Biblioteca Juridica Virtual del Instituto de Investigaciones Juridicas de la UNAM

HÄFelin, U. y Haller, W., Schweizerisches Bundesstaatsrecht, 4a. ed., Zürich, 1998.

Hamilton, A., The Federalist Papers, 1788 (trad. española: El Federalista, México, varias ediciones).

HaVerkate, G., Verfassungslehre, München, 1992.

HayeK, F. A., The Constitution of Liberty, Chicago, 1960.

HeLler, H., Staatslehre, Leiden, 1934, 6a. ed., Tübingen, 1989 (trad. española: Teoría del Estado, México, varias ediciones).

HENNIS, W., Verfassung und Verfassungswirklichkeit, Tübingen, 1968.

HerzoG, R., Allgemeine Staatslehre, Frankfurt M., 1971.

Hesse, K., Grundzüge des Verfassungsrechts der Bundesrepublik Deutschland, 20a. ed., Heidelberg, 1995 (reimp. 1999).

, Die normative Kraft der Verfassung, Tübingen, 1959.

Huber, E. R., Deutsche Verfassungsgeschichte seit 1789, 7 vols., Stuttgart, 1957 a 1984.

IsEnseE, J., "Staat und Verfassung”, en $i d$. y KIRCHHOF, P. (ed.), Handbuch des Staatsrechts, I, Heidelberg, 1987, 13 (2a. ed., 1995).

JELLINEK, G., Verfassungsänderung und Verfassungswandlung, Berlín, 1906.

-, Allgemeine Staatslehre, 3a. ed., 6a. reimp., Darmstadt, 1959 (trad. española: Teoría general del Estado, varias ediciones).

KäGI, W., Die Verfassung als rechtliche Grundordnung des Staates, Zürich, 1945 (reimp. 1971).

KELSEN, H., Allgemeine Staatslehre, Berlín, 1925 (reimpr. Bad Homburg, 1966; trad. española: Teoría general del Estado, varias ediciones).

KRAWIETZ, W. (ed.), Verfassungsstaat, Berlín, 1996.

KRIELE, M., Einfïhrung in die Staatslehre der geschichtlichen Legitimitätsgrundlagen des demokratischen Verfassungsstaates, 5a. ed., Opladen, 1994.

KRÜGER, H., Allgemeine Staatslehre, 2a. ed., Stuttgart, 1966.

KUnIG, P., Das Rechtsstaatsprinzip, Tübingen, 1986.

LASSALLE, F., Über Verfassungsweesen, Berlín, 1877 (trad. española: ¿Qué es una Constitución?, varias ediciones).

Landa Arroyo, C., Tribunal Constitucional y Estado democrático, Lima, 1999.

LANe, P. H., A Manual of Australian Constitutional Law, 4a. ed., Granville, 1987.

LOEWEnstein, K., Verfassungslehre, Tübingen, 1959 (3a. ed., Tübingen, 1975; trad. española: Teoría de la Constitución, Barcelona, varias ediciones).

Lo Stato delle istituzione italiane. Problemi e prospettive. Atti del convegno, Roma 30 giugno-2 luglio, 1993, Milán, 1994.

LORD HAILSHAM, On the Constitution, Londres, 1992. 
Este libro forma parte del acervo de la Biblioteca Juridica Virtual del Instituto de Investigaciones Juridicas de la UNAM

LUGAS VERDú, P., Estimativa y política constitucionales, Madrid, 1984.

, Teoría de la Constitución como ciencia cultural. Significado, función y finalidad de una teoría de la Constitución, Madrid, 1996.

LuHmann, N., "Politische Verfassungen im Kontext des Gesellschaftssystems", Der Staat, Berlín, vol. 12, 1973.

Maitland, F. W. Constitutional History of England, Cambridge, 1908.

MATTEUCGI, N., Lo stato moderno, Bolonia, 1993.

MaIlwain, Constitutionalism Ancient and Modern, Ithaca, Nueva York, 1947.

Mortati, C., Racolta di scritti, Milán, 1972.

—_, La Costituzione in senso materiale, Milán, 1940.

Müller, F., Juristische Methodik, 6a. ed., Berlín, 1997.

NANIA, R., Il valore de la Costituzione, Milán, 1986.

ÖHLINGER, T., Verfassungsrecht, 3a. ed., Viena, 1997.

Orlando, V. E., Principi di diritto costituzionale, Florencia, 1912.

PACE, A., La causa della rigidità costituzionale, 2a. ed., Padua, 1996.

PANUnZIO, S. P. (ed.), I costituzionalisti e le riforme, Milán, 1998.

PECES-BARBA, G., Los valores superiores, Madrid, 1986.

PÉREZ-LuÑo, A.-E. (coord.), Derechos humanos y constitucionalismo ante el Tercer Milenio, Madrid, 1996.

Pernthaler, P., Allgemeine Staatslehre und Verfassungslehre, 2a. ed., Viena-Nueva York, 1996.

Pizzorusso, A., La Costituzione, Turín, 1996.

PREUB, U. K. (ed.), Zum Begriff der Verfassung, Frankfurt-M., 1994.

REBUfFA, G., Costituzioni e costituzionalismo, Turín, 1990. 1995.

RIDOLA, P., Diritti di libertà e costituzionalismo, Turín, 1997. - (ed.), La costituzione europea tra cultura e mercato, Roma, 1997.

RIGAUX, M. F., La théorie des limites matérielles à l'exercice de la fonction constituante, Bruselas, 1985.

Romano, S., Principi di diritto costituzionale generale, Milán, 1947.

SALADIN, P., Die Kunst der Verfassungserneuerung, Basel-Frankfurt M., 1998. -, Wozu noch Staaten?, Bern, 1995.

SARTORI, G., Comparative Constitutional Engineering, Nueva York, 1994 (trad. española: Ingeniería constitucional comparada, México, 1994).

SCHEUNER, U., Staatstheorie und Staatsrecht, Berlín, 1978.

SCHINDLER, D., Verfassungsrecht und soziale Struktur, 4a. ed., Zürich, 1967. 
Este libro forma parte del acervo de la Biblioteca Juridica Virtual del Instituto de Investigaciones Juridicas de la UNAM

SchmidT-Assmann, E., Der Verfassungsbegriff in der deutschen Staatslehre der Aufklärung und des Historismus, Berlín, 1967.

SchMiTT, G., Verfassungslehre, Berlín, 1928 (6a. ed., 1983; trad. española: Teoría de la Constitución, varias ediciones).

SMEND, R., Staatsrechtliche Abhandlungen, 3a. ed., Berlín, 1994.

—, Verfassung und Verfassungsrecht, München-Leipzig, 1928.

Spadaro, A., Contributo per una teoria della costituzione, Milán, 1994.

SPyropoulos, PH., Constitutional Law in Hellas, La Haya-Londres-BostonAtenas, 1995.

STEINER, U., Verfassunggebung und verfassunggebende Gewalt des Volkes, Berlín, 1966.

STERn, K., Das Staatsrecht der Bundesrepublik Deutschland, I, 2a. ed., München, 1984 (trad. española: El derecho del Estado de la República Federal de Alemania, Madrid, 1987).

STERnBerGeR, D., Verfassungspatriotismus, Frankfurt M., 1990.

TRIBE, L. H., American Constitutional Law, Nueva York, 1879 (2a. ed., Min. 1988).

- Constitutional Choices, Cambridge, Mass., 1985.

Troper, M.-Jaume, L. (ed.)., 1789 et l'invention de la Constitution, París, 1994.

VegA, P. de, La reforma constitucional y la problemática del poder constituyente, Madrid, 1985.

Vergottini, G. de, Diritto costituzionale comparato, 5a. ed., Padua, 1999.

- Diritto costituzionale, Padua, 1997.

VORLÄNDER, H., Verfassung und Konsens, Berlín, 1981.

Weber, K. y Rath-Kathrein, I. (eds.), Neue Wege der Allgemeinen Staatslehre, Viena, 1996.

WiLloweit, D., Deutsche Verfassunsgeschichte, 3a. ed., München, 1997.

ZagrebelsKY, G., Stato-societa-costituzione, Turín, 1988.

—. Il diritto mite, 2a. ed., Turín, 1994 (trad. española: El derecho dúctil, Valladolid, 1995). 1996. 
Este libro forma parte del acervo de la Biblioteca Juridica Virtual del Instituto de Investigaciones Juridicas de la UNAM

\section{ÍNDICE ANALÍTICO}

administración pública 94, 207, 234

principio de legalidad de la 213

alternativas, pensamiento de las 47, $51 \mathrm{y}$

s., 190

v., también, posibilidades, pensamiento de las

ambiente, medio 10, 19, 77, 94, 97, 233

y s., 237,295

protección del 7, 25, 32, 61, 92, 94, 110, 114, 183, 206, 212, 230, 286, 291

América Latina 65, 168, 220, 298

"annus mirabilis" (1989) 1, 13 y s., 16, 43, 45, 56, 65, 69, 159, 184 y s., 195, 244, 246, 284, 292, 300

anti-ideológicas, cláusulas 6, 114, 187, 279

armada, fuerzas 80, 124, 130, 194, 209

arte 100, 171, 173, 188 y s., 207, 218, 220, 225 y s., 229, 235, 247 y s., 284 y s., 292

Asia 57, 65, 289

asilo, derecho de 22, 25, 178, 273

bases, artículos de 87 y s., 95, 168, 262, 267

bien común 31, 54, 96, 102, 113 y s., 142, 188, 196, 198, 206, 208, 229 у ss., 244 y s., 254, 280, 300

bienes culturales, protección de los $4 \mathrm{y}$ s., 291

ciencia 4, 11 y ss., 144, 149, 167, 170 y s., 173 y s., 190, 192, 198, 204, 212,
216, 219, 225, 229, 235, 243, 247, 269, 284 y s., 286, 296 y s., 300 cultural 2, 10, 13 y s, 20, 23, 44 y ss., 75 y ss., 229, 231, 240, 269, 285, 299 y s.

ciudadanos 1, 8, 13, 18, 22, 26 y s., 39, 65, 71, 79, 82 y s., 86, 91, 94, 97 y s., 100, 102 y s., 114 y s., 124, 142 y s., 147 y ss., 163, 169, 171, 175 y ss., 201, 205 y s., 219, 221 y s., 232 y ss., 245, 251, 259 y s., 264 y ss., 272 y ss., 295 derechos 86, 173, 175 y ss. textos (de los) 2, 4 y s., 43 y ss., 109, 113, 124, 131, 164, 182, 185, 230, 232, 244, 258, 277, 287, 301

"contra"- 44 y ss., 188

comparación cultural 153, 156

comparación jurídica 55 y ss., 101, 120, 154, 156, 212, 239, 274, 277 y ss., 280 como quinto método de la interpretación 121, 153 y ss., 177, 300

en el espacio y el tiempo 55 y s., 283

Comunidad Europea v. Unión Europea

Consejo de Europa 27, 63, 68, 72, 271

consenso 61, 80, 112, 133, 178 y ss., 231, 189

básico 14, 113 y ss., 127, 158, 231, 242

fuentes irracionales del 37, 80, 205, 264

Constitución 1 y ss., 11 y ss., 45

apertura de la 52, 112, 114, 238

como contrato $1,24,157,181$ y ss., 260 
Este libro forma parte del acervo de la Biblioteca Juridica Virtual del Instituto de Investigaciones Juridicas de la UNAM

como expresión de un estadio de desarrollo cultural 5, 25, 129, 298

como orden fundamental del Estado

y la sociedad 3, 109, 135, 156, 159, 230

como proceso público 3, 112 y s., 150, 158

de Europa 40 y s.

defensa de la 91 y s., 104, 137, 269 y ss., 275

del pluralismo 26 y ss., 179 y ss., 231, 237, 240, 243, 247

modificación y enmienda de la 16 , $22,25,49,70,61,91,131,133$ y ss., 137 y ss., 182, 188, 204, 265, 283, 289

pactada $13,39,127$

partes orgánica y dogmática 84 y ss., 103

proyectos de $31,62,101,116$ y ss., $125,263,283$ y s.

quebrantamiento de la 135, 270 y ss., 274

revisión parcial o total 22, 62, 76 y s.,

91, 98, 102, 112, 116, 119, $125 \mathrm{y}$

s., 128 y ss., 135 y ss., 283

supremacía de la 31 y s., 120, 188,

211,213 y s., 255, 274

teoría de la, $v$. teoría constitucional

texto $v$. textos constitucionales

unidad de la 104, 147, 261 y ss.

concepción de la 3 y ss., 13, 18, 53,

156, 295

antropocéntrica 109 y ss., 172

instrumental 105 y s., 113

material $8,41,85$ y s., 106 y s., 151,

179, 186, 237, 252, 265

mixta 3 y ss., 78 y ss., 109, 198, 201,

247

constitucional

Estado, v. Estado constitucional historia 48,55 y ss., 117, 123 y s., 187, 203 y s., 239 y s., 260,267 y s., 274,283

mandato $60,83,93,96,104$ y s., 181, 208, 227, 237, 261

mutación 59 y s., 133

política $v$. política constitucional

realidad y vida $9,39,44$ y ss., 57,77 , $116,121,142,167,222,278,300$

ys.

recurso 144 y s., 159, 269

retórica 105

teoría $v$. teoría constitucional

texto $v$. textos constitucionales

constitucionales, enunciados 79 y ss., 104

modelo de facultamiento y limitación 83 y s.

modelo de valores fundamentales 84 ys.

constituyente(s) 24, 77, 79, 81 y s., 85 y ss., 88 y s., 93, 95, 98, 100 y ss., 107 y s, 111 y s., 117,119 y s., 123 y ss., 131 y ss., 156, 159, 167, 180, 206, 212, 224, 244, 257 y ss., 261, 270 y ss., 283 y s.

constituyente, poder 38, 88, 123 y ss., 128 y ss.

del pueblo 123 y ss., 128

límites 127 y s.

normativización y constitucionalización 128, 234

constituyente, proceso(s) 6, 85, 107, 112,

123 y ss., 131 y ss., 159, 224, 244, 271 y s., 283

contenido esencial, garantía del $v$. fundamentales, derechos

contextos 2, 9, 11 y s., 16, 25, 33, 44, 79, $120,158,166$ y s., $198,203,217,230$ y s., $257,259,261,265,300$

contrato social 13 y s., 24, 45, 111, 156 y ss., 173 y s., 241 y ss., 289,297 
Este libro forma parte del acervo de la Biblioteca Juridica Virtual del Instituto de Investigaciones Juridicas de la UNAM

mundial 24, 174

cooperative federalism $v$. federalismo

Corte Europea de Derechos Humanos 63, 210

Corte Interamericana de Derechos $\mathrm{Hu}-$ manos 294, 300

cultura 1, 4, 10, 11 y ss., 19 y ss., 30, 32 y ss., 38, 44 y ss., 63, 75 y ss., 96 y ss., 110 y s., 127, 139, 159 y s., 162, $164,167,170,172$ y ss., 210, 216 y ss., 231, 233, 235 y s., 239, 241 y s., 246 y ss., 254, 258, 263, 266, 268 y ss., 272, 280, 282 y s., 285, 289 y ss., 296, 298 y ss.

como elemento del Estado 14, 19 y ss. concepto abierto de 15, 227 y s., 248 constitucional 33, 57 y s., 99, 119, 134, 138 y s., 159, 164, 181, 220, 272, 282 y s., 299

política 158, 198, 229, 270, 290

cultura jurídica $11,35,64,118,173$, 210, 214, 258, 296

datos personales, protección de 16, 194 democracia 2 y s., 12 y s., 17, 21 y s., 25, 27 y s., 31 y s., 34 y ss., 39, 44, 46, 49, 60, 103, 107 y ss., 113 y ss., 129, $139,141,144,149$ y s., 158, 161 y ss., 172, 180, 182, 183 y ss., 192, 194 y ss., 205, 208 y s., 216, 224 y s., 229 y s., 234, 236, 243 y ss., 250, 254, 264, 266 y s., 269, 271, 273 y ss., 280, 283, 289, 292

como consecuencia organizativa de la dignidad humana 183 y ss., 245, 280

en libertad 110, 185, 191, 273 y s.

pluralista 3, 49, 108, 114, 192, 229, 230, 236, 245

presidencial o parlamentaria 184, 199 representativa, semidirecta, directa 125, 184 y s., 200, 204, 280, 283, 289

teoría de la 149, 192, 254

variantes de la 183 y ss.

derecho constitucional 156, 171, 173, 296 y ss.

ciencia y teoría del 4, 47, 149, 157, $173,190,225$

común europeo 15, 57, 63 y s., 155, 250, 299 y s.

consuetudinario 77, 282

de la cultura 10, 34, 48, 182, 217 y ss., 225 y ss., 266, 280

del trabajo 240 y s., 257, 266

material 76 y s., 151, 179, 186, 201, 237, 265 y s.

nacional de Europa 64 y ss.

de la religión 202, 217, 261 y ss.

derecho internacional $67 \mathrm{y} \mathrm{ss.,} \mathrm{72,} 170 \mathrm{y}$

s., 174, 280, 287, 293 y ss., 300

derecho procesal constitucional 58, 66, $71,151,153,157,179,219,221$ y ss., 278, 280, 290 y s., 298 y s.

desarrollo, países en 7 y ss., 43

desobediencia civil 275 y s., 288

días festivos 29, 80, 87, 111, 218, 229, 263, 264 y ss.

garantías de los 80, 87, 218, 264 y ss.

y domingos $268 \mathrm{y} \mathrm{s}$.

dignidad humana 1, 3, 8, 10, 13, 32, 39, 43, 46, 92, 99, 109 y ss., 125, 139 y s., 158, 161 y ss., 166, 177 y s., 182 y s., 197, 216, 230, 238 y ss., 245, 258, 261, 264, 271, 277, 280, 287, 292, 295

como premisa antropológico-cultural 1, 3, 8, 13, 39, 161 y ss., 183, 239, 240, 245, 258, 280

y democracia 164 y ss., 183, 280 
Este libro forma parte del acervo de la Biblioteca Juridica Virtual del Instituto de Investigaciones Juridicas de la UNAM

división de poderes 1, 3 y ss., 36, 43, 45, $56,111,113,115,127,139$ y s., 150 , 165, 183, 185, 192 y ss., 201, 203, $207,210,213$ y s., 230, 245, 250, 252, 254, 271, 280, 294, 298, 301

en sentido amplio, pluralista 151, 192 y ss., 245,246 y ss, 249,280

en sentido estricto, estatal 150, 192 y ss.

horizontal y vertical 192 y ss., 194, 280, 282, 289

ecología $v$. ambiente, medio economía 65 y ss., 93 y ss., 100, 171, 189, 232, 235, 244 y s., 257, 281, 288, 290 social y ecológica de mercado 171 ,

239 y ss., 244 y ss., 281, 290

educación 222 y ss., 236, 238, 247 y s., 256, 265, 289

fines de la 1, 71, 80, 89, 91, 96, 101, $107,110,169$ y ss., 176, 178, 180 y ss., 178 y ss., 181 y ss., 219,222 y ss., $227,231,240$ y s., 246,256 y s., 263 y s., 266, 286

Ejecutivo, Poder $v$. gobierno, administración

emergencia, situaciones de $v$. excepción, estado de

emigrar, libertad de 22, 25

enfoque culturalista 5, 21, 25, 29, 109, 175, 246 y ss., 251, 264, 266, 277 y ss. esperanza, principio 6 y s., 48, 286, 292 espíritu abierto, filosofía del $v$. racionalismo crítico

"espíritu", artículos "en el" 80, 85, 87, 89, 104, 111, 140

espíritu de las Constituciones 2, 140 y s.

Estado 12 y s., 52

elementos del 7 y s., 19 y ss., 29, 31, 159 fines del 25, 30, 93, 95, 104, 107, 116 , 198, 207, 232 y ss., 266

funciones del 36, 53, 82, 93, 145, 198 y s., $211,229,232,237$

jefe de 36, 88, 198, 203 y s., 209, 264

poder del 3, 18, 20,38, 156, $165 \mathrm{y} \mathrm{s}$, 185

símbolos del 19 y ss., 25, 29 y ss., 264, 267

soberanía del 19, 68 y s., 87

tareas del, $v$. tareas

teoría (general) del 12, 14, 19, 34, 75, 101,233, 271

territorio del 7, 20 y s., 23 y ss.

Estado constitucional

como conquista cultural 1, 285

como tipo 1 y s., $6,23,25,27,30,35$,

38 y s., 57, 66, 82, 103, 108, 112,

119, 125 y ss., 128 y ss., 137, 140,

155, 167, 175, 179, 184, 186, 194,

203, 205, 211, 223, 232 y s., 239,

250 y ss., 258, 264, 272, 277 y s.,

287 y s.

comunidad universal del 28, 56, 71 y ss., 281

concepción de sí mismo del 71 y ss., 264

cooperativo $26,28,62$ y ss., 65 y ss., $155,281,287,294$ y ss., 298 y ss.

de cuño europeo/atlántico 3, 108, $155,245,278$

etapas evolutivas del 27, 63, 98, 107, 121, 167, 183, 233, 243, 253, 261, 277 y ss.

europeo 11, 28, 35, 63 y s., 77

identidad del 137 y ss., 189, 271

imagen del 238, 71 y ss., 170 y ss., 238, 264

necesidades de reforma del 277 y ss., 287 y ss, 292 
Este libro forma parte del acervo de la Biblioteca Juridica Virtual del Instituto de Investigaciones Juridicas de la UNAM

principios y elementos del 31, 132, 159, 197, 254, 279

procesos de crecimiento, producción y recepción en el 9 yss., 33, 56, 59, 76, 103, 173, 179, 246, 277 y ss., 286

y relaciones internacionales 66 y ss.

Estado de cultura 1, 4, 30, 197 y s., 207, 217, 225, 227, 233, 280

Estado de derecho 1, 30 y ss., 66, 111 , 165, 210, 212, 214 y s., 21 7, 244, 258, 281,293 y s.

principio del 5, 214 y s.

Estado e iglesias, relación entre 132, 262

Estado social 1, 77, 83, 198, 206 y s., 211 y ss., 230, 236, 243, 286, 295

de derecho 31, 59, 87, 116, 140, 211

y ss., 280, 295

principio del 7, 83, 215 y s., 245, 286

eternidad, cláusulas de 91, 135, 137 y ss., 189, 263, 271, 279

Europa 20, 26 y ss., 34 y ss., 40 y s., 55 y ss., 63 y ss., 69 y s., 72,77 y s., 85, 102, 114, 116 y s., 121, 132, 159, 164, $168,171,176,179,187,195,203 \mathrm{y}$ ss., 212 y s., $220,222,224$ y s., 250 y ss., 260, 267, 271 y ss., 278 y ss., 288, 290, 292, 298 y ss.

artículos sobre 64, 70, 281

casa constitucional de 12, 29, 41

oriental 5 y s., 8, 27, 29, 31, 56, 66, $69,72,77,114,117,159,176,187$, 195, 204, 212, 224, 232, 244 y s., 250, 263, 267, 271, 278 y ss., 288, 292

europeo, derecho 63, 121, 214, 250, 299 europeización 12, 24, 62 y ss., 121, 178 excepción, estado de 36, 274 y s. experimentación y experiencia, claúsulas de 61 y ss. extranjeros 22, 25, 64 y s., 71, 175 y s., 282

federales, estados 23, 84 y s., 128, 207, 246 y s., 250

federalismo 12 y s., 21, 25, 27, 56 y s, 194, 197, 200, 246 y ss., 250 y s., 253 y s., 271, 278, 280, 282, 289

cooperativo 57,246

festivo, lenguaje 79, 82

fuentes del derecho

apertura y pluralidad de las 118, 119 y ss.

doctrina de las 88, 119

europeización de las 121 y ss.

fundamentales, deberes 94, 96, 105, 178 y s.

fundamentales, derechos 1 y s., 10 y s., 17 y s., 22 y ss., 28, 30, 32, 47 y ss., 52, 57 y s., 63, 65, 73, 76 y s., 80 y s., 82 y ss., 86 y s., 91, 93 y ss, 107 y ss., 113 y ss., 132, 139, 150, 153 y ss., 157, 161, 164 y s., 173 y ss., 186, 188, 190 y s., 194, 198, 201 y ss., 208, 211, 214, 218, 224 y ss., 229 y s., 234 y ss, 240 y s., 243, 246, 254, 256 y s., 262, 270, 273 y s., 280, 282, 297

catálogos 83, 86, 107, 176, 203, 241, 294, 138

clásicos 96, 115

cláusulas de desarrollo 102, 120

como principios generales del derecho 57, 63, 71, 119 y ss., 154, 274, 295

comparación 153, 177

contenido esencial 270, 278, 297, 132

culturales 225 y ss.

efectos frente a terceros 3, 115, 157

garantías de los 1, 30, 52, 80, 154 y s., 177 
Este libro forma parte del acervo de la Biblioteca Juridica Virtual del Instituto de Investigaciones Juridicas de la UNAM

interpretación conforme a los derechos humanos 57, 176

optimización de los 116

pérdida 273

pluridimensionalidad de los 98

política de los 98

protección a través de la organización y el procedimiento 116, 99 y s., 104

realización de los 86, 91, 100, 102, 110,120 y s., 150, 190, 208, 256 sociales y culturales 47, 86, 100, 234 suspensión 274

tareas de los 95, 237

v., también, humanos, derechos

\section{generaciones}

contrato de las 14, 28, 156, 182, 228,

242, 260, 288, 297

protección de las 6, 19, 110, 221

globalización 24, 57, 65, 244, 291, 294

gobierno 194 y ss., 200 y ss., 205 y ss., 252, 260, 271, 274 y s., 298

himno nacional v. Estado, símbolos del homogeneidad $v$. federales, estados, regionalismo

humanos, derechos 6, 8, 16, 22, 24, $27 \mathrm{y}$ s., 31, 39, 57, 63, 66 y s., 69, 71 y ss., $90,101,111$ y s., $117,119,121,129$, 138, 140, 154 y s., 167 y ss., 180, 184 y s., 190, 197, 210, 213, 223 y s., 226, 240, 244, 256, 258 y s., 271, 275, 280 y ss., 289, 290 y s., 294, 298, 300, 301 v., también, fundamentales, derechos

identidad 20, 282

cláusulas de 10, 72, 88, 111, 113, 259

cultural 5, 10, 21, 26, 90, 128 y ss., $176,178,219$ y ss., $225,227,264$, 267, 299 europea 68

garantías de 104, 189, 271

individual 16, 162 y s.

nacional 26, 176, 219

iglesias 17, 81 y ss., 83, 91, 124, 132, $145,188,202,218,235,262$ y s.

igualdad, 10, 13, 15, 25, 31, 43, 60, 72, 88 y s., 94, 96, 102, 109, 114, 116, 177, 183, 188, 201, 216, 234, 239, 265

independencia judicial 1 y s., 148, 190, 294

internacional, derecho $v$. derecho internacional

interpretación 11, 29, 33, 44 y s., 51 y ss., 57, 59 y ss., 76, 78 y s., 53, 103, 105 y s., 109, 118 y ss., 123 y ss., 190, 212, 217, 244, 277 y s., 281, 283, 300 constitucional 52 y s., 76, 78 y s., 103, 105 y ss., 141 y ss., 179, 190 y s., 283

intérpretes constitucionales 11, 34, 44 y s., 142, 149, 172, 180 y s., 241, 277, 298

v. también, pluralismo, sociedad abierta

Islam 26, 161, 177, 285

islámicos, estados 66, 290

juez constitucional 141, 146, 151, 153

jurisdicción 18, 53, 66, 70, 89, 98, 144, 195, 198, 199, 209 y ss., 252

constitucional 12, 36, 38, 57, 60, 121, 123 y s., 132, 143, 156 y ss., 184, 192, 197, 198, 210, 272, 291, 298

jurisprudencia

alternativa 60

constitucional 3, 17, 76 y s., 92, 86 justicia 43, 68, 70 y s., 87, 89, 100, 103, 111,114 y s., 120, 125, 138, 140, 158, 
Este libro forma parte del acervo de la Biblioteca Juridica Virtual del Instituto de Investigaciones Juridicas de la UNAM

174 y s., 211, 213, 215, 230, 244 y s., 255 y ss., 260, 283, 288, 290, 295 máximas de 254 y ss. social 69, 80, 82, 90, 98, 113, 116, 212, 214, 256, 265 y s., 268, 277

law in public action 76, 148, 210

law in the books 76

legislación 46, 50, 53, 60 y s., 101, 108, 136, 198 y s., 202, 213 y s., 229 y s., 252

lengua 12, 26, 29 y ss., 37, 225, 251

artículos sobre la 88, 111, 219, 221 y ss.

lenguaje de las Constituciones 78 y ss., 106 y s., 108,111

leyes 50, 64 y s., 86, 95, 120, 176, 187, 198 y s., 215, 224, 245, 283

efectos anticipados de las 64 y ss.

libertad(es) 4, 7, 14 y s., 18 y s., 21 y s., $25,31,34,45$ y s., $48,51,54,80$ y ss., 84, 89, 95, 100, 102 y s., 109 y s., 146 y s., 149, 158, 162, 172 y ss., 240 y ss., 265 y s., 277

cultural(es) 4, 6, 16, 20 y s., 28 y ss.,

172 y ss., 218,225 y s., 228,235 ,

244, 250, 254, 280, 286

lingüística 27,221 y s.

públicas 16, 18, 36, 86, 280

real 115 y s., 150, 191, 205

v., también, fundamentales, derechos

límites, pensamiento en términos de 139, 235

mandatos legislativos 60 y s., 83, 93

mayoría, principio de la 73, 188 y ss., 199

medios de comunicación 4, 17, 114, 145, $225,237,247,280,288,291,300$ y s. mercado $v$. economía micro Estados 7 y ss., 20 y s., 24, 26, 43, 278

militares $v$. armadas, fuerzas

minoría y mayoría 49, 188 y s., 206

minorías

culturales 27

derechos de las 47

étnicas 27, 165, 250

protección de las 27, 30, 158, 188, 231, 263, 289

religiosas 27, 263

monarquía 34 y ss.

constitucional 34 y ss., 40, 203

parlamentaria 35 y ss., 40, 128

multicultural, sociedad 15, 289

municipal, autonomía 208, 250

necesidades, pensamiento de las 46, 54, 233

negociación, mesa de 13 y s., 45

opinión y prensa, libertad de $v$. libertad(es) oposición 17, 184, 186 yss., 200, 206, 215, 273

Organización de Estados Americanos (OEA) 67, 220, 227

Organización de las Naciones Unidas (ONU) 23, 69, 174, 279, 290, 295

Organización del Tratado del Atlántico Norte (OTAN) 67, 209

Organización Mundial de Comercio (OMC) 69

Organización para la Cooperación y el Desarrollo Económico (OCDE) 68

Organización para la Seguridad y la

Cooperación en Europa (OSCE) 39, 68, 72

orientación, valores de 1, 172, 178, 182

y ss., 292, 295

parlamentario, control 209 
Este libro forma parte del acervo de la Biblioteca Juridica Virtual del Instituto de Investigaciones Juridicas de la UNAM http://www.juridicas.unam.mx

Parlamento 16, 41, 44, 62, 68, 134 y s., 144, 194 y s., 198 y ss., 206, 213, 268, 275

Europeo 68, 41

partidos políticos 17, 43, 77, 117, 145 y ss., $149,157,182$ y ss., 190, 200 y ss., 230, 273, 278, 284

financiamiento de los 49, 184

pluralidad de los 3, 186, 188

programas de los 43, 77, 117, 131,

182 y s.

patrimonio cultural 170, 182 y s., 217 y

ss., 226, 251, 268 y s., 280, 287, 295

y s., 301

cláusulas sobre el 10, 89, 111 y ss., 280

"pedagogía constitucional" 178 y ss.

pluralismo 1 y s., 6, 15, 26 y ss., 31, 33, 44, 47, 49 y ss., 89, 100, 111, 114, 118 y ss., 124,126 y s., 157 y s., 179 y s., 187 y ss., 201, 203, 218, 226 y ss., 230 y s., 237, 240, 243, 246 y ss., 277, 279, 295

artículos sobre 6, 114, 180

cultural 240 y ss.

de los constituyentes 124, 127

de los intérpretes constitucionales 44, 141 y ss.

pluralista, sociedad 143, 245, 299

poder revisor $v$. Constitución, constituyente

política 48, 52, 146

constitucional 23, 52, 54, 93, 107, 129,133 y s., 136,159 y ss., 237, $244,257,275,282$ y ss., 287 y ss.

posibilidades, pensamiento de las $46 \mathrm{y}$ ss., 51 y ss., 180, 282 y ss.

pouvoir neutre 38, 40, 204

preámbulos 4, 10, 37, 79, 81 y s., 87, 89, 95, 99, 105, 111 y ss., 125, 129 y ss.,
140 y s., $168,180,218,241,255,257$, 258 y ss.

prensa $v$ medios de comunicación

presidente, $v$. Estado, jefe de

primacía, artículos de 92 y ss., 214

principios generales del derecho 57, 63,

71, 119 y s., 121, 154, 274, 295

privada, protección de la vida 16, 189, 208

producción y recepción, procesos de $v$.

Estado constitucional

propiedad 239 y ss.

publicidad de los actos administrativos y

de la administración 6

pública, opinión 17, 59, 143, 152, 157, 201, 206, 209, 273, 276, 284, 288, 292

público, espacio 15, 17, 33, 41, 47, 65 y s., 142, 145, 148 y s., 151, 167, 269, 294

mundial 15, 66, 167, 294

pluralista 148, 151, 269

pueblo $6,14,19$ y s., 25,36 y ss., 45,68 , 70 y s., 79 y ss., 84,87 y s., 90,92 y s., $96,99,103,111,113,123$ y ss., 128 y ss., 134, 148 y ss., 161, 164 y ss., 170 y ss., 174, 182 y ss., 190 y s., 199 y ss., 204 y s., 219 y s., 222, 226, 229, 231, 234,256 y s., 259,261 y s., 264 y ss., $270,273,275,280$ y s., 291,300

racionalismo crítico 28, 47, 51, 285 ratio y emotio 6, 105, 110 y s., 205, 264 realidad

configuración de la 115, 146

pensamiento de la 46, 53 y s., 300 reconocimiento, artículos y normas de 85,87 y s., 104, 129 y s., 267

reformados, Estados 8, 195, 212, 271, 278 v., también, Europa oriental 
Este libro forma parte del acervo de la Biblioteca Juridica Virtual del Instituto de Investigaciones Juridicas de la UNAM

regionalismo 21, 25, 27, 57, 194, 197, 200, 246 y ss., 250 y ss., 282, 289 cooperativo 57,252

religión, derecho constitucional de la $v$. derecho constitucional

religiosa, libertad 18, 172 y ss., 262 y ss., república 33 y ss., 59, 90, 102, 128, 158, 168, 170, 178, 204 y s., 224, 230

republicanos, triada de los ámbitos 15 y ss., 19, 235

resistencia, derecho de 275 y ss.

responsabilidad, principio 7, 43, 286, 292

rule of law 5, 31 y s., 214

salus publica 17, 33, 36, 205, 231

símbolos nacionales, v. Estado, símbolos del

soberanía 23, 120, 150

del príncipe o monarca 39, 165

estatal o nacional v. Estado, soberanía del

popular 1 y ss., 39, 125, 128, 150, 164 y ss., 185 y s., 191 y s.

socialistas, estados 65, 155, 184, 206, 209, 240, 267, 290

sociedad abierta 3 y s., 11, 13, 33 y s., 45, $52,65,118,141$ y ss., 152, 155, 180 y ss., 187, 201, 227, 231, 241 y s., 245, 277, 298

de los intérpretes constitucionales 11 , 45, 118, 141 y ss., 155, 180, 241, 277, 298

Sociedad de Naciones 67

sociedad mundial 20, 24, 120, 171, 174, 176

status mundialis hominis 15, 173 y s., 177

status quo, cláusulas y normas sobre el 93,

105 y s., 112 y s.

subsidiariedad, principio de 94, 236, 250,254
Sudamérica $v$. América Latina

Suprema Corte de los Estados Unidos 159,210

tareas

del Estado 10, 15, 19, 23, 25, 27, 80, 85 y s., 94 y s., 99 y ss., 108, 110, 112 y s., 115, 197 y s., 198, 232 y ss., 254, 281

normas de 86 y s., 93 y ss., 104, 114 y s., 218, 241

pensamiento en términos de 81, 96 y ss., 115

televisión $v$. medios de comunicación

teoría constitucional 1, 6, 8 y s., 15, 18,

21 y ss., 32 y s., 35, 38, 40, 46, 52 y s., 56, 63, 75, 78, 106, 111, 116, 118 , 121, 138, 148, 170, 174, 199, 204, 214, 219, 228 y s., 232, 237 y ss., 253, 255, 258, 262, 266, 269, 275, 285 у s., 299 y ss.

como ciencia cultural 58, 75 y ss., 78, 138, 198, 228 y s., 240

como ciencia jurídica de los textos y la cultura 11 y ss., 75, 79, 167, 170, 219, 247, 285

Tercer Mundo v., también, desarrollo, países en

territorio v. Estado, territorio del

textos constitucionales 2, 5 y ss., 10 y s., 13, 22, 24, 37, 44, 57, 69, 72, 75 y ss., 78 y ss., 99, 103 y ss., 115 y ss., 118, 123 y ss., 127, 129, 131, 139, 152, 165, 167, 179, 182, 185, 198, 203, 208, 214, 224, 226, 232 y ss., 244, 251, 255 y s., 261, 264, 277 y s., 282, 286 y s., 300 y s.

comparación de 48, 75, 77, 119, 129, $155,283,299$ y s.

diversidad y riqueza de $\operatorname{los} 78$ y ss., 103 y s., 107 y s., 220, 239

en sentido amplio 44, 178, 244, 301 
Este libro forma parte del acervo de la Biblioteca Juridica Virtual del Instituto de Investigaciones Juridicas de la UNAM

funciones de los 78 y ss., 108 y ss., 113 textuales, etapas 2, 6, 9, 16 y s., 35, 69,

75 y ss., 120, 167, 206, 212, 233, 239, 246 y s., 255, 262, 272, 275, 277 y ss., 300

evolución de las 2, 16, 33, 35, 69, 75, 115, 233, 243 y s., 247, 120, 167, 212

paradigma de las $6,17,167,275,277$ y s., 300

tiempo 43 y ss., 51 y s., 55 y ss., 58 y ss., 72,75 y ss., 83, 87, 97, 110, 112 y ss., 119, 130, 132 y ss., 167, 172, 184, 198, 210, 243, 247, 260, 266, 268 у ss., 278, 283

tolerancia 3 y s., 13 y s., 40, 45, 47, 51, 89, 114, 171, 178, 180, 182 y s., 187, 217, 223, 231, 242, 261, 266, 273

trabajo 97, 179 y ss., 239 y ss., 256 y s., 266, 269, 288

Tribunal Constitucional Federal alemán (TCFA) 16, 18, 36, 44, 60, 89, 144, 149, 152, 156, 159, 161, 164, 196, 216, 272, 300 como " tribunal social" 156 y ss.

Tribunal de Justicia de la Unión Europea $57,63,154,210,270$ tribunales $v$. jurisdicción

constitucionales $v$. jurisdicción constitucional

unitarios, Estados 23, 27

UNESCO 223, 300

Unión de Europa Occidental (UEO) 67

Unión Europea 40, 64, 170, 201, 209, 270, 294, 300 y s.

utopía 6 y s., 44, 51 y s., 105, 113, 164, 282, 285 y ss.

valores constitucionales 23 y s., 269, 290

valores fundamentales 21 y ss., 30 y ss., 71, 83 y s., 87 y ss., 104, 111, 113, 126,129 y s., 187, 190, 257, 264, 269, 273, 289

artículos y cláusulas sobre 88, 111, 113

verdad 28 y ss., 130, 180, 245, 247, 256, 283, 286 y s., 298

cláusulas de 6

problema en el Estado constitucional 28 y ss.

voto particular 51, 60, 76, 119, 189, 200, 283

v., también, jurisprudencia alternativa 
Este libro forma parte del acervo de la Biblioteca Juridica Virtual del Instituto de Investigaciones Juridicas de la UNAM

\section{ÍNDICE DE NOMBRES}

Aristóteles 43, 154, 198, 257, 301

Arndt, A. 13, 18

Bagehot, W. 200

Balaguer Callejón, F. 12, 251, 293

Balduino I 36, 39, 40, 205

Baruzzi, A. 242

Beatles, The 172

Bismarck, O. v. 48, 83, 84, 95, 204, 213

Bloch, E. 7, 47, 286

Blüm, N. 242

Böll, H. 34

Bohley, B. 258

Born, N. 34

Brandt, W. 10

Brecht, B. 182, 185

Burckhardt, J. 170

Burdeau, G. 108

Carter, J. 174

Cicerón 205, 301

Coing, H. 63

Constant, B. 204

Cruz Villalón, P. 12, 251

Dönhoff, G. 288

Dürig, G. 20, 163, 173, 214, 242

Duverger, M. 49

Ehmke, H. 3, 109, 139, 142, 147

Eichenberger, K. 37, 80, 190
Esser, J. 64, 118, 119, 121, 146, 147, 152

Freyer, H. 171

Gadamer, H. G. 219

Gandhi, M. 276

Gehlen, A. 228

Goethe, J. W. v. 21, 171, 290

Habermas, J. 15, 17, 48, 151, 171

Hattenhauer, H. 55

Hauriou, M. 5

Havel, V. 283

Hegel, G. W. F. 170, 176, 187

Heidegger, M. 56

Heinemann, G. 201

Heller, H. 4, 7, 14, 75, 91, 101, 109, 114 , 212, 286

Hennis, W. 106

Herder, J. G. 20, 22, 170

Hesse, K. 4, 17, 33, 40, 49, 58, 59, 78, 80, 83, 86, 87, 89, 91, 100, 101, 109, 120, 126, 139, 142, 163, 165, 173, 176, 179, 180, 184, 187, 189, 195, 198, 199, 204, 205, 207, 211, 214, 215, 217, 218, 222, 256, 261, 262, 266, 270, 271, 274

Heuss, A. 171

Heuss, T. 4

Hindenburg, O. v. 36

Hirschmann, A. 182

Hobbes, T. 44, 173, 176 
Este libro forma parte del acervo de la Biblioteca Juridica Virtual del Instituto de Investigaciones Juridicas de la UNAM http://www.juridicas.unam.mx

Hoffmann, H. 228

Hollerbach, A. 17, 106, 255, 262

Huber, E. 154

Huber, E. R. 38, 55

Huber, H. 136

Huber, P. M. 202

Humboldt, W. v. 29

Imboden, M. 116, 117

Ipsen, H. P. 7, 63, 67

Jaag, T. 284

Jellinek, G. 14, 17, 34, 35, 59, 133

Jonas, H. 7, 43, 72, 286

Juan Carlos I 36, 37, 205

Kägi, W. 4, 45, 109

Kant, I. 14, 20, 28, 43, 44, 72, 73, 110 , $111,113,158,170,174,285,287,301$

Kelsen, H. 84, 159

Kimminich, O. 40, 55

King, M. L. 205, 265, 276, 285

Kirsch, S. 26

Klerk, F. de 284

Kötz, H. 63

Krüger, H. 19, 34, 234

Kuhn,J. 35, 45

Kühn, T. 44

Kühn, D. 34

Küng, H. 170

Künhardt, L. 167, 290

Lenz, H. 46

Lessing, E. G. 29, 45

Locke, J. 13, 44, 45, 158, 173, 182, 193, 196

López Pina, A. 12

Luhmann, N. 48, 147, 163, 171

Mandela, N. 124, 131, 276, 284, 290
Mangoldt, H. v. 48, 212, 281

Mao Zedong 268

Marcic, R. 210

Marx, K. 44, 187, 242

Mitterrand, F. 221

Mohl, R. v. 212

Montesquieu, C. M. Secondat de 2, 4, 5, 43, 44, 56, 61, 182, 185, 192, 193, 195, 196, 210, 301

Müller-Graff, P.-C. 63

Musil, R. 47

Nossack, H.-E. 34

Orwell, G. 274, 285

Pardo, A. 90

Pernice, I. 68, 210

Picasso, P. 34

Platón 187, 286

Popper, K. 4, 28, 29, 146, 187, 192, 230, 244, 258, 277, 285, 286

Rawls, J. 13, 14, 43, 111, 257, 276, 301

Roosevelt, F. D. 60

Rousseau, J.-J. 44, 49, 150, 158, 165, 185, 191

Rubio Llorente, F. 12

Savigny, F. C. v. 121, 155, 156, 211, 277

Scheuner, U. 3, 34, 48, 85, 93, 136, 188, 205, 295

Schiller, F. 45, 182, 188

Schindler, D. 4, 246

Schmid, C. 212

Schmidt, H. 289

Schmitt, C. 38, 112, 128, 138, 140, 269

Scholl, hermanos 275

Schwarze, J. 63, 209

Senelle, R. 39 
Este libro forma parte del acervo de la Biblioteca Juridica Virtual del Instituto de Investigaciones Juridicas de la UNAM

Sieyès, E. 44, 124, 128

Thoreau, H. D. 275, 288

Simson, W. v. 19, 24, 28, 294

Smend, R. 3, 4, 13, 17, 18, 88, 105, 113, Vogel, K. 28 259, 264, 267, 295

Smith, A. 244

Soros, G. 29

Stahl, F.J. 212

Stein, Freiherr v. 208

Stern, K. 43, 78, 93, 125, 129, 135, 199, 212, 216, 233, 247, 248

Sternberger, D. 38, 165, 185

Stolleis, M. 38, 55, 232

Sumner, W. G. 161

Wagner, R. 22, 56

Walesa, L. 13, 14, 284

Walser, M. 34

Washington, G. 265

Werner, F. 207

Wieacker, F. 55, 116

Willoweit, D. 55

Zippelius, R. 162, 233

Zweigert, K. 57, 63 
Este libro forma parte del acervo de la Biblioteca Juridica Virtual del Instituto de Investigaciones Juridicas de la UNAM

\section{ÍNDICE GEOGRÁFICO Y DE DOCUMENTOS CONSTITUCIONALES GITADOS*}

Afganistán 285

África 5, 6, 65, 132, 169, 170, 204, 212, 263, 271, 275, 281, 289, 290

Albania 12, 40, 45n.

Alemana, República Democrática 195, 184, 223, 281

Alemania 7, 11, 12, 14, 16, 17, 27, 33, $38,49,61,70,83,108,124,125,126$, $130,134,159,164,168,176,179$, 184, 186, 189, 193, 199, 200, 202, 204, 207, 208, 209, 210, 211, 216, 222, 223, 225, 236, 239, 243, 244, 246, 247, 248, 250, 253, 259, 260, 272, 273, 274, 275, 280, 281, 283, 288, 289, 290, 293

Constitución de Bismarck (1871) 83, 84, 95, 204

Constitución de la Iglesia de San Pablo (1849) 43, 165n.

Constituciones prusianas (1848 y 1850) 125

Proyecto de Herrenchiemsee (1948) 33, 166

v., también, Weimar, República de

Alemania, República Federal de 33, 70, 78n., 108, 168n., 186n., 239, 246, 273

v., también, Länder de la, y Ley Fundamental de Bonn

América Latina 14, 56, 65, 72, 85, 168, 213, 220, 297, 298
Angola 88n., 91n., 180n., 186, 202, 263, 279, 282

Argentina 259, 297

Armenia 9n., 59n.

Asia 65, 57, 289

Australia 246n., 259

Austria 12, 36, 63, 76, 82, 84, 95, 108, 135, 136, 159, 186, 210, 237, 246n., 250, 271

v., también, Länder de

Azerbaiyán 6, 32n., 59n., 134, 137

Bálticas, Repúblicas 8

v., también, Estonia, Letonia, Lituania

Bélgica 35, 36, 37n., 39, 58n., 70, 84, 136, 189, 205, 252, 256, 288, 289

Benín 30n., 87n., 88, 97n., 180n., 211

Bophuthatswana 132

Bosnia y Herzegovina 9, 72

Brasil 213, 220, 226, 227, 293, 298, 299, 301

Bulgaria 12, 40, 136, 169n., 210, 263, 279

Burkina Faso 88, 97n., 256, 281

Camerún 91n., 282

Canadá 131

Cantones suizos 6, 43, 62, 95, 106, 130, $134,185,213,270,272,280,283$

* Las páginas que remiten a nota a pie (n.) también pueden contener citas al país o documento en el cuerpo del texto (N. del E.) 
Este libro forma parte del acervo de la Biblioteca Juridica Virtual del Instituto de Investigaciones Juridicas de la UNAM http://www.juridicas.unam.mx

Aargau 98n., 110n., 116, 213, 272

Appenzell A.Rh. 62, 117, 255

Basilea-Comarca 81, 100n., 101n., 104n., 109, 115n., 235n.

Berna 95n., 96n., 101n., 110n., 115n., 116, 117, 125, 213, 236n., 270,278

Glarus 129n.

Jura 80n., 98n., 134, 154, 168n., 238n., 255

Nidwalden 117

Solothurn 117, 129n.

Tessin 125

Uri 101n., 102n., 256

v., también, Suiza

Carta de Banjul 224

Carta de la Organización de Estados Americanos 67, 220, 227

Carta de las Naciones Unidas 23, 67, 290, 294, 295, 300

Carta Europea de la Autonomía Municipal 208, 250

Carta Social Europea 87n., 168n., 213

Chad 29n., 180n., 202, 204, 263, 271, 279, 280

Checa, República 11, 136, 169n., 176, 200

China, República Popular 268, 290, 293

Colombia 137n., 168, 298

Convención Americana sobre Derechos Humanos 175, 300

Convención Europea de Derechos Humanos 16, 28, 39, 63, 90n., 154, 168n., 174, 185, 259

Corea del Norte 66, 290

Corea del Sur 135n., 255

Costa de Marfil 268

Costa Rica 131n., 137n., 227, 294, 300

Croacia 9, 32n., 89n., 279, 297

Cuba 66, 290
Declaración de Derechos del Buen Pueblo de Virginia 43, 84n., 168, 174

Declaración de El Cairo sobre los Derechos Humanos en el Islam 177n.

Declaración francesa de los Derechos del Hombre y el Ciudadano 43, 58n., 84, 95, 109, 111n., 115, 127, 140, 168, 197, 198

Declaración Universal de los Derechos Humanos 43, 154, 155, 168, 174, 176, 223, 226, 289

Dinamarca 35, 37n., 39, 135, 139, 203, 262

Escocia 194, 250, 282

v., también, Gran Bretaña

Eslovaca, República 32n., 136, 169, 204

Eslovenia 9, 31, 200

España 6, 11, 12, 21, 30, 31, 34, 35, 36, $37,39,40,57,86,88,89,90,95,100$, $114,124,128,130,131,154,169$, 176, 179, 189, 194, 202, 205, 210, 213, 234, 250, 252, 253, 262, 283, 289, 297

Estados Unidos de América 3, 36, 56, 70, 128, 134, 159, 189, 194, 200, 202, 203, 209, 210, 213, 265, 283, 290, 298, 301

California 185

Estatutos de la Sociedad de Naciones 67

Estonia 9n., 32, 256, 271

v., también, Bálticas, Repúblicas

Etiopía 278

Europa 5n., 15, 20, 26, 27, 29, 34, 35, 36, 38n., 39, 40n., 41, 55, 56, 57, 63, 64n., 65, 66, 68, 70, 72, 78, 85, 116 , $118,121,132,164,168,171,179$, 203, 213, 220, 222, 224, 244, 250, 251, 254, 260n., 262, 271, 272, 281, 290, 298, 299, 300

artículos sobre 64, 70, 281 
Este libro forma parte del acervo de la Biblioteca Juridica Virtual del Instituto de Investigaciones Juridicas de la UNAM

casa constitucional de 12, 29, 41 oriental 5, 6, 8 y s., 27, 29, 31, 56, 66, 69, 72, 77, 114n., 117, 159, 176, 187, 195, 204, 212, 224, 232n., 244, 245, 250, 263, 267, 271, 278, 279, 280, 288, 292

Filipinas 209, 255, 263

Finlandia 6, 136, 262

Francia 11, 18, 26 y s., 30, 36, 58, 127 y s., 134, 139, 159, 167n., 176, 184, 186, 195, 205, 207, 209 y s., 221 y s., 224, 236, 252 y s., 253n., 258n., 263, $275,280,282$ y s., 288,290

Alsacia 221

Bretaña 221

Gabón 49, 114n., 139n.

Gales 194, 282

v., también, Gran Bretaña

Georgia 29n., 88n., 91, 96n., 169n.

Gran Bretaña 21, 35 y s., 184, 194, 250, 282, 289

v., también, Escocia, Gales, Inglaterra, Irlanda del Norte

Grecia 12, 38n., 40, 58n., 80, 94 y s., 97, 99 y s., 102, 131, 135 y s., 166, 210, 213, 235n., 262

Guatemala 6, 31, 81, 89 y s., 90n., 92 y s., 96n., 98n., 101n., 104n., 154n., 169, 175, 179, 219, 220, 221, 224, 255 y ss., 280

Guinea-Bissau 176

Guinea Ecuatorial 30n., 89n., 134, 180, 186, 212, 234n., 263, 282

\section{Honduras 137}

Hungría 155, 268, 271, 289

Indonesia 209, 259

Inglaterra 108, 128, 236 v., también, Gran Bretaña

Irán 285

Irlanda, República de 7, 30, 70, 86n., 88, 96n., 97n., 102, 134, 136, 255 у s., 259, 260, 262, 286

Irlanda del Norte 194, 282

v., también, Gran Bretaña

Islandia 135

Italia 11, 12, 27, 30, 40, 57, 59, 70, 88, 97n., 110n., 112n., 134, 167n., 168, 170n., 176, 194, 199, 204, 210, 213, 236n., 252, 262, 288 y s., 297

Japón 6, 68, 88n., 140, 165n., 203 y s., 258 .

Kazajstán 59n.

Länder de Austria

Baja Austria 95

Burgenland 166n.

Tirol 82n., 90n., 95

Vorarlberg 94n., 97n.

Länder de la República Federal de Alemania $6,27,82,130,138,179,184$, 207, 222, 223, 266, 281, 283

Baden 140, 169n., 186n., 260n., $293 n$.

Baden-Württemberg 23, 87n., 95, 135n., 168n., 255, 265 y s.

Baviera 58n., 80, 87, 91n., 92, 106n., 107n., 110n., 112, 113n., 134, 140, 169n., 178, 186 y s., 206, 208, 216, 217, 218, 222, 223, 253, 260, 260n., 267

Berlín 16, 88n., 89n., 194, 218, 259, 260, 288, 299

Brandemburgo 13, 16, 22, 27, 80n., 85, 87n., 89n., 90, 92n., 97n., 107n., 124, 136, 168n., 169n., 
Este libro forma parte del acervo de la Biblioteca Juridica Virtual del Instituto de Investigaciones Juridicas de la UNAM

185, 186, 217, 218, 235n., 256, 272

Bremen 22, 82, 91n., 92n., 97n., 106, $110,178,183,218,222$ y s., 260 , 266, 278n.

Hamburgo 7n., 89n., 90n., 107n., $186 \mathrm{n}$.

Hesse 58n., 59, 80, 86n., 87n., 89n., 91n., 179, 184, 217, 218, 222, 256, 266, 275

Mecklemburgo-Antepomerania 16, 90n., 96n., 124, 136, 169n., 186n., 208, 218, 238, 255, 260n.

Renania del Norte-Westfalia 16, 88, 92n., 216, 218, 260n., 264

Renania-Palatinado 89n., 90n., 91n., 92n., 96n., 97n., 137, 141n., 179, 216, 217, 255, 259, 264

Sajonia 27, 32n., 94n., 96n., 185, 236n., 260n.

Sajonia-Anhalt 136, 217, 218, 238

Sarre 90n., 92n., 96n., 107n., 218

Schleswig-Holstein 27, 86n., 218, 235 .

Turingia 6, 87n., 97n., 136, 183, 217, 218, 235n., 236n., 243, 245, 255, 256, 260n.

Letonia 8, 9n., 27

v., también, Bálticas, Repúblicas

Ley Fundamental de Bonn (LF) 3, 7, 11, 16, 17, 25, 33, 43n., 49 y s., 58 y ss., 64, 70, 77, 80, 86n., 87n., 96, 103, 105 y ss., 109,111 n., 115 y s., 124 y s., 126, 128, 132, 133 y ss., 138, 144, 147, 149, 150, 153, 158 y ss., 162n., 163n., 164, 166, 175, 177 y s., 181 y s., 184 y ss., 190 y s., 194 y ss., 200 y ss., 206, 209, 211 y ss., 231, 236, 237n., 248 y ss., 256 y s., 260, 261, 270 y ss., 279,281 y ss., 286

v. también, Alemania, República Federal de
Liechtenstein 21, 26, 35, 36, 37, 39, 40, 278 n.

Lituania 8, 9n., 32 v., también, Bálticas, Repúblicas

Luxemburgo 9, 35, 37n., 70, 97n., 135, 154, 298

Macedonia 9, 32n., 89n., 212, 279

Madagascar 29n., 82, 195, 212, 263, 268, 271, 278

Mali 255, 263, 271, 275, 281, 288

Malta 120n.

Moldavia 9n.

Mónaco 35, 37n.

Mongolia 255

Namibia 31, 120n.

Nicaragua 137

Níger 29n., 30, 71n., 90n., 212, 256, 263, 281

Noruega 35, 70, 89n., 139, 203, 281

Pactos internacionales de derechos humanos 16, 28, 39, 63, 72, 90n., 154, 168n., 174 y s., 176n., 223, 226, 258, 259, 300

Países Bajos 16, 35, 37n, 70, 80n., 85, 94, 97, 100n., 137, 213, 234, 235

Paraguay $71 \mathrm{n} ., 98 \mathrm{n} ., 100 \mathrm{n} ., 114 \mathrm{n}$.

Perú 31n., 81n., 90n., 91, 93, 101n., 113n., 168, 169, 179, 213, 220, 221, 224, 225, 227, 255, 256, 297, 298

Polonia 11, 14, 29n., 45n., 82, 90, 94n., 96n., 100n., 109, 110n., 155, 159, 178, 194, 195, 200, 202, 206, 208, 209, 211, 212, 232n., 235n., 256, 263, 267, 268, 270, 278, 279, 280, 282, 284, 298

Portugal 12, 16, 25, 30, 43, 68n., 71, 80, 86, 88n., 90n., 91n., 93, 94, 95n., 98n., 100n., 101n., 104, 105, 124n., 
Este libro forma parte del acervo de la Biblioteca Juridica Virtual del Instituto de Investigaciones Juridicas de la UNAM

130, 131, 135, 136, 137, 154n., 166n., 178, 179, 185, 202, 210, 213, 234n., 235n., 251, 256, 262, 263, 267, 271, 281, 282

Azores 251

Madeira 251

Ruanda 185, 291

Rumania 12, 32n., 40, 256, 279

Rusia 6, 31n., 136, 187, 255, 263, 279, 288, 301

Sao Tomé y Príncipe, República de 186

Senegal 281

Serbia 40

Sudáfrica 6, 13, 32, 57, 124, 132, 136, 169, 202, 204, 205, 206, 207n., 210, 237, 256, 272, 278, 279, 284, 290

Provincia de Kwazulu Natal 32, 59n., 284

Suecia 6, 35, 39, 70, 94n., 135, 139, 185, 186, 203, 234, 263

Suiza 6, 9, 12, 13, 27, 63, 76, 81n., 83, 95, 98, 101, 106, 107, 108, 116, 125, $128,129,130,132,137,139,154$, 176, 185, 200, 202, 210, 221, 233, 236n., 250, 270, 271, 274, 279n., 280, 281n., 282, 283, 284, 289, 290
Proyectos de Constitución federal (1977 y 1995) 62n., 98, 101n., 102n., 116, 131, 233

v., también, Cantones suizos

Togo 82, 204, 282

Tratados de la Comunidad/Unión Europea 28, 67, 210, 272

Turkmenistán 31, 136

Turquía 5n., 6n., 58n., 59n., 124n., 130, 136, 141, 169, 209, 255, 256, 260, 274

Ucrania 32, 59n., 114n., 180n., 187, 205, 206, 209, 212, 238n., 279, 280, 282

Uganda 32n., 98n., 255

Unión de Repúblicas Soviéticas Socialistas (URSS) 9, 61

Usbekistán 94n., 96n.

Venezuela 137, 267

Weimar, República de 11, 22, 36, 80, 85, 88, 106, 113n., 179, 184, 204, 208, 209, 212n., 218, 222, 256, 267, 269, $270,271,275$

Yugoslavia 9, 20, 66, 176, 291 
El Estado constitucional, segunda edición, editado por el Instituto de Investigaciones Jurídicas de la UNAM, se terminó de imprimir el 8 de diciembre de 2016 en Litográfica Dorantes, S. A. de C. V., Oriente 241-A 28 bis, colonia Agrícola Oriental, delegación Iztacalco, 08500 Ciudad de México. Se utilizó tipo Baskerville en 9, 10 y 11 puntos. En esta edición se empleó papel cultural 70 x $95 \mathrm{~cm}$ de 75 gramos para los interiores y cartulina couché de 250 gramos para los forros. Consta de 500 ejemplares (impresión offset). 